NIST NCSTAR 1-4B

Federal Building and Fire Safety Investigation of the World Trade Center Disaster

\title{
Fire Suppression Systems
}

Mark Hopkins

John Schoenrock

Edward Budnick 

NIST NCSTAR 1-4B

Federal Building and Fire Safety Investigation of the World Trade Center Disaster

\section{Fire Suppression Systems}

Mark Hopkins

John Schoenrock

Edward Budnick

Hughes Associates, Inc.

September 2005

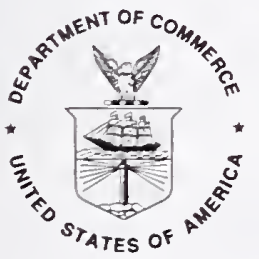

U.S. Department of Commerce

Carlos M. Gutierrez, Secretary

Technology Administration

Michelle O'Neill, Acting Under Secretary for Technology

National Institute of Standards and Technology

William Jeffrey, Director 


\title{
Disclaimer No. 1
}

Certain commercial entities, equipment, products, or materials are identified in this document in order to describe a procedure or concept adequately or to trace the history of the procedures and practices used. Such identification is not intended to imply recommendation, endorsement, or implication that the entities, products, materials, or equipment are necessarily the best available for the purpose. Nor does such identification imply a finding of fault or negligence by the National Institute of Standards and Technology.

\section{Disclaimer No. 2}

The policy of NIST is to use the International System of Units (metric units) in all publications. In this document, however, units are presented in metric units or the inch-pound system, whichever is prevalent in the discipline.

\section{Disclaimer No. 3}

Pursuant to section 7 of the National Construction Safety Team Act, the NIST Director has determined that certain evidence received by NIST in the course of this Investigation is "voluntarily provided safety-related information" that is "not directly related to the building failure being investigated" and that "disclosure of that information would inhibit the voluntary provision of that type of information" (15 USC 7306c).

In addition, a substantial portion of the evidence collected by NIST in the course of the Investigation has been provided to NIST under nondisclosure agreements.

\section{Disclaimer No. 4}

NIST takes no position as to whether the design or construction of a WTC building was compliant with any code since, due to the destruction of the WTC buildings, NIST could not verify the actual (or as-built) construction, the properties and condition of the materials used, or changes to the original construction made over the life of the buildings. In addition, NIST could not verify the interpretations of codes used by applicable authorities in determining compliance when implementing building codes. Where an Investigation report states whether a system was designed or installed as required by a code provision, NIST has documentary or anecdotal evidence indicating whether the requirement was met, or NIST has independently conducted tests or analyses indicating whether the requirement was met.

\section{Use in Legal Proceedings}

No part of any report resulting from a NIST investigation into a structural failure or from an investigation under the National Construction Safety Team Act may be used in any suit or action for damages arising out of any matter mentioned in such report (15 USC 281a; as amended by P.L. 107-231).

National Institute of Standards and Technology National Construction Safety Team Act Report 1-4B Natl. Inst. Stand. Technol. Natl. Constr. Sfty. Tm. Act Rpt. 1-4B, 278 pages (September 2005) CODEN: NSPUE2

\author{
U.S. GOVERNMENT PRINTING OFFICE \\ WASHINGTON: 2005
}

For sale by the Superintendent of Documents, U.S. Government Printing Office Internet: bookstore.gpo.gov — Phone: (202) 512-1800 - Fax: (202) 512-2250 Mail: Stop SSOP, Washington, DC 20402-0001 


\section{ABSTRACT}

The National Institute of Standards and Technology (NIST) conducted a building and fire safety investigation of the World Trade Center (WTC) disasters. The work documented in this report was performed in support of the investigation of active fire protection systems. Specifically, this effort involved documentation and evaluation of the automatic sprinkler and standpipe/pre-connected hose systems and their associated water supplies in WTC 1, 2, and 7.

An extensive literature review was performed in order to document the installed fire suppression features. Hydraulic analyses were performed to provide estimates of the baseline capabilities of the suppression systems as well as capabilities under different fire incident scenarios, including the events of September 11, 2001.

In general, the installed water supplies, automatic sprinkler, and standpipe/pre-connected hose systems in WTC 1,2, and 7 met or exceeded the capabilities of systems typically installed to protect high-rise office buildings. The sprinkler systems were capable of providing adequate water densities to areas as much as two or three times the typical design areas.

Based on initial building damage estimates. the sprinkler and standpipe systems sustained considerable damage in the impact areas of WTC 1 and WTC 2. However, even if the sprinkler systems had remained fully operational and had been designed to protect higher hazard levels (e.g., Extra Hazard), the size, number. and extended area of the initial fires would have opened a large number of sprinklers, involving floor areas significantly larger than those associated with the required water demand for the design area associated with the installed systems.

For the most part, the water supplics provided redundant sources of watcr for the standpipe and sprinkler system infrastructures. However, the typical floor level sprinkler systems were installed with a single connection to a sprinkler riser, providing the potential for single points of failure.

The standpipe/pre-connected hose systems were consistent with the applicable requirements of the Building Code of the City of New York, but were not consistent with the minimum flow rates and durations required in National Fire Protection Association (NFPA) 14.

In addition, selected areas in all three buildings, including the generator fuel day-tank enclosures on several floors in WTC 7. were not protected by automatic sprinklers.

Keywords: Hoses, hydraulic analyses, spray density, sprinkler systems, standpipes, suppression, water supply, World Trade Center. 
This page intentionally left blank. 


\section{TABLE OF CONTENTS}

Abstract

iii

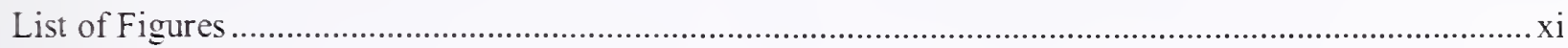

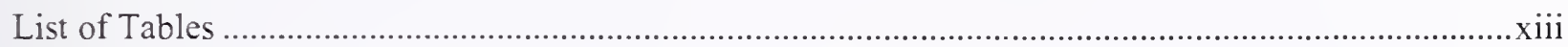

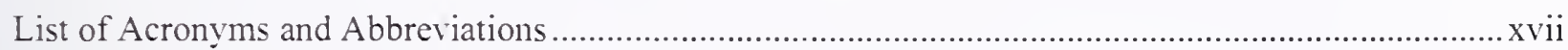

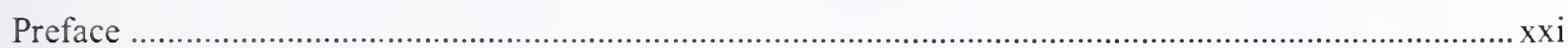

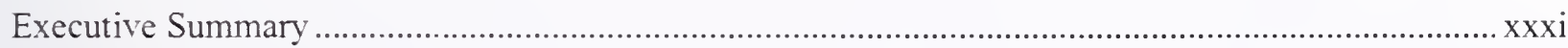

Chapter 1

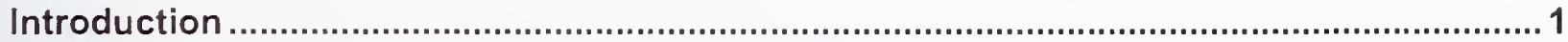

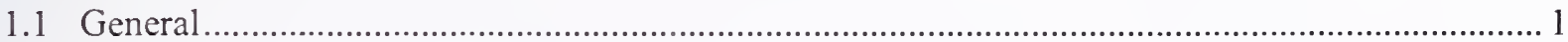

1.2 Scope 1

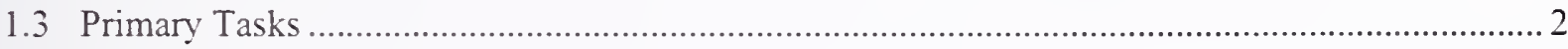

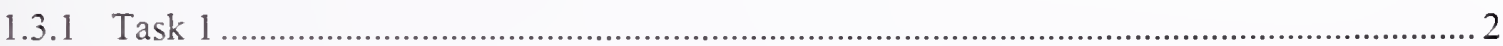

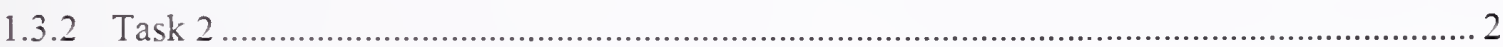

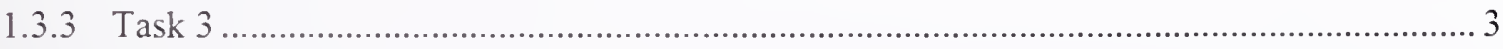

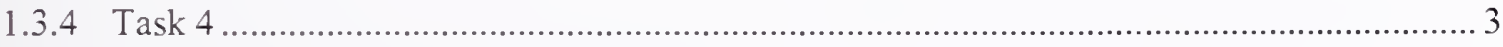

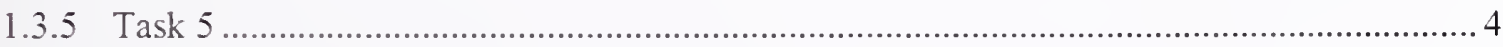

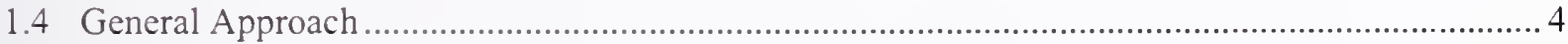

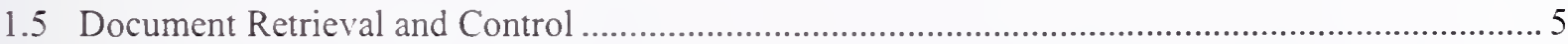

Chapter 2

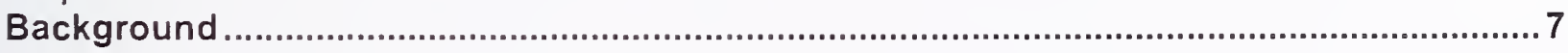

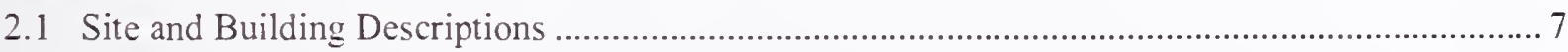

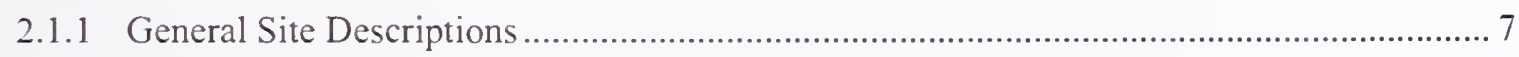

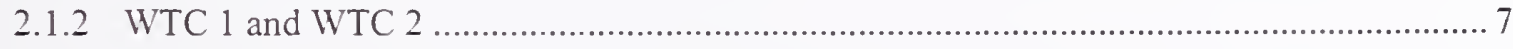

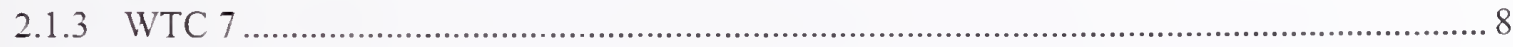

2.2 Installed Fire Suppression Features …............................................................................... 9

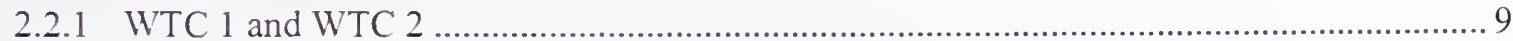

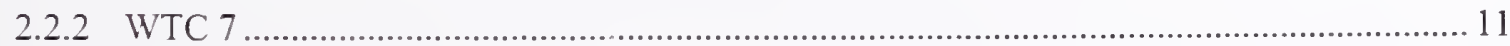

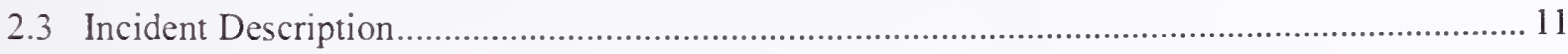

\section{Chapter 3}

Automatic Fire Sprinkler and Standpipe/Pre-Connected Hose Technologies .................. 13

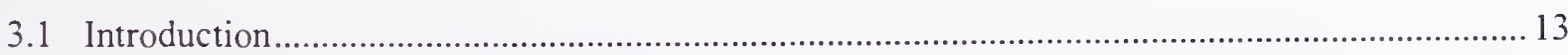




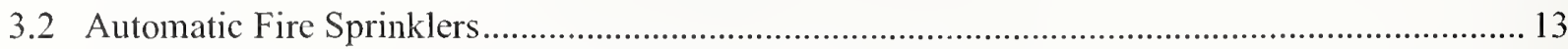

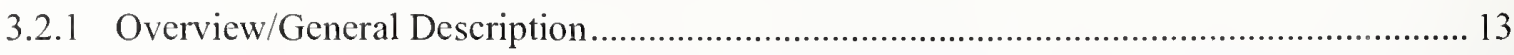

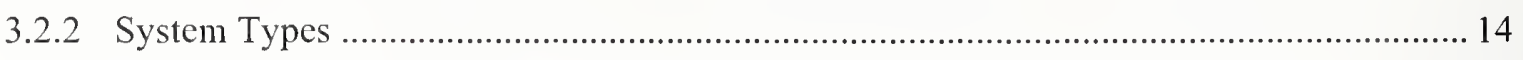

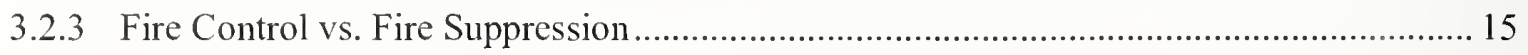

3.2.4 The Area/Density Occupancy Hazard Design Approach ............................................. 16

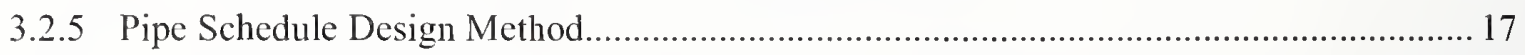

3.2.6 Hydraulic Calculation Design Method ......................................................................... 17

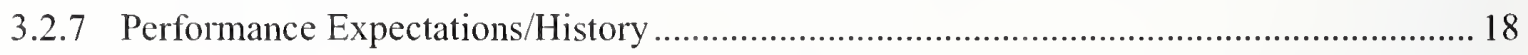

3.3 Standpipes and Pre-Connected Hoses ............................................................................ 19

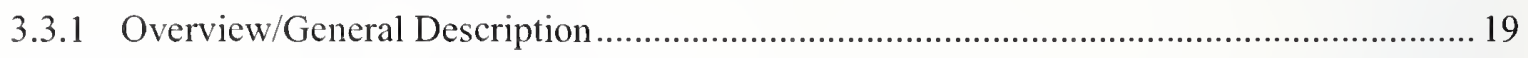

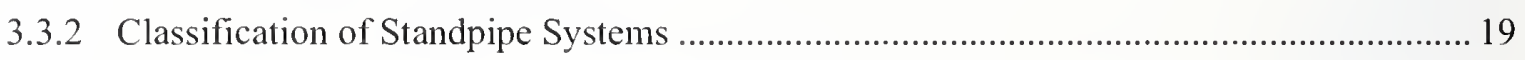

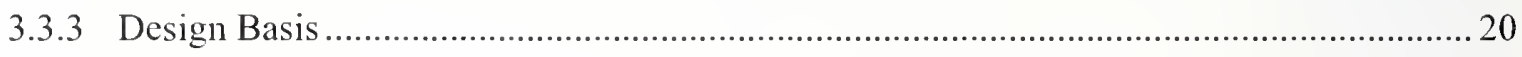

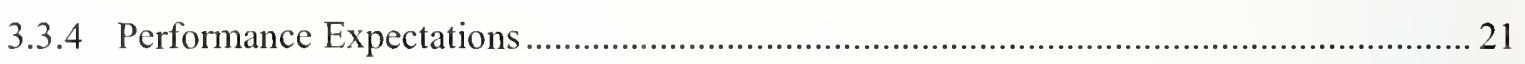

\section{Chapter 4}

Applicable Codes and Standards .......................................................................... 23

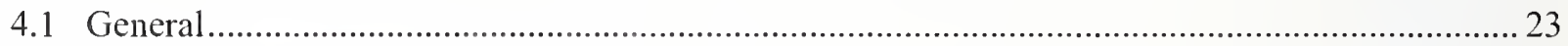

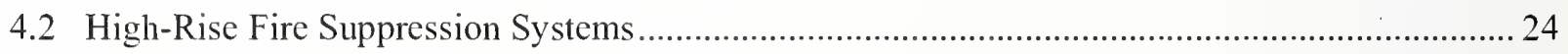

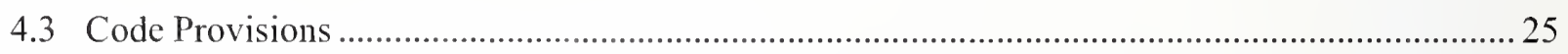

4.3.1 Code Provisions for Sprinkler System Installations, WTC 1 and WTC 2 .................... 25

4.3.2 Code Provisions for Sprinkler System Installations, WTC 7 ...................................... 25

4.3.3 Code Provisions for Standpipe System Installation, WTC 1, 2, and 7 ...........................26

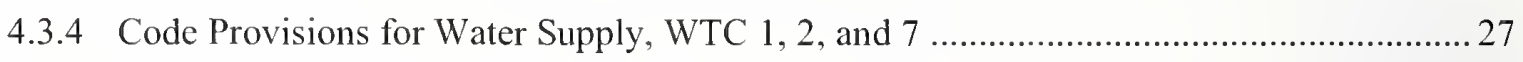

\section{Chapter 5}

Task 1: Water Supplies, Automatic Fire Sprinklers, and Standpipes (Pre-Connected Hoses) in WTC 1, 2, and 7 ..................................................................................... 29

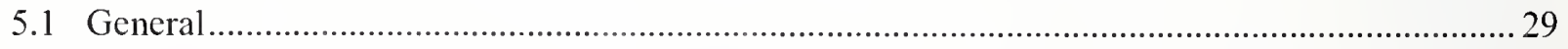

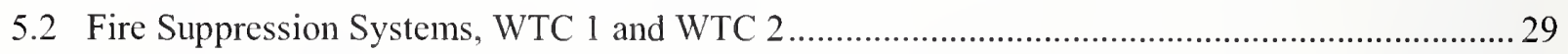

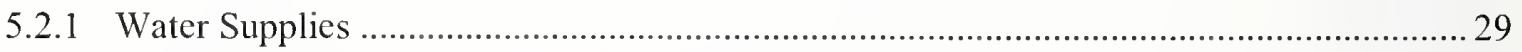

5.2.2 Standpipe and Pre-Connected Hose Systems .......................................................... 36

5.2 .3 Automatic Fire Sprinkler Systems................................................................... 42

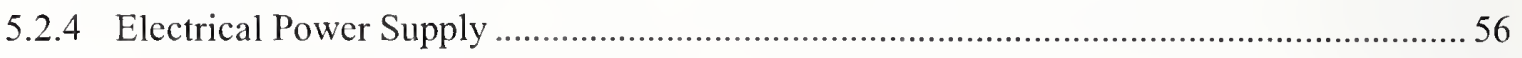

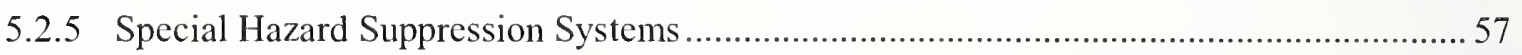

5.2.6 Fire Protection in the Initial Impact Areas ................................................................5 58

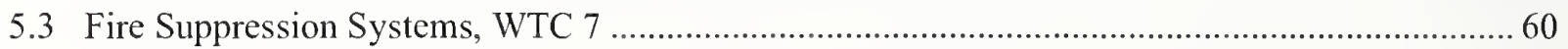




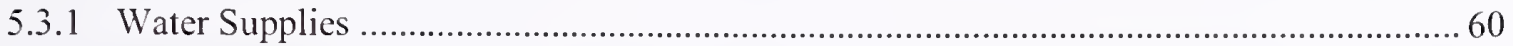

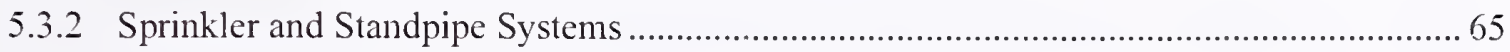

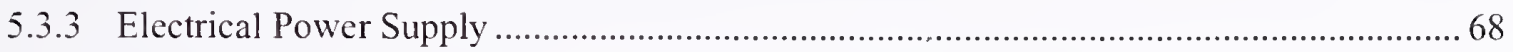

5.3.4 Fire Suppression Systems Associated with Fuel Oil Supply Systems ........................... 69

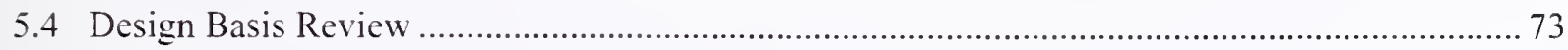

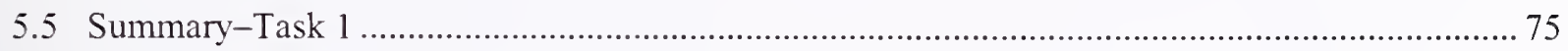

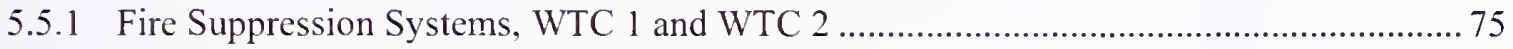

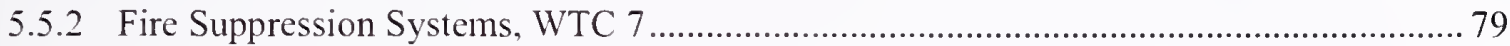

5.5.3 Consistency of Suppression System Designs with State-of-the-Art Engineering "Best Practices". .80

\section{Chapter 6}

Task 2: Evaluation of the Fire Sprinkler Water Supplies

6.1 General 83

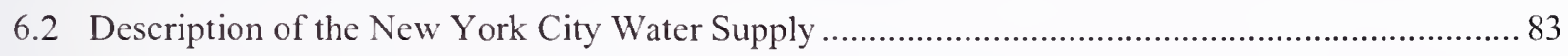

6.3 Evaluation of Sprinkler Systems Flow Capacity and Duration .............................................. 86

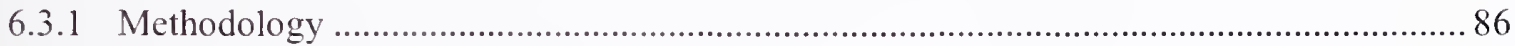

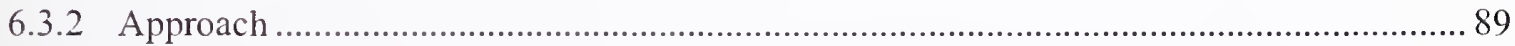

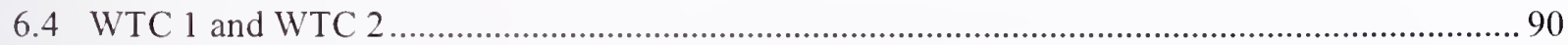

6.4.1 Floor System Layout, WTC 1, Floor 107 ..................................................................... 91

6.4.2 Floor System Layout, WTC 2, Floor 107 ............................................................... 91

6.4.3 Representative System Layout for all Other Floors ................................................. 92

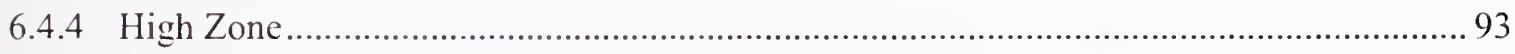

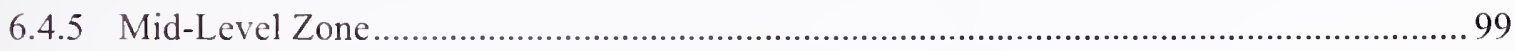

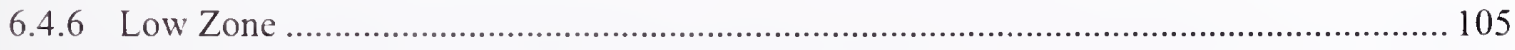

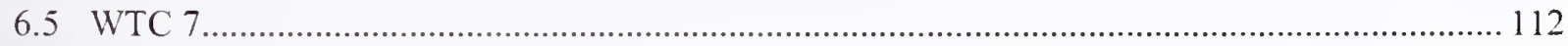

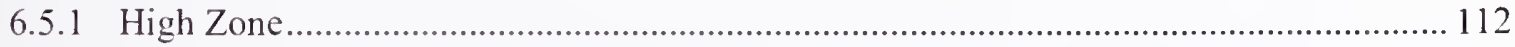

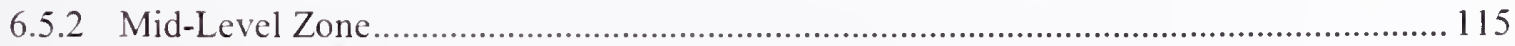

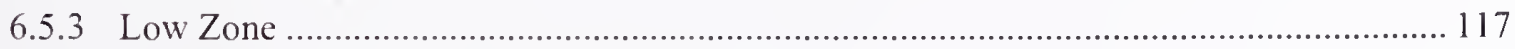

6.5.4 Manual Operations and Rclated Procedures........................................................... 119

6.6 Water Supply and Primary Sprinkler System Redundancies ............................................ 120

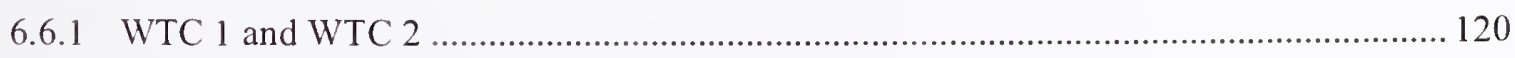

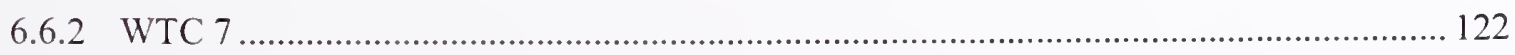

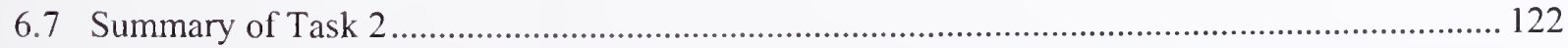




\section{Chapter 7}

Task 3: Differences in Installed Suppression Systems in WTC 1, 2, and 7

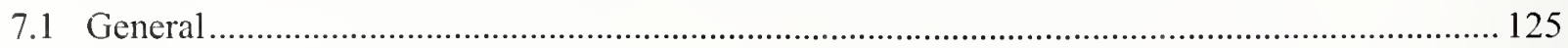

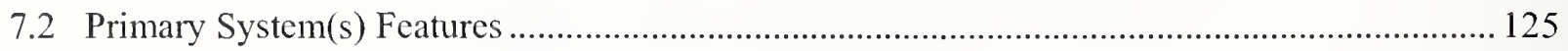

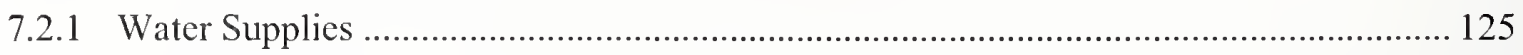

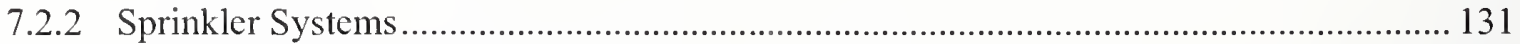

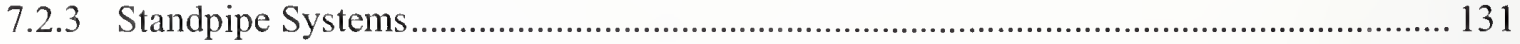

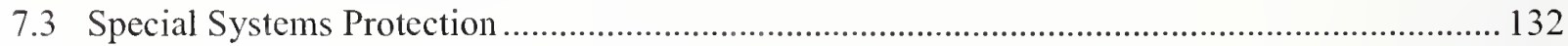

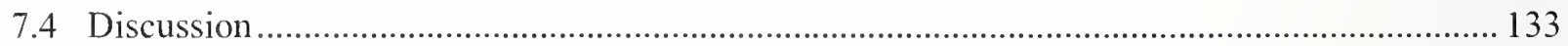

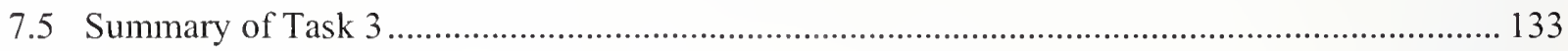

\section{Chapter 8}

Task 4: Expected Performance of the Suppression Systems Under Specific Building Fire Scenarios

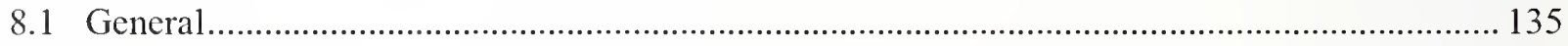

8.2 Hydraulic Analysis for Automatic Sprinkler Systems ....................................................... 135

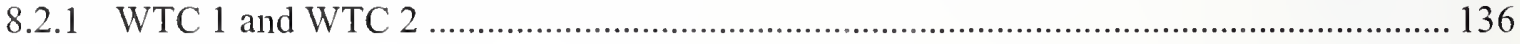

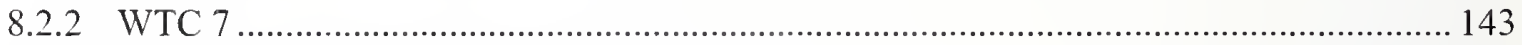

8.3 Standpipe/Pre-Connected Hose Performance ..................................................................... 148

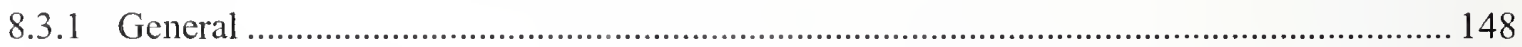

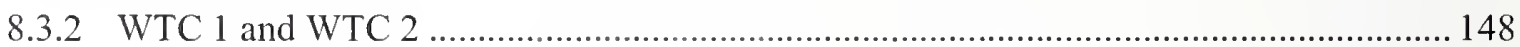

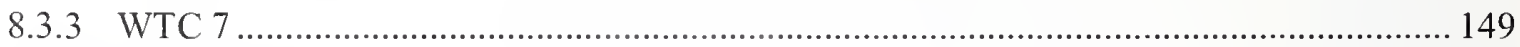

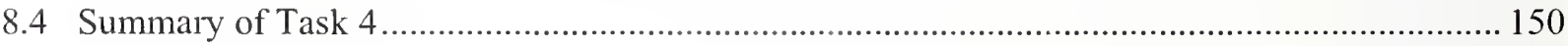

\section{Chapter 9}

Task 5: Suppression Systems Performance on September 11, 2001 ............................ 151

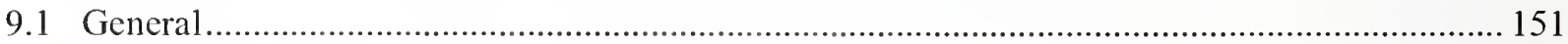

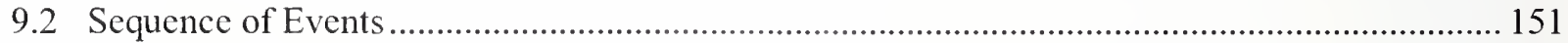

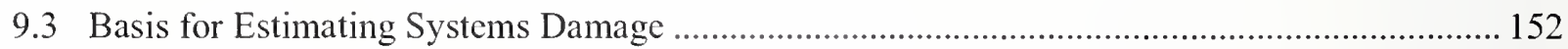

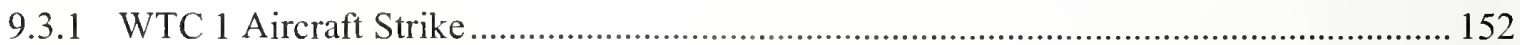

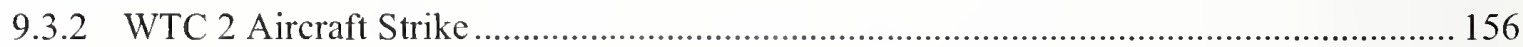

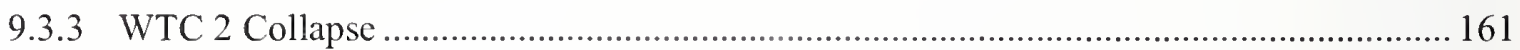

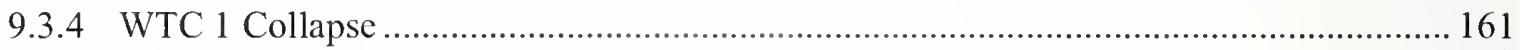

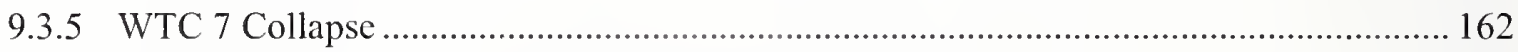

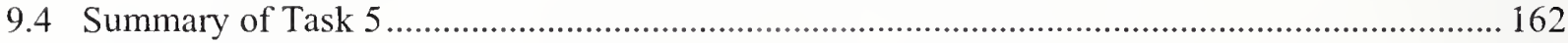




\section{Chapter 10}

Summary and Limitations 165

10.1 Summary 165

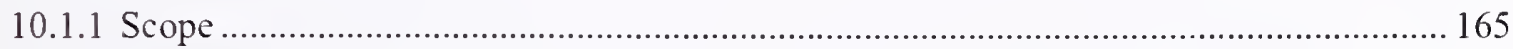

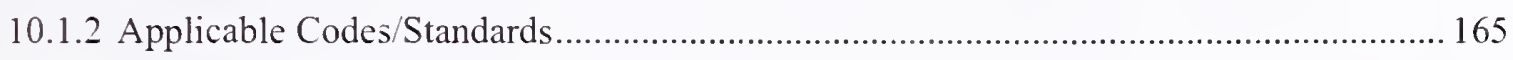

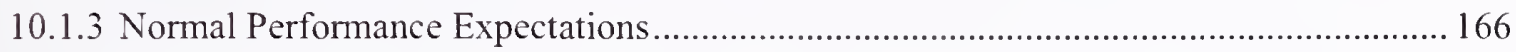

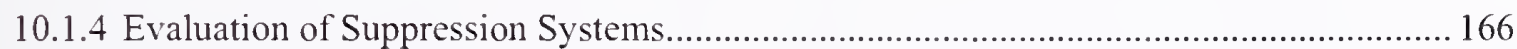

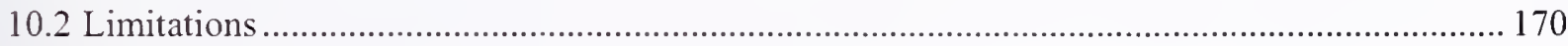

\section{Appendix A}

References.

Appendix B

Figures. 
This page intentionally left blank. 


\section{LIST OF FIGURES}

Figure P-1. The eight projects in the federal building and fire safety investigation of the WTC disaster.

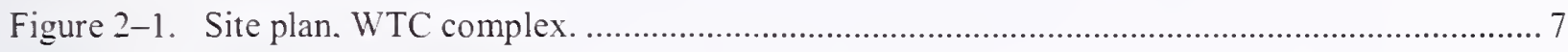

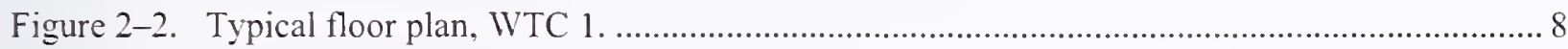

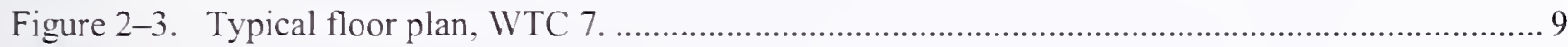

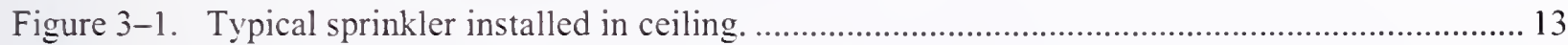

Figure 3-2. Area/density curves, NFPA 13, 1987 edition. .................................................. 18

Figure 5-1. Plan of water distribution system surrounding the WTC complex................................... 30

Figure 5-2. Typical 5,000 gal water storage tank, WTC 1 and WTC 2........................................ 31

Figure 5-3. Water storage tanks, high zone sprinkler systems.............................................. 32

Figure 5-4. Water storage tanks, mid-level zone sprinkler systems...............................................33

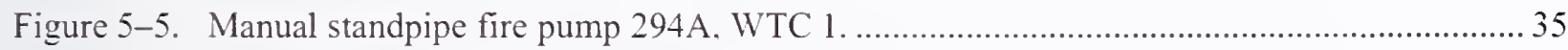

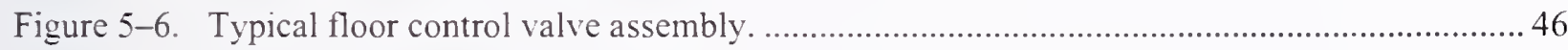

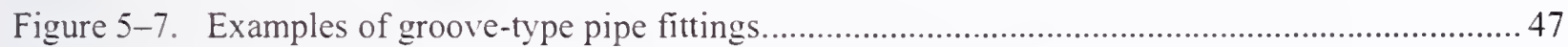

Figure 5-8. Combination pressure reducing control valve assembly.......................................... 48

Figure 5-9. Typical floor control valve assembly as installed in WTC 1 and WTC 2......................50

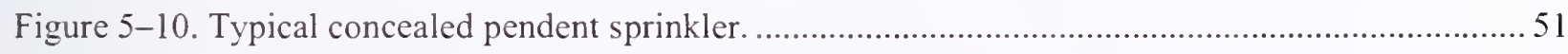

Figure 5-11. Typical standard spray pendent sprinkler............................................................ 51

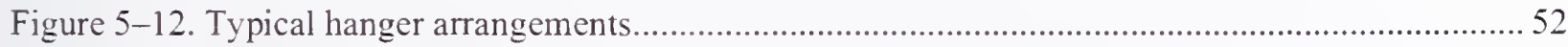

Figure 5-13. Automatic sprinkler system booster pump. …..................................................... 53

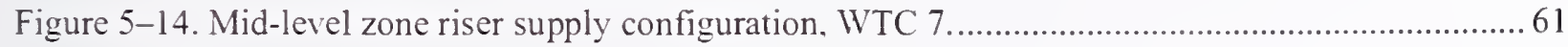

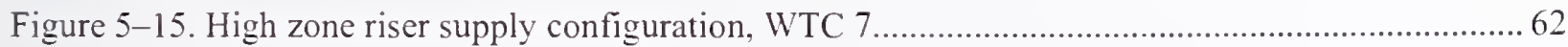

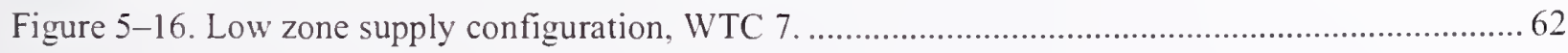

Figure 6-1. Municipal water distribution system surrounding WTC complex................................. 85

Figure 8-1. Summary of sprinkler systems performance for all zones-calculated average delivered density vs. number of open sprinklers, WTC 1 and WTC 2. 
Figure 8-2. High zone sprinkler systems performance-calculated average delivered density vs. number of open sprinklers, WTC 1 and WTC 2

Figure 8-3. Mid-level zone sprinkler systems performance-calculated average delivered density vs. number of open sprinklers, WTC 1 and WTC 2.

Figure 8-4. Low zone sprinkler systems performance-calculated average delivered density vs. number of open sprinklers, WTC 1 and WTC 2

Figure 8-5. Average delivered density vs. number of open sprinklers, WTC 7.

Figure 8-6. High zone, average delivered density vs. number of open sprinklers. 145

Figure 8-7. Mid-level zone, average delivered density vs. number of open sprinklers 145

Figure 8-8. Low zone, average delivered density vs. number of open sprinklers. 146

Figure 9-1. NIST damage estimates, WTC 1

Figure 9-2. NIST damage estimates, WTC 2 157 


\section{LIST OF TABLES}

Table P-1. Federal building and fire safety investigation of the WTC disaster. ...............................xxii

Table P-2. Public meetings and briefings of the WTC Investigation............................................ Xxv

Table 3-1. Sprinklers operating to control or extinguish fires in NYC, 1969-1978.

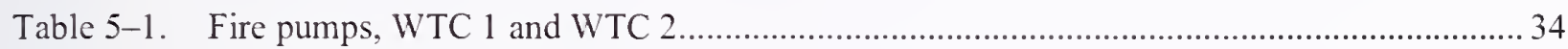

Table 5-2. FDNY recommended FDC pump pressures.......................................................... 36

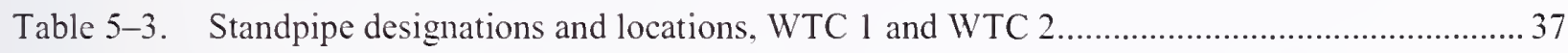

Table 5-4. Typical tower pipe and fitting zones. ....................................................................... 37

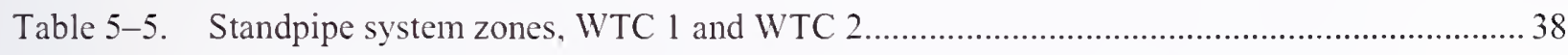

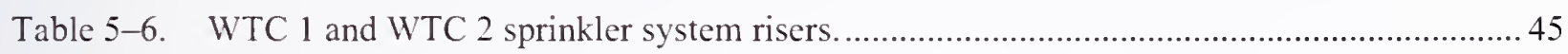

Table 5-7. Summary of WTC 1 and WTC 2 floor control valve assemblies.................................... 49

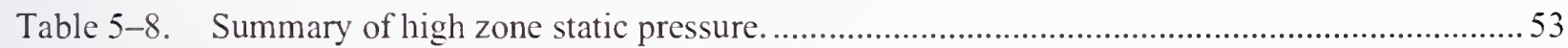

Table 5-9. Summary of mid-level zone static pressure............................................................... 55

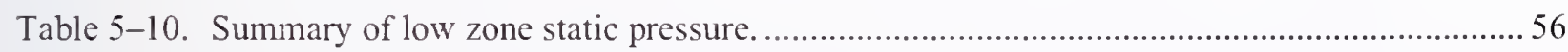

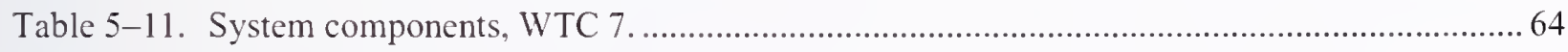

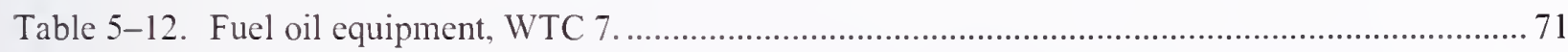

Table 6-1. Average water pressure observed at the 14th Street regulators.....................................8 84

Table 6-2. Number of operating sprinklers, 107th and 99th floor, Light Hazard cases....................... 95

Table 6-3. High zone Light Hazard hydraulic calculations summary, WTC 1 and WTC 2...............95

Table 6-4. Number of operating sprinklers, 107th and 99th floor Ordinary Hazard calculations. ........ 96

Table 6-5. High zone Ordinary Hazard hydraulic calculations summary, WTC 1 and WTC 2...........96

Table 6-6. High zone primary water supply duration, WTC 1 and WTC 2 _................................ 97

Table 6-7. Comparison of primary and secondary water supplies for high zone................................99

Table 6-8. Light Hazard hydraulic calculations summary, 107th floor, WTC 1 and WTC 2..............99

Table 6-9. Number of operating sprinklers, 98th, 87th, and 32nd floor, Light Hazard calculations,

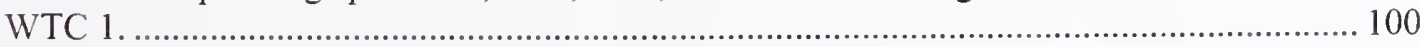

Table 6-10. Mid-level zone Light Hazard hydraulic calculations summary, WTC 1 and WTC 2........ 101

Table 6-11. Number of operating sprinklers, 98th, 87th, 86th and 32nd floor Ordinary Hazard calculations, WTC 1 . 
Table 6-12. Mid-level zone Ordinary Hazard hydraulic calculations summary, WTC 1 and WTC 2.

Table 6-13. Mid-level zone primary water supply duration, WTC 1 and WTC 2 ............................ 104

Table 6-14. Comparison of primary and secondary water supplies for mid-level zone. ..................... 105

Table 6-15. Number of operating sprinklers, 31st and 2nd floor Light Hazard calculations, WTC 1.... 106

Table 6-16. Low zone Light Hazard hydraulic calculations summary, WTC 1 and WTC 2.

Table 6-17. Number of operating sprinklers, 31st, 9th, 7th and 2nd floor Ordinary Hazard calculations, WTC 1. 108

Table 6-18. Low zone Ordinary Hazard hydraulic calculations summary, WTC 1 and WTC 2.......... 108

Table 6-19. Low zone primary water supply duration, WTC 1 and WTC 2 ................................... 109

Table 6-20. Comparison of primary and secondary water supplies for low zone................................ 110

Table 6-21. Low zone primary water supply duration, WTC 1 and WTC 2................................... 111

Table 6-22. Summary of manual fire pump pressure limitations at rated flow (750 gpm), WTC 1 and WTC 2.

Table 6-23. Number of operating sprinklers for hydraulic supply calculations, 47th and 40th floors, WTC 7.

Table 6-24. High zone hydraulic calculations summary, WTC 7.

Table 6-25. Number of operating sprinklers for hydraulic supply calculations, 39 th and 21 st floors, WTC 7

Table 6-26. Mid-level zone hydraulic calculations summary, WTC 7.

Table 6-27. Number of operating sprinklers for hydraulic supply calculations, 1 st and 20th floors, WTC 7.

Table 6-28. Low zone hydraulic calculations summary, WTC 7.

Table 7-1. Summary of active fire suppression system features, WTC 1, 2, and 7

Table 8-1. High zone average delivered density per floor vs. number of floors flowing (four sprinklers/floor), WTC 1 and WTC 2 .

Table 8-2. Mid-level zone average delivered density per floor vs. number of floors flowing (four sprinklers/floor), WTC 1 and WTC 2.

Table 8-3. High zone and mid-level zone average delivered density per floor vs. number of floors flowing (four sprinklers/floor), WTC 1 and WTC 2.

Table 8-4. High zone average delivered density per floor vs. number of floors flowing (eight sprinklers/floor), WTC 1 and WTC 2.

Table 8-5. Mid-level zone average delivered density per floor vs. number of floors flowing (eight sprinklers/floor), WTC 1 and WTC 2.

Table 8-6. Lowest residual pressure at open sprinklers for each system. 
Table 8-7. Average delivered density per floor vs. number of floors flowing (four sprinklers/floor).

Table 8-8. Average delivered density per floor vs. number of floors flowing (nine sprinklers/floor).

Table 9-1. Timeline and summary of major events.

Table 9-2. Summary of estimated initial damage, sprinkler and standpipe systems, 96th floor, WTC 1 .

Table 9-3. Summary of estimated initial damage, sprinkler and standpipe systems, 95th floor, WTC 1 .

Table 9-4. Summary of estimated initial damage, sprinkler and standpipe systems, 94th floor, WTC 1.

Table 9-5. Summary of estimated initial damage, sprinkler and standpipe systems, 81st floor, WTC 2.

Table 9-6. Summary of estimated initial damage, sprinkler, and standpipe systems, 80th floor, WTC 2.

Table 9-7. Summary of estimated initial damage, sprinkler and standpipe systems, 79th floor, WTC 2.

Table 9-8. Summary of estimated initial damage, sprinkler and standpipe systems, 78th floor, WTC 2. 
This page intentionally left blank. 


\section{LIST OF ACRONYMS AND ABBREVIATIONS}

\section{Acronyms}
AA
American Airlines
AHJ
authority having jurisdiction
ASTM
ASTM International
BCNYC
Building Code of the City of New York
BPS
Building Performance Study
BWS
Bureau of Water Supply
BWSO
Bureau of Water and Sewer Operations
Con-Ed
Consolidated Edison Company
DTAP
dissemination and technical assistance program
$\mathrm{EH}$
Extra Hazard
FCA
floor control assembly
FDC
fire department connection
FDNY The Fire Department of the City of New York
FEMA Federal Emergency Management Agency
FHC fire hose cabinets
FHV fire hose valves
HAI Hughes Associates, Inc.
HASS Hydraulic Analyzer of Sprinkler Systems
LH Light Hazard
MER mechanical equipment room
NCST National Construction Safety Team
NFPA National Fire Protection Association
NIST National Institute of Standards and Technology
NYC DEP New York City Department of Environmental Protection
NYC New York City
NYPD New York City Police Department
O\&M opcrations and maintenance
OEM Office of Emergency Management 
$\mathrm{OH} \quad$ Ordinary Hazard

OS\&Y outside screw and yoke

PANYNJ Port Authority of New York and New Jersey

PRV pressure relief valve

R\&D research and development

RASCO Reliable Automatic Sprinkler Corporation of America, Inc.

RJA Rolf Jensen \& Associates

RS Reference Standards

SEAoNY Structural Engineers Association of New York

UA United Airlines

USC United States Code

WTC World Trade Center

WTC $1 \quad$ World Trade Center 1 (North Tower)

WTC 2 World Trade Center 2 (South Tower)

WTC $7 \quad$ World Trade Center 7

\section{Abbreviations}

$\begin{array}{ll}{ }^{\circ} \mathrm{C} & \text { degrees Celsius } \\ { }^{\circ} \mathrm{F} & \text { degrees Fahrenheit } \\ \mu \mathrm{m} & \text { micrometer } \\ \mathrm{CO}_{2} & \text { carbon monoxide } \\ \mathrm{ft} & \text { foot } \\ \mathrm{ft}^{2} & \text { square foot } \\ \mathrm{gal} & \text { gallon } \\ \mathrm{gpm} & \text { gallons per minute } \\ \mathrm{h} & \text { hour } \\ \mathrm{in} . & \text { inch } \\ \mathrm{kW} & \text { kilowatt } \\ \mathrm{L} & \text { liter } \\ \mathrm{m} & \text { meter } \\ \mathrm{min} & \text { minute } \\ \mathrm{psi} & \text { pounds per square inch }\end{array}$


S

second

V

volt

W

watt 
This page intentionally left blank. 


\section{PREFACE}

\section{Genesis of This Investigation}

Immediately following the terrorist attack on the World Trade Center (WTC) on September 11, 2001, the Federal Emergency Management Agency (FEMA) and the American Society of Civil Engineers began planning a building performance study of the disaster. The week of October 7, as soon as the rescue and search efforts ceased. the Building Performance Study Team went to the site and began its assessment. This was to be a brief effort, as the study team consisted of experts who largely volunteered their time away from their other professional commitments. The Building Performance Study Team issued its report in May 2002. fulfilling its goal "to determine probable failure mechanisms and to identify areas of future investigation that could lead to practical measures for improving the damage resistance of buildings against such unforeseen events."

On August 21.2002. with funding from the U.S. Congress through FEMA, the National Institute of Standards and Technology (NIST) announced its building and fire safety investigation of the WTC disaster. On October 1. 2002, the National Construction Safety Team Act (Public Law 107-231), was signed into law. The NIST WTC Investigation was conducted under the authority of the National Construction Safety Team Act.

The goals of the investigation of the IVTC disaster were:

- To investigate the building construction, the materials used, and the technical conditions that contributed to the outcome of the WTC disaster.

- To serve as the basis for:

- Improvements in the way buildings are designed, constructed, maintained, and used;

- Improved tools and guidance for industry and safety officials;

- Recommended revisions to current codes, standards, and practices; and

- Improved public safety.

The specific objectives were:

1. Determine why and how WTC 1 and WTC 2 collapsed following the initial impacts of the aircraft and why and how WTC 7 collapsed;

2. Determine why the injuries and fatalities were so high or low depending on location, including all technical aspects of fire protection, occupant behavior, evacuation, and emergency response;

3. Determine what procedures and practices were used in the design, construction, operation, and maintenance of WTC 1,2, and 7; and

4. Identify, as specifically as possible, areas in current building and fire codes, standards, and practices that warrant revision. 
NIST is a nonregulatory agency of the U.S. Department of Commerce's Technology Administration. The purpose of NIST investigations is to improve the safety and structural integrity of buildings in the United States, and the focus is on fact finding. NIST investigative teams are authorized to assess building performance and emergency response and evacuation procedures in the wake of any building failure that has resulted in substantial loss of life or that posed significant potential of substantial loss of life. NIST does not have the statutory authority to make findings of fault nor negligence by individuals or organizations. Further, no part of any report resulting from a NIST investigation into a building failure or from an investigation under the National Construction Safety Team Act may be used in any suit or action for damages arising out of any matter mentioned in such report (15 USC 281a, as amended by Public Law 107-231).

\section{Organization of the Investigation}

The National Construction Safety Team for this Investigation, appointed by the then NIST Director, Dr. Arden L. Bement, Jr., was led by Dr. S. Shyam Sunder. Dr. William L. Grosshandler served as Associate Lead Investigator, Mr. Stephen A. Cauffman served as Program Manager for Administration, and Mr. Harold E. Nelson served on the team as a private sector expert. The Investigation included eight interdependent projects whose leaders comprised the remainder of the team. A detailed description of each of these eight projects is available at http://wtc.nist.gov. The purpose of each project is summarized in Table P-1, and the key interdependencies among the projects are illustrated in Fig. P-1.

\section{Table P-1. Federal building and fire safety investigation of the WTC disaster.}

\begin{tabular}{|c|c|}
\hline Technical Area and Project Leader & Project Purpose \\
\hline $\begin{array}{l}\text { Analysis of Building and Fire Codes and } \\
\text { Practices; Project Leaders: Dr. H. S. Lew } \\
\text { and Mr. Richard W. Bukowski }\end{array}$ & $\begin{array}{l}\text { Document and analyze the code provisions, procedures, and } \\
\text { practices used in the design, construction, operation, and } \\
\text { maintenance of the structural, passive fire protection, and } \\
\text { emergency access and evacuation systems of WTC } 1,2 \text {, and } 7 \text {. }\end{array}$ \\
\hline $\begin{array}{l}\text { Analysis; Project } \\
\text { lek }\end{array}$ & $\begin{array}{l}\text { Analyze the baseline performance of WTC } 1 \text { and WTC } 2 \text { under } \\
\text { design, service, and abnormal loads, and aircraft impact damage on } \\
\text { the structural, fire protection, and egress systems. }\end{array}$ \\
\hline $\begin{array}{l}\text { Mechanical and Metallurgical Analysis of } \\
\text { Structural Steel; Project Leader: Dr. Frank } \\
\text { W. Gayle }\end{array}$ & $\begin{array}{l}\text { anical and metallurgical properties } \\
\text { and connections from steel }\end{array}$ \\
\hline $\begin{array}{l}\text { Investigation of Active Fire } \\
\text { Systems; Project Leader: Dr } \\
\text { D. Evans; Dr. William Gross }\end{array}$ & $\begin{array}{l}\text { ance of the active fire protection systems in } \\
\text { neir role in fire control, emergency response, } \\
\text { nd responders. }\end{array}$ \\
\hline $\begin{array}{l}\text { f Thermal and Tenability } \\
\text { oject Leader: Dr. Richard }\end{array}$ & $\begin{array}{l}\text { Reconstruct the time-evolving temperature, thermal environment, } \\
\text { and smoke movement in WTC } 1,2 \text {, and } 7 \text { for use in evaluating the } \\
\text { structural performance of the buildings and behavior and fate of } \\
\text { occupants and responders. }\end{array}$ \\
\hline $\begin{array}{l}\text { Structura } \\
\text { Analysis } \\
\text { L. Gross }\end{array}$ & $\begin{array}{l}\text { Analyze the response of the WTC towers to fires with and without } \\
\text { aircraft damage, the response of WTC } 7 \text { in fires, the performance } \\
\text { of composite steel-trussed floor systems, and determine the most } \\
\text { probable structural collapse sequence for WTC } 1,2 \text {, and } 7 \text {. }\end{array}$ \\
\hline $\begin{array}{l}\text { Occupant Behavior, Egress, and Emergency } \\
\text { Communications; Project Leader: Mr. Jason } \\
\text { D. Averill }\end{array}$ & $\begin{array}{l}\text { and fate of occupants and responders, both } \\
\text { nd those who did not, and the performance of } \\
\text {. }\end{array}$ \\
\hline $\begin{array}{l}\text { Emergency Response Technologies and } \\
\text { Guidelines; Project Leader: Mr. J. Randall } \\
\text { Lawson }\end{array}$ & $\begin{array}{l}\text { Document the activities of the emergency responders from the time } \\
\text { of the terrorist attacks on WTC } 1 \text { and WTC } 2 \text { until the collapse of } \\
\text { WTC 7, including practices followed and technologies used. }\end{array}$ \\
\hline
\end{tabular}




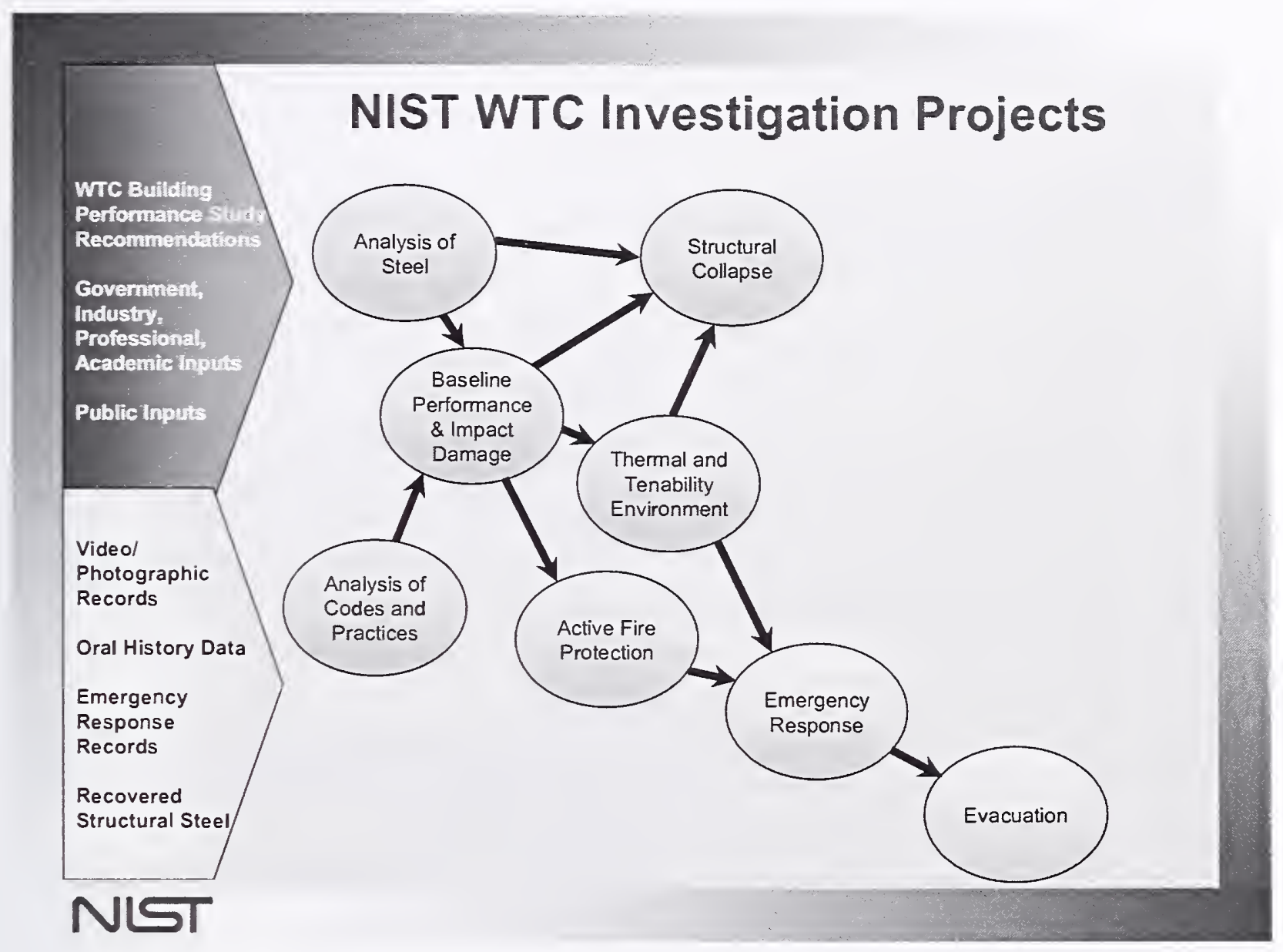

Figure P-1. The eight projects in the federal building and fire safety investigation of the WTC disaster.

\section{National Construction Safety Team Advisory Committee}

The NIST Director also established an advisory committee as mandated under the National Construction Safety Team Act. The initial members of the committee were appointed following a public solicitation. These were:

- Paul Fitzgerald, Executive Vice President (retired) FM Global, National Construction Safety Team Advisory Committee Chair

- John Barsom. President, Barsom Consulting, Ltd.

- John Bryan, Professor Emeritus, University of Maryland

- David Collins, President, The Preview Group, Inc.

- Glenn Corbett, Professor, John Jay College of Criminal Justice

- Philip DiNenno, President, Hughes Associates, Inc. 
- Robert Hanson, Professor Emeritus, University of Michigan

- Charles Thornton, Co-Chairman and Managing Principal, The Thornton-Tomasetti Group, Inc.

- Kathleen Tierney, Director, Natural Hazards Research and Applications Information Center, University of Colorado at Boulder

- Forman Williams, Director, Center for Energy Research, University of California at San Diego

This National Construction Safety Team Advisory Committee provided technical advice during the Investigation and commentary on drafts of the Investigation reports prior to their public release. NIST has benefited from the work of many people in the preparation of these reports, including the National Construction Safety Team Advisory Committee. The content of the reports and recommendations, however, are solely the responsibility of NIST.

\section{Public Outreach}

During the course of this Investigation, NIST held public briefings and meetings (listed in Table P-2) to solicit input from the public, present preliminary findings, and obtain comments on the direction and progress of the Investigation from the public and the Advisory Committee.

NIST maintained a publicly accessible Web site during this Investigation at http://wtc.nist.gov. The site contained extensive information on the background and progress of the Investigation.

\section{NIST's WTC Public-Private Response Plan}

The collapse of the WTC buildings has led to broad reexamination of how tall buildings are designed, constructed, maintained, and used, especially with regard to major events such as fires, natural disasters, and terrorist attacks. Reflecting the enhanced interest in effecting necessary change, NIST, with support from Congress and the Administration, has put in place a program, the goal of which is to develop and implement the standards, technology, and practices needed for cost-effective improvements to the safety and security of buildings and building occupants, including evacuation, emergency response procedures, and threat mitigation.

The strategy to meet this goal is a three-part NIST-led public-private response program that includes:

- A federal building and fire safety investigation to study the most probable factors that contributed to post-aircraft impact collapse of the WTC towers and the 47-story WTC 7 building, and the associated evacuation and emergency response experience.

- A research and development (R\&D) program to (a) facilitate the implementation of recommendations resulting from the WTC Investigation, and (b) provide the technical basis for cost-effective improvements to national building and fire codes, standards, and practices that enhance the safety of buildings, their occupants, and emergency responders. 
Table P-2. Public meetings and briefings of the WTC Investigation.

\begin{tabular}{|c|c|c|}
\hline Date & Location & Principal Agenda \\
\hline June 24,2002 & New York City, NY & $\begin{array}{l}\text { Public meeting: Public comments on the Draft Plan for the } \\
\text { pending WTC Investigation. }\end{array}$ \\
\hline August 21, 2002 & Gaithersburg. MD & Media briefing announcing the formal start of the Investigation. \\
\hline December 9,2002 & Washington, DC & $\begin{array}{l}\text { Media briefing on release of the Public Update and NIST request } \\
\text { for photographs and videos. }\end{array}$ \\
\hline April 8, 2003 & New York City, NY & $\begin{array}{l}\text { Joint public forum with Columbia University on first-person } \\
\text { interviews. }\end{array}$ \\
\hline April 29-30, 2003 & Gaithersburg, MD & $\begin{array}{l}\text { NCST Advisory Committee meeting on plan for and progress on } \\
\text { WTC Investigation with a public comment session. }\end{array}$ \\
\hline May 7,2003 & New York City, NY & Media briefing on release of May 2003 Progress Report. \\
\hline August 26-27.2003 & Gaithersburg. MD & $\begin{array}{l}\text { NCST Advisory Committee meeting on status of the WTC } \\
\text { investigation with a public comment session. }\end{array}$ \\
\hline September 17,2003 & New York City, NY & $\begin{array}{l}\text { Media and public briefing on initiation of first-person data } \\
\text { collection projects. }\end{array}$ \\
\hline December 2-3, 2003 & Gaithersburg, MD & $\begin{array}{l}\text { NCST Advisory Committee meeting on status and initial results } \\
\text { and release of the Public Update with a public comment session. }\end{array}$ \\
\hline February 12, 2004 & New York City, NY & $\begin{array}{l}\text { Public meeting on progress and preliminary findings with public } \\
\text { comments on issues to be considered in formulating final } \\
\text { recommendations. }\end{array}$ \\
\hline June 18.2004 & New York City, NY & Media/public briefing on release of June 2004 Progress Report. \\
\hline June $22-23,2004$ & Gaithersburg, MD & $\begin{array}{l}\text { NCST Advisory Committee meeting on the status of and } \\
\text { preliminary findings from the WTC Investigation with a public } \\
\text { comment session. }\end{array}$ \\
\hline August 24, 2004 & Northbrook, $1 \mathrm{~L}$ & $\begin{array}{l}\text { Public viewing of standard fire resistance test of WTC floor } \\
\text { system at Underwriters Laboratories, Inc. }\end{array}$ \\
\hline October 19-20, 2004 & Gaithersburg, MD & $\begin{array}{l}\text { NCST Advisory Committee meeting on status and near complete } \\
\text { set of preliminary findings with a public comment session. }\end{array}$ \\
\hline November 22, 2004 & Gaithersburg, MD & $\begin{array}{l}\text { NCST Advisory Committee discussion on draft annual report to } \\
\text { Congress, a public comment session, and a closed session to } \\
\text { discuss pre-draft recommendations for WTC Investigation. }\end{array}$ \\
\hline April 5, 2005 & New York City, NY & $\begin{array}{l}\text { Media and public briefing on release of the probable collapse } \\
\text { sequence for the WTC towers and draft reports for the projects on } \\
\text { codes and practices, evacuation, and emergency response. }\end{array}$ \\
\hline June 23,2005 & New York City, NY & $\begin{array}{l}\text { Media and public briefing on release of all draft reports for the } \\
\text { WTC towers and draft recommendations for public comment. }\end{array}$ \\
\hline $\begin{array}{l}\text { September 12-13, } \\
2005\end{array}$ & Gaithersburg, MD & $\begin{array}{l}\text { NCST Advisory Committee meeting on disposition of public } \\
\text { comments and update to draft reports for the WTC towers. }\end{array}$ \\
\hline $\begin{array}{l}\text { September } 13-15 \\
2005\end{array}$ & Gaithersburg, MD & $\begin{array}{l}\text { WTC Technical Conference for stakeholders and technical } \\
\text { community for dissemination of findings and recommendations } \\
\text { and opportunity for public to make technical comments. }\end{array}$ \\
\hline
\end{tabular}

- A dissemination and technical assistance program (DTAP) to (a) engage leaders of the construction and building community in ensuring timely adoption and widespread use of proposed changes to practices, standards, and codes resulting from the WTC Investigation and the R\&D program, and (b) provide practical guidance and tools to better prepare facility owners, contractors, architects, engineers, emergency responders, and regulatory authorities to respond to future disasters.

The desired outcomes are to make buildings, occupants, and first responders safer in future disaster events. 


\section{National Construction Safety Team Reports on the WTC Investigation}

A final report on the collapse of the WTC towers is being issued as NIST NCSTAR 1. A companion report on the collapse of WTC 7 is being issued as NIST NCSTAR 1A. The present report is one of a set that provides more detailed documentation of the Investigation findings and the means by which these technical results were achieved. As such, it is part of the archival record of this Investigation. The titles of the full set of Investigation publications are:

NIST (National Institute of Standards and Technology). 2005. Federal Building and Fire Safety Investigation of the World Trade Center Disaster: Final Report on the Collapse of the World Trade Center Towers. NIST NCSTAR 1. Gaithersburg, MD, September.

NIST (National Institute of Standards and Technology). 2006. Federal Building and Fire Safety Investigation of the World Trade Center Disaster: Final Report on the Collapse of World Trade Center 7. NIST NCSTAR 1A. Gaithersburg, MD.

Lew, H. S., R. W. Bukowski, and N. J. Carino. 2005. Federal Building and Fire Safety Investigation of the World Trade Center Disaster: Design, Construction, and Maintenance of Strnctural and Life Safety Systems. NIST NCSTAR 1-1. National Institute of Standards and Technology. Gaithersburg, MD, September.

Fanella, D. A., A. T. Dcrecho, and S. K. Ghosh. 2005. Federal Building and Fire Safety Investigation of the World Trade Center Disaster: Design and Construction of Structural Systems. NIST NCSTAR 1-1A. National Institute of Standards and Technology. Gaithersburg, MD, September.

Ghosh, S. K., and X. Liang. 2005. Federal Building and Fire Safety Investigation of the World Trade Center Disaster: Comparison of Building Code Structural Requirements. NIST NCSTAR 1-1B. National Institute of Standards and Technology. Gaithersburg, MD, September.

Fanella, D. A., A. T. Derecho, and S. K. Ghosh. 2005. Federal Building and Fire Safety Investigation of the World Trade Center Disaster: Maintenance and Modifications to Strnctural Systems. NIST NCSTAR 1-1C. National Institute of Standards and Technology. Gaithersburg, MD, Scptember.

Grill, R. A., and D. A. Johnson. 2005. Federal Building and Fire Safety Investigation of the World Trade Center Disaster: Fire Protection and Life Safety Provisions Applied to the Design and Construction of World Trade Center 1, 2, and 7 and Post-Construction Provisions Applied after Occupancy. NIST NCSTAR 1-1D. National Institute of Standards and Technology. Gaithersburg, $\mathrm{MD}$, September.

Razza, J. C., and R. A. Grill. 2005. Federal Building and Fire Safety Investigation of the World Trade Center Disaster: Comparison of Codes, Standards, and Practices in Use at the Time of the Design and Construction of World Trade Center 1, 2, and 7. NIST NCSTAR 1-1E. National Institute of Standards and Technology. Gaithersburg, MD, September.

Grill, R. A., D. A. Johnson, and D. A. Fanella. 2005. Federal Building and Fire Safety Investigation of the World Trade Center Disaster: Comparison of the 1968 and Current (2003) New 
York City Bnilding Code Provisions. NIST NCSTAR 1-1F. National Institute of Standards and Technology. Gaithersburg, MD, September.

Grill, R. A., and D. A. Johnson. 2005. Federal Building and Fire Safety Imvestigation of the World Trade Center Disaster: Amendments to the Fire Protection and Life Safety Provisions of the New York City Building Code by Local Laws Adopted While World Trade Center 1, 2, and 7 Were in Use. NIST NCSTAR 1-1G. National Institute of Standards and Technology. Gaithersburg, MD, September.

Grill, R. A., and D. A. Johnson. 2005. Federal Building and Fire Safety Investigation of the World Trade Center Disaster: Post-Constmction Modifications to Fire Protection and Life Safety Systems of World Trade Center 1 and 2. NIST NCSTAR 1-1H. National Institute of Standards and Technology. Gaithersburg, MD, September.

Grill, R. A., D. A. Johnson, and D. A. Fanella. 2005. Federal Building and Fire Safety Investigation of the World Trade Center Disaster: Post-Construction Modifications to Fire Protection, Life Safety, and Structural Systems of World Trade Center 7. NIST NCSTAR 1-1I. National Institute of Standards and Technology. Gaithersburg, MD, September.

Grill, R. A.. and D. A. Johnson. 2005. Federal Building and Fire Safety Investigation of the World Trade Center Disaster: Design, Installation, and Operation of Fmel System for Emergency Power in World Trade Center 7. NIST NCSTAR 1-1J. National Institute of Standards and Technology. Gaithersburg, MD, September.

Sadek, F. 2005. Federal Building and Fire Safety Investigation of the World Trade Center Disaster: Baseline Structmal Performance and Aircraft Impact Damage Analysis of the World Trade Center Towers. NIST NCSTAR 1-2. National Institute of Standards and Technology. Gaithersburg, MD, September.

Faschan, W. J., and R. B. Garlock. 2005. Federal Building and Fire Safety Investigation of the World Trade Center Disaster: Reference Structural Models and Baseline Performance Analysis of the World Trade Center Towers. NIST NCSTAR 1-2A. National Institute of Standards and Technology. Gaithersburg, MD, September.

Kirkpatrick, S. W., R. T. Bocchieri, F. Sadek, R. A. MacNeill, S. Holmes, B. D. Peterson, R. W. Cilke, C. Navarro. 2005. Federal Building and Fire Safety Investigation of the World Trade Center Disaster: Analysis of Aircraft Impacts into the World Trade Center Towers, NIST

NCSTAR 1-2B. National Institute of Standards and Technology. Gaithersburg, MD, September.

Gayle, F. W., R. J. Fields, W. E. Luecke, S. W. Banovic, T. Foecke, C. N. McCowan, T. A. Siewert, and J. D. McColskey. 2005. Federal Building and Fire Safety Investigation of the World Trade Center Disaster: Mechanical and Metallurgical Analys is of Structural Steel. NIST NCSTAR 1-3. National Institute of Standards and Technology. Gaithersburg, MD, September.

Luecke, W. E., T. A. Siewert, and F. W. Gayle. 2005. Federal Building and Fire Safety Investigation of the World Trade Center Disaster: Comtemporaneous Structural Steel Specifications. NIST Special Publication 1-3A. National Institute of Standards and Technology. Gaithersburg, MD, September. 
Banovic, S. W. 2005. Federal Building and Fire Safety Investigation of the World Trade Center Disaster: Steel Inventory and Identification. NIST NCSTAR 1-3B. National Institute of Standards and Technology. Gaithersburg, MD, September.

Banovic, S. W., and T. Foecke. 2005. Federal Building and Fire Safety Investigation of the World Trade Center Disaster: Damage and Failute Modes of Structural Steel Components. NIST NCSTAR 1-3C. National Institute of Standards and Technology. Gaithersburg, MD, September.

Luecke, W. E., J. D. McColskey, C. N. McCowan, S. W. Banovic, R. J. Fields, T. Foecke, T. A. Siewert, and F. W. Gayle. 2005. Federal Building and Fire Safety Investigation of the World Trade Center Disaster: Mechanical Properties of Structural Steels. NIST NCSTAR 1-3D. National Institute of Standards and Technology. Gaithersburg, MD, September.

Banovic, S. W., C. N. McCowan, and W. E. Luecke. 2005. Federal Building and Fire Safety Investigation of the World Trade Center Disaster: Plysical Properties of Structural Steels. NIST NCSTAR 1-3E. National Institute of Standards and Technology. Gaithersburg, MD, September.

Evans, D. D., R. D. Peacock, E. D. Kuligowski, W. S. Dols, and W. L. Grosshandler. 2005. Federal Building and Fire Safety Investigation of the World Trade Center Disaster: Active Fire Protection Systems. NIST NCSTAR 1-4. National Institute of Standards and Technology. Gaithersburg, MD, September.

Kuligowski, E. D., D. D. Evans, and R. D. Peacock. 2005. Federal Building and Fire Safety Investigation of the World Trade Center Disaster: Post-Construction Fires Prior to September 11, 2001. NIST NCSTAR 1-4A. National Institute of Standards and Technology. Gaithersburg, MD, September.

Hopkins, M., J. Schoenrock, and E. Budnick. 2005. Federal Building and Fire Safety Investigation of the World Trade Center Disaster: Fire Suppression Systems. NIST NCSTAR 1-4B. National Institute of Standards and Technology. Gaithersburg, MD, September.

Keough, R. J., and R. A. Grill. 2005. Federal Building and Fire Safety Investigation of the World Trade Center Disaster: Fire Alarm Systems. NIST NCSTAR 1-4C. National Institute of Standards and Technology. Gaithersburg, MD, September.

Ferreira, M. J., and S. M. Strege. 2005. Federal Building and Fire Safety Investigation of the World Trade Center Disaster: Smoke Management Systems. NIST NCSTAR 1-4D. National Institute of Standards and Technology. Gaithersburg, MD, September.

Gann, R. G., A. Hamins, K. B. McGrattan, G. W. Mulholland, H. E. Nelson, T. J. Ohlemiller, W. M. Pitts, and K. R. Prasad. 2005. Federal Building and Fire Safety Investigation of the World Trade Center Disaster: Reconstruction of the Fires in the World Trade Center Towers. NIST NCSTAR 1-5. National Institute of Standards and Technology. Gaithersburg, MD, September.

Pitts, W. M., K. M. Butler, and V. Junker. 2005. Federal Building and Fire Safety Investigation of the World Trade Center Disaster: Visual Evidence, Damage Estimates, and Timeline Analysis. NIST NCSTAR 1-5A. National Institute of Standards and Technology. Gaithersburg, MD, September. 
Hamins, A., A. Maranghides, K. B. McGrattan, E. Johnsson, T. J. Ohlemiller, M. Donnelly, J. Yang, G. Mulholland, K. R. Prasad, S. Kukuck, R. Anleitner and T. McAllister. 2005. Federal Building and Fire Safety Investigation of the World Trade Center Disaster: Experiments and Modeling of Structural Steel Elements Exposed to Fire. NIST NCSTAR 1-5B. National Institute of Standards and Technology. Gaithersburg, MD, September.

Ohlemiller, T. J., G. W. Mulholland, A. Maranghides, J. J. Filliben, and R. G. Gann. 2005. Federal Building and Fire Safety Investigation of the World Trade Center Disaster: Fire Tests of Single Office Workstations. NIST NCSTAR 1-5C. National Institute of Standards and Technology. Gaithersburg, MD, September.

Gann, R. G., M. A. Riley, J. M. Repp, A. S. Whittaker, A. M. Reinhorn, and P. A. Hough. 2005. Federal Building and Fire Safety Investigation of the World Trade Center Disaster: Reaction of Ceiling Tile Systems to Shocks. NIST NCSTAR 1-5D. National Institute of Standards and Technology. Gaithersburg, MD, September.

Hamins, A., A. Maranghides, K. B. McGrattan, T. J. Ohlemiller, and R. Anleitner. 2005. Federal Building and Fire Safety Investigation of the World Trade Center Disaster: Experinlents and Modeling of Multiple Workstations Burning in a Compartulent. NIST NCSTAR 1-5E. National Institute of Standards and Technology. Gaithersburg, MD, September.

McGrattan, K. B., C. Bouldin. and G. Forney. 2005. Federal Building and Fire Safety Investigation of the World Trade Center Disaster: Computer Simulation of the Fires in the World Trade Center Towers. NIST NCSTAR 1-5F. National Institute of Standards and Technology. Gaithersburg, MD, September.

Prasad, K. R., and H. R. Baum. 2005. Federal Building and Fire Safety Investigation of the World Trade Center Disaster: Fire Structure Interface and Thermal Response of the World Trade Center Towers. NIST NCSTAR 1-5G. National Institute of Standards and Technology. Gaithersburg, MD, September.

Gross, J. L., and T. McAllister. 2005. Federal Building and Fire Safety Investigation of the World Trade Center Disaster: Structural Fire Response and Probable Collapse Sequence of the World Trade Center Towers. NIST NCSTAR 1-6. National Institute of Standards and Technology. Gaithersburg, MD, September.

Carino, N. J., M. A. Starnes, J. L. Gross, J. C. Yang, S. Kukuck, K. R. Prasad, and R. W. Bukowski. 2005. Federal Building and Fire Safety Investigation of the World Trade Center Disaster: Passive Fire Protection. NIST NCSTAR 1-6A. National Institute of Standards and Technology. Gaithersburg, MD, September.

Gross, J., F. Hervey, M. Izydorek, J. Mammoser, and J. Treadway. 2005. Federal Building and Fire Safety Investigation of the World Trade Center Disaster: Fire Resistance Tests of Floor Truss Systems. NIST NCSTAR 1-6B. National Institute of Standards and Technology. Gaithersburg, MD, September.

Zarghamee, M. S., S. Bolourchi, D. W. Eggers, Ö. O. Erbay, F. W. Kan, Y. Kitane, A. A. Liepins, M. Mudlock, W. I. Naguib, R. P. Ojdrovic, A. T. Sarawit, P. R Barrett, J. L. Gross, and 
T. P. McAllister. 2005. Federal Building and Fire Safety Investigation of the World Trade Center Disaster: Component, Connection, and Subsystem Structural Analysis. NIST NCSTAR 1-6C. National Institute of Standards and Technology. Gaithersburg, MD, September.

Zarghamee, M. S., Y. Kitane, Ö. O. Erbay, T. P. McAllister, and J. L. Gross. 2005. Federal Building and Fire Safety Investigation of the World Trade Center Disaster: Global Structural Analysis of the Response of the World Trade Center Towers to Impact Danrage and Fire. NIST NCSTAR 1-6D. National Institute of Standards and Technology. Gaithersburg, MD, September.

McAllister, T., R. W. Bukowski, R. G. Gann, J. L. Gross, K. B. McGrattan, H. E. Nelson, L. Phan, W. M. Pitts, K. R. Prasad, F. Sadek. 2006. Federal Building and Fire Safety Investigation of the World Trade Center Disaster: Structural Fire Response and Probable Collapse Sequence of World Trade Center 7. (Provisional). NIST NCSTAR 1-6E. National Institute of Standards and Technology. Gaithersburg, MD.

Gilsanz, R., V. Arbitrio, C. Anders, D. Chlebus, K. Ezzeldin, W. Guo, P. Moloney, A. Montalva, J. Oh, K. Rubenacker. 2006. Federal Building and Fire Safety Investigation of the World Trade Center Disaster: Structural Analysis of the Response of World Trade Center 7 to Debris Damage and Fire. (Provisional). NIST NCSTAR 1-6F. National Institute of Standards and Technology. Gaithersburg, MD.

Kim, W. 2006. Federal Building and Fire Safety Investigation of the World Trade Center Disaster: Analysis of September 11, 2001, Seisnogram Data. (Provisional). NIST NCSTAR 1-6G. National Institute of Standards and Technology. Gaithersburg, MD.

Nelson, K. 2006. Federal Building and Fire Safety Investigation of the World Trade Center Disaster: The Con Ed Substation in World Trade Center 7. (Provisional). NIST NCSTAR 1-6H. National Institute of Standards and Technology. Gaithersburg, MD.

Averill, J. D., D. S. Mileti, R. D. Peacock, E. D. Kuligowski, N. Groner, G. Proulx, P. A. Reneke, and H. E. Nelson. 2005. Federal Building and Fire Safety Investigation of the World Trade Center Disaster: Occupant Behavior, Egress, and Emergency Conmunication. NIST NCSTAR 1-7. National Institute of Standards and Technology. Gaithersburg, MD, September.

Fahy, R., and G. Proulx. 2005. Federal Building and Fire Safety Investigation of the World Trade Center Disaster: Analysis of Published Accounts of the World Trade Center Evacuation. NIST NCSTAR 1-7A. National Institute of Standards and Technology. Gaithersburg, MD, September.

Zmud, J. 2005. Federal Building and Fire Safety Investigation of the World Trade Center Disaster: Teclmical Documrentation for Survey Administration. NIST NCSTAR 1-7B. National Institute of Standards and Technology. Gaithersburg, MD, September.

Lawson, J. R., and R. L. Vettori. 2005. Federal Building and Fire Safety Investigation of the World Trade Center Disaster: The Eniergency Response Operations. NIST NCSTAR 1-8. National Institute of Standards and Technology. Gaithersburg, MD, September. 


\section{EXECUTIVE SUMMARY}

\section{E.1 INTRODUCTION}

The National Institute of Standards and Technology (NIST) conducted a building and fire safety investigation of the World Trade Center (WTC) disaster. The work documented in this report was performed in support of the investigation of active fire protection systems. This effort involved investigation of the performance of pre-connected hoses, standpipes, and automatic fire sprinkler systems, and the associated water supplies for WTC 1,2 , and 7.

There was very little eyewitness or communications information regarding the performance of the fire suppression systems on September 11, 2001. The descriptions of the systems and their inherent operational capabilities described in this report are considered reasonably accurate. The performance of the individual suppression systems on September 11.2001 was based on review of the incident information accumulated by NIST, analysis of the likely initial impact effects on the systems, and historical performance records for automatic sprinklers. Where possible, significant events and/or effects were determined based on information from more than one source. However, due to the fragmentation of available information regarding the events of September 11, this could not always be accomplished.

Descriptions of suppression systems, likely events or actions, and subsequent effects were based on, and/or deduced from, available information. Events or effects that were considered "likely" or "probable," based on the accumulated information, were considered appropriate for inclusion.

\section{E.1.1 Incident Description}

On September 11,2001, WTC 1 was struck by a hijacked commercial aircraft. The impact occurred between the 93 rd and 99 th floors. Subsequently, WTC 2 was struck by a second hijacked aircraft. The impact of this second aircraft was between the 77 th and 85 th floors. Extensive impact damage occurred on multiple floors of both buildings. Fires extended over multiple floors in each building with a significant initial contributor to fire spread being the aviation fuel from the two aircrafts (McAllister 2002).

WTC 2 was the first building to collapse. Collapse occurred approximately 56 min after impact. WTC 1 collapsed approximately $1 \mathrm{~h}$ and $43 \mathrm{~min}$ after impact. Both buildings suffered total, progressive collapse, resulting in exposure of surrounding buildings to debris and burning materials.

WTC 7 burned for over $7 \mathrm{~h}$ before collapsing. The working hypothesis at the time this study was completed, involved an initial local failure of the structure below the 13 th floor due to fire and/or debris induced structural damage of a critical column. This incident resulted in a number of fires burning uncontrollably and global structural collapse of the building.

The collapses of the two tower buildings also caused damage to the New York City (NYC) water system in the streets surrounding the WTC complex. 


\section{E.1.2 Scope and Objectives}

Five specific objectives associated with this effort included the following:

1. Documentation of the design and installation of the fire sprinkler systems, standpipe systems, and pre-connected hoses and comparison of the designs to applicable code and standards requirements (Task 1).

2. Documentation of the design and capacity of the water supply to the fire sprinklers including provisions for redundancy (Task 2).

3. Identification and documentation of the differences in the design of the water supply, fire sprinkler systems, standpipe systems, and pre-connected hoses among WTC 1, 2, and 7 (Task 3).

4. Documentation of the normal operation and effect of fully functional fire sprinkler system, standpipe system, and pre-connected hoses for fire control (Task 4).

5. Documentation of the performance of the sprinkler systems, standpipe systems, and preconnected hoses on September 11, 2001 in WTC 1, 2, and 7 (Task 5).

\section{E.1.3 General Approach}

A literature review was performed in order to document the installed fire suppression features in WTC 1, 2 , and 7 as well as to provide any information regarding the performance of these systems on September 11, 2001. The primary source of documents and related information (e.g., drawings, specifications, procedures, etc.) were the documents collected and maintained by NIST during the WTC investigation. NIST had been accumulating information related to the design, construction, and operation of WTC 1, 2, and 7 as well as information related to the incidents on September 11. The information available from NIST was supplemented by information in the open literature, information from the Hughes Associates, Inc. (HAI) technical library, and inquiries by NIST to appropriate organizations in New York City. In addition, information related to applicable codes and standards of record was provided in studies performed by Rolf Jensen and Associates (RJA) as part of the NIST investigation (Razza and Grill 2005).

Based on available information and codes and standards documentation, the fire suppression features that existed in WTC 1, 2, and 7 were reconstructed and documented. Once this was completed, hydraulic analyses were performed to provide estimates of the baseline capabilities of the suppression systems as well as capabilities under different fire incident scenarios, including the events of September 11, 2001. Performance criteria for the suppression systems were selected based on requirements in National Fire Protection Association (NFPA) 13, Standard for the Installation of Sprinkler Systems, and NFPA 14, Standard for the Installation of Standpipe, Private Hydrant, and Hose Systems, the primary design and installation standards for fire suppression systems in high-rise buildings. 


\section{E.2 SITE AND BUILDING DESCRIPTIONS}

\section{E.2.1 General Site Descriptions}

The WTC complex consisted of seven buildings located on 16 acres in lower Manhattan in New York City. WTC buildings 1 through 6 were constructed on the primary WTC Plaza. WTC 7, completed in the mid-1980s, was the last building constructed, just north of the WTC Plaza. A six-level structure below the ground floor of the main WTC Plaza included utilities, parking, and subway stations.

\section{E.2.2 WTC 1 and WTC 2}

WTC 1 (North Tower) and WTC 2 (South Tower) were each 110 stories in height above the plaza level, and 7 stories below. For the most part, the two towers were similar in size and layout. Each floor was approximately $207 \mathrm{ft}$ by $207 \mathrm{ft}$, providing nearly an acre of floor area. A service core (approximately $87 \mathrm{ft}$ by $137 \mathrm{ft}$ ) was located in the center of each tower. The elevators, stairwells, primary piping, and ventilation duct systems were located in this service core.

\section{E.2.3 WTC 7}

WTC 7 was a 47 -story office building with nearly two million square feet of office space. Floors 8 through 47 were primarily office spaces. The elevators, stairwells, primary piping, and ventilation duct systems were located in the core of the building. Loading docks and an electrical substation that provided power to lower Manhattan were located in the lower part of the building at the ground level. Switchgear, generators, transformers, management offices, and transformer vaults were located on floors one through nine. Two 12,000 gal fuel tanks were located below the first floor loading dock, and one 6,000 gal fuel tank was located above ground on the first floor. These tanks supplied the 275 gal day tanks on the fifth, seventh, and eighth floors and a 50 gal day tank on the ninth floor. Also, there were two 6,000 gal tanks located below the first floor that supplied the fifth floor. A pressurized fuel distribution system extended to the fifth floor, supplied from these tanks.

\section{E.3 DESCRIPTION OF THE NYC WATER SUPPLY}

The primary source of water for the WTC complex was the NYC water supply and distribution system. This system was operated by the New York City Department of Environmental Protection (NYC DEP). Two separate divisions (bureaus) of the DEP were responsible for the water supply and distribution system: The Bureau of Water Supply (BWS) and the Bureau of Water and Sewer Operations (BWSO) (LZA 2002).

The NYC water distribution system in lower Manhattan surrounding the WTC complex was composed of a complex gridded network of $20 \mathrm{in}$. and $12 \mathrm{in}$. ductile iron mains. A $20 \mathrm{in}$. loop was located beneath the streets surrounding the main WTC complex where towers WTC 1 and WTC 2 were located. The mains were beneath Vesey Street to the north, Liberty Street to the south, Church Street to the east, and West Street to the west. These mains were inter-connected to a series of $20 \mathrm{in}$. and $12 \mathrm{in}$. mains. This permitted water to flow along a large number of flow paths, minimizing the effects of friction loss while flowing a large volume of water. The large volume of water within the distribution system mains, 
transmission mains, and at the source (watersheds in upstate New York) allowed for a large capacity of water to be available for fire fighting capabilities.

A 20 in. water main was located beneath West Broadway, immediately to the east of WTC 7. This main supplied water to the $20 \mathrm{in.}$ loop around the WTC plaza. A $12 \mathrm{in}$. main to the west of WTC 7 beneath Washington Street supplied two parallel 8 in. diameter lead-ins (feeder mains) for WTC 7 and connected to $12 \mathrm{in}$. main at the north side of WTC 7 beneath Barclay Street and the $20 \mathrm{in}$. main beneath Vesey Street. The 12 in. main on Barclay Street increased to a 20 in. diameter pipeline near the center of WTC 7 at Greenwich and interconnected to the $20 \mathrm{in.}$ main on West Broadway. A $12 \mathrm{in.main}$ and a separate 20 in. parallel main eonnected to the 20 in. water main on Barclay and continued to the north on Greenwich.

This arrangement of the water distribution system provided a near constant pressure for all flows that are normally anticipated for fire protection system demands, with a residual pressure that was nearly identical to the static pressure. Standard practice in New York City was to flow 500 gpm to 750 gpm through the 12 in. and 20 in. mains, respectively. Such flows typically would not cause a recognizable drop in the system pressure.

\section{E.4 INSTALLED FIRE SUPPRESSION FEATURES}

The scope of Task 1 included a detailed reconstruction and documentation of the water supplies, automatic sprinkler systems, standpipe, and pre-connected hose systems and any special fire suppression features or systems that existed in WTC 1, 2, and 7 on September 11, 2001.

\section{E.4.1 WTC 1 and WTC 2}

WTC 1 and 2 were protected by automatic fire sprinkler systems, essentially throughout. The sub-grade areas of the complex were provided with sprinkler systems during the initial construction. The systems were not installed in the towers during construction of the two buildings, but retrofit installations were carried out in two phases. The first phase included the installation of the sprinkler system infrastructures and sprinklers in common areas and certain tenant and Port Authority of New York and New Jersey (PANYNJ or Port Authority) spaces in response to the adoption of Local Law 5 (New York 1973). The second phase included the installation of the sprinkler systems throughout the remaining areas of the complex during the period from 1983 to 2001. The retrofit program had been completed prior to September 11, 2001.

In addition to automatic fire sprinkler systems, each building was configured with four vertical water supply zones that included three vertical standpipe risers in the stairwells of each zone. The standpipes provided fire suppression water to pre-connected hoses located in the stairwells at each floor. The standpipe systems were equipped with Class III pre-connected hose stations in all exit stair enclosures and in certain corridors and tenant spaces. Each hose station had a standpipe hose control valve, a $125 \mathrm{ft}$ long fire hose and a nozzle for use by a trained fire brigade or The Fire Department of the City of New York (FDNY).

The primary water supply for the standpipe systems was initially gravity-fed from reserve water storage tanks located above the standpipe system zone. Also, a series of manually operated fire pumps provided 
water supplied by the NYC water distribution system. The primary water supply consisted of a fire main that looped the WTC complex. The 12 in. diameter main was supplied directly from the municipal water supply by two redundant $16 \mathrm{in}$. diameter connections. Operating pressures were maintained by two 750 gpm high-pressure electric pumps that supplied the sub-grade loops and were located beneath the towers on the Bl level of the complex.

Each tower had three $750 \mathrm{gpm}$ manually operated electrical fire pumps, located on the $7 \mathrm{th}, 41 \mathrm{st}$ and 75 th floors, to supplement standpipe pressures. Each pump provided sufficient pressure for the standpipes to skip the next sequential pump above it if any failed to operate. In addition to the pumps, a single $500 \mathrm{gpm}$ automatic fire pump was provided in each tower on the 108th floor for the sprinkler systems located on the 99th through 107th floors and the hose stations in the mechanical rooms on the 108th through 110 th floors. Six emergency power generators were located in the basement at the B-6 level. These generators provided back-up power to the fire pumps, as well as to communications equipment, elevators, and emergency lighting.

Additional components of the water supply were 5,000 gal storage tanks, filled from the building's domestic water system. Tanks were located on the 20th, 41 st, 75 th and 110 th floors in each tower.

Although these tanks served as the secondary water supply, the tanks supplied the initial water supply to the fire brigade or the FDNY. Without supplemental water supplied by the domestic water system, the tanks provided approximately 10 min for the PANYNJ maintenance staff to manually start the fire pumps. The tank on the 20th floor directly supplied the main loop.

Fourteen fire department connection (FDC) stations were located at ground level for use by the FDNY to supplement the water supply and pressure to the fire suppression systems in the buildings. Any of the FDC stations could be used to supply the standpipe systems throughout the complex of sprinkler systems in WTC 1 and WTC 2 above the 32nd floor level. Isolation valves were installed between each consecutive FDC station. This provided independent supply and operation of the standpipe systems throughout the WTC complex. Two additional express FDC stations were provided to supply only the sprinkler systems in WTC 1 and WTC 2 above the 32nd floor level, and, two separate FDC stations were provided for the sprinkler systems in WTC 1 and WTC 2 below the 31 st floor level.

Several types of special suppression systems were used in WTC 1 and WTC 2. These systems included (a) kitchen ventilation, dry chemical and steam smothering systems, (b) carbon dioxide $\left(\mathrm{CO}_{2}\right)$ systems, and (c) Halon 1301 total flooding systems. These systems were supervised by the fire alarm systems at WTC 1 and WTC 2 and were designed to transmit signals to FDNY upon operation.

The Operations \& Maintenance (O\&M) manual for WTC 1 and WTC 2 indicated that ventilation and grease extraction systems were installed in restaurant kitchens above fryers, griddles, ranges, boilers, and ovens, but did not provide specific locations where these systems were installed (PANYNJ 1987a).

The O\&M manual identified that steam smothering systems were installed in the kitchens at the following locations:

- PA Cafeteria

- The "Big Kitchen" 
- $\quad$ The Sky Dive

- Windows on the World

- The New York State Cafeteria

- The Observation Deck

A total flooding $\mathrm{CO}_{2}$ system was used to protect the under floor space of a large computer room in WTC 2 (PANYNJ 1987a). There was reference to other systems at the WTC complex, but specific information regarding the locations of these systems was not found. The available drawings for WTC 1 show that two Halon 1301 systems were installed for protection of the computer room on the 70th floor (PANYNJ 1972). One system was installed for protection of the under floor space and the other for protection of the room.

\section{E.4.2 WTC 7}

Available documentation and drawings indicated that automatic fire sprinkler systems were installed in most areas of WTC 7. Sprinkler systems were not installed in the electrical equipment spaces, including switchgear, networking, and switchboard rooms. They were also not installed in bathrooms throughout the building. A majority of the fifth floor was not protected by sprinkler systems, with exception of the mechanical space to the east and the office area along the north side of the building (Syska \& Hennessy 1984). Finally, no evidence was found to indicate that sprinklers were present in enclosures on the fifth, seventh, eighth, and ninth floors, which housed the Office of Emergency Management (OEM) generators and day tanks.

A standpipe system was installed in each stairwell. Pre-connected hoses were located in the stairwells at each floor, connected to the standpipe. In addition, a supplemental pre-connected hose cabinet was located on the east side of each floor. Additional hose cabinets were installed in different locations on different floors in order to achieve the required reach for the hose lines.

The primary water supply for WTC 7 was provided by the 12 in. water main beneath Washington Street. FDCs were located on the south, east, and west sides of the building (Syska \& Hennessy 1984). A $750 \mathrm{gpm}$ manual fire pump that served the entire building was located on the ground floor. A $500 \mathrm{gpm}$ automatic fire pump, located on the ground floor, supplied the sprinkler and standpipe systems through the 20th floor (Syska \& Hennessy 1984). The 21 st floor through 39th floor sprinkler systems and 21 st floor through 44th floor standpipe systems were supplied from two gravity-fed water storage tanks on the 47th floor (Syska \& Hennessy 1984). Each tank had a holding capacity of 18,000 gal and a fire reserve capacity of 7,500 gal (Syska \& Hennessy 1984). The 40th floor through 47th floor sprinkler systems and the 45 th floor through 47 th floor standpipe systems were supplied from the storage tanks on the 47 th floor via a $500 \mathrm{gpm}$ booster pump on the 46th floor.

Emergency power generators were located on several floors to provide back-up power to emergency systems in the building, including the fire pumps (Swanke et al. 1998; GC Engineering 1998a; McAllister 2002; Grill and Johnson 2005b). 
The loading berth and fuel oil pump rooms in WTC 7 were protected by dry-pipe sprinkler systems (Swanke et al. 1998). The room containing the tank was protected by an Inergen clean agent fire suppression system (Swanke et al. 1998). The elevator storage area beneath the tank was protected by a wet pipe sprinkler system (Swanke et al. 1998).

\section{E.4.3 Consistency with Engineering "Best Practices"}

An evaluation of the consistency of the system installations with applicable codes and standards provisions and state-of-the-art engineering "best practices" during the time of construction of the buildings (or time of installation if a retrofit) was performed for WTC 1,2, and 7. The intent of this evaluation was to determine if the installed fire protection systems in these three buildings were designed and installed in a manner consistent with performance expectations associated with applicable codes and standards as well as those related to recommended best practices at the time of the design and construction of the buildings. The evaluation was limited to the installation features associated with the fire suppression systems. The results of this evaluation indicated that for the most part the fire protection systems in WTC 1,2, and 7 were installed in a manner consistent with state-of-the-art best practices in existence at the time of their installation. In fact, the installations would satisfy current best practices, with several exceptions.

While not inconsistent with code, standards, or best practices at the time of installation, several suppression system design features were identified that would not constitute current best practices. In WTC 1 and WTC 2, the supply pipe from the primary water storage tanks on the 110th floor to the sprinkler systems included a long horizontal length $(>100 \mathrm{ft}$ ) of pipe on the floor directly under the tanks that led to the vertical riser. Due to the associated friction loss in this run of pipe, the flow was unnecessarily restricted on the upper floors. This problem was not identified because the demand calculations were performed back to the riser, at floor level. Current best practices involve demand calculations back to the water supply. This approach, while not required by code at the time of installation, would have identified the excessive friction loss associated with the extended length of horizontal supply pipe located directly under the supply tanks.

The single supply point at each floor level connection of the sprinkler system to the sprinkler riser represented a single point failure location for the sprinkler systems on that floor. This resulted in an overall reduced operational reliability for the sprinkler systems under conditions where the standpipe was shut down for maintenance or the supply through one riser or standpipe was interrupted.

The supplemental water supply to WTC 1 and WTC 2 required operation of manual fire pumps. While the use of manual fire pumps was permitted in the Building Code of the City of New York (BCNYC), accessibility and operability of manually operated fire pumps by building personnel is inherently less reliable than automatic water supplies. The stored water tanks in WTC 1 and WTC 2 would have provided on the order of $20 \mathrm{~min}$ to $30 \mathrm{~min}$ of water to the sprinklers and standpipe/pre-connected hoses. An automatic supplemental supply is required in NFPA 14 and represents current best practice. However, due to the extent of damage to the sprinkler and risers on September 11, 2001, it is doubtful that an automatic water supply would have significantly improved the performance of the suppression systems in the upper floors of WTC 1 and WTC 2. 
In WTC 7, the automatic sprinkler systems on floors 1 through 20 were supplied directly from the city distribution system through an automatic fire pump located on the first floor. Either a loss of power to the fire pump or significant damage to the underground city main in the vicinity of the building could interrupt the water supply to these sprinkler systems. A simple means of backing up the primary water supply for floors 1 through 20 would have been to provide secondary access to the stored water on the upper floors of the building.

\section{E.5 EVALUATION OF SPRINKLER SYSTEMS WATER SUPPLY}

\section{E.5.1 Approach}

The objectives of Task 2 were to evaluate and document the flow capacity and duration of the water supplies to the floor level automatic sprinkler systems. Task 2 also included evaluation of the extent of redundant water supply paths to the sprinkler systems.

A detailed review of available information was performed in order to document the water supply system infrastructure and associated redundancies. The capacity of the water supply system was evaluated based on available water flow density. The duration of water supply was evaluated based on what would be considered normally expected conditions. These two parameters were the primary factors associated with the expected performance of the sprinkler systems in WTC 1,2, and 7.

The sprinkler and standpipe system infrastructures were reconstructed using the available documentation. Hydraulic calculations were performed to evaluate the expected sprinkler system performance based on the configuration of the water supply. The objective of the analysis was to determine any variations in the performance of the sprinkler systems in each building and within each water supply zone. The initial water supplies for the systems were primarily gravity-fed from stored water tanks. A group of sprinkler systems from each building was selected for analysis. Sprinkler systems near the top and the bottom of each water supply zone were selected to bound the effects of elevation on the performance of these sprinkler systems. In some cases intermediate systems were also selected for evaluation because the arrangements of the systems varied as a result of using outside screw and yoke (OS\&Y) or pressure reducing type control valves. A commercial computer program, Hydraulic Analyzer of Sprinkler Systems, Version 7.5 (HASS) was used to perform the calculations (HRS 2004).

Several factors were examined as part of this analysis. Supply calculations were used as a means to compare the flow rate of water delivered from the primary and secondary supplies to the sprinkler systems. Calculations were also performed with variations in the number of sprinklers flowing water. Calculations were performed for the highest and lowest floor level sprinkler systems to observe the effects of elevation on the discharge density of the sprinkler systems and water supply duration (i.e., how long the flow could be maintained). The intent of this analysis was to provide sufficient information to characterize the capabilities of the water supplies.

As part of this task, redundancies in the water supply infrastructure to the sprinkler and standpipe systems were identified. The redundancies included both automatic and manually operated features of the systems. 


\section{E.5.2 Task 2 Summary}

The automatic sprinkler systems were provided with both primary and secondary water supplies. In most cases the supply piping was configured to provide redundant supply paths to the water supply zones in the buildings. This arrangement would allow for continued sprinkler operability in the event that one of the supply paths was interrupted. In addition, the results of the hydraulic analyses indicated that the expected water densities and duration of the water supplies exceeded the baseline levels customarily required for fire hazards typically found in high-rise office building occupancies.

\section{Supply Sources and Redundancies}

The primary source of water for the WTC complex was the NYC water distribution system. A complex grid of $20 \mathrm{in}$. and $12 \mathrm{in.}$ mains surrounded the WTC complex, forming a dependable water supply with an average static pressure of 50 psi. Each building was supplied with water from the NYC water distribution system from multiple access points.

The WTC complex was provided with two separate supply connections at Vesey and Liberty Streets with isolation valves to permit independent operation. WTC 7 was provided with two connections from the 12 in. main on the Washington Street side of the building. These two connections were approximately $12 \mathrm{ft}$ apart.

The water supply components included water storage tanks, fire pumps and fire department connections. In most cases, the primary water supplies for the automatic fire sprinkler and standpipe systems consisted of gravity tanks and booster pumps.

Three separate 5,000 gal water storage tanks were provided for the high and mid-level zone sprinkler and standpipe systems at the tops of both WTC 1 and WTC 2. A fourth single 5,000 gal storage tank was provided on the 41 st floor of each tower. These tanks were interconnected by a 4 in. diameter pipe. Each tank was provided with a separate re-fill connection. The maintenance and engineering staff would supply water to the fire suppression systems using manually operated fire pumps. The FDNY could supply water to the fire suppression systems using the fire department connections.

The systems in WTC 7 included one automatic and two manually operated water supplies. The combined systems were provided with a single automatic fire pump for the low zone. The high and mid-level zones were supplied from two water storage tanks located on the 47th floor. The high zone also included a booster fire pump. A single 750 gpm fire pump supplied the secondary water. The FDNY could also supply water to the systems using the fire department connections.

\section{Calculated Design Densities and Flow Durations}

Hydraulic calculations were performed based on the requirements contained in the 2002 edition of NFPA 13. The results of the hydraulic calculations for the Light Hazard Occupancy sprinkler systems in WTC 1 and 2 indicated that the expected supply densities ranged from $0.14 \mathrm{gpm} / \mathrm{ft}^{2}$ to $0.27 \mathrm{gpm} / \mathrm{ft}^{2}$ for four open sprinklers. The associated flow rate could be maintained from the primary water supply source for approximately $33 \mathrm{~min}$ to $89 \mathrm{~min}$, depending on the location. A density of $0.13 \mathrm{gpm} / \mathrm{ft}^{2}$ to $0.18 \mathrm{gpm} / \mathrm{ft}^{2}$ could be maintained for eight open sprinklers for $18 \mathrm{~min}$ to $39 \mathrm{~min}$. And a density of $0.10 \mathrm{gpm} / \mathrm{ft}^{2}$ to $0.15 \mathrm{gpm} / \mathrm{ft}^{2}$ could be provided for 16 open sprinklers for $10.5 \mathrm{~min}$ to $32.7 \mathrm{~min}$. 
Similarly, the results of the calculations for the Ordinary Hazard Group 1 sprinkler systems in WTC 1 and WTC 2 indicated that a density ranging from $0.33 \mathrm{gpm} / \mathrm{ft}^{2}$ to $0.56 \mathrm{gpm} / \mathrm{ft}^{2}$ could be provided to four open sprinklers for $18 \mathrm{~min}$ to $61 \mathrm{~min}$. A density ranging from $0.22 \mathrm{gpm} / \mathrm{ft}^{2}$ to $0.38 \mathrm{gpm} / \mathrm{ft}^{2}$ could be provided for 15 open sprinklers for $8 \mathrm{~min}$ to $27 \mathrm{~min}$. A density of $0.18 \mathrm{gpm} / \mathrm{ft}^{2}$ to $0.25 \mathrm{gpm} / \mathrm{ft}^{2}$ could be provided to 20 sprinklers for $8 \mathrm{~min}$ to $25 \mathrm{~min}$. And, a density of $0.15 \mathrm{gpm} / \mathrm{ft}^{2}$ to $0.22 \mathrm{gpm} / \mathrm{ft}^{2}$ could be provided for up to 25 sprinklers for $8.7 \mathrm{~min}$ to $25.8 \mathrm{~min}$ on most floors.

The results of the calculations using the light hazard criteria for the sprinkler systems in WTC 7 indicate that the available water density ranging from $0.17 \mathrm{gpm} / \mathrm{ft}^{2}$ to $0.38 \mathrm{gpm} / \mathrm{ft}^{2}$ could be maintained for four open sprinklers for $87 \mathrm{~min}$ to $133 \mathrm{~min}$. A density of $0.16 \mathrm{gpm} / \mathrm{ft}^{2}$ to $0.22 \mathrm{gpm} / \mathrm{ft}^{2}$ could be provided to nine open sprinklers for $45 \mathrm{~min}$ to $61 \mathrm{~min}$. And a density of $0.11 \mathrm{gpm} / \mathrm{ft}^{2}$ to $0.16 \mathrm{gpm} / \mathrm{ft}^{2}$ could be provided to 18 open sprinklers for $31 \mathrm{~min}$ to $45 \mathrm{~min}$. The durations do not apply to the low zone sprinkler systems because water was supplied from an automatic fire pump drawing suction directly from the NYC distribution. For the low zone sprinkler systems, the supply would be continuously provided as long as the water distribution and electrical systems were intact and operational.

\section{E.6 SUPPRESSION SYSTEM INSTALLATION DIFFERENCES}

The objectives of Task 3 were to identify and document differences in the water supply, fire sprinkler systems, and standpipes/pre-connected hoses among WTC 1, 2, and 7.

WTC 1 and WTC 2 were constructed in the 1970s. Some of the fire suppression infrastructure was installed at that time. However, the automatic sprinkler systems were installed later, in the 1980s and 1990s. Construction of WTC 7 was completed in 1986, and all of the fire suppression features for WTC 7 were installed as part of the initial construction of the building. WTC 7 contained fuel tanks, pressurized fuel piping, and associated generators at several locations in the building for emergency power. Task 3 required identification of any significant differences in the design of the fire suppression systems in WTC 1,2, and 7, as well as estimation of the impact of these differences on the expected level of fire control.

The primary water source for all three buildings originated from the NYC water distribution system. The towers were supplied from the sub-grade loops on the north and south sides of the complex at two remote locations. The two mains provided redundant supplies and had isolation valves to allow for independent operation of either main without impairing the fire suppression systems in the WTC complex. Two mains located within $12 \mathrm{ft}$ of each other supplied WTC 7 from the same NYC water distribution system main. The primary difference between the sprinkler and standpipe systems in WTC 7 and those in the towers was that the sprinkler and standpipe systems in WTC 1 and WTC 2 were separate, and the sprinkler and standpipe systems in WTC 7 were combined. Both arrangements were permitted by code.

Multiple water supply zones were provided in each building. The standpipe systems in WTC 1 and WTC 2 included four vertical zones. The sprinkler system infrastructures in WTC 1 and WTC 2 included three vertical zones. The combined sprinkler and standpipe systems in WTC 7 had three vertical zones.

Water storage tanks were used as the primary water supplies for all sprinkler and standpipe system zones in WTC 1, 2 and 7, except for the low zones of WTC 7, which were supplied by the NYC water distribution system through a $500 \mathrm{gpm}$ automatic fire pump. A single $750 \mathrm{gpm}$ manual fire pump was 
used as the secondary water supply for the combined sprinkler and standpipe systems in WTC 7. A series of four vertical $750 \mathrm{gpm}$ manual fire pumps were used in each tower.

Automatic sprinkler systems were provided in most areas of WTC 1,2, and 7. Sprinklers were omitted from the mechanical equipment rooms (MERs) in WTC 1 and WTC 2. The electrical, data/telephone, and generator rooms that were part of the core areas in WTC 7, as well as the bathrooms, were not protected by sprinkler systems. Most of the fifth floor of WTC 7 was not protected by automatic sprinklers.

The sprinkler systems in all three of the buildings were designed and installed with looped mains and were capable of delivering robust discharge densities exceeding the code required minimum densities. Pressure reducing valves were used in all three buildings. Although the configurations were somewhat different, it is doubtful that there were any significant advantages or disadvantages associated with these differences relative to their performance on September 11, 2001.

The standpipe systems in all three buildings were similar in design configuration to NFPA 14 Class III type standpipes. The standpipes in WTC 1 and WTC 2 were separate from the automatic sprinkler system risers within the protection zones. In WTC 7, the systems were combined. Either method is permitted by code.

The types of special hazard fire suppression systems that were installed in each building were different. No information was found that indicated that these systems played a significant role in fire control or the loss of fire control on September 11,2001.

In WTC 7, the automatic sprinkler systems on floors 1 through 20 were supplied from the city water distribution system through an automatic fire pump located on the first floor. A loss of power to the fire pump or significant damage to the underground city main in the vicinity of the building could interrupt the water supply to the sprinklers on these floors.

\section{E.7 SUPPRESSION SYSTEM PERFORMANCE UNDER SELECTED FIRE SCENARIOS}

The objective of Task 4 was to determine the expected performance of the automatic sprinkler systems and the standpipe/pre-connected hose systems in WTC 1,2, and 7 under specified fire scenarios. A lack of performance criteria and history for standpipe systems limited the evaluation of the pre-connected hoses.

\section{E.7.1 Approach}

Hydraulic analyses relied on the minimum delivered density and pressure requirements in NFPA 13, Installation of Sprinkler Systems, as the basic criteria for evaluating the fire control capacity of the sprinkler systems. These criteria were generally applicable to the design and installation of sprinkler systems at the time the systems were retrofit installed in WTC 1 and WTC 2, as well as when the systems were originally installed at WTC 7. It is important to recognize that in NFPA 13, the required densities and pressures are based on the assumption that an installed fire sprinkler system is designed to control a single fire. In addition, in the analyses performed here, fires were assumed to be approximately the size 
of the area covered by a four-sprinkler array (i.e., $\sim 750 \mathrm{ft}^{2}$ ). In fact, available performance history indicates that typical fires in high-rise office buildings are controlled or suppressed by less than four sprinklers, lending conservatism to the estimates of system capacity presented here. Finally, the calculations were based on availability of the primary water supplies only, without any consideration for fire department actions to provide a secondary water supply.

In New York City, fire department operations to provide a supplemental water supply are routine, and the supplemental water supply is considered infinite in duration (FDNY 1990). Due to the normal availability of a reliable, high capacity secondary water supply, duration of water supply was not included in this analysis.

\section{E.7.2 Task 4 Summary}

Based on the analyses performed as part of Task 4, the installed sprinkler systems in WTC 1, 2, and 7 had the ability to simultaneously control or suppress multiple fires under "normally expected" operating conditions. The fires could have occurred at different locations on a single floor or on multiple floors. The results indicated that the water flow density and pressure associated with the installed sprinkler systems had the capacity to control fires on the order of two to three times the required sprinkler system design area $\left(1,500 \mathrm{ft}^{2}\right)$, depending on the location in the building, and the systems would be expected to control at least four to six simultaneously occurring smaller fires similar in area to that protected by a four-sprinkler array $\left(750 \mathrm{ft}^{2}\right)$.

The calculations identified limits of performance; however, these estimated limits were significantly greater than the minimum design density requirements contained in the 2002 edition of NFPA 13 . These systems would have been expected to control multiple small area fires or single large fires up to two or three times the sprinkler system design area, and would have been considered to have excess capacity. At the same time, if large fires were to open all of the sprinklers in an area equivalent to two to three times the design area of the sprinkler systems, the hydraulic capabilities of the system(s) would be expected to degrade. And, although these operating areas would be considered relatively large (i.e., $3,000 \mathrm{ft}^{2}$ to $4,500 \mathrm{ft}^{2}$ ), they only represented roughly 8 percent to 15 percent of the occupied floor areas in WTC 1,2 , and 7 .

Flow restrictions existed in the mid-level water supply zones in WTC 1 and WTC 2, but the limits of available water flow were still considerably higher than those required in NFPA 13 for control of typical light hazard occupancy fires.

While it is difficult to assess the performance capabilities of the standpipe/pre-connected hoses, hydraulic calculations indicated that the size of the standpipes and the capacity and number of fire pumps were adequate to meet the requirements for pressure and flow in the BCNYC. The booster pump on the 46th floor was undersized and could not provide the higher minimum flow and pressure required in NFPA 14, Standard for Installation of Standpipe, Private Hydrants and Hose Systems (NFPA 2000). While this was not a violation of the BCNYC it would not be considered "best engineering practice" 


\section{E.8 ESTIMATES OF SUPPRESSION SYSTEMS' PERFORMANCE ON SEPTEMBER 11, 2001}

The objective of the Task 5 analysis was to estimate the performance of the automatic fire sprinkler and standpipe systems in WTC 1, 2, and 7 on September 11,2001. Given the design and intended operation of the fire protection systems, an attempt was made to address specific questions related to the performance of these systems. These questions included:

- What initially happened to the operational condition of the systems as a result of each major event?

- How was the performance of the systems impacted by each event? and,

- At what point in the sequence of events were the systems lost?

The damage estimates for the sprinkler and standpipe systems are based on initial damage estimates provided by NIST as part of Project No. 2. Extensive initial structural and compartment damage to the core areas of the building were estimated to have occurred on floors (94 through 96 in WTC 1 and floors 78 through 81 in WTC 2. These damage estimates are illustrated in Figs. 9-1 and 9-2. Additional damage occurred outside the core areas. However, the focus of this analysis was limited to areas where the suppression system would have sustained damage to their infrastructures (i.e., risers and standpipes). This was primarily limited to the core areas of the buildings.

Final damage estimates resulting from further analyses that extended beyond the contract period for this effort are reported in NIST NCSTAR 1-6E and NCSTAR 1-7 (McAllister et al. 2005; Averill ct al. 2005). The areas of significant damage were extended to include floors 93 through 99 of WTC 1 and floors 77 through 85 of WTC 2. A comparison of the preliminary and final damage estimates indicated that the primary areas of damage associated with the core areas of WTC 1 and WTC 2 were consistent with the preliminary damage estimates. Since the primary areas of damage relevant to the suppression systems involved the core areas of the buildings, the preliminary and final damage estimates were similar, and the preliminary estimates were considered valid approximations for purposes of the analyses of the suppression systems performance.

The damage to WTC 1 as a result of the aircraft strike was concentrated on floors 94 through 97 . Based on initial impact damage estimates the following effects were likcly to have occurred:

- Loss of standpipe riser FS-F2.

- Possible loss of standpipe risers FS-F1 and FS-F3.

- Loss of standpipe system water supply after a limited amount of time as a result of the damage to the standpipe risers.

- Loss of sprinkler systems on the 94th through 96th floors.

- Effectiveness of the sprinkler systems in the high and mid level zones was reduced, however the systems were capable of containing small fires on multiple floors. 
- Possible loss of the sprinkler systems on other floors immediately above the 96 th floor and below the 94 th floor.

- Loss of sprinkler system water supply after a limited amount of time as a result of the damage to the standpipe risers.

Damage to the sprinkler and standpipe systems and associated water supplies in WTC 2 or WTC 7 was not likely as a result of the WTC 1 aircraft strike. Therefore, it was concluded that these systems remained intact and operational immediately after the initial aircraft impact.

The damage to WTC 2 as a result of the second aircraft strike was concentrated on floors 78 through 81 . Based on the initial damage extent, estimates of the operability and continued effectiveness of the sprinkler and standpipe systems in WTC 2 on the floors within the immediate impact areas included the following:

- Loss of sprinkler riser B.

- No foreseeable loss of the standpipe system risers.

- Loss of sprinkler and standpipe system water supplies after a limited amount of time as a result of the damage to sprinkler riser $B$.

- Loss of the sprinkler systems on the 78th through 81 st floors.

- Loss of water supply to the sprinkler systems on floors 32 through 78.

- Effectiveness of the sprinkler systems above the 79th floor was significantly reduced (as a result of the loss of riser B).

- Use of manual fire pumps and FDCs was still possible.

No information was found that indicated that the sprinkler and standpipe systems and associated water supplies in WTC 7 were damaged as a result of the WTC 2 aircraft strike. It is also unlikely that further damage to the sprinkler and standpipe systems in WTC 1 occurred as a result of the WTC 2 aircraft strike.

The collapse of WTC 2 impacted the fire protection systems in WTC 1 as a result of the damage incurred to the sub-grade sprinkler and standpipe loops and damage caused by vibration and pressure waves. In addition, the collapse of WTC 2 damaged the NYC water distribution system near WTC 2 (Beyler 2002). The configuration of the water supply system minimized any initial impact to the fire protection systems in WTC 1 and WTC 7.

No significant damage to WTC 7 as a result of the collapse of WTC 2 was reported.

It is likely that the collapse of WTC 1 caused significant damage to the NYC water distribution system. Damage due to structural materials and burning debris caused fires in WTC 7 as a result of the collapse of WTC 1. The FDNY was unable to provide fire fighting or supplemental water to WTC 7 after the collapse of WTC 1 . The fires in WTC 7 burned for nearly $7 \mathrm{~h}$ before the building collapsed. The effectiveness of the sprinkler systems in WTC 7 would have degraded considerably over that period of 
time. and, if the water supply to the building was interrupted, or there was a loss of power to the fire pump, the sprinkler systems on the lower 20 floors would not have had an adequate water supply.

\section{E.9 GENERAL SUMMARY}

\section{E.9.1 General}

For the most part. the water supplies, automatic sprinklers, and standpipe/pre-connected hose systems in WTC 1,2, and 7 were determined to be robust, and exceeded the minimum applicable code requirements as well as associated engineering best practices prevailing at the time of their installation. In fact, with few exceptions, they would also satisfy current best practices and meet or exceed current code requirements.

Preliminary damage estimates provided by NIST were used to determine the extent of damage to the related operability of the fire suppression systems in WTC 1 and WTC 2 resulting from the incidents on September 11,2001. Initial damage to the standpipe and sprinkler systems in WTC 1 as a result of the aircraft strike was primarily on floors 94 through 96 . In WTC 2, the initial damage to the suppression systems was on floors 78 through 81 . Based on review of the damage estimates, photographic and video records, and documented eyewitness reports, the adverse effects of the impacts on the operability of the suppression systems were extensive.

The collapse of WTC 1 caused extensive damage to the below grade water distribution system for the WTC complex. Although the primary water supplies to WTC 7 apparently survived the collapse of WTC 1 and WTC 2, it was reported that burning debris from the collapse of WTC 1 caused multiple fires in WTC 7 (Beyler 2002). Some of these fires, identified through review of photographic and video records and eyewitness accounts, started in areas of WTC 7 that contained electrical transformers and fuel day tanks (Averill et al. 2005). These areas were either not protected by automatic sprinklers or were not designed to control such hazards (PANYNJ 1987).

Primary and backup power was provided in all three buildings; however, the absence of remote redundancy of the power transmission lines to the emergency fire pumps would have affected the operability of the sprinkler and standpipe systems once primary power was lost.

Based on the available information, it appears that several factors could have led to the extensive fire spread and eventual collapse of WTC 7. Multiple fires occurred on different floors of WTC 7 (Smith 2002). Several of these fires spread beyond the design areas for the sprinkler system(s) and involved most of the floor areas. The stored water in WTC 7 would have provided, at most, 20 min to 30 min of supply to the sprinkler systems. The collapse of WTC 1 and WTC 2 damaged the surrounding water supply sufficiently to prevent prolonged water supply for the upper floors or provide for the primary supply to the lower floors, dramatically reducing the potential effectiveness of the sprinkler systems, assuming the systems were not critically damaged by the collapse of WTC 1. Finally, the sprinkler systems were not designed to protect combustible liquids hazards. 


\section{E.9.2 Water Supply}

The primary source of water for the WTC complex was the NYC water distribution system (McAllister 2002; Beyler 2002). A complex grid of 20 in. and 12 in. mains surrounded the WTC complex, forming a very robust water supply with an average steady state system wide pressure of 50 psi. The WTC complex was provided with two separate supply connections at Vesey and Liberty Streets with isolation valves to permit independent operation. WTC 7 was provided with two connections from the 12 in. main under Washington Street, spaced about $12 \mathrm{ft}$ apart (Syska \& Hennessy 1984; PANYNJ 1987).

The water supply components in WTC 1,2, and 7 included water storage tanks, fire pumps, and fire department connections (PANYNJ 1972, 1987, 1987a). The primary water supplies for the automatic sprinkler and standpipe systems for the most part consisted of gravity tanks and booster pumps, with secondary or backup supplies provided directly from the underground water distribution system.

Three separate 5,000 gal water storage tanks were provided for the high and mid-level zone sprinkler and standpipe systems at the tops of both WTC 1 and WTC 2. A fourth single 5,000 gal tank was provided on the 41 st floor of each tower (PANYNJ 1972). The tanks were interconnected through a 4 in. main (PANYNJ 1972, 1987b). Each tank was provided with a separate re-fill connection (PANYNJ 1972, 1987b). As supplements to the gravity tanks, the maintenance and engineering staff supplied water to the fire suppression systems from the city water distribution system using manually operated fire pumps. The fire department could also supply water through the fire department connections located at the street level throughout the complex (PANYNJ 1987b).

The systems in WTC 7 included one automatic and two manually operated water supplies. The combined systems were provided with a single automatic fire pump for the low zone. The high and mid-level zones were supplied from two water storage tanks located on the 47th floor (Syska \& Hennessy 1984;

PANYNJ 1987). The high zone also included a booster pump. A single 750 gpm fire pump supplied the secondary water (Syska \& Hennessy 1984; PANYNJ 1987). The FDNY could also supply water to the systems using the fire department connections (Syska \& Hennessy 1984; PANYNJ 1987). The water supply tanks located in the upper water supply zone of WTC 7 did not service the lower floors. Rather, the primary and secondary water supply for floors 1 through 20 were the two parallel service connections to the 12 in. main under Washington Street and associated FDCs.

\section{E.9.3 Standpipe/Riser Systems}

Standpipes supplied the pre-connected hoses in WTC 1 and WTC 2 (PANYNJ 1972, 1987b). The sprinkler systems were supplied separately by risers. In WTC 7, the standpipes and risers were combined into a single system.

The standpipe systems in WTC 1 and WTC 2 were interconnected at the top of each zone with check valves that prevented downward flow in two of the three risers (PANYNJ 1972, 1987b). This arrangement permitted upward flow through all three risers while operating in the secondary supply modes using the manual fire pumps or the fire department connections. The standpipe systems in WTC 7 did not have a similar interconnection at the top of the standpipe zones.

The standpipe/pre-connected hose systems in WTC 1 and WTC 2 were supplied by storage tanks and the underground loop. The hose stations were Class III hose stations with $125 \mathrm{ft}$ of hose and a nozzle for use by the fire brigade and/or the FDNY. Operating pressures were maintained by manually operated fire 
pumps with primary power and backup power generators located on the B6 level. Fire department connections were available to supplement the flow and pressure for the standpipe systems.

The standpipe/riser systems in all three buildings were installed in stairwells with hose stations at each floor as well as at other locations on specific floors.

No information was found to indicate if the dependence of the low zone standpipe system arrangement in WTC 7 on the two feeders located only $12 \mathrm{ft}$ apart under Washington Street had a significant adverse impact on the performance of the sprinkler and standpipe systems in WTC 7 on September 11, 2001. The standpipe system in WTC 7 was reportedly used to supply water to fight other nearby fires. This, along with any damage to the Washington Street supply mains due to the collapse of WTC 1 and WTC 2, would have significantly reduced the effectiveness of the sprinkler and standpipe systems to the lower floors of WTC 7 h before WTC 7 collapsed.

While it is difficult to assess the performance capabilities of the standpipe/pre-connected hoses, hydraulic calculations indicated that the size of the standpipes and the capacity and number of fire pumps were consistent with the requirements for pressure and flow in the BCNYC. However, the booster pump on the 46th floor of WTC 1 and WTC 2 was undersized, and could not provide the minimum pressure and flow requirements of NFPA 14.

In WTC 1 and WTC 2, if the maintenance or engineering staff failed to operate the manual fire pumps, or the fire department was delayed in supplementing the water supply through one of the fire department connections, water available for the sprinkler systems and manual fire fighting in the buildings was limited to the stored water tanks. While this arrangement was consistent with the BCNYC at the time of installation, more recent editions of NFPA 14 require automatic or semi-automatic operation of fire pumps. The use of automatic fire pumps also would have been consistent with "best practices" at the time of installation.

Manual fire pumps and booster pumps maintained the systems' operating pressures. Backup power to the pumps was supplied by emergency generators located on several floors in both buildings.

The installation of the supply piping from the storage tanks on the 110th floor in WTC 1 and WTC 2 resulted in restricted flow capacity to several floors in the mid-level water supply zones in both buildings. While the flow capacity was sufficient to supply the sprinkler and standpipe systems, the installation was not consistent with engineering best practices at the time of the installation.

The standpipe/pre-connected hose systems in WTC 1 and WTC 2 were consistent with the applicable requirements in the $\mathrm{BCNYC}$. They were not consistent with the flow rates and durations required in NFPA 14. These differences would manifest themselves if the standpipe systems were used simultaneously at multiple locations throughout WTC 1 and WTC 2 (i.e., very high demand) and the fire department failed to use the FDCs to back up the water supply. No information was found to indicate that the standpipes were extensively used on September 11, 2001.

\section{E.9.4 Sprinkler Systems}

Wet-pipe automatic sprinkler systems were installed throughout WTC 1 and WTC 2, with the exception of a few areas, including the mechanical spaces on the 108th through the 110 th floors, as well as the 
electrical rooms throughout the buildings (PANYNJ 1987a, 2000b). In these areas, either sprinkler systems were not required under the $\mathrm{BCNYC}$ or the spaces were provided with alternative special suppression systems. The systems were installed over the course of years, from 1983 to early 2001 (GC Engineering 1998). (Note that some systems were installed in the sub-grade levels when the buildings wcre built and others were installed around 1976 to protect core areas, maintenance areas, and select tenant spaces of the buildings.) The sprinkler systems in WTC 1 and WTC 2 were supplied by risers located in the stairwells. In WTC 7, the risers were located in janitor's closets and wet columns supplied from gravity fed storage tanks above each of four supply zones (Syska \& Hennessy 1984). The supply to all three buildings was supplemented by the underground water supply main that looped the WTC complex.

In WTC 7 wet-pipe, "control" type automatic sprinkler systems were installed in most areas and were supplied by a combined standpipe/riser system. Certain areas were not protected by sprinklers, including electrical equipment areas (switchgear, networking and switchboard rooms), generator rooms, and bathrooms (Syska \& Hennessy 1984; PANYNJ 1987). Sprinklers were not installed on most of the fifth floor, as well as on the seventh floor, which housed the OEM generators and fuel day tanks. A dry-pipe sprinkler system was installed to protect the fuel storage tanks on the first floor that supplied the high pressure fuel lines that serviced the emergency generators (Swanke et al. 1998).

WTC 7 contained fuel oil powered generators and day tanks located on the fifth, seventh, eighth, and ninth floors (Swanke et al. 1998; Emery et al. 1987; Syska \& Hennessy 1984; GC Engineering 1998; Grill and Johnson 2005b). The suppression protection varied for each component of the fuel oil supply system. A dry-pipe sprinkler system was provided for protection of two 12,000 gal fuel oil tanks located under the loading berths on the south side of the building, adjacent to Vesey Street (Swanke et al. 1998). An Inergen suppression system was provided for the $6,000 \mathrm{gal}$ fuel oil storage tank room located on the mezzanine, $8 \mathrm{ft}$ above the elevator storage area on the first floor (Swanke et al. 1998). The area below this room was protected by a wet pipe sprinkler system. The fuel pumps were located on the 1st floor near the loading dock and were protected by a dry-pipe sprinkler system (Swanke et al. 1998). The generator and day tank enclosures were not protected by automatic sprinklers (GC Engineering 1998; Grill and Johnson 2005b). These omissions of sprinkler coverage were consistent with the BCNYC.

The sprinkler systems installed in WTC 1,2, and 7 exceeded the required performance levels under the BCNYC and NFPA 13 for protection of high-rise office buildings by considerable margins. Based on historical incident data, systems having such characteristics would be expected to extinguish, rather than control, most fires that occur in these types of buildings.

The installed sprinkler systems in WTC 1,2, and 7 had the ability to simultaneously control or suppress multiple fires of varying sizes under "normally expected" operating conditions. The fires could have occurred at different locations on a single floor or on multiple floors. Water flow density and pressure associated with the installed systems had the capacity to control a single fire on the order of two to three times the sprinkler system design area, depending on the location in the building, and the systems would be expected to concurrently control at least four to six fires similar in area to that protected by a foursprinkler array (i.e., $750 \mathrm{ft}^{2}$ ). While these systems were considered very robust, a coverage area of two or three times the design area of the sprinkler system constituted less than 15 percent of the floor area of a typical single floor in these buildings. 
The intensity and extent of the fires in WTC 1 and WTC 2 on September 11, 2001 were considerably greater than two to three times the specified design areas and involved multiple floors. While there was no way to confirm the extent of the initial fires, it is likely that had the systems remained operable a large number of sprinklers would have been opened on multiple floors. Once the number of open sprinklers exceeded an area equivalent to two or three times the design areas, the system's ability to control the fire would have been reduced, and the duration of the primary water supply would have rapidly degraded. Furthermore, the likely damage to the suppression systems in WTC 1 and WTC 2 due to the aircraft impacts and the subsequent failures of structural components virtually ensured that significant parts of the systems were rendered inoperable, regardless of the extent of the initial fires.

Although consistent with applicable codes, the typical floor level sprinkler system was installed with only one connection to the sprinkler riser. This arrangement provided a single point of failure of the water supply to the floor level sprinklers.

Even if the sprinkler systems had been designed to protect much higher hazard levels (i.e., Ordinary Group II or Extra Hazard), the magnitude of the fires experienced in these buildings, as well as accompanying impact damage, would have most likely resulted in the fires not being controlled. 
This page intentionally left blank. 


\section{Chapter 1 \\ INTRODUCTION}

\section{$1.1 \quad$ GENERAL}

On September 11, 2001, the two World Trade Center (WTC) towers (WTC 1 and WTC 2) in New York City were each struck by individual commercial aircraft. These incidents were determined to be terrorist attacks, and resulted in extensive initial damage and subsequent collapse of both WTC 1 and WTC 2. Fuel from the aircrafts contributed significantly to fires in both towers. Fires also occurred in other adjoining buildings, along with extensive damage that included the collapse of WTC 7. Loss of life was estimated at just under 3.000 persons, including over 400 emergency responders.

The WTC Plaza in lower Manhattan in New York City extended over 16 acres. The buildings built as part of the WTC complex were constructed and maintained under the jurisdiction of the Port Authority of New York and New Jersey (PANYNJ).

The National Institute of Standards and Technology (NIST) conducted a building and fire safety investigation of the WTC disaster. The work documented in this report was performed in support of the investigation of active fire protection systems. This effort involved investigation of the performance of automatic fire sprinkler systems, standpipe/pre-connected hose systems, and the water supplies associated with IVTC 1, 2, and 7.

\subsection{SCOPE}

The evaluation involved detailed documentation of the installed fire suppression systems in WTC 1, 2, and 7 and examination of the expected performance of the suppression systems under a range of fire incident scenarios, including the incident that occurred on September 11,2001. The five specific tasks associated with this effort are as follows:

1. Documentation of the design and installation of the fire sprinkler systems, standpipe systems, and pre-connected hoses and comparison of the designs to applicable codes and standards requirements (Task 1 ).

2. Documentation of the design and capacity of the water supply to the fire sprinklers including provisions for redundancy (Task 2).

3. Identification and documentation of the differences in the design of the water supply, fire sprinkler systems, standpipe systems, and pre-connected hoses among WTC 1, 2, and 7 (Task 3).

4. Documentation of the normal operation and effect of fully functional fire sprinkler system, standpipe system, and pre-connected hoses for fire control (Task 4). 
5. Documcntation of the performance of the sprinkler systems, standpipe systems, and preconnected hoses on September 11, 2001, in WTC 1, 2, and 7 (Task 5).

\subsection{PRIMARY TASKS}

\subsubsection{Task 1}

Task 1 included documentation of the design and installation of the fire sprinkler systems, fire standpipe systems, and pre-connected hoses and comparisons of the designs to applicable code and standards provisions.

The necessary input required to evaluate the performance of the installed fire suppression systems in WTC 1, 2, and 7 included detailed documentation of what was in each building on September 11, 2001, as well as applicable codes and standards requirements. Task 1 involved identification and docunentation of such information at the grcatcst level of detail possible in order to address issues of performance in the follow-on tasks.

This task had several elements, including the following:

- Documentation of the major piping, water supply tanks, fire pumps, conncctions to the domestic water supply, fire department connections, isolation valves, and other controls that direct water flow.

- Documentation of cross connections between sprinkler and standpipe systems; documentation of areas of coverage and designed water flow for pre-connected hoses.

- Documentation of supporting information regarding hazard classification, design density, system pressure, and coverage areas in the three buildings, with particular attention to the systems located on floors 89-110 of WTC 1 and floors 74-90 of WTC 2.

- Detailed comparisons between documented existing systems for each of the three buildings and applicable code and standards requircments for these occupancies.

- Documentation of any areas in the buildings that were protected by special hazard sprinkler systems, including detailed design/installation information, with particular attention to floors 89 to 110 of WTC 1 and floors 74 to 90 of WTC 2.

- Documentation of any fire protection systems installed to protcct emergency power generation fuel tanks and the fuel distribution system in WTC 7.

\subsubsection{Task 2}

Task 2 included documentation of the design and capacity of the water supply systems to the fire sprinklers, including provisions for redundancy.

In order to evaluate the capabilities of the fire suppression systems, key characteristics of the water supply to the systems were required. These characteristics included estimates of the system pressure at the 
system supply point and the capacity. In addition, in order to evaluate partially disabled systems, design redundancies were identified and documented. This latter information was necessary to evaluate performance under scenario generated systematic failure modes consistent with documented events on September 11, 2001.

Key elements of this task were the following:

- Documentation of the normal operation of the primary water supply system(s) for fire sprinklers within the system design limits

- Documentation of any redundancies, including fire department actions, in fire sprinkler water supply to each of the three buildings, with particular attention to floors 89 to 110 of WTC 1 and floors 74 to 90 of WTC 2

\subsubsection{Task 3}

Task 3 included identification and documentation of the differences in the designs of the water supply systems, fire sprinkler systems, standpipe systems, and pre-connected hoses among WTC 1, 2, and 7.

Differences in basic construction existed between WTC 7 and the two tower buildings. In addition, WTC 7 contained fuel tanks for emergency power that required special fire sprinkler protection. These differences could have led to important effects on September 11, 2001, and therefore required specific consideration in evaluating the effectiveness of the fire suppression systems.

Elements of this task area included the following:

- Identification and documentation of differences in the design of the water supply system, fire sprinkler system, standpipe system, and pre-connected hoses among WTC 1, 2, and 7

- Estimation and documentation of the impact of any differences on the level of fire control provided by the designs

\subsubsection{Task 4}

Task 4 included documentation of the normally expected operation and effect of the fully functional fire sprinkler systems, standpipe systems, and pre-connected hoses for fire control.

Estimates were made of the likely performance of the systems that existed in each of the three buildings under varying fire exposures. These estimates were based on evaluation of the determined system design areas, water flow capacity, and pressure under specified fire scenarios.

Elements of this task included the following:

- Documentation of the expected operation of the fully functional fire sprinkler system to four separate fire scenarios associated with a business type occupancy

- Documentation of the fire control capabilities of the fire standpipe pre-connected hoses under the same fire scenarios 


\subsubsection{Task 5}

Task 5 documented the performance of the fire sprinkler systems, standpipe systems, and pre-connected hoses on September 11, 2001.

An important consideration in this effort was to provide some estimate of the likely performance of the fire suppression systems in WTC 1, 2, and 7 during the September 11, 2001, disaster. There were many factors to consider, including the initial impact and associated fires in WTC 1 and WTC 2 and any subsequent effects on WTC 7. Based on information provided by NIST regarding the initial damage estimates and the progression of key events in the collapse of each building, a systematic evaluation of the fire suppression capabilities was performed.

Elements of this task included the following:

- Documentation of the expected performance of each of the systems after the initial aircraft impacts in WTC 1 and WTC 2, assuming the systems continued to be fully functional

- Development and evaluation of initial damage scenarios to the fire suppression systems and the potential impact on fire suppression

\section{$1.4 \quad$ GENERAL APPROACH}

An extensive literature review was performed in order to document the installed fire suppression features in WTC 1, 2, and 7, as well as any information regarding the performance of these systems on September 11,2001. The primary source for documents and related information (e.g., drawings, specifications, procedures, etc.) were the documents collected and maintained by NIST during the investigation. These documents contain information related to the design, construction and operation of WTC 1, 2, and 7 as well as information related to the incidents on September 11, 2001. The information available from NIST was supplemented by information in the open literature, information from the Hughes Associates, Inc. (HAI) technical library, and inquiries by NIST to appropriate organizations in NYC. In addition, information related to applicable codes and standards of record was provided in a study performed by Rolf Jensen and Associates (RJA) as part of this NIST investigation (Razza and Grill 2005).

Based on the available information and codes and standards documentation, the fire suppression features that existed in WTC 1, 2, and 7 were reconstructed and documented. Once this was completed, hydraulic analyses were performed to provide estimates of the baseline capabilities of the suppression systems, as well as capabilities under different fire incident scenarios, including the events of September 11, 2001. Performance criteria were established based on requirements in National Fire Protection Association (NFPA) 13, Standard for the Installation of Sprinkler Systems, and NFPA 14, Standard for the Installation of Standpipe, Private Hydrant, and Hose Systems, the primary design and installation standards for fire suppression systems in high-rise buildings. The criteria were based on the applicable editions of these standards at the time the buildings were designed and constructed (i.e., codes and standards "of record").

1 References are located in Appendix A. 


\subsection{DOCUMENT RETRIEVAL AND CONTROL}

Documents that were reviewed as part of this effort were cataloged for reference. Those documents obtained from NIST WTC investigation document files were copied where necessary. A record of the copied documents was provided to NIST, and a database was developed by HAI to track the copied documents. This database included the references found throughout this report, and is provided as Appendix A.

All documents copied from the NIST WTC investigation document files were stored in a limited access file system similar to those used by HAI to maintain restricted materials for other clients (i.e., U.S. Department of Energy, U.S. Department of Defense). Access to the file system was limited to the project team. 
This page intentionally left blank. 


\section{Chapter 2 \\ BACKGROUND}

\subsection{SITE AND BUILDING DESCRIPTIONS}

\subsubsection{General Site Descriptions}

The World Trade Center (WTC) complex consisted of seven buildings located on 16 acres in lower Manhattan in New York City (NYC) (Fig. 2-1). WTC 1 through 6 were constructed on the primary WTC Plaza. WTC 7 was the last building constructed, just north of the WTC Plaza, completed in the mid-1980s. A six-level structure below the ground floor of the main WTC Plaza included utilities, parking, and subway stations (Beyler 2002; McAllister 2002).

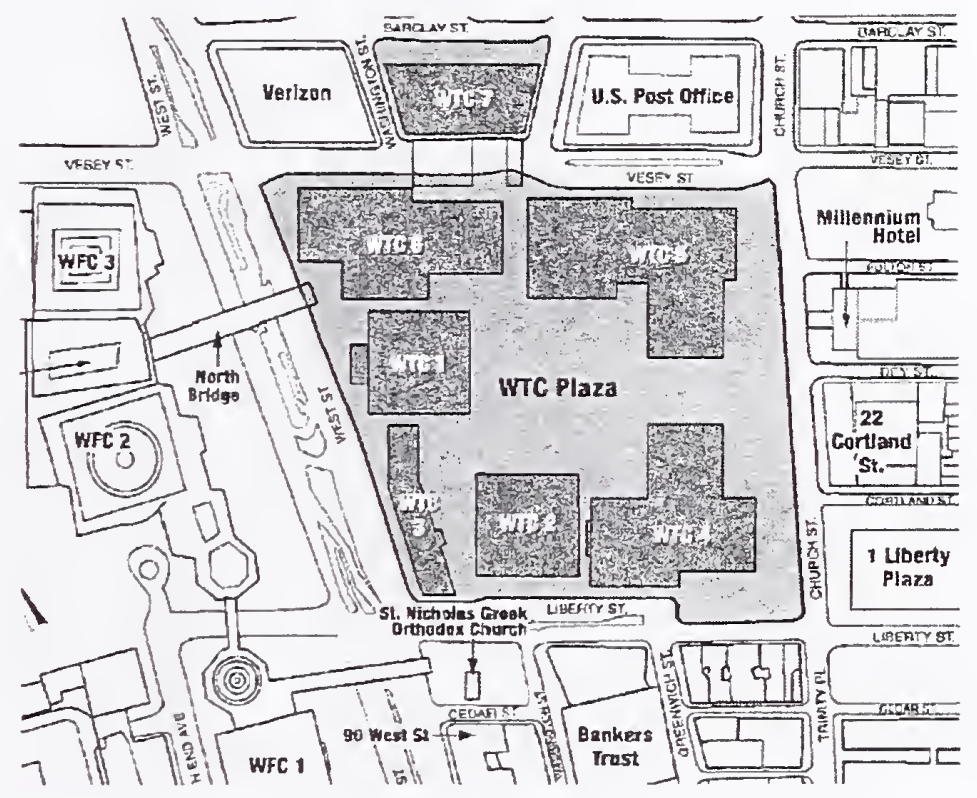

Source: Adapted from McAllister: FEMA, Fig. 1-1.

Figure 2-1. Site plan, WTC complex.

\subsubsection{WTC 1 and WTC 2}

WTC 1 (North Tower) and WTC 2 (South Tower) were each 110 stories in height above the plaza level, and 7 stories below. For the most part, the two towers were similar in size and layout. Each floor was approximately $207 \mathrm{ft}$ by $207 \mathrm{ft}$, providing nearly an acre of floor area. A service core (approximately $87 \mathrm{ft}$ by $137 \mathrm{ft}$ ) was located in the center of each tower. The elevators, stairwells, primary piping, and ventilation duct systems were located in this service core. Figure 2-2 illustrates the general layout of a typical floor. 


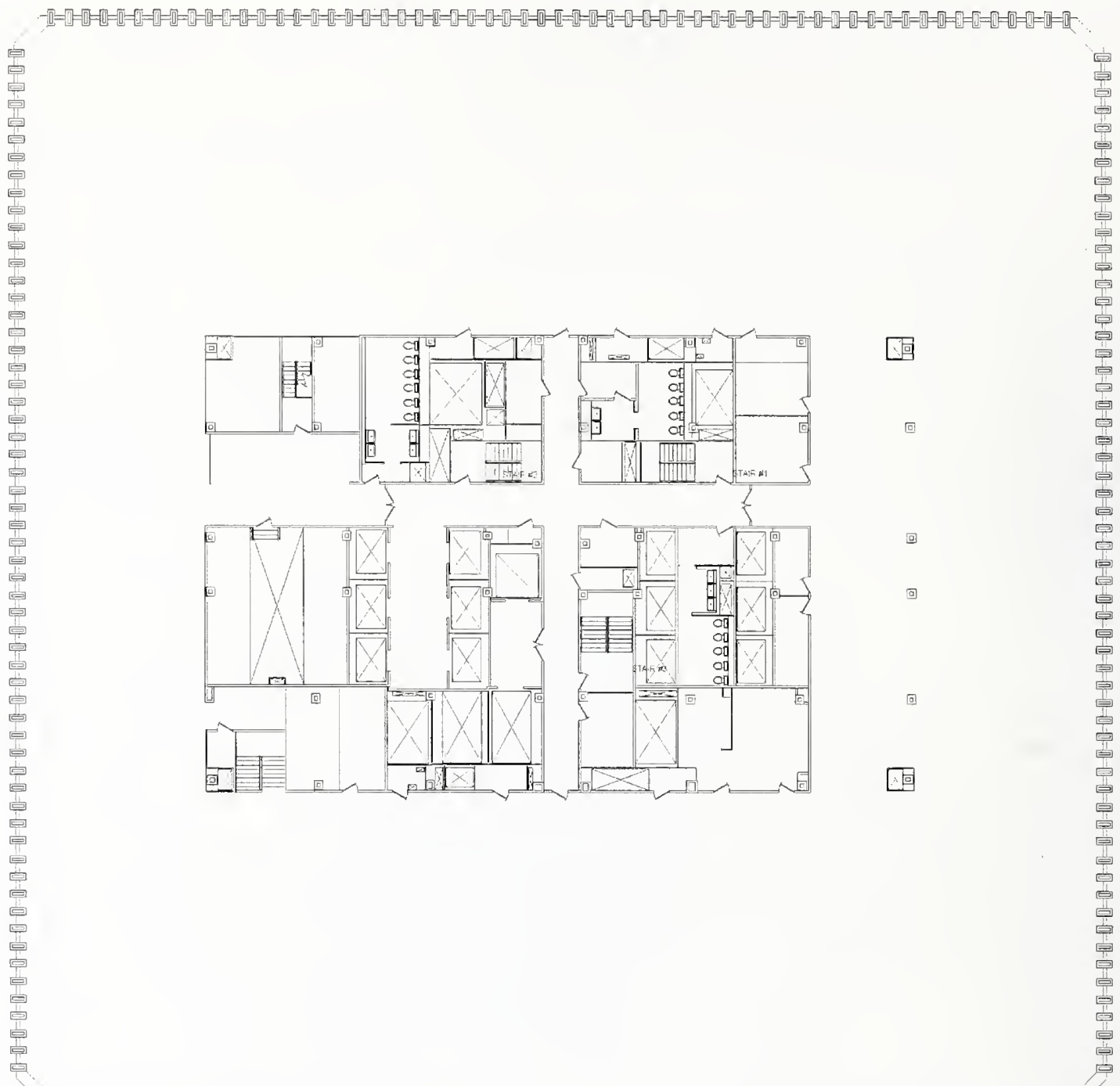

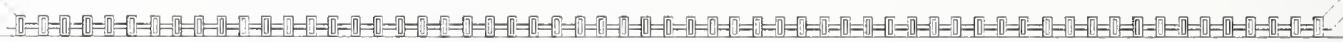
Source: Adapted from McAllister: FEMA, Fig. 2-1.

Figure 2-2. Typical floor plan, WTC 1.

\subsubsection{WTC 7}

WTC 7 was a 47 -story office building with nearly two million square feet of office space. Floors 8 through 47 were primarily office space. The elevators, stairwells, primary piping, and ventilation duct systems were located in the core of the building (Fig. 2-3). An electrical substation that provided power to lower Manhattan and loading docks was located in the lower part of the building at the ground level. Switchgear, generators, transformers, management offices, and transformer vaults were located on floors one through nine. The generators and fuel day tanks for the Office of Emergency Management (OEM) were located on the seventh floor. 


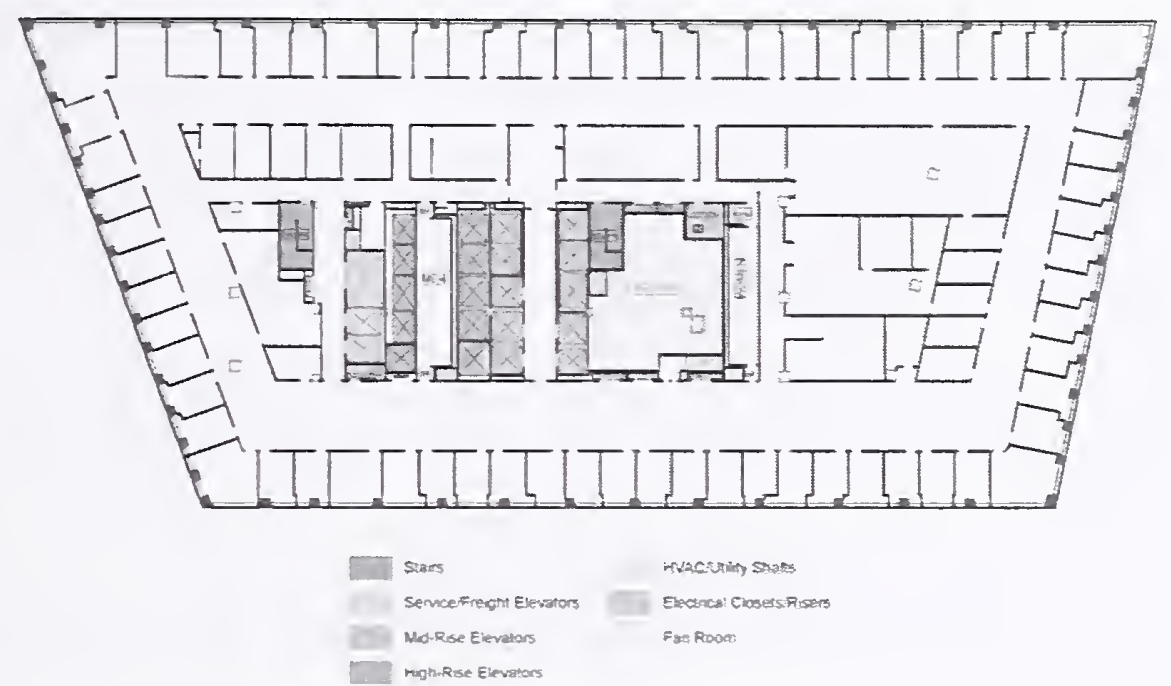

Source: Syska \& Hennessy 1984. Reproduced with permission of The Port Authority of New York and New Jersey.

Figure 2-3. Typical floor plan, WTC 7.

\subsection{INSTALLED FIRE SUPPRESSION FEATURES}

Documentation of the installed fire suppression features was based on review of design drawings and "Operations and Maintenance" (O\&M) manuals made available through NIST for WTC 1,2 and 7 by PANYNJ. In some cases reliance solely on design drawings to establish the existence of particular suppression systems was necessary due to the incomplete O\&M documentation available for review. However, for most of the primary suppression systems consistent information was found in the design drawings and the O\&M documentation, providing a reasonably high confidence in these systems as described in this report.

\subsubsection{WTC 1 and WTC 2}

This section provides a summary of the installed automatic sprinklers. standpipes, and pre-connected hoses. Additional detail and illustrations are provided in Chapters 5, 6, and 7.

As an interstate compact under the U.S. Constitution. the Port Authority was not subjected to any state or local building codes. WTC 1 and WTC 2 were protected by automatic fire sprinkler systems, essentially throughout. The sub-grade areas of the complex were provided with sprinkler systems during the initial construction (GC Engineering 1998). The systems were not installed in the towers during construction of the two buildings. but were retrofit installed in two phases (GC Engineering 1998). The first phase included the installation of the sprinkler system infrastructures and sprinklers in common areas and certain tenant and Port Authority of New York and New Jersey (PANYNJ or Port Authority) spaces based on the provisions of Local Law 5 (BCNYC 1973). The second phase included the installation of the sprinkler systems throughout the remaining areas of the complex and during the period from 1983 to 2001 (GC Engineering 1998). The retrofit program had been completed prior to September 11, 2001.

In addition to automatic fire sprinkler systems, each building had vertical standpipe systems located in the stairwells (PANYNJ 1972, 1987a; 1987b). The standpipe systems were configured with four vertical 
water supply zones and included three standpipe risers in each zone (PANYNJ 1972, 1987b). The standpipes provided fire suppression water to pre-connected hoses located in the stairwells at each floor (PANYNJ 1972, 1987b). WTC 1 and WTC 2 were equipped with standpipe systems containing Class III pre-connected hose stations in all exit stair enclosures and in certain corridors and tenant spaces. Each hose station was equipped with a standpipe hose control valve, a $125 \mathrm{ft}$ long fire hose, and a nozzle for use by the trained fire brigade or The Fire Department of the City of New York (FDNY).

The primary water supply for the standpipe systems was initially gravity fed from reserve water storage tanks located above the standpipe system zone (PANYNJ 1987b). A series of manually operated fire pumps provided water supplied by the NYC water distribution system (PANYNJ 1987b). The primary water supply consisted of a fire main that looped the WTC complex. The $12 \mathrm{in}$. diameter main was supplied directly from the municipal water supply by two redundant $16 \mathrm{in}$. diameter connections. Operating pressures were maintained by two $750 \mathrm{gpm}$ high-pressure electric pumps that supplied the subgrade loops and were located beneath the towers on the Bl level of the complex (PANYNJ 1972, 1987b).

Each tower had three 750 gpm manual electrical fire pumps located on the 7th, 41 st and 75 th floors to supplement standpipe pressures (PANYNJ 1972, 1987b). Each pump provided sufficient pressure for the standpipes to skip the next sequential pump above it if any failed to operate (Beyler 2002; Powers 1979). In addition to the pumps, a single $500 \mathrm{gpm}$ automatic fire pump was provided in each tower on the 108th floor for the sprinkler systems located on the 99th through 107th floors and the hose stations in the mechanical rooms on the 108th through 110th floors (PANYNJ 1972, 1987b). Six emergency power generators were located in the basement at the B-6 level. These generators provided back-up power to the fire pumps, as well as to communications equipment, elevators, and emergency lighting (PANYNJ 1987b).

A secondary water supply consisted of 5,000 gal storage tanks, filled from the building's domestic water system (PANYNJ 1972, PANYNJ 1987). Tanks were located on the 20th, 41st, 75th and 110th floors in each tower. Although these tanks served as the secondary water supply, the tanks supplied the initial water supply to the fire brigade or the FDNY. Without supplemental water supplied by the domestic water system, the tanks provided approximately $10 \mathrm{~min}$ for the PANYNJ maintenance staff to manually start the fire pumps. The tank on the 20th floor directly supplied the main loop (PANYNJ 1972).

Fourteen fire department connection (FDC) stations were located at ground level for use by the FDNY to supplement the water supply and pressure to the fire suppression systems in the buildings (PANYNJ 1972, PANYNJ 1987b). All of the FDC stations could be used to supply the standpipe systems throughout the complex or sprinkler systems in WTC 1 and WTC 2 above the 32nd floor level (PANYNJ 1972, 1987b). Isolation valves were installed between each consecutive FDC station (PANYNJ 1972, 1987b). This provided independent supply and operation of the standpipe systems throughout the WTC complex. Two additional express FDC stations were provided to supply only the sprinkler systems in WTC 1 and WTC 2 above the 32nd floor level (PANYNJ 1972, 1987b). Two separate FDC stations were provided for the sprinkler systems in WTC 1 and WTC 2 below the 31 st floor level (PANYNJ 1972, 1987b). 


\subsubsection{WTC 7}

Automatic sprinkler systems were installed in most areas of WTC 7 and were supplied by a combined standpipe/riser system (PANYNJ 1987). However, a detailed review of the architectural/sprinkler drawings and specifications for WTC 7 (Syska \& Hennessy 1984) indicated that sprinklers were not to be installed in the electrical equipment spaces including switchgear, networking, and switchboard rooms. They were also not to be installed in the generator rooms or bathrooms, nor on most of the fifth floor (with exception of the mechanical space to the east and the office area along the north side of the building). The drawing and specification review also showed no evidence that sprinklers were installed on the seventh floor which housed the OEM generators and fuel day tanks (Syska \& Hennessy 1984). The exclusion of automatic sprinklers in these areas was consistent with the code of record.

A standpipe system was installed in each stairwell (PANYNJ 1987). Pre-connected hoses were located in the stairwells at each floor, connected to the standpipe (PANYNJ 1987). In addition, a supplemental preconnected hose cabinet was located on the east side of each floor. Additional hose cabinets were installed in different locations on different floors (PANYNJ 1987).

The primary water supply for WTC 7 was provided by the 12 in. water main beneath Washington Street. FDCs were located on the south, east, and west sides of the building (PANYNJ 1987; Syska \& Hennessy 1984). A 750 gpm manual fire pump that served the entire building was located on the ground floor (PANYNJ 1987; Syska \& Hennessy 1984). A 500 gpm automatic fire pump, located on the ground floor, supplied the sprinkler and standpipe systems through the 20th floor (PANYNJ 1987; Syska \& Hennessy 1984). The 21 st through 39 th floor sprinkler systems and 21 st through 44th floor standpipe systems were supplied from two gravity-fed water storage tanks on the 47 th floor. Each tank had a holding capacity of 18,000 gal and a fire reserve capacity of 7,500 gal (PANYNJ 1987; Syska \& Hennessy 1984). The 40th through 47 th floor sprinkler systems and 45 th through 47 th floor standpipe systems were supplied from the storage tanks on the 47 th floor via a 500 gpm booster pump on the 46th floor (PANYNJ 1987: Syska \& Hennessy 1984).

Emergency power generators were located on several floors to provide back-up power to emergency systems in the building, including the fire pumps (PANYNJ 1987).

\subsection{INCIDENT DESCRIPTION}

WTC 1 was the first building struck by a commercial aircraft on September 11, 2001. The impact occurred between the 93rd and 99th floors (McAllister et al. 2005). Shortly after this occurred, WTC 2 was also struck by a commercial aircraft, between the 77th and 85th floors (McAllister et al. 2005). Extensive impact damage occurred on multiple floors of both buildings. Fires extended over multiple floors; a significant initial contributor to fire spread being the aviation fuel from the two aircrafts (McAllister 2002; Smith 2002). WTC 2 was the first building to collapse, which occurred a little less than an hour after the initial aircraft impact. WTC 1 collapsed later, $1 \mathrm{~h}$ and $43 \mathrm{~min}$ after impact. Both buildings experienced total, progressive structural collapse, resulting in exposure of surrounding buildings to falling burning debris and structural materials. The collapse of WTC 1 and WTC 2 caused considerable damage to the NYC water supply system in the streets surrounding the WTC complex (Beyler 2002; McAllister 2002). 
Based on available photographic and videographic records, WTC 7 burned for over $7 \mathrm{~h}$ before collapsing. The working hypothesis at the time this study was completed involved an initial local failure of the structure below the 13th floor due to fire and/or debris-induced structural damage of a critical column. The structural damage and the accompanying multiple fires throughout WTC 7 were due to exposure of the building to the collapsing WTC 1 . This incident progressed to a global structural collapse of the building (McAllister 2002). 


\section{Chapter 3 \\ Automatic FIRE SPRINKLER AND STANDPIPE/PRE-ConNeCted HOSE TECHNOLOGIES}

\section{$3.1 \quad$ INTRODUCTION}

World Trade Center (WTC) 1, 2, and 7 had installed automatic fire sprinkler systems and standpipes with pre-connected hoses. The discussion in this chapter is intended to familiarize the reader with the basic design components of these types of systems, how they typically work, and acceptable performance expectations in the context of fire safety in structures. The primary sources for this information were Bryan (1990), Cote (2003), National Fire Protection Association (NFPA) 13 (NFPA 1966, 1982, 1987, 2002) and NFPA 14 (NFPA 1968, 1982, 2000) for comprehensive descriptions and details relied upon by engineers and contractors in the design, installation, commissioning, and periodic testing of these systems.

\subsection{AUTOMATIC FIRE SPRINKLERS}

\subsubsection{Overview/General Description}

Automatic fire sprinkler technology is a 19 th century invention. Modern systems have evolved over time and are fundamentally straightforward in their operation. A major innovation in fire sprinkler technology occurred with the introduction of the "spray" sprinkler in the early 1950s. The spray sprinkler was designed to provide a relatively uniform distribution of the water spray to the area to be protected. This was a significant advancement beyond previously used sprinkler devices that produced non-uniform sprays that resulted in inefficient use of the water and gaps in the coverage.

In simple terms, an automatic fire sprinkler system consists of a water supply, a series of distribution pipes and individual sprinkler devices. The basic systems are supported by control valves, pumps, and water flow alarms. The valves and pumps are used to maintain the water demand, both before and during a fire incident. Most people recognize the individual sprinklers that are usually uniformly spaced at or near the ceiling in a typical installation (Fig. 3-1).

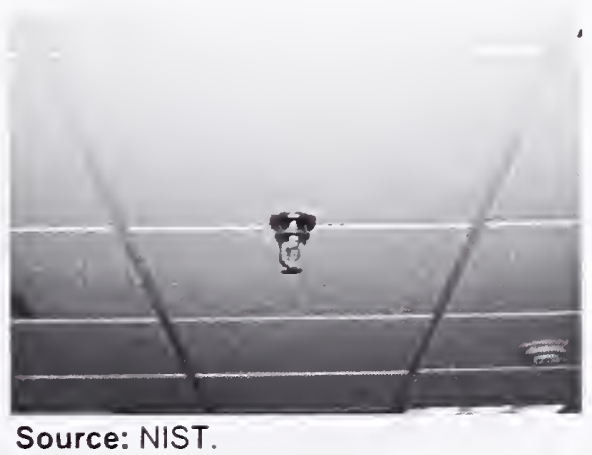

Figure 3-1. Typical sprinkler installed in ceiling. 
While there are variations, the basic operating principle involves operation of each sprinkler device, individually, when exposed to a rising temperature condition (i.e., due to the thermal output from a fire). Typically, if a fire becomes large enough, a sprinkler device in the vicinity of the fire will operate, discharging water at a predetermined rate. If the fire continues to grow, additional sprinklers operate. This continues until the fire is controlled or extinguished, or until the available water supply is depleted. An incorrect assumption associated with automatic fire sprinkler operation is that if a fire occurs, all of the sprinklers operate. Only those directly exposed to an amount of heat that exceeds some threshold actually operate and discharge water.

\subsubsection{System Types}

The primary types of automatic fire sprinkler systems commonly used today include the following:

- Wet-pipe

- Dry-pipe

- Pre-action

Based on the available documentation it appears that all three types were present in WTC 1, 2, and 7. The primary office and support spaces in the buildings were protected by wet- pipe systems, the most commonly used type of automatic sprinklers to protect office buildings. Dry-pipe and pre-action systems were installed on a limited basis to protect computer and/or other special hazards areas. The latter systems were used in less than 10 percent of the floor areas of WTC 1, 2, and 7.

\section{Wet-Pipe Sprinkler Systems}

The wet-pipe automatic fire sprinkler system is the oldest and most reliable type of sprinkler system available. These systems are simple, contain few mechanical parts limiting the potential for failure, and typically do not require human intervention. A network of piping transports water from the supply to the sprinklers located throughout the building. Wet-pipe sprinkler systems are filled with water at all times; The water is discharged immediately upon the fusing of a single sprinkler. The excellent performance record for properly designed, installed, and maintained wet-pipe sprinkler systems have made these systems desirable for most building applications.

\section{Dry-Pipe Sprinkler Systems}

One of the limitations of wet-pipe sprinkler systems is that sufficient heat is required to prevent the water in the pipes from freezing under normal conditions. NFPA 13 requires that a minimum temperature of $40^{\circ} \mathrm{F}$ be maintained at all times and in all locations where wet-pipe sprinkler systems are installed. Dry-pipe sprinkler systems were developed to accommodate building locations where the environmental conditions could cause water filled pipes to freeze. Usually, dry-pipe sprinkler systems are installed because heating the building or a portion of the building is either impractical or undesirable. Examples of locations within buildings where dry-pipe sprinkler systems are used include: loading docks, cold storage warehouses, and attics. 
The overhead portion of a dry-pipe sprinkler system is typically filled with pressurized air. Upon operation of a sprinkler, the air pressure is released, allowing the water pressure to open a special check valve. known as a dry-pipe valve, which allows water to flow into the system and out of sprinklers that have opened due to exposure to heat from a fire. Unlike with wet-pipe sprinkler systems, with dry-pipe sprinkler systems there is a delay between the time at which a sprinkler operates and the application of water. This delay is associated with the time required for the system to discharge air until reaching the trip pressure of the dry-pipe valve, typically 20 psi, and the transit time for water to travel through the system piping to the open sprinkler. The term trip pressure applies to the point in the process where the air pressure in the system no longer exceeds the water pressure. At this point the valve opens, allowing water to flow into the system. NFPA 13 limits the size and configuration of the overhead portion of dry pipe systems to limit the time delay between the operation of a sprinkler and the discharge of water spray from the system. The time for a dry-pipe sprinkler system to provide water to the inspector's test connection at the most remote area of the system is no greater than $60 \mathrm{~s}$.

Additional system design features are required for dry-pipe sprinkler systems to account for the difference in the operation of dry-pipe systems and wet-pipe systems. Wet-pipe systems discharge water immediately after the response of the first sprinkler. With dry-pipe sprinkler systems, a larger number of sprinklers are expected to open as a result of the delay associated with the operation of the dry-pipe valve and the time it takes for water to flow to the sprinklers which have operated. NFPA 13 requires the design area for dry-pipe sprinkler systems to be increased by 30 percent above the required design areas for wet-pipe systems while maintaining the same discharge density. The 30 percent increase in the design area is to compensate for the delay. Additionally, NFPA 13 imposes limitations for the internal volume of the system piping. The $60 \mathrm{~s}$ water delivery time limit is considered to be a performance-based alternative to the volume limit.

\section{Pre-Action Systems}

Pre-action systems are different than both wet-pipe and dry-pipe sprinkler systems. In pre-action systems, water is not normally stored in the system piping like a wet-type sprinkler system. The water is kept out of the system of piping by a pre-action (deluge) valve until the system response is required as a result of the opening of a sprinkler and/or the activation of a detection device. These systems are normally only used in special hazard applications, such as computer rooms, due to the increased installation costs. Preaction systems require the installation of a separate fire detection system, a releasing panel and additional valves and components. There are several types of pre-action systems: non-interlocked, single interlocked, and double interlocked. Depending on the goal of the installation, each type of pre-action system has benefits.

\subsubsection{Fire Control vs. Fire Suppression}

Sprinkler systems are typically designed to meet one of two objectives, either fire control or fire suppression. Although the term fire suppression systems is often used to refer to automatic fire sprinkler systems, it is a misnomer. As with most automatic fire sprinkler installations in high-rise office occupancies, the sprinkler systems provided in the WTC complex were designed to provide fire "control." Therefore, these systems were actually control-mode sprinkler systems. The main objectives for controlmode sprinkler systems are to limit fire growth (heat release rate) and contain the fire to the room or area of origin, which is referred to as fire control. While incident records indicate that control-mode automatic 
sprinkler systems routinely fully extinguish fires, it is clearly understood that "control" of the growth and spread of the fire is the performance objective and that full extinguishment may require intervention by the responding fire department.

Recent sprinkler technology developments have resulted in a special class of sprinkler systems that are intended to provide early response sensitivity and fire extinguishment. Typical applications include storage facilities and residential occupancies, where more efficient application of water during the earliest stages of a developing fire is desired. The information available indicated that control-mode sprinkler systems were used in WTC 1,2, and 7.

For more information regarding the various types of sprinklers available for use and the different options available to designers, the reader is referred to NFPA 13, The Standard for the Installation of Sprinkler Systems (NFPA 2002).

\subsubsection{The Area/Density Occupancy Hazard Design Approach}

The design method used for the sprinkler systems in the WTC buildings is referred to in NFPA 13 as the occupancy hazard fire control approach. The general approach used in the design of these types of sprinkler systems is to determine the occupancy hazard classification of the spaces protected by the system: light hazard, ordinary hazard group 1 or 2, or extra hazard group 1 or 2 . The hazard classification determines the minimum water spray density and an assumed minimum area of sprinkler operation to be used as input for the hydraulic calculations. Hydraulic calculations are used to determine the hydraulic demand (flow and pressure) for the system.

\section{Light Hazard}

The term Light Hazard (LH) Occupancy refers to buildings or portions of buildings where the quantity and combustibility of contents is low and where fires that burn with low rates of heat release are expected. This definition requires an understanding of burning rates and combustibility and knowledge of fuel loading; examples are provided in the appendix of NFPA 13. Such examples include the types of areas contained in the WTC complex. Examples are offices, including data processing facilities, clubs and restaurant seating areas, commercial shops, etc.

\section{Ordinary Hazard}

The term Ordinary Hazard $(\mathrm{OH})$ Occupancy refcrs to buildings or portions of buildings where combustibility is low to high, quantities are moderate, and fires of moderate heat release are expected. NFPA 13 further divides OH Occupancies into two categories referred to as $\mathrm{OH}$ Group 1 and $\mathrm{OH}$ Group 2. Editions of NFPA 13 prior to the 1991 edition included a third OH Group 3 category. In the 1991 edition, the three groups were merged into the two that exist today. Examples of OH Group 1 Occupancy areas are: manufacturing and processing plants, laundries, and restaurant service areas. Examples of $\mathrm{OH}$ Group 2 Occupancy areas include: dry cleaners, library stack areas, post office, and repair garages. OH Group 1 installations were present in specific areas of WTC 1, 2, and 7. 


\section{Extra Hazard}

The term Extra Hazard (EH) Occupancy refers to buildings or portions of buildings where the quantity and combustibility of contents is very high and where flammable or combustible liquids are used or stored, and rapidly developing fires with high rates of heat release are expected. NFPA 13 also subdivides the EH Occupancies into two categories. EH Group 1 and EH Group 2. The difference between the two classifications is based on the use of flammable or combustible liquids. EH Group 1 areas contain little or no flammable or combustible liquids. Examples of EH Group 1 Occupancies include: metal extruding and plywood and particleboard manufacturing plants. EH Group 2 areas contain moderate to substantial amounts of flammable or combustible liquids or contain shielding of combustibles. Examples of EH Group 2 Occupancies include: flammable liquid spray booths and open oil quenching areas.

\subsubsection{Pipe Schedule Design Method}

The term pipe schedule refers to a prescriptive design method utilizing predefined tables (schedules) of pipe sizes to be used to design sprinkler systems. The pipe schedule method requires the system designer to compare the actual building use to the examples for each of the occupancy hazards identified in NFPA 13. Three separate pipe schedules were formulated to encompass a variety of fire hazards and occupancy uses. These groupings are referred to as Light, Ordinary, and Extra Hazard Occupancies.

The design of sprinkler systems in the late 1960s and early 1970s using the pipe schedule method was subjective and required approval from the authorities having jurisdiction. The pipe schedule method is often referred to as the "cookbook" design approach due to the simplicity of its use and the ability to pull required information from tabulated data for each of the Occupancies. Separate tables for each occupancy hazard group include the listing of the maximum number of sprinklers that can be supplied by each pipe size (diameter) for both steel and copper pipe.

\subsubsection{Hydraulic Calculation Design Method}

Modern designs using hydraulic calculations and the occupancy hazard fire control approach are based on the minimum performance criteria specified in NFPA 13 for the particular occupancy hazard groups contained within the building or area. Designs using hydraulic calculations and variations of this methodology have been commonly used since the early 1970s. This design method requires identifying the particular occupancy hazard as identified above and obtaining the minimum required application density and design area from the figure provided in NFPA 13.

The application or discharge density refers to a water flow rate over a unit area. Densities are described in units of gallons per minute per square foot $\left(\mathrm{gpm} / \mathrm{ft}^{2}\right)$. Design areas are described in units of square feet or square meters in metric units. The density is used to specify the minimum flow rate to be discharged from an individual sprinkler, the minimum "end sprinkler" conditions, and the minimum flow rate required for the system. By multiplying the distance between sprinklers along a branchline and the distance between branchlines, the sprinkler coverage area is obtained. Then by multiplying the density by the coverage area per sprinkler, the minimum required flow rate is determined. This is used to define an end sprinkler condition, which is then used as the starting point in the hydraulic calculations. Chapter 6 includes a more detailed discussion of the hydraulic calculation design method as it applied to WTC 1, 2, 
and 7. As an illustration, Fig. 3-2 depicts typical area/density curves taken from the 1987 edition of NFPA 13. While the design curves have been modified in more recent editions of NFPA 13, the curves in Fig. 3-2 did not change over the period of time when the sprinkler systems in WTC 1, 2, and 7 were designed and installed.

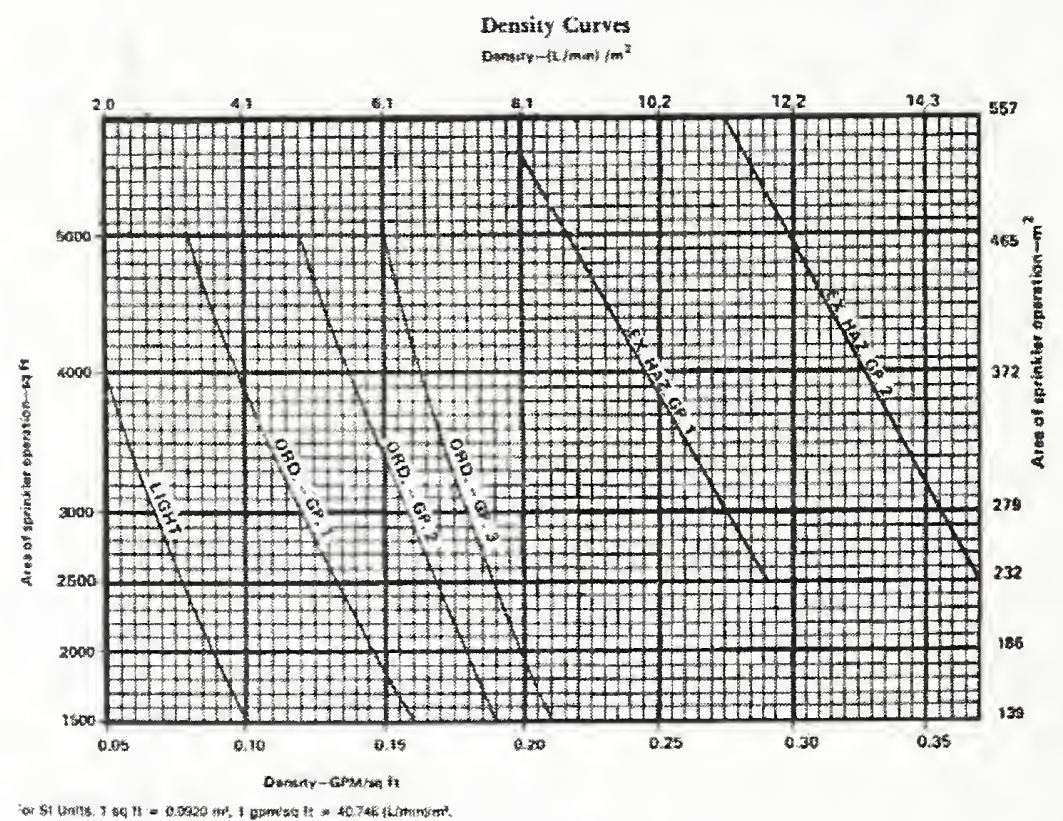

Source: Reproduced with permission of The National Fire Protection Association.

Figure 3-2. Area/density curves, NFPA 13, 1987 edition.

\subsubsection{Performance Expectations/History}

Automatic sprinklers have a long history of highly effective performance as a major component of fire and life safety in structures. Both fatality rates and property damage amounts have been estimated to be significantly lower for sprinklered versus non-sprinklered buildings (Rohr 2003). In fact, these estimates should be treated as lower bounds. The number of fires that are controlled by sprinkler systems and not reported to the fire department is a potentially significant number. Inclusion of these unreported incidents would increase the estimated effectiveness of sprinkler systems.

Another important factor associated with automatic sprinkler performance in buildings is the actual number of sprinklers required to control or extinguish fires. Sprinkler systems are designed to provide a minimum water spray density over a specified design area, usually involving 10 to 15 sprinklers. However, incident data from multiple sources indicate that over one-half of all fires are controlled or extinguished by one or two sprinklers (Bryan 1990; Maybee 1988; Powers 1979). The study reported by Powers involved evaluation of sprinkler system effectiveness for fires that occurred in high-rise buildings in NYC from 1969 to 1978. The results of this study indicated that over 90 percent of the fires in sprinklered buildings in NYC were controlled or extinguished by three sprinklers or less, and, 97 percent of the cases were controlled or extinguished by six sprinklers or less (Table 3-1). 
Table 3-1. Sprinklers operating to control or extinguish fires in NYC, 1969-1978.

\begin{tabular}{|c|c|c|c|c|c|c|}
\hline \multicolumn{4}{|c|}{ High-Rise Buildings } & \multicolumn{3}{c|}{ Low-Rise Buildings } \\
\hline $\begin{array}{c}\text { Number } \\
\text { of Sprinklers }\end{array}$ & $\begin{array}{c}\text { Number } \\
\text { of Fires }\end{array}$ & Percent & $\begin{array}{c}\text { Cumulative } \\
\text { Percent }\end{array}$ & $\begin{array}{c}\text { Number } \\
\text { of Fires }\end{array}$ & Percent & $\begin{array}{c}\text { Cumulative } \\
\text { Percent }\end{array}$ \\
\hline 1 & 1,054 & 65.4 & 65.4 & 2,159 & 57.1 & 57.1 \\
\hline 2 & 308 & 19.1 & 84.5 & 653 & 17.3 & 74.3 \\
\hline 3 & 110 & 6.8 & 91.3 & 302 & 8.0 & 82.3 \\
\hline 4 & 49 & 3.0 & 94.4 & 193 & 5.1 & 87.4 \\
\hline 5 & 31 & 1.9 & 96.3 & 120 & 3.2 & 90.6 \\
\hline 6 & 16 & 1.0 & 97.3 & 77 & 2.0 & 92.6 \\
\hline 7 or more & 44 & 2.7 & 100.0 & 280 & 7.4 & 100.0 \\
\hline Total & $\mathbf{1 , 6 1 2}$ & & & $\mathbf{3 , 7 8 4}$ & & \\
\hline
\end{tabular}

Source: Bryan 1990; Powers 1979.

These results indicate that for typical, anticipated fire events in high-rise buildings, the hazard classifications and the density and design area requirements provide adequate firc control capability (Bryan 1990; Powers 1979). The primary causes for failure to achieve fire control in sprinklered buildings include a closed water supply valve; partial, antiquated, poorly maintained, or inappropriate systems; and explosions or flash fires that overpower the system before the sprinklers can react (Rohr 2003).

\subsection{STANDPIPES AND PRE-CONNECTED HOSES}

\subsubsection{Overview/General Description}

Standpipe systems are fixed piping systems that provide water to designated areas of a building to support manual fire fighting efforts (Cote 2003). Standpipe systems provided for high-rise buildings consist of risers with hose connections at each floor supplied by pumps and at least one fire department connection. The connections may or may not include pre-connected hoses, depending on the type of system and the requirements of the local code authority. The number of standpipe risers and connections are dependent on the building configuration and size. Usually, the systems are pressure monitored to ensure operability.

The basic concept of standpipe systems has not changed appreciably over the last 90 years, although specific requirements have been modified from time to time. The nationally recognized design and installation standard for standpipe systems is NFPA 14, Standard for the Installation of Standpipe and Hose Systems, which was originally adopted in 1915 (Bryan 1990). While the Building Code of the City of New York (BCNYC) does not reference NFPA 14 specifically, the recognized types and classifications of standpipe systems, as well as associated rcquirements in the BCNYC have becn consistent with those found in NFPA 14.

\subsubsection{Classification of Standpipe Systems}

Typically, standpipe systems are installed to support fire department operations, use by building occupants, or both. In NFPA 14, standpipe systems are classified accordingly, as Class I, Class II or Class III systems. The following is a brief description of each class, in accordance with NFPA 14. As 
indicated above, while the BCNYC does not specifically use these designations, the descriptions are similar.

\section{Class I Systems}

Class I standpipe systems are designed to provide $2 \frac{1}{2}$ in. hose (standpipe) valves, which are used to provide heavy streams for fire department personnel usage in advanced stages of fire. At the time of construction, hose valves were required in all exit stair enclosures and throughout all portions of a story or building section, such that all portions of the building would be within $30 \mathrm{ft}$ of a nozzle at the end of a $100 \mathrm{ft}$ hose.

\section{Class II Systems}

Class II systems are designed to provide $1 \frac{1}{2}$ in. hose stations, which are used to provide small streams for trained building occupants or fire brigades to fight incipient fires and for mop up efforts. Hoses and nozzles are provided at the hose stations and are spaced similarly to Class I hose valves except hose stations are required at all areas within $20 \mathrm{ft}$ of a nozzle at the end of a $100 \mathrm{ft}$ hose.

\section{Class III Systems}

Class III standpipe systems are a combination of Class I and II systems; Class III systems are the same as Class I systems with added $1 \frac{1}{2} \mathrm{in}$. outlets or $1 \frac{1}{2} \mathrm{in}$. adapters and hose. Class III systems are designed for use by the fire department, trained building occupants, or a fire brigade. The standpipe systems in WTC 1, 2, and 7 were similar to Class III systems but were designed according to the provisions of the $\mathrm{BCNYC}$.

\subsubsection{Design Basis}

The basis of design for Class I and Class III standpipe systems specify a performance requirement of $500 \mathrm{gpm}$ at $100 \mathrm{psi}$ to be supplied to the most hydraulically remote standpipe and $250 \mathrm{gpm}$ at 100 psi to be supplied to each additional standpipe up to a maximum of 1,250 gpm. This performance requirement anticipates the use of two $2 \frac{1}{2} \mathrm{in}$. hose lines connected to the most remote standpipe and an additional hose line connected to each of the other standpipes. The term remote refers to hydraulic remoteness and not physical or spatial remoteness. The most hydraulically remote standpipe is the standpipe that requires the highest initial pressure to provide the specified flow and pressure to the end standpipe valve. The energy lost to friction as a result of water moving through the pipe increases the initial pressure. This could be the standpipe valve located on the top floor of a building or at the farthest end of a building from the water supply. The configuration of the system, including diameter of pipes, changes in elevation, and changes in direction, affects the amount of energy (pressure) required to meet the performance requirement of the system. For this reason, an analysis is typically performed to determine the hydraulically most demanding standpipe (NFPA 14 2000; Cote 2003).

The design of Class II standpipe systems includes $100 \mathrm{gpm}$ for the most hydraulically demanding standpipe at $65 \mathrm{psi}$. This is significantly less than the performance requirements for Class I and Class III systems, however, the procedure and analysis are similar (NFPA 14 2000; Cote 2003). 
In addition to classification, standpipe systems are further categorized by the type of water supply. The terms wet, damp, and dry are used to define the type of water supply.

Wet systems are the preferred arrangement, but require heat for all portions of the building occupied by standpipe system components to prevent freezing. These systems are filled with water at all times and are provided with a direct connection to an automatic water supply, such as a city water distribution system, tank and pump, elevated tank, or pressure tank.

Dry standpipe systems contain atmospheric or pressurized air filled pipe and are further differentiated as automatic, semiautomatic, or manual dry standpipes. Manual dry standpipes are provided with FDCs only; this type of system is not provided with any connections to an automatic water supply. Automatic dry standpipes contain a dry-pipe valve that maintains pressurized air or nitrogen within the system. The valve contains a differential clapper designed to prevent water from entering the system while pressurized with air. The lower air pressure on the system side of the clapper pushes against a larger surface area than the water supply, which pushes on the other side of the clapper at a higher pressure over a smaller surface area. When a standpipe valve is opened, air is released from the system piping until the water pressure can overcome the force applied by the air pressure on the top surface of the clapper. Once this happens, water fills the standpipe system and allows water to flow through the hose valve that was opened. A semiautomatic dry standpipe system is a system that is normally filled with atmospheric air and includes a connection to an automatic water supply that is kept closed (Cote 2003; Bryan 1990).

\subsubsection{Performance Expectations}

Performance records are not maintained for standpipe and pre-connected hose systems. However, there is little doubt that eliminating the need for extended hose lays from the fire department apparatus to the fire location on an upper floor in a high-rise building improves initial attack manual fire fighting operations. While pre-connected hoses are provided in many buildings, including WTC 1,2, and 7, concerns over reliance on these hoses by building occupants have been a long standing dcbate. In some jurisdictions, only Class I or similar standpipe systems are permitted, for use only by the fire department. In addition, standpipe systems are not considered to be an alternative to automatic fire suppression, e.g., automatic sprinklers. 
This page intentionally left blank. 


\section{Chapter 4 \\ APPLICABLE CODES AND STANDARDS}

\subsection{GENERAL}

Codes and standards are developed as a guide for the design and installation of building systems, and when adopted by governmental jurisdictions are considered to be legal minimums. Building and design professionals, as well as authorities having jurisdiction (AHJ), use codes and standards to ensure that a minimum level of life safety is maintained in new and existing buildings. Generally, design professionals use codes and standards as a guide for design. while the AHJ references and enforces the same codes and standards to verify that the minimum levels of life safety are met in the building design and construction.

The World Trade Center (WTC) was constructed and maintained under the jurisdiction of The Port Authority of New York and New Jersey (PANYNJ or Port Authority). Although the PANYNJ was not subject to the provisions of the Building Code of the City of New York (BCNYC), the Port Authority voluntarily adopted the provisions within the BCNYC for the design and construction of WTC 1, 2, and 7. In addition. certain reference standards (RS) referenced within the BCNYC were adopted. The reference standards include locally established standard documents. as well as nationally recognized standard documents with local modifications (Razza and Grill 2005).

A summary is provided here of the applicable codes and standards, including New York City (NYC) local law revisions to the BCNYC as they apply to automatic sprinkler systems. standpipes and pre-connected hoses. and water supplies for WTC 1.2. and 7. The information was derived from review of related documentation, including a report based on a study performed by Rolf Jensen \& Associates (RJA) (Razza and Grill 2005) as part of the analysis of building and fire codes and practices of the National Institute of Standards and Technology (NIST) WTC Investigation. The scope of that study included documentation of the code requirements in the code of record under which IVTC 1, 2, and 7 were built, as well as the changes in building code regulations that occurred subsequent to the construction of the buildings that were retroactively adopted by the Port Authority.

As discussed in the RJA report, WTC 1 and WTC 2 were constructed under the 1968 edition of the BCNYC. The 1968 BCNYC, along with amendments up through January 1, 1985, was used to provide the fire safety provisions during the primary design and construction of WTC 7.

The codes and standards applicable to the fire and life safety provisions for WTC 1, 2, and 7 were as follows (PANYNJ 1987a, 1987b; Razza and Grill 2005):

- $\quad$ WTC 1 and WTC 2

- BCNYC 1968

- Local Law No. 5. Fire Safety Requirements and Controls in Certain Office Buildings. January 18, 1973 
- RS 17: Standard for Water Tanks for Private Fire Protection, NFPA 22 (1962), with modifications

- RS 17-1: Standpipe Construction

- RS 17-2: Standard for the Installation of Sprinkler Systems, NFPA 13 (1966), with modifications

- RS 17-3: Standard for the Installation of Fire, Sprinkler, Standpipe, Smoke Detection, and other Alarm and Extinguishing Systems

\section{- WTC 7}

- $\quad$ BCNYC 1968, including amendments to January 1, 1985

- Local Law No. 5, Fire Safety Requirements and Controls in Certain Office Buildings, January 18, 1973

- Local Law No. 16, March 27, 1984

- RS 17-1: Standpipe System Construction

- RS 17-2: Standard for the Installation of Sprinkler Systems, NFPA 13 (1982), with modifications

- RS 17-3: Standard for the Installation of Fire, Sprinkler, Standpipe, Smoke Detection, and other Alarm and Extinguishing Systems

- NFPA 22: Standard for Water Tanks for Private Fire Protection, 1981

\subsection{HIGH-RISE FIRE SUPPRESSION SYSTEMS}

In the BCNYC, the term "high-rise building" refers to any building over $75 \mathrm{ft}$ in height (Razza and Grill 2005). Such buildings pose a unique challenge for fire suppression since firefighting and rescues for the upper floors must be staged from within the building without the use of aerial ladder or elevated platform trucks for assistance. Additionally, fires on the upper levels require fire fighters to travel greater distances with their equipment. Due to these challenges and others imposed by high-rise buildings, the building codes require specific fire and life safety features for all new high-rise structures.

Additionally, many building codes have retroactive requirements for existing structures with either specified timelines for compliance or thresholds built into the code provisions that require upgrades based on percentages of building construction, modifications, or cost. (High-rise buildings constructed today are required by building codes to have both standpipe and sprinkler systems installed throughout.) Limitations imposed by material costs and the working pressures of pipe, fittings, and equipment limit the ability to design a high-rise building using a single water supply zone. For this reason sprinkler and standpipe systems for high-rise buildings are usually designed with multiple vertical water supply zones. 


\subsection{CODE PROVISIONS}

The applicable sections of the BCNYC with the amendments associated with Local Laws 5/73 and 16/84 establish the provisions for the scope of the installation of sprinkler systems, standpipe systems and associated water supplies for high-rise business occupancies in New York City (Razza and Grill 2005). The scope of the required installations refers to the type, location, quantity, etc. The actual installation provisions for each system are established in the RS sections referenced in the BCNYC. The code provisions established in the BCNYC are listed below for each building. This section identifies only what the provisions were at the time of design and installation. Installation provisions established in the RS sections are addressed in later sections where applicable.

\subsubsection{Code Provisions for Sprinkler System Installations, WTC 1 and WTC 2}

The 1968 edition of the BCNYC required sprinkler systems for underground spaces. However, sprinkler systems were not required in new Group E business occupancy buildings. Therefore, sprinkler systems were installed throughout the sub-grade levels of the WTC complex during the initial building construction, and the WTC 1 and WTC 2 towers were constructed without sprinkler systems. The PANYNJ decided to retrofit sprinkler systems in WTC 1 and WTC 2 in response to the enactment of NYC Local Law 5 in 1973. A description of the BCNYC code requirements for sprinkler system installations and the applicable local laws is provided as part of the fire code analysis of the NIST WTC Investigation.

\subsubsection{Code Provisions for Sprinkler System Installations, WTC 7}

The 1968 edition of the BCNYC was in effect for the design and construction of WTC 7. However, by 1984, Local Law 16 of 1984 was in effect, establishing the following requirements for automatic sprinkler systems (Grill and Johnson 2005):

- Automatic sprinkler protection should be designed and installed in accordance with Section C26-1703.1 and RS 17-2 in the following areas:

- Buildings classified in occupancy Group E, $100 \mathrm{ft}$ or more in height having airconditioning and/or mechanical ventilation systems that serve more than the floor in which the equipment is located

- Regardless of occupancy, any story above grade and the first story below grade with required ventilation:

a. All other stories below grade.

b. Sprinklers may be omitted in toilets, shower rooms, stairs, mechanical rooms and electrical rooms. 


\subsubsection{Code Provisions for Standpipe System Installation, WTC 1, 2, and 7}

The following were the primary provisions used for the design and installation of the fire standpipe systems in WTC 1, 2, and 7 (Grill and Johnson 2005a; Grill and Johnson 2005). Each provision was required per the applicable section of the BCNYC.

- C26-1702(a)(1) Wet standpipes designed and installed in accordance with Section C26-1702.1 and RS 17-1 should be provided.

- C26-1702.4 The number of standpipes should be such that every point of every floor can be reached by a $20 \mathrm{ft}$ stream from a nozzle attached to not more than $125 \mathrm{ft}$ of hose connected to a riser outlet valve.

- C26-1702.5(a) Standpipe risers and $2 \frac{1}{2}$ in. hose valves should be located within stairway enclosures.

- C26-1702.5(a) When stairway enclosures are not available within the 125 plus $20(145) \mathrm{ft}$ distance, risers and valves should be located as near to the enclosure as practicable.

- C26-1702.7, Table 17-1 Standpipe risers should be at least 4 in. in diameter where the riser height is $150 \mathrm{ft}$ or less from the highest hose outlet to the level of the entrance floor, $6 \mathrm{in}$. in diameter where greater than $150 \mathrm{ft}$.

- C26-1702.1.1(a)(2) The highest riser should be extended above the roof with a 3-way manifold with $2 \frac{1}{2} \mathrm{in}$. hose valves.

- C26-1702.11(a)(1) A $2 \frac{1}{2}$ in. hose outlet should be provided at each standpipe riser on each floor served, and on the entrance floor above the riser control valve, located between $5 \mathrm{ft}$ and $6 \mathrm{ft}$ above the landing or floor.

- C26-1702.10(a) Standpipe systems that include more than one riser should have all risers cross-connected at, or below, the street entrance floor level.

- C26-1702.10(b) Standpipe systems having more than one zone should be arranged such that the risers supplied from each zone are cross-connected below, or in, the story of the lowest hose outlets from the water source in each zone.

- C26-1702.11(b) Hose stations should be located at the standpipe risers, either inside or adjacent to the entrance of stairway enclosures.

- C26-1702.11(b)(1) Hose stations should be located to satisfy the 125 plus 20 (145) ft requirement.

- C26-1702.11(c) Hose should be $1 \frac{1}{2}$ in. unlined (flax-line) hose in Groups C, E and F; $2 \frac{1}{2}$ in. (unlined) in Group B.

- C26-1702.11(c)(4), C26-1702.11(d) Auxiliary hose stations equipped with $1 \frac{1}{2} \mathrm{in}$. (unlined) hose are permitted in Groups C, E and F. 


\subsubsection{Code Provisions for Water Supply, WTC 1, 2, and 7}

- C26-1702.14 Standpipe systems should have a primary water supply available at all times to every hose outlet or made available automatically when the hose valve at any outlet is opened.

- C26-1702.14(b) Combinations of two or more of the following sources should serve as the primary water supply; in using such combinations, the siamese connections shall be considered as a source of supply.

- Direct connection to city water system

- Direct connection to a private yard main

- Gravity $\operatorname{tank}(\mathrm{s})$

- Pressure tank(s)

- Automatic fire pump:

a. In buildings higher than $300 \mathrm{ft}$ the automatic fire pump should be used only for the lower $300 \mathrm{ft}$. Zones above $300 \mathrm{ft}$ should be supplied by either a gravity or pressure tank.

- C26-1702.15(a) An additional standpipe system water supply should be provided for standpipes in buildings over $300 \mathrm{ft}$ high:

- C26-1702.15(a) The primary water supply to the standpipe system should be supplemented by one or more manually operated fire pumps.

- C26-1703.8(a) At least one of the following automatic source of water supply should be provided for sprinklers:

- Gravity tanks

- Pressure tank(s)

- Automatic fire pump

- Direct connection to public water system

- C26-1703.8(b) Auxiliary sources of water supply for sprinkler systems may include a manually actuated fire pump or siamese connection.

- C26-1703.8(c) Combined water supplies:

- Fire pumps may simultaneously serve as the required auxiliary water supply for standpipe and sprinkler systems in accordance with Section C26-1702.15(d);

- Tanks used to provide the required primary water supply to a standpipe system may also be used as a supply for an automatic sprinkler system. 
- C26-1702.9(a), C26-1703.6(a)(1) One standpipe system and one sprinkler system siamese connection should be provided for each $300 \mathrm{ft}$ of exterior building wall or fraction thereof facing each street or public space:

- Modifications based on street frontage as permitted by Sections C26-1702.9(b)-(f).

- C26-1702.10(f) Each siamese connection should be connected to a riser or to a crossconnection connecting other siamese connections or risers.

- C26-1703.6(a)(2) In below grade sprinkler systems for garage occupancies, a sprinkler siamese connection should be provided within $50 \mathrm{ft}$ of every exit or entrance used by motor vehicles.

- Siamese connections for partial sprinkler systems should be in accordance with Section C26-1703.6(a)(3). 


\section{Chapter 5 \\ TASK 1: WATER SUPPLIES, AUTOMATIC FIRE SPRINKLERS, AND STANDPIPES (PRE-CONNECTED HOSES) IN WTC 1, 2, AND 7}

\subsection{GENERAL}

One of the objectives of Task 1 was to provide a detailed description of the water supplies and the automatic fire sprinkler and standpipe systems in World Trade Center (WTC) 1, 2, and 7. Another objective was to evaluate the installations in terms of engineering "best practices" and associated engineering standards, which existed at that time. Selected figures and tables are used in this chapter to highlight specific information. In addition, frequent reference is made to detailed design drawings reproduced in Appendix B. Most of the information in this chapter is based on information obtained from the Port Authority of New York and New Jersey (PANYNJ).

The descriptions of the fire suppression systems provided in this report are based on available information. The accuracy of the information regarding the sprinkler systems infrastructure, standpipe systems, and water supply tanks was considered sufficient. However, due to the retrofit program for the automatic sprinkler systems in WTC 1 and WTC 2, detailed layout of the sprinkler systems for each floor was not available in some cases. This was not considered a significant limitation because design specifications were available that allowed sufficient estimation of the floor level sprinkler layouts to evaluate the hydraulic demands. Additionally, documentation was found that illustrated typical sprinkler system main layouts that were considered consistent with accepted practice.

Separate sprinkler and standpipe systems were provided in WTC 1 and WTC 2. However, certain features of these systems were interconnected, such as the water supplies, distribution piping, and fire department connections. For example, the standpipe system reserve water storage tanks and the manual fire pumps could be used to supply water to the sprinkler systems and the standpipe systems (PANYNJ 1987a), and, the reserve water storage tank located on floor 20 of WTC 1 was used to supply the initial water supply for the low zone standpipe systems in both buildings (PANYNJ 1987a). In WTC 7, the sprinkler and standpipe systems were combined.

\subsection{FIRE SUPPRESSION SYSTEMS, WTC 1 AND WTC 2}

\subsubsection{Water Supplies}

A combination of automatic and manual water supplies was provided for the fire suppression systems in WTC 1 and WTC 2 (PANYNJ 1972, 1987a). The automatic water supplies were provided by gravity feed water storage tanks, which are discussed in the standpipe and sprinkler sections of this chapter. Additionally, an automatic fire pump was used in each tower to supply the combination high zone sprinkler systems and the hose racks at the 110 th floor level. The manual water supplies consisted of manual fire pumps and fire department connections. 
The source of all water for the fire suppression systems was the New York City (NYC) water distribution system (reference Chapter 6 for a detailed description and evaluation of the water supply). A 12 in. fire service main with dual connections to the NYC water distribution system supplied water to the WTC complex. A single 16 in. connection to the 20 in. NYC distribution system main was provided beneath Vesey Street at the north side of the complex. A parallel connection at the south side of the WTC complex was provided with a 16 in. tap to the 20 in. main beneath Liberty Street. Figure $5-1$ is an illustration of the water distribution system surrounding the WTC complex.

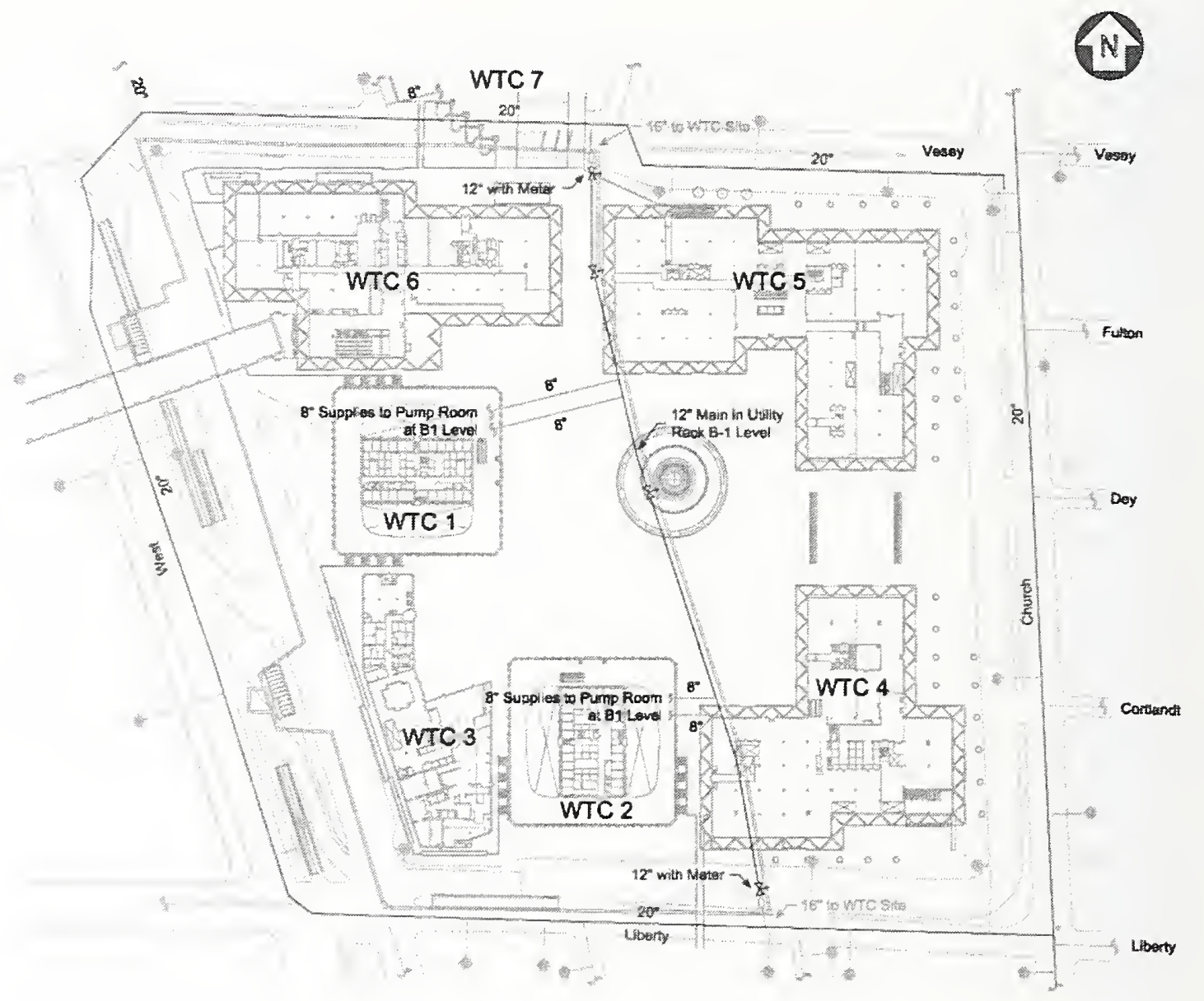

Sources: Beyler 2002. Reproduced with permission of the Silverstein Properties Group.

Figure 5-1. Plan of water distribution system surrounding the WTC complex.

\section{Water Storage Tanks}

The water supply for each vertical standpipe system zone consisted of one or more water storage tanks. These tanks were used as the primary automatic water supplies for manual fire suppression efforts. The reserve water storage tanks provided time to allow personnel to start the manual fire pumps to provide water to the sprinklers and standpipes directly supplied by the NYC water distribution system.

The water storage tanks were located above the elevation of the standpipe system, using the force of gravity to provide pressure to the system from the top of the standpipe in the "initial operating mode." 
The exception to this arrangement were the high zone hose stations located on the 110 th floor, which were supplied with water from a combination sprinkler and standpipe system booster pump located on the 108th floor (PANYNJ 1972, 1987a).

Reserve water supply tanks were located in the mechanical equipment room (MER) floor levels of both towers. In most cases, the MER levels were two stories in height. The MER levels were located at the following elevations:

- $\quad$ Floor levels 7 and 8

- Floor levels 41 and 42

- Floor levels 75 and 76

- Floor levels 108 and 109

- $\quad$ Bulkhead deck 110

Four reserve water storage tanks were provided in WTC 1 to supply the standpipes. Each tank had a holding capacity of 5,000 gal for a total of 20,000 gal of water dedicated for manual fire suppression. These tanks were located on floors 20,41,75, and 110. The tanks were designated FSP storage tank No. 20A. FSP storage tank No. 41A. FSP storage tank No. 75A, and FSP storage tank No. 110A, respectively (PANYNJ 1987a). Figure 5-2 illustrates a typical water storage tank (Merritt \& Harris Inc. 2000).

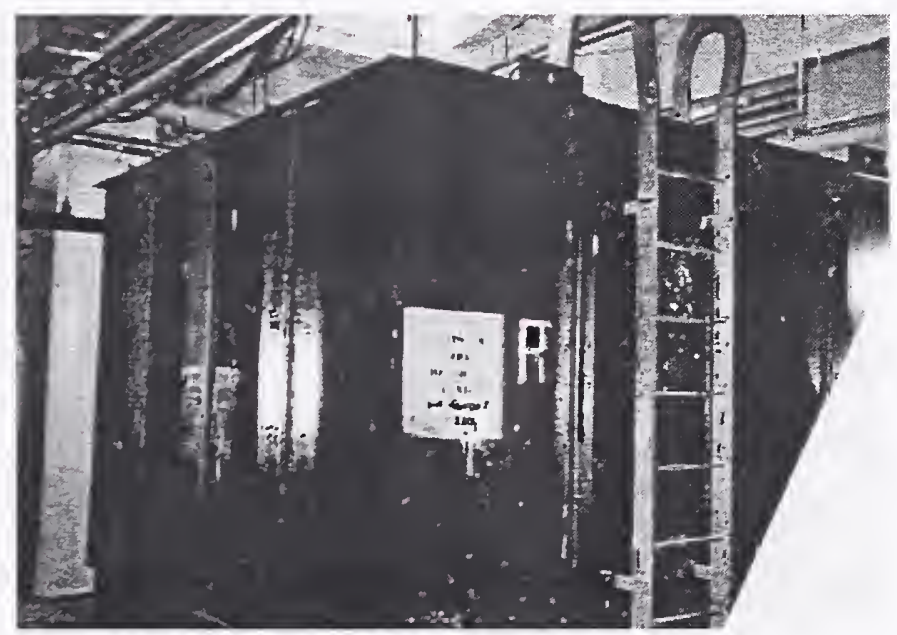

Source: Merritt \& Harris Inc. 2000. Reproduced with permission of The Port Authority of New York and New Jersey.

Figure 5-2. Typical 5,000 gal water storage tank, WTC 1 and WTC 2.

The water storage tank located on the 20th floor of WTC 1 supplied water to the sub-grade loops and the low zone standpipes in both towers. A similar tank was not provided in WTC 2.

Three reserve water storage tanks were provided in WTC 2 to supply the standpipes. These tanks were located on floors 42, 76, and 110. The tanks were designated FSP storage tank No. 41B, FSP storage tank 
No. 75B, and FSP storage tank No. 110B respectively. Similar to WTC 1, each of the tanks had a holding capacity of 5,000 gal of water. The total holding capacity of the tanks in WTC 2 was $15,000 \mathrm{gal}$ (PANYNJ 1987).

Two parallel 5,000 gal water storage tanks were provided on the 110 th floor in each of the towers. These tanks provided a dedicated water supply of 10,000 gal for the high and mid-level zone sprinkler systems. The 5,000 gal standpipe reserve water storage tank on the 110 th floor level also served as a secondary automatic watcr supply for the high and mid-level automatic fire sprinkler systems. Figure $\mathrm{B}-\mathrm{l}^{2}$ is a riser diagram of the WTC 1 and WTC 2 tower sprinkler and standpipe systems. Figure B-1 illustrates the interconnection of the standpipe and sprinkler systems within the towers. Figures 5-3 and 5-4 depict the configuration of the sprinkler system reserve storage tanks for the high and mid-level zone sprinkler systems.

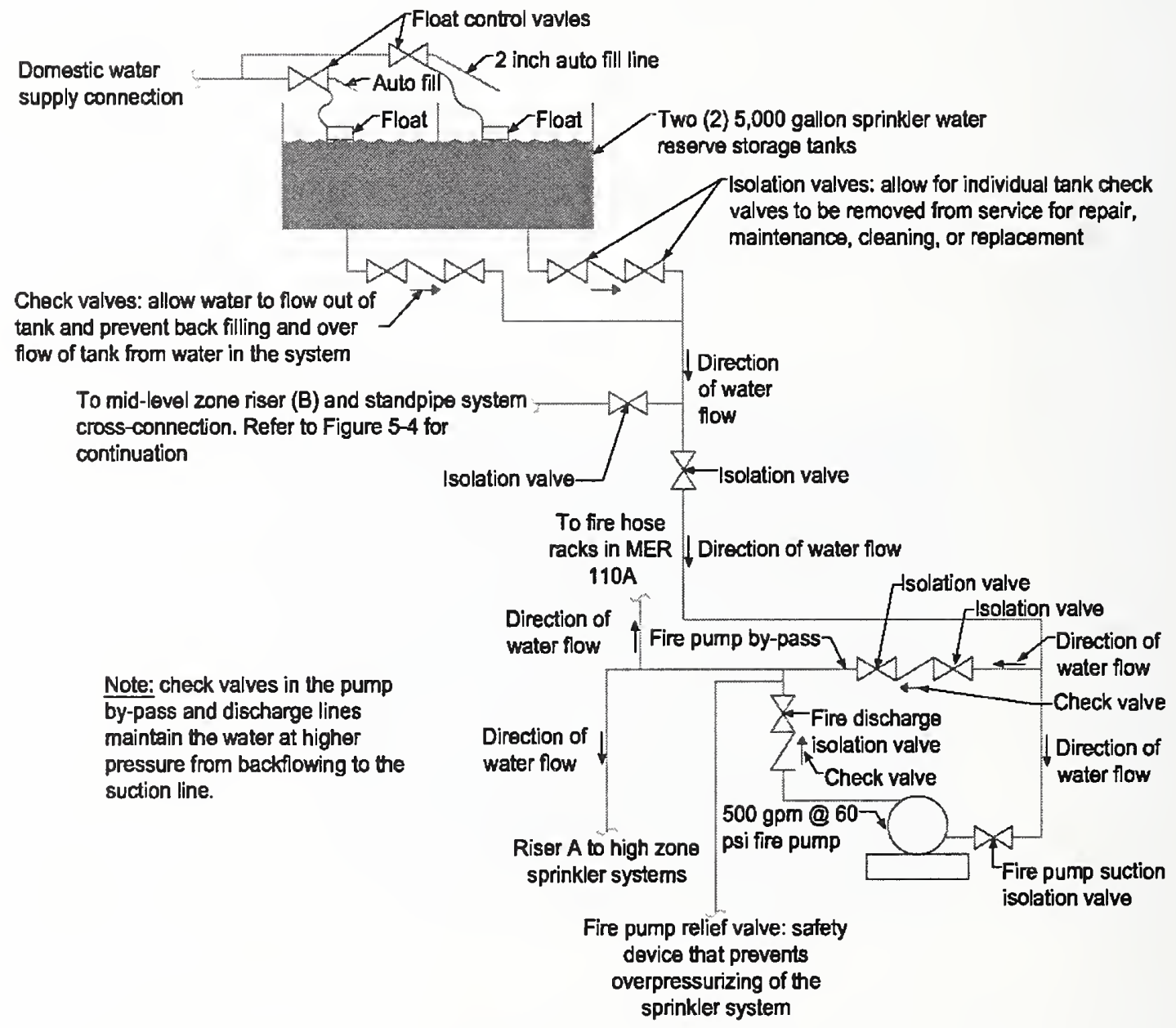

Figure 5-3. Water storage tanks, high zone sprinkler systems.

2 Refer to Appendix B for detailed figures. 


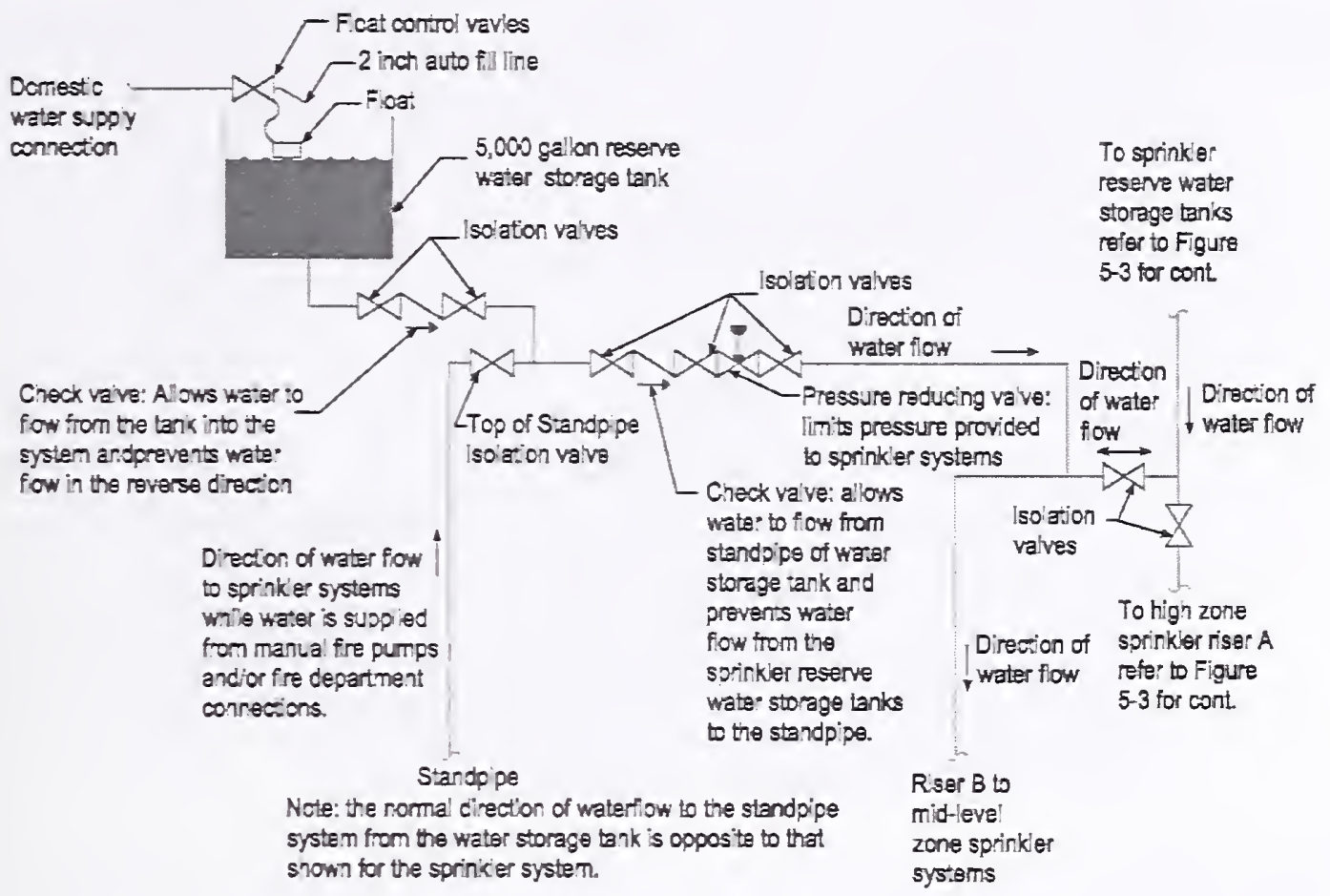

Figure 5-4. Water storage tanks, mid-level zone sprinkler systems.

The 5.000 gal water storage tanks located in the 41 st floor level mechanical rooms were arranged to provide the primary water supply for the low zone sprinkler systems and the standpipe system zone ser'ing floors 8 through 31 . Therefore. a minimum of 5,000 gal was provided for the standpipe and sprinkler systems in each tower. Since each tank was also equipped with a 2 in. diameter automatic fill line supplied by the domestic water system, the volume of water in the tank would be partially replenished as the water was depleted from the tank.

The domestic plumbing system was provided with a separate and independent connection to the NYC water distribution system from the fire service connections. Water was supplied to the water storage tanks through the domestic plumbing system. This is identified on the plumbing system design documents as the fire make-up system. The water for the domestic system was supplied by an $8 \mathrm{in}$. connection to the distribution system with multiple. staged high pressure domestic pumps capable of delivering water to the tanks as well as serving the domestic demand requirements for the building. Each tank was equipped with a float control valve that automatically filled the tank through a 2 in. fill line (PANYNJ 1972, 1983, 1987a).

\section{Fire Pumps}

The WTC complex was provided with 12 fire pumps and a single vertical turbine jockey pump PANYNJ 1972. 1987a). Table 5-1 provides a summary of the fire pump locations for the WTC 1 and 2 sprinkler and standpipe systems. 
Table 5-1. Fire pumps, WTC 1 and WTC 2.

\begin{tabular}{|c|c|c|c|c|c|c|}
\hline Tower & & Fire Pump & Size & Location & System & Operation \\
\hline \multirow{7}{*}{ WTC 1} & 1 & Standpipe Pump 294A & 750 gpm@360 psi (831ft) & B1 level & Standpipe & Manual \\
\hline & 2 & Sprinkler Pump 294A & 1,500gpm@100psi (231ft) & B1 level & Sprinkler & Manual \\
\hline & & Jockey Pump & & B1 level & Sprinkler & Automatic \\
\hline & 3 & Pump 7A & 750 gpm@346 psi (800ft) & 7th floor & Standpipe & Manual \\
\hline & 4 & Pump 41A & 750 gpm@360 psi (831ft) & 41 st floor & Standpipe & Manual \\
\hline & 5 & Pump 75A & 750 gpm@228 psi (527ft) & 75th floor & Standpipe & Manual \\
\hline & 6 & Pump 108A & 500 gpm@60 psi (139ft) & 108th floor & Sprinkler & Automatic \\
\hline \multirow{6}{*}{ WTC 2} & 7 & Standpipe Pump 294B & 750 gpm@360 psi (831ft) & B1 level & Standpipe & Manual \\
\hline & 8 & Sprinkler Pump 294B & 1,500gpm@100psi (231ft) & B1 level & Sprinkler & Manual \\
\hline & 9 & Pump 7B & 750 gpm@346psi (800 ft) & 7th floor & Standpipe & Manual \\
\hline & 10 & Pump 41B & 750 gpm@360psi (831ft) & 41 st floor & Standpipe & Manual \\
\hline & 11 & Pump 75B & 750 gpm@228 psi (527ff) & 75th floor & Standpipe & Manual \\
\hline & 12 & Pump 108B & 500 gpm@60 psi (139ft) & 108th floor & Sprinkler & Automatic \\
\hline
\end{tabular}

Two manual fire pumps were used to supply water to the B1 and concourse level loops for the automatic fire sprinkler systems. These 1,500 gpm pumps were located on the B1 sub-grade level. Sprinkler pump 294A and the jockey pump were located in WTC 1, and sprinkler pump 294B was located in WTC 2. The jockey pump was used to maintain the sub-grade sprinkler loops at $155 \mathrm{psi}$. These two pumps supplied water to the sub-grade sprinkler loops and throughout the WTC complex but did not supply water to the sprinkler systems in the WTC 1 and WTC 2 towers (PANYNJ 1972, 1987b).

Two parallel 750 gpm manual standpipe fire pumps, designated 294A and 294B, were installed for the standpipe system sub-grade loops. The B1 level fire pumps for the sprinkler and standpipe systems were provided with separate $8 \mathrm{in}$. fire service connections to a centralized $12 \mathrm{in}$. main connected to the NYC water distribution system at two locations. Figure 5-5 is a photograph of standpipe fire pump 294A taken from the Operation and Maintenance (O\&M) manual (PANYNJ 1972, 1987b).

The standpipe system infrastructures in WTC 1 and WTC 2 included three additional 750 gpm staged, manually operated fire pumps at the 7th, 41 st, and 75th MER floor levels (PANYNJ 1972). The initial operating mode for the standpipe systems relied on gravity pressure supplied by the reserve water storage tanks to supply water for manual fire fighting and automatic sprinkler system activities prior to the operation of the manual fire pumps in the tower. The reserve water storage tanks were also intended to be used as an initial water supply for the manually operated fire pumps serving the higher standpipe system zones and upper level fire pumps. As water was supplied from the fire department connections or lower level tanks, the need for water supplied from the reserve water storage tanks would be reduced. 


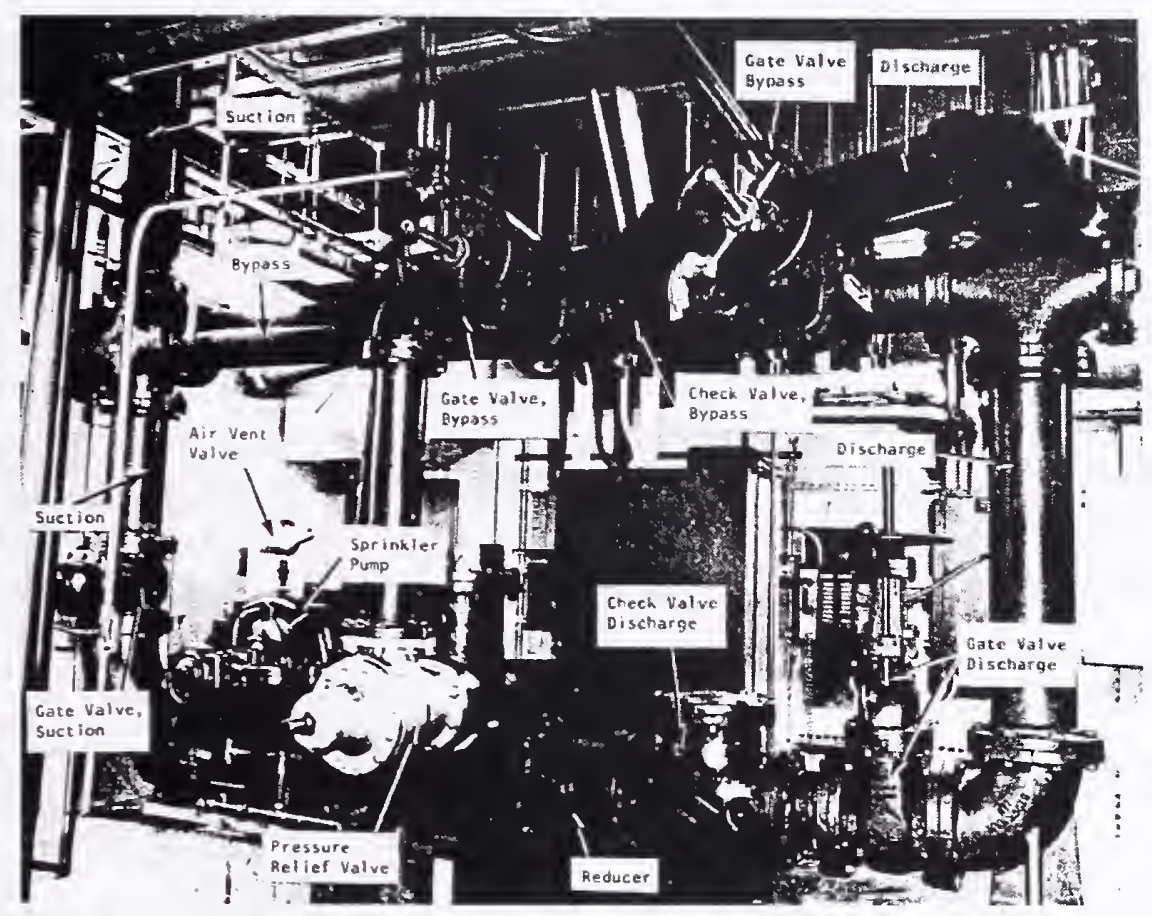

Source: PANYNJ 1987a. Reproduced with permission of The Port Authority of New York and New Jersey.

\section{Figure 5-5. Manual standpipe fire pump 294A, WTC 1.}

The standpipe system reserve storage tanks located on the 75 th and 41 st floor mechanical rooms were configured to serve as secondary manual water supplies for the high and mid-level zone automatic sprinkler systems. The use of these storage tanks required the manual operation of the fire pumps to lift the water to the 110 th floor level. Any two manual fire pumps operating in series were capable of providing adequate capacity and pressure to supply the fire protection (suppression) systems within the high or mid-level sprinkler or standpipe systems.

A single fire (booster) pump was provided in each tower at the 108 th floor level for the high zone sprinkler systems and the hose connections located on the 110 th floor level. The suction line for each of the fire pumps received water from the sprinkler and standpipe reserve water storage tanks located in the mechanical rooms on the 110 th floor. The 15,000 gal combined water capacity within the tanks was capable of supplying water to the booster pump at a flow rate of $500 \mathrm{gpm}$, the 100 percent capacity of the fire pump, for a minimum duration of 30 min without any supplemental water being supplied by the domestic water system. This duration would be reduced to $20 \mathrm{~min}$ if the pump was operating at $750 \mathrm{gpm}$ (the 150 percent capacity of the fire pump), which is the maximum required flow rate for a $500 \mathrm{gpm}$ pump.

\section{Fire Department Connections}

The WTC complex was provided with 14 separate fire department connection (FDC) stations, with a total of 32 fire department (siamese) connections. Figure B-2 provides an overview of the layout for the fire department connections at the WTC complex (PANYNJ 1972, 1987a). 
All of the FDC stations included a two-barrel siamese connection for the WTC complex sub-grade sprinkler loops and a separate siamese connection for the WTC complex standpipe systems. Any of the standpipe system FDC stations could be used to supply water to the WTC 1 and WTC 2 standpipe systems. The standpipe FDC connections could also be used to supply water to the sprinkler systems above the 31 st floors in the WTC 1 and 2 towers. Any standpipe FDC and a single manual fire pump were able to supply water to any floor in the respective tower where the fire pump was located (PANYNJ 1972, 1987a).

Two additional high-pressure siamese connections were provided at the north and south sides of the complex at Vesey and Liberty Streets, respectively. These high-pressure connections permitted the fire department to use a high-pressure pumper to supply water to the standpipe systems at any floor in the towers. They were also used to supply water to the sprinkler systems above the 31 st floor in either tower. The high-pressure pumpers have a third stage that can supply $500 \mathrm{gpm}$ at 700 psi (Syska \& Hennessy 1984; PANYNJ 1972, 1987a; FDNY 1990).

The two final siamese connections were provided for the tower low zone sprinkler systems, floors 1-31 of WTC 1 and WTC 2. These were located at Liberty and West Streets (PANYNJ 1972).

The FDNY high-rise office buildings firefighting procedures and fire operations manual provides recommended pump pressures to support manual fire suppression efforts in high-rise office buildings (FDNY 1990). Table 5-2 provides a summary of the recommended pump pressures.

Table 5-2. FDNY recommended FDC pump pressures.

\begin{tabular}{|l|c|c|}
\hline \multicolumn{1}{|c|}{ Floors } & $\begin{array}{c}\text { Controlling Nozzle Pressure } \\
\text { (psi) }\end{array}$ & $\begin{array}{c}\text { Fog Nozzle Pressure } \\
\text { (psi) }\end{array}$ \\
\hline 1 to 10 & 150 & 200 \\
\hline 11 to 20 & 200 & 250 \\
\hline 21 to 30 & 250 & 300 \\
\hline 31 to 40 & 300 & 350 \\
\hline 41 to 50 & 350 & 400 \\
\hline 51 to 60 & 400 & 450 \\
\hline 61 to 70 & 450 & 500 \\
\hline 71 to 80 & 500 & 550 \\
\hline 81 to 90 & 550 & 600 \\
\hline 91 to 100 & 600 & 650 \\
\hline 101 to 110 & 650 & 700 \\
\hline
\end{tabular}

\subsubsection{Standpipe and Pre-Connected Hose Systems}

The standpipe systems for the WTC 1 and WTC 2 towers were provided with two separate infrastructures, one for the sub-grade levels and one for the towers. Figure B-3 illustrates the WTC 1 and WTC 2 tower standpipe system risers. Figures B-4 and B-5 illustrate the standpipe and parallel sprinkler loops on the concourse and B1 levels respectively. A separate standpipe system with multiple vertical water supply zones was provided in WTC 1 and WTC 2. The standpipe systems were composed of an automatic water supply, distribution piping, fittings, control valves, check valves, standpipe risers, hose 
valves, hose stations, hose cabinets, fire department connections, and a secondary water supply (PANYNJ 1972).

\section{Standpipe Risers}

Each tower contained three separate standpipe risers to supply water to the hose stations located on floors 1 through 110. One standpipe riser was provided in each exit stair enclosure. Table 5-3 provides a summary of the standpipe designations and locations.

Table 5-3. Standpipe designations and locations, WTC 1 and WTC 2.
\begin{tabular}{|c|c|c|l|}
\hline \multirow{3}{*}{ Tower } & Stair Enclosure & $\begin{array}{c}\text { Standpipe Riser } \\
\text { Designations }\end{array}$ & Location of Stair Enclosure \\
\hline \multirow{3}{*}{ WTC 1 (A) } & Stairway B (3) & FS-F1 & South \\
\cline { 2 - 4 } & Stairway C (2) & FS-F2 & Northwest \\
\cline { 2 - 4 } & Stairway A (1) & FS-F3 & Northeast \\
\hline \multirow{3}{*}{ WTC 2 (B) } & Stairway B (3) & FS-F1 & East \\
\cline { 2 - 4 } & Stairway C (2) & FS-F2 & Southwest \\
\cline { 2 - 4 } & Stairway A (1) & FS-F3 & Northwest \\
\hline
\end{tabular}

Standpipe risers FS-F1, FS-F2 and FS-F3 were located within and supplied water to pre-connected hose racks located in each respective stair enclosure. Figure B-6 shows a typical hose rack arrangement with a typical intermediate isolation valve. Standpipe riser FS-F1 also supplied water to auxiliary hose cabinets located in the corridors and tenant areas of both buildings (PANYNJ 1972, 2000b).

The design documents for the towers indicated that the standpipes included six separate pipe and fitting zones within the towers. Since the working pressure within the standpipe systems varied as a function of elevation, the construction of the standpipe risers also varied as a function of elevation. Table 5-4 provides a summary of the standpipe system component specifications (PANYNJ 1972, 1987b, 2000b).

Table 5-4. Typical tower pipe and fitting zones.

\begin{tabular}{|c|l|c|c|c|}
\hline Zone & \multicolumn{1}{|c|}{ Pipe Specification } & \multicolumn{1}{|c|}{ Fitting Specification } & $\begin{array}{c}\text { Lower Floor } \\
\text { (Elevation) }\end{array}$ & $\begin{array}{c}\text { Upper Floor } \\
\text { (Elevation) }\end{array}$ \\
\hline 1 & $\begin{array}{l}\text { Standard weight, } \\
\text { Schedule 40, black steel }\end{array}$ & $\begin{array}{l}350 \text { \#WWP threaded, } \\
\text { cast iron Class 250 }\end{array}$ & $102(1,552 \mathrm{ft})$ & Roof $(1,673 \mathrm{ft})$ \\
\hline 2 & $\begin{array}{l}\text { Standard weight, } \\
\text { Schedule 40, black steel }\end{array}$ & $\begin{array}{l}350 \# \text { WWP threaded, } \\
\text { cast iron Class 250 }\end{array}$ & $89(1,396 \mathrm{ft})$ & $101(1,540 \mathrm{ft})$ \\
\hline 3 & $\begin{array}{l}\text { Standard weight, } \\
\text { Schedule 40, black steel }\end{array}$ & $\begin{array}{l}350 \# \text { WWP threaded, } \\
\text { cast iron Class 250 }\end{array}$ & $76(1,236 \mathrm{ft})$ & $88(1,384 \mathrm{ft})$ \\
\hline 4 & $\begin{array}{l}\text { Extra strong, } \\
\text { Schedule 80, black steel }\end{array}$ & $\begin{array}{l}500 \# \text { WWP threaded, } \\
\text { malleable iron Class 300 }\end{array}$ & $58(1,012 \mathrm{ft})$ & $75(1,222 \mathrm{ft})$ \\
\hline 5 & $\begin{array}{l}\text { Extra strong, } \\
\text { Schedule 80, black steel }\end{array}$ & $\begin{array}{l}800 \# \text { WWP threaded, } \\
\text { malleable iron Class 300 }\end{array}$ & $20(546 \mathrm{ft})$ & $57(1,000 \mathrm{ft})$ \\
\hline 6 & $\begin{array}{l}\text { Extra strong, } \\
\text { Schedule 80, black steel }\end{array}$ & $\begin{array}{l}1,000 \text { \#WWP threaded, } \\
\text { malleable iron Class 300 }\end{array}$ & B6 $(242 \mathrm{ft})$ & $19(534 \mathrm{ft})$ \\
\hline
\end{tabular}




\section{Vertical Supply Zones}

The standpipe systems within each tower were installed with four vertical water supply zones (PANYNJ 1987a):
1. High (upper)
2. Upper mid-level
3. Lower mid-level
4. Low

Table 5-5 provides a summary of the zones.

Table 5-5. Standpipe system zones, WTC 1 and WTC 2.

\begin{tabular}{|l|c|l|c|c|l|}
\hline & Zone & \multicolumn{1}{|c|}{ Description } & $\begin{array}{c}\text { Lower } \\
\text { Floor }\end{array}$ & $\begin{array}{c}\text { Upper } \\
\text { Floor }\end{array}$ & \multicolumn{1}{|c|}{ Notes } \\
\hline \multirow{3}{*}{ WTC 1 (A) } & 1 & High & 77 & 110 & Floor 75 was occupied by a 2-story MER \\
\cline { 2 - 6 } & 2 & Upper mid-level & 42 & 76 & Hose rack on FS-F1 only \\
\cline { 2 - 6 } & 3 & Lower mid-level & 9 & 41 & Floor 41 was occupied by a 2-story MER \\
\cline { 2 - 6 } & 4 & Low & 1 & 8 & Floor 7 was occupied by a 2-story MER \\
\hline WTC 2 (B) & 1 & High & 77 & 110 & Floor 75 was occupied by a 2-story MER \\
\cline { 2 - 6 } & 2 & Upper mid-level & 42 & 76 & Hose rack on FS-F1 only \\
\cline { 2 - 6 } & 3 & Lower mid-level & 9 & 41 & Floor 41 was occupied by a 2-story MER \\
\cline { 2 - 6 } & 4 & Low & 1 & 8 & Floor 7 was occupied by a 2-story MER \\
\hline
\end{tabular}

The terminology for the vertical water supply zones was established for the purpose of describing the standpipe systems within this report. In the initial operating mode with water supplied from the water storage tanks only, each of these standpipe system zones functioned separately from the other zones. A series of check valves were installed between zones that prevented water from flowing downward from one zone to the next. In other operating modes, water was permitted to flow upward from one zone to the next. The manual fire pumps were used to supply water from the NYC water distribution system to all floors within either tower. The fire department connections were also used by the FDNY to supply water to the standpipe systems from the ground level (FDNY 1988; PANYNJ 1972, 1987a).

\section{High Zone}

The high zone in both WTC 1 and WTC 2 included three standpipe risers spanning all floors between the 77 th and 110th floors. Figure B-7 shows the configuration of the WTC 1 high zone standpipe system with notations of the differences in the WTC 2 system. A single standpipe riser was provided in each of the three exit stair enclosures of both towers. As previously described, the standpipe risers were identified as FS-F1, FS-F2 and FS-F3 as shown in Fig. B-7. The high zone standpipes were interconnected near the top on the 109th floor and at the bottom on the 76th floor. Standpipe hose racks were provided at floors 77 through 109 in each stair enclosure. The high zone standpipe systems also 
contained a single hose valve manifold on the 110 th floor of each tower that included three 6 by $2 \frac{1}{2}$ in. outlets (PANYNJ 1972, 1987a).

A single 5,000 gal water storage tank, FSP $110 \mathrm{~A}$, located on the 110 th floor, was the primary water supply for the high zone standpipe system in WTC 1. The tank was equipped with an automatic re-fill connection, which was controlled by a float valve and supplied by the domestic water system. The domestic water supply was provided with a separate water service connection to the NYC water distribution system. Other than supplying the water storage tanks, the domestic water system was completely independent from the fire suppression systems. The reserve water storage tanks were intended to allow manual fire suppression efforts to begin before the manual fire pumps were turned on. The tanks were capable of supplying $500 \mathrm{gpm}$ for $10 \mathrm{~min}$ without any additional water supply from the domestic water supply system. During this period, it was expected that the manual fire pumps would be placed into operation (PANYNJ 1972, 1983, 1987a).

A similar 5,000 gal tank. FSP 110B was located on the 110th floor of WTC 2. All of the water storage tanks in both buildings were equipped with a check valve centered between two isolation valves at the discharge outlet from the tank. The check valves prevented water pressure in the standpipe system from backfilling or overflowing water from the tanks.

High zone riser FS-F 1 in WTC 1 was a 6 in. standpipe with Class III style hose racks and hose cabinets used for manual fire suppression activities. This standpipe was located in stairway B (3) at the center of the south side of the core area. This standpipe contained hose racks on every floor level between floor 77 and 107. This standpipe also supplied hose cabinets in corridors and tenant spaces on floors 89 through 91 and floors 80 and 81 . Sectional isolation valves were provided at the base of the standpipe riser at floor level 76, at the top of the risers at floor level 109, and at two intermediate locations at floor levels 88 and 99 (PANYNJ 19872a, 2000).

Riser FS-F1 was configured to provide bi-directional flow in the upward and downward directions. Initially, water flowed downward from tank FSP $110 \mathrm{~A}$. However, once the manual fire pumps were started, the direction of water flow changed. In the normal operating mode, water was initially gravity supplied from the 5,000 gal standpipe reserve storage tank on the 110th floor to the three standpipes. Water was supplied to the top of standpipe riser FS-F1 in the downward direction and to the other two standpipes from the bottom up. Although the standpipes were interconnected on the 109th floor, check valves prevented water from being supplied directly from the tank to standpipes FS-F2 and FS-F3. After the manual fire pumps were started, water was supplied upward through all three standpipes (PANYNJ 1987a, 2000).

Riser FS-F1 in WTC 2 was similar to the one in WTC 1, except that this riser was located at the center of the east side of the core area in stairway B (3) of WTC 2. The riser supplied water from tank FSP 110 B to all three risers allowing bi-directional flow and had isolation valves at the same locations. This riser also supplied a hose rack on floor 110 but did not supply additional hose cabinets on floors 80, 81, or 89 through 91 (PANYNJ 1972, 1987a).

Riser FS-F3 was configured the same in both towers. This standpipe was located at the northeast corner of the core area in WTC 1 and the northwest corner of the core area in WTC 2. The risers were configured to permit flow in the upward direction only. Riser FS-F3 was a 6 in. standpipe with Class III style hose racks at every floor level between 77 and 110. A check valve located at the top of the riser prevented 
water from flowing in the downward direction. Similar to riser FS-F1, sectional isolation valves were provided at the base of the risers at floor level 76, at the top of the risers at floor level 109, and at two intermediate locations at floor levels 88 and 99 (PANYNJ 1972, 1987a).

Riser FS-F2 in WTC 2 was identical to riser FS-F3 and was located at the southwest corner of the core area. This riser was located in the northwest corner of the WTC 1 core area. Riser FS-F2 in WTC 1 was similar, except that this riser also supplied a hose cabinet on the $82 \mathrm{nd}$ floor level.

Based on available information, it appears that hose racks were located in all stair enclosures at approximately $4 \frac{1}{2} \mathrm{ft}$ above the finished floor level of the primary stair landing. This arrangement allowed the fire department to access the standpipe valve without having to traverse a half flight of stairs. PotterRoemer 2700 series hose rack assemblies were specified for use throughout both towers. Adjustable pressure restricting devices were installed for the hose racks on floors 77 through 94 (PANYNJ 1972, 1987a, 2000b).

The typical hose rack arrangement included a $2 \frac{1}{2} \mathrm{in}$. standpipe valve, a $2 \frac{1}{2}$ by $1 \frac{1}{2} \mathrm{in}$. reducer coupling, and a hose station or hose cabinet containing $125 \mathrm{ft}$ of fire hose and a nozzle. This arrangement allowed the fire department or fire brigade to stage manual fire suppression efforts using the $1 \frac{1}{2} \mathrm{in}$. hose line without having to carry fire hoses from the ground floor level to the upper levels of the building.

Additional hose stations were provided at the 110 th floor level in each tower. These hose stations were supplied with water from automatic fire (booster) pumps located on the 108th floor level and were combined with the high zone sprinkler systems.

\section{Upper Mid-Level Zone}

The upper mid-level zone in each tower included floors 42 through 76 . As with the high zone, three standpipe risers were provided, such that a single standpipe riser was provided in each of the three exit stair enclosures. The standpipes were interconnected near the top and bottom of the upper mid-level zone on floor levels 75 and 42, respectively. As with the high zone, the standpipe risers were identified as FS-F1, FS-F2 and FS-F3. Figure B-8 illustrates the configuration of the high mid-zone standpipe systems. The diagram shows the configuration of the system in WTC 1 with references to the differences in WTC 2 (PANYNJ 1987a, 2000b).

A 5,000 gal storage tank, FSP 75A, located in the MER on floors 75 and 76, was the primary water supply for the upper mid-level zone standpipe system in WTC 1. A similar 5,000 gal tank, FSP 75B was located in WTC 2. Check valves were installed within the tank discharge outlets to prevent backflow into the tanks from high pressure or surges in the standpipe system. These tanks were also equipped with automatic re-fill connections supplied by the domestic water system.

The tanks also served as intermediate water supply stages for the high zone standpipe systems. Manual fire pumps were installed to boost pressure in the system in order to provide sufficient energy to counteract the effects of gravity and lift the water to the 110 th floor level. Check valves were provided within the pump discharge and by-pass piping to prevent water from the high zone from flowing down into the lower zones below. 
As with the high zone, riser FS-F1 was a 6 in. standpipe located in stairway B (3) (PANYNJ 1972, 1987a). Water was supplied to this riser from the reserve water storage tank on the MER on the 75th floor level. This riser was configured to permit bi-directional water flow and was used to supply water to the other two standpipes. Sectional isolation valves were provided at the base of the riser at floor level 42 , at the top of the riser at floor level 76, and at two intermediate locations at floor levels 54 and 65.

Class III style hose racks were provided at all floor levels between 42 and 75 . Riser FS-F1 of WTC 1 also supplied a hose cabinet on floor 50; the riser in WTC 2 did not, however.

Risers FS-F2 and FS-F3 in WTC 2 were similar; both standpipes contained check valves at the top, allowing water to flow through the standpipe in the upward direction only. Although the location of the standpipes varied laterally within the stair enclosures, these risers were all similar. Each standpipe supplied hose racks on all floor levels between 43 and 74. Riser FS-F2 supplied an additional hose rack at the 75th floor level. Adjustable pressure restricting devices were installed for the hose racks on all three risers for floors 59 through 42 .

The risers in WTC 1 also supplied hose cabinets. These risers all contained intermediate sectional isolation valves at floor levels 54 and 65. Riser FS-F2 supplied a hose cabinet on the 44th floor. Riser FS-F3 supplied a hose cabinet on the 48th floor (PANYNJ 1972, 1987a, 2000b).

\section{Lower Mid-Level Zone}

The standpipes in this zone were also interconnected near the top and bottom at floors 41 and 8 , respectively. As with the two zones above, these risers were identified as FS-F1, FS-F2 and FS-F3. Figure B-9 shows the configuration of the low mid-zone standpipe system in WTC 1 with reference to the differences in the WTC 2 system.

The water supplies for lower mid-level zones included 5,000 gal reserve storage tanks, FSP 41A and FSP 41B, located on the 41st MERs. These tanks were also used as intermediate water supply stages for the standpipe system zones above. Manual fire pumps were installed with check valves in the discharge and by-pass piping to prevent backflow of water from the zones above.

As with the higher zones, riser FS-F1 in WTC 1 was a 6 in. standpipe located in stairway B (3). Water was supplied to this riser from the reserve water storage tank in the 41 st floor MER and was used to supply water to the other two standpipes within the zone. The riser in WTC 2 was also located in stairway B (3) and functioned the same. This riser was configured to permit bi-directional water flow. Sectional isolation valves were provided at the base of the riser at floor level 8 , at the top of the riser at floor level 41, and at two intermediate locations at floor levels 21 and 32. Class III style hose racks were provided at all floor levels between 9 and 41. Riser FS-F1 of WTC 1 also supplied hose cabinets on floors 10 through $15,18,19,21$ through 26,29 through 31,33 through 35,39 and 40 . The standpipe system in WTC 2 did not include these additional hose cabinets.

Risers FS-F2 and FS-F3 in WTC 2 and WTC 1 were all similar; these standpipes contained check valves at the top, allowing water to flow through the standpipe in the upward direction only. Each standpipe supplied hose racks on all floor levels between 9 and 41 . These risers all contained intermediate sectional isolation valves at floor levels 21 and 32. Adjustable pressure restricting devices were installed for the hose racks on all three risers for floors 9 through 25 (PANYNJ 1972, 1987a, 2000b). 


\section{Low Zone}

The low zone standpipe systems included floors one through seven in each of the WTC 1 and WTC 2 towers. Figure B-10 shows the configuration of the low zone standpipe systems. These systems were also interconnected with the high zone standpipe systems above in each individual tower. The two systems were also interconnected with each other and the two distribution loops that supplied water throughout the WTC complex. The primary water supply for the low zone standpipe systems in both towers was provided by a single 5,000 gal storage tank, FSP storage tank $20 \mathrm{~A}$, located on the 20 th floor of WTC 1. A similar tank was not provided in WTC 2.

Water was supplied from tank FSP 20A through a single 6 in. riser in WTC 1 to the 8 in. distribution loop on the B1 level. This distribution loop was interconnected at two locations with a second 8 in. loop located on the concourse level. These distribution loops interconnected the standpipe systems for the six buildings in the main WTC complex, including WTC 1 through WTC 6 . The loops also distributed water to the sub-grade standpipe systems. Figures B-4 and B-5 illustrate the configuration of the two loops.

Similar to the higher zones of the standpipe systems, three 6 in. risers were used to supply hose stations throughout the low zone. Again each tower was provided with risers FS-F1, FS-F2, and FS-F3, which were interconnected at the bottom and top of the zone. All of the risers included control valves at the tops and bottoms at floors 7 and the B1 levels, respectively. However, the low zone risers FS-F2 and FS-F3 were not equipped with check valves at the top. Therefore, all three of the standpipe risers allowed for bidirectional water flow. The low zone systems were similar but did not supply hose racks at all floor levels. Therefore, these risers will be discussed individually by tower (PANYNJ 1972).

Riser FS-F1 of WTC 1 supplied hose racks in stair B on the third, sixth, and seventh floors. In addition, this riser supplied a remote hose rack located on the first floor level. A hose cabinet located at the first floor level was supplied by a separate 4 in. main attached to the sub-grade level standpipe system riser in stair B. Riser FS-F2 included hose racks in stair C on the second and seventh floor levels only. A hose cabinet located in stair $\mathrm{C}$ on the first floor level was equipped with a separate $4 \mathrm{in}$. main connected to the sub-grade level standpipe system. Riser FS-F3 supplied hose racks in stair A on the second and seventh floors only (PANYNJ 1972, 1987a).

Riser FS-F2 of WTC 2 supplied hose racks at the first, second, and seventh floor levels in stair B. An additional hose rack was supplied at the first floor level of stair B by a separate $4 \mathrm{in}$. main attached to the sub-grade level standpipe system riser. Riser FS-F2 supplied hose racks on the second and seventh floor levels. A hose cabinet was provided at the first floor level, however, it was supplied by a separate 4 in. main attached to the sub-grade level system. Riser FS-F3 supplied hose racks in stair A on the third through seventh floor levels. Two additional remote hose stations on the first floor level were provided with separate 4 in. risers attached to the sub-grade level standpipe systems (PANYNJ 1972, 1987a).

\subsubsection{Automatic Fire Sprinkler Systems}

The automatic fire sprinkler systems for the towers were configured with two distinctly separate infrastructures, one for the sub-grade levels and another for the towers, similar to the arrangement for the standpipe systems (PANYNJ 1972, 1987a). The system infrastructure associated with the sub-grade levels was also used to supply automatic fire sprinkler systems in the WTC 4 and WTC 5 buildings (PANYNJ 1987a). Although a brief description of the sub-grade level sprinkler systems is provided in 
this report, the primary focus was directed at describing the tower sprinkler systems. Figures B-4 and B5 illustrate the configuration of the sprinkler system loops on the concourse and B1 levels.

The sprinkler systems for the sub-grade levels were equipped with two separate and independent connections to the NYC water distribution systems (PANYNJ 1972, 1987a). This configuration provided two redundant water supply connections for the sub-grade sprinkler systems. Two fire pumps were used to supply water to the sprinkler systems on the sub-grade levels. Similar to the configuration of the standpipe systems on the sub-grade levels. two loops were provided for the sprinkler systems, one loop on the B1 level and a second loop on the concourse level. This sprinkler system infrastructure was completely separate from the standpipe systems (PANYNJ 1972, 1987a). However, the sprinkler system infrastructure for the towers was supplied with water from the standpipe systems.

The sprinkler systems for the towers were configured such that each floor level was provided with an independent sprinkler system. Figure B-11 provides a representation of the tower sprinkler systems. These sprinkler systems were supplied with water from a single shared sprinkler riser within the vertical water supply zones. The primary "automatic" water supply for each zone was provided from a series of gravity supplied water storage tanks dedicated to the automatic sprinkler systems or combined with the standpipe systems.

Separate sprinkler and standpipe risers were provided, even though the two systems shared the standpipe system infrastructure to provide water in addition to the initial reserve water supply stored in the gravity tanks. These systems were unlike most typical "combined systems" that have both sprinkler system floor control valve assemblies and standpipe hose valves directly connected to the same risers. In this case, the standpipe systems served as the secondary or tertiary water supplies for the sprinkler systems depending on the riser. Both the fire department connections and manual pumps could be used simultaneously to supply water to the standpipes and automatic fire sprinkler systems (PANYNJ 1972. 1987a).

\section{Installation Schedule}

The automatic fire sprinkler systems in the WTC 1 and WTC 2 towers were retrofit after the buildings were constructed. The initial base building installation included the standpipe system and the sprinkler systems throughout the sub-grade levels. The retrofit sprinkler systems were installed in the towers in two phases in response to the enactment of Local Law 5. The first phase was completed in 1976 and consisted of the installation of the sprinkler system infrastructure within the towers. This phase included the installation of the sprinkler system risers, cross-mains, and sprinklers throughout the core areas and in select tenant spaces operated by the PANYNJ. The second phase included the installation of sprinkler systems throughout the tenant areas. This phase occurred from 1983 through early 2001 (FDNY 1993b; PACO 2002; GC Engineering 1998).

\section{Design Basis and Associated Criteria}

In 2001, the buildings were equipped throughout with sprinklers in all areas. except mechanical and electrical rooms. The designs of the sprinkler systems in WTC 1 and WTC 2 were based on the PANYNJ guideline specifications, which required all tenant spaces to be provided with automatic fire sprinklers. The core areas, PANYNJ spaces, and select tenant spaces were equipped throughout with automatic fire sprinklers in 1976 as part of the first phase of the tower retrofit installations. 
New tenants were required to install automatic fire sprinkler protection throughout (PANYNJ 2000b). Existing tenant spaces were required to install or modify sprinkler systems to comply with the partition layout if the spaces were renovated (PANYNJ 2000b). These systems were designed and installed from 1983 to 2001, during the final phase of the sprinkler systems installations (GC Engineering 1998). All sprinkler systems were designed in accordance with the requirements of the BCNYC, NFPA 13, and the PANYNJ/World Trade Division (PANYNJ 1987a, 2000a). The designs for all sprinkler systems were based on the occupancy hazard fire control approach and were hydraulically calculated. Other referenced standards were used for specialized hazards.

Modifications to existing sprinkler systems during renovations were permitted to use the pipe schedule method, an alternative to the hydraulic calculation method (PANYNJ 2000a). However, except for minor renovations that required relocations of sprinklers without adding sprinklers, the designs were hydraulically calculated (PACO 2002). Modifications to sprinkler systems in tenant spaces that resulted in the same number of sprinklers before and after completion used the pipe schedule method. All tenant spaces were provided with temporary sprinkler protection during renovations (PACO 2002).

The design guidelines and associated drawings indicated that wet-pipe sprinkler systems were designed and installed throughout, using the hydraulic calculation method as follows:

- All tenant spaces, lobbies, public spaces, and restaurant seating areas

- Wet-pipe sprinkler system based on NFPA 13 and RS-17 Light Hazard Occupancy requirements with a density of $0.10 \mathrm{gpm} / \mathrm{ft}^{2}$ over $1,500 \mathrm{ft}^{2}$

- Mechanical equipment rooms, mechanical spaces, janitor closets, and mail room, restaurant services areas

- Wet-pipe sprinkler system based on NFPA 13 and RS-17 Ordinary Hazard Group 1 requirements with a density of $0.16 \mathrm{gpm} / \mathrm{ft}^{2}$ over $1,500 \mathrm{ft}^{2}$

- Commercial and storage spaces

- Wet-pipe sprinkler system based on Special Hazard in accordance with NFPA 13, NFPA 15, NFPA 16, NFPA 231, or NFPA 231C

The PANYNJ design criteria paralleled NFPA 13 criteria regarding the omission of sprinklers from spaces containing energized electrical equipment. The following four specific criteria were required for omission (PACO 2002):

1. The closet had to be dedicated to electrical equipment only and was not used for storage.

2. A $2 \mathrm{~h}$ fire resistance rated enclosure was provided, penetrations were protected with through penetration fire-stop systems, and opening protectives were used.

3. A smoke detector connected to the base building fire alarm system had to be installed in the closet.

4. Only dry type electrical equipment was used. 
Sprinklers were installed in electric closets, communicating closets, telephone closets, emergency generator spaces, transformer and switchgear spaces, and telephone equipment rooms, unless the room configuration and contents met the screening criteria outlined above for omission (PACO 2002).

Pre-action sprinkler systems were specified for some computer rooms in place of wet-pipe sprinkler systems. In other computer rooms, clean agent total flooding fire suppression systems were specified instead of automatic fire sprinklers. The Operations and Maintenance (O\&M) manuals document that these types of systems were installed. However, the actual locations where pre-action sprinkler systems and clean agent suppression systems were installed could not be verified based on the information available at this time.

Water curtains were installed for the protection of internal open staircases. The design approach closely resembled the design option outlined in the "special design approaches" section of NFPA 13. A draft stop was installed around the perimeter of the opening and closely spaced sprinklers ( $6 \mathrm{ft}$ on center) were positioned 12 in. from the opening (PACO 2002).

\section{Sprinkler System Risers}

Existing documentation refers to the tower sprinkler systems as two separate zones with three risers (PANYNJ 1987a, 1972). The zones are identified as the high zone and the low zone. However, the high zone was separated into two different sub-sections using two separate risers. Therefore, the towers were actually separated into three vertical water supply zones. These zones are referred to as the high, mid-level, and low zones in this report. Each zone was provided with a separate sprinkler system riser as identified in Table 5-6. Figure B-1 1 illustrates the configuration of the risers within both towers. In all cases, the primary direction of water flow was downward from the top of the riser to the sprinkler systems. However, the low zone risers were arranged to allow water to flow upward while using a secondary water supply.

Table 5-6. WTC 1 and WTC 2 sprinkler system risers.

\begin{tabular}{|l|c|c|c|}
\hline \multicolumn{1}{|c|}{ Zone } & Riser & Lower Floor & Upper Floor \\
\hline High & $\mathrm{A}$ & 99 & 107 \\
\hline Mid-level & $\mathrm{B}$ & 98 & 33 \\
\hline Low & $\mathrm{C}$ & 32 & 1 \\
\hline
\end{tabular}

Each sprinkler riser was supplied with water through a single connection to the standpipe system. Risers $\mathrm{A}$ and $\mathrm{B}$ in both towers were connected to the water storage tanks and standpipe system on the 109th floor. Riser A in each tower is referred to in this report as the high zone. Similarly riser B is referred to as the mid-level zone. Riser $\mathrm{C}$ was connected to the combined standpipe and sprinkler system tank on the 41 st floor and supplied water to the low zone in each tower. The A risers were unique from the other gravity supply risers, since these risers were equipped with small booster pumps located on the 108th floor. Additionally, the A risers supplied standpipe hose stations on the 110th floor.

Sectional isolation valves were provided at floors 1 and 15 for riser C of WTC 1. A single sectional isolation valve was provided at floor 67 in riser B of WTC 1. Sectional isolation valves were also provided at floors 1 and 15 for riser C of WTC 2. However, a single sectional isolation valve was 
provided at floor 77 in riser B of WTC 2. Neither of the high zone (A) risers was provided with an intermediate sectional isolation valve (PANYNJ 1987a, 1972).

\section{Floor Level Sprinkler System Components}

A separate and independent sprinkler system was provided at each floor level. These systems were connected to the shared riser and water supply within each respective zone. Each system contained a floor control valve assembly separating it from the shared infrastructure. Figure 5-6 shows the configuration of a typical floor control valve assembly. In general, automatic fire sprinkler protection was provided throughout the WTC 1 and WTC 2 buildings, with the exception of the mechanical equipment room (MER) floor levels. Figure B-11 illustrates the areas of the building that were equipped with automatic sprinkler systems (PANYNJ 1972, 1987a, 2000).

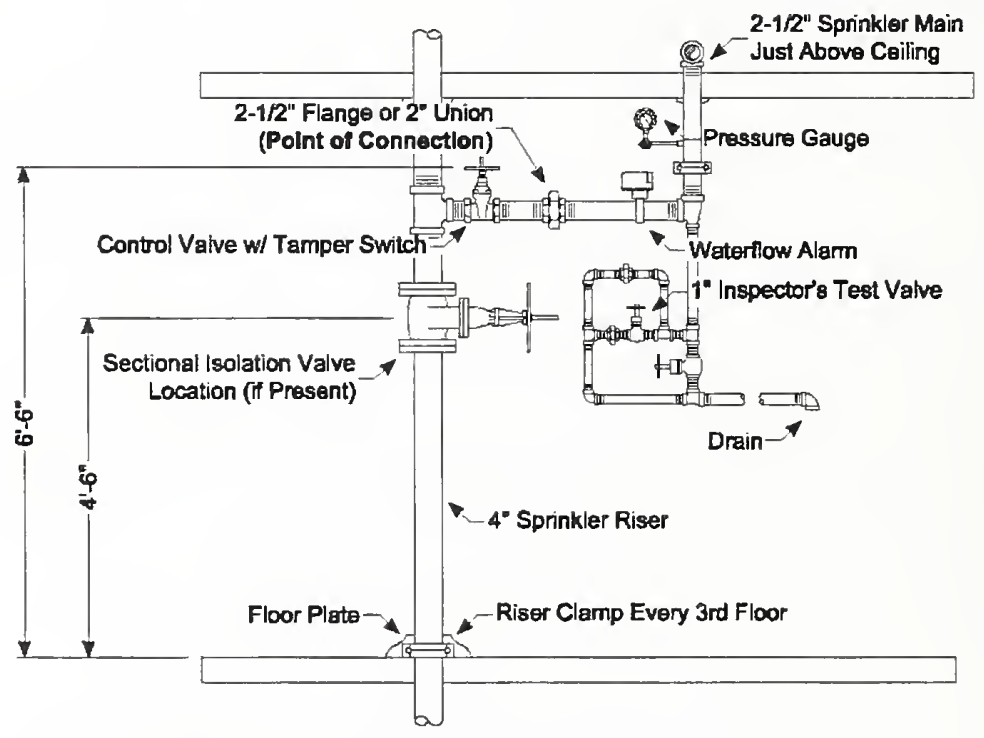

Source: Reproduced with permission of The Port Authority of New York and New Jersey.

Figure 5-6. Typical floor control valve assembly.

\section{Pipe and Fittings}

The Port Authority fire protection design guidelines indicated that all sprinkler system piping was required to be standard weight schedule 40 black steel pipe with threaded cast Class 125 or malleable Class 150 iron fittings. The available drawings indicated that all floor sprinkler system piping was installed according to these specifications. The guideline specifications also explicitly excluded schedule 10 light-wall pipe, and schedule 30 pipe, groove and mechanical pipe joining methods. However, special approval could be given for the use of groove-type fittings. Figure 5-7 shows that groove-type fittings were installed. This photograph was taken from the O\&M manual for the sprinkler systems (PANYNJ 1972, 1987a, 2000b). 
The guideline specifications also identified the following requirements:

- Extra-heavy shoulder type nipples and made of the same material as the pipe. Close nipples, adjustable sprinkler nipples, and bushings were not permitted.

- Unions for piping connections 2 in. and smaller or flanged connections for piping $2 \frac{1}{2} \mathrm{in}$. or larger.

- Full-face gaskets for flanges made of rubber or neoprene $1 / 16$ in. thick after compression with punched holes.

- Schedule 40 galvanized pipe with galvanized threaded fittings were permitted to be installed for pre-action systems.

- Schedule 40 galvanized pipe sleeves and chrome plated escutcheons for piping penetrating masonry walls. Openings around pipes were limited to $1 / 2$ in. between pipe and sleeves.

- Insulation for all sprinkler piping and fittings within $15 \mathrm{ft}$ of exterior walls.

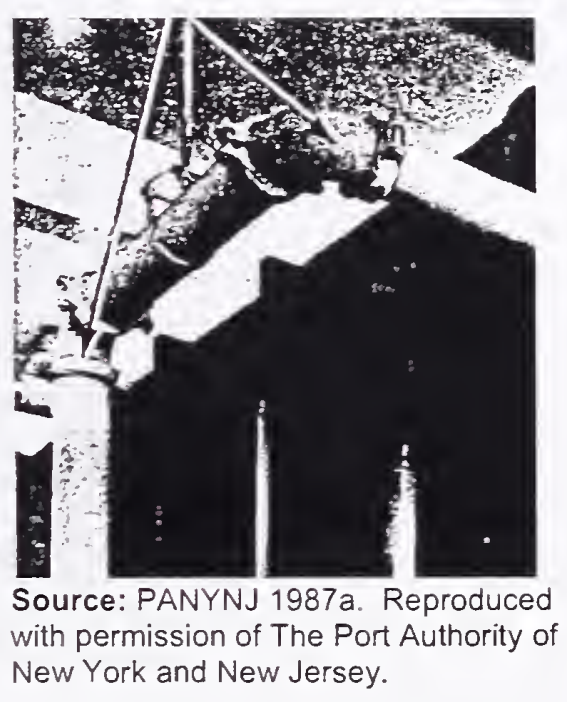

Figure 5-7. Examples of groove-type pipe fittings.

Information contained in the O\&M manual for the sprinkler systems indicated that provisions were included in the design of the systems in WTC 1 and WTC 2.

\section{Floor Control Valve Assemblies}

The sprinkler risers and floor control valve assemblies were located in a janitor's closet within the core area of each tower. Although the location of the risers varied within the buildings, all of the risers were located within the core area. Due to the large pressure differences established as a result of the elevation changes within each zone, two different types of control valve assemblies were required. One arrangement included an outside screw and yoke (OS\&Y) valve rated for $175 \mathrm{psi}$ and the other a combination control and pressure-reducing valve. The two assemblies were used since the piping for the 
sprinkler systems on each floor were installed with standard weight schedule 40 pipe and fittings rated for 175 psi. The guideline specifications also identified the following requirements for valves:

- 2 in. and smaller-threaded bronze body valves.

- $\quad 2 \frac{1}{2}$ in. and larger-flanged iron body valves.

- 6 in. and larger valves also required a by-pass connection.

The sprinkler system infrastructure experienced elevated pressure due to the extreme elevation differences. These pressure differences are discussed later in this report. The pressure-reducing valve type of floor control valve assembly was used to prevent water pressure from damaging sprinkler system components. These assemblies also included a pressure relief valve on the floor level sprinkler system side of the valve as an additional safety precaution to prevent damage to the sprinkler system piping. Figure 5-8 demonstrates a typical floor control valve assembly with a combination pressure-reducing control valve. This photograph was taken from the O\&M manual (PANYNJ 1972, 1987a, 2000b).

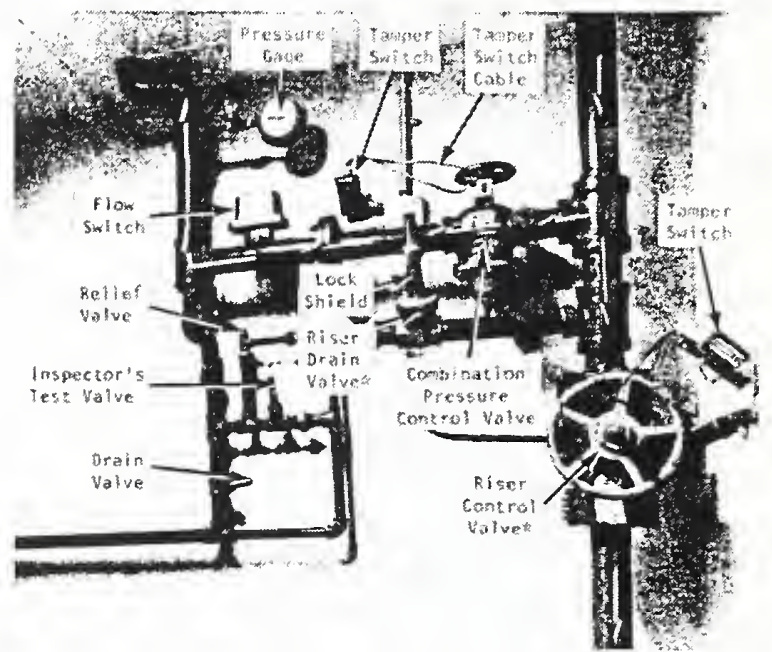

Source: PANYNJ 1987a. Reproduced with permission of The Port Authority of New York and New Jersey.

Figure 5-8. Combination pressure reducing control valve assembly.

A summary of the locations where each type of valve was used within each tower is provided in Table 5-7. 
Table 5-7. Summary of WTC 1 and WTC 2 floor control valve assemblies.

\begin{tabular}{|c|c|c|c|c|c|c|}
\hline Tower & Riser & $\begin{array}{l}\text { Lower } \\
\text { Floor }\end{array}$ & $\begin{array}{l}\text { Upper } \\
\text { Floor }\end{array}$ & $\begin{array}{l}\text { OS\&Y } \\
\text { Valve }\end{array}$ & $\begin{array}{l}\text { Pressure Reducing } \\
\text { Valve with Pressure } \\
\text { Relief Valve }\end{array}$ & Comments \\
\hline \multirow[t]{5}{*}{ WTC 1} & $\mathrm{~A}$ & 99 & 107 & - & & \\
\hline & B & 87 & 98 & - & & \\
\hline & B & 32 & 86 & & - & $\begin{array}{l}\text { MER floors } 41,42 \text { and } 76 \text { did not } \\
\text { contain sprinkler systems }\end{array}$ \\
\hline & $\mathrm{C}$ & 9 & 31 & - & & \\
\hline & C & 1 & 8 & & • & $\begin{array}{l}\text { MER floors } 7 \text { and } 8 \text { were provided } \\
\text { with } 21 / 2 \text { in. capped outlets only }\end{array}$ \\
\hline \multirow[t]{5}{*}{ WTC 2} & A & 99 & 107 & - & & \\
\hline & B & 87 & 98 & - & & \\
\hline & B & 32 & 86 & & • & $\begin{array}{l}\text { MER floors } 41,42 \text { and } 76 \text { did not } \\
\text { contain sprinkler systems }\end{array}$ \\
\hline & $\mathrm{C}$ & 9 & 31 & - & & \\
\hline & $\mathrm{C}$ & 1 & 8 & & - & $\begin{array}{l}\text { MER floors } 7 \text { and } 8 \text { were provided } \\
\text { with } 2 \frac{1}{2} \text { in. capped outlets only }\end{array}$ \\
\hline
\end{tabular}

The floor control valve assemblies also required the following:

- Floor control valves were required to have electrical tamper switches to monitor the position of the valves. The tamper switches were electrically connected to the fire alarm system and were used to detect and indicate when a valve was closed. Information in the O\&M manual indicates that tamper switches were installed for the control valves in WTC 1 and WTC 2 (PANYNJ 1987a, 2000a).

- Drain and test valves were required at system low points. The drains were required to be connected to a drain receptacle or have a threaded hose and adapter at the valve outlet. Photographs of the sprinkler system riser and express drains in the O\&M manual illustrate that drains were generally installed as required (PANYNJ 1987a, 2000a).

- Swing type check valves where required for all sprinkler systems and were installed as follows:

- 2 in. and smaller - threaded bronze type

- $2 \frac{1}{2}$ in. and larger-iron body type

- Vane or pressure type water flow switches were required to sense water flow. The flow switches were required to have two single-pole double-throw switches and adjustable pneumatic retard to prevent nuisance alarms associated with pressure surges. Information on the design drawings and in the O\&M manual demonstrates that flow switches were installed (PANYNJ 1987a, 2000a).

- Pressure gauges, sight glasses, and valve tags were also installed. 
Figure 5-9 demonstrates a typical floor control valve assembly with an OS\&Y valve. This photograph was taken from the O\&M manual (PANYNJ 1987a).

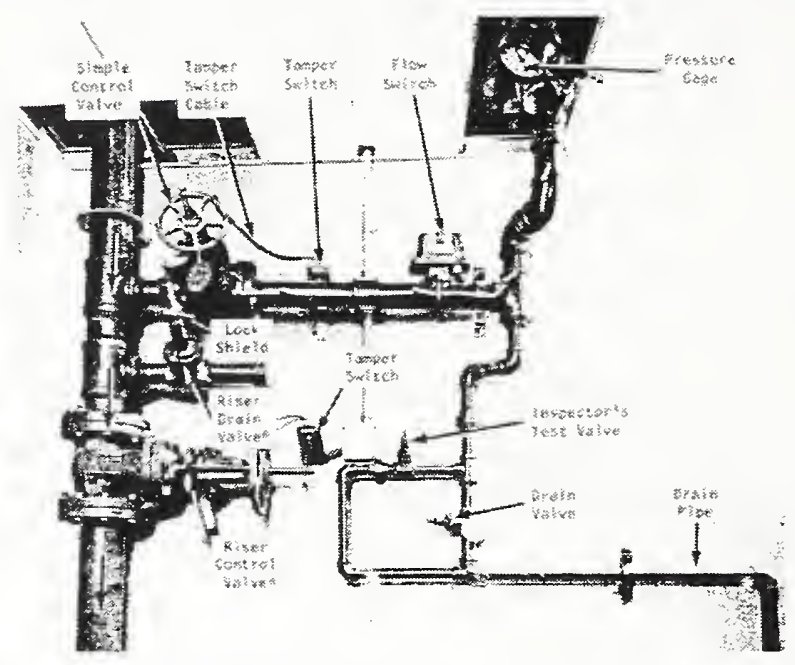

Source: PANYNJ 1987a. Reproduced with permission of The Port Authority of New York and New Jersey.

Figure 5-9. Typical floor control valve assembly as installed in WTC 1 and WTC 2.

Pre-action systems required OS\&Y type control valves and hydraulically operated differential diaphragm type deluge valves with manual and electric detectors. Pre-action systems also required self-contained automatic air maintenance devices. Information provided in the design documents and the O\&M manual indicated that these features were included in the design of the sprinkler systems in WTC 1 and WTC 2 (PANYNJ 1987a).

\section{Sprinklers}

Concealed pendent sprinklers with chrome cover plates were installed in all finished areas. Figure 5-10 is a photograph of a typical concealed sprinkler cover plate. Upright or pendent type sprinklers were installed in areas without finished ceilings (PANYNJ 1987a). Figure 5-11 is a photograph of a standard spray pendent sprinkler. Sprinklers with an operating temperature rating of $165^{\circ} \mathrm{F}$ were installed throughout most areas (PANYNJ 1987a). Higher temperature rated sprinklers were installed in areas with ceiling temperatures above $100^{\circ} \mathrm{F}$ (PANYNJ 1987a). Protective guards or shields were installed in areas where sprinklers were potentially subject to mechanical damage (PANYNJ 1987a). Documentation indicated that $1 / 2$ in. orifice sprinklers with a $\mathrm{k}$-factor of 5.6 were installed throughout WTC 1 and WTC 2 (PANYNJ 1987a). 


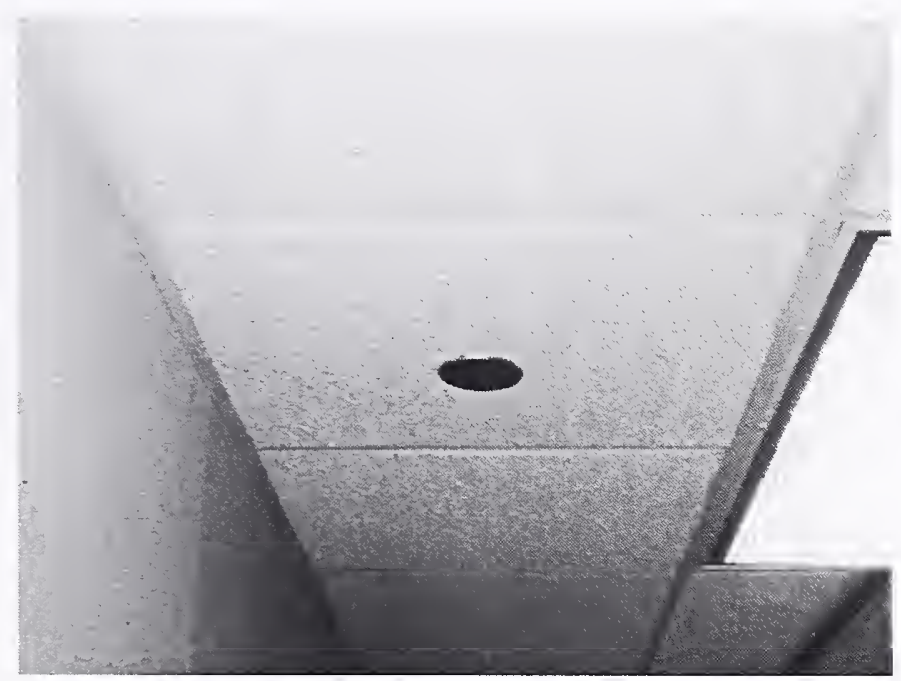

Source: NIST.

Figure 5-10. Typical concealed pendent sprinkler.

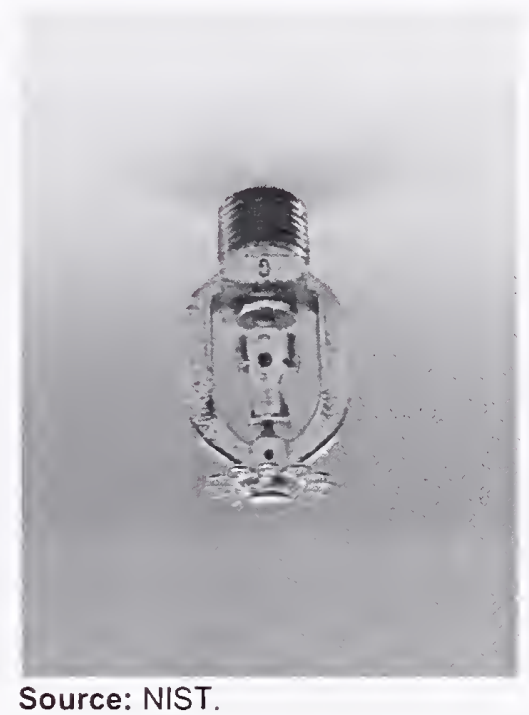

Figure 5-11. Typical standard spray pendent sprinkler.

\section{Hangers and Supports}

Clevis type hangers were used for the support of all sprinkler piping (PANYNJ 1972, 1987a). Additional anchors and support were required to accommodate all forces imposed by expansion joints in addition to the normal structural requirements (PANYNJ 2000a). Adequate clearances were specified to be maintained between sprinkler pipes and all other piping, equipment, and structures. Two typical hanger arrangements were permitted, one for attachment to steel beams or joists and the other for direct attachment to concrete floors and ceiling assemblies. Figure 5-12 illustrates the two arrangements. The hanger assembly for attachment to concrete assemblies included a concrete insert anchor, threaded rod, and a clevis hanger. The steel arrangement included a "c-clamp" or top-beam clamp attached to a steel beam or joist, a steel retaining strap, threaded rod, and a clevis hanger. 


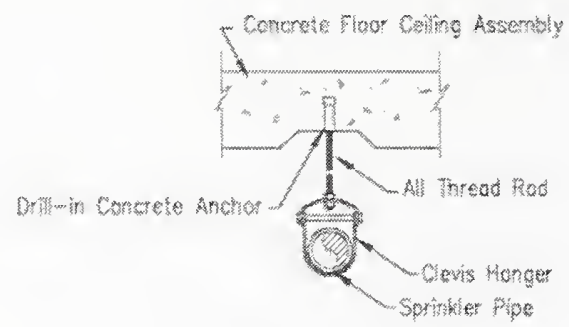

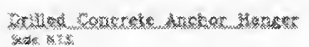

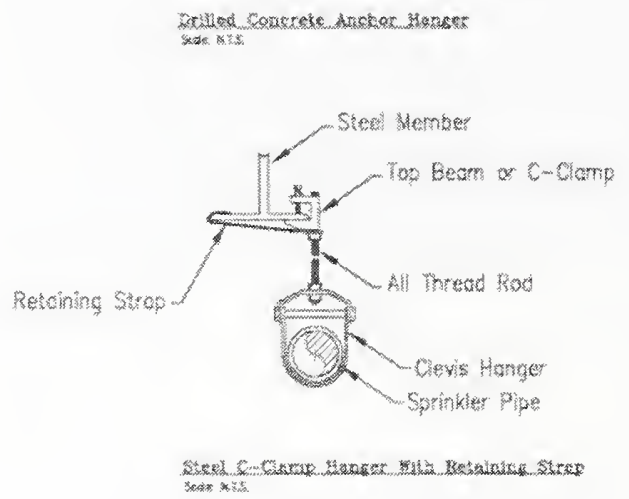

Figure 5-12. Typical hanger arrangements.

\section{High Zone Sprinkler Systems}

The sprinkler systems supplied by riser A are referred to as the high zone and included the systems for floors 99 through 107. Figure B-12 provides a schematic representation of the high zone sprinkler system infrastructure. These systems were supplied with water from an automatic $500 \mathrm{gpm}$ at 60 psi rated fire (booster) pump located in the mechanical room on the 108th floor of each tower. Figure 5-13 shows the fire pump from WTC 1, which was taken from the O\&M manual (PANYNJ 1987a). The fire pumps were used to increase the water pressure for the sprinkler systems on the upper levels since the pressure due to the elevation difference between the water level in the tanks and the sprinkler pipes was less than the required pressure for the proper operation of the sprinkler systems. 


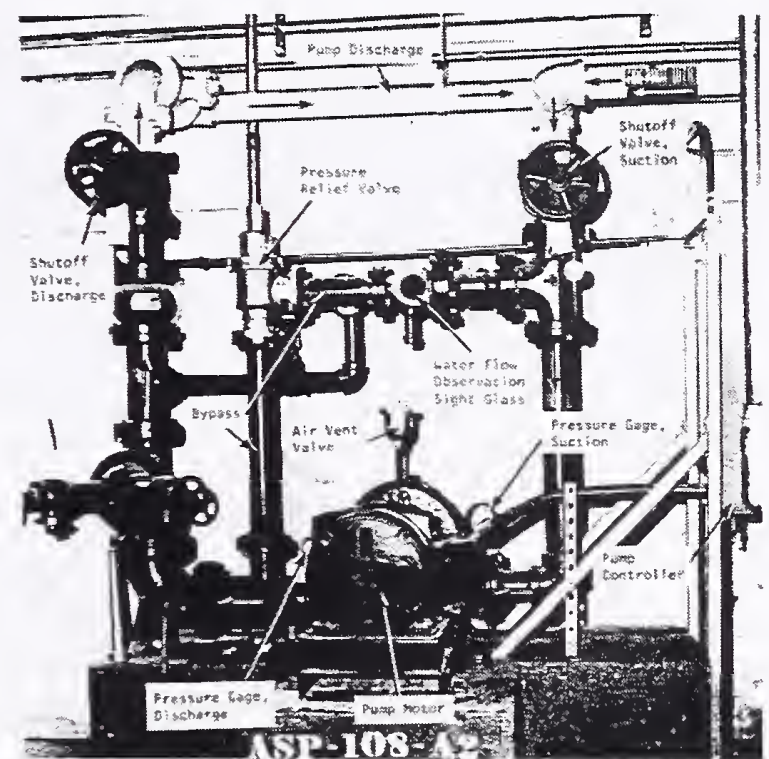

Source: PANYNJ 1987a. Reproduced with permission of The Port Authority of New York and New Jersey.

Figure 5-13. Automatic sprinkler system booster pump.

Pressure reducer type control valves were not required for the high zone sprinkler systems since the static pressures at the floor control valve elevations were less than the maximum working pressure of $175 \mathrm{psi}$ for standard weight sprinklers and fittings. Therefore, OS\&Y valves were installed for all floor level sprinkler systems in the high zone (PANYNJ 1972, 1987a). Table 5-8 provides a summary of the static pressures at each high zone sprinkler system floor control valve elevation along riser A within each tower.

Table 5-8. Summary of high zone static pressure.

\begin{tabular}{|c|c|c|c|c|c|c|c|}
\hline \multicolumn{8}{|c|}{ Riser A Static Pressure at Floor Control Valves } \\
\hline Floor & $\begin{array}{c}\text { Pressure } \\
\text { (psi) }\end{array}$ & $\begin{array}{c}\text { WTC } 1 \\
\text { Elevation } \\
\text { (ft) }\end{array}$ & $\begin{array}{c}\text { WTC } 2 \\
\text { Elevation } \\
\text { (ft) }\end{array}$ & Floor & $\begin{array}{l}\text { Pressure } \\
\text { (psi) }\end{array}$ & $\begin{array}{c}\text { WTC } 1 \\
\text { Elevation } \\
\text { (ft) }\end{array}$ & $\begin{array}{c}\text { WTC } 2 \\
\text { Elevation } \\
\text { (ft) }\end{array}$ \\
\hline 110 & 1.3 & 1,658 & 1,652 & 104 & 116.4 & 1,576 & 1,570 \\
\hline 109 & 8.6 & 1,646 & 1,640 & 103 & 121.6 & 1,564 & 1,558 \\
\hline 108 & 88.6 & 1,632 & 1,626 & 102 & 126.8 & 1,552 & 1,546 \\
\hline 107 & 99.8 & 1,614 & 1,608 & 101 & 132.0 & 1,540 & 1,534 \\
\hline 106 & 106.0 & 1,600 & 1,594 & 100 & 137.2 & 1,528 & 1,522 \\
\hline 105 & 111.2 & 1,588 & 1.582 & 99 & 142.4 & 1,516 & 1,510 \\
\hline
\end{tabular}

\section{Mid-Level Zone Sprinkler Systems}

The sprinkler systems for floors 32 to 98 were included in the mid-level zone. The primary water supply for these sprinkler systems was provided from tank 110A in WTC 1. Similarly, tank 110B provided water to the sprinkler systems in WTC 2. The primary and back-up water supplies for the mid-level zone sprinkler systems were shared with the high zone sprinkler systems. However, the mid-level zone sprinkler systems were supplied separately through riser B. 
Unlike the high zone systems, a booster pump was not provided for the mid-level zone sprinkler systems. The pressure in the system increased at the rate of 0.433 psi per foot of elevation and is referred to as elevation or gravity head pressure. The water storage tanks were located on the 110 th floor far above the mid-level zone sprinkler systems. The elevation difference was used to supply pressure to the mid-level zone sprinkler systems. The tank was located approximately $155 \mathrm{ft}$ above the 98 th floor sprinkler system, the highest of the mid-level zone systems. This elcvation difference resulted in a normal operating pressure of approximately $67.5 \mathrm{psi}$ at the 98 th floor sprinkler system. Table 5-9 provides a summary of the static pressure at each floor control valve assembly for the systems supplied by riser B in the midlevel zone (PANYNJ 1972, 1987a, 2000b).

The mid-level zone served the largest number of floors, which resulted in the greatest variation in pressure from the top to the bottom of the sprinkler riser (PANYNJ 1972, 1987a). There was an elevation pressure difference of 351 psi between the sprinkler systems at the top (98th) and bottom (32nd) floors of the mid-level zone. A normal static pressure of 67.5 psi was observed at 98 th floor sprinkler system (PANYNJ 1987a). However, a normal static pressure of $418.5 \mathrm{psi}$ was observed at the 32nd floor sprinkler system. Since standard weight fittings rated at 175 psi were used for all individual floor level sprinkler systems, pressure-reducing valves were required to regulate the system pressures to within the working tolerances of the pipe and fittings (PANYNJ 1987a, 2000a). Table 5-7 identifies that combination control and pressure reducing valves were used for the sprinkler systems on floors 32 through 86 in both towers.

\section{Low Zone Sprinkler Systems}

The sprinkler systems floors 1 through 31 were identified as the low zone (PANYNJ 1987a). The primary water supply for the low zone sprinkler systems in WTC 1 was provided by reserve water storage tank 42A, which was located in the $41 \mathrm{st} / 42$ nd floor MER. The riser for the low zone sprinkler system, riser C, was interconnected with the low zone system for WTC 2 through a 4 in. diameter main located on the B1 level (PANYNJ 1972, 1987a). The interconnecting pipe was provided with a manually operated isolation valve between the two building systems, which was referred to as the "tower isolating valve" (PANYNJ 1987a). This arrangement permitted the water storage tanks to be used as the primary water supply within the tower where the tank was located and the secondary water supply in the other tower. Refer to Fig. B-1. For example, tank 42B, located on the 42nd floor of WTC 2, was used as the secondary water supply for the low zone sprinklcr systems in WTC 1. Similar to the mid-level zone sprinkler systems, water pressure was supplied by gravity. Table 5-10 provides a summary of the static pressure observed at each floor control valve assembly connected to riser $\mathrm{C}$ in the low zone. 
Table 5-9. Summary of mid-level zone static pressure.

\begin{tabular}{|c|c|c|c|c|c|c|c|}
\hline \multicolumn{8}{|c|}{ Riser B Static Pressure at Floor Control Valves } \\
\hline Floor & $\begin{array}{c}\text { Pressure } \\
\text { (psi) }\end{array}$ & $\begin{array}{c}\text { WTC } 1 \\
\text { Elevation } \\
(\mathrm{ft})\end{array}$ & $\begin{array}{c}\text { WTC } 2 \\
\text { Elevation } \\
\text { (ft) }\end{array}$ & Floor & $\begin{array}{c}\text { Pressure } \\
\text { (psi) }\end{array}$ & $\begin{array}{c}\text { WTC } 1 \\
\text { Elevation } \\
\text { (ft) }\end{array}$ & $\begin{array}{c}\text { WTC } 2 \\
\text { Elevation } \\
\text { (ft) }\end{array}$ \\
\hline 98 & 67.5 & 1,504 & 1,498 & 64 & 248.3 & 1,084 & 1,082 \\
\hline 97 & 72.7 & 1,492 & 1,486 & 63 & 253.4 & 1.072 & 1,070 \\
\hline 96 & 77.9 & 1,480 & 1,474 & 62 & 258.5 & 1,060 & 1,058 \\
\hline 95 & 83.1 & 1,468 & 1,462 & 61 & 263.6 & 1,048 & 1,046 \\
\hline 94 & 88.3 & 1,456 & 1,450 & 60 & 269.0 & 1,036 & 1,034 \\
\hline 93 & 93.5 & 1.444 & 1,438 & 59 & 274.1 & 1,024 & 1,022 \\
\hline 92 & 98.7 & 1,432 & 1,426 & 58 & 279.2 & 1,012 & 1,010 \\
\hline 91 & 103.9 & 1.420 & 1,414 & 57 & 284.3 & 1,000 & 998 \\
\hline 90 & 109.1 & 1,408 & 1,402 & 56 & 289.4 & 988 & 986 \\
\hline 89 & 114.3 & 1,396 & 1,390 & 55 & 294.6 & 976 & 974 \\
\hline 88 & 119.5 & 1,384 & 1,378 & 54 & 300.0 & 964 & 962 \\
\hline 87 & 124.7 & 1,372 & 1,366 & 53 & 305.1 & 952 & 950 \\
\hline 86 & 129.9 & 1,360 & 1,354 & 52 & 310.3 & 940 & 938 \\
\hline 85 & 135.1 & 1,348 & 1.342 & 51 & 315.5 & 928 & 926 \\
\hline 84 & 140.3 & 1,336 & 1,330 & 50 & 320.7 & 916 & 914 \\
\hline 83 & 145.5 & 1,324 & 1.318 & 49 & 326.0 & 904 & 902 \\
\hline 82 & 150.7 & 1,312 & 1,306 & 48 & 331.1 & 892 & 890 \\
\hline 81 & 155.9 & 1,300 & 1,294 & 47 & 336.3 & 880 & 878 \\
\hline 80 & 161.1 & 1,288 & 1,282 & 46 & 341.5 & 868 & 866 \\
\hline 79 & 166.3 & 1,276 & 1.270 & 45 & 346.7 & 856 & 854 \\
\hline 78 & 172.3 & 1,262 & 1,256 & 44 & 352.8 & 842 & 840 \\
\hline 77 & 177.5 & 1,250 & 1.244 & 43 & 358.8 & 828 & 828 \\
\hline 76 & 183.5 & 1,236 & 1,230 & 42 & 364.0 & 814 & 814 \\
\hline 75 & 189.5 & 1,222 & 1.216 & 41 & 371.0 & 800 & 800 \\
\hline 74 & 195.5 & 1,208 & 1,202 & 40 & 377.0 & 786 & 786 \\
\hline 73 & 200.7 & 1,196 & 1,190 & 39 & 382.1 & 774 & 774 \\
\hline 72 & 205.8 & 1,184 & 1,178 & 38 & 387.3 & 762 & 762 \\
\hline 71 & 210.9 & 1,172 & 1,166 & 37 & 392.5 & 750 & 750 \\
\hline 70 & 216.0 & 1,160 & 1,154 & 36 & 397.7 & 738 & 738 \\
\hline 69 & 221.1 & 1,148 & 1,142 & 35 & 403.0 & 726 & 726 \\
\hline 68 & 226.2 & 1,136 & 1,130 & 34 & 408.1 & 714 & 714 \\
\hline 67 & 233.0 & 1,120 & 1,118 & 33 & 413.3 & 702 & 702 \\
\hline 66 & 238.1 & 1,108 & 1,106 & 32 & 418.5 & 690 & 690 \\
\hline 65 & 243.2 & 1,096 & 1,094 & & & & \\
\hline
\end{tabular}


Table 5-10. Summary of low zone static pressure.

\begin{tabular}{|c|c|c|c||c|c|c|c|}
\hline \multicolumn{7}{|c|}{ Riser C Static Pressure at Floor Control Valves } \\
\hline Floor & $\begin{array}{c}\text { Pressure } \\
(\mathbf{p s i})\end{array}$ & $\begin{array}{c}\text { WTC 1 } \\
\text { Elevation } \\
(\mathbf{f t})\end{array}$ & $\begin{array}{c}\text { WTC 2 } \\
\text { Elevation } \\
\text { (ft) }\end{array}$ & Floor & $\begin{array}{c}\text { Pressure } \\
\text { (psi) }\end{array}$ & $\begin{array}{c}\text { WTC 1 } \\
\text { Elevation } \\
(\mathbf{f t})\end{array}$ & $\begin{array}{c}\text { WTC 2 } \\
\text { Elevation } \\
\text { (ft) }\end{array}$ \\
\hline 31 & 59.0 & 678 & 678 & 15 & 142.9 & 486 & 486 \\
\hline 30 & 65.0 & 666 & 666 & 14 & 148.1 & 474 & 474 \\
\hline 29 & 70.1 & 654 & 654 & 13 & 153.3 & 462 & 462 \\
\hline 28 & 75.3 & 642 & 642 & 12 & 158.5 & 450 & 450 \\
\hline 27 & 80.5 & 630 & 630 & 11 & 163.7 & 438 & 438 \\
\hline 26 & 85.7 & 618 & 618 & 10 & 168.9 & 426 & 426 \\
\hline 25 & 90.9 & 606 & 606 & 9 & 174.1 & 414 & 414 \\
\hline 24 & 96.1 & 594 & 594 & 8 & 178.4 & 404 & 404 \\
\hline 23 & 101.3 & 582 & 582 & 7 & 184.5 & 390 & 390 \\
\hline 22 & 106.5 & 570 & 570 & 6 & 189.5 & 379 & 379 \\
\hline 21 & 117.7 & 558 & 558 & 5 & 194.5 & 367 & 367 \\
\hline 20 & 116.9 & 546 & 546 & 4 & 199.4 & 356 & 356 \\
\hline 19 & 122.1 & 534 & 534 & 3 & 204.3 & 344 & 344 \\
\hline 18 & 127.8 & 522 & 522 & 2 & 209.4 & 332 & 332 \\
\hline 17 & 132.5 & 510 & 510 & 1 & 214.5 & 310 & 310 \\
\hline 16 & 137.7 & 498 & 498 & & & & \\
\hline
\end{tabular}

\subsubsection{Electrical Power Supply}

The primary electrical power supply for the WTC complex (including WTC 1 and WTC 2) was provided by the Consolidated Edison Company (Con-Ed) substation located in WTC 7 (McAllister 2002; Beyler 2002). Several substations and transformers were used to distribute power throughout the WTC complex. The primary electrical feeders were routed from the WTC 7 substation through the sub-grade level beneath the truck ramp to the main power distribution center on the B3 level. Reports indicate that the main power distribution center remained intact after the collapses of both WTC 1 and WTC 2. Separate feeders were independently routed from the main power distribution center to each tower (LZA Technology 2002; Beyler 2002).

The secondary power supply was provided by six 1,200 kW emergency generators (Beyler 2002; McAllister 2002). The critical equipment included, but was not limited to, emergency lighting, elevators and fire pumps. The generators were located on the B6 level along the West Street side of the complex and were reported to be intact after the collapse (Beyler 2002). Documentation of the secondary electrical system indicates that a single circuit supplied power to the manual fire pumps on the B1 level in both WTC 1 and WTC 2. It is likely that this circuit was lost after the collapse of WTC 2. 


\subsubsection{Special Hazard Suppression Systems}

Several types of special suppression systems were installed in WTC 1 and WTC 2 on a limited basis to protect specific areas (PANYNJ 1987b). These systems included:

- Dry chemical and steam smothering systems

- Carbon dioxide $\left(\mathrm{CO}_{2}\right)$ systems

- Halon 1301 total flooding systems

These systems were supervised by the fire alarm systems in WTC 1 and WTC 2 and were designed to transmit signals to the FDNY upon activation (Keough and Grill 2005).

\section{Dry Chemical Systems}

Restaurant cooking appliances were equipped with dry chemical fire suppression systems (PANYNJ 1987b). These systems contained dry chemical fire suppression agents (potassium bicarbonate or ammonium phosphate). The dry chemical agents were stored in cylinders and were released by an actuator that would discharge the agent upon fusing of a thermal link located above the cooking appliance or within the exhaust duct. The dry chemical systems were also provided with manual release mechanisms to allow for the occupants to actuate the systems manually. The O\&M manual described that these systems were installed in WTC 1 and WTC 2, but again did not identify specific locations.

\section{Limited Steam Smothering Systems}

The use of steam systems for fire suppression preceded the use of $\mathrm{CO}_{2}$ and dry chemical fire suppression systems (PANYNJ 1987b). The exhaust ducts in the large kitchens at the WTC complex were equipped with steam smothering systems. The O\&M manual indicated that steam smothering systems were installed in the kitchens at the following locations:

- PA Cafeteria

- The "Big Kitchen"

- The Sky Dive

- Window's on the World

- The New York State Cafeteria

- The Observation Deck

\section{Carbon Dioxide Systems}

Carbon dioxide $\left(\mathrm{CO}_{2}\right)$ is electrically nonconductive and is commonly used to extinguish fires involving electrical equipment. $\mathrm{CO}_{2}$ suppression systems were installed in computer rooms in WTC 1 and WTC 2. 
Smoke and heat detectors were used to detect fire and to actuate the releasing mechanism causing $\mathrm{CO}_{2}$ to discharge into the room (PANYNJ 1987b).

A total flooding $\mathrm{CO}_{2}$ system was used to protect the under floor space of a large computer room in WTC 2 (PANYNJ 1987b). Reference was found to other systems at the WTC complex, but there were no specific indications regarding the locations or details of these systems. $\mathrm{CO}_{2}$ can cause asphyxiation to the displacement of air. These systems were provided with local alarm bells to indicate to the occupants that the system was activated and the room should be evacuated.

\section{Halon 1301 Systems}

The term halon refers to halogenated hydrocarbon gases which are used as fire extinguishing agents. (Halogenated compounds contain fluorine, chlorine, bromine and iodine.) Halon agents extinguish fires by interrupting the combustion process. These systems also require evacuation during activation.

Halon systems are used in both local and total flooding applications, similar to $\mathrm{CO}_{2}$ systems. Halon 1301 total flooding systems were used for the protection of computer rooms in WTC 1 and WTC 2. Halon total flooding systems protect enclosed rooms or areas. Halon is stored in holding cylinders, which are actuated upon the response of a two cross-zoned smoke detectors. The O\&M manual describes that two separate cross-zoned detection system zones were installed, and release occurred upon activation of a detector within each zone. The available drawings for WTC 1 show that two Halon 1301 systems were installed for protection of the computer room on the 70th floor. One system was installed for protection of the under floor space and the other for protection of the room (PANYNJ 1972, 1987a).

\subsubsection{Fire Protection in the Initial Impact Areas}

The fire protection systems in the initial impact areas were basically the same as all other areas throughout the towers. The damage estimates and operability of the fire suppression systems in WTC 1 and WTC 2 as a result of the September 11, 2001 incident are provided in Chapter 9.

\section{WTC 1, Floors 89 through 110}

The initial damage to the fire protection systems was sustained on floors 93-99 of WTC 1 within the initial impact area as a result of the collision by a commercial jet aircraft on September 11, 2001 (McAllister et al. 2005). This section of the report provides a description of the fire protection systems on those floors as well as multiple floors above and below the initial impact areas. A description of the fire protection systems on floors 89 through 110 is included in this section.

The high zone standpipe system in WTC 1 included all floors vertically between the 77 th floor and the 110th floor (PANYNJ 1972). Three separate standpipes were installed, one in each stair enclosure (PANYNJ 1987a). The standpipes were interconnected at the bottom of the zone on the 76th floor and at the top of the zone on the 109th floor (PANYNJ 1972, 1987a). Check valves were installed at the top of two of the standpipes, FS-F2 and FS-F3, preventing water from flowing downward (PANYNJ 1972, 1987a). The third standpipe, FS-F1, was not provided with a check valve (PANYNJ 1972, 1987a). Each standpipe supplied $2 \frac{1}{2}$ in. hose valves with $2 \frac{1}{2}$ by $1 \frac{1}{2}$ in. reducers and either a hose cabinet or hose rack (PANYNJ 1972, 1987a). 
Water was gravity supplied to standpipe FS-F1 from the 5,000 gal standpipe water storage tank on the 110 th floor in the initial operating mode (PANYNJ 1987a). Water was supplied to the other standpipes from FS-F1. A series of manual fire pumps was installed to supply water to the standpipe system (PANYNJ 1987a). The high zone standpipe system was interconnected with the upper mid-level zone standpipe system immediately below the high zone (PANYNJ 1972, 1987a). A series of manual fire pumps were installed to supply water to the standpipe system. The standpipe system was also used to supply the secondary water supply to the sprinkler systems on floors 32 through 110 . Two additional water storage tanks dedicated to the sprinkler systems were provided on the 110th floor (PANYNJ 1972 , 1987a).

Two separate sprinkler risers supplied water to the sprinkler systems on floors 89 through 110 (PANYNJ 1972, 1987a). The high zone riser (riser A) was equipped with a single automatic $500 \mathrm{gpm}$ electric drive fire pump. Riser A was located in a janitor's closet located in the building core at the north side of the building (PANYNJ 1972, 1987a). This riser supplied the high zone sprinkler systems on the 99th through 107th floors. Sprinkler systems were not installed in the mechanical rooms on the 108th through 110th floors (PANYNJ 1987a). Local application deluge systems were provided for protection of the fan filters in the air-handling units (PANYNJ 1987a).

The mid-level zone riser (riser B) gravity supplied water to the sprinkler systems on the 33rd through 98th floors. Isolation valves were provided at the top of the risers that would have permitted the individual shutdown of either sprinkler riser. An additional intermediate isolation valve was provided for riser $\mathrm{B}$ on the 77th floor. Riser B was located in the janitor's closet adjacent to stair 3.

The sprinkler systems on floors 89 through 110 each contained separate control valves and alarm switches. Each sprinkler system was installed in a complex loop configuration. The sprinkler systems were primarily designed for the protection of Light Hazard Occupancies. No information was found regarding the presence of special suppression systems on floors 89 through 110 .

\section{WTC 2, Floors 74 through 90}

The fire protection systems in WTC 2 sustained damage on the 77th through 85 th floors as a result of the initial impact by a commercial aircraft on September 11, 2001 (McAllister et al. 2005). This section of the report provides a description of the fire protection systems on the 74th through 90th floors of WTC 2.

The high zone standpipe system in WTC 2 was basically the same as the system that was installed in WTC 1. Three separate standpipes were installed, one in each stair enclosure (PANYNJ 1972, 1987a). The standpipes spanned floors 77 through 110 and were interconnected at the bottom of the zone on the 76th floor and at the top of the zone on the 109th floor (PANYNJ 1972, 1987a). Check valves were installed at the top of two of the standpipes. The third standpipe was not provided with a check valve (PANYNJ 1972, 1987a). Each standpipe supplied $21 / 2$ in. hose valves with $2 \frac{1}{2}$ by $1 \frac{1}{2}$ in. reducers and either a hose cabinet or hose rack (PANYNJ 1972, 1987a).

Water was gravity supplied to the standpipes from the 5,000 gal standpipe water storage tank on the 110th floor in the initial operating mode (PANYNJ 1987a). The high and upper mid-level zones of the standpipe system were interconnected within the MER on the 75th and 76th floors (PANYNJ 1972, 1987a). A $750 \mathrm{gpm}$ manual fire pump was provided on the 75th floor (PANYNJ 1972, 1987a). This 
pump was connected in series with three manual fire pumps within WTC 2 below (PANYNJ 1972, 1987a). These fire pumps were all manually operated and intended to provide water for manual fire suppression efforts (PANYNJ 1972, 1987a). The standpipe system also provided a secondary water supply for the sprinkler systems (PANYNJ 1987a).

The mid-level zone riser (riser B) gravity supplied water to the sprinkler systems on the 33rd through 98th floors. Therefore, all of the sprinkler systems on floors 74 through 90 were gravity supplied with water from riser B. Isolation valves were provided at the top of the risers that would have permitted the individual shutdown of either sprinkler riser (PANYNJ 1972, 1987a). An additional intermediate isolation valve was provided for riser B on the 67th floor (PANYNJ 1972, 1987a). Riser B was located in the janitor's closet adjacent to stair 3 (PANYNJ 1972).

The sprinkler systems on floors 74 through 90 each contained separate control valves and alarm switches. Each sprinkler system was installed in a complex loop configuration. The sprinkler systems were primarily designed for the protection of Light Hazard Occupancies (PANYNJ 1972, 1987a). Sprinkler systems were not provided for the MERs on the 75th and 76th floors (PANYNJ 1972, 1987a). Local application deluge systems were provided for protection of the fan filters in the air handling units (PANYNJ 1987a). No information was found that indicated the presence of special suppression systems on floors 74 through 90 of WTC 2.

\subsection{FIRE SUPPRESSION SYSTEMS, WTC 7}

\subsubsection{Water Supplies}

The following is a description of each water supply and the zone that each supplied in WTC 7. Check valves were located at the top of the low and mid-level zones for isolation. The check valves were oriented such that water from the automatic booster pump on the 46th floor could only supply the high zone, and the water storage tanks on the 46th floor could only supply the mid-level zone (Gensler and Associates 1995). See Fig. B-13 for the flow path and check valve orientation.

\section{Water Storage Tanks}

The combination system for the mid-level zone was primarily supplied with water from two 17,500 gal storage tanks (Syska \& Hennessy 1984). The water storage tanks were located on the 46th floor and extended up to the 47 th floor level. The tanks were used as a domestic water storage system (Syska \& Hennessy 1984). However, each tank had a fire suppression system reserve capacity of 17,500 gal (Syska \& Hennessy 1984).

The make-up water to fill each tank was supplied by three $435 \mathrm{gpm}$ capacity booster pumps via an 8 in. domestic express supply riser from the second floor (Syska \& Hennessy 1984). Each pump was provided with two electrode level control units in each tank (Syska \& Hennessy 1984). A single pump operated when the water level dropped to a set point established by the electrode control unit (Syska \& Hennessy 1984). The pumps operated individually but would operate simultaneously if the load exceeded the capacity of one pump (Syska \& Hennessy 1984). The tanks were combination domestic and fire water storage tanks. Therefore, the pumps would turn on at a certain drop in water level, due to domestic usage or fire water usage. 
The three domestic booster pumps on the second floor were supplied with water from two 7,000 gal domestic suction tanks on the third floor. Each suction tank had approximately 5,300 gal of useful capacity. These tanks were supplied directly from the $8 \mathrm{in}$. city service main. The supply to each tank was individually controlled using a solenoid valve located in the 4 in. fill pipe connections (Gensler and Associates 1995).

The domestic water storage tanks on the 46 th floor were joined at the base by a connecting 8 in. pipe (Syska \& Hennessy 1984). A control valve was in place below each tank on the discharge piping, such that the tanks could be isolated from the system. The 8 in. pipe supplied the automatic booster pump on the 46th floor and the risers in the mid-level zone (Syska \& Hennessy 1984).

The elevation of the storage tanks was approximately $600 \mathrm{ft}$ from the first floor (Syska \& Hennessy 1984). The tanks provided a gravity fed supply to the base of risers R-5 and R-6 on the 20th floor (approximate elev. $255 \mathrm{ft}$ ) via standpipe riser R-4. Figure B-13 illustrates the arrangement. Note the location of the riser control valves.

The control valve at the base of riser R-4 would isolate the tank water supply from riscrs R-5 and R-6 if closed. Common practice would require valves to be provided to allow isolation of a standpipe without interrupting the supply to other standpipes for the same source of supply (NFPA 2000). Figure 5-14 illustrates the mid-level zone riser configuration.

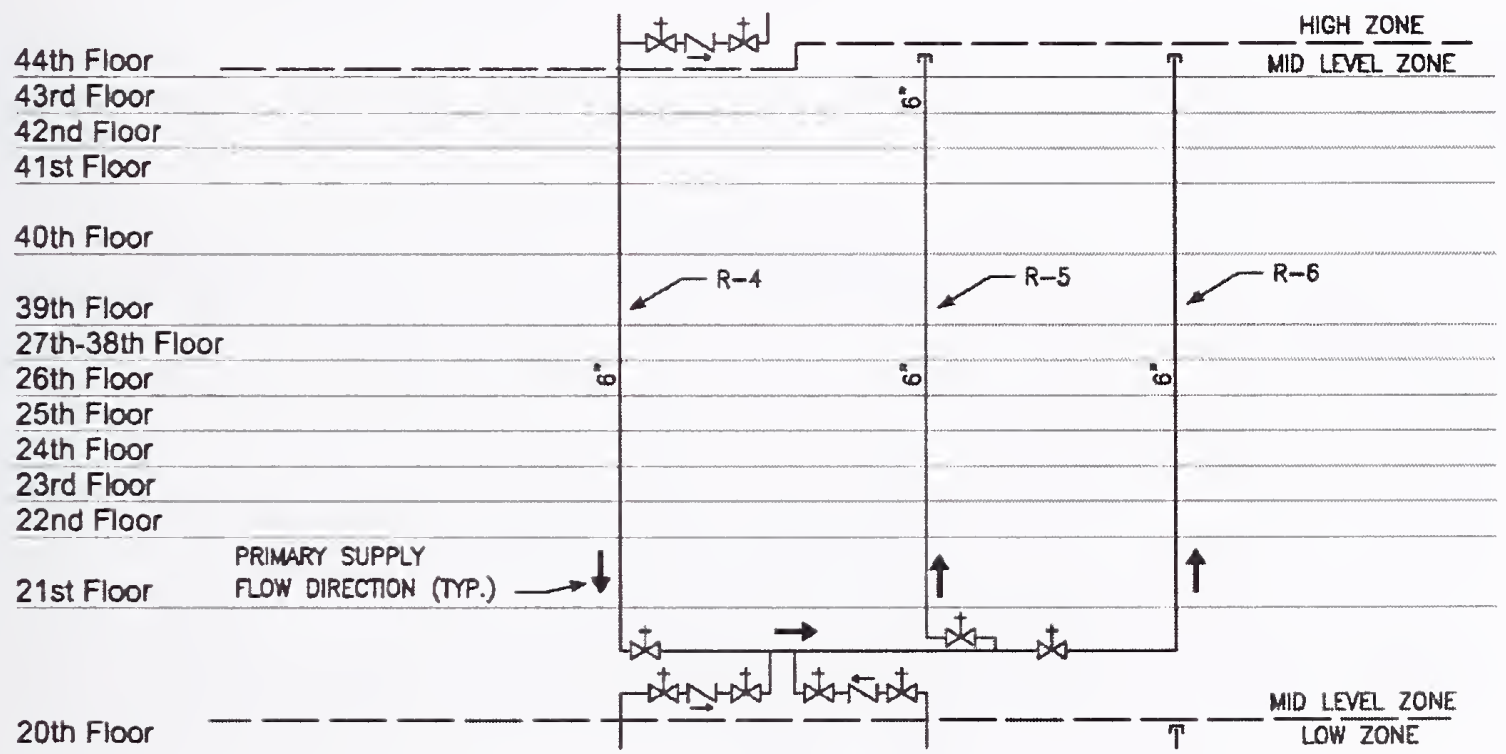

Figure 5-14. Mid-level zone riser supply configuration, WTC 7.

\section{Fire Pumps}

The automatic booster pump on the 46th floor supplied the combination system risers in the high zone. The pump was a single stage pump rated for 55 psi at $500 \mathrm{gpm}$ (Syska \& Hennessy 1984). The water supply for the booster pump came directly from the water storage tanks. Figure 5-15 illustrates the high zone supply riser configuration. 


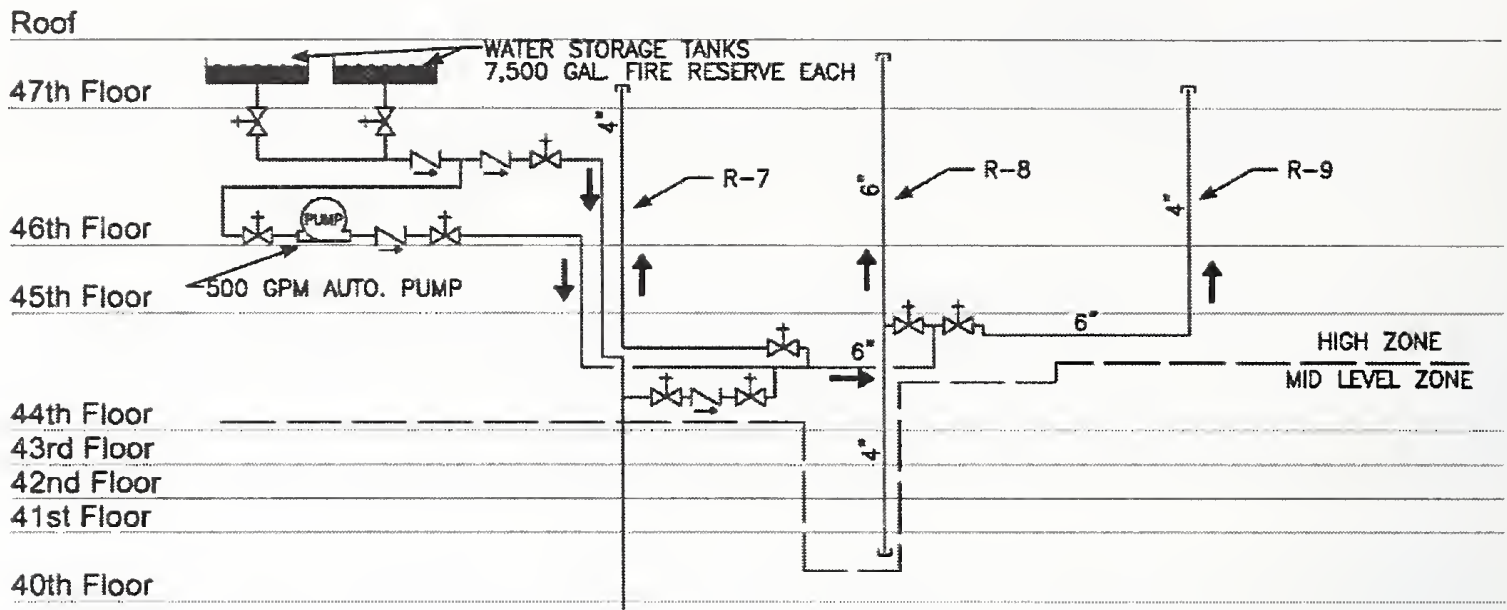

Figure 5-15. High zone riser supply configuration, WTC 7.

An automatic fire pump on the first floor supplied the combination system risers, hose connections, and sprinkler control valve assemblies in the low zone. The water supply for the fire pump came directly from two separate $8 \mathrm{in}$. connections to the $12 \mathrm{in.} \mathrm{main} \mathrm{on} \mathrm{Washington} \mathrm{Street.} \mathrm{The} \mathrm{connections} \mathrm{to} \mathrm{the} 12 \mathrm{in}$. main were separated using an isolation valve (Gensler and Associates 1995).

The pump was a single stage horizontal split case pump rated for $120 \mathrm{psi}$ at $500 \mathrm{gpm}$. The pump was equipped with a $50 \mathrm{hp}, 460$-volt, 3-phase electric driver. The pump was provided with an emergency power source via an automatic transfer switch (Syska \& Hennessy 1984). Figure 5-16 illustrates the low zone supply configuration.

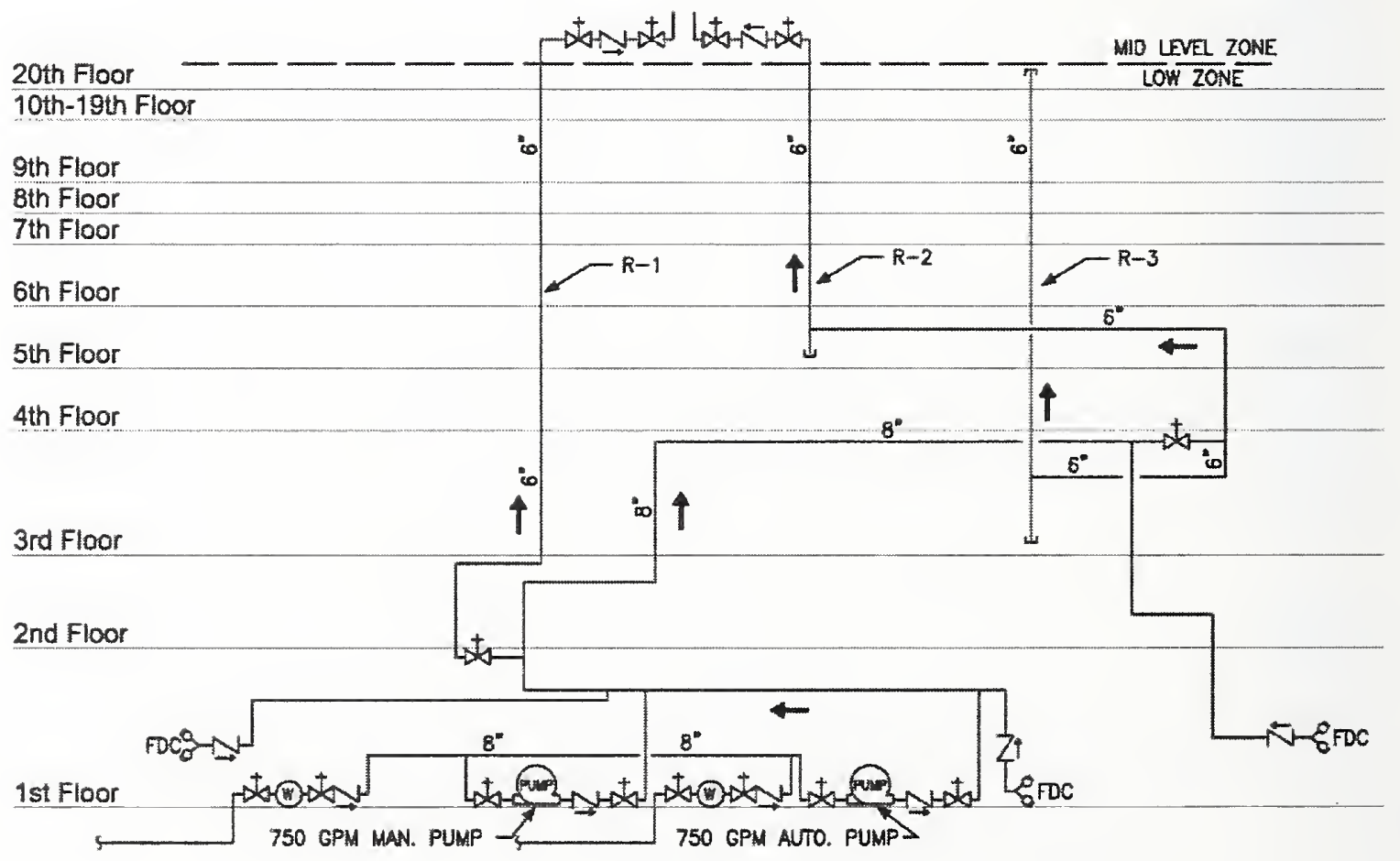

Figure 5-16. Low zone supply configuration, WTC 7. 
A manual fire pump was connected in parallel with the automatic fire pump on the first floor as illustrated in Fig. B-14. The manual fire pump served as a secondary water supply for the entire combined system throughout the building (Gensler and Associates 1995).

The manual fire pump was a 3-stage horizontal split case pump rated for 750 gpm at 310 psi. The pump was equipped with a $250 \mathrm{hp}, 460$-volt, 3 -phase electric driver. The motor controller was set up at predetermined speeds to provide 100 psi initially and 50 psi for each additional increment (Syska \& Hennessy 1984).

The use of the manual fire pump required system piping, valves, and other equipment to be specified to withstand the high system pressures associated with the manual fire pump. Table 5-11 lists the type, rating, and location of the components that were under the influence of the high pressures (Syska \& Hennessy 1984). 
Table 5-11. System components, WTC 7.

\begin{tabular}{|c|c|c|}
\hline Component & Specification & Location \\
\hline \multirow[t]{2}{*}{ System piping } & $\begin{array}{l}\text { Malleable iron or cast iron } \\
\text { Minimum } 350 \mathrm{psi}\end{array}$ & 14th floor and above \\
\hline & $\begin{array}{l}\text { Extra heavy malleable iron or extra heavy } \\
\text { cast iron } \\
\text { Minimum } 500 \text { psi }\end{array}$ & 13th floor and below \\
\hline \multirow[t]{2}{*}{ Sprinkler piping } & $\begin{array}{l}\text { Option 1: Standard weight fittings } \\
175 \mathrm{psi}\end{array}$ & All floors \\
\hline & $\begin{array}{l}\text { Option } 2 \text { : Schedule } 10 \text { light weight steel } \\
2 \text { in. through } 5 \text { in. diameter only } \\
\text { Threaded or cut grooved not permitted }\end{array}$ & All floors \\
\hline Pump suction piping & $\begin{array}{l}\text { Schedule } 40 \text { galvanized } \\
\text { Standard weight fittings }\end{array}$ & Pump suction side of pumps \\
\hline \multirow[t]{2}{*}{ Control valves ( 2 in. and smaller) } & $\begin{array}{l}\text { OS\&Y gate valves and wafer type ball } \\
\text { valves } \\
\qquad 175 \mathrm{psi}\end{array}$ & 37th floor and above \\
\hline & $250 \mathrm{psi}$ & 37th floor and below \\
\hline \multirow[t]{4}{*}{$\begin{array}{l}\text { Control valves ( } 21 / 2 \text { in. and } \\
\text { larger) }\end{array}$} & $\begin{array}{l}\text { Flanged OS\&Y gate valves } \\
175 \mathrm{psi}\end{array}$ & 37th floor and above \\
\hline & $250 \mathrm{psi}$ & 25th through 36th floors \\
\hline & $350 \mathrm{psi}$ & 14th through 24th floors \\
\hline & $500 \mathrm{psi}$ & 13th floor and below \\
\hline $\begin{array}{l}\text { Pressure reducing valves at } \\
\text { sprinkler connections }\end{array}$ & $\begin{array}{l}\text { Rough brass female threaded } \\
400 \mathrm{psi}\end{array}$ & 1 st through 25 th floors \\
\hline \multirow[t]{4}{*}{ Check valves } & $\begin{array}{r}\text { Swing Type } \\
175 \text { psi } \\
\end{array}$ & 37 th floor and above \\
\hline & $250 \mathrm{psi}$ & 25 th through 36 th floors \\
\hline & $350 \mathrm{psi}$ & 14th through 24 th floors \\
\hline & $500 \mathrm{psi}$ & 13 th floor and below \\
\hline \multirow[t]{2}{*}{ Hose valves } & $\begin{array}{l}\text { Standard rough brass } \\
300 \mathrm{psi}\end{array}$ & 26th floor and above \\
\hline & $\begin{array}{l}\text { Automatic pressure reducing } \\
\qquad 400 \mathrm{psi}\end{array}$ & 25 th floor and below \\
\hline
\end{tabular}

\section{Fire Department Connections}

Three siamese FDCs were provided for the system as illustrated in Figure B-15. FDCs were flush wall type located on the perimeter of the building on the west along Washington Street, on the east along West Broadway, and on the south along Vesey Street. Each FDC was 3 in. by 3 in. by 5 in. and was connected directly to the core system infrastructure through 6 in. galvanized piping. A check valve with automatic ball drip was located between each FDC and the core infrastructure in the interior of the building. Each FDC was arranged to supply water to all system risers in the building (Syska \& Hennessy 1984). 


\subsubsection{Sprinkler and Standpipe Systems}

This section of the report provides documentation of the suppression infrastructure and systems in WTC 7. In addition, WTC 7 contained a unique hazard in the generator rooms. The generators were fueled by fuel oil that was stored in day tanks on various floors in the building. The protection that existed for the generator and day tank storage rooms is also documented in this section.

\section{Design Basis and Associated Criteria}

WTC 7 was designed in the mid-1980s. The following criteria were used to design and install the suppression systems in the building. These design criteria are found on the Syska \& Hennessy design drawings (Gensler and Associates 1995) and technical specifications (Syska \& Hennessy 1984).

The design criteria indicated on the design drawings (latest revision dated March 29, 1985) that an entire sprinkler system be hydraulically calculated and sized for:

- All tenant spaces, lobbies, and public spaces

- Wet-pipe sprinkler systems based on NFPA 13 and RS-17 Light Hazard Occupancy requirements with a density of $0.10 \mathrm{gpm} / \mathrm{ft}^{2}$ over $1,500 \mathrm{ft}^{2}$

- Mechanical equipment rooms, mechanical spaces, janitor closets, and mail room

- Wet-pipe sprinkler system based on NFPA 13 and RS-17 Ordinary Hazard Group 1 requirements with a density of $0.16 \mathrm{gpm} / \mathrm{ft}^{2}$ over $1,500 \mathrm{ft}^{2}$

- Loading berth area, fuel oil pump room, elevator pit service area

- Dry-pipe sprinkler system based on NFPA 13 and RS-17 Ordinary Hazard Group 1 requirements for loading berth area with a density of $0.16 \mathrm{gpm} / \mathrm{ft}^{2}$ over $1,950 \mathrm{ft}^{2}$

- Dry-pipe sprinkler system based on NFPA 13 and RS-17 Ordinary Hazard Group 3 requirements for fuel oil pump rooms with a density of $0.21 \mathrm{gpm} / \mathrm{ft}^{2}$ over the entire fuel oil pump hazard area

The design criteria indicated that sprinkler piping was not to be installed in electric closets, communicating closets, telephone closets, emergency generator rooms, transformer and switchgear rooms, and telephone equipment rooms. Section $1.02 \mathrm{~A} .1$ of the technical specification prohibited sprinkler piping in electrical rooms and closets, telephone rooms and closets, and elevator rooms. The specification further prohibited piping over or within $5 \mathrm{ft}$ of transformers, substations, switchboards, motor control centers, standby power plant, bus ducts, and motors except for branch piping to equipment. The Syska \& Hennessy building core construction drawings also indicated that sprinklers were not provided in bathrooms in the original design.

The design documentation indicated the intent to protect hazards such as the fuel oil pump spaces with Ordinary Hazard Group 3 protection, in accordance with NFPA 13 (1983 edition) as modified in RS-17. It was also clear that the emergency generator spaces were not to be protected as indicated on the 
drawings and in the specifications. No information was found regarding protection for the fuel oil day tanks located in the generator rooms.

\section{Combination Automatic Fire Sprinkler and Standpipe Systems}

WTC 7 had combined automatic sprinkler and standpipe systems consisting of nine vertical risers in three zones (Syska \& Hennessy 1984). Each zone consisted of three risers, one combination sprinkler/standpipe riser, and two standpipes for manual firefighting activities (Syska \& Hennessy 1984). Therefore, the water supply for a particular zone was common for sprinkler piping and standpipes within that zone. The type, arrangement, and interconnection of the water supplies to the sprinkler systems and hose connections, including standpipe and sprinkler riser locations, and zones of influence and isolation valves are addressed in this section. System components such as valve type, pipe type, and valve locations are also described. Refer to Fig. B-13 for the water supply riser configuration, valving arrangements and vertical zones.

\section{High Zone}

The high zone included two standpipes and one combination riser that were supplied by an automatic booster pump on the 46th floor (Syska \& Hennessy 1984). The standpipes are identified as riser 7 (R-7) and riser 9 (R-9). The combination riser is identified as riser 8 (R-8). A cross connection main located on the 44th floor connected each riser (Syska \& Hennessy 1984). Each riser could be individually isolated from the cross connection main supplying each riser (Syska \& Hennessy 1984). Note the direction of flow in Fig. B-13. The water discharged from the tank on the 46th floor, flowing down to the cross connection on the 44th floor where it fed each riser.

Check valves were located at the top of riser $4(\mathrm{R}-4)$ of the mid-level zone at the connection with the high zone cross connection main (Syska \& Hennessy 1984). The check valve was oriented so that water could not flow from the high zone down to lower zones. However, the high zone could be served from lower zones through the check valve by the manual fire pump, which served as a secondary supply.

Figure B-16 illustrates the vertical orientation of each riser in relation to the fire hose valves (FHV), fire hose cabinets (FHC), and floor control assemblies (FCA) on each floor.

Riser 7 (R-7) was a 6 in. standpipe used for manual fire suppression activities. The standpipe was located in stair 1 on the west side of the building and extended from the isolation valve on the 44th floor through to the roof level (Syska \& Hennessy 1984). Riser 7 supplied FHVs on the 45th, 46th, and 47th floors and a 3 by $2 \frac{1}{2} \mathrm{in}$. manifold roof hydrant.

Riser 8 (R-8) was a combination sprinkler/standpipe riser located in stair 2 in the center of the building between the 40 th floor and the 47 th floor. Riser 8 was a 6 in. combination riser, supplying the FCAs and FHVs between the 45 th and 47 th floors (Syska \& Hennessy 1984). It then was reduced to a 4 in. riser between the 40th and 44th floors where it only supplied the FCAs. Refer to Fig. B-16.

Riser 9 (R-9) was a 6 in. riser located in the utility shaft on the east side of the building. This riser extended from the isolation valve on the 44th floor to the FHC on the 47th floor and supplied FHCs on the 45th, 46th, and 47th floors (Syska \& Hennessy 1984). 


\section{Mid-Level Zone}

The mid-level zone also included two standpipes and one combination automatic sprinkler/standpipe riser, identified as riser 4 (R-4), riser 6 (R-6), and riser 5 (R-5), respectively (Syska \& Hennessy 1984). The gravity tanks on the 47 th floor were the primary supplies for the mid-level zone.

A cross connection main located on the 20th floor connected each riser. The isolation valves located at the base of risers 5 and 6 could be closed to isolate each riser, respectively. Riser 4 also had a riser isolation valve located at its base. However, the gravity tanks supplied riser 5 and 6 via riser 4 (Fig. B-13).

Therefore, closing the riser isolation valve at the base of riser 4 would also isolate risers 5 and 6 from their primary supply. Risers 5 and 6 were not connected at the top. Although not required at the time of installation, typical industry practice today would be to connect the standpipes at the top, as well as at the bottom, complying with NFPA 14 Section 5-5 (2000 edition). Check valves would be installed at the base of the standpipes in such a case to prevent circulation.

Check valves were located at the top of riser $1(\mathrm{R}-1)$ and riser $2(\mathrm{R}-2)$ of the low zone at the connection with the mid-level zone cross connection main (Syska \& Hennessy 1984). The check valves were oriented so that water could not flow from the mid-level zone down to the low zone. However, the mid-level zone could be served from the low zone through the check valves by the manual fire pump (which served as a secondary supply) or from excess pressure served by the city supply and automatic fire pump serving the low zone.

The following is a description of each mid-level zone riser and the systems that they served. Figure B-16 illustrates the vertical orientation of each riser in relation to the FHVs, FHCs, and FCAs on each floor.

- Riser 4 (R-4) was a 6 in. standpipe used for manual fire suppression activities in addition to serving as the primary supply for risers 5 and 6 (Syska \& Hennessy 1984). Riser 4 was located in stair 1 on the west side of the building. Riser 4 supplied FHVs on the west side of the building from the 21 st through the 44 th floors.

- Riser 5 (R-5) was a 6 in. combination sprinkler/standpipe riser (Syska \& Hennessy 1984). Riser 5 extended from the cross connection main on the 20 th floor through the 44 th floor. The riser was located in stair 2 through the 23rd floor. Riser 5 remained in stair 2 through the 44 th floor, however, stair 2 shifted approximately $20 \mathrm{ft}$ towards the west from the 24 th through the 46 th floors. Riser 5 supplied the FCAs and FHVs on each floor from the 21 st through the 39 th floors. Riser 5 only supplied the FHVs on the 40th through the 44th floors. Each FCA on the 21 st through the 25 th floors contained a pressure-reducing valve. The pressure-reducing valve regulated the high supply pressure produced by the manual fire pump to within the listed rating of 175 psi for the sprinkler piping.

- Riser 6 (R-6) was a 6 in. standpipe that supplied FHCs (Syska \& Hennessy 1984). This riser was located in the utility shaft below riser 9 . It extended from the 21 st through the 44 th floors. The primary supply for riser 6 was from the water storage tanks on the 47 th floor level via riser 4 and the cross connection main on the 20 th floor. 


\section{Low Zone}

The low zone included two standpipes and one combination sprinkler/standpipe riser. Additionally, sprinkler system FCAs and FHVs were located off of the infrastructure piping on the first through fourth floors (Gensler and Associates 1995). Refer to Fig. B-16 for piping and valving arrangements. The standpipes and combination riser are identified as riser 1 (R-1), riser 3 (R-3), and riser 2 (R-2), respectively. The automatic fire pump located on the first floor was the primary supply for the low zone.

Riser 1 was connected to the discharge side of the pump manifold. The isolation valve for riser 1 was located in the first floor pump room. An 8 in. cross connection main extended from the first floor fire pump room, on the west side of the building, up to the third floor via stair 1 . The cross connection extended to the east side of the building to an isolation valve in stair 2. Figure B-13 illustrates that both risers 2 and 3 were controlled from a single isolation valve (Gensler and Associates 1995).

The following is a description of each low zone riser and the systems that they served. Figure B-16 illustrates the vertical orientation of each riser in relation to the FHVs, FHCs, and FCAs on each floor.

Riser 1 (R-1) was a 6 in. standpipe feeding FHVs only (Gensler and Associates 1995). Riser 1 was located in stair 1 on the west side of the building. It extended from the 1 st floor fire pump room through the 20th floor. On the fifth floor riser 1 shifted further towards the center of the building with the stair 1 . Note the valving orientation at the top of riser 1 . Water could feed the mid-level zone from riser 1 by flowing through the check valve. The mid-level and high zones could also be isolated from the system infrastructure by closing the isolation valve at the top of risers 1 and 2 .

Riser 2 (R-2) was a 6 in. combination sprinkler/standpipe riser (Gensler and Associates 1995). Riser 2 was located in stair 2, which was located in the west side of the building through the fourth floor. Stair 2 then shifted to the center of the building on the fifth floor. Therefore, riser 2 also shifted to the center of the building on the fifth floor. Riser 2 supplied the FCAs and FHVs at the stair landings on the 5th through 20 th floors. The top of riser 2 was equipped with a valving arrangement similar to riser 1 , allowing isolation or flow to the mid-level cross connection. Also, each FCA on riser 2 was equipped with a pressure-reducing valve to regulate the pressure produced by the manual fire pump down to within the ratcd working pressure of the sprinkler piping.

Riser 3 (R-3) was a 6 in. standpipe that fed FHCs (Gensler and Associates 1995). Riser 3 was located in a utility shaft on the east side of the building below riser 6 . It extended from the 3 rd to the 20 th floors. Riser 3 was only used to supply the FHCs on each floor; it was not connected to the mid-level cross connection as were risers 1 and 2 .

\subsubsection{Electrical Power Supply}

The primary electrical distribution system for WTC 7 was served by Con-Ed (Syska \& Hennessy 1984). The Con-Ed power station, which supplied primary power to the WTC complex was located below WTC 7. The main building transformers for WTC 7 were located on the third floor. Power was distributed throughout the building via two main $277 / 480 \mathrm{~V}, 3$ phase risers located on each end of the building core (Syska \& Hennessy 1984). Each riser supplied $2 \mathrm{~W} / \mathrm{ft}^{2}$ for lighting and $2 \mathrm{~W} / \mathrm{ft}^{2}$ for floor power to each tenant of the building. The power to each floor was provided by local 120/208 V, three-phase transformers (Syska \& Hennessy 1984). 
The base building emergency power supply for WTC 7 was served from two $900 \mathrm{~kW}$ diesel generators located in the fifth floor generator room on the south side of the building facing the WTC complex (Emery et al. 1987). The generators provided $480 / 277 \mathrm{~V}$ to two separate risers designated $\mathrm{B}$ and $\mathrm{C}$, respectively.

Upon loss of power, sensors in the diesel generator control cabinet automatically initiated onc or both generators to start (GC Engineering 1998; Grill and Johnson 2005b). Once the generators achieved the designated voltage and frequency, the generator output circuit breaker closed, energizing the bus in each generator switch gear. The loading of each generator then began in a scheduled progrcssion. The transfer switches automatically switched over to emergency power.

There were emergency power circuits located on the 1st, 3rd, 4th, 5th, 9th and every 5 th floor through the 44th floor (Swanke et al. 1998; Grill and Johnson 2005b). These circuits were provided with power from the primary system until power loss, when they were provided with emergency power from emergency power risers B and C on each respective floor (Swanke et al. 1998; Grill and Johnson 2005b).

Both manual and automatic fire pumps on the first floor were directly connected to the generator via an automatic transfer switch (Swanke et al. 1998; Grill and Johnson 2005b). The automatic booster pump was connected to the generator through a $200 \mathrm{amp}$ fuse.

In 1998, WTC 7 was retrofitted with an emergency power system for the Office of Emergency Management (OEM) located on the 23rd floor (GC Engineering 1998). Three generators, each a $50 \mathrm{~kW}$ diesel power plant located on the seventh floor, supplied the OEM.

\subsubsection{Fire Suppression Systems Associated with Fuel Oil Supply Systems}

Fuel oil powered generators were located on the fifth, seventh, eighth, and ninth floors of WTC 7 (Swanke et al. 1998; GC Engineering 1998; Grill and Johnson 2005b). The generators were configured in two separate systems and served as the emergency power supplies for the building (GC Engineering 1998; Grill and Johnson 2005b). The generator sets and associated fuel supplies were installed in the building as part of several projects including the base building installation (Silverstcin Propcrtics) designed in 1987, the Salomon Brothers installation in 1990, the Ambassador Construction modifications (U.S. Secret Service as of September 11, 2001) in 1994, the American Express modifications in 1994, and the NYC Mayor's Office of Emergency Management modification in 1999 (Emery et al. 1987; GC Engineering 1998; Grill and Johnson 2005, Swanke et al. 1998). All of the installations and modifications were part of the base building (Silverstein Propertics) system with exception of the Salomon Brothers (SB) installation in 1990. The Salomon Brothers installation was a separate systcm from the base building installation (GC Engineering; Grill and Johnson 2005b).

There were 16 generators, two 12,000 gal fuel oil storage tanks, three 6,000 gal fuel oil storage tanks, three 275 gal day tanks, and one 50 gal day tank located in WTC 7. (McAllister 2002; Grill and Johnson 2005; GC Engineering 1998).

Two $900 \mathrm{~kW}$ generators with a 275 gal day tank were installed in the southwest corner of the 5th floor as part of the Silverstein Properties (SP) installation (Emery et al. 1987; Gensler and Associates 1995). A duplex pump set located on the first floor supplied fuel oil from two 12,000 gal storage tanks located under the loading births on the south side of the building to the day tank on the 5th floor (Emery et al. 
1987; Gensler and Associates 1995). The riser was located in a pipe chase adjacent to the core elevator banks.

One $125 \mathrm{~kW}$ generator with a $50 \mathrm{gal}$ day tank on the northwest comer of the ninth floor was installed as part of the U.S. Secret Service (USSS) system (Grill and Johnson 2005b; McAllister 2002). This day tank was supplied with fuel oil from the base building riser located in a pipe chase adjacent to the core elevator banks.

One $350 \mathrm{~kW}$ generator with 275 gal day tank located on the west side of the building on the 8th floor was installed as part of the American Express (AM) modifications (Gensler and Associates 1995). The day tank was the sole supply to the generator. This day tank was manually supplied with fuel oil by transporting containers to the day tank.

Three $500 \mathrm{~kW}$ generators with a 275 gal day tank located on the south side of the building on the 7th floor were installed as part of the Mayor's OEM modifications (Swanke et al. 1998; McAllister 2002; Grill and Johnson 2005). The day tank was supplied from a single pump located on the first floor in the first floor fuel oil pump room. Fuel oil was pumped from a separate 6,000 gal tank located on the first floor (Swanke et al. 1998). This tank was supplied with fuel oil by the two 12,000 gal storage tanks installed as part of the base building installation (Swanke et al. 1998).

Six $1,725 \mathrm{~kW}$ generators in the north side of the fifth floor and three $1,725 \mathrm{~kW}$ generators in the southwest corner of the fifth floor were installed as part of the separate system for the Salomon Brothers (SB) addition (Swanke et al. 1998; Grill and Johnson 2005b). A day tank was not provided for these generators. These generators were supplied by a pressurized fuel oil loop on the fifth floor. The pressurized loop was supplied by two 6,000 gal storage tanks via a 75 gpm pump (Swanke et al. 1998; Grill and Johnson 2005b). The storage tanks were located under the loading births west of the two 12,000 gal storage tanks (Swanke et al. 1998; Grill and Johnson 2005b). The supply and return risers were located in a mechanical shaft in the southwest corner of the building (Swanke et al. 1998; Grill and Johnson 2005b).

The fire suppression protection varied for each component of the emergency power system. The major components, including fuel oil storage tanks, fuel oil pumps, distribution piping, day tanks, and generator rooms are included in Table 5-12. Table 5-12 provides a description of the fire suppression features provided in the area of each component. 
Table 5-12. Fuel oil equipment, WTC 7.

\begin{tabular}{|c|c|c|c|}
\hline Component & Location & Protection & Notes \\
\hline $\begin{array}{l}\text { Two } 12,000 \text { gal fuel oil } \\
\text { storage tanks } \\
\text { System: SP }\end{array}$ & $\begin{array}{l}\text { - Below first floor } \\
\text { loading berths } \\
\text {-South side adjacent to } \\
\text { Vesey Street. }\end{array}$ & $\begin{array}{l}\text {-The loading berths above } \\
\text { the tank locations were } \\
\text { protected by a dry pipe } \\
\text { automatic sprinkler } \\
\text { system. } \\
\text {-The design indicated the } \\
\text { area was protected by } \\
\text { Ordinary Hazard Group } 1 \\
\text { criteria (Swanke et al. } \\
\text { 1998) }\end{array}$ & $\begin{array}{l}\text {-The fuel oil tank fill } \\
\text { boxes were located in } \\
\text { front of the building } \\
\text { along Vesey Street. }\end{array}$ \\
\hline $\begin{array}{l}\text { Two } 6,000 \text { gal fuel oil } \\
\text { storage tanks } \\
\text { System: SB }\end{array}$ & $\begin{array}{l}\text {-Below first floor } \\
\text { loading berths, west of } \\
\text { two } 12,000 \text { gal storage } \\
\text { tanks } \\
\text {-South side adjacent to } \\
\text { Vesey Street }\end{array}$ & $\begin{array}{l}\text { - The loading berths above } \\
\text { the tank locations were } \\
\text { protected by a dry pipe } \\
\text { automatic sprinkler } \\
\text { system. } \\
\text { - The design indicated the } \\
\text { area was protected by } \\
\text { Ordinary Hazard Group } 1 \\
\text { criteria (Swanke et al. } \\
\text { 1998) }\end{array}$ & \\
\hline $\begin{array}{l}\text { One } 6,000 \text { gal fuel oil } \\
\text { storage tank } \\
\text { System: SP }\end{array}$ & $\begin{array}{l}\text {-1st floor } \\
\text {-Televator storage room } \\
\text {-North of loading dock }\end{array}$ & $\begin{array}{l}\text { - The room containing the } \\
\text { tank was protected by an } \\
\text { Inergen clean agent fire } \\
\text { protection system. } \\
\text { - The Televator storage } \\
\text { area below the tank was } \\
\text { protected by a wet pipe } \\
\text { automatic sprinkler system } \\
\text { (Swanke et al. 1998). }\end{array}$ & $\begin{array}{l}\text {-The tank was located on } \\
\text { a mezzanine } 8 \mathrm{ft} \text { above } \\
\text { the televator storage area } \\
\text { on the } 1 \text { st floor. } \\
\text {-The Inergen system was } \\
\text { to be actuated upon } \\
\text { initiation of the } 2 \text { heat } \\
\text { detectors at the ceiling } \\
\text { above the tank. }\end{array}$ \\
\hline $\begin{array}{l}\text { Multiple fuel oil pump sets } \\
\text { System: SP }\end{array}$ & $\begin{array}{l}\text {-1st floor } \\
\text {-Fuel oil pump room } \\
\text {-North of loading dock } \\
\text {-Accessed through rear } \\
\text { of loading dock }\end{array}$ & $\begin{array}{l}\text {-Fuel oil pump room was } \\
\text { protected by a dry pipe } \\
\text { automatic sprinkler system } \\
\text { (Emery et al. 1987). } \\
\text {-The design indicated the } \\
\text { area was protected by } \\
\text { Ordinary Hazard Group } 3 \\
\text { criteria }\end{array}$ & $\begin{array}{l}\text {-All pump sets for the } \\
\text { building were located in } \\
\text { this room } \\
\text { (GC Engineering 1998b). }\end{array}$ \\
\hline $\begin{array}{l}\text { Single fuel oil pump set } \\
\text { System: SB }\end{array}$ & $\begin{array}{l}\text {-1st floor } \\
\text {-Fire pump room } \\
\text {-West of loading dock }\end{array}$ & $\begin{array}{l}\text {-The fire pump room was } \\
\text { protected by a wet pipe } \\
\text { sprinkler system } \\
\text {-The design indicated the } \\
\text { area was protected by } \\
\text { Ordinary Hazard Group } 1 \\
\text { criteria }\end{array}$ & \\
\hline
\end{tabular}




\begin{tabular}{|c|c|c|c|}
\hline Component & Location & Protection & Notes \\
\hline $\begin{array}{l}\text { Piping between } 12,000 \mathrm{gal} \\
\text { storage tanks and } 6,000 \mathrm{gal} \\
\text { storage tank and pump sets } \\
\text { System: SP }\end{array}$ & $\begin{array}{l}\text {-Underground } \\
\text {-Adjacent to back wall of } \\
\text { loading dock }\end{array}$ & $\begin{array}{l}\text {-No suppression protection } \\
\text { (Swanke et al. 1998). }\end{array}$ & $\begin{array}{l}\text {-Piping was enclosed in } \\
\text { underground concrete } \\
\text { trench (GC Engineering } \\
1998 \text { ). } \\
\text {-Piping between } 6,000 \\
\text { gal tank and pump sets } \\
\text { was enclosed in } 2 \text { h fire } \\
\text { resistance rated } \\
\text { construction }\end{array}$ \\
\hline $\begin{array}{l}\text { Vertical piping from pump } \\
\text { sets to day tanks and } \\
\text { emergency generator sets } \\
\text { System: SP }\end{array}$ & $\begin{array}{l}-2 \text { vertical masonry } \\
\text { shafts } \\
\text {-Adjacent to each side of } \\
\text { the west elevator banks } \\
\text {-Approximately } 25-30 \mathrm{ft} \\
\text { back from the face of the } \\
\text { building along Vesey } \\
\text { Street }\end{array}$ & $\begin{array}{l}\text {-No suppression protection } \\
-2 \mathrm{~h} \text { fire resistance rated } \\
\text { construction } \\
\text { (Swanke et al. 1998). }\end{array}$ & $\begin{array}{l}\text {-Vertical piping } \\
\text { transporting fuel to } \\
\text { higher floors is only } \\
\text { located in these locations } \\
\text { through } 2 \mathrm{~h} \text { fire-resistant } \\
\text { rated shafts with } \\
\text { exception to the SB riser. }\end{array}$ \\
\hline $\begin{array}{l}\text { Vertical piping from pump } \\
\text { set to nine emergency } \\
\text { generator sets on fifth } \\
\text { floor } \\
\text { System: SB }\end{array}$ & $\begin{array}{l}\text {-Utility Shaft in south } \\
\text { west corner of building }\end{array}$ & $\begin{array}{l}\text {-No suppression protection } \\
\text { (Emery et al. 1987). }\end{array}$ & \\
\hline $\begin{array}{l}\text { Two generator sets and } \\
275 \text { gal day tank } \\
\text { System: SP }\end{array}$ & $\begin{array}{l}-5 \text { th floor } \\
\text {-Southwest corner of } \\
\text { building }\end{array}$ & $\begin{array}{l}\text {-No suppression protection } \\
\text { (Gensler Associates 1995; } \\
\text { Emery et al. 1987). }\end{array}$ & $\begin{array}{l}-5 \text { th floor was open to } \\
6 \text { th floor level in this } \\
\text { generator room. }\end{array}$ \\
\hline $\begin{array}{l}\text { Nine generator sets and } \\
\text { pressurized fuel oil loop } \\
\text { System: SB }\end{array}$ & $\begin{array}{l}-5 \text { th floor } \\
\text {-Loop supplied three } \\
\text { generators in the } \\
\text { southwest mechanical } \\
\text { room, two along the } \\
\text { north wall on the west } \\
\text { side of the building and } \\
\text { four along the north wall } \\
\text { on the east side of the } \\
\text { building }\end{array}$ & & \\
\hline $\begin{array}{l}\text { Three generator sets and } \\
275 \text { gal day tank } \\
\text { System: SP }\end{array}$ & $\begin{array}{l}\text {-7th floor } \\
\text {-South side of building } \\
\text { adjacent to Vesey Street }\end{array}$ & $\begin{array}{l}\text {-No suppression protection } \\
\text { (Swanke et al. 1998). }\end{array}$ & $\begin{array}{l}\text {-PANYNJ review } \\
(4 / 28 / 98) \text { of CD } \\
\text { submittal required } \\
\text { sprinkler protection in } \\
\text { proposed generator and } \\
\text { tank room (Item } 47) \\
\text { (PANYNJ 1998b). } \\
\end{array}$ \\
\hline $\begin{array}{l}\text { One generator set and } 275 \\
\text { gal day tank } \\
\text { System: SP }\end{array}$ & $\begin{array}{l}\text {-8th floor } \\
\text {-Along west wall of } \\
\text { building }\end{array}$ & $\begin{array}{l}\text {-Generator room provided } \\
\text { with sprinkler protection } \\
\text { (Gensler \& Associates } \\
\text { 1994). }\end{array}$ & $\begin{array}{l}\text {-Manual fill } \\
\text {-House fuel piping was } \\
\text { not connected to this } \\
\text { generator }\end{array}$ \\
\hline
\end{tabular}




\begin{tabular}{|c|c|c|c|}
\hline Component & Location & Protection & Notes \\
\hline $\begin{array}{l}\text { One generator set with self } \\
\text { contained } 50 \text { gal day tank } \\
\text { System: SP }\end{array}$ & $\begin{array}{l}-9 \text { th floor } \\
\text {-Along west wall of } \\
\text { building }\end{array}$ & $\begin{array}{l}\text {-Generator room provided } \\
\text { with sprinkler protection } \\
\text { (GC Engineering } 1998 \mathrm{~b} \text {; } \\
\text { Grill and Johnson } 2005 \mathrm{~b} \text { ). } \\
\text {-Floor protected with wet } \\
\text { pipe sprinkler system } \\
\text { designed to Light Hazard } \\
\text { occupancy criteria } \\
\text {-Unknown design criteria }\end{array}$ & $\begin{array}{l}\text {-Fuel oil piping extended } \\
\text { from the shaft location to } \\
\text { the generator room in the } \\
\text { northwest corner of the } \\
\text { building. }\end{array}$ \\
\hline
\end{tabular}

Source: Gensler Associates 1995; Swanke et al. 1998; Grill and Johnson 2005b; Emery et al. 1987; PANYNJ 1998b; McAllister 2002: GC Engineering 1998 b.

\subsection{DESIGN BASIS REVIEW}

As part of this task, an evaluation of the design basis for WTC 1,2, and 7 was performed. The intent of this evaluation was to determine if the installed fire protection systems in these three buildings were designed and installed in a manner consistent with performance expectations associated with applicable codes and standards as well as those related to recommended "best practices" at the time of the design and construction of the buildings. The evaluation was limited to the installation features associated with the fire suppression systems. A related hydraulic analysis was also performed as part of Task 2, the results of which are reported in Chapter 6.

This effort included evaluation of applicable design provisions and recommended best practices for the primary and secondary water supplies, the standpipes and pre-connected hoses, the automatic fire sprinkler systems, and the special suppression systems. Special suppression systems were located in WTC 7.

Applicable codes and standards associated with the design and installation of the fire protection systems in WTC 1 and WTC 2 included the following (Grill and Johnson 2005):

- $\quad$ Building Code of New York City, 1968

- Local Law No. 5, Fire Safety Requirement and Controls in Certain Office Buildings, January 18, 1973

- $\quad$ RS 17, Standard for Water Tanks for Private Fire Protection, NFPA 22 (1962 ed.), with modifications

- $\quad$ RS 17-1, Standpipe Construction

- RS 17-2, Standard for the Installation of Sprinkler Systems, NFPA 13 (1966 ed.), with modifications

- RS 17-3, Standard for the Installation of Fire Sprinkler, Standpipe, Smoke Detection, and other Alarm and Extinguishing Systems 
The construction of WTC 7 was completed in the mid-1980s. The primary codes and standards applicable to the design and construction of the fire suppression systems were similar to those for WTC 1 and WTC 2 with some exceptions. They included the following (Grill and Johnson 2005; 2005a):

- Building Code of New York City, 1986, with Amendments through January 1, 1985

- Local Law No 5 (same as for WTC 1 and WTC 2)

- Local Law No. 16, Local Laws of the City of New York for the Year 1984 (effective date immediately except as noted), March, 1984

- RS 17-1 (same as for WTC 1 and WTC 2)

- RS 17-2, Standard for the Installation of Sprinkler Systems, NFPA 13 (1982 edition), with modifications

- $\quad$ RS 17-3 (same as for WTC 1 and 2)

- NFPA 22, Standard for Water Tanks for Private Fire Protection (1981 edition)

Detailed descriptions of the installed fire suppression systems are provided in Sec. 5.2 and 5.3. The descriptions are based on an extensive rcview of background information and associated design drawings, building/tenant records and manufacturers literature made available through the NIST WTC investigation document files and related information in the open literature.

Based on review of available design and operations/maintenance documentation, the fire protection systems in WTC 1, 2, and 7 appeared for the most part to be installed in a manner consistent with state-ofthe-art bcst practices in existence at the time of their construction. A more detailed evaluation of specific performance aspects of the installed automatic sprinkler systems and the primary and secondary water supply systems that supplied them is presented in Chapter 6. The evaluation in Chapter 6 includes examination of factors such as the estimated xpected water spray density available to each sprinkler system, the sprinkler coverage areas used as part of the original design basis, and the occupancy hazard classification of the buildings, as well as other factors that could affect the performance of the systems.

Differences in related provisions of codes and standards that were applicable to the buildings resulted in some inconsistencies associated with the installed suppression systems. None of these inconsistencies were determined to result in the potential for degraded performance. For example, a provision in NFPA 13 required a $30 \mathrm{~min}$ stored volume primary water supply for the automatic fire sprinkler systems.

However, Local Law No. 5 had a provision that permitted a 20 min stored volume provided that a source was available to automatically refill the stored water tank or reservoir to maintain the primary water supply for an additional $10 \mathrm{~min}$. While the latter design was adopted, under the design conditions that existed the refill rate provided a continual water supply in excess of $30 \mathrm{~min}$. In fact, based on calculations presented in Chapter 6, the duration exceeded the $30 \mathrm{~min}$ period in all but a few locations without accounting for the refill rate to the stored water tanks. Therefore, while a minor inconsistency existed, the design of the sprinkler systems appears to have met or exceeded the performance expectations that existed at the time of construction of these three buildings. 


\subsection{SUMMARY-TASK 1}

There were several objectives associated with Task 1. Included were the following:

- Documentation of the fire suppression systems and related system infrastructures

- Identification of any special hazards suppression systems

- Description of particular suppression system features within the immediate initial impact areas in WTC 1 and WTC 2

- Assessment of the consistency of the system designs with applicable codes and standards provisions and state-of-the-art engineering "best practices" during the time of construction of the buildings

The following is a summary of Task 1 as related to these objectives.

\subsubsection{Fire Suppression Systems, WTC 1 and WTC 2}

The fire suppression systems in WTC 1 and WTC 2 included automatic sprinklcr systems, standpipe systems, the related infrastructures, and water supplies. The WTC complex had two basic water supply system infrastructures, one for the sprinkler systems and the other for the standpipc systems.

\section{Water Supplies}

The source of water for WTC 1 and WTC 2 was the NYC water distribution system (PANYNJ 1972, 1987a, 1987b; Beyler 2002). Each system infrastructure had two loops, one on the B1 lcvel and the other on the concourse level (PANYNJ 1972, 1987a, 1987b; Beyler 2002). All of the sprinkler and standpipc systems for the sub-grade levels and WTC 1 through WTC 6 were supplied by these loops. Two parallel (redundant) pumps were provided for each infrastructure (PANYNJ 1972, 1987a, 1987b; Beyler 2002). Twelve fire pumps and a single jockey pump were provided for the WTC complex (PANYNJ 1972, 1987a, 1987b; Beyler 2002).

Three $750 \mathrm{gpm}$ manual electric drive fire pumps were installed in series for each tower standpipe system (PANYNJ 1972, 1987b). Additionally, onc 500 gpm automatic clectric drive fire pump was provided for the sprinkler systems for the 99th through 107th floors and pre-connected hose stations for the 110th floor and the rooftops (PANYNJ 1972, 1987b).

Three 5,000 gal water storage tanks were provided in WTC 1 and WTC 2 with a total holding capacity of 15,000 gal for the standpipe systems in each building (PANYNJ 1972, 1987b). These tanks were located on the 41 st, 75 th, and 110 th floors. WTC 1 also contained a fourth tank located on the 20th floor (PANYNJ 1972, 1987b). Each building also had two additional 5,000 gal water storage tanks on the 110 th floor for the sprinkler systems (PANYNJ 1972, 1987b).

The WTC complex was provided with 14 separate fire department connection (FDC) stations (PANYNJ 1972, 1987b). A total of 32 siamese type FDCs were provided for the sprinkler and standpipe systems (PANYNJ 1972, 1987b). 


\section{Standpipe Systems}

The standpipe systems in WTC 1 and WTC 2 included four vertical water supply zones:

1. High (77th through the 110 th floors)

2. Upper mid-level (42nd through 76 th floors)

3. Lower mid-level ( 8 th through the 41 st floors)

4. Low (1st through 8 th floors and the sub-grade levels)

The standpipes were installed during the original construction of the buildings. Three $6 \mathrm{in}$. standpipe risers (FS-F1, FS-F2, and FS-F3) were provided within each zone (PANYNJ 1972, 1987b). Standpipe riser FS-F1 was used to supply water to the other two risers for the initial fire suppression efforts. Water was gravity supplied by the storage tanks to the pre-connected hose lines for the standpipe systems until the manual fire pumps were started or water was pumped into the system by the FDNY through one of the FDCs.

\section{Sprinkler Systems}

The wet pipe automatic sprinkler systems in WTC 1 and WCT 2 were separate from the sub-grade sprinkler systems (PANYNJ 1987a, 1987b). The sprinkler systems for the towers were configured such that each floor was provided with a separate system (PANYNJ 1987a, 1987b). However, these systems shared common infrastructures and water supplies. The sprinkler system infrastructure included two dedicated water storage tanks, three sprinkler risers (A, B, and C), and connections to the standpipe systems (PANYNJ 1987a, 1987b).

The high zone sprinkler riser (A) was equipped with a single automatic 500 gpm electric drive fire pump and supplied water to the sprinkler systems on the 99th through 110th floors (PANYNJ 1972, 1987a). The mid-level zone sprinkler risers (B) were gravity supplied with water from the water storage tanks located on the 110 th floors. The mid-level zone risers supplied the sprinkler systems on the 33rd through 98 th floors. The low zone sprinkler risers were gravity supplied with water from the storage tanks located in the 41 st/42nd floor mechanical room. Riser C supplied water to the sprinkler systems on the 1st through 32nd floors.

The sprinkler systems were installed in three phases. The sub-grade sprinkler systems were installed as part of the original construction (GC Engineering 1998). The second phase was completed in 1976 and included the retrofit installation of sprinkler risers and sprinkler systems for the core areas and select tenant spaces (GC Engineering 1998). The final phase included the installation of sprinkler systems throughout all tenant space areas and was completed from 1983 through early 2001 (GC Engineering 1998; PACO 2002). The sprinkler systems were designed and installed in accordance with the requirements of the $\mathrm{BCNYC}$, NFPA 13 and the PANYNJ requirements.

Sprinkler systems were not installed in the mechanical rooms on the 108th through 110th floors (GC Engineering 1998, PANYNJ 1987a). Local application deluge systems were provided for protection of 
the fan filters in the air-handling units. Sprinklers were omitted from electrical rooms that met specific criteria outlined for omission (PANYNJ 1987a, 2000b).

\section{Electrical Power Supply}

The primary electrical power supply for the WTC complex (including WTC 1 and WTC 2) was provided by the Consolidated Edison Company (Con-Ed) substation located in WTC 7 (Beyler 2002;

McAllister 2002). Separate feeders were independently routed from the main power distribution center to each tower (Beyler 2002).

The secondary power supply to fire pumps was provided by six emergency generators on the B6 level. Documentation of the secondary electrical system indicates that a single circuit supplied power to the manual fire pumps on the B1 level in both WTC 1 and WTC 2 (Beyler 2002).

\section{Special Hazards Suppression Systems}

Several types of special suppression systems were used in WTC 1 and WTC 2 (PANYNJ 1987b). These systems included (a) kitchen ventilation, dry chemical, and steam smothering systems, (b) carbon dioxide $\left(\mathrm{CO}_{2}\right)$ systems, and (c) Halon 1301 total flooding systems. These systems were supervised by the fire alarm systems in WTC 1 and WTC 2 and were designed to transmit signals to the FDNY upon activation.

The O\&M manual indicated that ventilation and grease extraction systems were installed in rcstaurant kitchens above fryers, griddles, ranges, boilers and ovens, but did not provide specific locations where these systems were installed in WTC 1 and WTC 2 (PANYNJ 1987b).

The O\&M manual indicated that steam smothering systems were installed in the kitchens at the following locations:

- PA Cafeteria

- The "Big Kitchen"

- The Sky Dive

- Windows on the World

- The New York State Cafeteria

- The Observation Deck

A total flooding $\mathrm{CO}_{2}$ system was used to protect the under floor space of a large computer room in WTC 2. There is reference to other systems at the WTC complex, but specific information regarding the locations of these systems was not found. The available drawings for WTC 1 show that two Halon 1301 systems were installed for protection of the computer room on the 70th floor. One system was installed for protection of the under floor space and the other for protection of the room (PANYNJ 1972, 1987b). 


\section{WTC 1, Floors 89 through 110}

The floors involved in the initial impact were essentially protected by wet pipe automatic sprinkler systems. The initial damage to the fire protection systems was most likely sustained on three floors (94 through 96) of WTC 1, within the initial impact area (McAllister et al. 2005). The area hit by the aircraft was within the high standpipe system zone. The high zone standpipe system in WTC 1 included all floors vertically between the 77 th and the 110 th floors. Three separate standpipes were installed, one in each stair enclosure (PANYNJ 1972, 1987b). Each standpipe supplied 21/2 in. hose valves with 21/2 in. by $1 \frac{1}{2}$ in. reducers and either a hose cabinet or hose rack. The water supply storage tanks were not located on the floors that incurred the initial impact damage (PANYNJ 1972, 1987b).

Two separate sprinkler risers supplied water to the sprinkler systems for floors 89 through 110 (PANYNJ 1972, 1987a). The high zone riser (riser A) was equipped with a single automatic $500 \mathrm{gpm}$ electric drive fire pump (PANYNJ 1972, 1987a). This riser supplied the high zone sprinkler systems on the 99th through 107th floors. Sprinkler systems were not installed in the mechanical rooms on the 108th through 110th floors (PANYNJ 1972, 1987a). Local application deluge systems were provided for protection of the fan filters in the air-handling units. The mid-level zone riser (riser B) gravity supplied water to the sprinkler systems on the 33 rd through 98 th floors.

The sprinkler systems on floors 89 through 110 each contained separate control valves and alarm switches (PANYNJ 1987a). Each sprinkler system was installed in a loop configuration (PANYNJ 1972, 1987a). The sprinkler systems were primarily designed for the protection of Light Hazard Occupancies. No information was found that indicated the presence of special fire suppression systems on floors 89 through 110 .

\section{WTC 2, Floors 74 through 90}

The fire protection systems in WTC 2 most likely sustained damage on the 78th through 81 st floors as a result of the initial impact (McAllister 2005). The area hit by the aircraft was within the high standpipe system zone. The high zone standpipe system in WTC 2 was basically the same as the system that was installed in WTC 1. The high zone standpipe system in WTC 2 included all floors vertically between the 77th and the 110th floors (PANYNJ 1972, 1987b).

Water was gravity supplied to the standpipes from the $5,000 \mathrm{gal}$ standpipe water storage tank on the 110 th floor in the initial operating mode (PANYNJ 1987b). The high and upper mid-level zones of the standpipe system were interconnected within the MER on the 75th and 76th floors. A 750 gpm manual fire pump was provided on the 75th floor (PANYNJ 1972, 1987b). This pump was connected in series with three manual fire pumps in WTC 2. These fire pumps were all manually operated and intended to provide water for manual fire suppression efforts. The standpipe system also provided a secondary water supply for the sprinkler systems.

The mid-level zone riser (riser B) gravity supplied water to the sprinkler systems on the 33rd through 98th floors. Therefore, all of the sprinkler systems on floors 74 through 90 were gravity supplied with water from riser B. The sprinkler systems on floors 74 through 90 each contained separate control valves and alarm switches. Each sprinkler system was installed in a loop configuration. The sprinkler systems were primarily designed for the protection of Light Hazard Occupancies. 
Sprinkler systems were not provided for the MERs on the 75th and 76th floors (PANYNJ 1987a). Local application deluge systems were provided for protection of the fan filters in the air handling units (PANYNJ 1987a, 1987b). No information was found that indicated the presence of other special fire suppression systems on floors 74 through 90.

\subsubsection{Fire Suppression Systems, WTC 7}

The fire suppression systems in WTC 7 also included automatic sprinkler systems, standpipe systems, the related infrastructures, and water supplies. The wet pipe sprinkler systems were designed and installed during construction in the mid 1980 s.

\section{Water Supplies}

The water supplies for WTC 7 included a direct connection to the NYC water distribution system, water storage tanks. fire pumps. and fire department connections (Syska \& Hennessy 1984; McAllister 2002; Beyler 2002). A single 500 gpm automatic electric drive fire pump and a 750 gpm manual electric drive fire pump located on the first floor supplied water to the lower 20 floors (Syska \& Hennessy 1984; McAllister 2002; Beyler 2002). Two water storage tanks with a fire protection water reserve capacity of 7,500 gal each were located on the 47th floor (Syska \& Hennessy 1984). These tanks supplied water to the upper floors (Syska \& Hennessy 1984). Check valves located on the 20th floor prevented the downward flow of water from the storage tanks to the standpipes and sprinkler systems in the low zone (refer to Fig. B-13) (Syska \& Hennessy 1984). A second 500 gpm automatic fire pump was located on the 46th floor (Syska \& Hennessy 1984). This pump was used to supply the high zone sprinkler and standpipe systems. The two fire pumps on the first floor were used to provide the secondary water supply for the upper levels of the building through the combined sprinkler and standpipe system infrastructure piping.

\section{Combined Standpipe and Sprinkler System Infrastructure}

The infrastructure for the automatic sprinkler systems was combined with the standpipe systems. It included nine vertical risers. WTC 7 was divided into three basic water supply zones:

\section{High \\ 2. Mid-level \\ 3. Low}

The high zone included two 6 in. standpipe risers (risers 7 and 9) and one 6 in. combined (riser 8) riser. These risers were interconnected on the 44 th floor and were supplied by the 500 gpm automatic fire pump located on the 46th floor. The mid-level zone included two 6 in. standpipe (risers 4 and 6 ) and one 6 in. combined (riser 5) riser. Water was gravity fed to these risers from the water storage tanks located on the 47 th floor. Riser 4 was used to supply water from the tank to the other two risers. The low zone also included two 6 in. standpipe risers (risers 1 and 3) and one 6 in. combined (riser 2) riser. The low zone standpipe/risers were not supplied by the stored water supply. 


\section{Sprinkler Systems}

The occupied areas in WTC 7 were protected by automatic sprinklers, with the exception of the electrical equipment areas (switchgear, networking, and switchboard rooms), generator rooms, and bathrooms. Sprinklers were not installed on most of the fifth floor nor on the seventh floor, which housed the OEM generators and fuel day tanks. A dry-pipe sprinkler system protected the first floor fuel storage tanks.

\section{Electrical Power Supply}

The primary electrical distribution system for WTC 7 was served by the Con-Ed power station located in WTC 7. The main building transformers for WTC 7 were located on the third floor. Power was distributed throughout the building via two main risers located on each end of the building core. The base building emergency power supply for WTC 7 was served from two $900 \mathrm{~kW}$ diesel generators located in the fifth floor generator room on the south side of the building facing the WTC complex. Three additional $500 \mathrm{~kW}$ diesel generators were retrofitted on the seventh floor 1998 for the OEM office on the 23rd floor.

\section{Special Hazards-Protection of the Fuel Oil System}

WTC 7 contained fuel oil powered generators located on the fifth, seventh, eighth, and ninth floors. Each generator set, with the exception of the generator on the eighth floor, was fueled via 275 gal day tanks located within the generator rooms (Swanke et al. 1998; GC Engineering 1998b; Grill and Johnson $2005 \mathrm{~b}$ ). The generator set on the eighth floor was manually filled. The day tanks were supplied with fuel oil by risers that extended from the first floor to the respective generator floor. The risers were located in two $2 \mathrm{~h}$ fire resistance rated shafts adjacent to the southeastern most elevators along Vesey Street (PANYNJ 2000a). The fuel oil was pumped to the day tanks from two $12,000 \mathrm{gal}$ and one $6,000 \mathrm{gal}$ fuel storage tanks. The fuel oil pump room was located on the first floor between the eastern most elevator shafts, behind the loading dock.

The fuel oil entering the day tank on the seventh floor was regulated by two high level switches. If the first switch failed to shut down the pump then the second switch would remain open and close the solenoid valve on the line entering the day tank as well as shut down the pump.

The loading berth and fuel oil pump rooms were protected by dry-pipe sprinkler systems. The room containing the tank was protected by an Inergen clean agent fire suppression system. The elevator storage area beneath the tank was protected by a wet pipe sprinkler system.

\subsubsection{Consistency of Suppression System Designs with State-of-the-Art Engineering "Best Practices"}

An evaluation of the consistency of the suppression system designs with applicable codes and standards provisions and state-of-the-art engineering "best practices" during the time of construction of the buildings was performed for WTC 1,2 , and 7 . The intent of this evaluation was to determine if the installed fire protection systems in these three buildings were designed in a manner consistent with performance expectations associated with applicable codes and standards as well as those related to recommended best practices at the time of the design and construction of the buildings. The evaluation was limited to the installation features associated with the fire suppression systems. The results of this 
evaluation indicated that the fire protection systems in WTC 1,2, and 7 were for the most part installed in a manner consistent with the state-of-the-art best practices in existence at the time of their construction. Several exceptions to this were identified, but none of the exceptions would have specifically affected the performance of the suppression systems under the impact effects that occurred on September 11, 2001. 
This page intentionally left blank. 


\section{Chapter 6 \\ TASK 2: EVALUATION OF THE FIRE SPRINKLER WATER SUPPLIES}

\subsection{GENERAL}

The objective of Task 2 was to document the design and capacity of the water supply system to the automatic fire sprinkler systems in World Trade Center (WTC) 1, 2 and 7, including supply system redundancies. Of particular interest were the capacity and duration of the water flow to the automatic fire sprinkler systems for normal operational conditions. Attention was also given to the role of system redundancies, including fire department capabilities, in supporting demand for water supply.

A detailed review of available information was performed in order to document the water supply infrastructure. The capacity of the water supply system was evaluated based on the available water flow "density" and duration to the automatic fire sprinkler systems under what would be considered normally expected conditions. These two parameters are the primary water supply factors associated with expected performance of control type automatic fire sprinklers. Finally, based on review of available drawings and information, key water supply redundancies were documented.

Selected information and results are summarized in this chapter. Extensive reference is made to detailed drawings located in Appendix B. The results documented in this chapter were input for analyses in Chapters 8 and 9 .

\subsection{DESCRIPTION OF THE NEW YORK CITY WATER SUPPLY}

The primary source of water for the WTC complex was the New York City (NYC) water supply and distribution system. This system is operated by the New York City Department of Environmental Protection (NYC DEP). Two separate divisions (bureaus) of the DEP are responsible for the water supply and distribution system. The Bureau of Water Supply (BWS) and the Bureau of Water and Sewer Operations (BWSO) (LZA Technology 2002).

The BWS manages and operates three separate "upstate" reservoir systems, which supply approximately 1.1 to 1.2 billion gal of water a day to New York City. The reservoir systems are known as the Catskill, Delaware, and Croton watersheds. The reservoir systems are composed of 19 reservoirs (watersheds) and three controlled lakes with an approximate combined storage capacity of 580 billion gal. A series of interconnections are provided between the three reservoir watcr collection systems to permit water to be transferred between the systems. This increases the flexibility in the use and operation of these systems by controlling localized flooding and droughts (LZA Technology 2002; Beyler 2002).

The watersheds supply water to the NYC water distribution system through three scparate transmission mains (aqueducts). Accordingly, these are referred to as the Catskill, Delaware, and Croton aqueducts. In the normal operating mode, approximately 95 percent of the supplied water is by gravity flow and 5 percent by pump systems. This provides a reliable water supply that is only minimally affected by power outages. However, additional pumping is required during drought conditions (Beyler 2002). 
The BWSO is responsible for the operation and maintenance of the NYC water distribution system. The water transmission mains provide water to the NYC distribution system within a narrow pressure range controlled by multiple pressure reducing stations (valves). The pressure reducing valves maintain an approximate average steady state pressure of 50 psi (Beyler 2002).

The NYC DEP is responsible for regulation of the pressure and flow throughout the NYC water distribution system (Beyler 2002). Information reported at the 14th Street pressure regulators on September 11,2001, from 6:40 a.m. and 11:50 a.m. was reported by Hoffer and is provided in Table 6-1. The data in Table 6-1 demonstrate stability of the water supply throughout the morning of September 11, 2001, while manual and automatic fire suppression systems were in operation at the WTC complex.

Table 6-1. Average water pressure observed at the 14th Street regulators.

\begin{tabular}{|l|l|c|}
\hline Aqueduct - 14th Street & \multicolumn{1}{|c|}{ Regulator Identification } & $\begin{array}{c}\text { Average Steady State Pressure } \\
\text { 6:40 a.m. to 11:50 a.m., } \\
\text { September 11, 2001 }\end{array}$ \\
\hline Tunnel No.1, Shaft 18 & SE Regulator: \#1 Pressure & $51 \mathrm{psi}$ \\
\hline Tunnel No.1, Shaft 18 & SW Regulator: \#2 Pressure & $44 \mathrm{psi}$ \\
\hline Tunnel No.1, Shaft 18 & NW Regulator: \#3 Pressure & $50 \mathrm{psi}$ \\
\hline Tunnel No.1, Shaft 19 & Regulator & $49 \mathrm{psi}$ \\
\hline Tunnel No.1, Shaft 20 & SE Regulator & $50 \mathrm{psi}$ \\
\hline Tunnel No.1, Shaft 20 & NE Regulator & $53 \mathrm{psi}$ \\
\hline Tunnel No.1, Shaft 20 & NW Regulator & $50 \mathrm{psi}$ \\
\hline Tunnel No.1, Shaft 21 & Channel 3 & $60 \mathrm{psi}$ \\
\hline
\end{tabular}

Source: Beyler 2002; Hoffer 2002.

The NYC water distribution system in lower Manhattan surrounding the WTC complex is composed of a complex gridded network of $20 \mathrm{in}$. and 12 in. ductile iron mains. Figure 6-1 provides a representation of the water distribution systcm surrounding the WTC complcx. A $20 \mathrm{in}$. loop was located beneath the streets surrounding the WTC plaza where towers WTC 1 and WTC 2 were located. The mains were beneath Vesey Street to the north, Liberty to the south, Church Street to the east, and West Street to the west. These mains were inter-connected to a series of $20 \mathrm{in}$. and $12 \mathrm{in.} \mathrm{mains,} \mathrm{which} \mathrm{permitted} \mathrm{water} \mathrm{to}$ flow along a large number of flow paths, minimizing the effects of friction loss while flowing a large volume of water. The large volume of water within the distribution system mains, transmission mains, and at the source (watersheds in upstate New York) allowed for a large capacity of water to be available for firefighting capabilities (Bcyler 2002).

A 20 in. main was located beneath West Broadway immediately to the east of WTC 7. This main supplied water to the $20 \mathrm{in.} \mathrm{loop} \mathrm{around} \mathrm{the} \mathrm{WTC} \mathrm{plaza.} \mathrm{A} 12$ in. main to the west of WTC 7, beneath Washington, supplied two parallel 8 in. lead-ins (feeders) for WTC 7 and connected to a 12 in. main at the north side of WTC 7 beneath Barclay and the 20 in. main beneath Vesey. The 12 in. main on Barclay increased to $20 \mathrm{in}$. diameter near the center of WTC 7 at Greenwich and interconnected to the $20 \mathrm{in}$. main on West Broadway. A 12 in. and a separate 20 in. parallel main connected to the 20 in. main on Barclay and continued to the north on Greenwich (Beyler 2002). 

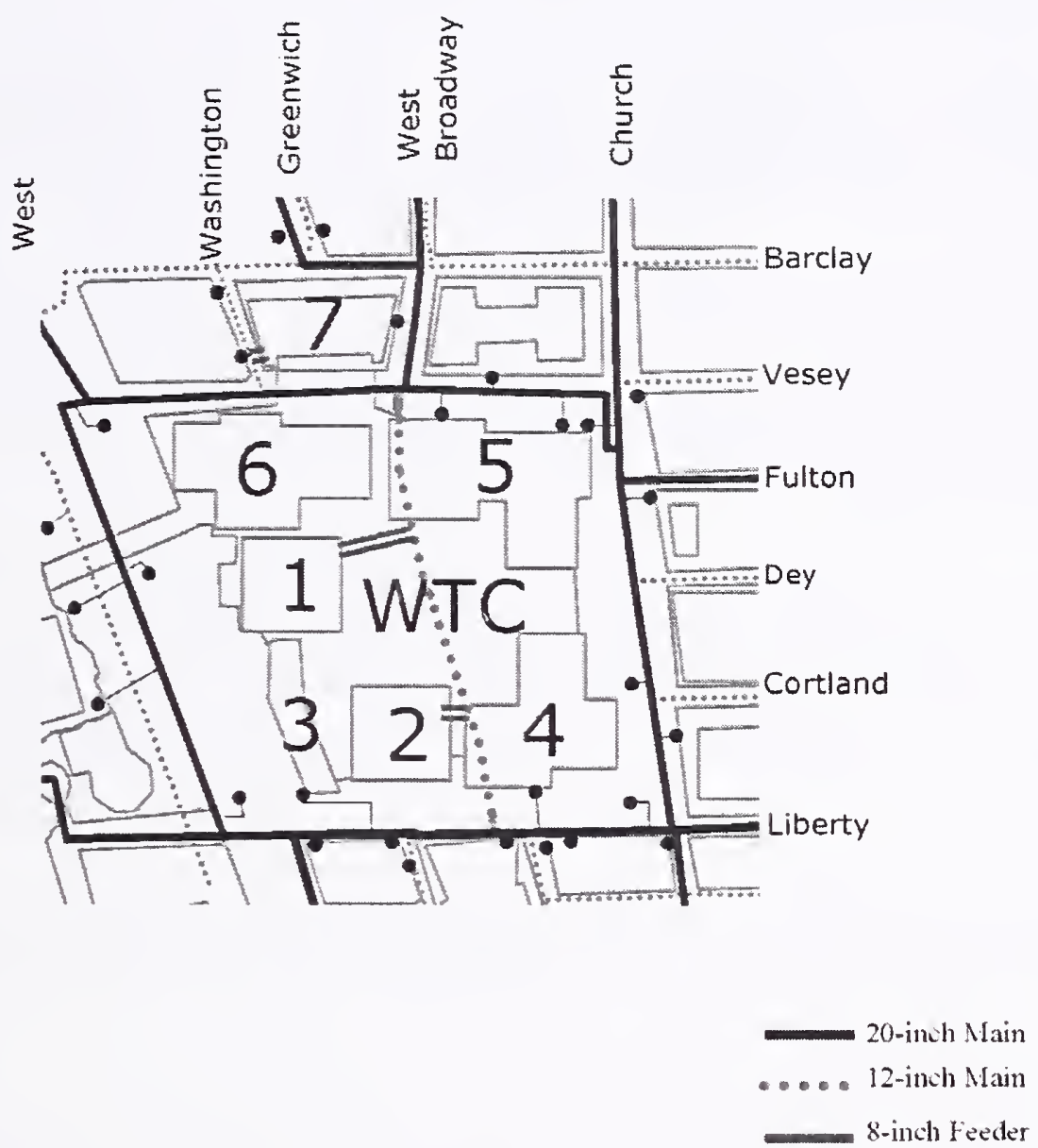

Source: Beyler 2002. Reproduced with permission of Silverstein Properties, Inc.

Figure 6-1. Municipal water distribution system surrounding WTC complex.

This arrangement of the water distribution system provides a near constant pressure for all flows that are normally anticipated for fire protection system demands i.e., the water supply provides a residual pressure that is nearly identical to the static pressure. Information provided by Beyler indicated that standard practice is to flow 500 to $750 \mathrm{gpm}$. Such flows typically would not cause a recognizable drop in the system pressure (Beyler 2002).

Based on review of documented water supply tests and related data, the following assumptions were used regarding the city water supply in performing the hydraulic calculations which served as the basis for evaluation of the water supply and the suppression systems:

- Static pressure: 50 psi

- Residual pressure: 11 psi

- Residual flow: 150,000 gpm 


\subsection{EVALUATION OF SPRINKLER SYSTEMS FLOW CAPACITY AND DURATION}

Hydraulic calculations were performed to evaluate the expected sprinkler system performance based on the configuration of the water supplies. The objective of the analysis was to determine any variations in the performance of the sprinkler systems in each building and within each water supply zone. The systems were primarily gravity fed. A group of sprinkler systems from each building was selected for analysis. Sprinkler systems near the top and the bottom of each water supply zone were selected to bound the effects of elevation on the performance of these sprinkler systems. In some cases, intermediate systems were also selected for evaluation because the arrangements of the systems varied as a result of using outside screw and yoke (OS\&Y) or pressure reducing type control valves. A commercial computer program, Hydraulic Analyzer of Sprinkler Systems (HASS), version 7.5, was used to perform the calculations (HRS 2004).

Several factors were examined as part of this analysis. Supply calculations were used as a means to compare the flow rate of water delivered from the primary and secondary supplies to the sprinkler systems. Calculations were performed for the highest and lowest floor level sprinkler systems to observe the effects of elevation on the discharge density of the sprinkler systems and water supply duration (i.e., how long the flow could be maintained). Calculations were also performed with variations in the number of sprinklers flowing water. The intent of this analysis was to provide sufficient information to characterize the capabilities of the water supplies.

As part of this task, redundancies in the water supply infrastructure to the sprinkler and standpipe systems were identified. The redundancies included both automatic and manually operated features of the systems.

\subsubsection{Methodology}

Hydraulic calculations are routinely used to characterize water flow through a pipe network, such as a sprinkler, standpipe, or water distribution system. Such calculations are typically conducted for design or analysis. As such, there are two types of hydraulic calculations that are used to evaluate sprinkler systems: demand calculations and supply calculations.

Demand calculations are used in the design of sprinkler systems to verify that minimum defined pressure and flow are provided to all sprinklers included in a defined design area. Sprinkler systems typically use the occupancy hazard fire control method as described in National Fire Protection Association (NFPA) 13, Standard for the Installation of Sprinkler Systems (NFPA 2002). Sprinkler systems designed or analyzed using the occupancy hazard fire control method are based on criteria specified for the particular occupancy hazard group contained within the building or building area. This methodology has existed in NFPA 13 for some time, including the periods when the sprinkler systems were designed for WTC 1,2, and 7. Refer to Chapter 3 for a more detailed discussion of the occupancy hazard fire control design method.

For a demand calculation, the minimum performance requirements are defined in terms of an application or discharge density and a minimum design area as required by NFPA 13 or in this case the PANYNJ (which adopted NFPA 13 with modifications) (PANYNJ 2000b). The application or discharge density refers to a water flow rate over a unit area. For example, the design of a sprinkler system in an office area 
classified as a Light Hazard Occupancy according to the occupancy hazard fire control method is required to discharge $0.1 \mathrm{gpm} / \mathrm{ft}^{2}$ over a design area of $1,500 \mathrm{ft}^{2}$. The spacing and coverage area per sprinkler dictates the number of sprinklers required to be included in the hydraulic calculations. The minimum number of sprinklers is determined by dividing the design area by the coverage area per sprinkler. A sprinkler system with branchlines spaced at $14 \mathrm{ft}$ on center and sprinklers spaced at $14 \mathrm{ft}$ on center along each branchline would require eight sprinklers. The coverage area per sprinkler would be $196 \mathrm{ft}^{2}$ $(14 \mathrm{ft}$. by $14 \mathrm{ft})$. The number of sprinklers is determined by dividing the design area $\left(1,500 \mathrm{ft}^{2}\right)$ by the coverage area per sprinkler $\left(196 \mathrm{ft}^{2}\right)$.

Water density $\left(\mathrm{gpm} / \mathrm{ft}^{2}\right)$ is used to specify the minimum flow rate to be discharged from an individual sprinkler in order to achieve adequate fire control for a particular hazard (NFPA 2002). In demand calculations, the minimum design density is specified for the group of sprinklers within the design area. Each sprinkler in the design area is required to flow sufficient water at sufficient pressure to provide the required discharge density. In the case of a Light Hazard Occupancy with sprinklers spaced at $196 \mathrm{ft}^{2}$ per sprinkler, a flow of 19.6 gpm would be required (NFPA 2002).

The defined flow also results in a minimum required pressure based on the orifice diameter and resulting $\mathrm{k}$-factor for the sprinkler (NFPA 2002; COte 2003). However the actual amount of water (flow)

discharged from each individual sprinkler is directly related to system pressure at the sprinkler orifice and varies from sprinkler to sprinkler.

The required pressure is determined by the equation (NFPA 2002; Cote 2003):

$$
Q=k \sqrt{p}
$$

where:

$$
\begin{aligned}
& Q=\text { flow }, \mathrm{gpm} \\
& k=\text { constant }, \mathrm{gpm} / \mathrm{psi}^{1 / 2} \\
& p=\text { pressure }, \mathrm{psi}
\end{aligned}
$$

The flow rate $\mathrm{Q}$ is equal to a constant, $\mathrm{k}$, times the square root of the pressure (NFPA 2002; Cote 2003). The constant, or $\mathrm{k}$-factor, is related to the orifice size (diameter) of the individual sprinkler installed. The Port Authority of New York and New Jersey (PANYNJ) guideline specifications indicated the use of Reliable Automatic Sprinkler Corporation of America. Inc. (RASCO) model G standard spray sprinklers (PANYNJ 2000b). The $\mathrm{k}$-factor for this sprinkler is $\mathrm{k}=5.6 \mathrm{gpm} / \mathrm{psi}^{i / 2}$ for a typical $1 / 2 \mathrm{in}$. diameter sprinkler. The flow rate from the sprinkler equals the $\mathrm{k}$-factor times the square root of the minimum required pressure. The end sprinkler condition is defined as the greater of the flow associated with a minimum operating pressure of $7 \mathrm{psi}$, or the flow associated with the density times the sprinkler coverage area (NFPA 2002; Cote 2003).

The required flow and pressure at the most remote sprinkler are referred to as the "end sprinkler conditions" and ensure that the system is capable of providing the specified discharge density over the entire design area. The end sprinkler conditions are used as the starting point in demand calculations (NFPA 2002). By multiplying the discharge density by the design area, the minimum required flow rate 
can be determined. The flow rate in part defines the sprinkler system demand. The pressure or energy to overcome elevation and pressure loss through the sprinkler system, while flowing water defines the other component of the sprinkler system demand.

The flow of water through a length of pipe results in pressure loss due to friction (Cote 2003). An empirical relationship known as the Hazen-Williams formula was derived based on a series of laboratory tests to account for this pressure or friction loss (NFPA 2002; Cote 2003). The equation is expressed as follows (NFPA 2002; Cote 2003):

$$
p_{f l}=4.52 \frac{Q^{1.85}}{C^{1.85} d^{4.87}}
$$

where:

$$
\begin{aligned}
& p_{n}=\text { pressure loss due to friction, } \mathrm{psi} / \mathrm{ft} \\
& Q=\text { flow }, \mathrm{gpm} \\
& C=\text { constant } \\
& d=\text { inside diameter of pipe, inches }
\end{aligned}
$$

For a demand calculation, the pressure and water flow required to meet the end system conditions is related back to the sprinkler system supply (NFPA 2002; Cote 2003). At this point, a comparison of the sprinkler system demand and the water supply indicates whether the system is capable of providing the minimum required discharge density for the design area. This is shown graphically in Fig. B-18. If the sprinkler system demand is at or below the water supply on the graph, then the sprinkler system design and water supply are adequate to provide the minimum required discharge density for the design area. If the sprinkler system demand is above the water supply curve then the minimum discharge density is not provided, and a pump, water tank, or other provisions must be provided in order to meet the sprinkler system demand conditions.

For a "supply" calculation, the water supply and sprinkler system configuration are given. The water flow from the supply is relayed forward through the system, overcoming the pressure losses due to friction and elevation, until the water discharges from the designated sprinklers. Supply calculations are used to show the actual or maximum discharge density that the water supply is capable of delivering to the sprinkler system. Good practice in the design of sprinkler systems is to provide a margin of safety between the sprinkler system demand and the water supply (Cote 2003).

The margin of safety is usually a fixed percentage of the static pressure, such as 10 percent or 20 percent, or, the margin of safety can be defined as a fixed pressure, such as 10 psi or 20 psi. A margin of safety can be used to account for variations in a water supply, such as tanks with large changes in water level or seasonal or daily fluctuations in a water supply. These effects would not have been likely in the systems at the WTC buildings. However, a margin of safety is also included to account for modifications to systems and the addition of fittings and extra pipe that might be necessary to accommodate field installation conditions, which would have been common for tenant fit-outs. 
The difference between the required discharge density and actual delivered discharge density is a direct indication of the margin of safety between the sprinkler system demand and the water supply curve. Supply calculations do not include "end sprinkler conditions." Therefore, the user must interpret whether the minimum required discharge density is provided by the sprinkler system with the selected water supply. In supply calculations, the required design density, is used as a benchmark relative to the actual flow rate per unit area delivered by the system. If the delivered density is greater than the required design density then the system meets the requirements of the occupancy hazard fire control approach specified in NFPA 13. Since the objective of Task 2 was to evaluate the performance of the sprinkler systems water supply, these calculations were performed.

\subsubsection{Approach}

Hydraulic calculations using the supply calculation approach were used to analyze the capacity of the water supply to the sprinkler systems in WTC 1,2, and 7. It was considered impractical to perform hydraulic calculations for every floor and every subsystem. Therefore, representative system configurations were selected to represent conditions within each water supply zone. Configurations were chosen to provide bounding results (in terms of available pressure, flow, and duration) for each vertical hydraulic zone in the buildings.

This approach limited the number of cases to a manageable level and at the same time provided representative results applicable to any location in the buildings. The results also provided the baseline information needed to evaluate the performance capabilities of the sprinkler systems. The calculations were based on the following bounding conditions for each vertical zone:

- Water supply

- Primary-water storage tanks and/or automatic fire pumps

- Secondary-manual fire pumps or water storage tanks

- Number of operating (opened) sprinklers

- 4 sprinklers-smaller than the required design area

- 8 to 15 sprinklers-design area for Light or Ordinary Hazard Occupancy

- $\quad 18$ to 25 sprinklers-larger than the required design area

- Floor level within the vertical zone

- WTC 1 and WTC 2

- 107 th floor (highest floor system in high water supply zone)

- 99 th floor (lowest floor system in high water supply zone)

- 98 th floor (highest floor system in mid-level water supply zone) 
- 87 th floor (lowest floor system in mid-level water supply zone without a PRV)

- 86th floor (highest floor system in mid-level water supply zone with a PRV)

- 32 nd floor (lowest floor system in mid-level water supply zone with a PRV)

- 31 st floor (highest floor system in low water supply zone)

- 9th floor (lowest floor system in low water supply zone without a PRV)

- 7th floor (highest floor system in low water supply zone with a PRV)

- 2nd floor (lowest floor system in low water supply zone with a PRV)

- WTC 7

- 47 th floor (highest floor system in high water supply zone)

- 40th floor (lowest floor system in high water supply zone)

- 39 th floor (highest floor system in mid-level water supply zone)

- 21 st floor (lowest floor system in mid-level water supply zone)

- 20th floor (highest floor system in low water supply zone)

- 1st floor (lowest floor system in low water supply zone)

Each combination of the conditions was used to develop supply calculations. The supply calculations provided estimates of the actual water flow rate and pressure that would be expected based on typical sprinkler system arrangements. The duration was determined by dividing the storage capacity by the calculated flow rate. The calculations did not account for the supplemental make-up supplies from the automatic re-fill lines supplied by the domestic water supply systems. The results of these calculations were intended to approximate the actual delivered discharge densities based on representative sprinkler system layouts provided from the available documentation of the systems. The results are considered to more accurately represent the actual performance as compared to using the minimum required flow rates determined by multiplying the density times the design area specified by NFPA 13 for the applicable hazard.

Calculations for the sprinkler systems in WTC 1 and WTC 2 were performed for several different coverage areas based on the available documentation for the systems. The calculations for Light Hazard areas in WTC 7 used a coverage area of $168 \mathrm{ft}^{2}$. The calculations for all systems used $\mathrm{k}=5.6 \mathrm{gpm} / \mathrm{psi}^{1 / 2}$, $1 / 2$ in. orifice sprinklers.

\subsection{WTC 1 AND WTC 2}

The sprinkler systems on floors 99 through 107 in WTC 1 and WTC 2 comprised the high zone and shared a common riser and water supply. These systems were supplied with water from the reserve 
storage tanks located on the 110 th floor. Figure B-19 provides a representation of the water storage tanks and the feed main that supplied water to the top of riser A. Positive suction pressure was provided to a single shared booster pump located on the 108th floor, which supplied riser A and the high zone sprinklcr systems. Figure B-20 illustrates the path of water flow from the water storage tanks at calculation node AST to the floor control assemblies (FCA) at the 107th and 99th floors (PANYNJ 1972).

Hydraulic calculations were performed for the sprinkler systems on the 107th and 99th floors of WTC 1. These systems represented the bounding conditions for the high zone water supply with sprinkler systems designed for the protection of Light Hazard Occupancies.

\subsubsection{Floor System Layout, WTC 1, Floor 107}

The sprinkler system layout for the restaurant located on the 107th floor was documented in a series of four drawings. Therefore, the drawings were used to lay out the hydraulic nodes used to represent that sprinkler system for the hydraulic analysis. The drawings are included as Figs. B-21 through B-24 and show the portions of the sprinkler system in the Northwest (NW), Northeast (NE), Southeast (SE), and Southwest (SW) quadrants of WTC 1, respectively.

The water supply to the sprinkler system was composed of a 4 in. diameter feed main connected to riser A at node A107 and to the FCA at node FM. Node FM to FCA included a 21/2 in. diameter floor control assembly comprised of a control valve, vane-type water flow switch, and drain assembly as depicted in Fig. 5-6. A check valve was also included in the calculations although not shown in Fig. 5-6.

The floor level sprinkler system was a 2 in. diameter looped main with 2 in. interior cross connections, except where a $2 \frac{1}{2}$ in. diameter main connected calculation node FCA to calculation node M1. The mains are identified as nodes M1 through M9. A series of tree (dead-end) branchlines extended to the interior of the loop and outward toward the exterior walls of the building. Ten branchlines werc included in the system layout. The configuration of the branchlines varied throughout the system and included $1 \mathrm{in}$. through 2 in. diameter pipes. Nodes B 1 through B4 and B 11 through B15 were used to represent the hydraulic nodes at the supply points to the branchlines from the looped $2 \mathrm{in}$. cross-mains.

The branchlines were identified using $\mathrm{L}$ and $\mathrm{S}$ nodes to represent tees and sprinklers, rcspectively, along each branchline. The average spacing per sprinkler was $101 / 2 \mathrm{ft}$ by $12 \mathrm{ft}$, resulting in an average coverage area of $126 \mathrm{ft}^{2}$ per sprinkler. Note that the spacing of sprinklers in other areas of the system varied somewhat from this arrangement.

\subsubsection{Floor System Layout, WTC 2, Floor 107}

The 107 th floor sprinkler system in WTC 2 was significantly different than the WTC 1 systcm due to the location of an observatory on this floor in WTC 2. The fire sprinkler system was designed using the requirements for an Ordinary Hazard Group 1 Occupancy. Figures B-25 through B-28 depict the sprinkler system for the 107 th floor in WTC 2 using quadrants similar to the layout of the system in WTC 1. The NW quadrant drawing indicated that the system was designed to provide a discharge density of $0.16 \mathrm{gpm} / \mathrm{ft}^{2}$ over a design area of $1,500 \mathrm{ft}^{2}$ (PANYNJ 1972). 
The water supply to the sprinkler system used a $3 \mathrm{in}$. feed main and floor control assembly that supplied a $2 \frac{1}{2}$ in. looped cross-main. Branchlines extended to the floor area inside of the looped cross-main and outward toward the exterior walls of the building. Sprinklers were spaced at approximately $14 \mathrm{ft}$ by $81 / 2 \mathrm{ft}$ on center, resulting in an average coverage area of $119 \mathrm{ft}^{2}$ per sprinkler. However, the sprinklers closest to the exterior wall were located less than one-half the spacing between sprinklers along a branchline, rcquiring additional sprinklers to be included in the application (design) area. A total of 18 sprinklers were required in the approximate $1,500 \mathrm{ft}^{2}$ design area. Although dividing the application area by the number of sprinklers results in actual average coverage area of $83 \mathrm{ft}^{2}$, a coverage area of $119 \mathrm{ft}^{2}$ per sprinkler was used in this analysis. The sprinklers at the end of the branchlines flow water as if these sprinklers are protecting additional area beyond the exterior walls. This is referred to as a "phantom area" and is accountable for the additional five sprinklers that are required in the design area.

The nodes for this system were labeled in a similar manner as the system for WTC 1 . The nodes for the mains were designated using $\mathrm{M} \#$ nodes; the numbers for the supply point for the branchlines at the crossmains were designated using B\#; and the sprinklers and tees were designated using S and L, respectively.

\subsubsection{Representative System Layout for all Other Floors}

Accurate layouts of the systems for the 99th floor were not found in the documents associated with the literature review. Therefore, representative system layouts were designed using information from a number of different drawings (PANYNJ 1972). This approach resulted in prototype designs for the analysis that were not necessarily exact replications of the systems that were present in WTC 1 or WTC 2. However, the representative design layouts were adequate to accurately evaluate the capacity and duration available from the water supply.

The riser locations, layout for the feed mains and the cross-mains, in the core area were taken from PANYNJ drawings SP-4 through SP-8. The location and configuration of the floor control valve assemblies are shown on drawings SP-19 and SP-20. Figures B-29 through B-31 show the typical riser locations and core layouts for the high, mid-level, and low zone systems.

The layout for the $2 \frac{1}{2} \mathrm{in}$. looped cross-main was identified and located on drawings SP-13 and SP-14 for the 78th floor systems in WTC 1 and WTC 2 respectively. The typical arrangement of $2 \frac{1}{2} \mathrm{in}$. looped cross-main is shown in Fig. B-32.

The layout for a typical Ordinary Hazard system was taken from drawing SP-12, showing a partial system layout for the 44th floor system. This drawing shows a grid system configuration with 1-1/4 in. branchlines and a far grid main near the exterior wall. Each branchline also contained a single outrigger sprinkler on a 1 in. branchline pipe. Figure B-33 shows the typical grid sprinkler system layout. Spacing of 13-1/4 ft between branchlines and $9 \mathrm{ft}$ between sprinklers along a branchline were used for the calculations. This resulted in an average coverage area of $119 \mathrm{ft}^{2}$ per sprinkler. A total of 15 sprinklers were included in the design area based on the actual configuration observed on the drawing. Again, the end sprinklers were located approximately $1 \mathrm{ft}$ to $2 \mathrm{ft}$ from the exterior wall, resulting in a phantom area.

The layout for a Light Hazard system was derived from the Ordinary Hazard system layout. The branchlines wcre changed to $1 \mathrm{in}$. diameter pipe, and the far grid cross-main was removed from the system. This created a loop system with tree type branchlines extended outward from the $2 \frac{1}{2}$ in. cross- 
main toward the exterior walls and inward toward the core. The sprinkler along each branchline that was closest to the cross-main was increased to 1-1/4 in. pipe for hydraulic calculations for the 98th, 86th, 7th and 31 st floor system calculations. These systems were the upper floors in the respective zones or the highest floors with pressure reducing valves.

A case was examined with a sprinkler spacing of $12 \mathrm{ft}$ between branchlines and $14 \mathrm{ft}$ between sprinklers along a branchline. This resulted in an average coverage area of $168 \mathrm{ft}^{2}$ per sprinkler. Nine sprinklers were included in the $1,512 \mathrm{ft}^{2}$ design area. However, this arrangement did not provide results that represented the performance of typical sprinkler systems designed to protect a Light Hazard Occupancy. Therefore, a sprinkler spacing of $14 \mathrm{ft}$ between branchlines and $14 \mathrm{ft}$ between sprinklers along a branchline was examined for use in the calculations. This resulted in an average coverage area of $196 \mathrm{ft}^{2}$ per sprinkler. Eight sprinklers were included in the application area for a total of $1,568 \mathrm{ft}^{2}$ as the baseline case for each floor level sprinkler system. The results of the calculations using this arrangement were considered to represent a typical sprinkler system designed to protect a Light Hazard Occupancy. Therefore, the $14 \mathrm{ft}$ by $14 \mathrm{ft}$ sprinkler spacing was used in the hydraulic calculations for the Light Hazard scenarios.

\subsubsection{High Zone}

The hydraulic analysis of the high zone sprinkler systems includcd an assessment of the sprinkler systems on the 107th floor and the 99th floor of WTC 1 using the requirements outlined above for Light Hazard Occupancies. Additional hydraulic calculations were performed for the 107th floor system of WTC 2, which used the criteria for an Ordinary Hazard Group 1 Occupancy as outlined above. The sprinkler system layout for the 99th floor of WTC 1 was modified to represent a sprinklcr system designed in accordance with an Ordinary Hazard Occupancy for comparative purposes.

The hydraulic analysis was also performed using the supply calculation conditions. A series of demand calculations were performed for the 107th floor system of WTC 1 to demonstrate the differences in the supply and demand calculations.

Calculations were performed with the number of sprinklers considered to represent the actual design application areas for the systems. Additional calculations were performed to examine the change in system performance with less than the requircd number of sprinklers and with more than the required number of sprinklers. These calculations were conducted for four different cases involving the sprinkler systems on the 107th and 99th floors using Light or Ordinary Hazard Group 1 conditions.

Additional hydraulic calculations were then performed to evaluate the operation of the sprinkler systems for the four cases using the required number of design sprinklers. The results of these calculations were used to compare the differences in the performance of the sprinkler systems using the primary and secondary water supplies.

The primary water supply for the high zone sprinkler systems included two 5,000 gal sprinkler reserve water storage tanks located on the 110th floor. Calculations were performed to determine the duration of a single 5,000 gal tank, the combined 10,000 gal for the two tanks, and for the condition including the third 5,000 gal standpipe system reserve storage tank. A booster pump located on the 108th floor was also used to increase the pressure for the high zone sprinkler systems since the gravity pressure provided 
by water storage tanks was not sufficient for the sprinkler systems. The fire pump was modeled as a 500 gpm pump operating at 60 psi using the default performance curve provided in the HASS computer hydraulics program.

The secondary water supply condition was selected to represent water being supplied to the sprinkler system by the standpipe system. There were a number of different arrangements that could have been used to supply water to the sprinkler systems using the standpipe systems infrastructure. Some of the possible cases included the following:

- The fire department using a single high pressure pumper and one of the two high pressure FDCs

- The fire department using a single FDC and any single manually operated fire pump in the standpipe system in series

- The Bl level or 7th floor level fire pump and another fire pump on an upper level used in series

- One or more upper level fire pumps using water stored in the standpipe system reserve water storage tanks

The secondary water supply condition was evaluated in a similar manner to the water storage tanks. The data entered for the water storage tanks were based on a fixed or constant water supply. The data were entered as residual pressure only. For the tanks on the 110th floor, a pressure of 1.3 psi was used. This information was taken from the static pressure diagram included in the O\&M manual and drawings SP-22 and SP-23 (PANYNJ 1972, 1987a). The secondary water supply was identified as the pressure reducing valve station on the 109th floor where the standpipe system was interconnected to the high and mid-level zone sprinkler systems. The pressure reducing valve was configured to provide a maximum of $50 \mathrm{psi}$ outlet pressure, which was identified in general note 2 on drawings SP-22 and SP-23 and the O\&M manual. The water supply was modeled using a fixed pressure water supply with a residual pressure of 50 psi.

\section{Light Hazard Calculations for High Zone with Primary Water Supply}

A series of seven hydraulic calculation cases were performed using the Light Hazard requirements outlined above to evaluate the performance of the sprinkler systems connected to riser A and supplied with water by the high zone supply. Table 6-2 provides a summary of the number of operating sprinklers included in each of the cases evaluated.

Table 6-3 provides a summary of the results of these calculations.

The calculated delivered densities in Table 6-2 were obtained by dividing the total system flow by the actual application area. The maximum and minimum delivered flows were extracted from the hydraulic calculation results. Sprinklers at the remote ends of branchlines typically discharge less water than sprinklers closer to the sprinkler main. The reason for this difference is due to the pressure loss through the branchline pipes. 
Table 6-2. Number of operating sprinklers, 107th and 99th floor, Light Hazard cases.

\begin{tabular}{|c|c|l|}
\hline Floor & $\begin{array}{c}\text { Number of } \\
\text { Operating Sprinklers }\end{array}$ & \multicolumn{1}{|c|}{ Sprinkler Node Identification } \\
\hline 107 & 4 & S1, through S4 \\
\hline 107 & 12 & S1 through S12 \\
\hline 107 & 13 & S1 through S13 \\
\hline 107 & 16 & S1 through S16 \\
\hline 99 & 4 & S11 through S14 \\
\hline 99 & 8 & S11 through S14, and S16 through S19 \\
\hline 99 & 16 & $\begin{array}{l}\text { S1 through S4, S6 through S9, S11 } \\
\text { through S14, and S16 through S19 }\end{array}$ \\
\hline
\end{tabular}

Table 6-3. High zone Light Hazard hydraulic calculations summary, WTC 1 and WTC 2.

\begin{tabular}{|c|c|c|c|c|c|c|c|c|}
\hline Floor & $\begin{array}{c}\text { Number of } \\
\text { Operating } \\
\text { Sprinklers }\end{array}$ & $\begin{array}{c}\text { Area } \\
\left(\mathbf{f t}^{2}\right)\end{array}$ & $\begin{array}{c}\text { Maximum } \\
\text { Area per } \\
\text { Sprinkler } \\
\left(\mathbf{f t}^{2}\right)\end{array}$ & $\begin{array}{c}\text { Flow } \\
(\mathbf{g p m})\end{array}$ & $\begin{array}{c}\text { Calc. } \\
\text { Delivered } \\
\text { Density } \\
\left(\mathbf{g p m} / \mathbf{f t}^{2}\right)\end{array}$ & $\begin{array}{c}\text { Required } \\
\text { Density } \\
\left(\mathbf{g p m} / \mathbf{f t}^{2}\right)\end{array}$ & $\begin{array}{c}\text { Highest } \\
\text { Delivered } \\
\text { Flow } \\
(\mathbf{g p m})\end{array}$ & $\begin{array}{c}\text { Lowest } \\
\text { Delivered } \\
\text { Flow } \\
(\mathbf{g p m})\end{array}$ \\
\hline 107 & 4 & 504 & 126 & 112 & 0.22 & 0.10 & 36.6 & 23.2 \\
\hline 107 & 12 & 1512 & 126 & 272 & 0.18 & 0.10 & 27.9 & 16.1 \\
\hline 107 & 13 & 1638 & 126 & 286 & 0.17 & 0.10 & 29.5 & 15.1 \\
\hline 107 & 16 & 2016 & 126 & 306 & 0.15 & 0.10 & 23.5 & 13.4 \\
\hline 99 & 4 & 784 & 196 & 137 & 0.18 & 0.10 & 45.6 & 27.5 \\
\hline 99 & 8 & 1568 & 196 & 252 & 0.16 & 0.10 & 42.1 & 25.2 \\
\hline 99 & 16 & 3136 & 196 & 407 & 0.13 & 0.10 & 34.2 & 20.2 \\
\hline
\end{tabular}

The cases involved in this series of hydraulic calculations included variations on the number of sprinklers operating and the vertical location of the sprinkler system within the high water supply zone. For WTC 1, four cases were examined for the 107th floor system and three for the 99th floor system. Thesc calculations represented the performance range for the sprinkler systems in the high water supply zone that were designed for the protection of Light Hazard Occupancies. Although the system layouts and number of operating sprinklers in the baseline cases could not be directly compared, the results demonstrated the declining pressure principle. As the number of sprinklers operating in a particular system increased, the average delivered density decreased as a result of the decreasing pressure available at the location of each sprinkler due to the friction loss associated with the increase in water flow. The range of densities for the 107 th floor system was $0.223 \mathrm{gpm} / \mathrm{ft}^{2}$ with four sprinklers operating to $0.152 \mathrm{gpm} / \mathrm{ft}^{2}$ with 16 sprinklers operating. The range of densities for the 99 th floor system was from $0.175 \mathrm{gpm} / \mathrm{ft}^{2}$ with four sprinklers operating to $0.130 \mathrm{gpm} / \mathrm{ft}^{2}$ with 16 sprinklers operating.

\section{Ordinary Hazard Calculations for High Zone with Primary Water Supply}

Additional hydraulic calculations were used to evaluate the performance of sprinkler systems designed to protect Ordinary Hazard Occupancy areas. Calculations were performed for the sprinkler system on the 
107th floor of WTC 2 and the 99th floor of WTC 1 using the spacing criteria consistent with Ordinary Hazard criteria. Table 6-4 identifies the assumed number of operating sprinklers in each of the cases.

Table 6-4. Number of operating sprinklers, 107th and 99th floor Ordinary Hazard calculations.

\begin{tabular}{|c|c|l|}
\hline Floor & $\begin{array}{c}\text { Number of Operating } \\
\text { Sprinklers }\end{array}$ & \multicolumn{1}{|c|}{ Sprinkler Node Identification } \\
\hline 107 & 4 & S1 through S4 \\
\hline 107 & 18 & S1 through S18 \\
\hline 107 & 22 & S1 through S22 \\
\hline 99 & 4 & S1 through S4 \\
\hline 99 & 15 & S6 through S20 \\
\hline 99 & 20 & S1 through S20 \\
\hline 99 & 25 & S1 through S25 \\
\hline
\end{tabular}

A summary of the results for the hydraulic calculations of the sprinkler systems connected to the high water supply zone and designed using the criteria for Ordinary Hazard Occupancies is provided in Table 6-5.

Table 6-5. High zone Ordinary Hazard hydraulic calculations summary, WTC 1 and WTC 2.

\begin{tabular}{|c|c|c|c|c|c|c|c|c|}
\hline Floor & $\begin{array}{l}\text { Number of } \\
\text { Operating } \\
\text { Sprinklers }\end{array}$ & $\begin{array}{c}\text { Area } \\
\left(\mathrm{ft}^{2}\right)\end{array}$ & $\begin{array}{c}\text { Maximum } \\
\text { Area per } \\
\text { Sprinkler } \\
\left(\mathrm{ft}^{2}\right)\end{array}$ & $\begin{array}{c}\text { Flow } \\
\text { (gpm) }\end{array}$ & $\begin{array}{c}\text { Calc. } \\
\text { Delivered } \\
\text { Density } \\
\left(\mathrm{gpm} / \mathrm{ft}^{2}\right)\end{array}$ & $\begin{array}{c}\text { Required } \\
\text { Density } \\
\left(\mathrm{gpm} / \mathrm{ft}^{2}\right)\end{array}$ & $\begin{array}{c}\text { Highest } \\
\text { Delivered } \\
\text { Flow } \\
\text { (gpm) }\end{array}$ & $\begin{array}{c}\text { Lowest } \\
\text { Delivered } \\
\text { Flow } \\
\text { (gpm) }\end{array}$ \\
\hline 107 & 4 & 476 & 119 & 172 & 0.36 & 0.15 & 44.5 & 41.3 \\
\hline 107 & 18 & 1,502 & 119 & 376 & 0.25 & 0.15 & 23.4 & 17.5 \\
\hline 107 & 22 & 1,749 & 119 & 388 & 0.22 & 0.15 & 21.3 & 12.6 \\
\hline 99 & 4 & 476 & 119 & 221 & 0.46 & 0.15 & 55.5 & 54.9 \\
\hline 99 & 15 & 1,680 & 119 & 507 & 0.30 & 0.15 & 34.3 & 33.2 \\
\hline 99 & 20 & 2,226 & 119 & 545 & 0.26 & 0.15 & 27.8 & 26.6 \\
\hline 99 & 25 & 2,793 & 119 & 566 & 0.20 & 0.15 & 23.4 & 21.9 \\
\hline
\end{tabular}

The calculated delivered densities in Table 6-5 were based on the same methods outlined above for Table 6-3. In all cases the calculated delivered density exceeded the required discharge density of $0.15 \mathrm{gpm} / \mathrm{ft}^{2}$. It should be noted however that the minimum required flow was not delivered in all cases. For example, the case involving 22 sprinklers operating on the 107th floor of WTC 2 resulted in a condition where the average density exceeded the minimum required density. However, the flow per sprinkler ranged from $21.3 \mathrm{gpm}$ to $12.6 \mathrm{gpm}$. For $1 / 2 \mathrm{in}$. orifice sprinklers, the minimum flow is $14.82 \mathrm{gpm}$ and the required pressure is 7 psi for all sprinklers. Therefore, there would be some concern regarding the performance of a sprinkler that operated at this lower pressure and resulting flow. This calculated pressure and resulting flow were localized and in this case would not be expected to affect the overall system performance. 


\section{Calculation of Water Supply Duration}

The water supply duration for the high zone sprinkler systems was evaluated using one, two, and three 5,000 gal storage tanks. The supply durations were calculated using the fixed volume of the tank, disregarding the make-up supply connections to the tanks. Therefore, the estimates of duration should be considered minimums. Table 6-6 provides a summary of the water supply durations for the Light and Ordinary Hazard scenarios presented above for sprinkler systems in the high water supply zone. As mentioned previously, the Ordinary Hazard calculations for the 107th floor apply to WTC 2 only.

Table 6-6. High zone primary water supply duration, WTC 1 and WTC 2.

\begin{tabular}{|c|c|c|c|c|c|c|}
\hline \multirow[b]{2}{*}{ Floor } & \multirow{2}{*}{$\begin{array}{l}\text { Number of } \\
\text { Operating } \\
\text { Sprinklers }\end{array}$} & \multirow[b]{2}{*}{ Hazard } & \multirow{2}{*}{$\begin{array}{c}\text { Flow } \\
(\mathrm{gpm})\end{array}$} & \multicolumn{3}{|c|}{ Duration (min) } \\
\hline & & & & 5,000 gal & $10,000 \mathrm{gal}$ & $15,000 \mathrm{gal}$ \\
\hline 107 & 4 & Light & 112 & 44.56 & 89.13 & 133.69 \\
\hline 107 & 12 & Light & 272 & 18.37 & 36.74 & 55.11 \\
\hline 107 & 13 & Light & 286 & 17.49 & 34.99 & 52.48 \\
\hline 107 & 16 & Light & 306 & 16.34 & 32.68 & 49.02 \\
\hline 99 & 4 & Light & 137 & 36.52 & 73.05 & 109.57 \\
\hline 99 & 8 & Light & 252 & 19.81 & 39.62 & 59.43 \\
\hline 99 & 16 & Light & 407 & 12.30 & 24.60 & 36.90 \\
\hline 107 & 4 & Ordinary & 172 & 29.04 & 58.07 & 87.11 \\
\hline 107 & 18 & Ordinary & 376 & 13.29 & 26.57 & 39.86 \\
\hline 107 & 22 & Ordinary & 388 & 12.89 & 25.78 & 38.67 \\
\hline 99 & 4 & Ordinary & 221 & 22.67 & 45.33 & 68.00 \\
\hline 99 & 15 & Ordinary & 507 & 9.86 & 19.71 & 29.57 \\
\hline 99 & 20 & Ordinary & 545 & 9.18 & 18.37 & 27.55 \\
\hline 99 & 25 & Ordinary & 566 & 8.84 & 17.67 & 26.51 \\
\hline
\end{tabular}

The water supply durations indicated in Table 6-6 are bascd on all of the sprinklers operating in each case. The calculations do not account for the independent operation of individual sprinklcrs. The durations were calculated by dividing the fixed water storage volume in each tank $(5,000 \mathrm{gal})$ by the calculated flow rate for the case. Therefore, the durations indicated for each case are considered to be thc minimums.

\section{Comparison of Primary and Secondary Water Supply Calculations}

Hydraulic calculations were performed to evaluate the changes in the system performancc while operating in a secondary water supply mode. The secondary water supply calculations used a fixed pressure of $50 \mathrm{psi}$ at the pressure-reducing valve that was provided between the connection of the sprinkler systems to the standpipe system. Table 6-7 provides a comparison of the sprinkler system densities while operating in the primary and secondary water supply modes. 
Table 6-7. Comparison of primary and secondary water supplies for high zone.

\begin{tabular}{|c|l|c|l|c|c|c|c|c|}
\hline Floor & $\begin{array}{c}\text { Water } \\
\text { Supply } \\
\text { Mode }\end{array}$ & $\begin{array}{c}\text { Area } \\
\left.\mathbf{f f t}^{2}\right)\end{array}$ & Hazard & $\begin{array}{c}\text { Supply } \\
(\mathbf{g p m})\end{array}$ & $\begin{array}{c}\text { Calc. } \\
\text { Delivered } \\
\text { Density } \\
\left(\mathbf{g p m} / \mathbf{f t}^{2}\right)\end{array}$ & $\begin{array}{c}\text { Required } \\
\text { Density } \\
\left(\mathbf{g p m} / \mathbf{f t}^{2}\right)\end{array}$ & $\begin{array}{c}\text { Highest } \\
\text { Delivered } \\
\text { Flow } \\
(\mathbf{g p m})\end{array}$ & $\begin{array}{c}\text { Lowest } \\
\text { Delivered } \\
\text { Flow } \\
(\mathbf{g p m})\end{array}$ \\
\hline 107 & Primary & 1,512 & Light & 272 & 0.18 & 0.1 & 27.9 & 16.1 \\
\hline 107 & Secondary & 1,512 & Light & 352 & 0.23 & 0.1 & 35.2 & 21.0 \\
\hline 99 & Primary & 1,568 & Light & 252 & 0.16 & 0.1 & 42.1 & 25.2 \\
\hline 99 & Secondary & 1,568 & Light & 300 & 0.19 & 0.1 & 49.9 & 30.1 \\
\hline 107 & Primary & 1,502 & Ordinary & 376 & 0.25 & 0.15 & 23.4 & 17.5 \\
\hline 107 & Secondary & 1,502 & Ordinary & 481 & 0.32 & 0.15 & 29.8 & 22.5 \\
\hline 99 & Primary & 1,680 & Ordinary & 507 & 0.30 & 0.15 & 34.3 & 33.2 \\
\hline 99 & Secondary & 1,680 & Ordinary & 591 & 0.38 & 0.15 & 39.9 & 38.7 \\
\hline
\end{tabular}

The added pressure to the sprinkler systems due to the addition of the secondary water supplies resulted in both higher individual sprinkler flows and average discharge densities. Secondary water supply durations were not calculated due to the complexities of quantifying a fixed volume of secondary water storage with multiple possible arrangements.

\section{Comparison of Supply and Demand Calculations}

Demand calculations were performed for the WTC 1107 th floor sprinkler system to compare to the supply calculations that were performed using $4,12,13$, and 16 operating sprinklers. The comparison shows the difference between the minimum required density and the calculated delivered density. Table 6-8 provides a summary of the supply and demand calculation results.

The baseline cases for comparison were the demand and supply calculations with 12 sprinklers. These cases represent the intended design of $0.1 \mathrm{gpm} / \mathrm{ft}^{2}$ with an application area of $1,512 \mathrm{ft}^{2}$. This comparison also incorporates a margin of safety that is typically included in the design of sprinkler systems. The design calculations identified that the actual density based on the system demand was $0.168 \mathrm{gpm} / \mathrm{ft}^{2}$, and the primary water supply was actually capable of delivering a discharge density of $0.18 \mathrm{gpm} / \mathrm{ft}^{2}$.

The case involving 16 sprinklers resulted in less than 7 psi at several sprinklers; therefore, the results of the demand calculation were not valid for this condition. This is observed by looking at the flow at the sprinkler with the lowest flow rate. Dividing $13.4 \mathrm{gpm}$ by a coverage area of $126 \mathrm{ft}^{2}$ results in a calculated delivered density of $0.106 \mathrm{gpm} / \mathrm{ft}^{2}$. However, a flow of $13.4 \mathrm{gpm}$ equates to a minimum end pressure of approximately $5.73 \mathrm{psi}$. This pressure is less than the minimum requirement of 7 psi for end sprinkler pressure in NFPA 13. 
Table 6-8. Light Hazard hydraulic calculations summary, 107th floor, WTC 1 and WTC 2.

\begin{tabular}{|l|c|r|c|c|c|c|c|}
\hline $\begin{array}{c}\text { Calculation } \\
\text { Type }\end{array}$ & $\begin{array}{c}\text { Number of } \\
\text { Operating } \\
\text { Sprinklers }\end{array}$ & $\begin{array}{c}\text { Area } \\
\left(\mathbf{f t}^{2}\right)\end{array}$ & $\begin{array}{c}\text { Flow } \\
(\mathbf{g p m})\end{array}$ & $\begin{array}{c}\text { Calc. } \\
\text { Delivered } \\
\text { Density } \\
\left(\mathbf{g p m} / \mathbf{f t}^{2}\right)\end{array}$ & $\begin{array}{c}\text { Required } \\
\text { Density } \\
\left(\mathbf{g p m} / \mathbf{f t}^{2}\right)\end{array}$ & $\begin{array}{c}\text { Highest } \\
\text { Delivered } \\
\text { Flow } \\
(\mathbf{g p m})\end{array}$ & $\begin{array}{c}\text { Lowest } \\
\text { Delivered Flow } \\
\text { (gpm) }\end{array}$ \\
\hline Supply & 4 & 504 & 112 & 0.22 & 0.10 & 36.6 & 23.2 \\
\hline Demand & 4 & 504 & 73.4 & 0.15 & 0.10 & 24.2 & 15 \\
\hline Supply & 12 & 1,512 & 272 & 0.18 & 0.10 & 27.9 & 16.1 \\
\hline Demand & 12 & 1,512 & 254.7 & 0.17 & 0.10 & 26.1 & 15 \\
\hline Supply & 13 & 1,638 & 286 & 0.17 & 0.10 & 29.5 & 15.1 \\
\hline Demand & 13 & 1,638 & 284.4 & 0.17 & 0.10 & 29.4 & 15 \\
\hline Supply & 16 & 2,016 & 306 & 0.15 & 0.10 & 23.5 & 13.4 \\
\hline
\end{tabular}

\subsubsection{Mid-Level Zone}

The sprinkler systems on floors 32 through 98 in WTC 1 and WTC 2 composed the mid-level zone and shared a common riser and water supply (PANYNJ 1972, 1987a). These systems were supplied with water from the reserve storage tanks located on the 110 th floor. Figure B-19 provides a representation of the water storage tanks and the feed main that supplied water to the top of riser A. Riser B supplied the mid-level sprinkler systems using gravity pressure. Figure B-34 demonstrates the path of water flow from the water storage tanks at node AST to the floor control assemblies at the 98th, 87th, 86th, and 32nd floors.

The representative layout identified in the high zone section was used for the hydraulic calculations for the systems in the mid-level zone. The sprinkler systems on floors 86 through 32 contained pressurereducing type control valves. An additional hydraulic node PRV was added to the hydraulic calculations using the primary water supply. This node is identified as FPRV in the 32nd floor hydraulic calculations using the secondary water supply, and was treated as a fixed pressurc loss device. The pressure was adjusted, and the reiterations of the hydraulic calculations were performed until the inlct and outlet pressures were in agreement with the specified pressure loss curves for the $2 \frac{1}{2} \mathrm{in}$. valves.

The hydraulic analysis of the mid-level zone sprinkler systems included supply calculations using the requirements for both Light and Ordinary Hazard Group 1. Calculations were performed to determine the water supply durations for the primary water supply.

Additional hydraulic calculations were performed for the Light Hazard and Ordinary Hazard layouts using the secondary water supply configuration. Four secondary supply calculations werc performed, onc calculation for each scenario involving the number of sprinklers included in the required design area at the 32 nd floor and 98 th floor sprinkler systems. The secondary water supply was simulated in the same manner that was used in the high zone analysis. A fixed pressure of $50 \mathrm{psi}$ was identified at the hydraulic node PRV, as identified in Fig. B-19, at the connection of the standpipe system and sprinkler system infrastructure piping in the 109th floor MER. 


\section{Light Hazard Calculations for Mid-Level Zone with Primary Water Supply}

Twelve cases were evaluated for the mid-level zone sprinkler systems. Table 6-9 provides a summary of the scenarios.

Table 6-9. Number of operating sprinklers, 98th, 87 th, and 32 nd floor, Light Hazard calculations, WTC 1.

\begin{tabular}{|c|c|l|}
\hline Floor & $\begin{array}{c}\text { Number of } \\
\text { Operating } \\
\text { Sprinklers }\end{array}$ & \multicolumn{1}{|c|}{ Sprinkler Node Identification } \\
\hline 98 & 4 & S11 through S14 \\
\hline 98 & 8 & S11 through S14, and S16 through S19 \\
\hline 98 & 16 & S1 through S4, S6 through S9, S11 through S14, and S16 through S19 \\
\hline 87 & 4 & S1 through S4 \\
\hline 87 & 9 & S11 through S14, and S16 through S19 \\
\hline 87 & 18 & S5 through S7, S10 through S24 \\
\hline 87 & 4 & S11 through S14 \\
\hline 87 & 8 & S11 through S14, and S16 through S19 \\
\hline 87 & 16 & S1 through S4, S6 through S9, S11 through S14, and S16 through S19 \\
\hline 32 & 4 & S11 through S14 \\
\hline 32 & 8 & S11 through S14, and S16 through S19 \\
\hline 32 & 16 & S1 through S4, S6 through S9, S11 through S14, and S16 through S19 \\
\hline
\end{tabular}

A series of three hydraulic calculations was performed for four different representative Light Hazard systems. The system on the 87 th floor was used to determine an appropriate sprinkler spacing and coverage area to use in the calculations for all of the sprinkler systems. Two different system arrangements were selected. The first used sprinklers spaced at $14 \mathrm{ft}$ by $12 \mathrm{ft}$ and the other $14 \mathrm{ft}$ by $14 \mathrm{ft}$. These scenarios resulted in coverage areas of $168 \mathrm{ft}^{2}$ and $196 \mathrm{ft}^{2}$, respectively. The results of these calculations are summarized in Table 6-10.

The performance of the sprinklcr system on this floor using the coverage area of $196 \mathrm{ft}^{2}$ was considered to accurately represent a Light Hazard sprinkler system design. Therefore, all of the other calculations used this typical arrangement.

The results indicate that the system capabilities exceedcd the minimum requirements for the design. This is attributed to the arrangement of the cross-mains. The interior cross-mains routed through the corridor of the core area significantly increased the flow capacity throughout the floor. A second 3 in. riser was used to supply water to the 32 nd through 82 nd floor level systems. A secondary floor control valve assembly and feed main was provided for the systems on these floor levels. However, only one riser was accounted for in the calculation of the sprinkler systems on these floors. Under normal operating conditions, additional water would be available from the other riser supplying the floor, increasing the average delivcred density to the design sprinklcrs. However, in practice, risers are sometimes isolated due to maintenance while still providing protection to all sprinklers through the other riser. Therefore, this was a conservative approach to determining the supply capabilities of the water supply system. 
Table 6-10. Mid-level zone Light Hazard hydraulic calculations summary, WTC 1 and WTC 2.

\begin{tabular}{|c|c|c|c|c|c|c|c|c|}
\hline Floor & $\begin{array}{c}\text { Number of } \\
\text { Operating } \\
\text { Sprinklers }\end{array}$ & $\begin{array}{c}\text { Area } \\
\left(\mathbf{f t}^{2}\right)\end{array}$ & $\begin{array}{c}\text { Maximum } \\
\text { Area per } \\
\text { Sprinkler } \\
\left.\mathbf{f f t}^{2}\right)\end{array}$ & $\begin{array}{c}\text { Flow } \\
(\mathbf{g p m})\end{array}$ & $\begin{array}{c}\text { Calc. } \\
\text { Delivered } \\
\text { Density } \\
\left(\mathbf{g p m} / \mathbf{f t}^{2}\right)\end{array}$ & $\begin{array}{c}\text { Required } \\
\text { Density } \\
\left(\mathbf{g p m} / \mathbf{f t}^{2}\right)\end{array}$ & $\begin{array}{c}\text { Highest } \\
\text { Delivered } \\
\text { Flow } \\
(\mathbf{g p m})\end{array}$ & $\begin{array}{c}\text { Lowest } \\
\text { Delivered } \\
\text { Flow } \\
(\mathbf{g p m})\end{array}$ \\
\hline 98 & 4 & 784 & 196 & 117 & 0.15 & 0.10 & 39.1 & 23.3 \\
\hline 98 & 8 & 1,568 & 196 & 210 & 0.13 & 0.10 & 35.2 & 20.9 \\
\hline 98 & 16 & 3,136 & 196 & 322 & 0.10 & 0.10 & 27.2 & 15.8 \\
\hline 87 & 4 & 672 & 168 & 185 & 0.27 & 0.10 & 44.2 & 28.1 \\
\hline 87 & 9 & 1,512 & 168 & 293 & 0.19 & 0.10 & 49.1 & 25.1 \\
\hline 87 & 18 & 3,024 & 168 & 441 & 0.15 & 0.10 & 34.6 & 18.8 \\
\hline 87 & 4 & 784 & 196 & 138 & 0.18 & 0.10 & 45.8 & 27.6 \\
\hline 87 & 8 & 1,568 & 196 & 251 & 0.16 & 0.10 & 42 & 25.1 \\
\hline 87 & 16 & 3,136 & 196 & 398 & 0.13 & 0.10 & 33.5 & 19.7 \\
\hline 32 & 4 & 784 & 196 & 151 & 0.19 & 0.10 & 50.3 & 30.4 \\
\hline 32 & 8 & 1,568 & 196 & 272 & 0.17 & 0.10 & 45.3 & 27.2 \\
\hline 32 & 16 & 3,136 & 196 & 436 & 0.14 & 0.10 & 36.7 & 21.7 \\
\hline
\end{tabular}

The calculations involving the 32 nd floor system used a fixed pressure loss device to simulate the pressure-reducing valve. A pressure-reducing valve was required to maintain the system pressure below the 175 psi threshold for the floor level sprinkler system components. The pressure-reducing valve also reduced the calculated delivered density to these systems. The use of the pressure-reducing valves resulted in uniform performance within the range established for the systems on the 98th and 87th floors, which did not include pressure-reducing valves, and therefore, demonstrated the true effect of gravity (head) pressure.

\section{Ordinary Hazard Calculations for Mid-Level Zone with Primary Water Supply}

Fourteen Ordinary Hazard calculations were performed for the mid-level zone sprinkler systems. Hydraulic calculations were performed for the highest and lowest floor level systems with and without pressure-reducing valves. Calculations were performed to evaluate three scenarios:

1. The performance of the sprinkler systems using an equivalent number of sprinklers to the design area

2. The performance of the systems using four operational sprinklers (less than the design area)

3. The performance of the systems with large number of operational sprinklers (more than the number of sprinklers in the design area)

The hydraulic calculations revealed an inherent limitation in the design of sprinkler riser B, which supplied the sprinkler systems in the mid-level zone. An imposed flow limitation existed as a result of friction loss within the 4 in. diameter supply pipe connecting the water storage tanks to the top of riser B. 
The friction loss due to the long travel distance exceeded the net positive head pressure provided by the elevated water storage tank, creating a negative atmospheric pressure (vacuum) at flows exceeding $440 \mathrm{gpm}$.

The arrangement of the mid-level zone sprinkler systems and the extremely high head pressure resulted in significant excess flow being provided to these sprinkler systems. In several cases, the large number of sprinklers assumed to be operating resulted in excess flow that exceeded the $440 \mathrm{gpm}$ limitation of the supply pipe on the 109th floor. In these cases, the pressure observed at the top of riser B was lower than atmospheric pressure, and the HASS hydraulic program terminated the calculations. A maximum of 25 sprinklers was included for all systems. The cases shown in Table 6-11 and Table 6-12 with maximum values of less than 25 sprinklers indicate the actual number of sprinklers that could be supported by the water supply systems before termination, based on output from the hydraulic analysis.

The combined effects of gravity and the grid system layout resulted in significant flow rates and densities being supplied to the mid level zone sprinkler systems as shown in Table 6-12. The fixed losses for the pressure-reducing valves in the calculations for the $32 \mathrm{nd}$ and 86 th floor system calculations required reiterative calculations to account for the pressure loss effects of these valves. The systems on the 32 nd and 86 th floors demonstrated similar performance for the cases with four sprinklers operating. As with the calculations using the Light Hazard requirements, the performance of the sprinkler systems with the pressure-reducing valves were within the range established by the highest and lowest floor sprinkler systems without pressure-reducing valves.

Table 6-11. Number of operating sprinklers, 98th, 87th, 86th and 32nd floor Ordinary Hazard calculations, WTC 1.

\begin{tabular}{|c|c|l|}
\hline Floor & $\begin{array}{c}\text { Number of Operating } \\
\text { Sprinklers }\end{array}$ & \multicolumn{1}{|c|}{ Sprinkler Node Identification } \\
\hline 98 & 4 & S6 through S9 \\
\hline 98 & 15 & S6 through S20 \\
\hline 98 & 20 & S1 through S20 \\
\hline 98 & 25 & S1 through S25 \\
\hline 87 & 4 & S1 through S4 \\
\hline 87 & 15 & S6 through S20 \\
\hline 87 & 20 & S1 through S20 \\
\hline 86 & 4 & S1 through S4 \\
\hline 86 & 15 & S6 through S20 \\
\hline 86 & 20 & S1 through S20 \\
\hline 86 & 25 & S1 through S25 \\
\hline 32 & 4 & S1 through S4 \\
\hline 32 & 15 & S6 through S20 \\
\hline 32 & 16 & S5 through S20 \\
\hline
\end{tabular}


Table 6-12. Mid-level zone Ordinary Hazard hydraulic calculations summary, WTC 1 and WTC 2.

\begin{tabular}{|c|c|c|c|c|c|c|c|c|}
\hline Floor & $\begin{array}{l}\text { Number of } \\
\text { Operating } \\
\text { Sprinklers }\end{array}$ & $\begin{array}{l}\text { Area } \\
\left(\mathrm{ft}^{2}\right)\end{array}$ & $\begin{array}{c}\text { Maximum } \\
\text { Area per } \\
\text { Sprinkler } \\
\left(\mathrm{ft}^{2}\right)\end{array}$ & $\begin{array}{c}\text { Flow } \\
(\mathrm{gpm})\end{array}$ & $\begin{array}{c}\text { Calc. } \\
\text { Delivered } \\
\text { Density } \\
\left(\mathrm{gpm} / \mathrm{ft}^{2}\right)\end{array}$ & $\begin{array}{l}\text { Required } \\
\text { Density } \\
\left(\mathrm{gpm} / \mathrm{ft}^{2}\right)\end{array}$ & $\begin{array}{l}\text { Highest } \\
\text { Delivered } \\
\text { Flow } \\
\text { (gpm) }\end{array}$ & $\begin{array}{c}\text { Lowest } \\
\text { Delivered } \\
\text { Flow } \\
\text { (gpm) }\end{array}$ \\
\hline 98 & 4 & 476 & 119 & 163 & 0.34 & 0.15 & 41.1 & 40.6 \\
\hline 98 & 15 & 1,680 & 119 & 371 & 0.22 & 0.15 & 25.1 & 24.3 \\
\hline 98 & 20 & 2.226 & 119 & 402 & 0.18 & 0.15 & 20.5 & 19.6 \\
\hline 98 & 25 & 2,793 & 119 & 420 & 0.15 & 0.15 & 17.4 & 16.2 \\
\hline 87 & 4 & 476 & 119 & 219 & 0.46 & 0.15 & 55.2 & 54.5 \\
\hline 87 & 15 & 1,680 & 119 & 509 & 0.30 & 0.15 & 34.4 & 33.3 \\
\hline 87 & 20 & 2,226 & 119 & 548 & 0.25 & 0.15 & 28 & 26.7 \\
\hline 86 & 4 & 476 & 119 & 176 & 0.37 & 0.15 & 44.3 & 43.8 \\
\hline 86 & 15 & 1,680 & 119 & 363 & 0.22 & 0.15 & 24.5 & 23.7 \\
\hline 86 & 20 & 2,226 & 119 & 397 & 0.18 & 0.15 & 20.3 & 19.3 \\
\hline 86 & 25 & 2,793 & 119 & 424 & 0.15 & 0.15 & 17.6 & 16.3 \\
\hline 32 & 4 & 476 & 119 & 174 & 0.37 & 0.15 & 43.8 & 43.2 \\
\hline 32 & 15 & 1,680 & 119 & 440 & 0.26 & 0.15 & 29.7 & 28.8 \\
\hline 32 & 16 & 1,904 & 119 & 441 & 0.23 & 0.15 & 28 & 27 \\
\hline
\end{tabular}

\section{Calculation of Water Supply Duration}

The water supply duration for the sprinkler systems connected to riser B in the mid-level water supply zone were evaluated using one, two, and three 5,000 gal tanks. This was the same method used to evaluate the primary water supply for the high water supply zone. Two sprinkler reserve storage tanks and the single standpipe reserve storage tank on the 110 th floor were included in this analysis. These tanks were shared with the high zone sprinkler systems. A summary of the water supply durations is provided in Table 6-13. 
Table 6-13. Mid-level zone primary water supply duration, WTC 1 and WTC 2.

\begin{tabular}{|c|c|c|c|c|c|c|}
\hline \multirow[b]{2}{*}{ Floor } & \multirow{2}{*}{$\begin{array}{l}\text { Number of } \\
\text { Operating } \\
\text { Sprinklers } \\
\end{array}$} & \multirow[b]{2}{*}{ Hazard } & \multirow{2}{*}{$\begin{array}{c}\text { Flow } \\
(\mathrm{gpm})\end{array}$} & \multicolumn{3}{|c|}{ Duration (min) } \\
\hline & & & & $5,000 \mathrm{gal}$ & 10,000 gal & 15,000 gal \\
\hline 98 & 4 & Light & 117 & 42.81 & 85.62 & 128.42 \\
\hline 98 & 8 & Light & 210 & 23.83 & 47.66 & 71.50 \\
\hline 98 & 16 & Light & 322 & 15.54 & 31.08 & 46.63 \\
\hline 87 & 4 & Light & 185 & 27.10 & 54.20 & 81.30 \\
\hline 87 & 9 & Light & 293 & 17.06 & 34.13 & 51.19 \\
\hline 87 & 18 & Light & 441 & 11.33 & 22.66 & 33.99 \\
\hline 87 & 4 & Light & 138 & 36.36 & 72.73 & 109.09 \\
\hline 87 & 8 & Light & 251 & 19.89 & 39.78 & 59.67 \\
\hline 87 & 16 & Light & 398 & 12.56 & 25.12 & 37.68 \\
\hline 32 & 4 & Light & 151 & 33.03 & 66.05 & 99.08 \\
\hline 32 & 8 & Light & 272 & 18.40 & 36.81 & 55.21 \\
\hline 32 & 16 & Light & 436 & 11.47 & 22.94 & 34.41 \\
\hline 98 & 4 & Ordinary & 163 & 30.62 & 61.24 & 91.86 \\
\hline 98 & 15 & Ordinary & 371 & 13.48 & 26.96 & 40.44 \\
\hline 98 & 20 & Ordinary & 402 & 12.45 & 24.90 & 37.35 \\
\hline 98 & 25 & Ordinary & 420 & 11.92 & 23.84 & 35.76 \\
\hline 87 & 4 & Ordinary & 219 & 22.82 & 45.64 & 68.46 \\
\hline 87 & 15 & Ordinary & 509 & 9.83 & 19.67 & 29.50 \\
\hline 87 & 20 & Ordinary & 548 & 9.12 & 18.23 & 27.35 \\
\hline 86 & 4 & Ordinary & 176 & 28.39 & 56.79 & 85.18 \\
\hline 86 & 15 & Ordinary & 363 & 13.79 & 27.58 & 41.37 \\
\hline 86 & 20 & Ordinary & 397 & 12.58 & 25.17 & 37.75 \\
\hline 86 & 25 & Ordinary & 424 & 11.80 & 23.59 & 35.39 \\
\hline 32 & 4 & Ordinary & 174 & 28.77 & 57.54 & 86.31 \\
\hline 32 & 15 & Ordinary & 440 & 11.37 & 22.75 & 34.12 \\
\hline 32 & 16 & Ordinary & 441 & 11.35 & 22.69 & 34.04 \\
\hline
\end{tabular}

As with all of the cases, the water supply duration for each case did not account for progressive operation of the sprinklers, but rather assumed that all of the operating sprinklers opened at the same time. The calculations were based on the flow rates determined from the hydraulic supply calculations. The durations were calculated by dividing the fixed volume of water in the storage tank by the flow rate for each case. Therefore, as previously explained, the duration would be expected to be significantly greater than indicated in Table 6-13 from the beginning stages of fire growth when the first sprinkler(s) operate. 


\section{Comparison of Primary and Secondary Water Supply Calculations}

Calculations were performed to simulate the operation of the sprinkler system in a secondary supply mode. These calculations used a fixed pressure of $50 \mathrm{psi}$ at the pressure-reducing valve at the interconnection of the sprinkler and standpipe system infrastructures. Table 6-14 provides a summary of the results for the sprinkler system operating performance while operating in the primary and secondary supply modes.

Table 6-14. Comparison of primary and secondary water supplies for mid-level zone.

\begin{tabular}{|c|c|c|c|c|c|c|c|c|}
\hline Floor & $\begin{array}{l}\text { Water } \\
\text { Supply } \\
\text { Mode }\end{array}$ & $\begin{array}{l}\text { Area } \\
\left(\mathrm{ft}^{2}\right)\end{array}$ & Hazard & $\begin{array}{c}\text { Supply } \\
\text { (gpm) }\end{array}$ & $\begin{array}{c}\text { Calc. } \\
\text { Delivered } \\
\text { Density } \\
\left(\mathrm{gpm} / \mathrm{ft}^{2}\right)\end{array}$ & $\begin{array}{l}\text { Required } \\
\text { Density } \\
\left(\mathrm{gpm} / \mathrm{ft}^{2}\right)\end{array}$ & $\begin{array}{c}\text { Highest } \\
\text { Delivered } \\
\text { Flow } \\
\text { (gpm) }\end{array}$ & $\begin{array}{c}\text { Lowest } \\
\text { Delivered } \\
\text { Flow } \\
\text { (gpm) }\end{array}$ \\
\hline 98 & Primary & 1,568 & Light & 210 & 0.13 & 0.1 & 35.2 & 20.9 \\
\hline 98 & Secondary & 1,568 & Light & 281 & 0.18 & 0.1 & 46.8 & 28.2 \\
\hline 32 & Primary & 1.568 & Light & 272 & 0.17 & 0.1 & 45.3 & 27.2 \\
\hline 32 & Secondary & 1,568 & Light & 277 & 0.18 & 0.1 & 46.1 & 27.8 \\
\hline 98 & Primary & 1,680 & Ordinary & 371 & 0.22 & 0.15 & 25.1 & 24.3 \\
\hline 98 & Secondary & 1.680 & Ordinary & 510 & 0.33 & 0.15 & 34.4 & 33.4 \\
\hline 32 & Primary & 1,680 & Ordinary & 440 & 0.26 & 0.15 & 29.7 & 28.8 \\
\hline 32 & Secondary & 1,680 & Ordinary & 643 & 0.41 & 0.15 & 43.4 & 42.2 \\
\hline
\end{tabular}

In all cases the secondary water supply resulted in increased water flow and discharge density. The cascs involving the Light Hazard calculations demonstrated uniformity in the performance of the systems in the secondary supply mode. The Ordinary Hazard calculations indicated a significant increase in the water flow rates and discharge densities while operating in the secondary supply mode. Additionally, the results showed a significant increase due to the effects of elevation.

The different configurations used for the Light Hazard and Ordinary Hazard system layouts had a significant impact on the hydraulic performance of the systems. The Light Hazard systems were configured with dead-end branchlines extending from a $21 / 2 \mathrm{in.} \mathrm{looped} \mathrm{cross-main.} \mathrm{The} \mathrm{Ordinary} \mathrm{Hazard}$ system layout also included this looped cross-main and a secondary (far) grid cross-main near the exterior of the building. This far cross-main reduced the effects of friction loss and provided evenly distributed water throughout the application area. This accounted for the increased flows observed in the hydraulic calculations for the sprinkler systems based on the Ordinary Hazard layout.

\subsubsection{Low Zone}

The sprinkler systems on floors 1 through 31 in each tower comprised the low zone. A single 5,000 gal water storage tank was provided on the 41 st floor in WTC 1 to supply the low zone systems. A similar tank was provided in WTC 2. Figure B-35 illustrates the water storage tank and feed main arrangement on the 41 st floor. The low zone (C) risers for both towers were interconnected on the B1 level and were provided with an isolation valve that permitted the risers to function as part of the same system or separately. Figure B-36 shows the arrangement of the low zone risers. This arrangement permitted the tank in either building to serve as the primary water supply for the low water supply zone in the building 
in which it is located and the secondary water supply for the other building. The storage tanks were also shared with the standpipe systems in both WTC 1 and WTC 2 (PANYNJ 1987a).

The typical sprinkler system layout described in the discussion of the high zone sprinkler system design was used for the hydraulic calculations for all of the low zone sprinkler systems. Documentation for the configuration of typical low zonc floor layouts was unavailable. Therefore, the typical sprinkler layout used for the high zone calculations was used in this case to determine what would be expected for a supply to the low zone floors. Although this is not the actual rcpresentation of the typical low zone floors, it is reasonable that the actual typical layout was similar, and therefore, the hydraulic supply calculations would be similar.

As with the mid-level zone, two types of floor control valve assemblies were used, one arrangement with a pressure-reducing valve and one with an OS\&Y valve. The systems on floors 9 through 31 were equipped with OS\&Y valves. The systems on floors 1 through 7 were equipped with pressure-reducing valves. An additional node PRV was added to the hydraulic calculations for the floor level systems with the pressure-reducing valves. The method described above in the mid-level zone section was used to simulatc the pressure-reducing valve as a fixed pressure loss device in the hydraulic calculations.

Both Light Hazard and Ordinary Hazard hydraulic supply calculations were performed for the low zone systems. Additionally, calculations were performed to evaluate the water supply duration for the baseline cases involving the number of sprinklers included in both the Light and Ordinary Hazard application areas. The calculations to evaluate the secondary water supply included the tank and riser in WTC 2, the pipe interconnecting the two towers, and the riser in WTC 1. In these cases, the tank in WTC 2 was used to supply water to the sprinkler systems on the 2 nd and 31 st floors of WTC 1.

\section{Light Hazard Calculations For Low Zone with Primary Water Supply}

Six Light Hazard calculation cases were performed to evaluate the systems on the 2 nd and 31 st floors. Similarly to the calculations described for the high and mid-level zones, the cases represented the actual design area and situations involving fewer and more sprinklers than would be included in the design area. The calculations included four, eight and sixteen operating sprinklers for each floor level system. Table 6-15 provides a summary of the cases analyzed along with the assumed number of operating sprinklers in the hydraulic calculations.

Table 6-15. Number of operating sprinklers, 31st and 2nd floor Light Hazard calculations, WTC 1.

\begin{tabular}{|c|c|l|}
\hline Floor & $\begin{array}{c}\text { Number of Operating } \\
\text { Sprinklers }\end{array}$ & \multicolumn{1}{|c|}{ Sprinkler Node Identification } \\
\hline 31 & 4 & S16 through1 S19 \\
\hline 31 & 8 & S11 through S14, and S16 through S19 \\
\hline 31 & 16 & S5 and S10 through S24 \\
\hline 2 & 4 & S16 through S19 \\
\hline 2 & 8 & S11 through S14, and S16 through S19 \\
\hline 2 & 16 & $\begin{array}{l}\text { S1 through S4, S6 through S9, S11 through S14, and S16 } \\
\text { through S19 }\end{array}$ \\
\hline
\end{tabular}


A summary of the hydraulic calculation results for the Light Hazard sprinkler systems supplied by riser C is provided in Table 6-16.

Table 6-16. Low zone Light Hazard hydraulic calculations summary, WTC 1 and WTC 2.

\begin{tabular}{|c|c|c|c|c|c|c|c|c|}
\hline Floor & $\begin{array}{c}\text { Number of } \\
\text { Operating } \\
\text { Sprinklers }\end{array}$ & $\begin{array}{c}\text { Area } \\
\left(\mathbf{f t}^{2}\right)\end{array}$ & $\begin{array}{c}\text { Maximum } \\
\text { Area per } \\
\text { Sprinkler } \\
\left.\mathbf{( f t}^{2}\right)\end{array}$ & $\begin{array}{c}\text { Flow } \\
(\mathbf{g p m})\end{array}$ & $\begin{array}{c}\text { Calc. } \\
\text { Delivered } \\
\text { Density } \\
\left(\mathbf{g p m} / \mathbf{f t}^{2}\right)\end{array}$ & $\begin{array}{c}\text { Required } \\
\text { Density } \\
\left(\mathbf{g p m} / \mathbf{f t}^{2}\right)\end{array}$ & $\begin{array}{c}\text { Highest } \\
\text { Delivered } \\
\text { Flow } \\
(\mathbf{g p m})\end{array}$ & $\begin{array}{c}\text { Lowest } \\
\text { Delivered } \\
\text { Flow } \\
(\mathbf{g p m})\end{array}$ \\
\hline 31 & 4 & 784 & 196 & 110 & 0.14 & 0.10 & 36.8 & 21.9 \\
\hline 31 & 8 & 1.568 & 196 & 200 & 0.13 & 0.10 & 33.5 & 19.8 \\
\hline 31 & 16 & 3,136 & 196 & 319 & 0.10 & 0.10 & 27.6 & 15.6 \\
\hline 2 & 4 & 784 & 196 & 150 & 0.19 & 0.10 & 50 & 30.2 \\
\hline 2 & 8 & 1,568 & 196 & 270 & 0.17 & 0.10 & 45 & 27.1 \\
\hline 2 & 16 & 3,136 & 196 & 477 & 0.15 & 0.10 & 40 & 23.8 \\
\hline
\end{tabular}

The results of the calculations demonstrate that the system capabilities meet or exceed the minimum requirements for Light Hazard Occupancies. The results also demonstrate that the lower level systems were capable of discharging more than the upper level systems as a result of the increased pressure. The pressure-reducing valves installed on the lower level systems restricted the flow somewhat.

\section{Ordinary Hazard Calculations for Low Zone with Primary Water Supply}

Fourteen Ordinary Hazard cases were analyzed for the low zone sprinkler systems. The calculations included floors 31 and 9, which represented the highest and lowest floor level systems without pressurereducing valves. Additional calculations were included for floors 2 and 7, which represented the highest and lowest floor level systems with pressure-reducing valves. Multiple calculations were performed to evaluate the range of scenarios involving more than, less than, and equal to the number of sprinklers in the design area. Table 6-17 provides a summary of the active sprinklers in each scenario.

The calculations for the systems on the ninth floor with more than nine operating sprinklers resulted in pressure lower than atmospheric pressure at the top of riser C. Again, this is the result of the friction loss exceeding the net positive head pressure provided by the elevated tank. The friction loss through the supply pipe to the top of riser C imposed an inherent water flow limitation of approximately $640 \mathrm{gpm}$ to the low zone sprinkler systems. The results of the calculations for all of the Ordinary Hazard calculations for the low zone sprinkler systems are provided in Table 6-18. 
Table 6-17. Number of operating sprinklers, $31 \mathrm{st}, 9$ th, 7 th and 2 nd floor Ordinary Hazard calculations, WTC 1.

\begin{tabular}{|c|c|l|}
\hline Floor & $\begin{array}{c}\text { Number of Operating } \\
\text { Sprinklers }\end{array}$ & \multicolumn{1}{|c|}{ Sprinkler Node Identification } \\
\hline 31 & 4 & S1 through S4 \\
\hline 31 & 15 & S6 through S20 \\
\hline 31 & 20 & S1 through S20 \\
\hline 31 & 25 & S1 through S25 \\
\hline 9 & 4 & S1 through S4 \\
\hline 9 & 15 & S6 through S20 \\
\hline 7 & 4 & S1 through S4 \\
\hline 7 & 15 & S6 through S20 \\
\hline 7 & 20 & S1 through S20 \\
\hline 7 & 25 & S1 through S25 \\
\hline 2 & 4 & S1 through S4 \\
\hline 2 & 15 & S6 through S20 \\
\hline 2 & 20 & S1 through S20 \\
\hline 2 & 25 & S1 through S25 \\
\hline
\end{tabular}

Table 6-18. Low zone Ordinary Hazard hydraulic calculations summary, WTC 1 and WTC 2.

\begin{tabular}{|c|c|c|c|c|c|c|c|c|}
\hline Floor & $\begin{array}{c}\text { Number of } \\
\text { Operating } \\
\text { Sprinklers }\end{array}$ & $\begin{array}{c}\text { Area } \\
\left.\mathbf{( f t}^{2}\right)\end{array}$ & $\begin{array}{c}\text { Maximum } \\
\text { Area per } \\
\text { Sprinkler } \\
\left.\mathbf{( f t}^{2}\right)\end{array}$ & $\begin{array}{c}\text { Flow } \\
(\mathbf{g p m})\end{array}$ & $\begin{array}{c}\text { Calc. } \\
\text { Delivered } \\
\text { Density } \\
\left(\mathbf{g p m} / \mathbf{f t}^{2}\right)\end{array}$ & $\begin{array}{c}\text { Required } \\
\text { Density } \\
\left(\mathbf{g p m} / \mathbf{f t}^{2}\right)\end{array}$ & $\begin{array}{c}\text { Highest } \\
\text { Delivered } \\
\text { Flow } \\
(\mathbf{g p m})\end{array}$ & $\begin{array}{c}\text { Lowest } \\
\text { Delivered } \\
\text { Flow } \\
(\mathbf{g p m})\end{array}$ \\
\hline 31 & 4 & 476 & 119 & 157 & 0.33 & 0.15 & 39.6 & 39.1 \\
\hline 31 & 15 & 1,680 & 119 & 401 & 0.24 & 0.15 & 27.1 & 26.3 \\
\hline 31 & 20 & 2,226 & 119 & 447 & 0.20 & 0.15 & 22.8 & 21.8 \\
\hline 31 & 25 & 2,793 & 119 & 476 & 0.17 & 0.15 & 19.7 & 18.3 \\
\hline 9 & 4 & 476 & 119 & 265 & 0.56 & 0.15 & 66.7 & 65.9 \\
\hline 9 & 15 & 1,680 & 119 & 636 & 0.38 & 0.15 & 42.9 & 41.7 \\
\hline 7 & 4 & 476 & 119 & 209 & 0.44 & 0.15 & 52.7 & 52 \\
\hline 7 & 15 & 1,680 & 119 & 486 & 0.29 & 0.15 & 32.8 & 31.9 \\
\hline 7 & 20 & 2,226 & 119 & 553 & 0.25 & 0.15 & 28.3 & 27 \\
\hline 7 & 25 & 2,793 & 119 & 576 & 0.21 & 0.15 & 23.9 & 22.2 \\
\hline 2 & 4 & 476 & 119 & 240 & 0.50 & 0.15 & 60.4 & 59.7 \\
\hline 2 & 15 & 1,680 & 119 & 486 & 0.29 & 0.15 & 32.8 & 31.8 \\
\hline 2 & 20 & 2,226 & 119 & 549 & 0.25 & 0.15 & 28 & 26.7 \\
\hline 2 & 25 & 2,793 & 119 & 575 & 0.21 & 0.15 & 23.6 & 22.2 \\
\hline
\end{tabular}

The low zone sprinkler systems demonstrated similar performance to the systems in the mid-level zone. The calculated discharge density and flow rate for the system on the 31 st floor were nearly identical to those for the systems on the 98th floor. As would be expected, the results also demonstrated a decrease in 
discharge density as the number of operating sprinklers increased. The average discharge density for all cases exceeded the minimum required density. The hydraulic calculations for the sprinkler systems on the seventh and second floors included a fixed pressure loss device representing the pressure-reducing valves. The value of the fixed pressure loss was adjusted to match the pressure loss curves for the straight pattern pressure-reducing valve at the calculated flow rate. This required multiple iterations for each case. This approach reasonably simulated the pressure limits and associated maximum water flow to the floor level sprinkler systems through the pressure-reduction valves.

\section{Calculation of Water Supply Duration}

The water supply duration for the low zone sprinkler systems was evaluated using one 5,000 gal storage tank. Table 6-19 provides a summary of the calculated water supply duration for each of the low zone scenarios.

Table 6-19. Low zone primary water supply duration, WTC 1 and WTC 2.

\begin{tabular}{|c|c|c|c|c|}
\hline Floor & $\begin{array}{l}\text { Number of } \\
\text { Operating } \\
\text { Sprinklers }\end{array}$ & Hazard & $\begin{array}{l}\text { Flow } \\
(\mathrm{gpm})\end{array}$ & $\begin{array}{c}\text { Duration (min) } \\
\text { Based on } 5,000 \text { gal }\end{array}$ \\
\hline 31 & 4 & Light & 110 & 45.50 \\
\hline 31 & 8 & Light & 200 & 25.05 \\
\hline 31 & 16 & Light & 319 & 15.70 \\
\hline 2 & 4 & Light & 150 & 33.27 \\
\hline 2 & 8 & Light & 270 & 18.51 \\
\hline 2 & 16 & Light & 477 & 10.48 \\
\hline 31 & 4 & Ordinary & 157 & 31.79 \\
\hline 31 & 15 & Ordinary & 401 & 12.46 \\
\hline 31 & 20 & Ordinary & 447 & 11.19 \\
\hline 31 & 25 & Ordinary & 476 & 10.52 \\
\hline 9 & 4 & Ordinary & 265 & 18.88 \\
\hline 9 & 15 & Ordinary & 636 & 7.87 \\
\hline 7 & 4 & Ordinary & 209 & 23.89 \\
\hline 7 & 15 & Ordinary & 486 & 10.28 \\
\hline 7 & 20 & Ordinary & 553 & 9.04 \\
\hline 7 & 25 & Ordinary & 576 & 8.69 \\
\hline 2 & 4 & Ordinary & 240 & 20.84 \\
\hline 2 & 15 & Ordinary & 486 & 10.29 \\
\hline 2 & 20 & Ordinary & 549 & 9.12 \\
\hline 2 & 25 & Ordinary & 575 & 8.70 \\
\hline
\end{tabular}

The fixed water storage volume of a single 5,000 gal storage tank was divided by the calculated flow rate to determine the duration. The actual operation sequence of individual sprinklers was not accounted for in the calculation. Additionally, the calculation does not account for supplemental water supplied to the 
tank by the domestic water system through the 2 in. automatic re-fill connection. Therefore, the calculated durations represent a lower limit for the assumed number of operating sprinklers under normal conditions. A case involving both the primary and secondary water storage tanks is examined in the next section.

\section{Comparison of Primary and Secondary Water Supply Calculations}

Hydraulic calculations were performed using the secondary water supply for the low zone sprinkler systems. Table 6-20 provides a comparison of the results to the similar cases with the primary water supply mode.

Table 6-20. Comparison of primary and secondary water supplies for low zone.

\begin{tabular}{|c|l|c|l|c|c|c|c|c|}
\hline Floor & $\begin{array}{c}\text { Water } \\
\text { Supply } \\
\text { Mode }\end{array}$ & $\begin{array}{c}\text { Area } \\
\left(\mathbf{f t}^{2}\right)\end{array}$ & Hazard & $\begin{array}{c}\text { Supply } \\
(\mathbf{g p m})\end{array}$ & $\begin{array}{c}\text { Calc. } \\
\text { Delivered } \\
\text { Density } \\
\left(\mathbf{g p m} / \mathbf{f t}^{\mathbf{2}}\right)\end{array}$ & $\begin{array}{c}\text { Required } \\
\text { Density } \\
\left(\mathbf{g p m} / \mathbf{f t}^{2}\right)\end{array}$ & $\begin{array}{c}\text { Highest } \\
\text { Delivered } \\
\text { Flow } \\
(\mathbf{g p m})\end{array}$ & $\begin{array}{c}\text { Lowest } \\
\text { Delivered } \\
\text { Flow } \\
(\mathbf{g p m})\end{array}$ \\
\hline 31 & Primary & 1,568 & Light & 200 & 0.14 & 0.10 & 36.8 & 21.9 \\
\hline 31 & Secondary & 1,568 & Light & 172 & 0.11 & 0.10 & 29.1 & 17.1 \\
\hline 2 & Primary & 1,568 & Light & 270 & 0.17 & 0.10 & 45 & 27.1 \\
\hline 2 & Secondary & 1,568 & Light & 272 & 0.17 & 0.10 & 45.3 & 27.3 \\
\hline 31 & Primary & 1,680 & Ordinary & 401 & 0.24 & 0.15 & 27.1 & 26.3 \\
\hline 31 & Secondary & 1,680 & Ordinary & 266 & 0.17 & 0.15 & 34.4 & 33.4 \\
\hline 2 & Primary & 1,680 & Ordinary & 486 & 0.29 & 0.15 & 32.8 & 31.8 \\
\hline 2 & Secondary & 1,680 & Ordinary & 436 & 0.28 & 0.15 & 43.4 & 42.2 \\
\hline
\end{tabular}

Unlike the high and mid-level zones, the friction loss associated with the long travel path from the water storage tank in one building through the risers and sub-grade level piping resulted in less water being delivered to the sprinkler systems in the secondary supply mode. The average density provided in the secondary water supply mode exceeded the minimum. However, the minimum required end sprinkler pressure was not maintained for all sprinklers in the Light Hazard case for the 31 st floor.

Table 6-21 provides a comparison of the calculated water supply durations for the low zone sprinkler systems operating in both the primary and secondary modes.

The combined water supply duration adds the two single tank durations. The calculations do not account for refilling of the tanks, the individual operation of sprinklers, or fire department operations. 
Table 6-21. Low zone primary water supply duration, WTC 1 and WTC 2.

\begin{tabular}{|c|c|c|c|c|c|c|}
\hline Floor & $\begin{array}{c}\text { Water } \\
\text { Supply Mode }\end{array}$ & $\begin{array}{l}\text { Number of } \\
\text { Operating } \\
\text { Sprinklers }\end{array}$ & Hazard & $\begin{array}{l}\text { Flow } \\
(\mathrm{gpm})\end{array}$ & $\begin{array}{c}\text { Duration (min) } \\
\text { Based on } 5,000 \text { gal }\end{array}$ & $\begin{array}{c}\text { Combined } \\
\text { Duration of } \\
\text { Primary and } \\
\text { Secondary } \\
\text { Supplies (min) }\end{array}$ \\
\hline 31 & Primary & 8 & Light & 200 & 25.05 & \multirow[t]{2}{*}{54.11} \\
\hline 31 & Secondary & 8 & Light & 172 & 29.06 & \\
\hline 2 & Primary & 8 & Light & 270 & 18.51 & \multirow[t]{2}{*}{36.89} \\
\hline 2 & Secondary & 8 & Light & 272 & 18.38 & \\
\hline 31 & Primary & 15 & Ordinary & 401 & 12.46 & \multirow[t]{2}{*}{31.25} \\
\hline 31 & Secondary & 15 & Ordinary & 266 & 18.79 & \\
\hline 2 & Primary & 15 & Ordinary & 486 & 10.29 & \multirow[t]{2}{*}{21.76} \\
\hline 2 & Secondary & 15 & Ordinary & 436 & 11.47 & \\
\hline
\end{tabular}

\section{Manual Operations and Related Procedures}

The building maintenance and engineering staff at the WTC complex included supervisors and approximately 15 maintenance personnel. Two O\&M manuals indicated some of the required emergency procedures for the engineering and maintenance staff (PANYNJ 1987a). The information in O\&M Manual 23 Fire Protection Systems provided an overview of the intended operations for the fire pumps, sprinkler systems, and standpipe systems in WTC 1 and WTC 2. Additional information in O\&M Manual 18 Sprinkler Systems provided clarification regarding the operation of the sprinkler systcm and pumps and requirements of the standpipe systems.

The primary action required of the engincering and maintenance staff involved operation of the manual fire pumps. Chapter 11 of O\&M Manual 23 provided a description of the fire pumps in WTC 1 and WTC 2. Fire pumps were provided on the B1, 7th floor, 41st floor and 75th floor levels of cach tower. The O\&M manual indicatcd that the maintenance staff was required to place pump 294A or 294B in operation for a fire anywhere in the complex. Either of these pumps was capable of providing water to any of the other upper level pumping stations. The O\&M manual also describes the following:

- Pump 7A (WTC 1) or 7B (WTC 2) was required to be manually started if a fire was reported on any floor between the 7 th floor and the roof.

- Pump 41A (WTC 1) or 41B (WTC 2) was required to be manually started if a fire was reported on any floor between the 41 st floor and the roof.

- Pump 75A (WTC 1) or 75B (WTC 2) was required to be manually started if a fire was reported on any floor between the 75 th floor and the roof.

All of the pumps were rated at $750 \mathrm{gpm}$. Table 6-22 provides a summary of the net pressure head provided by each of the pumps, indicating the height that the pumps could lift water in the systems. 
Table 6-22. Summary of manual fire pump pressure limitations at rated flow (750 gpm), WTC 1 and WTC 2.

\begin{tabular}{|c|l|l|c|c|c|}
\hline \multirow{2}{*}{ Tower } & Pump & Floor & $\begin{array}{c}\text { Floor and (Net) } \\
\text { Elevation in Feet }\end{array}$ & $\begin{array}{c}\text { Net Head } \\
\text { Provided by Pump (ft) }\end{array}$ & $\begin{array}{c}\text { Net Head Pressure } \\
\text { Provided by Pump (psi) }\end{array}$ \\
\hline \multirow{3}{*}{ WTC 1 } & 294A & B1 Level & $294(0)$ & 831 & 360 \\
\cline { 2 - 6 } & 7A & 7th floor & $390(96)$ & 800 & 346 \\
\cline { 2 - 6 } & 41A & 41st floor & $800(506)$ & 831 & 360 \\
\cline { 2 - 6 } & 75A & 75th floor & $1,222(928)$ & 526 & 228 \\
\hline \multirow{3}{*}{ WTC 2 } & 294B & Bl Level & $294(0)$ & 831 & 360 \\
\cline { 2 - 6 } & 7B & 7th floor & $390(96)$ & 800 & 346 \\
\cline { 2 - 6 } & 41B & 41st floor & $800(506)$ & 831 & 360 \\
\cline { 2 - 6 } & 75B & 75th floor & $1,216(922)$ & 526 & 228 \\
\hline
\end{tabular}

The operating procedures for the buildings included manually starting either pump 294A or 294B for a fire on any floor in WTC 1 or WTC 2. The operating procedures also identified that the pumps on the B1 level and the 7 th floor level would be manually started for fires reported between the 7 th and the 40th floors in the respective building, and, pumps 294A and 7A would be started in WTC 1 and pumps 294B and 7B would be started in WTC 2 (PANYNJ 1987a).

The operating procedures describe that the pumps on the B1, 7th floor and 41st floor levels were to be manually started for fires reported between the $4 \mathrm{lst}$ and 74th floors. Pumps 294A, 7A, and 41 A were to be manually started in WTC 1, and pumps 294B, 7B and 41B were to be manually started in WTC 2.

The operating procedures also identify that fires reported on the 75th floor or above would have all four fire pumps manually started in the respective tower. The maintenance staff was available to open and close sectional isolation valves or control valves.

\section{$6.5 \quad$ WTC 7}

\subsubsection{High Zone}

\section{Representative Sprinkler Layout}

Supply calculations were performed for the highest (most demanding) and lowest (least demanding) floors of each zone. Floors 40 and 47 were calculated for the high zone. In performing the supply calculations for WTC 7, the proper selection of the sprinkler design area was necessary so that the performance of the sprinkler systems on different floors could be compared to one another. In determining the design area for analysis, two factors were considered, location and hydraulic remoteness.

The location for the design area on the 47th floor was designated at the end of the northeast supply main as illustrated in Fig. B-37. This area was chosen because it was the hydraulically most remote area on the floor based on the 4 in. main location indicated in the figure (Gensler and Associates 1995).

The location for the design area on the 40th floor was designated on the south side of the $2 \frac{1}{2} \mathrm{in}$. sprinkler loop as illustrated on the typical floor layout in Fig. B-38. This area was primarily chosen due to its 
hydraulic remoteness from the connection to the system riser and its location along Vesey Street, or the "exposed" side of the building facing south towards the WTC complex.

A representative coverage area of $168 \mathrm{ft}^{2}$ per sprinkler was used to determine the number of sprinklers flowing in the calculations for the 47 th floor system and 40th floor systems, as illustrated in Figs. B-37 and B-38. The sprinkler spacing on the 40 th floor was $14 \mathrm{ft}$ by $12 \mathrm{ft}$, based on drawing reviews (Gensler and Associates 1995; Disk 2, \# 52). Figures B-39 and B-40 illustrate a typical sprinkler layout as defined by the Syska and Hennessy construction drawings. Although Fig. B-40 illustrates a spacing of $15 \mathrm{ft}$ by $12 \mathrm{ft}$ along Vesey Street where the remote area is defined, typical ceiling tiles are arranged in $2 \mathrm{ft}$ by $2 \mathrm{ft}$ or $2 \mathrm{ft}$ by $4 \mathrm{ft}$ units. Therefore, sprinklers installed in a center of tile arrangement with a maximum spacing of $12 \mathrm{ft}$ on center by $14 \mathrm{ft}$ on center are representative for the $40 \mathrm{th}$ floor. It should be noted that the maximum spacing for a Light Hazard Occupancy is $15 \mathrm{ft}$ by $15 \mathrm{ft}$, or $225 \mathrm{ft}^{2}$.

Having reviewed the available system and subsystem drawings, a $12 \mathrm{ft}$ by $14 \mathrm{ft}$ spacing was considered representative and suitable for hydraulic calculations on the 40 th and 47 th floor.

\section{Analysis and Results}

The primary supply for the high zone was an automatic fire (booster) pump on the 46th floor that took suction from the two 7,500 gal water storage tanks. The booster pump was rated to supply $500 \mathrm{gpm}$ with a discharge head pressure of $120 \mathrm{psi}$. The booster pump was a model 41F12B single stage horizontal split case fire pump manufactured by Peerless Pump Company, Inc. (PANYNJ 1987a, Syska \& Hennessy 1984). The characteristic fire pump curve, obtained from the manufacturer, was used in the hydraulic calculations.

Refer to Figs. B-41, B-37, and B-38 for the hydraulic node placement that identifies all pipe intersections and diameter changes. The flow path from the discharge side of the pump to the supply side of the floor control valve assemblies on the 40 th and 47 th floors are illustrated in Fig. B-41. The primary supply flow path for the high zone systems extends from node PD3 through TR4C, MR8A and MR8B to each floor level sprinkler system supplied by riser 8 . Nodes TR8 and BR8 represent the nodes on the supply side of the floor control valves on the 47 th floor and 40 th floor, respectively.

A $750 \mathrm{gpm}$ at $310 \mathrm{psi}$ manual fire pump located on the first floor was used to provide the secondary supply for all of the sprinkler and standpipe system zones. The manual fire pump was supplied with water through a redundant dircct connection to the NYC water distribution system. The pump was a Peerless model 5 TUTF 16 single stage, horizontal split case pump. The characteristic pump curve, obtained from the manufacturer, was used in the calculations.

The flow path from the manual fire pump to the high zone is illustrated in Fig. B-41. The flow path extended from the discharge side of the manual fire pump at node PD2, up risers 1 and 2 to nodes TR 1 and TR2, respectively. The flow path then extended up riser 4 to node TR4C.

Three supply calculations were performed on each floor for each water supply. The calculations were conducted with four, nine and eighteen operating sprinklers. Refer to Fig. B-37 for the sprinkler locations on the 47th floor and Fig. B-38 for the sprinkler locations on the 40th floor. Table 6-23 lists the number of operating sprinklers for each scenario on the respective floor. 


\section{Table 6-23. Number of operating sprinklers for hydraulic supply calculations, 47th and 40th floors, WTC 7.}

\begin{tabular}{|c|c|l|}
\hline Floor & $\begin{array}{c}\text { Number of Operating } \\
\text { Sprinklers }\end{array}$ & \multicolumn{1}{|c|}{ Sprinkler Node Identification } \\
\hline 47 & 4 & S1, S2, S5, S6 \\
\hline 47 & 9 & S1, S2, S3, S4, S5, S6, S7, S8, S12 \\
\hline 47 & 18 & S1 through S18 \\
\hline 40 & 4 & S8, S9, S11. S12 \\
\hline 40 & 9 & S4, S5, S6, S7, S8, S9, S10, S11, S12 \\
\hline 40 & 18 & S1 through S18 \\
\hline
\end{tabular}

The calculation results are summarized in Table 6-24. The supply column lists the calculated delivered flow rate for the given number of operating sprinklers for the respective supply. The delivered density is the average ratio of the calculated delivered flow rate, or supply, over the applicable sprinkler coverage area associated with the number of sprinklers assumed to be operating. It should be noted that the representative sprinkler spacing on the 40th and 47th floors was $168 \mathrm{ft}^{2}$ for each sprinkler. Therefore, the sprinkler coverage area was $168 \mathrm{ft}^{2}$ times the number of operating sprinklers. The "required density" is the minimum flow rate per unit area specified for a Light Hazard Occupancy in accordance with RS-17 and NFPA 13 as referenced in the BCNYC (BCNYC 1968).

The supply duration is the time of water availability for the specific flow and corresponding density. The volume available in the tanks limited the primary supply for the high zone sprinkler systems. The supply duration was equal to the number of gallons available in the tanks divided by the supplied flow rate. The durations listed in Table 6-24 for the normal operating conditions do not account for the make-up water available to the tanks, the use of stored domestic water in the tanks, or the incremental increase in actuated sprinklers. The durations were calculated using the calculated flow for all of the sprinklers flowing water at the same time. Therefore, as previously described, the durations listed in Table 6-24 are considered to be minimums.

The supply duration for the secondary water supply is not listed because the water supplicd from the city main is not limited. The calculations were conducted under normal operating conditions for the systems.

The coverage area that involved nine sprinklers was $1,512 \mathrm{ft}^{2}$. This corresponded to a required density of $0.10 \mathrm{gpm} / \mathrm{ft}^{2}$ per NFPA 13 for a Light Hazard Occupancy. The calculations involving the nine sprinkler scenario on the 47th floor resulted in an average delivered density of $0.18 \mathrm{gpm} / \mathrm{ft}^{2}$ and $0.25 \mathrm{gpm} / \mathrm{ft}^{2}$ for the primary and secondary water supplies, respectively. This demonstrates that the primary supply for the high zone was not only adequate, but delivered almost twice the necessary demand required by NFPA 13 . The 47th floor was the most demanding floor in the high zone.

The coverage area that involved 18 sprinklers was approximately $3,024 \mathrm{ft}^{2}$, twice the required system design area per NFPA 13. The calculation results indicate that the primary and secondary water supplies for the 40th and 47th floors were also above the minimum required for a Light Hazard Occupancy per NFPA 13. 
Table 6-24. High zone hydraulic calculations summary, WTC 7.

\begin{tabular}{|c|c|c|l|l|c|c|c|c|c|}
\hline Floor & $\begin{array}{c}\text { Calc. } \\
\text { I.D. }\end{array}$ & $\begin{array}{c}\text { Qty/Area } \\
\left(\mathbf{f t}^{2}\right)\end{array}$ & Source & $\begin{array}{c}\text { Supply } \\
(\mathbf{g p m})\end{array}$ & $\begin{array}{c}\text { Calc. } \\
\text { Delivered } \\
\text { Density } \\
\left(\mathbf{g p m} / \mathbf{f t}^{2} \mathbf{)}\right.\end{array}$ & $\begin{array}{c}\text { High } \\
\text { Delivered } \\
\text { Density } \\
\left(\mathbf{g} \mathbf{p m} / \mathbf{f t}^{2}\right)\end{array}$ & $\begin{array}{c}\text { Low } \\
\text { Delivered } \\
\text { Density } \\
\left(\mathbf{g p m} / \mathbf{f t}^{2}\right)\end{array}$ & $\begin{array}{c}\text { Required } \\
\text { Density } \\
\left(\mathbf{g p m} / \mathbf{f t}^{2}\right)\end{array}$ & $\begin{array}{c}\text { Supply } \\
\text { Duration } \\
(\mathbf{m i n})\end{array}$ \\
\hline 47 & $1 \mathrm{a}$ & $9 / 112$ & Primary & 265 & 0.18 & 0.22 & 0.14 & 0.10 & 57 \\
\hline 47 & $1 \mathrm{c}$ & $9 / 1512$ & Secondary & 371 & 0.25 & 0.31 & 0.21 & 0.10 & NA \\
\hline 40 & $2 \mathrm{a}$ & $9 / 1512$ & Primary & 336 & 0.22 & 0.24 & 0.21 & 0.10 & 45 \\
\hline 40 & $2 \mathrm{c}$ & $9 / 1512$ & Secondary & 423 & 0.28 & 0.30 & 0.26 & 0.10 & NA \\
\hline 47 & $4 \mathrm{a}$ & $4 / 672$ & Primary & 125 & 0.19 & 0.19 & 0.18 & 0.10 & 120 \\
\hline 47 & $4 \mathrm{c}$ & $4 / 672$ & Secondary & 177 & 0.26 & 0.27 & 0.26 & 0.10 & NA \\
\hline 40 & $5 \mathrm{a}$ & $4 / 672$ & Primary & 172 & 0.26 & 0.26 & 0.25 & 0.10 & 87 \\
\hline 40 & $5 \mathrm{c}$ & $4 / 672$ & Secondary & 218 & 0.32 & 0.33 & 0.32 & 0.10 & NA \\
\hline 47 & $7 \mathrm{a}$ & $18 / 3024$ & Primary & 430 & 0.14 & 0.17 & 0.12 & 0.10 & 35 \\
\hline 47 & $7 \mathrm{c}$ & $18 / 3024$ & Secondary & 588 & 0.19 & 0.23 & 0.16 & 0.10 & NA \\
\hline 40 & $8 \mathrm{a}$ & $18 / 3024$ & Primary & 480 & 0.16 & 0.18 & 0.15 & 0.10 & 31 \\
\hline 40 & $8 \mathrm{c}$ & $18 / 3024$ & Secondary & 596 & 0.20 & 0.22 & 0.18 & 0.10 & NA \\
\hline
\end{tabular}

The water supply duration was determined by dividing the water supply source volume by the supply flow rate. The supply duration is only relevant for the primary supply because the secondary supply takes suction from the city water service. Also, the most demanding floor with regard to water supply duration is the lowest floor in the zone, due to the larger head pressure and flow rate. The nine sprinkler calculation on the 40th floor resulted in a supply duration of $45 \mathrm{~min}$. Reference Standard RS-17-2, Section 2-1 of the BCNYC, requires a minimum water supply duration of $30 \mathrm{~min}$. This does not take into account the make-up water provided by the 8 in. express riser from the three $450 \mathrm{gpm}$ domestic pumps on the third floor.

Note the water supply duration for the 18 sprinkler calculation on the 40 th floor. The 31 min duration still exceeded the $30 \mathrm{~min}$ requirement when twice the number of required sprinklers for a Light Hazard Occupancy were flowing.

\subsubsection{Mid-Level Zone}

\section{Representative Sprinkler Layout}

The location for the design area on the 39th and 21 st floors was designated on the south side of the 4 in. diameter sprinkler loop on the 39th floor, and the $2 \frac{1}{2} \mathrm{in}$. sprinkler loop on the 21 st floor as illustrated on the typical floor layout in Fig. B-38. This area was chosen because, like the 40th floor, it was located along Vesey Street, the "exposed" side of the building facing south toward the WTC complex. The floor plan, as defined in the high zone narrative and Fig. B-38 provides a representation that was typical for the floors on the mid-level zone. The representative coverage area of $168 \mathrm{ft}^{2}$ was also typical. 


\section{Analysis}

The primary water supply for the mid-level zone consisted of two 7,500 gal (fire reserve) gravity tanks on the 47 th floor. Refer to Figs. B-41 and B-38 for the hydraulic node placement used in the calculations. The flow path from the gravity tanks continued down riser 4 to the $6 \mathrm{in}$. cross connection on the 20th floor. The flow path continued to node BR5 at the base of riser 5, then up to node MR5A on the 21 st floor and node TR5A on the 39 th floor.

The secondary supply for the mid-level zone was the manual fire pump on the first floor as described in the high zone narrative.

Pressure reducing valves were located on each floor zone on the system side of the floor control valve on the 1st through 25 th floors. The valve was a number 33 Xomatic manufactured by Ford Regulator Valve Corporation (Syska \& Hennessy 1984). The valve had 12 adjustable static pressure settings at the valve outlet from 50 psi to 160 psi at 10 psi increments. It is unknown what the valve settings were. However, for the purposes of thcse calculations, a setting of 160 psi was used. At a 160 psi setting, the maximum outlet residual pressure was achieved for a given flow rate. It is reasonable to assume, for the interest of providing comparable hydraulic calculations, that as long as the residual pressure was below the maximum allowable sprinkler system pressure of 175 psi, the 160 psi setting would have been an appropriate setting.

Three supply calculations were performed on each floor for each water supply. The four, nine and eighteen sprinkler operation cases were evaluated. Refer to Fig. B-38 for the sprinkler locations on the 39 th and 21 st floors. Table 6-25 lists the active sprinklers for each case on the respective floor.

\section{Table 6-25. Number of operating sprinklers for hydraulic supply calculations, 39 th and 21 st floors, WTC 7}

\begin{tabular}{|c|c|l|}
\hline Floor & $\begin{array}{c}\text { Number of Operating } \\
\text { Sprinklers }\end{array}$ & \multicolumn{1}{|c|}{ Sprinkler Node Identification } \\
\hline 39 & 4 & $\mathrm{~S} 8, \mathrm{~S} 9, \mathrm{~S} 11, \mathrm{~S} 12$ \\
\hline 39 & 9 & $\mathrm{~S} 4, \mathrm{~S} 5, \mathrm{~S} 6, \mathrm{~S} 7, \mathrm{~S} 8, \mathrm{~S} 9, \mathrm{~S} 10, \mathrm{~S} 11, \mathrm{~S} 12$ \\
\hline 39 & 18 & $\mathrm{~S} 1$ through S18 \\
\hline 21 & 4 & $\mathrm{~S} 8, \mathrm{~S} 9, \mathrm{~S} 11, \mathrm{~S} 12$ \\
\hline 21 & 9 & $\mathrm{~S} 4, \mathrm{~S} 5, \mathrm{~S} 6, \mathrm{~S} 7, \mathrm{~S} 8, \mathrm{~S} 9, \mathrm{~S} 10, \mathrm{~S} 11, \mathrm{~S} 12$ \\
\hline 21 & 18 & $\mathrm{~S} 1$ through S18 \\
\hline
\end{tabular}

The calculation results are provided in Table 6-26.

The primary supply calculation involving nine sprinklers on the 39 th floor resulted in an average delivered density of $0.16 \mathrm{gpm} / \mathrm{ft}^{2}$ and a minimum delivered density of $0.15 \mathrm{gpm} / \mathrm{ft}^{2}$. Therefore, the most demanding sprinkler system on the mid-level zone was estimated to provide a delivered density that exceeded the minimum delivered density required for systems designed according to NFPA 13.

The density provided by the secondary supply exceeded the density provided by the primary supply in all cases on each floor, and, the water supply duration for each scenario was well above $30 \mathrm{~min}$. 
Table 6-26. Mid-level zone hydraulic calculations summary, WTC 7.

\begin{tabular}{|c|c|c|c|c|c|c|c|c|c|}
\hline Floor & $\begin{array}{l}\text { Calc. } \\
\text { I.D. }\end{array}$ & $\begin{array}{c}\text { Qty/Area } \\
\left(\mathrm{ft}^{2}\right)\end{array}$ & Source & $\begin{array}{c}\text { Supply } \\
\text { (gpm) }\end{array}$ & $\begin{array}{c}\text { Calc. } \\
\text { Delivered } \\
\text { Density } \\
\left(\mathrm{gpm} / \mathrm{ft}^{2}\right)\end{array}$ & $\begin{array}{c}\text { High } \\
\text { Delivered } \\
\text { Density } \\
\left(\mathrm{gpm} / \mathrm{ft}^{2}\right)\end{array}$ & $\begin{array}{c}\text { Low } \\
\text { Delivered } \\
\text { Density } \\
\left(\mathrm{gpm} / \mathrm{ft}^{2}\right)\end{array}$ & $\begin{array}{c}\text { Required } \\
\text { Density } \\
\left(\mathrm{gpm} / \mathrm{ft}^{2}\right)\end{array}$ & $\begin{array}{c}\text { Supply } \\
\text { Duration } \\
\text { (min) }\end{array}$ \\
\hline 39 & $10 a$ & $9 / 1,512$ & Primary & 245 & 0.16 & 0.18 & 0.15 & 0.10 & 61 \\
\hline 39 & $10 c$ & $9 / 1.512$ & Secondary & 492 & 0.33 & 0.35 & 0.30 & 0.10 & $\mathrm{NA}$ \\
\hline 21 & $11 \mathrm{a}$ & $9 / 1,512$ & Primary & 290 & 0.19 & 0.21 & 0.18 & 0.10 & 52 \\
\hline 21 & $11 \mathrm{c}$ & $9 / 1,512$ & Secondary & 303 & 0.20 & 0.22 & 0.19 & 0.10 & $\mathrm{NA}$ \\
\hline 39 & $13 a$ & $4 / 672$ & Primary & 113 & 0.17 & 0.17 & 0.16 & 0.10 & 133 \\
\hline 39 & $13 c$ & $4 / 672$ & Secondary & 230 & 0.34 & 0.35 & 0.33 & 0.10 & $\mathrm{NA}$ \\
\hline 21 & $14 \mathrm{a}$ & $4 / 672$ & Primary & 183 & 0.27 & 0.28 & 0.27 & 0.10 & 82 \\
\hline 21 & $14 c$ & $4 / 672$ & Secondary & 190 & 0.28 & 0.29 & 0.28 & 0.10 & NA \\
\hline 39 & $16 a$ & $18 / 3,024$ & Primary & 411 & 0.14 & 0.15 & 0.13 & 0.10 & 36 \\
\hline 39 & $16 c$ & $18 / 3.024$ & Secondary & 813 & 0.27 & 0.29 & 0.25 & 0.10 & NA \\
\hline 21 & $17 \mathrm{a}$ & $18 / 3,024$ & Primary & 337 & 0.11 & 0.12 & 0.10 & 0.10 & 45 \\
\hline 21 & $17 c$ & $18 / 3.024$ & Secondary & 356 & 0.12 & 0.13 & 0.11 & 0.10 & NA \\
\hline
\end{tabular}

Note the difference between the average delivered density on the 39 th floor and 21 st floor in the 18 sprinkler scenario. The average delivered density with the secondary supply was $0.12 \mathrm{gpm} / \mathrm{ft}^{2}$ on the $21 \mathrm{st}$ floor and $0.27 \mathrm{gpm} / \mathrm{ft}^{2}$ on the 39 th floor. This large difference was due to the pressure reducing valve on the $21 \mathrm{st}$ floor. The delivered flow rate on the $21 \mathrm{st}$ floor was $356 \mathrm{gpm}$, while the flow rate on the 39 th floor was $813 \mathrm{gpm}$. This example demonstrates the effect the pressure reducing valves havc on the system.

\subsubsection{Low Zone}

\section{Representative Sprinkler Layout}

The location for the design area on the 20th floor was designated on the south side of the $4 \mathrm{in}$. sprinkler loop as illustrated on the typical floor layout on Fig. B-38 (Gensler and Associates 1995). This area was chosen because it represents a hydraulically remote portion of the floor, and it is on the side of the building directly exposed to the balance of the WTC complex. The floor plan, as defined in the high zone narrative and Fig. B-38 was representative for the floors on the low level zone, with exception of the unsprinklered areas addressed in previous chapters. The representative coverage area of $168 \mathrm{ft}^{2}$ was used in the calculations.

The first floor loading dock area was provided with a dry pipe sprinkler system. The layout for this system was consistent with Ordinary Hazard spacing. Refer to Fig. B-42 (Swanke Hayden Connell 1998). The spacing was approximately $10 \frac{1}{2} \mathrm{ft}$ by $12 \mathrm{ft}$ with a coverage area of approximately $126 \mathrm{ft}^{2}$ per sprinkler. The maximum coverage area for an Ordinary Hazard Occupancy is $130 \mathrm{ft}^{2}$ per sprinkler, in accordance with NFPA 13. 


\section{Analysis}

The primary water supply for the 1st through 20th floors was the automatic fire pump in the 1st floor fire pump room (Syska \& Hennessy 1984). The pump was a horizontal split case, model 3ABF9 fire pump manufactured by Peerless Pump Company, Inc. (Syska \& Hcnnessy 1984) The fire pump had a rating of $500 \mathrm{gpm}$ at $120 \mathrm{psi}$ (Syska \& Hennessy 1984). The characteristic pump curve obtained from the manufacturer was utilized in the calculations. The secondary supply was provided from the manual fire pump, also located in the fire pump room on the first floor.

Three supply calculations were performed on each floor for the primary water supply and secondary water supply. The calculations were conducted with 4,9 , and 18 sprinklers operating as described in the methodology for the 20th floor system, and 4, 12, and 18 sprinklers operating for the 1 st floor calculations. A case assuming 12 open sprinklers was evaluated because 12 sprinklers at $126 \mathrm{ft}^{2}$ equals a total flow area of $1,512 \mathrm{ft}^{2}$. The total required design area for an Ordinary Hazard Group area is $1,500 \mathrm{ft}^{2}$ at a density of $0.15 \mathrm{gpm} / \mathrm{ft}^{2}$ per NFPA 13. Refer to Figs. B-41, B-38, and B-43. Table 6-27 lists the number of open sprinklers assumed for each case on the respective floor.

Table 6-27. Number of operating sprinklers for hydraulic supply calculations, 1 st and 20th floors, WTC 7.

\begin{tabular}{|c|c|l|}
\hline Floor & $\begin{array}{c}\text { Number of } \\
\text { Operating Sprinklers }\end{array}$ & \multicolumn{1}{|c|}{ Sprinkler Node Identification } \\
\hline 20 & 4 & S8, S9, S11, S12 \\
\hline 20 & 9 & S4, S5, S6, S7, S8, S9, S10, S11, S12 \\
\hline 20 & 18 & S1 through S18 \\
\hline 1 & 4 & S14, S15, S17, S18 \\
\hline 1 & 9 & S7 through S18 \\
\hline 1 & 18 & S1 through S18 \\
\hline
\end{tabular}

The results are provided in Table 6-28.

Table 6-28. Low zone hydraulic calculations summary, WTC 7.

\begin{tabular}{|c|c|c|l|c|c|c|c|c|c|}
\hline Floor & Calc. I.D. & $\begin{array}{c}\text { Qty/Area } \\
\left(\mathbf{f t}^{2}\right)\end{array}$ & Source & $\begin{array}{c}\text { Supply } \\
(\mathbf{g p m})\end{array}$ & $\begin{array}{c}\text { Calc. } \\
\text { Delivered } \\
\text { Density } \\
\left(\mathbf{g p m} / \mathbf{f t}^{2}\right)\end{array}$ & $\begin{array}{c}\text { High } \\
\text { Delivered } \\
\text { Density } \\
\left(\mathbf{g p m} / \mathbf{f t}^{2}\right)\end{array}$ & $\begin{array}{c}\text { Low } \\
\text { Delivered } \\
\text { Density } \\
\left(\mathbf{g p m} / \mathbf{f t}^{2}\right)\end{array}$ & $\begin{array}{c}\text { Required } \\
\text { Density } \\
\left(\mathbf{g p m} / \mathbf{f t}^{2}\right)\end{array}$ & $\begin{array}{c}\text { Supply } \\
\text { Duration } \\
(\mathbf{m i n})\end{array}$ \\
\hline 20 & $19 \mathrm{a}$ & $9 / 112$ & Primary & 285 & 0.19 & 0.21 & 0.18 & 0.10 & NA \\
\hline 20 & $19 \mathrm{c}$ & $9 / 1,512$ & Secondary & 436 & 0.29 & 0.31 & 0.27 & 0.10 & NA \\
\hline 1 & $20 \mathrm{a}$ & $12 / 1,512$ & Primary & 311 & 0.21 & 0.24 & 0.18 & 0.15 & NA \\
\hline 1 & $20 \mathrm{c}$ & $12 / 1,512$ & Secondary & 312 & 0.21 & 0.24 & 0.18 & 0.15 & NA \\
\hline 20 & $22 \mathrm{a}$ & $4 / 672$ & Primary & 151 & 0.22 & 0.23 & 0.22 & 0.10 & NA \\
\hline 20 & $22 \mathrm{c}$ & $4 / 672$ & Secondary & 214 & 0.32 & 0.33 & 0.31 & 0.10 & NA \\
\hline 1 & $23 \mathrm{a}$ & $4 / 504$ & Primary & 191 & 0.38 & 0.39 & 0.36 & 0.15 & NA \\
\hline 1 & $23 \mathrm{c}$ & $4 / 504$ & Secondary & 192 & 0.38 & 0.40 & 0.37 & 0.15 & NA \\
\hline 20 & $25 \mathrm{a}$ & $18 / 3,024$ & Primary & 391 & 0.13 & 0.14 & 0.12 & 0.10 & NA \\
\hline 20 & $25 \mathrm{c}$ & $18 / 3,024$ & Secondary & 644 & 0.21 & 0.23 & 0.20 & 0.10 & NA \\
\hline 1 & $26 \mathrm{a}$ & $18 / 2,268$ & Primary & 341 & 0.15 & 0.19 & 0.12 & 0.15 & NA \\
\hline 1 & $26 \mathrm{c}$ & $18 / 2,268$ & Secondary & 344 & 0.15 & 0.19 & 0.12 & 0.15 & NA \\
\hline
\end{tabular}




\subsubsection{Manual Operations and Related Procedures}

The WTC 7 building maintenance and engineering staff was familiar with the locations of emergency equipment and the required actions to support the systems in an emergency situation. Such actions during a fire event included starting the manual fire pump on the first floor. Other emergency actions included closing isolation valves to support systems in the case of a ruptured pipe. The operations and maintenance manual included a riser diagram that indicated the arrangement of valves on the systems (PANYNJ 1987). The use of system isolation valves was referenced as follows: "Emergency conditions unrelated to a system response to a fire, which may require actions based on this manual include: Isolation of a riser or sprinkler zone because of a rupture, also a mechanical failure which will activate the flow switch resulting in an alarm. Both conditions require isolation of the ruptured pipe or sprinkler head."

The City of New York has a common firefighting challenge with other large cities. The challenge involves firefighting operations among the ever-growing number of high-rise office buildings. The Fire Department of New York (FDNY) addressed this challenge by developing a standard set of procedures for dealing with high-rise office building fires. In 1986, the FDNY developed Fire Fighting Procedures and Fire Operations for High-Rise Office Buildings to meet the challenge (FDNY 1990). Among the procedures and operations outlined in the manual are the methods used by the FDNY to supplement automatic sprinkler systems and standpipe systems within high-rise office buildings.

The NYC Building Code requires all new high-rise buildings to have a primary water supply and a secondary water supply to supplement the fire protection water demands (BCNYC 1968). In buildings over $300 \mathrm{ft}$, a manual fire pump, or combination of manual fire pumps must be installed as a secondary water supply. However, fire department connections (FDC) are also required as an auxiliary water supply. Therefore, in buildings over $300 \mathrm{ft}$. the FDNY procedures include connecting to the FDC to provide a tertiary supply to the automatic sprinkler systems and standpipe systems in high-rise office buildings (Grill and Johnson 2005, 2005a). A system of color-coded caps identify whether the FDC supplies a standpipe system, automatic fire sprinkler system, combined sprinkler and standpipe system, or a high pressure supply for upper floor level systems. Specific procedures and recommended pressures are outlined in the Fire Fighting Procedures and Fire Operations for High-Rise Office Buildings manual developed by the FDNY (FDNY 1990, 1990a).

The FDNY has two types of pumper engines, conventional and high-pressure. The conventional pumpers contain two-stage pumps with either 1,000 or $2,000 \mathrm{gpm}$ capacity. The high-pressure pumpers contain a third stage capability that can supply $500 \mathrm{gpm}$ at $700 \mathrm{psi}$. Whether used singly or supplementarily, these pumpers have the capability of supplying floors in high-rise buildings up to 110 stories. The Fire Fighting Procedures and Fire Operations for High-Rise Office Buildings manual suggests supplying the standpipe systems with at least two pumpers at two different siamese connections to ensure that an adequate water supply is added to the system.

The Fire Fighting Procedures and Fire Operations for High-Rise Office Buildings manual outlines the recommended pump pressures to be used based on floor level and nozzle type attached to the hose lines. The pressures are based on calculations that take into account nozzle pressure, friction loss of three lengths of $21 / 2$ in. hose, head loss, system friction losses, and the friction loss of two lengths of $31 / 2 \mathrm{in}$. hose supplying the siamese FDC. Table 5-2 provides a summary of the recommended FDNY pump pressure for high-rise buildings (FDNY 1990). 


\subsection{WATER SUPPLY AND PRIMARY SPRINKLER SYSTEM REDUNDANCIES}

The following section provides a discussion of the redundant features provided in WTC 1, 2, and 7.

\subsubsection{WTC 1 and WTC 2}

The redundant features of the automatic fire sprinkler and standpipe systems are indicated on Figs. B-44 through B-49.

\section{Water Supply}

The WTC complex was provided with two separate feed (supply) connections to the NYC water distribution system. Three isolation valves were positioned to permit the independent shut down of either of these connections without impairing the sprinkler and standpipe systems at the WTC complex. Figure B-44 shows isolation valves on the 12 in. supply main for the WTC complex and the two connections to the NYC water distribution system (Beyler 2002).

\section{Fire Pumps}

Separate distribution infrastructures were provided for the sprinkler and standpipe systems for the low zone systems and sub-grade levels (Beyler 2002).

Two parallel, manually controlled fire pumps were provided on the Bl level for the standpipe systems infrastructure. Either of the pumps could be manually started for a fire anywhere in the complex. The failure of either pump could be overcome by starting the other Bl level pump. Refer to Figs. B-44 and B-45.

Two additional parallel, manually controlled pumps were provided on the Bl level for the sub-grade sprinkler systems infrastructure. Either of these pumps could be manually started to supply water to the sub-grade sprinkler systems anywhere in the complex. Configuration of the system as shown in Figs. B-44 and B-45 permits the failure of either pump to be overcome by starting the other B1 level pump.

Each building was provided with four manually operated fire pumps connected in series, including the Bl level pumps. Refer to Fig. B-45. The B1 level pump and any of the other pumps could supply water at sufficient flow (750 gpm to $1,125 \mathrm{gpm}$ ) and sufficient pressure to supply water to the high or mid-level sprinkler systems. Failure of any two tower pumps would not impact the function of the sprinkler systems. Two fire pumps would be able to supply adequate water volume to a single standpipe for manual fire suppression efforts. Any single manual fire pump and a single FDNY pumper could supply adequate water to the sprinkler systems in both the high and mid-level zones without additional pumping operations.

\section{Tanks}

Three separate 5,000 gal tanks were provided for the upper and mid-level zone sprinkler and standpipe systems (PANYNJ 1972, 1987b; GC Engineering 1998). Refer to Figs. B-45, B-46, and B-47. Each tank 
was provided with a separate automatic fill (make-up) connection from the domestic watcr supply, and was provided with a separate discharge isolation valve at the connection to the standpipe system infrastructure on the 109th floor level (PANYNJ 1972, 1987b). The configuration of the water storage tanks for the high and mid-level zone sprinkler systems allowed for independent operation of cither sprinkler reserve water storage tank. The impairment of a single tank would allow the sprinkler systems to remain fully operational (PANYNJ 1987b).

A single 5,000 gal tank was provided in each tower on the 41 st floor (PANYNJ 1972, 1987b). These two tanks were interconnected through the 4 in. tower cross-connection on the Bl level of the complex (PANYNJ 1972, 1987b). This configuration is shown in Figs. B-45 and B-48. Each tank was provided with a separate automatic fill connection provided by the domestic water supply (PANYNJ 1972, 1987b). Additionally, each tank was provided with a separate discharge isolation valve at the connection to the sprinkler risers. The automatic operation of the sprinkler systems would be maintained in both towers if either tank were disabled.

\section{Standpipes}

The standpipe systems in WTC 1 and WTC 2 were configured with four vertical water supply zones with three risers per zone (PANYNJ 1972, 1987b). Damage to any single standpipe riser within a single zone could be localized using the isolation valves. Refer to Fig. B-45. In the normal operating mode, water would be supplied to the standpipes using the manual fire pumps and FDCs. The closure of two isolating valves on a standpipe riser would allow water to be supplied to the preconnectcd hose stations from the storage tanks (PANYNJ 1972, 1987b). The section of the riser below the lower valve would be supplied with water from the manual fire pumps and FDCs.

\section{Fire Department Connections}

The FDNY was provided with a number of different ways to provide water to the high and mid-lcvel water supply zones as shown in Fig. B-49. Two (total) high-pressure FDCs were provided for WTC 1 and WTC 2. Refer to Fig. B-2 (PANYNJ 1987b). The FDNY could use either of these FDCs to provide watcr to the high and mid-level zone standpipe systems without the use of the manual fire pumps in the building (PANYNJ 1987b; FDNY 1990).

Fourteen separate FDCs were provided around the perimeter of the WTC complex (PANYNJ 1972 , 1987b). The FDC at any location in combination with any single fire pump could provide water to the high and mid-level zone sprinkler and standpipe systems (PANYNJ 1987b; Beyler 2002). The low zone standpipe systems were also supplied by these FDCs as shown in Figs. B-45 and B-49. Isolation valves were provided between the FDC stations (PANYNJ 1972, 1987b). The isolation valves allowed the FDNY to isolate an individual building or section of the WTC complex in the event that damage was sustained to the sub-grade loops. The FDNY could then supply water to the systems through a pumper supplied by the fire hydrants (FDNY 1990; PANYNJ 1987b).

Two separate FDCs were provided for the low zone sprinkler systems (PANYNJ 1972, 1987b). Figures B-45, B-48, and B-49 show that isolation valves were provided to permit the operation of either FDC if a single FDC was impaired. 


\subsubsection{WTC 7}

\section{Water Supply}

The systems infrastructure had three water supplies, one automatic and two manually operated (Syska \& Hennessy 1984). The combined standpipe and sprinkler systems infrastructure included three water supply zones. The primary water supply for each zone was automatic (Syska \& Hennessy 1984). A booster pump with tank was provided for the high zone, gravity water storage tank was provided for the mid level zone, and an automatic fire pump was provided for the lower zone (Syska \& Hennessy 1984). The secondary water supplies for all zones were provided by the manual fire pump on the first floor and the three fire department connections on the pcrimeter of the building. If the primary supplies were to fail, the building maintenance and engineering personnel and the FDNY could provide water to the systems via the manual fire pump and fire department connections (PANYNJ 1987; FDNY 1990).

\section{Fire Pumps}

The automatic fire pump on the 1st floor was a redundant water supply for the 21 st through 24 th floors. These floors were primarily supplied by the gravity tanks on the 47th floor and secondarily supplied by the manual firc pump and fire department connections on the 1st floor. Refer to Fig. B-50.

\section{Water Service}

The building was provided with two 8 in. fire water scrvices (Syska \& Hennessy 1984). The services were connected to the $12 \mathrm{in}$. water main on Washington Street on opposite sides of an isolation valve. One scrvice could be isolated from the system for repairs while maintaining a supply from the othcr water service main. The original design criteria required that all standpipe and sprinkler system calculations be conducted with the assumption that one of the two fire services from the city was to be disconnected (Gensler and Associates 1995).

\subsection{SUMMARY OF TASK 2}

The objective of Task 2 was to document the design and capacity of the water supply system to the automatic fire sprinkler systems and pre-connected hose systems in WTC 1,2, and 7. A detailed review of available information was performed in order to document the water supply system infrastructure and associated redundancies. The capacity of the water supply system was evaluated based on available water flow density. The duration of water supply was evaluatcd based on what would be considered normally expectcd conditions. These two parameters were the primary factors associated with the expected performance of the sprinkler systems in WTC 1,2, and 7.

The primary source of water for the WTC complex was the New York City water distribution system. A complex grid of $20 \mathrm{in}$. and $12 \mathrm{in.} \mathrm{mains} \mathrm{surrounded} \mathrm{the} \mathrm{WTC} \mathrm{complex,} \mathrm{forming} \mathrm{a} \mathrm{robust} \mathrm{water} \mathrm{supply}$ with an average steady state pressure of 50 psi. Each building was supplied with water from the NYC water distribution system. 
The WTC complex was provided with two separate supply connections at Vesey and Liberty Streets with isolation valves to permit independent operation. WTC 7 was provided with two connections from the 12 in. main on the Washington Street side of the building within $12 \mathrm{ft}$ of each other.

The water supply components included water storage tanks, fire pumps, and fire department connections. The primary water supplies for the automatic fire sprinkler and standpipe systems, in most cases, consisted of gravity tanks and booster pumps.

Three separate 5,000 gal water storage tanks were provided for the high and mid-level zone sprinkler and standpipe systems at the tops of WTC 1 and WTC 2. A single 5,000 gal storage tank was provided on the 41 st floor of each tower, and they were interconnected through a 4 in. main. Each tank was provided with a separate re-fill connection. The maintenance and engineering staff supplied water to the fire suppression systems using manually operated fire pumps. The FDNY could supply water to the fire suppression systems using the fire department connections.

The systems in WTC 7 included one automatic and two manually operated water supplies. The combined systems were provided with a single automatic firc pump for the low zone. The high and mid-level zones were supplied from two water storage tanks located on the 47 th floor. The high zone also included a booster fire pump. A single $750 \mathrm{gpm}$ fire pump supplied the secondary water. The FDNY could also supply water to the systems using the fire department connections.

The sprinkler and standpipe system infrastructures werc reconstructed using the available documentation of the systems. Typical floor sprinkler systems were also reconstructed based on available documentation. Hydraulic calculations were performed to evaluate the normally expccted performance of the sprinkler systems based on the configuration of the primary and secondary water supplies. Several sprinkler systems were selected to evaluate each water supply zone.

A commercial computer program, HASS, was used to perform the calculations. Bounding conditions were established to limit the number of calculations and to allow for comparison of the results. Calculations were performed based upon the performance criteria for both Light and Ordinary Hazard areas. The results of the analysis demonstrate robust performance of the sprinkler systems throughout the buildings.

The supply calculations provided estimates of the actual water flow rate and allowed for calculation of the water supply duration. The volume of water stored in tanks was divided by the calculated flow rate to determine the duration. Variations in the number of operating sprinklers or supplemental make-up supplies were not accounted for in this evaluation.

The results of the calculations using the Light Hazard criteria for the sprinkler systems in WTC 1 and WTC 2 indicate that a density of 0.14 to $0.27 \mathrm{gpm} / \mathrm{ft}^{2}$ could be provided to four sprinklers for 33.3 to $89 \mathrm{~min}$; a density of 0.13 to $0.17 \mathrm{gpm} / \mathrm{ft}^{2}$ could be provided to eight sprinklers for 18.5 to $47.7 \mathrm{~min}$; and a density of 0.10 to $0.16 \mathrm{gpm} / \mathrm{ft}^{2}$ could be provided to 16 sprinklers for 10.5 to $32.7 \mathrm{~min}$.

The results of the calculations using the criteria for Ordinary Hazard Group 1 for the sprinkler systems in WTC 1 and WTC 2 indicate that a density of 0.33 to $0.56 \mathrm{gpm} / \mathrm{ft}^{2}$ could be provided to four sprinklers for 18.9 to $61.2 \mathrm{~min}$; a density of 0.22 to $0.38 \mathrm{gpm} / \mathrm{ft}^{2}$ could be provided to 15 sprinklers for 7.9 to $27.6 \mathrm{~min}$; 
a density of 0.18 to $0.26 \mathrm{gpm} / \mathrm{ft}^{2}$ could be provided to 20 sprinklers for 9.0 to $25.2 \mathrm{~min}$; and a density of 0.15 to $0.21 \mathrm{gpm} / \mathrm{ft}^{2}$ could be provided for up to 25 sprinklers for 8.7 to $23.9 \mathrm{~min}$ on most floors.

The results of the calculations using the Light Hazard criteria for the sprinkler systems in WTC 7 indicate that a density of 0.17 to $0.38 \mathrm{gmm} / \mathrm{ft}^{2}$ could be provided to four sprinklers for 82 to $133 \mathrm{~min}$; a density of 0.16 to $0.22 \mathrm{gpm} / \mathrm{ft}^{2}$ could be provided to nine sprinklers for 45 to $61 \mathrm{~min}$; and a density of 0.11 to $0.16 \mathrm{gpm} / \mathrm{ft}^{2}$ could be provided to 18 sprinklers for 31 to $45 \mathrm{~min}$. The durations do not apply to the low zone sprinkler systems because water was supplied from an automatic fire pump drawing suction from the NYC distribution. Therefore, the supply would be provided as long as the water distribution and electrical systems were intact and operational. 


\section{Chapter 7 \\ TASK 3: DIFFERENCES IN INSTALLED SUPPRESSION SYSTEMS IN WTC 1, 2, AND 7}

\subsection{GENERAL}

Differences existed in basic construction between World Trade Center (WTC) 7 and the two towers (WTC 1 and WTC 2). In addition, WTC 7 contained fuel tanks for emergency power that required special fire protection features. The objectives of Task 3 were to identify significant differences in the design of the fire suppression systems in WTC 1,2, and 7 and to estimate the impact of these differences on the level of fire control provided.

\subsection{PRIMARY SYSTEM(S) FEATURES}

The primary elements of the fire suppression systems that were compared for each of the three buildings included the following:

- Primary Water Supply for Sprinkler Systems

- Primary Water Supply for Standpipe Systems

- Primary Water Supply Redundancy

- Secondary Water Supply for Sprinkler Systems

- Secondary Water Supply for Standpipe Systems

- Sprinkler Systems

- Standpipe Systems

- Special Systems Protection Areas

The major features of the suppression systems in WTC 1, 2, and 7 are summarized in Table 7-1. Most of the information in Table 7-1 was derived from the analyses and documentation in Chapters 5 and 6.

\subsubsection{Water Supplies}

\section{Primary Water Supplies for Sprinkler Systems}

The primary water source for all three buildings originated from the New York City (NYC) water distribution system (Beyler 2002). The city water distribution system had the capacity to provide a nearly infinite supply to the buildings, provided that the integrity of the distribution system was maintained.

Two separate and remote $16 \mathrm{in}$. connections supplied a single $12 \mathrm{in}$. fire service main located in the utility 
rack for the WTC complex. The two supplies were located at Vesey and Liberty Streets at the north and south sides of the complex. Isolation valves allowed for the independent shut down of either connection without impairing the fire suppression systems in WTC 1 and WTC 2. Two 8 in. mains were also provided for WTC 7. The two mains were supplied from the same $12 \mathrm{in}$. water distribution system main on Washington Street at the southwest corner of the building. The two mains were located approximately $12 \mathrm{ft}$ apart and supplied both the automatic and manual fires pumps for WTC 7.

Table 7-1. Summary of active fire suppression system features, WTC 1, 2, and 7

\begin{tabular}{|c|c|c|}
\hline System Component & WTC 1 and WTC 2 & WTC 7 \\
\hline Primary water source & $\begin{array}{l}\text { NYC water distribution system for entire } \\
\text { complex. Nearly infinite capacity. }\end{array}$ & $\begin{array}{l}\text { NYC water distribution system for entire } \\
\text { complex. Nearly infinite capacity. }\end{array}$ \\
\hline $\begin{array}{l}\text { Primary water supply } \\
\text { for sprinkler systems }\end{array}$ & $\begin{array}{l}\text { Two } 5,000 \text { gal storage tanks with } 2 \text { in. } \\
\text { automatic refill supplied the high and } \\
\text { mid-level zone systems. The high and } \\
\text { mid-level zones were supplied from } \\
\text { independent risers each tower. } \\
\text { The high zone riser was supplied by a } \\
500 \text { gpm booster pump located on the } \\
108 \text { th floor. The mid-level riser was } \\
\text { gravity supplied. } \\
\text { A single } 5,000 \text { gal storage tank with a } \\
2 \text { in. automatic refill was provided for the } \\
\text { low zone systems in each tower. The two } \\
\text { low zone sprinkler systems infrastructures } \\
\text { were connected through a } 4 \text { in. main } \\
\text { located on the Bl level. }\end{array}$ & $\begin{array}{l}\text { Two } 18,000 \text { gal storage tanks with } 7,500 \text { gal } \\
\text { fire protection reserve and make-up supply } \\
\text { connections were provided for the high and } \\
\text { mid-level zone combined standpipe and } \\
\text { sprinkler systems. } \\
\text { The primary water supply for the high zone } \\
\text { standpipes and sprinkler systems was a } \\
500 \text { gpm at } 55 \text { psi booster pump that took } \\
\text { suction from the two } 7,500 \text { gal storage } \\
\text { tanks. } \\
\text { The mid-level sprinkler systems were } \\
\text { gravity supplied water from the two } \\
7,500 \text { gal gravity storage tanks. } \\
\text { The primary supply for the low zone } \\
\text { systems was a single } 500 \text { gpm at } 120 \text { psi } \\
\text { automatic fire pump that took suction from } \\
\text { the NYC water distribution system. }\end{array}$ \\
\hline $\begin{array}{l}\text { Primary water supply } \\
\text { for standpipe systems }\end{array}$ & $\begin{array}{l}\text { The primary water supply for the } \\
\text { standpipe systems included several } \\
5,000 \text { gal storage tanks located on the } \\
110 \text { th, } 76 \text { th, and } 42 \text { nd floors. The tank } \\
\text { located on the } 110 \text { th floor supplied the } \\
\text { high zone standpipe system risers, the } \\
\text { tank on the } 76 \text { th floor supplied the upper } \\
\text { mid-level zone standpipe system risers, } \\
\text { and the tank on the } 42 \text { nd floor supplied } \\
\text { the lower mid-level zone standpipe } \\
\text { system risers. } \\
\text { A single } 5,000 \text { gal storage tank was } \\
\text { provided on the } 20 \text { th floor of WTC } 1 \text { for } \\
\text { the low zone standpipe systems in both } \\
\text { towers and other portions of the WTC } \\
\text { complex. }\end{array}$ & $\begin{array}{l}\text { Since the building contained a combination } \\
\text { sprinkler/standpipe system, the primary } \\
\text { supply described for the sprinkler systems } \\
\text { also applies to the standpipe systems. }\end{array}$ \\
\hline $\begin{array}{l}\text { Primary water supply } \\
\text { redundancy }\end{array}$ & $\begin{array}{l}\text { The sprinkler system supply tanks for the } \\
\text { upper zones each functioned } \\
\text { independently. The automatic make-up } \\
\text { water connections could have refilled the } \\
\text { tanks at a rate equal to or greater than the } \\
\text { water depletion rate through the single } \\
4 \text { in. connection. }\end{array}$ & $\begin{array}{l}\text { Two water storage tanks supplied the high } \\
\text { and mid-level zones. Water was supplied to } \\
\text { both tanks by an } 8 \text { in. express riser, which } \\
\text { was provided with three } 450 \text { gpm automatic } \\
\text { domestic pumps on the } 2 \text { nd floor. }\end{array}$ \\
\hline
\end{tabular}




\begin{tabular}{|c|c|c|}
\hline System Component & WTC 1 and WTC 2 & WTC 7 \\
\hline $\begin{array}{l}\text { Secondary water } \\
\text { supply for sprinkler } \\
\text { systems }\end{array}$ & $\begin{array}{l}\text { The secondary water supplies were } \\
\text { provided for the sprinkler systems from } \\
\text { the standpipe system. A cross connection } \\
\text { at the top of the standpipe zones at the } \\
109 \text { th floor and } 41 \text { st floor supplied a } \\
\text { secondary source to the sprinkler risers. } \\
\text { The standpipe storage tanks and the } \\
750 \text { gpm manual fire pumps functioned as } \\
\text { secondary water supplies for the sprinkler } \\
\text { systems. } \\
\text { High pressure and standard pressure fire } \\
\text { department connections also served as a } \\
\text { secondary supply. }\end{array}$ & $\begin{array}{l}\text { The secondary water supply to all three } \\
\text { zones was from a } 750 \text { gpm manual fire } \\
\text { pump on the } 1 \text { st floor. } \\
\text { The three fire department connections on } \\
\text { the perimeter of the building acted as a } \\
\text { secondary supply capable of supplying the } \\
\text { entire sprinkler and standpipe system. }\end{array}$ \\
\hline $\begin{array}{l}\text { Secondary water } \\
\text { supply for standpipe } \\
\text { systems }\end{array}$ & $\begin{array}{l}\text { The secondary water supply for the } \\
\text { standpipe systems was from the } 750 \mathrm{gpm} \\
\text { manual fire pumps located on the B1 } \\
\text { level, } 7 \text { th, } 41 \text { st. and } 75 \text { th floors. }\end{array}$ & $\begin{array}{l}\text { Since this was a combined } \\
\text { sprinkler/standpipe system, the secondary } \\
\text { supplies were provided from the } 750 \text { gpm } \\
\text { manual fire pump on the lst floor and the } \\
\text { fire department connections, described } \\
\text { above. }\end{array}$ \\
\hline $\begin{array}{l}\text { Sprinkler system } \\
\text { description }\end{array}$ & $\begin{array}{l}\text { Sprinklers were provided throughout the } \\
\text { buildings except in MERs and electrical } \\
\text { rooms. } \\
\text { A wet pipe sprinkler system infrastructure } \\
\text { was provided throughout each tower. The } \\
\text { infrastructures were composed of three } \\
\text { vertical water supply zones each supplied } \\
\text { by a separate riser. } \\
\text { The high zone sprinkler riser supplied } \\
\text { water to floors } 99 \text { through } 110 \text { using a } \\
500 \text { gpm booster fire pump located on the } \\
108 \text { th floor. The mid-level zone sprinkler } \\
\text { riser supplied water to the sprinkler } \\
\text { systems on floors } 32 \text { through } 98 \text {, and the } \\
\text { low zone sprinkler riser supplied water to } \\
\text { the sprinkler systems on the } 31 \text { st floor } \\
\text { and below. } \\
\text { Each floor was provided with a separate } \\
\text { wet pipe sprinkler system. }\end{array}$ & $\begin{array}{l}\text { The sprinkler systems provided throughout } \\
\text { the building were automatic wet pipe } \\
\text { systems with exception to the } 1 \text { st floor dock } \\
\text { area. This area was a dry system. } \\
\text { Sprinklers were not installed in bathrooms, } \\
\text { electrical rooms, telephone/data rooms, } \\
\text { most of the } 5 \text { th floor, or the OEM generator } \\
\text { room on the } 7 \text { th floor. } \\
\text { The system infrastructure was a } \\
\text { combination wet pipe sprinkler/standpipe } \\
\text { system. }\end{array}$ \\
\hline $\begin{array}{l}\text { Standpipe system } \\
\text { description }\end{array}$ & $\begin{array}{l}\text { The standpipe system was similar to the } \\
\text { nationally recognized Class } 11 \mathrm{I} \text { automatic } \\
\text { wet pipe system. } \\
\text { The system was equipped with: } 2 \frac{1}{2} \text { in. } \\
\text { hose valves, } 2 \frac{1}{2} \mathrm{in} \text {. by } 1 \frac{1}{2} \mathrm{in} \text {. adapters, } \\
125 \mathrm{ft} \text { of } 1 \frac{1}{2} \text { in. hose, and a nozzle at } \\
\text { every floor level of every stair. Additional } \\
\text { hose cabinets were provided such that the } \\
\text { entire building was within } 25 \mathrm{ft} \text { of the end } \\
\text { of a hose nozzle. }\end{array}$ & $\begin{array}{l}\text { The standpipe system was similar to the } \\
\text { nationally recognized Class III automatic } \\
\text { wet pipe system that was part of the } \\
\text { combination sprinkler/standpipe system. } \\
\text { The system was equipped with: } 21 / 2 \text { in. hose } \\
\text { valves, } 21 / 2 \text { in. by } 1 \frac{1}{2} \text { in. adapters, } 125 \mathrm{ft} \text { of } \\
11 / 2 \mathrm{in} \text {. hose, and a nozzle at every floor } \\
\text { level of every stair. Additional hose } \\
\text { cabinets were provided such that the entire } \\
\text { building was within } 25 \mathrm{ft} \text { of the end of a } \\
\text { hose nozzle. }\end{array}$ \\
\hline $\begin{array}{l}\text { Number of vertical } \\
\text { zones }\end{array}$ & $\begin{array}{l}\text { There were three zones for the sprinkler } \\
\text { infrastructure and four zones for the } \\
\text { standpipe infrastructure. }\end{array}$ & $\begin{array}{l}\text { There were three zones for the } \\
\text { combinations sprinkler/standpipe } \\
\text { infrastructure. }\end{array}$ \\
\hline
\end{tabular}




\begin{tabular}{|c|c|c|}
\hline System Component & WTC 1 and WTC 2 & WTC 7 \\
\hline $\begin{array}{l}\text { Number of sprinkler } \\
\text { risers per vertical } \\
\text { zone }\end{array}$ & $\begin{array}{l}\text { One sprinkler riser was provided per } \\
\text { vertical zone. } \\
\text { All sprinkler risers were supplied from } \\
\text { tanks above. }\end{array}$ & $\begin{array}{l}\text { There was one sprinkler riser per vertical } \\
\text { zone. } \\
\text { All sprinkler zones were supplied from } \\
\text { tanks above, except the low zone was } \\
\text { supplied from an automatic fire pump } \\
\text { located on the 1st floor. }\end{array}$ \\
\hline $\begin{array}{l}\text { Number of standpipe } \\
\text { risers per vertical } \\
\text { zone }\end{array}$ & $\begin{array}{l}\text { There were three standpipes per vertical } \\
\text { zone. }\end{array}$ & $\begin{array}{l}\text { There were three standpipes per vertical } \\
\text { zone. }\end{array}$ \\
\hline $\begin{array}{l}\text { Type of sprinklers } \\
\text { (response and } \\
\text { characteristics) }\end{array}$ & $\begin{array}{l}\text { In general, ordinary temperature }\left(165^{\circ} \mathrm{F}\right) \\
\text { sprinklers were used. High temperature } \\
\text { sprinklers were used where required } \\
\text { based on environmental conditions. } \\
\text { Standard spray sprinklers were used in all } \\
\text { sprinkler systems. } \\
\text { Both quick response and standard } \\
\text { response were used. }\end{array}$ & $\begin{array}{l}\text { In general, ordinary temperature }\left(165^{\circ} \mathrm{F}\right) \\
\text { sprinklers were used. High temperature } \\
\text { sprinklers were used where required based } \\
\text { on environmental conditions. } \\
\text { Standard spray sprinklers were used in all } \\
\text { sprinkler systems. } \\
\text { Both quick response and standard response } \\
\text { were used. }\end{array}$ \\
\hline Type of hose stations & $\begin{array}{l}\text { Hose stations and hose cabinets were } \\
\text { located in the stair enclosures. Additional } \\
\text { hose cabinets were used in corridors and } \\
\text { tenant spaces to provide adequate } \\
\text { coverage on some floors. }\end{array}$ & $\begin{array}{l}\text { Hose reels located in the stair enclosures } \\
\text { and hose cabinets located throughout the } \\
\text { floors in order to provide adequate } \\
\text { coverage. }\end{array}$ \\
\hline Hose length & $125 \mathrm{ft}$ & $125 \mathrm{ft}$ \\
\hline $\begin{array}{l}\text { Special hazard } \\
\text { suppression systems }\end{array}$ & $\begin{array}{l}\text { Dry chemical fire suppression systems } \\
\text { were provided for the protection of } \\
\text { cooking appliances and hoods. } \\
\text { Steam smothering systems were provided } \\
\text { for the protection of the exhaust duct } \\
\text { systems. } \\
\text { Carbon dioxide, Halon 1301, and clean } \\
\text { agent systems were used to protect large } \\
\text { and valuable computer rooms. } \\
\text { Local application deluge sprinkler } \\
\text { systems were used for the protection of } \\
\text { fan units. }\end{array}$ & $\begin{array}{l}\text { A dry-pipe sprinkler system was provided } \\
\text { for the protection of the two } 12,000 \text { gal fuel } \\
\text { oil storage tanks located beneath the loading } \\
\text { berths on the south side of the building } \\
\text { adjacent to Vesey Street. } \\
\text { An Inergen clean agent suppression system } \\
\text { was provided for the protection of a } \\
6,000 \text { gal fuel oil storage tank room located } \\
\text { on a mezzanine } 8 \mathrm{ft} \text { above the elevator } \\
\text { storage area on the } 1 \text { st floor. } \\
\text { The fuel pumps were located on the } 1 \mathrm{st} \\
\text { floor near the loading dock and were } \\
\text { protected by a dry-pipe sprinkler system. }\end{array}$ \\
\hline
\end{tabular}

Water storage tanks were provided as the primary supply for all of the sprinkler systems in WTC 1 and WTC 2. The water storage tanks were supplied by the water distribution system via domestic water supply pumps (Beyler 2002; PANYNJ 1987, 1987a).

The sprinkler systems on the 21 st through 47 th floors of WTC 7 were also supplied from water storage tanks. However, the 1st through 20th floors were supplied from an automatic fire pump located on the 1st floor that took suction directly from the city water distribution system.

As indicated in Chapters 5 and 6, the water supply capacity and durations were similar for these three buildings. 


\section{Primary Water Supply for Standpipe Systems}

Each standpipe system zone in WTC 1 and WTC 2 was supplied by 5,000 gal water storage tanks on the 110 th, 76th, and 42nd floors of WTC 1 and WTC 2 and the 20th floor of WTC 1 (PANYNJ 1972, 1987b). The standpipe system for WTC 7 was supplied by the same sources as the sprinkler systems (i.e., a combined sprinkler/standpipe system) (Syska \& Hennessy 1984). Automatic booster pumps located on the 108th floor of both WTC 1 and WTC 2 and the 46th floor of WTC 7 supplied the highest zone of each building (PANYNJ 1972, 1987b; Syska \& Hennessy 1984).

The only differences in primary water supplies were the number of vertical zones and the number of risers supplying each zone. The high and mid-level zones in WTC 1 and WTC 2 shared two 5,000 gal sprinkler reserve water storage tanks. The low zone sprinkler zones were supplied from a single 5,000 gal storage tank shared with the standpipe system located on the 42 nd floor. The two system infrastructures were interconnected to allow the tanks to supply the sprinkler systems in the other building.

The combined sprinkler and standpipe systems in WTC 7 were supplied by two 18,000 gal water storage tanks located on the 47th floor (Syska \& Hennessy 1984). Each tank was used for combined domestic and fire protection use and contained a 7.500 gal fire protection reserve water storage capacity (Syska $\&$ Hennessy 1984). These tanks supplied water to the high and mid-level zone systems on the 21 st through 47 th floors (Syska \& Hennessy 1984).

As discussed above, the automatic fire pump located on the 1st floor served as the primary water supply for the low zone sprinkler and standpipe systems located on the 1st through 20th floors of WTC 7. This pump took suction from the NYC water distribution system. Since both the primary and secondary water supplies for the low zone sprinkler and standpipe systems in WTC 7 were provided by the NYC water distribution system. loss of the water main on Washington Street could have prevented water from being supplied to these systems.

It is unknown if the dependence of the low zone standpipe system arrangement in WTC 7 on the Washington Street supply main had a significant impact on the performance of the sprinkler and standpipe systems in WTC 7 on September 11,2001. The standpipe system in WTC 7 was reportedly used to supply water to fight fires at other buildings. This, along with any damage to the Washington Street supply main due to the collapse of WTC 1 and WTC 2. would have significantly reduced the effectiveness of the sprinkler and standpipe systems to the lower floors in WTC 7.

Differences in the water supplies were relatively insignificant, and were limited primarily to the capacity and location of the supply tanks, which basically affected the maximum available duration of the primary water supply(s). However, the capacities and supply durations were consistent with the associated requirements in the $\mathrm{BCNYC}$ and would normally have provided adequate primary water supply until fire department operations were initiated to supplement the water supply.

\section{Primary Water Supply Redundancies}

The three 5,000 gal water storage tanks located on the 110th floors of WTC 1 and WTC 2 were designed to operate independently, providing redundant water supplies for the sprinkler systems from the $32 \mathrm{nd}$ through 98th floors (PANYNJ 1972, 1987b). The 5,000 gal storage tank located on the 42nd floor of WTC 1 and the 5,000 gal storage tank on the 42nd floor of WTC 2 were interconnected at the B1 level 
(PANYNJ 1972, 1987b). Each of these tanks also functioned independently and could redundantly supply the sprinkler systems on the 2 nd through 32 nd floors of the other building.

The two water storage tanks in WTC 7, each with a fire reserve capacity of 7,500 gal, also functioned independently (Syska \& Hennessy 1984; PANYNJ 1987). These tanks provided redundant water supplies to the sprinklers on the 21 st through 47 th floors. A single 500 gpm automatic fire pump supplied the 1 st through 20th floors of WTC 7 (Syska \& Hennessy 1984; PANYNJ 1987). The automatic fire pump was supplied from two independent $8 \mathrm{in}$. water service connections from the $12 \mathrm{in}$. water supply main on Washington Street. The stored water tanks in WTC 7 did not supply the lower zone (i.e., floors 1 through 20).

\section{Secondary Water Supply for Sprinkler Systems}

The 750 gpm manual fire pumps that wcre located at the base of each vertical standpipe zone of WTC 1 and WTC 2 provided a secondary water supply to the sprinkler systems (PANYNJ 1972, 1987a). A connection was made at the top of the highest standpipe zone between the standpipe system and the sprinkler system (PANYNJ 1972, 1987a). The connection was made through a check valve allowing flow from the standpipe system to the sprinkler system (PANYNJ 1972, 1987a). Therefore, the manual fire pumps from the standpipe system provided a secondary water supply to the sprinkler systems on the 33rd floor through the 110 th floor from the connection on the 110th floor. Fire department connections located around the perimeter of WTC 1 and WTC 2 also provided a secondary supply to the sprinkler systems (PANYNJ 1972, 1987a). Two high pressure and 14 low pressure fire department connection stations were provided for the upper zone sprinkler systems through the standpipes (PANYNJ 1972, 1987a). Two fire department connections were provided for the low zone sprinkler systems (PANYNJ 1972, 1987a).

The 750 gpm manual fire pump that was located in the first floor fire pump room in WTC 7 was installed in parallel with the automatic fire pump (Syska \& Hennessy 1984; PANYNJ 1987). Since the standpipe system and sprinkler system infrastructure was a combination sprinkler/standpipe system, i.e., a standpipe served as a sprinkler riser, the 750 gpm manual fire pump served as a secondary supply to all of the sprinkler systems in the building (Syska \& Hennessy 1984; PANYNJ 1987). The three fire department connections for the building served as a tertiary supply that served all of the systems in the building (Syska \& Hennessy 1984; PANYNJ 1987).

\section{Secondary Water Supply for Standpipe Systems}

The secondary water supply for WTC 1 and WTC 2 consisted of 750 gpm manual fire pumps located on the B-1, 7th, 41st, 75th and 108th floor of each building (PANYNJ 1972, 1987a). These fire pumps supplied the entire building. The secondary water supply for WTC 7 was a single $750 \mathrm{gpm}$ manual fire pump.

Additionally, WTC 1 and WTC 2 were equipped with standard and high pressure fire department connections that served as the secondary supplies to the standpipe systems (PANYNJ 1972, 1987a). Typically, a high pressure pumper truck could have supplied the entire standpipe system in WTC 1 and WTC 2 by connecting to the high pressure connections (FDNY 1990). The three fire department connections surrounding WTC 7 also provided the secondary supply to the standpipe systems (PANYNJ 1987). 
Three standpipe risers were used in WTC 1 and WTC 2 to supply each zone above the locations of the manual fire pumps. Therefore, if two of the three standpipes were isolated on each vertical standpipe zone for WTC 1 or WTC 2, water could still be supplied to zones above. However, in WTC 7 only two of the three standpipes were used to supply water to the 20th floor, and, only one standpipe supplied floors 21 through 47.

The primary difference in the secondary supplies to the standpipe systems was the redundancy in the supply risers. While WTC 1 and WTC 2 supplied upper zones with three risers (interconnected at the top), IVTC 7 supplied the mid-level zone with only two risers and the high zone with one riser, without interconnections. Additionally, the single standpipe used to provide the secondary water supply to the upper zone standpipe systems served as the primary supply riser for the mid-level sprinkler systems.

\subsubsection{Sprinkler Systems}

All three buildings were protected essentially throughout by wet pipe automatic fire sprinkler systems (PANYNJ 1972, 1987a). Some areas of the buildings were excluded from coverage by the wet pipe systems. Each building contained three vertical water supply zones (PANYNJ 1972, 1987a). The primary differences in the sprinkler systems in WTC 1, 2, and 7 were that the systems in WTC 7 were supplied from a combined sprinkler and standpipe system infrastructure. Although the standpipe systems in WTC 1 and WTC 2 were used to supply secondary and tertiary water supplies to the high and mid-level zone sprinkler systems, the sprinkler system infrastructures in WTC 1 and WTC 2 functioned separately from the standpipe systems in the primary water supply mode (PANYNJ 1987b).

The mechanical and electrical rooms in WTC 1 and WTC 2 were the only areas in these buildings above the Bl levels that were not protected by automatic sprinklers (PANYNJ 1987a; GC Engineering 1998). The generator rooms for WTC 1 and WTC 2 were located on the B1 levels (PANYNJ 1972).

The electrical, data/telephone, day tank, and generator rooms that were part of the core areas in WTC 7 were not protected by wet pipe sprinkler systems (Syska \& Hennessy 1984; PANYNJ 1987). One exception was the seventh floor generator room, which was protected by a wet pipe automatic sprinkler system. Portions of the first floor loading dock area in WTC 7 were protected by a dry pipe automatic fire sprinkler system in order to prevent freezing of the system (Swanke et al. 1998).

The absence of sprinkler protection in bathrooms of Light Hazard Occupancy buildings is not an unusual practice and is permitted under both the Building Code of the City of New York (BCNYC) and National Fire Protection Association (NFPA) 13. Based on the limited information available, it is doubtful that the absence of automatic fire sprinkler protection in the bathrooms of WTC 7 played a significant role in the collapse of WTC 7 on September 11, 2001. In addition, the hydraulic analyses documented in Chapters 5 and 6 indicate that the fire sprinkler system would be expected to control a fire that occurred in an unsprinklered bathroom unless an unusual fire load was present.

\subsubsection{Standpipe Systems}

The standpipe systems in all three buildings were similar to Class III standpipes. The standpipe systems in WTC 1 and WTC 2 were separate from the automatic sprinkler systems within the protection zones. In WTC 7, the systems were combined. Either method is commonly used to protect these types of buildings. 
The standpipe systems in WTC 1 and WTC 2 were virtually the same. The primary differences in the standpipe systems in WTC 1 and 2 included additional hose stations in the corridors and tenant spaces on individual floors and an additional storage tank located on the 20th floor of WTC 1.

The standpipe systems in WTC 1 and WTC 2 were interconnected at the top of each zone with check valves that prevented downward flow in two of the three risers. This arrangement permitted upward flow through all three risers while operating in the secondary supply modes using the manual fire pumps or fire department connections. The standpipe systems in WTC 7 did not have a similar interconnection at the top of the standpipe zones. This could have adversely affected firefighting activities, as well as automatic sprinkler performance on the upper floors of WTC 7, if the main tank supplies had been interrupted.

\subsection{SPECIAL SYSTEMS PROTECTION}

Several special hazards fire suppression systems were installed in WTC 1, 2, and 7. Special hazards systems in WTC 1 and WTC 2 were provided for the protection of kitchen hoods and ducts, HVAC fan units, and computer rooms. Special hazards systems in WTC 7 were provided for protection of the fuel oil systems (Syska \& Hennessy 1984; Emery et al. 1987; Gensler and Associates 1995; Swanke et al. 1998).

Dry chemical fire suppression systems were provided for protection of cooking appliances and hoods in the restaurants in WTC 1 and WTC 2 (PANYNJ 1987b). Steam smothering systems were provided for the protection of the exhaust duct systems. Carbon dioxide, Halon 1301, and clean agent systems were used to protect computer rooms in WTC 1 and WTC 2 (PANYNJ 1987b). Local application deluge sprinkler systems were used for the protection of fan units in WTC 1 and WTC 2 (PANYNJ 1987a). It is unlikely that the presence of these localized systems in WTC 1 and WTC 2 had any significant impact on the outcome of the events on September 11.

WTC 7 contained fuel oil powered generators and day tanks located on the fifth, seventh, eighth, and ninth floors. The fire suppression protection varied for each component of the fuel oil supply to the generators. A dry-pipe sprinkler system was provided for the protection of the two 12,000 gal fuel oil storage tanks located beneath the loading berths on the south side of the building adjacent to Vesey Street. An Inergen suppression system was provided for the protection of the 6,000 gal fuel oil storage tank room located on a mezzanine $8 \mathrm{ft}$ above the elevator storage area on the first floor. The area below this room was protected by a wet pipe sprinkler system. The fuel pumps were located on the first floor near the loading dock and were protected by a dry-pipe sprinkler system.

The piping between the pumps and the storage tanks was located in an underground concrete trench. No fire suppression was provided in these areas. The vertical risers for the fuel oil systems were located in two vertical masonry shafts that did not have fire suppression. The generator and day tank enclosures on the fifth, eighth, and ninth floors were not protected by automatic sprinklers. These omissions of sprinkler coverage were permitted under the BCNYC. They also resulted in the potential for large quantities of combustible liquids (fuel oil) to become involved in the fires which occurred on September 11, 2001, in WTC 7. This would have significantly contributed to rapid fire spread in these areas. 


\section{$7.4 \quad$ DISCUSSION}

The comparisons drawn among the fire suppression features in WTC 1, 2, and 7 demonstrate that the differences were primarily a function of the sizes of the systems. For example, WTC 7 required only one manual fire pump to provide a secondary supply to the standpipe system through the 47th floor, while WTC 1 and WTC 2 required two of the five manual fire pumps per building to provide a secondary supply to the entire building. Although the sizes and configurations of system components differed, there were no appreciable differences in expected fire control based on the major fire suppression features identified.

There was one relatively major difference between the standpipe systems that were in each of the three buildings and the type of systems that are currently required by NFPA 14, Standard for the Installation of Standpipe and Hose Systems. BCNYC did not specify an automatic water supply requirement for standpipe systems. NFPA 14, Standard for the Installation of Standpipe and Hose Systems

(2003 Edition), Section 5.4.1.2 requires that "Class I standpipe systems in buildings classified as high-rise buildings be automatic, or semi-automatic." Section 5.4.3 states that all Class II and Class III standpipe systems be automatic-wet or semiautomatic-wet systems...," regardless of whether it is in a building classified as a high-rise or not. Therefore, in all three buildings, if the fire department or building personnel did not activate the manual fire pumps, or if a pumper truck was unavailable to connect to a fire department connection, the only water available for manual fire fighting activities on the fire floor would have been from residual flow available from the water storage tanks. The automatic water supply required by NFPA 14 is $250 \mathrm{gpm}$ at the two most remote hose connections on the most remote standpipe and $250 \mathrm{gpm}$ at the most remote hose connections at the next most remote standpipes, not to exceed $1,000 \mathrm{gpm}$ for a fully sprinklered building. The minimum required residual pressure is $100 \mathrm{psi}$.

The water storage tanks provided a reasonable level of fire control from the hose connections at floors well below the water storage tanks. However, the level of fire control provided from a standpipc system installed in accordance with NFPA 14 would have greatly increased the capacity of the automatic water supply available, assuming continued access to the city water supply. While not a requirement in the BCNYC, it has been a requirement in NFPA 14, and would represent "best practice" at the timc of installation as well as today.

\subsection{SUMMARY OF TASK 3}

The primary water source for all three buildings originated from the New York City water distribution system. The towers were supplied from the sub-grade loops on the north and south sides of the complex at two remote locations. The two mains provided redundant supplies and had isolation valves to allow for independent operation of either main without impairing the fire suppression systems in the WTC complex. Two mains, located within $12 \mathrm{ft}$ of each other, supplied WTC 7 from the samc NYC water distribution system main.

The primary difference between the sprinkler and standpipe systems in WTC 7 and those in the towers was that the sprinkler and standpipe systems in WTC 1 and WTC 2 were separate, and the sprinkler and standpipe systems in WTC 7 were combined. Both arrangements were permitted. 
Multiple water supply zones were provided in each building. The standpipe systems in WTC 1 and WTC 2 included four vertical zones. The sprinkler systems infrastructures in WTC 1 and WTC 2 included three vertical zones. The combined sprinkler and standpipe systems in WTC 7 included three vertical zones.

Water storage tanks were used as the primary water supplies for all sprinkler and standpipe system zones in WTC 1,2, and 7, except for the low zones of WTC 7, which were supplied by the NYC water distribution system through a $500 \mathrm{gpm}$ automatic fire pump.

A single $750 \mathrm{gpm}$ manual fire pump was used as the secondary water supply for the combined sprinkler and standpipe systems in WTC 7. A series of four vertical $750 \mathrm{gpm}$ manual fire pumps were used in each tower.

Sprinklers were provided essentially throughout all areas of WTC 1,2, and 7. Sprinklers were omitted in the mechanical equipment rooms (MERs) in WTC 1 and WTC 2. In addition, the electrical, data/telephone, and generator rooms that were part of the core areas in WTC 7 were not protected by the wet pipe sprinkler systems. This included areas on floors $5,7,8$, and 9 .

The sprinkler systems in all three of the buildings were designed with looped mains and were capable of delivering robust discharge densities exceeding the code required minimum densities. Pressure reducing valves were used in all three buildings.

The standpipe systems in all three buildings were similar to Class III standpipes. The standpipe systems in WTC 1 and WTC 2 were separate from the automatic sprinkler systems within the protection zones. In WTC 7, the systems were combined. In practice, either method is used.

The types of special hazard fire suppression systems in each building were different, but no information was found that indicated that these systems played a significant role in fire control or the loss of fire control on September 11, 2001.

While limited information was available regarding the actual performance of the installed fire suppression systems on September 11,2001, several design features were identified that could be improved upon in future installations. For example, in WTC 1 and WTC 2, the supply pipe from the primary water storage tanks on the 110th floor to the sprinkler systems included a long horizontal length ( $>100 \mathrm{ft}$ ) of pipe on the floor directly under the tanks that leads to the vertical riser. Due to the associated friction loss in this run of pipe, the flow was restricted to the upper floors.

In WTC 7, the automatic sprinkler systems on floors 1 through 20 were supplied directly from the city distribution system through an automatic fire pump located on the 1st floor. Either a loss of power to the fire pump or significant damage to the underground city main in the vicinity of the building could interrupt the water supply to these sprinkler systems. A simple means of backing up the primary water supply for floors 1 through 20 would have been to provide secondary access to the stored water on the upper floors of the building. 


\section{Chapter 8 \\ TASK 4: EXPECTED PERFORMANCE OF THE SUPPRESSION SYSTEMS UNDER SPECIFIC BUILDING FIRE SCENARIOS}

\subsection{GENERAL}

The objective of Task 4 was to determine the expected performance of the automatic fire sprinkler systems and the standpipe/pre-connected hoses in World Trade Center (WTC) 1,2 and 7 under a number of representative fire conditions. The analysis used for this task included hydraulic calculations of the sprinkler and standpipe systems in each building with several variations to observe performance of the suppression systems for four scenarios specified in the scope of work. A lack of performance criteria and history for standpipe systems limited the evaluation of the pre-connected hoses. Therefore, the primary emphasis was on evaluation of the performance expectations of the installed automatic sprinkler systems. Some analysis and discussion of the capacity of the standpipe/pre-connected hose systems are included in Sec. 8.3.

\subsection{HYDRAULIC ANALYSIS FOR AUTOMATIC SPRINKLER SYSTEMS}

This analysis relied extensively on the baseline hydraulic calculations documented in Chapter 6 . The calculations in Chapter 6 demonstrated the "normal" performance of the sprinkler systems with discharge application areas corresponding to the design areas specified in National Fire Protection Association (NFPA) 13, Installation of Sprinkler Systems. In the analysis presented here, the discharge application area was varied to assess conditions involving small fires (less than the design area), large fires (larger than the design area). and multiple fires on multiple floors. The following fire scenarios were evaluated as part of this analysis:

- A single fire much smaller than the design area

- A single fire much larger than the design area

- Multiple fires on different floors that result in a number of small fires

- Multiple fires assumed to be equivalent to the design area on the same or multiple floors

The performance of the sprinkler systems was measured in terms of the calculated delivered density for the application area and the remote end-sprinkler pressure, based on the number of operating sprinklers. Hydraulic calculations were performed to determine the average delivered density of the sprinkler systems over the entire application area, based on the available water supply. The minimum density and pressure established in NFPA 13 were used as the performance limits for this analysis. It was assumed that if the calculated average delivered density and pressure were at or above the minimum levels specified in NFPA 13, then fire control or suppression would be expected. 
This analysis was intended to identify conditions where the minimum pressures and design densities would be reduced to levels below the minimum recommended levels in NFPA 13. As the system pressures and densities drop below these levels, some degradation in system performance could begin to occur.

\subsubsection{WTC 1 and WTC 2}

Based on the sprinkler system descriptions developed in Chapter 5, it was concluded that the installed sprinkler systems in WTC 1 and WTC 2 were essentially the same. Therefore, the hydraulic analyses presented in this section were based on the assumption that the results from WTC 1 would apply to both WTC 1 and WTC 2.

\section{Baseline Capacity}

An analysis was conducted to determine the effects of an increasing number of sprinklers operating on a single floor. This analysis was intended to assess the two scenarios involving fires smaller than the design area and fires larger than the design area on a single floor. The analysis used the Light Hazard Occupancy sprinkler system arrangements described in Chapter 6 as representative of those that existed in both WTC 1 and WTC 2. The highest and lowest floor level sprinkler systems in each of the high, mid-level, and low water supply zones were included. The calculated average delivered densities for these systems were used to estimate the limits for the anticipated performance range of the sprinkler systems within the associated zone. This approach was appropriate for systems without pressure reducing valves. Floor level sprinkler systems with pressure reducing valves were also evaluated to compare the performance of these systems with those systems without the pressure reducing valves.

The sprinkler systems on seven floor levels were selected to evaluate the performance range throughout WTC 1 and WTC 2. The sprinklers systems on floors 107 and 99 were selected to represent the high zone. Neither of these systems incorporated pressure-reducing valves. The sprinkler systems on floors 98 , 87 , and 32 were used to evaluate the sprinkler systems in the mid-level zone. The sprinklers on floors 98 and 87 provided the limitations of the sprinkler systems without pressure-reducing valves, and the sprinkler system on floor 32 provided an estimate of the performance of the systems with pressurereducing valves. The sprinkler systems on floors 2 and 31 were evaluated for the low zone. The sprinkler systems on floors 2 through 8 were equipped with pressure-reducing valves. The other floors in the low zone did not have pressure-reducing valves.

The evaluation of each individual sprinkler system included the calculation of the sprinkler system hydraulic performance for a range of specified coverage areas involving the operation of up to 24 sprinklers. Figure 8-1 provides a depiction of the performance ranges within each of the vertical water supply zones. 


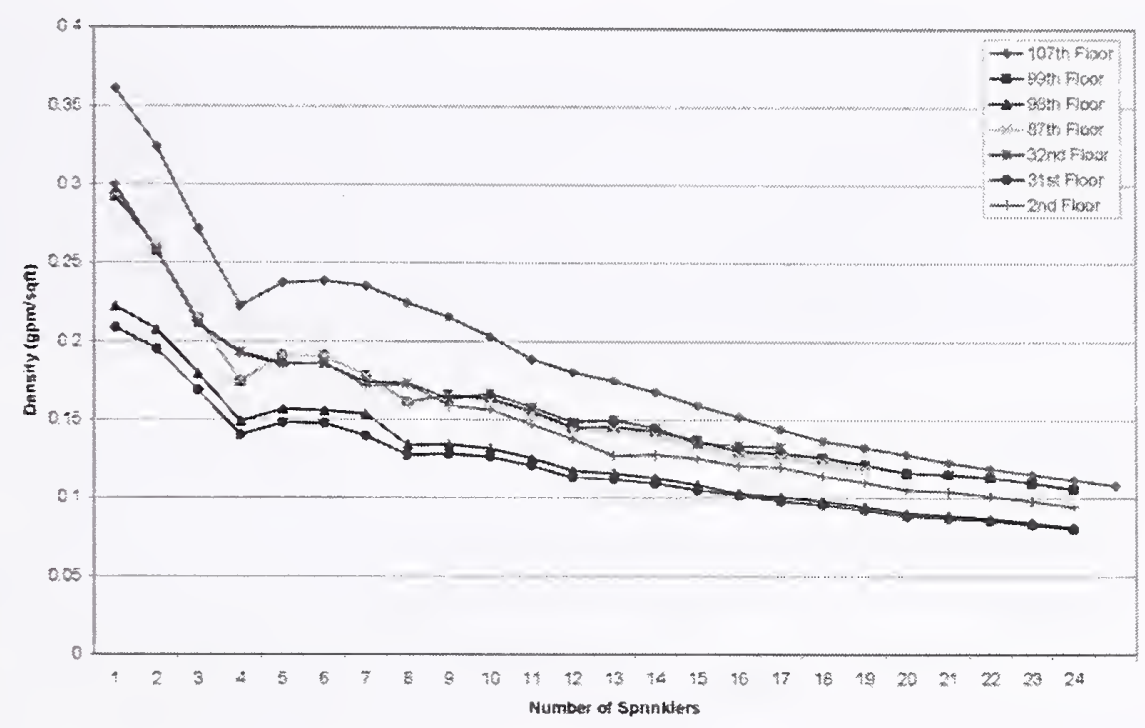

Figure 8-1. Summary of sprinkler systems performance for all zones-calculated average delivered density vs. number of open sprinklers, WTC 1 and WTC 2.

The analysis of the high zone included hydraulic calculations for the sprinklers systems on the 107 th and 99th floors in WTC 1. These systems would be expected to bound the hydraulic performance of all of the sprinkler systems in the high zone. As previously discussed in Chapters 5 and 6, all of the sprinkler systems in the high water supply zone included floor control valve assemblies with outside screw and yoke (OS\&Y) type control valves. None of these systems contained the pressure reducing type of control valves. Although the 107 th floor sprinkler system layout differed from the typical layout used for the other sprinkler systems, the hydraulic capacity of this system represented an upper limit relative to all other floor level systems in the zone. Figure 8-2 illustrates the effect on delivered density of assuming sequentially opened sprinklers on floors 99 and 107.

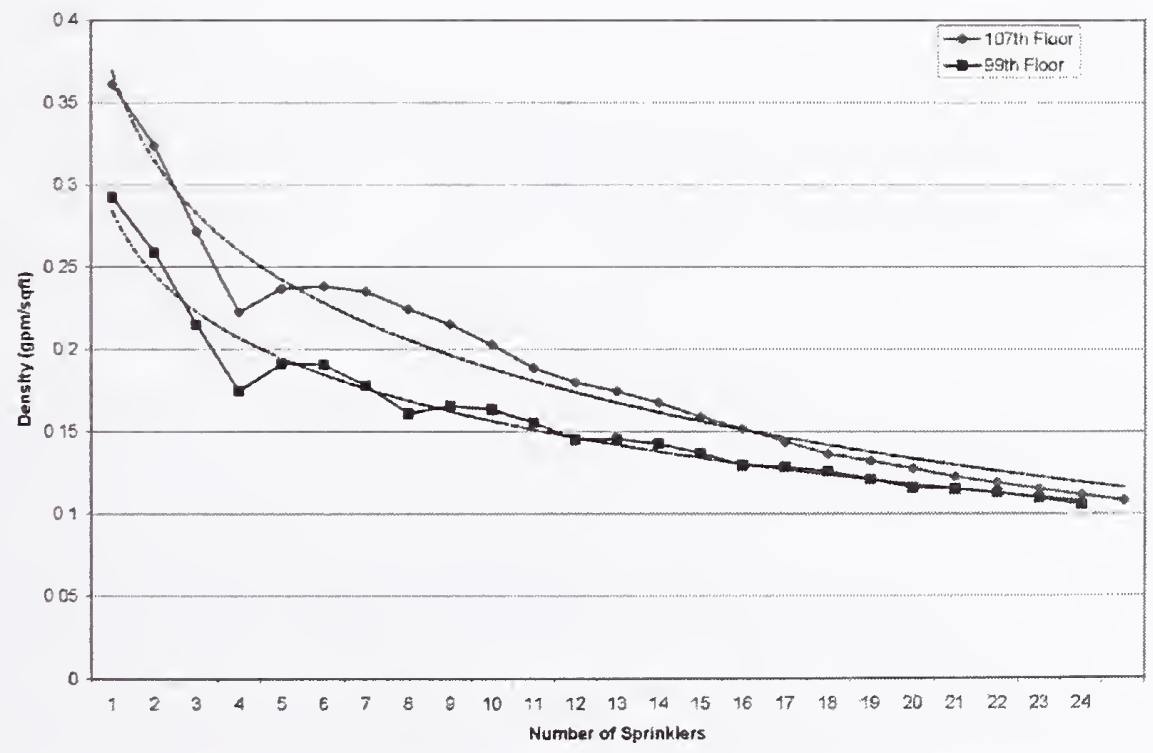

Figure 8-2. High zone sprinkler systems performance-calculated average delivered density vs. number of open sprinklers, WTC 1 and WTC 2. 
The performance of the sprinkler systems on the 99th and 107th floors of WTC 1 was evaluated by conducting a series of hydraulic calculations to determine the maximum number of sprinklers that could be supplied by the available water supply before the delivered density dropped below $0.1 \mathrm{gpm} / \mathrm{ft}^{2}$. The initial calculation included a single sprinkler. Each subsequent hydraulic calculation included the addition of a single sprinkler, up to 24 operating sprinklers. From these calculations it was determined that a maximum of 24 sprinklers, three times the number for the design area, could operate and still maintain at least an average delivered water density of $0.1 \mathrm{gpm} / \mathrm{ft}^{2}$.

Representative cases of the mid-level zone sprinklcr systems in WTC 1 and WTC 2 included sprinklers systems on the 98th, 87th, and 32nd floors. The systems on the 98th and 87th floors of WTC 1 represented limiting cases for the mid-level zone sprinkler systems without pressure-reducing valves. The systems on the 32 nd through 86 th floor levels included pressure-reducing valves. The hydraulic calculations for the 32nd floor sprinkler system represented the performance of the sprinkler systems with pressure-reducing valves. Figure $8-3$ provides a graphical depiction of the effect of the number of operating sprinklers on the calculated delivered water density for the mid-lcvel zone.

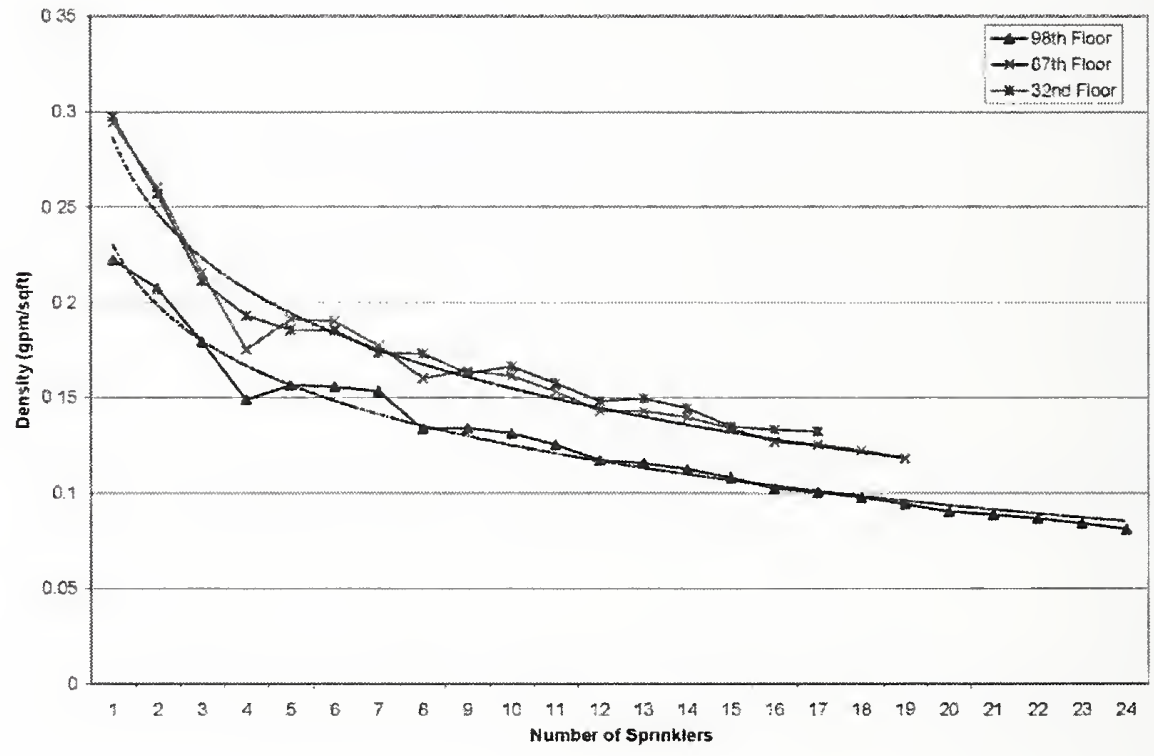

Figure 8-3. Mid-level zone sprinkler systems performance-calculated average delivered density vs. number of open sprinklers, WTC 1 and WTC 2.

The performance of the sprinkler systems on the 98th and 87th floors of WTC 1 bounded the mid-level sprinkler systems. As observed in Fig. 8-3, the hydraulic capacity of the sprinkler systems on the 32nd and 87 th floors were nearly identical. However, the maximum flow rate to the sprinkler systems was limited by the flow of water to the supply main on the 109 th floor level. The water flow to riser B was limited to approximately $440 \mathrm{gpm}$. As a result, the sprinkler system on the 87 th floor was limited to 19 sprinklers, and the system on the 32 nd floor was limited to 17 sprinklers. The hydraulic calculations for the sprinkler system on the 98 th floor demonstrated that the infrastructure and water supply were capable of providing the minimum 7 psi operating pressure to 17 sprinklers at or above a density of $0.1 \mathrm{gpm} / \mathrm{ft}^{2}$, which was over twice the size of the design area. 
Hydraulic calculations of the sprinkler systems on the 31 st and 2nd floors in WTC 1 were used to evaluate the hydraulic capacity of the low zone floor level sprinkler systems for WTC 1 and WTC 2. These systems were expected to bound the performance of the low zone sprinkler systems. The hydraulic calculations for the second floor sprinkler system represented the performance of a sprinkler system with a pressure-reducing valve. The systems on the second through eighth floor levels included pressurereducing valves. Figure $8-4$ provides a graphical depiction of the effect on delivered density associated with operating increasing numbers of sprinklers on these two floors in the low zone.

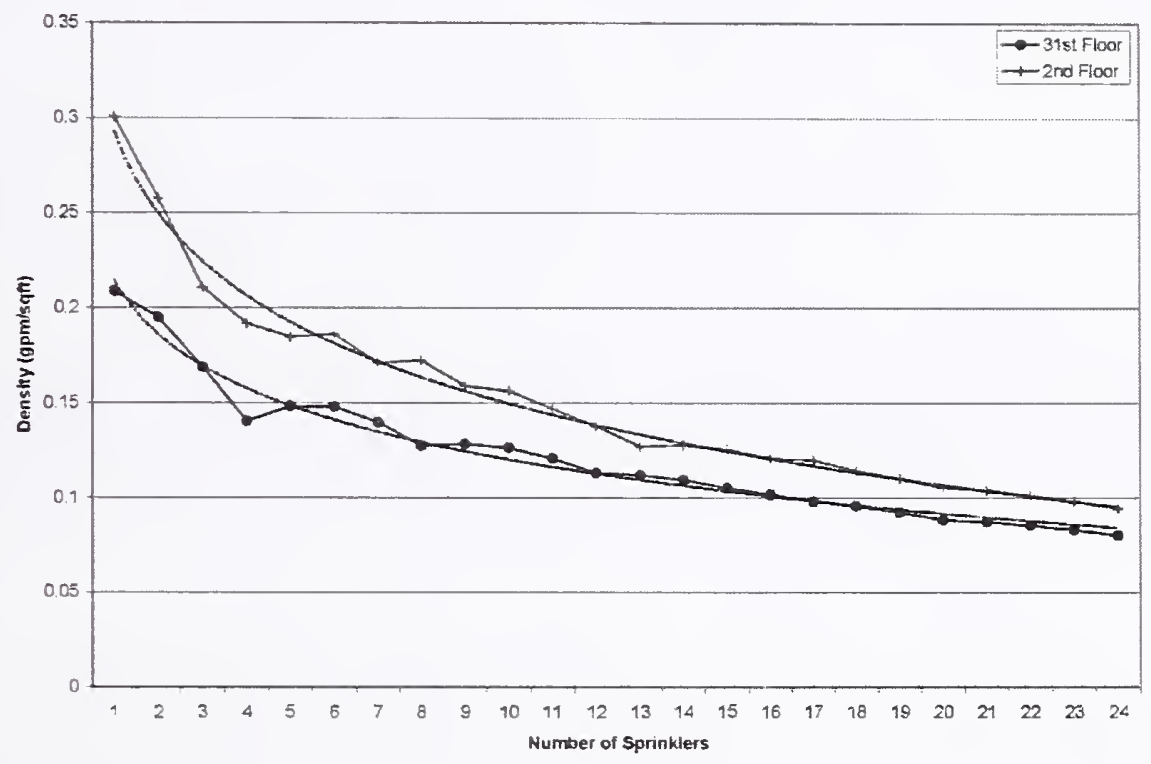

\section{Figure 8-4. Low zone sprinkler systems performance-calculated average delivered density vs. number of open sprinklers, WTC 1 and WTC 2.}

The performance of the sprinkler systems on the 31 st and 2nd floors of WTC 1 bounded the low zone sprinkler systems in both WTC 1 and WTC 2. The sprinkler systems on the 32 nd floor were able to provide the minimum 7 psi operating pressure and $0.1 \mathrm{gpm} / \mathrm{ft}^{2}$ density for up to as many as 16 sprinklers, which is twice the size of the design area. The system on the second floor was able to provide the minimum 7 psi operating pressure and $0.1 \mathrm{gpm} / \mathrm{ft}^{2}$ density for up to 21 sprinklers.

\section{Operation of Sprinklers on Multiple Floor Levels}

Calculations were performed to evaluate the likely performance of the sprinkler systems with an increasing number of sprinklers operating on multiple floors. This analysis was intended to assess two scenarios, one involving fires smaller than the dcsign area, and the other involving fires approximately equal to the size of the design area on multiple floor levels in WTC 1 and WTC 2. The analysis used the Light Hazard system layouts described in Chapter 6. 


\section{Multiple Small Fires on Different Floors}

This analysis was intended to evaluate the effects of multiple small fires in the high and mid-level zones. Three separate scenarios were investigated, as follows:

1. Sprinkler systems in the high zone

2. Sprinkler systems in the mid-level zone

3. Sprinkler system in both the high and mid-level zones

Seven sets of hydraulic calculations were performed to evaluate the scenario involving multiple small fires on the 99th through 107th floor levels. Each calculation included a four-sprinkler array per system starting with the 107th floor level system and adding four sprinklers on the subsequent floor level below. Table $8-1$ provides a summary of the results for the different scenarios.

Table 8-1. High zone average delivered density per floor vs. number of floors flowing (four sprinklers/floor), WTC 1 and WTC 2.

\begin{tabular}{|c|c|c|c|c|c|c|c|c|}
\hline Floor & $\mathbf{1 0 7}$ & $\mathbf{1 0 6} \& \mathbf{1 0 7}$ & $\mathbf{1 0 5}-\mathbf{1 0 7}$ & $\mathbf{1 0 4 - 1 0 7}$ & $\mathbf{1 0 3}-\mathbf{1 0 7}$ & $\mathbf{1 0 2}-\mathbf{1 0 7}$ & $\mathbf{1 0 1 - 1 0 7}$ & $\mathbf{1 0 0 - 1 0 7}$ \\
\hline 107 & 0.3188 & 0.3060 & 0.2883 & 0.2683 & 0.2399 & 0.1573 & 0.1354 & 0.1141 \\
\hline 106 & - & 0.1571 & 0.1492 & 0.1398 & 0.1273 & 0.1140 & 0.1015 & 0.0895 \\
\hline 105 & - & - & 0.1548 & 0.1455 & 0.1329 & 0.1196 & 0.1074 & 0.0957 \\
\hline 104 & - & - & - & 0.1513 & 0.1388 & 0.1258 & 0.1133 & 0.1020 \\
\hline 103 & - & - & - & - & 0.1446 & 0.1319 & 0.1199 & 0.1084 \\
\hline 102 & - & - & - & - & - & 0.1378 & 0.1263 & 0.1151 \\
\hline 101 & - & - & - & - & - & - & 0.1327 & 0.1217 \\
\hline 100 & - & - & - & - & - & - & - & 0.1283 \\
\hline
\end{tabular}

Based on this analysis, the water supply was considered sufficient to provide a minimum water density of $0.1 \mathrm{gpm} / \mathrm{ft}^{2}$ to a four-sprinkler array on up to seven floors. The water supply was capable of providing water to small fires on eight consecutive floor levels in the high zone, but resulted in the calculated density dropping slightly below $0.1 \mathrm{gpm} / \mathrm{ft}^{2}$ on two of the floors (refcr to Table 8-1).

Hydraulic calculations were also performed to evaluate the scenario involving multiple small fires in the mid-level zone. Each calculation included four sprinklers per array starting with the 98th floor level and adding a four-sprinkler array on each subsequent floor level. Table 8-2 provides a summary of the results of these calculations.

Table 8-2. Mid-level zone average delivered density per floor vs. number of floors flowing (four sprinklers/floor), WTC 1 and WTC 2.

\begin{tabular}{|c|c|c|c|c|}
\hline Floor & $\mathbf{9 8}$ & $\mathbf{9 7 ~ \& ~ 9 8}$ & $\mathbf{9 6 - 9 8}$ & $\mathbf{9 5 - 9 8}$ \\
\hline 98 & 0.1513 & 0.1444 & 0.1347 & 0.1230 \\
\hline 97 & - & 0.1508 & 0.1411 & 0.1298 \\
\hline 96 & - & - & 0.1477 & 0.1367 \\
\hline 95 & - & - & - & 0.1431 \\
\hline
\end{tabular}


The results indicated that the water supply could support four operating sprinklers on four consecutive floor level systems in the mid-level zone. The pressure loss through the supply main on the 109th floor level limited the flow of water and the maximum number of sprinklers that could be supported by the water supply. The maximum flow rate that could be supplied to the mid-level systems was determined to be approximately $440 \mathrm{gpm}$. This was observed in all cases involving the mid-level zone calculations.

Additional calculations were performed to evaluate scenarios involving sprinkler systems at the interface of the high and mid-level zones. Calculations were conducted for the systems on the 98th floor and 99th floor. These calculations demonstrated the performance of the systems with four open sprinklers on a single floor. i.e., either four sprinklers on the 98th floor or four sprinklers on the 99th floor. Next, hydraulic calculations were performed with four sprinklers operating simultaneously on both floors. Additional calculations were performed adding sprinklers on the 100th, 97th, and 101 st floor levels. Table 8-3 summarizes the results of these calculations.

Table 8-3. High zone and mid-level zone average delivered density per floor vs. number of floors flowing (four sprinklers/floor), WTC 1 and WTC 2.

\begin{tabular}{|c|c|c|c|c|c|c|}
\hline Floor & $\mathbf{9 8}$ & $\mathbf{9 9}$ & $\mathbf{9 8 ~ \& ~ 9 9}$ & $\mathbf{9 8 - 1 0 0}$ & $\mathbf{9 7 - 1 0 0}$ & $\mathbf{9 7 - 1 0 1}$ \\
\hline 101 & - & - & - & - & - & 0.1656 \\
\hline 100 & - & - & - & 0.1832 & 0.1811 & 0.1707 \\
\hline 99 & - & 0.1967 & 0.1957 & 0.1880 & 0.1860 & 0.1760 \\
\hline 98 & 0.1513 & - & 0.1497 & 0.1472 & 0.1390 & 0.1360 \\
\hline 97 & - & - & - & - & 0.1457 & 0.1426 \\
\hline
\end{tabular}

The results indicated that the water supply could support four sprinklers on five consecutive floor levels at the interface of the high and mid-level zones.

\section{Multiple Fires Equivalent to the Design Area}

Calculations were performed to evaluate the scenarios involving larger fires, equivalent in size to the design area of the sprinkler systems. Two separate locations were investigated, one involving sprinkler systems in the high zone and the other involving sprinkler systems in the mid-level zone.

Scenarios were evaluated involving multiple fires on the 102nd through 106th floor levels, i.e., representing the high zone. Each case included eight sprinklers per system starting with the 106th floor level system and adding eight sprinklers on the subsequent floor level below until the water supply could not support any additional sprinklers and maintain the limiting delivered density of $0.1 \mathrm{gpm} / \mathrm{ft}^{2}$. Table 8-4 summarizes the results from the cases evaluated. 
Table 8-4. High zone average delivered density per floor vs. number of floors flowing (eight sprinklers/floor), WTC 1 and WTC 2.

\begin{tabular}{|c|c|c|c|c|c|}
\hline & & & & & \\
Floor & $\mathbf{1 0 6}$ & $\mathbf{1 0 5} \mathbf{8} \mathbf{1 0 6}$ & $\mathbf{1 0 4}-\mathbf{1 0 6}$ & $\mathbf{1 0 3}-\mathbf{1 0 6}$ & $\mathbf{1 0 2 - 1 0 6}$ \\
\hline 106 & 0.1386 & 0.1268 & 0.1101 & 0.0913 & 0.0753 \\
\hline 105 & - & 0.1314 & 0.1149 & 0.0964 & 0.0803 \\
\hline 104 & - & - & 0.1200 & 0.1018 & 0.0858 \\
\hline 103 & - & - & - & 0.1074 & 0.0920 \\
\hline 102 & - & - & - & - & 0.0983 \\
\hline
\end{tabular}

The results indicated that the water supply could support eight sprinklers on three consecutive floor levels and provide a minimum average density greater than $0.1 \mathrm{gpm} / \mathrm{ft}^{2}$. The results also indicated that the water supply and supply piping could support a maximum of five sprinkler systems, although the delivered densities and end-sprinkler pressures could drop slightly below $0.1 \mathrm{gpm} / \mathrm{ft}^{2}$ and $7 \mathrm{psi}$, respectively.

Calculations were performed to evaluate scenarios involving multiple fires on the 98 th and 97 th floor. Table 8-5 provides a summary of the results of these calculations.

Table 8-5. Mid-level zone average delivered density per floor vs. number of floors flowing (eight sprinklers/floor), WTC 1 and WTC 2.

\begin{tabular}{|c|c|c|}
\hline Floor & $\mathbf{9 8}$ & $\mathbf{9 7} \& \mathbf{9 8}$ \\
\hline 98 & 0.1288 & 0.1200 \\
\hline 97 & - & 0.2346 \\
\hline
\end{tabular}

The results involving the sprinkler systems in this mid-level zone indicate that the riser and water supply would be expected to control or extinguish two fires equal to the size of the design area. The supply riser size limited the water flow to $440 \mathrm{gpm}$, which was a limiting factor for the system capabilities. As a result of this limitation, further analysis of the high and mid-level zones was not performed.

\section{Single Fire Larger than the Design Area}

Estimates of the maximum fire size (greater than the design area of the sprinkler system) were made based on the results in Tables $8-4$ and $8-5$. The results indicated that a fire approximately three times the size of the design area $\left(\sim 4,500 \mathrm{ft}^{2}\right)$ located in the upper water supply zone would be controlled by the sprinkler system, based on the performance criteria used in this analysis. The maximum fire size was approximately two times the design area for the mid-level locations.

The estimates of the maximum fire size coincided with the maximum sprinkler coverage area that could deliver the minimum spray density of $0.1 \mathrm{gpm} / \mathrm{ft}^{2}$ at pressures greater than or equal to 7 psi throughout the coverage area. These fire sizes $\left(3,000\right.$ to $\left.4,500 \mathrm{ft}^{2}\right)$ represent a relatively small part of the total occupied floor area of approximately $31,000 \mathrm{ft}^{2}$. However, automatic sprinkler systems are designed to control or suppress fires that are initially considerably smaller than the $1,500 \mathrm{ft}^{2}$ design area, which are the types of fires normally encountered in high-rise office buildings. 


\subsubsection{WTC 7}

Hydraulic calculations were performed to evaluate the potential for fire control or suppression of the four fire scenarios outlined in Sec. 8.1. Similar to the analysis of the system capabilities for WTC 1 and WTC 2, the focus was on the ability of the sprinkler systems to maintain average delivered water densities and a minimum system pressure at the most remote sprinklers. Maintenance of these minimum performance levels would be expected to provide adequate performance under fire exposures typically experienced in high-rise buildings.

\section{Single Fire Smaller Than the Design Area}

The design area for each of the sprinkler systems analyzed in WTC 7 was approximately $1,500 \mathrm{ft}^{2}$. This design area corresponds to a minimum required density of $0.1 \mathrm{gpm} / \mathrm{ft}^{2}$ for a Light Hazard Occupancy and $0.15 \mathrm{gpm} / \mathrm{ft}^{2}$ for an Ordinary Hazard Group 1 Occupancy using standard spray sprinklers. Based on a sprinkler spacing of $168 \mathrm{ft}^{2}$ per sprinkler for the Light Hazard Occupancies, the design area consisted of nine sprinklers. Therefore, any number of operating sprinklers below nine would constitute a fire size less than the design area for Light Hazard Occupancy areas. The 47th, 40th, 39th, 21 st, and 20th floors were analyzed as Light Hazard Occupancies. The first floor was analyzed as an Ordinary Hazard Occupancy area. The sprinkler spacing on this floor was based on $126 \mathrm{ft}^{2}$ per sprinkler. Therefore, a design area of $1,500 \mathrm{ft}^{2}$ corresponded to 12 sprinklers.

Calculations were performed to characterize the sprinkler system if a fire smaller than the design area were to actuate the sprinkler system on the high or low floors in each vertical zone. The calculations were conducted by assuming one open sprinkler at a time. The order in which sprinklers were activated was from the relatively most remote sprinkler toward the source. After each incremental calculation, the delivered flow rate and total area, including each incremcntal sprinkler area, was recorded. Figure 8-5 provides a graphical summary of the results of the calculations.

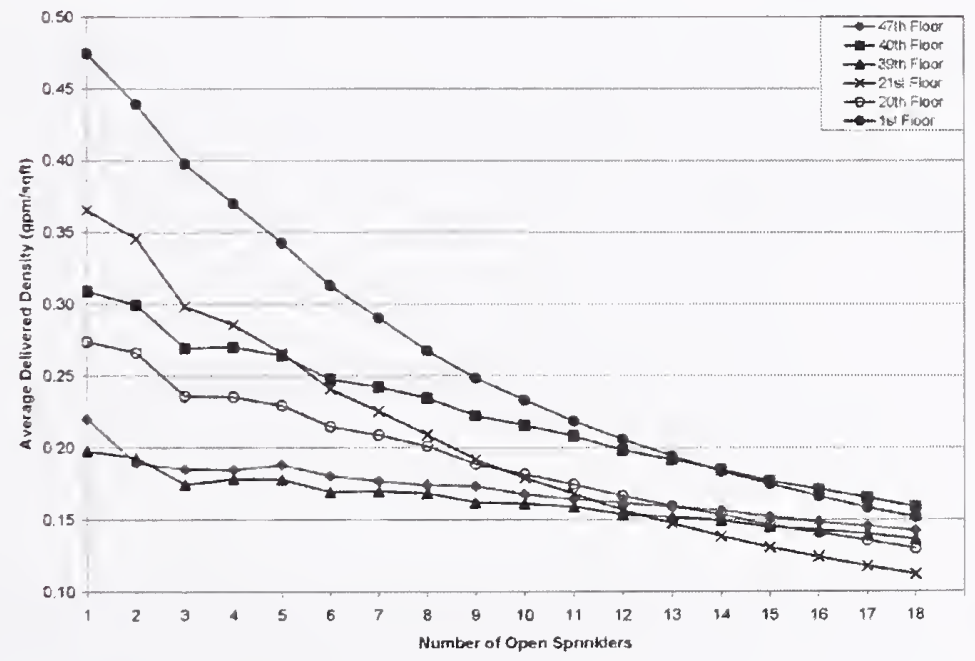

Figure 8-5. Average delivered density vs. number of open sprinklers, WTC 7.

For a small fire, significantly less than the total design area, the calculated average delivered density was much greater than the minimum required density. With the exception of the systems on the 39 th and 47 th floors, the average delivered density was more than twice the minimum required density. The average 
delivered density for the Ordinary Hazard system on the first floor was also much greater than was required. For instance, for a fire area of $750 \mathrm{ft}^{2}$, or six sprinklers, the calculated average delivered density was greater than $0.3 \mathrm{gpm} / \mathrm{ft}^{2}$. This is twice the required density of $0.15 \mathrm{gpm} / \mathrm{ft}^{2}$ for Ordinary Hazard Group 1 Occupancies in NFPA 13.

\section{Single Fire Larger than the Design Area}

In the case of the Light Hazard Occupancy floors, greater than nine opened sprinklers corresponded to a fire area greater than the design area. The results in Fig. 8-5 illustrate the results up to 18 sprinklers. This corresponds to an area of approximately $3,000 \mathrm{ft}^{2}$, or twice the Light Hazard design area.

The delivered densities remained greater than $0.15 \mathrm{gpm} / \mathrm{ft}^{2}$ for up to 12 sprinklers. The delivered densities remained above the minimum required density of $0.1 \mathrm{gpm} / \mathrm{ft}^{2}$ for up to 18 open sprinklers. The trend, with the exception of the 1 st and 21 st floors, indicated that the actual delivered density would remain above the minimum required Light Hazard density as additional sprinklers greater than 18 were added. The trend for the Ordinary Hazard system on the first floor indicated that the average delivered density would remain above $0.15 \mathrm{gpm} / \mathrm{ft}^{2}$ for up to 18 open sprinklers. (Note that a sprinkler activation area of $3,000 \mathrm{ft}^{2}$ corresponds to approximately 7 percent to 8 percent of the total typical floor area of $42,000 \mathrm{ft}^{2}$ in WTC 7).

Table 8-6 lists the lowest residual pressure for each system when 18 sprinklers (i.e., twice the design area) were opened. The lowest pressure occurred at the most remote sprinkler in the design area. The results provided in Table 8-6 are consistent with the results graphed in Fig. 8-5. The first floor Ordinary Hazard system approached the minimum required density of $0.15 \mathrm{gpm} / \mathrm{ft}^{2}$ and minimum pressure of $7 \mathrm{psi}$ when 18 sprinklers were assumed to be open and flowing water. The 40th floor system provided an average delivered density of approximately $0.16 \mathrm{gpm} / \mathrm{ft}^{2}$ with a minimum residual sprinkler pressure of 19.3 psi, well above the minimum required for a Light Hazard Occupancy.

\section{Table 8-6. Lowest residual pressure at open sprinklers for each system.}

\begin{tabular}{|c|c|}
\hline Floor & Pressure (psi) \\
\hline 47 & 12.2 \\
\hline 40 & 19.3 \\
\hline 39 & 14.1 \\
\hline 21 & 9.4 \\
\hline 20 & 12.8 \\
\hline 1 & 7.5 \\
\hline
\end{tabular}

Figures $8-6,8-7$, and $8-8$ illustrate the calculated average delivered density compared to the number of open sprinklers for the high, mid-level, and low zones, respectively. Each set of results was fit with a trend line. Each trend line was extrapolated to the minimum required density for the respective hazard classification. 


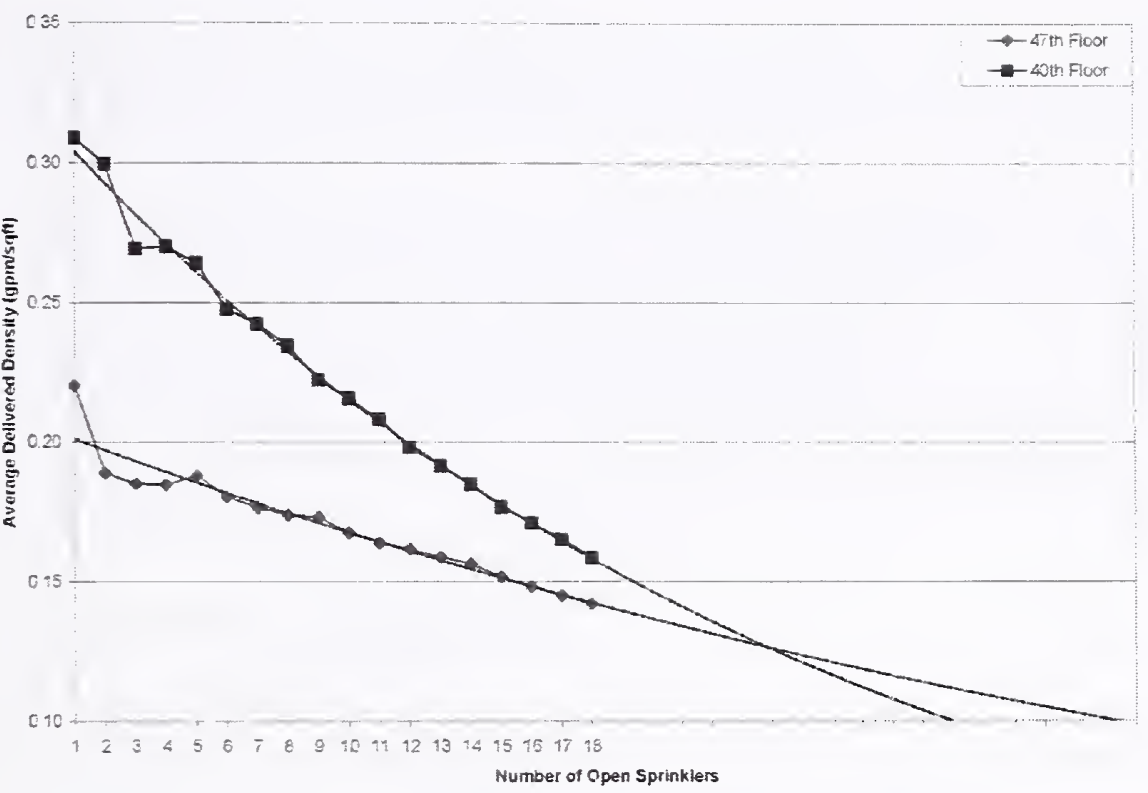

Figure 8-6. High zone, average delivered density vs. number of open sprinklers.

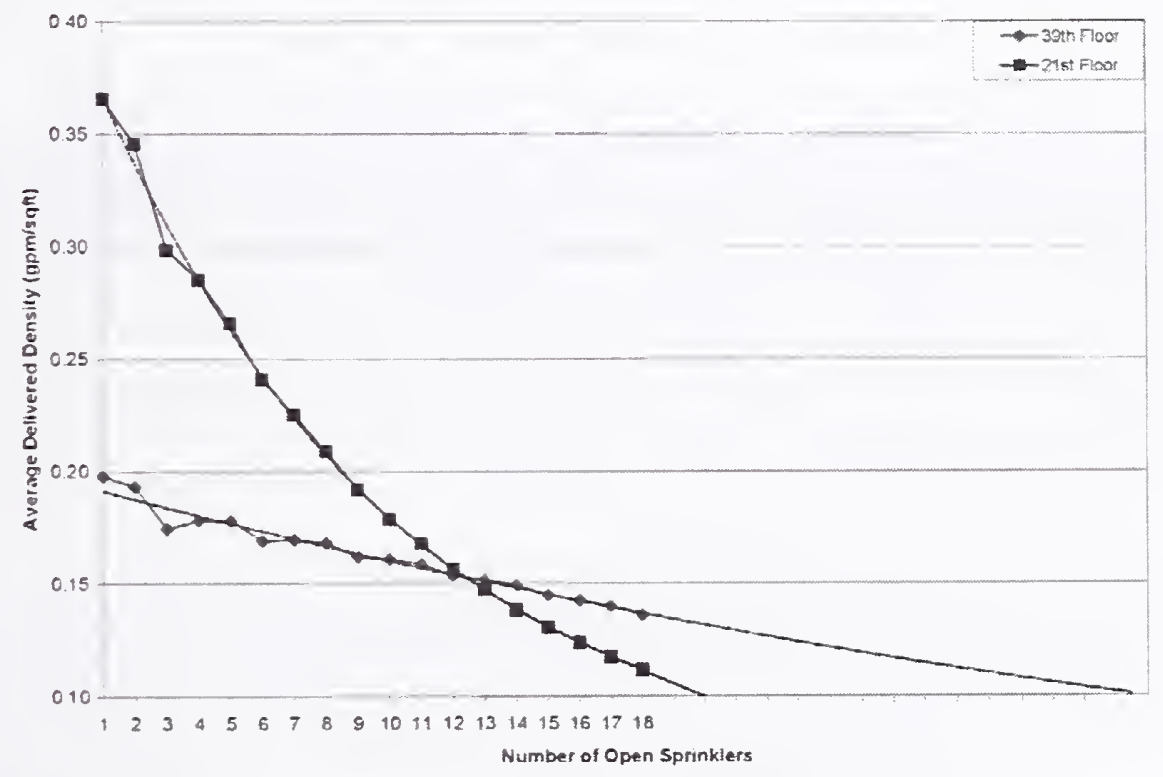

Figure 8-7. Mid-level zone, average delivered density vs. number of open sprinklers. 


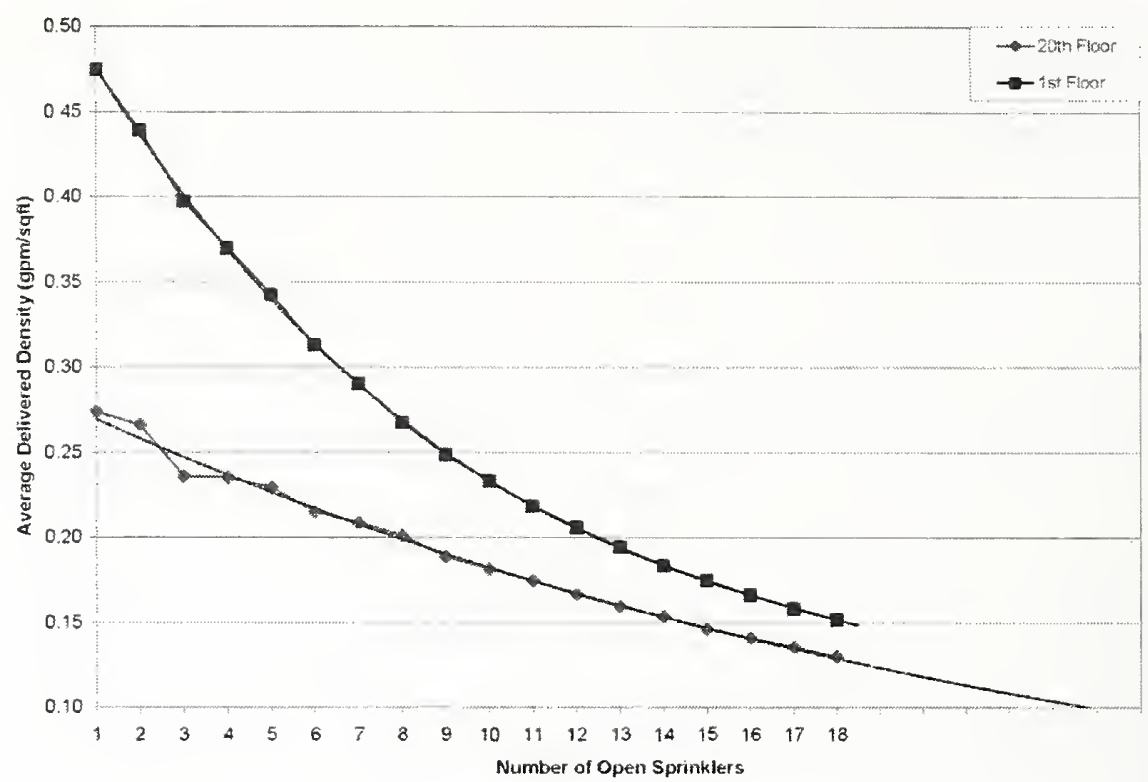

Figure 8-8. Low zone, average delivered density vs. number of open sprinklers.

\section{Multiple Small Fires}

The third scenario involved calculations to determine the capacity and expected performance of the sprinkler systems when small fires occur on multiple floors. For these cases it was assumed that the fires would open no more than four sprinklers. This was a conservative assumption since most fires in highrise office buildings are controlled or suppressed by less than four sprinklers. The floors to be analyzed started with the 39th floor. The 39th floor was chosen because it represents the hydraulically most demanding floor supplied from the primary water supply. Four sprinklers were assumed to have operated on each subsequent floor, incrementally. Table 8-7 provides a summary of the results of the calculations by comparing the average delivered density to the floor number for each multiple fire floor scenario.

Table 8-7. Average delivered density per floor vs. number of floors flowing (four sprinklers/floor).

\begin{tabular}{|c|c|c|c|c|c|c|c|c|c|}
\hline Floor & $\mathbf{3 9}$ & $\mathbf{3 8} \mathbf{\&} \mathbf{3 9}$ & $\mathbf{3 7 - 3 9}$ & $\mathbf{3 6 - 3 9}$ & $\mathbf{3 5}-\mathbf{3 9}$ & $\mathbf{3 4 - 3 9}$ & $\mathbf{3 3 - 3 9}$ & $\mathbf{3 2 - 3 9}$ & $\mathbf{3 1 - 3 9}$ \\
\hline 39 & 0.1677 & 0.1637 & 0.1577 & 0.1494 & 0.1396 & 0.1286 & 0.1158 & 0.1021 & 0.0863 \\
\hline 38 & - & 0.1759 & 0.1699 & 0.1625 & 0.1536 & 0.1435 & 0.1321 & 0.1199 & 0.1071 \\
\hline 37 & - & - & 0.1780 & 0.1711 & 0.1631 & 0.1542 & 0.1438 & 0.1333 & 0.1223 \\
\hline 36 & - & - & - & 0.1813 & 0.1735 & 0.1649 & 0.1548 & 0.1455 & 0.1354 \\
\hline 35 & - & - & - & - & 0.1845 & 0.1765 & 0.1679 & 0.1589 & 0.1491 \\
\hline 34 & - & - & - & - & - & 0.1875 & 0.1795 & 0.1711 & 0.1619 \\
\hline 33 & - & - & - & - & - & - & 0.1902 & 0.1818 & 0.1735 \\
\hline 32 & - & - & - & - & - & - & - & 0.1926 & 0.1845 \\
\hline 31 & - & - & - & - & - & - & - & - & 0.1955 \\
\hline
\end{tabular}


It should be noted that the calculated average delivered density was still greater than the minimum required density for the case involving water flow on eight floors. The minimum residual sprinkler pressure was 8.8 psi for the eight-floor case. The minimum sprinkler pressure occurred on the 39th floor.

When a 31 st floor was added (for total of 9 floors), the average delivered density on the 39th floor dropped below $0.10 \mathrm{gpm} / \mathrm{ft}^{2}$ to approximately $0.087 \mathrm{gpm} / \mathrm{ft}^{2}$. Also, the minimum sprinkler pressure on the 39 th floor was $6.3 \mathrm{psi}, 0.7 \mathrm{psi}$ below the minimum required pressure per the requirements of NFPA 13. Therefore, the hydraulic analysis indicated, based on the minimum density and pressure selected for this analysis, that up to eight fires (limited to an area covered by four sprinklers) could simultaneously occur in different locations or on different floors and the installed sprinkler systems would be expccted to control or extinguish them.

\section{Multiple Fires Equivalent to the Design Area}

The fourth scenario involved calculations to determine the performance of the sprinkler system when multiple fires approximately equivalent to the design area occurred at different locations, including on different floors. The design area was determined to be approximately $1,500 \mathrm{ft}^{2}$. Like the previous scenario, the floors to be analyzed started with the 39 th floor. Table $8-8$ provides a summary of the calculation results.

Table 8-8. Average delivered density per floor vs. number of floors flowing (nine sprinklers/floor).

\begin{tabular}{|c|c|c|c|c|c|}
\hline Floor & $\mathbf{3 9}$ & $\mathbf{3 8} \mathbf{\&} 39$ & $\mathbf{3 7 - 3 9}$ & $\mathbf{3 6 - 3 9}$ & $\mathbf{3 5}-\mathbf{3 9}$ \\
\hline 39 & 0.1620 & 0.1468 & 0.1286 & 0.1084 & 0.0866 \\
\hline 38 & - & 0.1600 & 0.1434 & 0.1255 & 0.1069 \\
\hline 37 & - & - & 0.1434 & 0.1284 & 0.1135 \\
\hline 36 & - & - & - & 0.1399 & 0.1262 \\
\hline 35 & - & - & - & - & 0.1392 \\
\hline
\end{tabular}

Based on these results, the sprinkler system could deliver more than the minimum required density over a design area of 1,500 $\mathrm{ft}^{2}$ for up to four simultaneous fires on the same or different floors. The calculated average delivered density dropped below $0.10 \mathrm{gpm} / \mathrm{ft}^{2}$ when a fifth fire was included in the calculations. The minimum residual sprinkler pressure for the five floor calculation occurred on the 39 th floor. The minimum residual sprinklcr pressure on the 39th floor, assuming fires on all five floors, was 5.7 psi.

The results in Table 8-8 indicate that sprinklers within the required design area could be activated on four different floors or at four separate locations on one floor, and the system would still have had the capacity to deliver more than the minimum required density. The fire hazard occupancy control approach to sprinkler system design, applicable to systems designed in accordance with NFPA 13, only requires the water supply to provide the minimum density to sprinklers that cover a single design area. The water supply system in WTC 7 was capable of supplying the minimum required density to all sprinklers within the design area for four separate fires, each roughly the size of the design area. This would normally be considered a very robust capability for an installed fire sprinkler system. 


\subsection{STANDPIPE/PRE-CONNECTED HOSE PERFORMANCE}

\subsubsection{General}

Hydraulic calculations were performed to determine if the standpipe systems were designed to provide flow rates and pressures consistent with the provisions of the BCNYC (BCNYC 1968) and NFPA 14, Standard for the Installation of Standpipes and Hose Systems (NFPA 14 2000). The BCNYC does not provide specific performance requirements as outlined in NFPA 14, so a direct comparison was not made.

The BCNYC specifies how to configure standpipe systems, but does not specify minimum performance criteria for all situations. However, the $\mathrm{BCNYC}$ specifies that pressure-reducing valves at $2 \frac{1}{2} \mathrm{in}$. outlets should limit the discharge pressure to a maximum of $50 \mathrm{psi}$ for a flow rate of $200 \mathrm{gpm}$. And pressurereducing valves at $1 \frac{1}{2} \mathrm{in}$. hose stations should limit the discharge pressure to a maximum of 85 psi for a flow rate of $70 \mathrm{gpm}$.

NFPA 14 specifies the following minimum flow rate and pressure requirements for Class III standpipe systems. A flow rate of $500 \mathrm{gpm}$ is required at the hydraulically most remote standpipe, and $250 \mathrm{gpm}$ is requircd at each additional standpipe, up to a maximum combined flow rate of 1,250 gpm. NFPA 14 also identifies a maximum flow rate that is acceptable in buildings protected throughout with automatic sprinkler systems.

\subsubsection{WTC 1 and WTC 2}

The arrangement of the standpipe systems in WTC 1 and WTC 2 included a multiple supply configuration. Each water supply zone included three 6 in. diameter standpipes. The design of these systems included multiple $750 \mathrm{gpm}$ fire pumps that could operate in parallel or in series. Refer to Fig. B-1. Two pumps on the Bl level were arranged in parallel, meaning that either pump could be used to supply water to the sub-grade loops and both towers. The pumps on the 7 th, 41 st, and 75 th floors of each tower were configured in a series arrangement with the sub-grade loops and the B1 level pumps.

Hydraulic calculations were performed using the Hydraulic Analyzer of Sprinkler Systems (HASS) (HRS 2004) hydraulic calculation program for three specific configurations involving the operation of four, three, and two manual fire pumps. The first configuration involved the operation of three preconnected hose valves on the 109th floor and one pre-connected hose valve on the 110th floor since these were the hydraulically most remote hose valve locations in the building. A flow rate of $250 \mathrm{gpm}$ was specified at each hose valve. The results of the hydraulic calculations indicated that the standpipe systems were able to provide $250 \mathrm{gpm}$ to the four hose stations with three or four pumps in operation. The calculation for four pumps provided $250 \mathrm{gpm}$ to each hose valve at approximately $400 \mathrm{psi}$. The calculations for three pumps operating indicated that a flow of $250 \mathrm{gpm}$ would be delivered to the four hose valves with a minimum pressure of 128 psi. Therefore, based on this analysis, it appears that the standpipe systems exceeded the requirements of NFPA 14 and the BCNYC. The calculations for two pumps operating indicated that $250 \mathrm{gpm}$ could have supplied a single hose valve on the 110 th floor.

The BCNYC required these systems to provide significantly less water than the pumps were designed to provide. Operating additional fire pumps or supplying water through a standard FDC or a single highpressure FDC would further augment the performance of the standpipe systems. Calculations demonstrating that the Fire Department of The City of New York (FDNY) operations using the FDCs 
resulted in acceptable performance of the standpipe systems was independently confirmed in by Beyler (Beyler 2002). Therefore, it appears that excess pressure and flow were available to the standpipes and the pre-connected hose stations throughout WTC 1 and WTC 2 in the "normal" operating mode.

\subsubsection{WTC 7}

In WTC 7, the hose connections throughout the building were supplied from the combination wet pipe standpipe/sprinkler systems. Therefore, the primary supply zones to the hose connections were the same as for the sprinkler systems.

The primary supply to the high zone was the automatic booster pump located on the 46th floor. Section $27-945$ (b)(5)(b.) of the BCNYC specified that the automatic fire pump must have had a capacity to provide at least $500 \mathrm{gpm}$ at $25 \mathrm{psi}$ to the highest hose outlet station supplied by the pump. The NFPA 14 requirements for Class III standpipe systems specified a flow rate of $500 \mathrm{gpm}$ required at the hydraulically most remote standpipe/pre-connected hose outlet and $250 \mathrm{gpm}$ at each additional outlet. The minimum pressure requirement was $100 \mathrm{psi}$, or $65 \mathrm{psi}$ if approved by the authority having jurisdiction $(\mathrm{AHJ})$.

Similarly to the analysis for WTC 1 and WTC 2, hydraulic calculations were performed to assess the standpipe systems for consistency with the provisions of NFPA 14 and the BCNYC. The calculations were performed for the most remote hose connections on the three standpipes of the high zone. These involved the hose connections on the 47th floor of riser R-7, 47th floor of riser R-8, 46th floor of riser R-9, and 47 th floor of riser R-9.

The first calculation was conducted using the criteria established by the BCNYC with the primary water supply. The BCNYC criteria only required that $500 \mathrm{gpm}$ flow at $25 \mathrm{psi}$ at the most remote hose connections. The hose connection calculated was the 47 th floor of riser R-9. The results indicated that the $500 \mathrm{gpm}$ ( $55 \mathrm{psi}$ head) booster pump would easily provide the $500 \mathrm{gpm}$ flow at above the minimum required pressure.

NFPA 14 required that the minimum required flow and pressure be provided by an automatic source. However, the automatic booster pump present on the 46th floor was undersized to provide the flow and pressure that would have been required by NFPA 14. The booster pump was rated for $500 \mathrm{gpm}$, while the minimum required design flow for NFPA 14 would have been 1,000 gpm, or 200 percent of the rated pump capacity. Therefore, a second calculation was conducted using the criteria established by NFPA 14 utilizing the $750 \mathrm{gpm}$ manual fire pump located in the first floor fire pump room. The results of this calculation indicated that the capacity of the $750 \mathrm{gpm}$ manual fire pump was less than the minimum flow and pressure requirements in NFPA 14 for the high zone hose connections. In fact, the hydraulic calculations indicated that the manual fire pump could only provide a flow rate of $250 \mathrm{gpm}$ to each hose connection at approximately 20 psi.

Based on these results, it appeared that the standpipe systems met or exceeded the requirements of the $\mathrm{BCNYC}$, but were somewhat under-designed based on the requirements in NFPA 14. 


\subsection{SUMMARY OF TASK 4}

The hydraulic analyses relied on the minimum delivered density and pressure requirements in NFPA 13 as the basic criteria for evaluating the fire control capacity of the sprinkler systems. It is important to recognize that in NFPA 13, the required densities and pressures are based on the assumption that an installed fire sprinkler system is designed to control a single fire. In addition, in the analyses performed here, small fires were assumed to be approximately the size of the area covered by a four-sprinkler array (approximately $750 \mathrm{ft}^{2}$ ). In fact, available performance history indicates that typical fires in high-rise office buildings are controlled or suppressed by less than four sprinklers, lending additional conservatism to the estimates of system capacity presented here. Finally, the calculations were based on availability of the primary water supplies only, without any consideration for fire department actions to provide a secondary water supply. In NYC such action is routine, and the secondary water supply is considered infinite in duration, with equivalent or higher capacity to the primary water supply. At the same time, due to the normal availability of a reliable, high capacity secondary water supply, duration of water supply was not included in this analysis.

Based on the analyses performed as part of this task, the installed sprinkler systems in WTC 1, 2, and 7 had the ability to simultaneousiy control or suppress multiple fires of varying sizes under "normally expected" operating conditions. The fires could have occurred at different locations on a single floor or on multiple floors. The results of extensive hydraulic calculations indicated that the water flow density and pressure associated with the installed sprinkler systems had the capacity to control fires on the order of two to three times the sprinkler system design area $\left(1,500 \mathrm{ft}^{2}\right)$, depending on the location in the building, and the systems would be expected to concurrently control at least four to six smaller fires similar in area to that protected by a four-sprinkler array $\left(750 \mathrm{ft}^{2}\right)$.

The calculations identified limits of performance, but these estimated limits were significantly greater than the limits associated with the requirements in NFPA 13. The available densities and pressures indicated that the installed systems generally exceeded the minimum requirements in NFPA 13 by significant margins. These systems would have been expected to control multiple small fires or fires up to three or four times the sprinkler system design area and would have been considered robust installations with considerable excess capacity. At the same time, if large fires were to opcn all of the sprinklers in an area equivalent to three to four times the design area of the sprinkler systems, the hydraulic capabilities of the system(s) would begin to degrade, and, although these fire areas would be considered relatively large $\left(4,500\right.$ to $\left.6,000 \mathrm{ft}^{2}\right)$, they represented roughly 8 to 15 percent of the occupied floor areas in WTC 1,2 , and 7 .

Flow restrictions existed at selected locations in WTC 1 and WTC 2, but the limits of available water flow were still considerably greater than those required in NFPA 13 for control of typical Light Hazard fire incidents.

While it is difficult to assess the performance capabilities of the standpipe/pre-connected hoses, hydraulic calculations indicated that the size of the standpipes and the capacity and number of fire pumps were consistent with the requirements for pressure and flow in the BCNYC. However, the booster pump on the 46th floor was undersized and could not provide the relatively higher minimum flow and pressure required in NFPA 14. 


\section{Chapter 9 \\ TASK 5: SUPPRESSION SYSTEMS PERFORMANCE ON SEPTEMBER 11, 2001}

\section{$9.1 \quad$ GENERAL}

The objective of the Task 5 analysis was to document to the extent possible the design and performance of the automatic fire sprinkler and standpipe systems in World Trade Center (WTC) 1, 2 and 7 on September 11.2001. Given the design and intended operation of the fire protection systems, an attempt was made to address specific questions related to the performance of these systems. These questions included:

- What initially happened to the operational condition of systems as a result of each major event?

- How was the performance of the systems impacted by each event? and,

- At what point in the sequence of events were the systems lost?

This section of the report outlines the sequence of major events and the impact to the critical fire protection system components resulting from each event.

The estimates of performance relied on the detailed information and analyses documented in the preceding sections of this report, along with relevant evaluations performed by others (i.e., McAllister 2002; Beyler 2002).

\subsection{SEQUENCE OF EVENTS}

An evaluation was conducted of the operational readiness and performance of the automatic sprinkler and standpipe/pre-connected hose systems and the associated water supplies. The evaluation was based on estimates of conditions in the buildings at the time of each major event in the sequence of impacts and building collapses. The timeline for these events is presented in Table 9-1. along with the departure times of the two flights.

Table 9-1. Timeline and summary of major events.

\begin{tabular}{|l|l|}
\hline \multicolumn{1}{|c|}{ Time } & \multicolumn{1}{|c|}{ Event } \\
\hline 7:59 a.m. & AA flight 11 departs from Logan \\
\hline 8:14 a.m. & UA flight 175 departs from Logan \\
\hline 8:46 a.m. & Initial aircraft strike: WTC 1 \\
\hline 9:03 a.m. & Initial aircraft strike: WTC 2 \\
\hline 9:58 a.m. & Collapse of WTC 2 \\
\hline 10:29 a.m. & Collapse of WTC 1 \\
\hline 5:21 p.m. & Collapse of WTC 7 \\
\hline
\end{tabular}




\subsection{BASIS FOR ESTIMATING SYSTEMS DAMAGE}

The extent of damage to the water supply, automatic sprinklers, and the standpipe systems on each individual floor was estimated using structural damage estimates prepared by the National Institute of Standards and Technology (NIST) (see Figs. 9-1 and 9-2) as part of the baseline structural performance and aircraft impact damage analysis. The exact extent of suppression systems damage could not be accurately determined due to the collapse of all three structures. Therefore, the initial damage to system components was assumed to correspond to areas associated with initial structural damage. This approach was considered a reasonable first approximation, particularly considering the limited information available regarding the status and performance of the suppression systems on September 11. The sprinkler and standpipe system components were overlaid on diagrams of the preliminary impact damage estimates prepared by NIST as part of the baseline structural performance and aircraft impact damage analysis. Then, it was assumed that if the components were located within the initial impact damage areas, the integrity of system components was compromised or lost. Based on the proximity of the critical components to the initial impact area, additional assessments were made regarding the integrity and operability of the primary and secondary water supplies, standpipes, sprinkler system infrastructure, and the sprinkler systems on individual floors. Estimates of the available sprinkler water density and duration of supply were based on analyses documented in Chapters 6 through 8 .

The preliminary damage estimates included floors 94 through 96 in WTC 1 and floors 78 through 81 in WTC 2. These estimates were subsequently revised by NIST as additional analyses were completed. The result was to extend the initial damage estimates to include areas on floors 93 through 99 in WTC 1 and floors 77 through 85 in WTC 2.

Comparison of the preliminary and more recent damage estimates was performed in order to determine if the damage estimates associated with the suppression systems would be changed significantly based on the newer impact damage estimates in NIST NCSTAR 1-2. ${ }^{3}$ Based on this comparison, it was determined that the primary changes in the damage estimates involved additional floors, outside the core areas of the buildings. Since the primary areas of damage of relevance to the suppression systems involved the core areas of the buildings, the estimates of damage to the suppression systems resulting from use of the preliminary impact damage estimates were considered valid approximations. Therefore, it was not necessary to repeat the analysis of the damage estimates that was already completed based on the initial damage assessment.

\subsubsection{WTC 1 Aircraft Strike}

A rough estimate of the initial damage that resulted from the impact of the aircraft on WTC 1 was based on the extent of damage illustrated in Fig. 9-1. The sprinkler system component locations were compared to the initial structural damage estimates. The integrity and operability of system components were assumed to be compromised if they were located within the primary area of damage. Figure 9-1 shows the primary damage in WTC 1 that occurred on floors 94 through 96. 3 This reference is to one of the companion documents from this Investigation. A list of these documents appears in the Preface
to this report. 


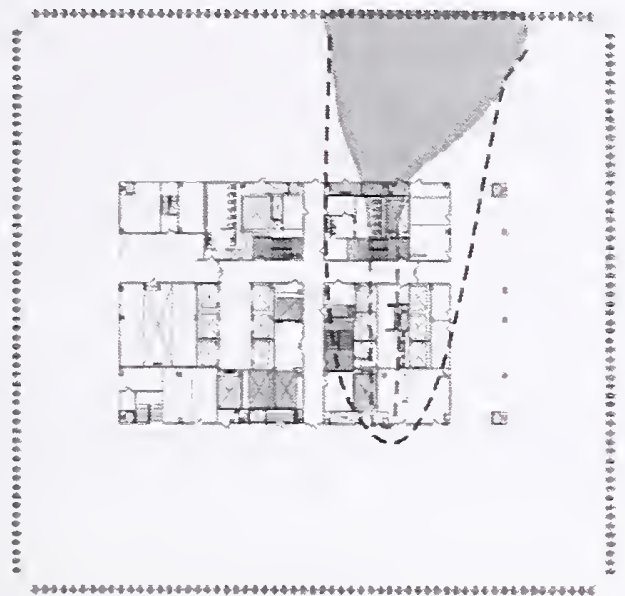

\section{4th Floor}

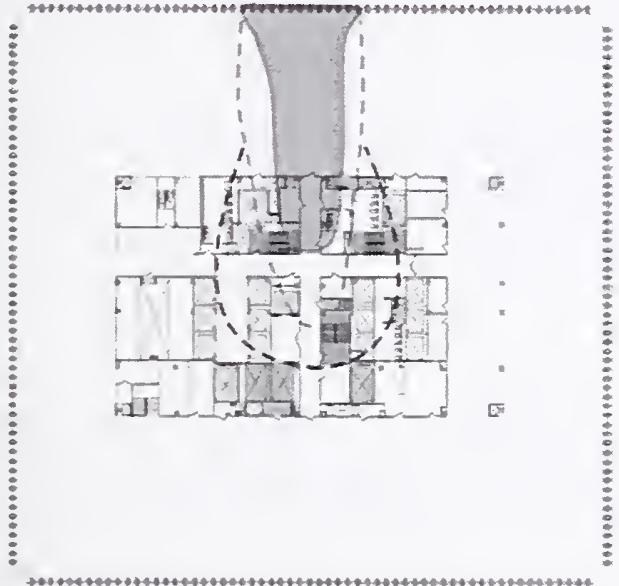

\section{5th Floor}

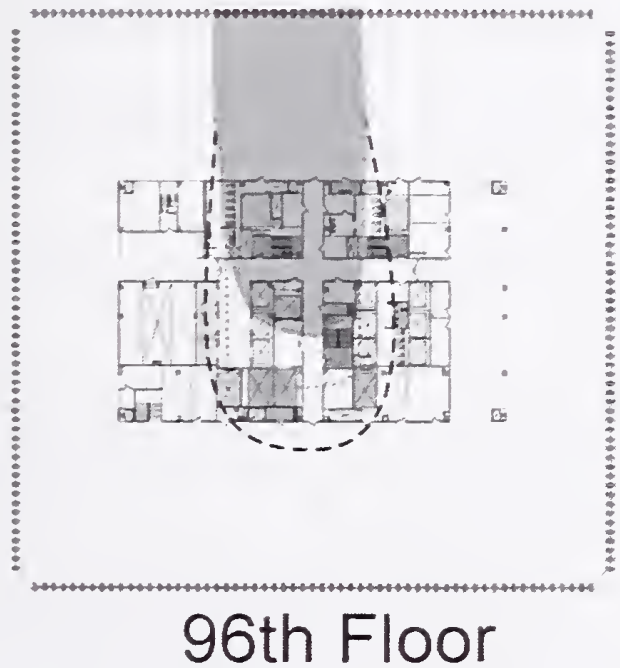

\section{WTC 1}

Probable Damage Estimate (NIST - Appendix A)

- Maximum Damage Estimate

(NIST - Appendix A

- Possible Additional Damage

L - to Drywall Shafts

Exit Stairways

Electrical Closets

HVAC Shafts

Freight Elevator 50

(full height elevator)

Express Elevators

(full height elevators)

Source: Adopted from McAllister 2002. Reproduced with permission of The Port Authority of New York and New Jersey.

Figure 9-1. NIST damage estimates, WTC 1. 
The sprinkler system on floor 96 was within the area of significant impact damage at the northwcst quadrant of the building. It is unlikely that the aircraft would have avoided the sprinkler system on this floor. However, the system was supplied with water from riser B, which was located in the janitor's closet immediately south of stair 3, the southernmost stair enclosure. Based on the initial damage estimates it did not appear that initial damage was sustained to riser B. The other sprinkler risers (A and C) did not pass through this floor and were assumed to be unaffected by the initial impact.

A portion of stair 3 was located within the initial impact area, exposing riser FS-F1 to sustained damage at the 96th floor. Stair 2 was located in the northwest quadrant of the core area and was entirely within the initial impact area. Therefore, the high zone standpipe riser FS-F2 was severed and inoperable as a result of the initial impact.

Stair 1 was located in the northeast quadrant of the core area and sustained damage. It is possible that standpipe riser FS-F3 was damaged, however, it was located outside of the immediate damage area. Table 9-2 provides a summary of the initial damage estimates to the sprinkler and standpipe systems on the 96 th floor.

Based on the initial damage estimates, it appeared that the sprinkler system on the 96th floor was compromised at the north side of the building. A portion of the structure at the center of the floor on the north side sustained significant damage as a result of the impact. It is likely that the sprinkler system on this floor was in the direct path of the aircraft. This system was also supplied from riser B which remained intact and operable.

Stair 3 and standpipe riser FS-F1 were outside the initial impact area and appear to be unaffected on the 95th floor. A portion of stair 2 was located in the initial impact area. It is possible that riser FS-F2 was damaged. Stair 1 and standpipe riser FS-F3 were most likely unaffected since they were located outside of the immediate damage area. Table 9-3 provides a summary of initial damage estimates to the sprinkler and standpipe systems on the 95 th floor.

Table 9-2. Summary of estimated initial damage, sprinkler and standpipe systems, 96th floor, WTC 1.

\begin{tabular}{|l|l|l|}
\hline \multicolumn{1}{|c|}{ Component } & \multicolumn{1}{|c|}{ Location } & \multicolumn{1}{c|}{ Initial Impact Damage Estimate } \\
\hline Sprinkler system & Northwest quadrant & Significant damage to sprinkler system. \\
\hline Sprinkler riser A & Did not pass through this floor. & \\
\hline Sprinkler riser B & $\begin{array}{l}\text { Core-janitor's closet located } \\
\text { adjacent to stair 3 to the south. }\end{array}$ & No initial damage to the riser on this floor. \\
\hline Sprinkler riser C & & Did not pass through this floor. \\
\hline Standpipe riser FS-F1 & Core-stair B (3)-south & $\begin{array}{l}\text { A portion of the stair enclosure was within the } \\
\text { initial impact area. Possible damage to the riser. }\end{array}$ \\
\hline Standpipe riser FS-F2 & Core-stair C (2)-northwest & $\begin{array}{l}\text { The entire stair was within the initial impact area; } \\
\text { loss of riser likely. }\end{array}$ \\
\hline Standpipe riser FS-F3 & Core-stair A (1)-northeast & $\begin{array}{l}\text { A portion of the stair enclosure was within the } \\
\text { initial impact area. Possible damage to the riser. }\end{array}$ \\
\hline Stored water supplies & None located on this floor & No initial damage. \\
\hline
\end{tabular}


Table 9-3. Summary of estimated initial damage, sprinkler and standpipe systems, 95th floor, WTC 1.

\begin{tabular}{|l|l|l|}
\hline \multicolumn{1}{|c|}{ Component } & \multicolumn{1}{c|}{ Location } & \multicolumn{1}{c|}{ Initial Impact Damage } \\
\hline Sprinkler system & North side & Significant damage to sprinkler system likely. \\
\hline Sprinkler riser A & Did not pass through this floor. & \\
\hline Sprinkler riser B & $\begin{array}{l}\text { Core-janitor's closet located } \\
\text { adjacent to stair 3 to the south }\end{array}$ & No initial damage to the riser on this floor. \\
\hline Sprinkler riser C & & Did not pass through this floor. \\
\hline Standpipe riser FS-F1 & Core-stair B (3)-south & No initial damage to the riser on this floor. \\
\hline Standpipe riser FS-F2 & Core-stair C (2)-northwest & $\begin{array}{l}\text { A portion of the stair enclosure was within the } \\
\text { initial impact area. Possible damage to the riser. }\end{array}$ \\
\hline Standpipe riser FS-F3 & Core-stair A (1)-northeast & No initial damage to the riser on this floor. \\
\hline Stored water supplies & None located on this floor & No initial damage \\
\hline
\end{tabular}

At the northeast comer of the 94th floor on the north side, the building sustained significant damage as a result of the impact. The sprinkler system on the 94th floor was also in the direct path of the aircraft and sustained extensive damage. It was noted that this system was supplied with water from riser $\mathrm{B}$, which did not sustain direct initial damage, so while the floor level systems in the vicinity of the 94th floor were not functional, the water supply was maintained for some period of time.

Stair 3 was located in the immediate initial impact area on the 94th floor (refer to Fig. 9-1). The standpipe riser FS-F1 was in the initial impact area and was damaged. Stairs 1 and 2 were unaffected since they were located outside of the immediate estimated damage area. Therefore, risers FS-F2 and FSF3 were undamaged at the 94th floor as a result of the aircraft impact. Table 9-4 provides a summary of initial damage estimates to the sprinkler and standpipe systems on the 94 th floor.

Table 9-4. Summary of estimated initial damage, sprinkler and standpipe systems, 94th floor, WTC 1.

\begin{tabular}{|l|l|l|}
\hline \multicolumn{1}{|c|}{ Component } & \multicolumn{1}{c|}{ Location } & \multicolumn{1}{c|}{ Initial Impact Damage } \\
\hline Sprinkler system & Northeast quadrant & Significant damage to sprinkler system likely. \\
\hline Sprinkler riser A & Did not pass through this floor. & \\
\hline Sprinkler riser B & $\begin{array}{l}\text { Core-Janitor's closet located } \\
\text { adjacent to stair 3 to the south }\end{array}$ & No initial damage to the riser on this floor. \\
\hline Sprinkler riser C & Did not pass through this floor. & \\
\hline Standpipe riser FS-F1 & Core-stair B (3)-south & $\begin{array}{l}\text { A portion of the stair enclosure was within the } \\
\text { initial impact area. Possible damage to the riser. }\end{array}$ \\
\hline Standpipe riser FS-F2 & Core-stair C (2)-northwest & No initial damage to the riser on this floor. \\
\hline Standpipe riser FS-F3 & Core-stair A (1)-northeast & No initial damage to the riser on this floor. \\
\hline Stored water supplies & None located on this floor & No initial damage. \\
\hline
\end{tabular}

The stored water supply tanks for the sprinkler and standpipe systems were located on the 110th, 76th, $42 \mathrm{nd}$, and 20th floors. The initial impact damage to the standpipe risers likely caused the 5,000 gal water storage tank FSP 110A to drain. The water supplies on the other floors were unaffected by the initial impact because these tanks were located below the impact zone. Damage initially sustained by the standpipe risers reduced or interrupted water flow availability from the manual fire pumps and FDCs to 
the standpipe and sprinkler systems above the 32nd floor. Damage sustained to the sprinkler systems on the 94th, 95th, and 96th floors caused the 10,000 gal of sprinkler reserve water storage to drain from the tanks, reducing the effectiveness of the sprinkler systems on the 32 nd through 107 th floors. Damage to the booster pump would have occurred after the water tanks were drained, resulting in failure of the pump.

The fire protection systems in WTC 2 and WTC 7 were basically unaffected by the impact of the aircraft that crashed into WTC 1. The standpipe systems below the high zone in WTC 1 continued to be operational. The high zone standpipe system was partially intact but would have required manual intervention to reinstate service. The low zone sprinkler systems were unaffected by the impact. The high and mid-level zone sprinkler systems were adverscly affected by a decreased water supply capacity and duration as a result of the damage sustained to the standpipe riser and sprinkler systems on the 94th through 96th floors. The effectiveness of the sprinkler systems in the high and mid-level zones was reduccd as a result of the damage to the sprinkler systems on the 94th through 96th floors. However, these sprinkler systems located away from the immediate impact zone, were capable of containing a number of small isolated fires on multiple floors for some time until the water supply was lost as demonstrated in the analysis described in Chapter 8 . However, large fires on multiple floors that significantly exceeded the design areas of the sprinkler systems would have overwhelmed the sprinkler systems.

In summary, the following effects on the operational status of the standpipe and sprinkler systems were determined, based on system damage estimates resulting from the initial aircraft impact on WTC 1:

- Loss of standpipe riser FS-F1, FS-F2.

- Possible loss of standpipe riser FS-F3.

- Loss of standpipe system water supply after a limited amount of time as a result of the damage to the standpipe risers.

- Loss of the sprinkler systems on the 94th through 96th floors.

- The effectiveness of the sprinkler systems in the high and mid-level zones was reduced, however, the systems were capable of containing small fires on multiple floors.

- Possible loss of the sprinkler systems on other floors immediately above the 96 th floor and below the 94 th floor.

- Loss of sprinkler system water supply after a limited amount of time as a result of the damage to the standpipe risers.

\subsubsection{WTC 2 Aircraft Strike}

An estimate of the initial damage to the standpipes and sprinkler systems in WTC 2 that resulted from the second aircraft impact was based on the preliminary structural damage estimates in Fig. 9-2. Figure 9-2 illustrates that extensive initial damage in WTC 2 occurred on floors 78 through 81 . No evidence was found to indicate that the fire protection systems in WTC 1 or WTC 7 were affected in any way by the initial impact of the aircraft that crashed into WTC 2. 

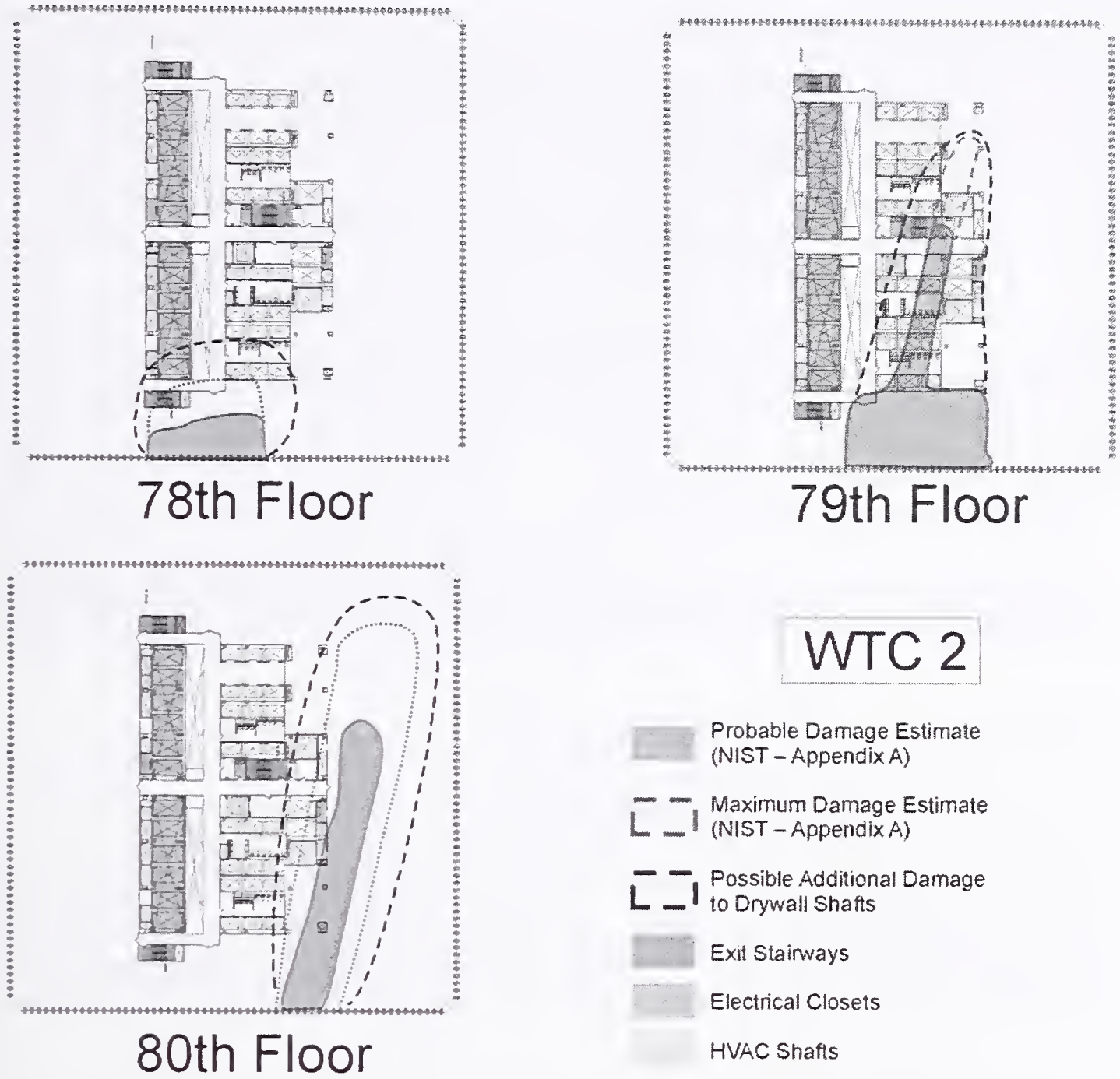

\section{WTC 2}

Probable Damage Estimate (NIST - Appendix A)

- Maximum Damage Estimate

L INIST - Appendix A)

L_ - Possible Additional Damage

Exit Stainways

Electrical Closets

HVAC Shafts

Freight Elevator 50

(full height elevator)

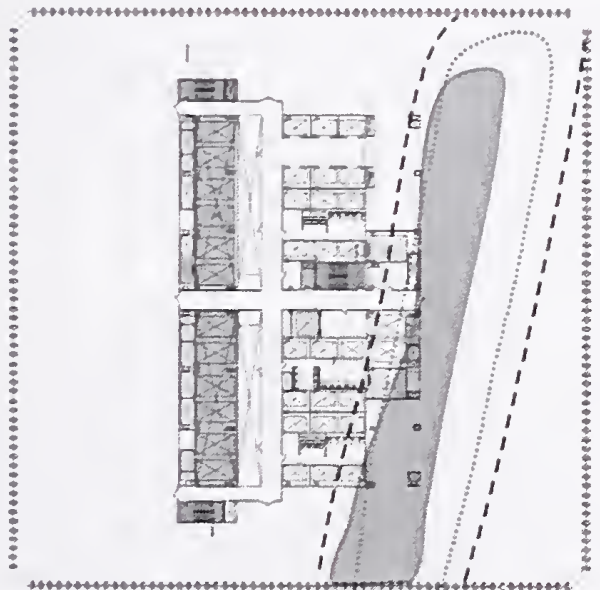

Express Elevators (full height elevators)

\section{1 st Floor}

Source: Adapted from McAllister 2002. Reproduced with permission of The Port Authority of New York and New Jersey.

Figure 9-2. NIST damage estimates, WTC 2. 
Based on the extent of the estimated structural damage, it was concluded that the sprinkler system on floor 81 was damaged at the southeast and northeast quadrants due to the initial impact. A portion of the structure in this area was extensively damaged by the impact. The sprinkler system in this area was supplied from riser B, located in the janitor's closet located immediately to the east of stair 3 . Based on the established damage estimates, no initial damage was sustained to riser B on the 81 st floor. The other sprinkler risers (A and C) did not pass through this floor and were, therefore, unaffected by the impact.

The impact area on the 81 st floor was concentrated in the tenant and core areas at the east side of the building. None of the standpipe risers passed directly through this area and, therefore, they were not likely to have been significantly damaged by the initial impact. In addition, there were no water supplies on this floor level. Table 9-5 provides a summary of the initial damage estimates for the 81 st floor sprinkler and standpipe systems.

Table 9-5. Summary of estimated initial damage, sprinkler and standpipe systems, 81 st floor, WTC 2.

\begin{tabular}{|l|l|l|}
\hline \multicolumn{1}{|c|}{ Component } & \multicolumn{1}{|c|}{ Location } & \multicolumn{1}{c|}{ Initial Impact Damage } \\
\hline Sprinkler system & $\begin{array}{l}\text { East side of building from south } \\
\text { face }\end{array}$ & Significant damage to sprinkler system likely \\
\hline Sprinkler riser A & Did not pass through this floor. & \\
\hline Sprinkler riser B & $\begin{array}{l}\text { Core-janitor's closet located } \\
\text { adjacent to stair 3 to the east. }\end{array}$ & No initial damage to the riser on this floor. \\
\hline Sprinkler riser C & Did not pass through this floor. & No initial damage to the riser on this floor. \\
\hline Standpipe riser FS-F1 & Core-stair B (3)-east & No initial damage to the riser on this floor. \\
\hline Standpipe riser FS-F2 & Core-stair C (2)-southwest & No initial damage to the riser on this floor. \\
\hline Standpipe riser FS-F3 & Core-stair A (1)-northwest & $\begin{array}{l}\text { Initial damage as a result of impact on 79th } \\
\text { floor. }\end{array}$ \\
\hline Stored water supplies & None located on this floor & \\
\hline
\end{tabular}

It is likely that the sprinkler system on the 80th floor of WTC 2 was damaged at the south and east sides of the building as a result of the initial impact. A portion of the structure in this area was significantly damaged by the aircraft impact. The sprinkler system on the 80th floor was supplied with water from riser B, which was located in the janitor's closet immediately east of stair 3 and outside the initial impact zone. There were no water storage tanks or pumps located on this floor. Table 9-6 provides a summary of the initial damage estimates for the 80th floor sprinkler and standpipe systems.

The sprinkler system on the 79th floor was supplied with water from riser B, located in the janitor's closet immediately east of stair 3. Figure 9-2 shows that the area of the janitor's closet where riser B was located was within the likely area of initial damage. Damage to riser B would have reduced the effectiveness of the sprinkler systems on floors 80 through 107 and prevented water from reaching the systems on floors 32 through 79. It is likely that the damaged sprinkler riser drained the water storage tanks on the 110 th floor within a short period of time. It is also likely that the water from the storage tanks and the sprinkler systems drained from riser B on the 79th floor and into the stair and elevator shafts. This would be consistent with eyewitness accounts of large quantities of water draining down the stairs and onto lower floors. 
Table 9-6. Summary of estimated initial damage, sprinkler, and standpipe systems, 80th floor, WTC 2.

\begin{tabular}{|l|l|l|}
\hline \multicolumn{1}{|c|}{ Component } & \multicolumn{1}{c|}{ Location } & \multicolumn{1}{c|}{ Initial Impact Damage } \\
\hline Sprinkler system & $\begin{array}{l}\text { East side of building from } \\
\text { south face }\end{array}$ & Significant damage to sprinkler system likely. \\
\hline Sprinkler riser A & Did not pass through this floor. & \\
\hline Sprinkler riser B & $\begin{array}{l}\text { Core-janitor`s closet located } \\
\text { adjacent to stair 3 to the east. }\end{array}$ & No initial damage to the riser on this floor. \\
\hline Sprinkler riser C & Did not pass through this floor. & \\
\hline Standpipe riser FS-F1 & Core-stair B (3)-east & No initial damage to the riser on this floor. \\
\hline Standpipe riser FS-F2 & Core-stair C (2)-southwest & No initial damage to the riser on this floor. \\
\hline Standpipe riser FS-F3 & Core-stair A (1)-northwest & No initial damage to the riser on this floor. \\
\hline Stored water supplies & None located on this floor & Initial damage as a result of impact on 79th floor. \\
\hline
\end{tabular}

The standpipe risers on the 79th floor did not appear affected by the initial impact. There were no water storage tanks or pumps located on this floor. Table 9-7 provides a summary of the initial damage estimates for the 79 th floor sprinkler and standpipe systems.

The sprinkler system on the 78th floor of WTC 2 was most likely extensively damaged by the impact of the aircraft. A large part of the sprinkler system at the south side of the building was damaged, significantly compromising its effectiveness. In addition, the sprinkler system on the 78th floor was supplied with water from riser B. Although there was no damage to this riser on the 78th floor, the damage incurred at the 79th floor compromised the integrity of all of the sprinkler systems within the high and mid-level zones. The damage to the sprinkler riser likely drained the watcr storage tanks on the 110 th floor within 20 to $35 \mathrm{~min}$. (Note: These calculated times are based on the flow limitation of $440 \mathrm{gpm}$ reported in the Chapter 6 analysis and assumes that the supplemental rcfill connection was not operational.)

Table 9-7. Summary of estimated initial damage, sprinkler and standpipe systems, 79th floor, WTC 2.

\begin{tabular}{|l|l|l|}
\hline \multicolumn{1}{|c|}{ Component } & \multicolumn{1}{c|}{ Location } & \multicolumn{1}{c|}{ Initial Impact Damage } \\
\hline Sprinkler system & East side of building from south face. & Significant damage to sprinkler system likely. \\
\hline Sprinkler riser A & Did not pass through this floor. & \\
\hline Sprinkler riser B & $\begin{array}{l}\text { Core-janitor's closet located adjacent } \\
\text { to stair 3 to the east. }\end{array}$ & Damage sustained to riser B was likely. \\
\hline Sprinkler riser C & Did not pass through this floor. & \\
\hline Standpipe riser FS-F1 & Core-stair B (3) -east & No initial damage to the riser on this floor. \\
\hline Standpipe riser FS-F2 & Core-stair C (2)-southwest & No initial damage to the riser on this floor. \\
\hline Standpipe riser FS-F3 & Core-stair A (1)-northwest & No initial damage to the riser on this floor. \\
\hline Stored water supplies & None located on this floor & Initially damaged. \\
\hline
\end{tabular}

The standpipe risers on the 78th floor of WTC 2 were unaffected by the aircraft impact. There were no water storage tanks or pumps located on this floor. Table 9-8 provides a summary of the initial damage estimates for the 78th floor sprinkler and standpipe systems. 
Table 9-8. Summary of estimated initial damage, sprinkler and standpipe systems, 78th floor, WTC 2.

\begin{tabular}{|c|c|c|}
\hline Component & Location & Initial Impact Damage \\
\hline Sprinkler system & East side of building from south face & $\begin{array}{l}\text { Significant damage to sprinkler system } \\
\text { likely. }\end{array}$ \\
\hline Sprinkler riser A & Did not pass through this floor. & \\
\hline Sprinkler riser B & $\begin{array}{l}\text { Core-Janitor's closet located } \\
\text { adjacent to stair } 3 \text { to the east }\end{array}$ & $\begin{array}{l}\text { No initial damage to the riser on this } \\
\text { floor. }\end{array}$ \\
\hline Sprinkler riser $\mathrm{C}$ & Did not pass through this floor. & \\
\hline Standpipe riser FS-F1 & Core-stair B (3)-east & $\begin{array}{l}\text { No initial damage to the riser on this } \\
\text { floor. }\end{array}$ \\
\hline Standpipe riser FS-F2 & Core-stair C (2)-southwest & $\begin{array}{l}\text { No initial damage to the riser on this } \\
\text { floor. }\end{array}$ \\
\hline Standpipe riser FS-F3 & Core-stair A (1)-northwest & $\begin{array}{l}\text { No initial damage to the riser on this } \\
\text { floor. }\end{array}$ \\
\hline Stored water supplies & None located on this floor & $\begin{array}{l}\text { Initial damage as a result of impact on } \\
791 \mathrm{~h} \text { floor }\end{array}$ \\
\hline Other-Fire carts & $\begin{array}{l}\text { Cores }-78 \text { th, } 44 \text { th floors and } \\
\text { concourse level }\end{array}$ & No initial damage. \\
\hline
\end{tabular}

The likely damage to riser B would have compromised the integrity of the sprinkler system infrastructure for the mid-level and high zones. The impact of the loss of riser B on the 79th floor is significant since this riser supplied the sprinkler systems on the 32nd through 98 th floors. The damage to riser B would have prevented adequate pressure and flow from being provided to the sprinkler systems above the 79 th floor, as well as significantly compromising the water supply to the sprinkler systems on floors 32 through 78 .

Riser B was supplied with water from the sprinkler and standpipe storage tanks located on the 110 th floor. The damage to riser B resulted in the loss of integrity of the water supply to the high zone sprinkler systems and the high zone standpipe system. The 10,000 gal sprinkler reserve water storage tanks and the 5,000 gal standpipe tank likely drained as a result of the impact. The booster pump that supplied the high zone sprinkler systems would have sustained damage after the tanks drained unless supplemental water was provided through the fire department connections (FDCs).

The low zone sprinkler systems were unaffected by the initial impact and should have been operational. The high zone sprinkler systems were compromised by decreased water supply capacity and duration as a result of the damage sustained to the standpipe riser and sprinkler systems on the 94th through 96th floors.

The standpipe systems below the high zone were not directly affected and remained operational. The high zone standpipe system was intact, and it is likely that the fire cart located on the 78th floor was intact. The amount of time that water was available was limited due to the failure of sprinkler riser B. 
In summary. the following adverse effects on the standpipe and sprinkler systems in WTC 2 were likely caused by the initial aircraft impact on WTC 2:

- Loss of sprinkler riser B. although the other standpipe system risers remained operable.

- Loss of sprinkler and standpipe system water supplies after a limited amount of time as a result of the damage to sprinkler riser $\mathrm{B}$.

- Loss of the sprinkler systems on the 78th through 81 st floors.

- Loss of water supply to the sprinkler systems on floors 32 through 78.

- The effectiveness of the sprinkler systems above the 79th floor was significantly reduced as a result of the loss of riser $B$.

- Possible loss of the sprinkler systems on other floors immediately above the 96 th floor and below the 94 th floor.

- Use of manual fire pumps and FDCs was possible.

\subsubsection{WTC 2 Collapse}

There was no significant damage to WTC 7 reported as a result of the collapse of WTC 2. However, there was significant damage to the 12 in. supply main in the utility rack on the sub-grade level and the distribution system in the surrounding area of WTC 2 (Beyler 2002). The power supply for the two B1 level standpipe pumps was supplied by a single circuit which was likely damaged as a result of the collapse, rendering the B1 level pump beneath IVTC 1 inoperable. Significant damage to the concourse and Bl sprinkler and standpipe loops was also likely.

The configuration of the sub-grade loops included isolation valves to prevent major water supply interruption due to broken pipe segments. FDCs were located between each series of isolation valves, allowing water to be pumped through the FDCs to the sprinkler and standpipe systems in WTC 1 after the collapse of WTC 2.

The low zone sprinkler systems in WTC 1 and WTC 2 were interconnected. The water supply for the WTC 1 low zone systems would have drained until the manual tower-isolating valve was closed. This would have isolated the WTC 1 sprinkler systems from the damaged portions of the system infrastructure resulting from the collapse of WTC 2. The FDCs for the low zone could have been used to supply water to these systems (Beyler 2002). However, once WTC 2 collapsed, accessibility to isolation valves and FDCs was significantly reduced.

\subsubsection{WTC 1 Collapse}

The collapse of WTC 1 resulted in extensive damage to the below grade water supply for the WTC complex. Although the redundant water supplies to WTC 7, located under Washington Street, most likely survived the collapses of WTC 1 and 2 (Beyler 2002), multiple fires were reported in WTC 7 as a result of burning debris and structural materials from the WTC 1 collapse (NIST 2003). Photographic and 
videographic records, along with eyewitness accounts, indicated that extensive fires were burning throughout WTC 7 for a number of hours before the building collapsed (NIST 2003).

\subsubsection{WTC 7 Collapse}

No fire department actions were taken to suppress the fires in WTC 7 once the building was evacuated (Smith 2002). Insufficient documentation existed to allow determination of the performance of the suppression systems in WTC 7. However, it is unlikely that the sprinklers provided more than nominal protection once multiple fires were burning on different floors.

The analysis of the WTC 7 sprinkler system design indicated that the sprinkler systems were capable of controlling multiple fires, or a fire which exceeded the sprinkler system design areas, for some period of time. However, photographic records indicated that the fires were extensive on multiple floors (Averill et al. 2005; McAllister et al. 2005). For example, a fire on the 12th floor burned for several hours, and eventually burned out; the sprinkler systems were not able to suppress this fire. In addition, the water supply to the upper floors (floors 21 through 47) consisted of a stored water source and risers connected to the FDCs. The stored water provided, at the most, 20 to 30 minutes of supply before reliance on the fire department for continued supply became acute. Therefore, once multiple fircs occurred in WTC 7 and the fire department was unable to support the water demand from the street, the sprinkler systems would have been quickly overwhelmed.

An eyewitness account indicated that at some point there was no water to the standpipes in WTC 7 (Smith 2002). The cause of this is unknown, but could have resulted from a loss of power to the fire pumps, diversion of the water from the standpipes for other fire department operations (Smith 2002), and/or the documented fact that the fire department was unable to supplement the water supply to WTC 7 through the FDCs (Smith 2002). In addition, combustible liquids storage and supply piping existed at the first floor, as well as on floors 5, 7, and 8. Analyses of the arcas associated with the fuel storage tanks on the first floor detccted no fuel residual, indicating that the fuel contributed to the fires in WTC 7 (McAllister et al. 2005). The automatic sprinkler systems were not designed to protect a combustible liquids hazard. The sprinklers would likely have provided some control, depending on the extent of the fuel spill fire areas, for a limited amount of time. However, even if the sprinkler systems were fully opcrational at this point, with the limited duration of the stored water supply and the absence of supplemental water from the FDCs to the sprinkler systems, the result would have been failure of the sprinkler systems to control the fires, leading to extensive fire spread on multiple floors.

\subsection{SUMMARY OF TASK 5}

Preliminary structural damage estimates provided by NIST were used to determine the extent of damage to and related operability of the fire suppression systcms in WTC 1 and WTC 2 resulting from the incidents on September 11, 2001. Initial damage to the standpipe and sprinkler systems in WTC 1 as a result of the aircraft strike was primarily on floors 94 through 96 . Based on review of the damage estimates, photographic and video records, and documented eyewitness accounts, the effects of the impact on the operability of the suppression system was estimated to include the following:

- Loss of standpipe riser FS-F1 and FS-F2. 
- Possible loss of standpipe riser FS-F3.

- Loss of standpipe risers Loss of standpipe system water supply after a limited amount of time as a result of the damage to the standpipe risers.

- Loss of the sprinkler systems on the 94th through 96th floors.

- The effectiveness of the sprinkler systems in the high and mid level zones was reduced, however the systems were capable of containing small fires on multiple floors.

- Possible loss of the sprinkler systems on other floors immediately above the 96th floor and below the 94 th floor.

- Loss of sprinkler system water supply after a limited amount of time as a result of the damage to the standpipe risers.

Floor control valves on floors 94 through 96 of WTC 1 for these suppression as well as standpipe isolation valves on the 88th and 99th floors could potentially have been used to isolate the initial impact zone, but, such an action would have required immediate, precise information and would not have prevented building collapse. It is unlikely that the sprinkler and standpipe systems in WTC 2 or WTC 7 were immediately damaged by the aircraft strike on WTC 1.

The damage to WTC 2 as a result of the second aircraft strike was concentrated on floors 78 through 81 . The resulting effects on the condition and operability of the standpipe and automatic sprinklers in WTC 2 were estimated to include the following:

- Loss of sprinkler riser B.

- Operability of the standpipe system risers not lost due to initial impact.

- Loss of sprinkler and standpipe system water supplies after a limited amount of time as a result of the damage to sprinkler riser $\mathrm{B}$.

- Loss of the sprinkler systems on the 78th through 81 st floors.

- Loss of water supply to the sprinkler systems on floors 32 through 78.

- The effectiveness of the sprinkler systems above the 79th floor was significantly reduced as a result of the loss of riser $B$.

- Possible loss of the sprinkler systems on other floors immediately above the 96 th floor and below the 94 th floor.

- Use of manual fire pumps and FDCs was possible.

The damage to sprinkler riser B was significant and could not be bypassed by closing one or more isolation valves. Considerable efforts would have been required to reinstate service to riser $\mathrm{B}$. 
The collapse of WTC 2 damaged the sub-grade sprinkler and standpipe loops and portions of the water distribution system in the surrounding area. It is also possible that vibration and pressure waves caused additional damage to the systems in WTC 1.

The collapse of WTC 1 caused extensive damage to the below grade water distribution system for the WTC complex. It was reported that burning debris from the collapse of WTC 1 caused multiple fires in WTC 7 (Smith 2002). WTC 7 burned for nearly 7 h before collapse (Smith 2002). Although the Task 2 and Task 4 analyses demonstrated that the sprinkler systems in WTC 7 were robust, multiple fires were reported in the building, and several areas of the building that contained electrical transformers, generators, fuel day tanks, and pressurized fuel piping were either not protected by automatic sprinklers or sprinklers in those areas were not designed to control such hazards.

Limited documentation was available regarding the performance of the suppression systems in WTC 7. However, even though the installed sprinkler and riser/standpipe systems, as well as the water supplies, were robust, multiple factors led to failure of the suppression systems and the eventual collapse of WTC 7. These factors included the following:

- Multiple fires occurred on different floors as a result of burning debris from the collapse of WTC 1. Many of these fires extended beyond the sprinkler system design areas and involved most of the floor areas.

- The stored water supply on the 47 th floor of WTC 7 would have provided, at most, 20 to 30 min of supply to the sprinkler systems.

- The inability of the fire department to supplement the water supply for the upper floors significantly reduced the performance of the sprinkler systems.

- The sprinkler systems were not designed to protect a combustible liquids hazard. 


\section{Chapter 10 \\ SUMMARY AND LIMITATIONS}

\subsection{SUMMARY}

The following is a summary of this report. Descriptions of the fire protection systems were based on extensive review of original design drawings and specifications, operations and maintenance manuals, and other related documents maintained by The Port Authority of New York and New Jersey (PANYNJ). Limited factual information or eyewitness accounts were found regarding the performance of the fire suppression systems on September 11, 2001. Therefore, estimates of the damage to the fire suppression systems and the effects on operability were largely based on review of structural damage impact estimates and available investigative reports. The use of anecdotal input or "hearsay" information was generally avoided unless such information was later corroborated by an independent source.

\subsubsection{Scope}

The scope of this effort included investigation of the suppression features in World Trade Center (WTC) 1,2, and 7. This effort focused on (1) documentation of the installed fire suppression features, and (2) examination of the expected performance of the suppression features under a range of fire incident scenarios, including the incidents that occurred on September 11,2001. Five tasks were performed as part of this work. including the following:

- Task 1: Documentation of the design and installation of the fire sprinkler, standpipe, and preconnected hose systems, and comparison of the designs to applicable codes and standards requirements

- Task 2: Documentation of the design and capacity of the water supply to the suppression systems, including provisions for redundancy

- Task 3: Identification and documentation of the differences in the design of the water supply, fire sprinkler systems, standpipe systems and pre-connected hoses among WTC 1, 2, and 7

- Task 4: Documentation of the normal operation and effect of fully functional fire sprinkler, standpipe and pre-connected hose systems for fire control

- Task 5: Documentation of the performance of the sprinklers, standpipes, and pre-connected hoses on September 11, 2001, in WTC 1, 2, and 7

\subsubsection{Applicable Codes/Standards}

The WTC was constructed and maintained under the jurisdiction of PANYNJ. Although PANYNJ was not subject to the provisions of the Building Code of the City of New York (BCNYC), the PANYNJ voluntarily adopted the provisions within the BCNYC for the design and construction of WTC 1, 2, and 7. In addition, certain reference standards (RS) identified in the BCNYC were adopted. The reference 
standards included locally established standard documents, as well as nationally recognized standards with local modifications.

WTC 1 and WTC 2 were constructed under the 1968 edition of the BCNYC. The 1968 BCNYC, along with amendments up through January 1, 1985, was used to provide the fire safety provisions during the primary design and construction of WTC 7. A detailed review of the applicable codes and standards is provided in (Razza and Grill 2005), which was prepared as part of the analysis of building fire codes and practices of the NIST WTC Investigation. The applicable sections of the BCNYC with the amendments associated with Local Laws 5/73 and 16/84 were the documents that established the provisions for the scope of the installation of automatic sprinklers, standpipe/pre-connected hose systems and associated water supplies for high-rise business occupancies in New York City (NYC). The actual installation provisions for each type of system were described in the RS sections of the BCNYC.

\subsubsection{Normal Performance Expectations}

Automatic sprinklers have a long history of highly effective performance. Both fatality rates and property damage have been estimated to be significantly lower for sprinkler protected versus non-sprinkler protected buildings. Incident data from multiple sources indicate that over half of all fires are controlled or extinguished by one or two sprinklers. A study of sprinkler performance in high-rise buildings in NYC indicate that over 90 percent of all fires in sprinkler protected high-rise buildings were controlled or extinguished by three or less operating sprinklers, and, 97 pcrcent of the incidents were controlled or extinguished by six or less sprinklers. Although rare, system failures have been attributed primarily to partial sprinkler coverage, antiquated or poorly maintained systems, and explosions or flash fires that overpowered the systems.

The design and installation requirements in National Fire Protection Association (NFPA) 13, as well as the BCNYC, were not developed in anticipation of simultaneous, multiple large fires at multiple locations. The requirements also are not based on consideration for extensive impact damage or building collapse.

Performance records are not maintained in the public litcrature for standpipe and pre-connected hose systems. There is little doubt that a properly installed and maintained standpipe/pre-connected hose system in a high-rise building is of significant benefit to fire department operations. Standpipe systems are not considered to be an alternative to automatic fire suppression, e.g., automatic sprinklers.

\subsubsection{Evaluation of Suppression Systems}

\section{General}

For the most part, the water supplies, automatic sprinklers, and standpipe/pre-connected hose systems in WTC 1, 2, and 7 were determined to be robust, and exceedcd the minimum applicable code requirements as well as associated engineering best practices prevailing at the time of their installation. In fact, with few exceptions they would satisfy current best practices, as well, and meet or exceed current code requirements.

Preliminary damage estimates provided by NIST were used to determine the extent of damage to the related operability of the fire suppression systems in WTC 1 and WTC 2 resulting from the incidents on 
September 11, 2001. Initial damage to the standpipe and sprinkler systems in WTC 1 as a result of the aircraft strike was primarily on floors 94 through 96. In WTC 2 the initial damage to the suppression systems was on floors 78 through 81 . Based on review of the damage estimates, photographic and video records, and documented eyewitness reports, the adverse effects of the impacts on the opcrability of the suppression systems were extensive.

The collapse of WTC 1 caused extensive damage to the below grade water distribution system for the WTC complex. Although the primary water supplies to WTC 7 apparently survived the collapse of WTC 1 and WTC 2, it was reported that burning debris from the collapse of WTC 1 caused multiple fires in WTC 7. Some of these fires, identified through review of photographic and video records and eyewitness accounts. started in areas of WTC 7 that contained electrical transformers, fuel day tanks, and pressurized fuel piping. These areas were either not protected by automatic sprinklers or the sprinklers in these areas were not designed to control such hazards.

Primary and backup power was provided in all three buildings, but the absence of remote redundancy of the power transmission lines to the emergency fire pumps would have affected the operability of the sprinkler and standpipe systems once primary power was lost.

Based on the available information it appears that several factors could have led to the extensive fire spread and eventual collapse of WTC 7. Multiple fires occurred on different floors of WTC 7, started by burning debris from WTC 1. Several of these fires spread beyond the design areas for the sprinkler system(s) and involved most of the floor areas. The stored water in WTC 7 would have provided, at most, 20 to 30 min of supply to the sprinkler systems. The inability of The Fire Department of Ncw York (FDNY) to supplement the water supply for the upper floors or provide the primary supply to the lower floors dramatically reduced the potential effectiveness of the sprinkler systems, assuming the systems were not critically damaged by the collapse of WTC 1. And finally, the sprinkler systems wcre not designed to protect combustible liquid hazards.

\section{Water Supply}

The primary source of water for the WTC complex was the New York City watcr distribution system. A complex grid of $20 \mathrm{in}$. and $12 \mathrm{in.} \mathrm{mains} \mathrm{surrounded} \mathrm{the} \mathrm{WTC} \mathrm{complex,} \mathrm{forming} \mathrm{a} \mathrm{very} \mathrm{robust} \mathrm{watcr}$ supply with an average steady state system-wide pressure of 50 psi. The WTC complex was provided with two separate supply connections at Vesey and Liberty Streets with isolation valves to permit independent operation. WTC 7 was provided with two connections from the $12 \mathrm{in}$. main under Washington Street, about $12 \mathrm{ft}$ apart.

The water supply components in WTC 1, 2, and 7 included water storagc tanks, fire pumps, and fire department connections (FDS). The primary water supplies for the automatic sprinkler and standpipe systems for the most part consisted of gravity tanks and booster pumps, with secondary or back up supplies directly from the underground water distribution system.

Three separate 5,000 gal water storage tanks were provided for the high and mid-level zone sprinkler and standpipe systems at the tops of WTC 1 and WTC 2. A single 5,000 gal tank was provided on the 41 st floor of each tower. The tanks were interconnccted through a 4 in. main. Each tank was provided with a separate refill connection. As supplements to the gravity tanks, the maintenance and engineering 
staff supplied water to the fire suppression systems from the city water distribution system using manually operated fire pumps. The fire department could also supply water through the fire department connections located at the street level throughout the complex.

The systems in WTC 7 included one automatic and two manually operated water supplies. The combined systems were provided with a single automatic fire pump for the low zone. The high and mid-level zones were supplied from two water storage tanks located on the 47 th floor. The high zone also included a booster pump. A single $750 \mathrm{gpm}$ fire pump supplied the secondary water. The FDNY could also supply water to the systems using the fire department connections. The water supply tanks located in the upper water supply zone of WTC 7 did not service the lower floors. Rather, the primary and secondary water supply for floors 1 through 20 were the two parallel service connections to the $12 \mathrm{in}$. main under Washington Street and associated FDCs.

\section{Standpipe/Riser Systems}

Standpipes supplied the pre-connected hoses in WTC 1 and WTC 2. The sprinkler systems were supplied separately by risers. In WTC 7, the standpipes and risers were combined into a single system.

The standpipe systems in WTC 1 and WTC 2 were interconnected at the top of each zone with check valves that prevented downward flow in two of the three risers. This arrangement permitted upward flow through all three risers while operating in the secondary supply modes using the manual fire pumps or the fire department connections. The standpipe systems in WTC 7 did not have a similar interconnection at the top of the standpipe zoncs.

The standpipe/pre-connected hose systems in WTC 1 and WTC 2 were supplied by storage tanks and the underground loop. The hose stations were Class III hose stations with $125 \mathrm{ft}$ of hose and a nozzle for use by the fire brigade and/or the FDNY. Operating pressures were maintained by manually operated fire pumps with primary power and backup power generators located on the B6 level. Fire department connections were available to supplement the flow and pressure for the standpipe systems.

The standpipe/riser systems in all three buildings were installed in stairwells with hose stations at each floor as well as at other locations on specific floors.

No information was found to indicate if the dependence of the low zone standpipe system arrangement in WTC 7 on the two feeders located only $12 \mathrm{ft}$ apart under Washington Street had a significant adverse impact on the performance of the sprinkler and standpipe systems in WTC 7 on September 11, 2001. The standpipe system in WTC 7 was reportedly used to supply water to fight other nearby fires. This, along with any damage to the Washington Street supply mains due to the collapse of WTC 1 and WTC 2, would have significantly reduced the effectiveness of the sprinkler and standpipe systems to the lower floors of WTC 7 h before WTC 7 collapsed.

While it is difficult to assess the performance capabilities of the standpipe/pre-connected hoses, hydraulic calculations indicated that the size of the standpipes and the capacity and number of fire pumps were adequate to meet the requirements for pressure and flow contained in the BCYNC. However, the booster pump on the 46th floor of WTC 1 and WTC 2 was undersized, and could not provide the minimum pressure and flow requirements of NFPA 14. 
In WTC 1 and WTC 2, if the maintenance or engineering staff failed to operate the manual fire pumps, or the fire department was delayed in supplementing the water supply through one of the fire department connections, water available for the sprinkler systems and manual firefighting in the buildings would be limited to the stored water tanks. While this arrangement was consistent with the BCNYC at the time of installation, more recent editions of NFPA 14 require automatic or semi-automatic operation of fire pumps. The use of automatic fire pumps would have also been consistent with "best practices" at the time of installation.

Manual fire pumps and booster pumps maintained the systems operating pressures. Backup power to the pumps was supplied by emergency generators located on several floors of WTC 7.

The installation of the supply piping from the storage tanks on the 110th floor in WTC 1 and WTC 2 resulted in restricted flow capacity to several floors in the mid-level water supply zones in both buildings. While the flow capacity was sufficient to supply the sprinkler and standpipe systems, the installation was not consistent with engineering "best practices" at the time of the installation.

The standpipe/pre-connected hose systems were consistent with the applicable requirements in the BCNYC. They were not consistent with the flow rates and durations required in NFPA 14. These differences would manifest themselves if the standpipe systems were used simultaneously at multiple locations throughout the building (i.e., very high demand) and the fire department failed to usc the FDCs to back up the water supply. No information was found to indicate that the standpipes were in excessive use on September 11.

\section{Sprinkler Systems}

Wet pipe automatic sprinkler systems were installed throughout WTC 1 and WTC 2, with exception of a few areas, including the mechanical spaces on the 108th through the 110th floors and the electrical rooms throughout the buildings. In these areas, either sprinkler systems were not required under the BCNYC or the spaces were provided with alternative special suppression systems. The systems were "control" type sprinkler systems and were phased in from 1983 to early 2001 (Note that some systems were installed in the sub-grade levels when the buildings were built, and others were installed around 1976 to protect core areas, maintenance areas. and select tenant spaces of the buildings.) The sprinkler systems in WTC 1 and WTC 2 were supplied by vertical risers located in the stairwells. In WTC 7, the risers were locatcd in janitor's closets and wet columns supplied from gravity fed storage tanks above each of four supply zones. The supply to all three buildings was supplemented by the underground water supply main that looped the WTC complex.

In WTC 7 wet-pipe, "control" type automatic sprinkler systems were installed in most areas and were supplied by a combined standpipe/riser system. Certain areas were not protected by sprinklers, including electrical equipment areas (switchgear, networking, and switchboard rooms), generator rooms, and bathrooms. Sprinklers were not installed on most of the 5th floor nor on the 7 th floor, which housed the OEM generators and fuel day tanks. A dry-pipe sprinkler system was installed to protect the fuel storage tanks on the 1st floor that supplied the high pressure fuel lines that serviced the emergency generators.

WTC 7 contained fuel oil powered generators and day tanks located on the fifth, seventh, eighth, and ninth floors. The suppression protection varied for each component of the fuel oil supply system. A dry- 
pipe sprinkler system was provided for protection of two 12,000 gal fuel oil tanks located under the loading berths on the south side of the building, adjacent to Vesey Street. An Inergen suppression system was provided for the $6,000 \mathrm{gal}$ fuel oil storage tank room located on the mezzanine, eight feet above the elevator storage area on the first floor. The area below this room was protected by a wet pipe sprinkler system. The fuel pumps were located on the lst floor near the loading dock and were protected by a drypipe sprinkler system. The generator and day tank enclosures werc not protected by automatic sprinklers. These omissions of sprinkler coverage were consistent with the BCNYC.

The sprinkler systems installed in WTC 1,2, and 7 exceeded the required performance levels undcr the BCNYC and NFPA 13 for protection of high-rise office buildings by considerable margins. Based on historical incident data, systems having such characteristics would be expected to extinguish, rather than control, most fires that occur in these types of buildings.

The installed sprinkler systems in WTC 1,2, and 7 had the ability to simultancously control or suppress multiple fires of varying sizes under "normally expccted" operating conditions. The fires could have occurred at different locations on a single floor or on multiple floors. Water flow density and pressure associated with the installed systems had the capacity to control a single fire on the order of two to three times the sprinklcr system design area, depending on the location in the building, and, the systems would be expected to concurrently control at least four to six fires similar in area to that protected by a foursprinkler array (i.e., $750 \mathrm{ft}^{2}$ ). While these systems were considered very robust, a coverage area of two or three times the design area of the sprinkler system constituted less than 15 percent of the floor area of a typical single floor in these buildings.

The intensity and extent of the initial fires in WTC 1 and WTC 2 on September 11, 2001, were considerably greater than two to three times the specified design areas and involved multiple floors. While there was no way to confirm the extent of the initial fires, it is likely that had the systems remained operable, a large number of sprinklers would have been opened on multiple floors. Once the number of open sprinklers exceeded an area equivalent to two or three times the design areas, the system's ability to control the fire would have been reduced and the duration of the primary water supply rapidly degraded. Furthermore, the likely damage to the suppression systems in WTC 1 and WTC 2 due to the aircraft impacts and the subsequent failures of structural components virtually ensured that significant parts of the systems were rendered inoperable, regardless of the extent of the initial fires.

Although consistent with the BCNYC, the typical floor level sprinkler system was installed with only one connection to the infrastructure riser. This arrangement provided a single point of failure of the water supply to the floor level sprinklers.

Even if the sprinkler systems had been designed to protect much higher hazard levels (i.e., Ordinary Group II or Extra Hazard), the magnitude of the fires experienced in these buildings and accompanying impact damage would have most likely resulted in the fires not being controlled.

\section{$10.2 \quad$ LIMITATIONS}

There was very little eyewitness or communications information regarding the performance of the fire supprcssion systems on September 11, 2001. The descriptions of the systems and their inherent operational capabilities described in this report are considered reasonably accurate. The performance of 
the individual suppression systems on September 11,2001, was based on review of the incident information accumulated by NIST, analysis of the likely initial impact effects on the systems, and historical performance records for automatic sprinklers. Where possible, significant events and/or effects were determined based on information from more than one source. However, due to the fragmentation of available information regarding the events of September 11, this could not always be accomplished.

Descriptions of suppression systems, likely events or actions, and subsequent effects were based on, and/or deduced from, available information. Events or effects that were considered "likely" or "probable," based on the accumulated information, were considered appropriate for inclusion. 
This page intentionally left blank. 


\section{Appendix A \\ REFERENCES}

Averill, J. D., R.D. Peacock, E.D. Kuligowski, and P.A. Reneke. 2005. Federal Building and Fire Safety Investigation of the World Trade Center Disaster: Occupant Behavior, Egress, and Emergency Communication. NIST NCSTAR 1-7. National Institute of Standards and Technology. Gaithersburg. MD, May.

BCNYC (Building Code of the City of New York). 1968. Building Code-Local Law No. 76 of the City of New York. New York, NY.

BCNYC (Building Code of the City of New York). 1973. Fire Safety Requirements and Controls Local Law No. 5 of the City of New York. New York, NY. January.

Beyler, C.L. 2002. Analysis of the Fire Aspects of the World Trade Center Terrorist Attacks: 11 September 2001. Hughes Associates Inc. Baltimore, MD, July 31.

Bryan, J.L. 1990. Automatic Sprinkler and Standpipe Systems. NFPA (National Fire Protection Association). Quincy, MA, August.

Corcoran, D. 1993. Fire Department of New York, New York, NY, personal communication to J. Hodgens, Fire Department of New York, New York, NY, Status Report - World Trade Center Complex, Nos. 1, 2, 4. 5 Life/Fire Safety and Building Systems. April 27.

Cote, A. 2003. Fire Protection Handbook, 19th Ed., National Fire Protection Association, Quincy, MA.

Emery Roth and Sons, P.C. 1987. "7 World Trade Center." Fire Protection Drawings (PFP-1, PFP-2). Sep. 25.

FDNY (Fire Department of New York). 1988. Fire Safety Plan: 7 World Trade Center. New York, NY, April.

FDNY (New York City Fire Department). 1990. Fire Fighting Procedures and Fire Operations for HighRise Office Buildings, New York, NY.

FDNY (New York City Fire Department). 1990. Firefighting Procedures Fire Operations, Book 5, vol. 1. New York, NY, March.

GC Engineering Inc. 1998 Miscellaneous Life Safety Improvements and Sprinklerization Program, World Trade Center (WTCI-327-STB).

GC Engineering Inc. 1998. Fuel Oil Plans and Diagrams. New York, NY.

Gensler and Associates. 1995. American Express Bank: $13^{\text {th }}$ Floor Sprinkler Plan. New York, NY, January. 
Grill, R.A., and D.A. Johnson. 2005. Federal Building and Fire Safety Investigation of the World Trade Center Disaster: Fire Protection and Life Safety Provisions Applied to the Design and Construction of World Trade Center 1, 2, and 7. NIST NCSTAR 1-1D. National Institute of Standards and Technology. Gaithersburg, MD, May.

Grill, R.A. and D. A. Johnson. 2005a. Federal Building and Fire Safety Investigation of the World Trade Center Disaster: Amendments to the Fire Protection and Life Safety Provisions of the New York City Building Code by Local Laws Adopted While World Trade Center 1, 2, and 7 Were in Use. NIST NCSTAR 1-1G. National Institute of Standards and Technology. Gaithersburg, MD, May.

Grill. R.A., and D.A. Johnson. 2005b. Federal Building and Fire Safety Investigation of the World Trade Center Disaster: Design, Installation, and Operation of Fuel System for Emergency Power in WTC 7. NIST NCSTAR I-1J. National institute of Standards and Technology. Gaithersburg, MD, May.

Grill, R.A., D.A. Johnson, and D.A. Fanella. 2005. Federal Building and Fire Safety Investigation of the World Trade Center Disaster: Comparison of the 1968 and Current (2003) New York City Building Code Provisions. NIST NCSTAR 1-1F. National Institute of Standards and Technology. Gaithersburg, MD. May.

Hoffer, M. 2002. NYC Department of Environmental Protection, New York, NY, personal communication to Marc Wolinsky, Esq., Wachtell, Lipton, Rosen, \& Klatz, New York, NY, Providing Pressure trace data for September 11, 2001. May 16.

HRS Systems, Inc. 2004. HASS (Hydraulic Amalyzer of Sprinkler Systens) Version 7.5. Software. 2004.

Keough, R.J., and R.A. Grill. 2005. Federal Building and Fire Safety Investigation of the World Trade Center Disaster: Fire Alarnl Systems for Active Fire Protection. NIST NCSTAR 1-4C. National Institute of Standards and Technology. Gaithersburg, MD. May.

Lin, J. 1998. The Port Authority of New York \& New Jersey, New York, NY, personal communication to L. Menno, World Trade Tenant Services, New York, NY, WTC Alteration Application. March 9.

LZA Technology. 2002. Danrage/Debris Assessment Report. New York, NY, August.

Maybee, W. 1988. A Chronology of Federal Fire Losses. U.S. Department of Energy. Washington, DC, April.

McAllister, T., ed. 2002. World Trade Center Building Performance Study: Data Collection, Preliminary Observations, and Recommendations. FEMA 403. Federal Emergency Management Agency. Washington, DC, May.

McAllister, T., et al. 2005. Federal Building and Fire Safely Investigation of the World Trade Center Disaster: Most Probable Collapse Sequences for tlre World Trade Center Towers. NIST NCSTAR 1-6E. National Institute of Standards and Technology. Gaithersburg, MD. May.

Merritt \& Harris Inc. 2000. Color Photographs from Report 20-251E of the exterior and interior of WTC 1 and WTC 2, Retail Mall and Plaza, Central Plant, and Sub-grade. Photograph. 2000. 
NFPA 13. Standard for the Installation of Sprinkler Systems, National Fire Protection Association, Quincy, MA, USA (1966 ed.)

NFPA 13. Standard for the Installation of Sprinkler Systems, National Fire Protection Association, Quincy, MA, USA (1982 ed.)

NFPA 13. Standard for the Installation of Sprinkler Systems, National Fire Protection Association, Quincy, MA, USA (1987 ed.)

NFPA 13. Standard for the Installation Sprinkler Systems, National Fire Protection Association, Quincy, MA, USA (2002 ed.)

NFPA 14. Standard for the Installation Of Standpipe and Hose Systems, National Fire Protection Association, Quincy, MA, USA (1968 ed.)

NFPA 14. Standard for the Installation Of Standpipe and Hose Systems, National Fire Protection Association, Quincy, MA, USA (1982 ed.)

NFPA 14. Standard for the Installation Of Standpipe and Hose Systems, National Fire Protection Association, Quincy, MA, USA (2000 ed.)

NFPA 14, Standard for the Installation Of Standpipe and Hose Systems, National Fire Protection Association, Quincy, MA, USA (2003 ed.)

NFPA 22, Standard for Water Tanks for Private Fire Protection, National Fire Protection Association, Quincy, MA. USA (1962 ed.)

NFPA 22, Standard for Water Tanks for Private Fire Protection, National Fire Protection Association, Quincy, MA. USA (1966 ed.)

NFPA 22, Standard for Water Tanks for Private Fire Protection, National Fire Protection Association, Quincy, MA, USA (1981 ed.)

NIST (National Institute of Standards and Technology.) 2004. NIST Special Publication 1000-5. Progress Report on the Federal Building and Fire Safety Investigation of the World Trade Center Disaster. Gaithersburg, MD. June.

PACO Group Inc. and Flack \& Kurtz, Inc. 2002. World Trade Center: General Description of All Building Systems and The Capital Program. New York, NY, January.

PANYNJ (The Port Authority of New York and New Jersey). 1972. World Trade Center: Ponya Office Space - Tower A - Fire Protection Drawings. New York, NY, April.

PANYNJ (The Port Authority of New York and New Jersey). 1983. World Trade Center Instruction Manual No. 14: Operation and Maintenance of Domestic Water System Towers $A \&$ \& . New York, NY, November. 
PANYNJ (The Port Authority of New York and New Jersey). 1987. Operation and Maintenance Manual for 7 World Trade Center: Fire Standpipe and Sprinkler Systells. New York, NY, February.

PANYNJ (The Port Authority of New York and New Jersey). 1987a. World Trade Center Instruction Manual No. 18: Operation and Maintenance of Sprinkler Systenis. New York, NY, April.

PANYNJ (The Port Authority of New York and New Jersey). 1987b. World Trade Center Instruction Manual No. 23: Operation and Maintenance of Fire Protection System. New York, NY, February.

PANYNJ (The Port Authority of New York and New Jersey). 2000a. Tenant Alteration Application Drawings: Disk 5, Picture FLM01659-1660. CD-ROM, 2000.

PANYNJ (The Port Authority of New York and New Jersey). 2000b. Design Guidelines, Guide Specification, and Standard Details: HVAC, Plumbing, and Fire Protection. New York, NY, September.

Powers, W.R. 1979. Sprinkler Experience in High-Rise Buildings (1969-1979). Society of Fire Protection Engineers. TR 79-1. Boston, MA.

Razza, J.C., and R.A. Grill. 2005. Federal Building and Fire Safety Investigation of the World Trade Center Disaster: Comparison of Codes, Standards, and Practices in Use at the Time of the Design and Construction of World Trade Center 1,2 and 7. NIST NCSTAR 1-1E. National Institute of Standards and Technology. Gaithersburg, MD, May.

Rohr, K. 2003. U.S. Experience with Sprinklers. NFPA (National Fire Protection Agency). Quincy, MA, November.

Smith, D. 2002. Report from Ground Zero. Penguin Putnam Inc. New York, NY.

Stempler, S. 1984. World Trade Center Tenants Manual. World Trade Operations Division. New York, NY.

Swanke Hayden Connell Ltd. 1998. Fire Protection - $1^{\text {st }}$ Floor Plan. Dwg. No. FP-1. New York, NY.

Syska \& Hennessy Group Inc. 1984. 7 World Trade Center: Summary of Mechanical and Electrical Systems. New York, NY, May. 
Appendix B

FIGURES 


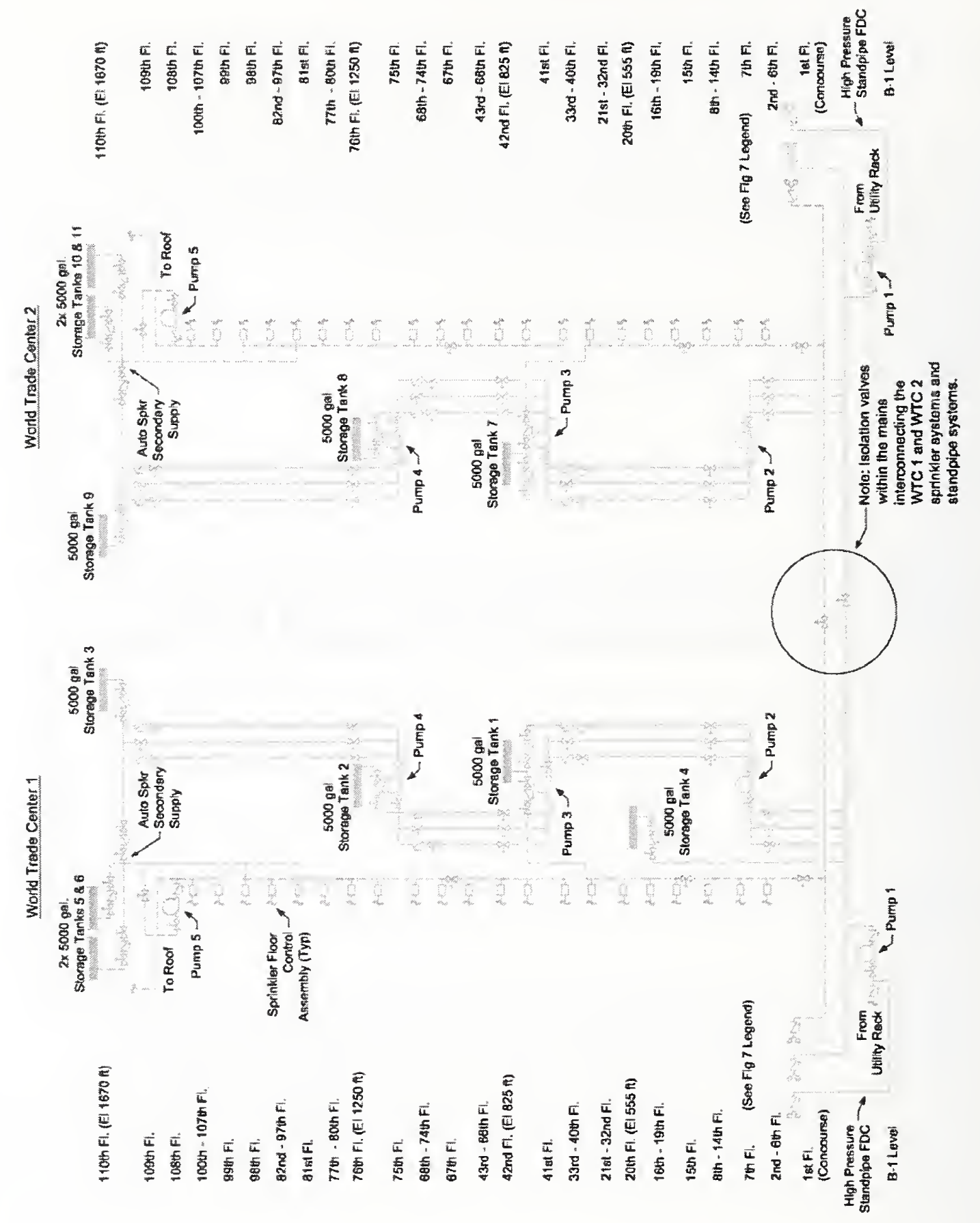

Figure B-1. Riser diagram, tower sprinkler and standpipe systems. 


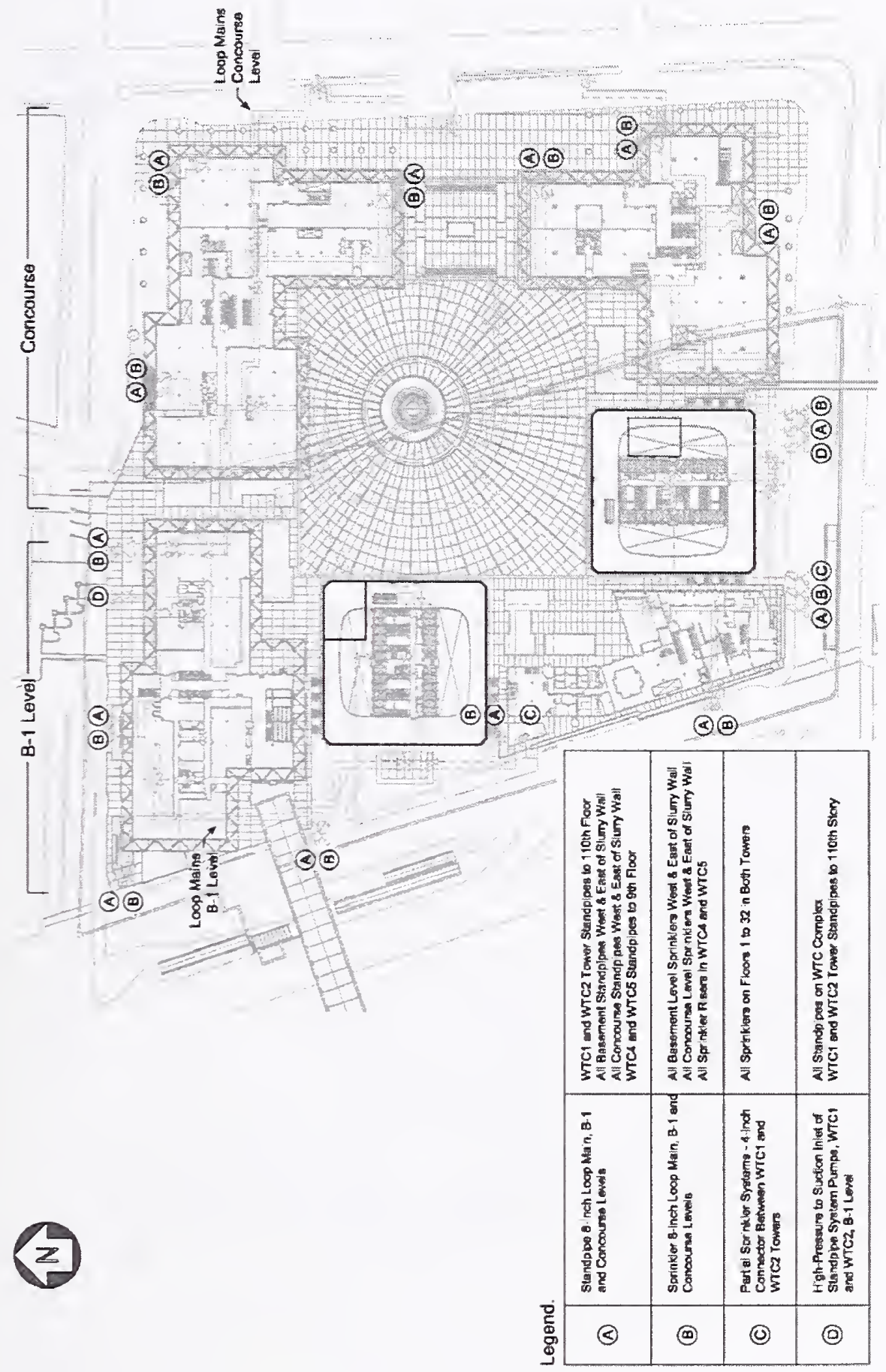

Source: Reproduced with permission of The Port Authority of New York and New Jersey.

Figure B-2. Layout of the WTC complex fire department connections. 


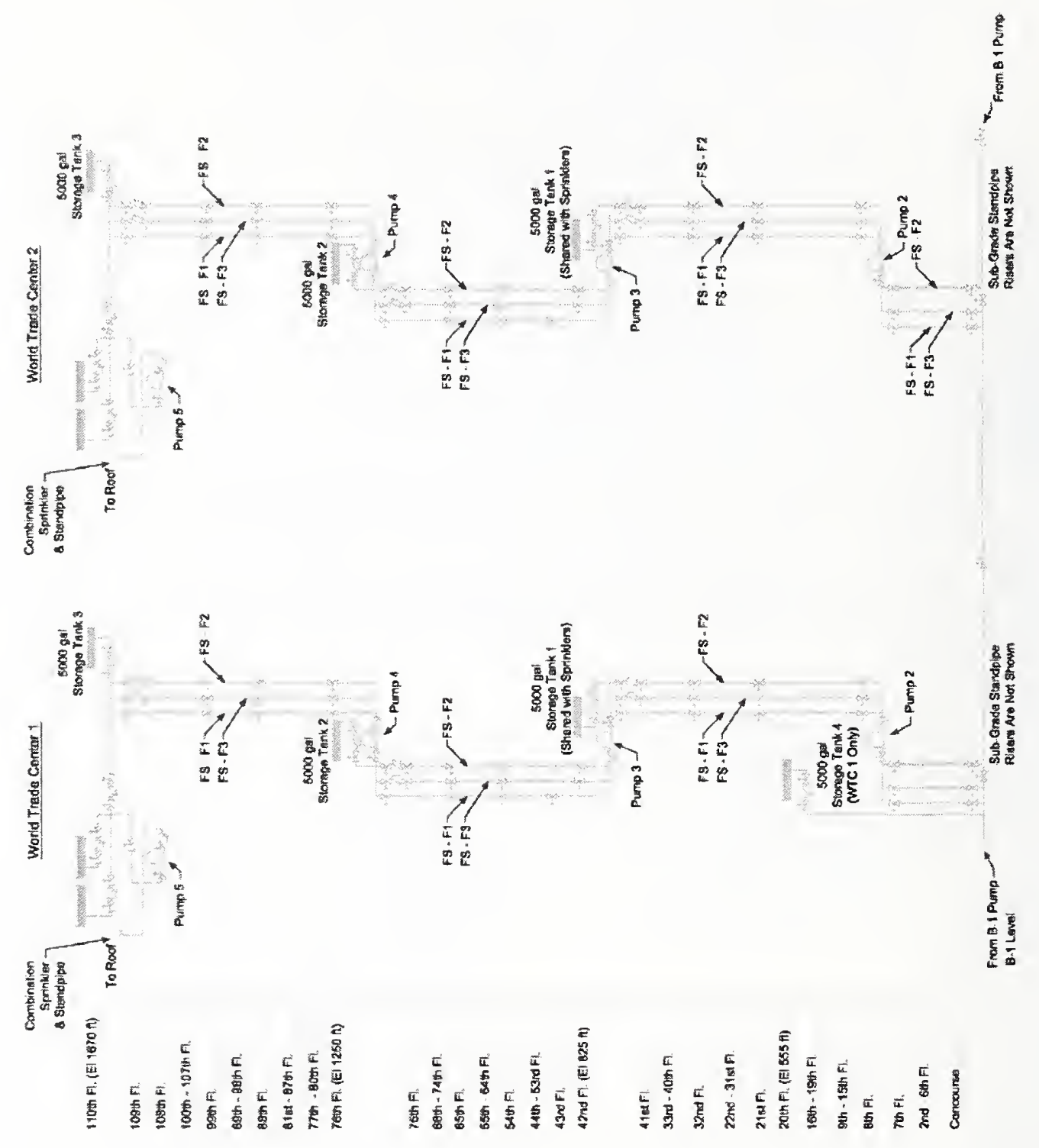

Figure B-3. Riser diagram, tower standpipe systems, WTC 1 and WTC 2. 
2
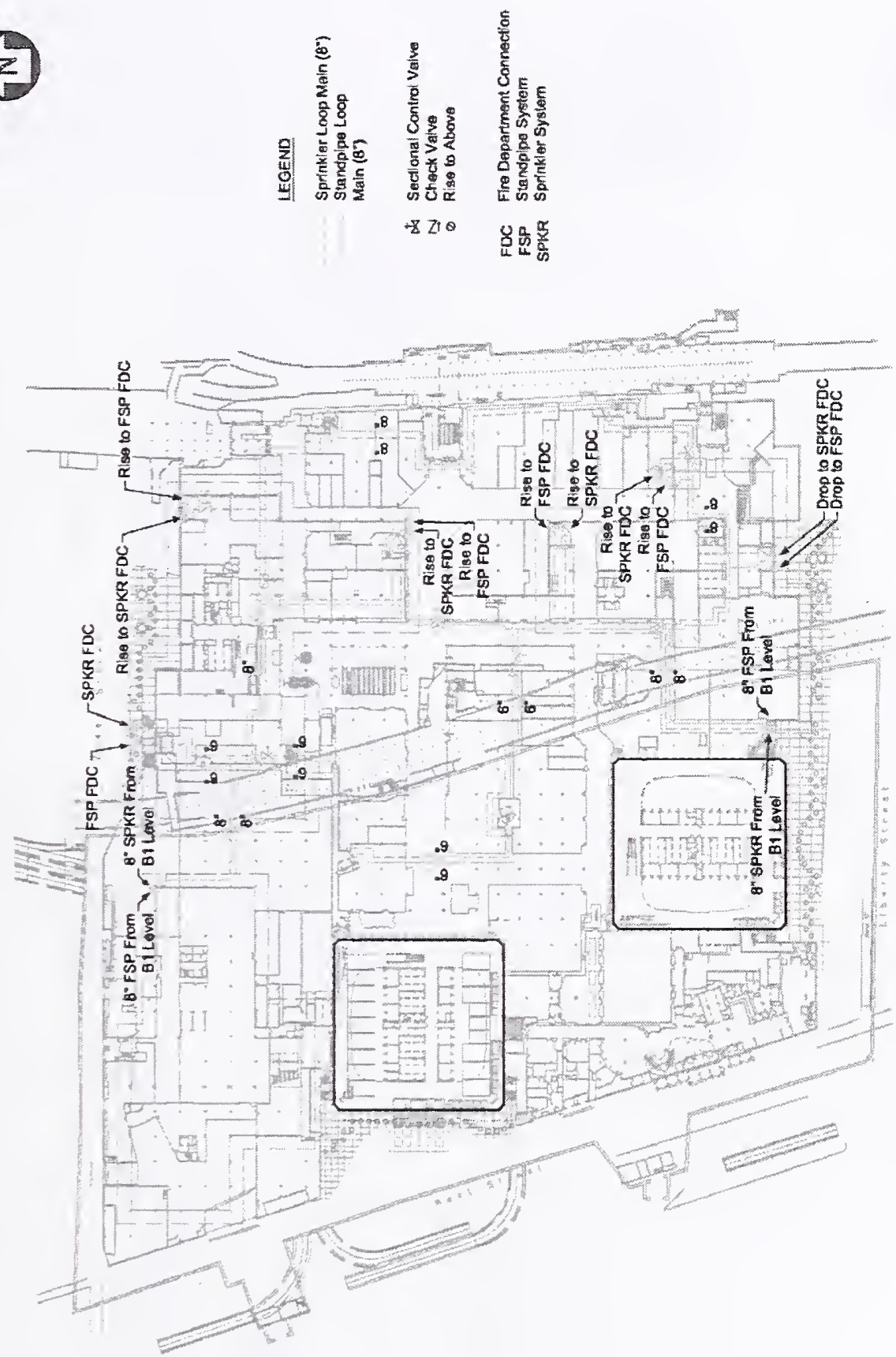

Source: Reproduced with permission of The Port Authority of New York and New Jersey.

Figure B-4. Standpipe and sprinkler loops, concourse level. 


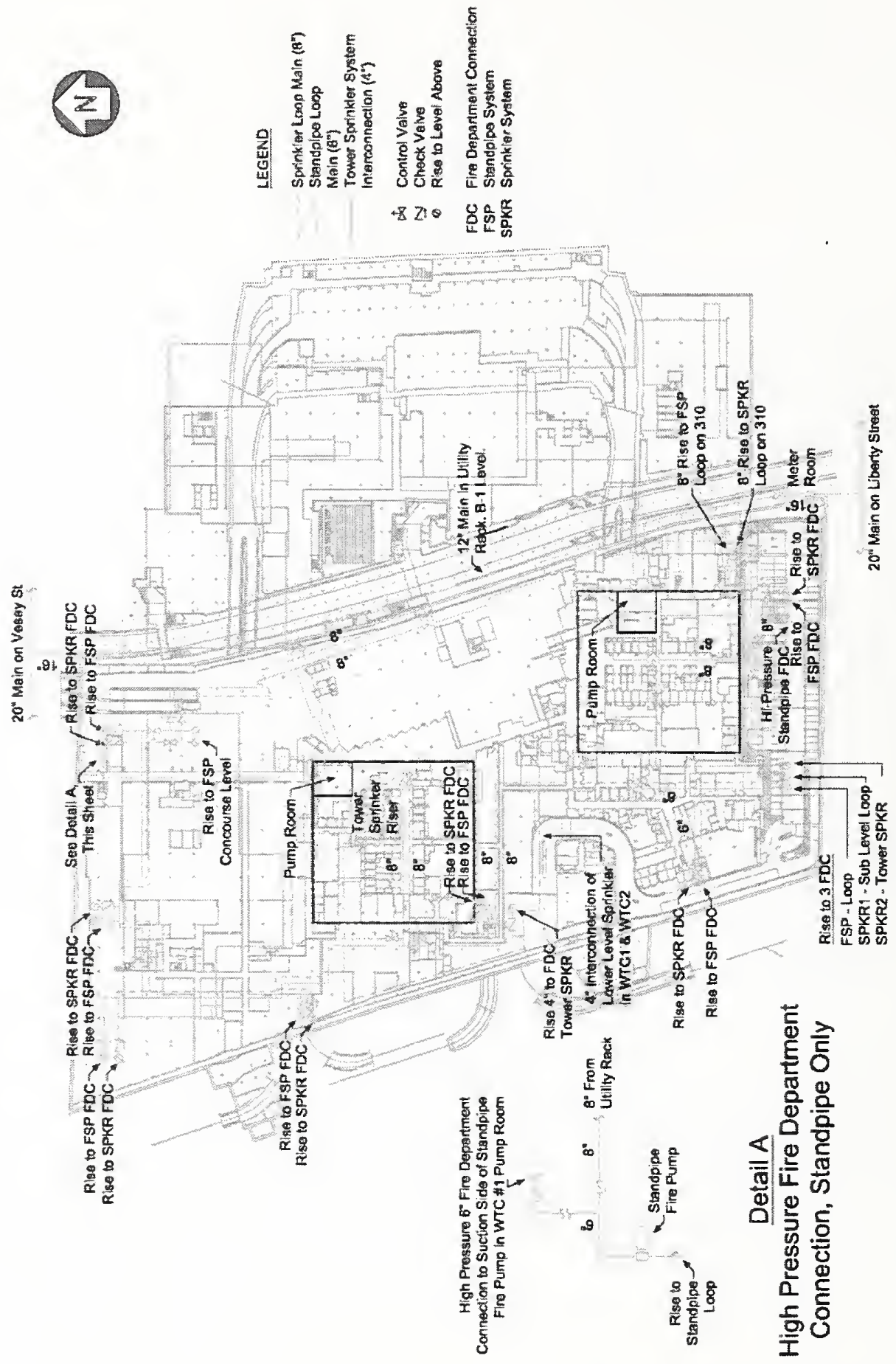

Source: Reproduced with permission of The Port of Authority of New York and New Jersey.

Figure B-5. Standpipe and sprinkler loops, B1 level. 


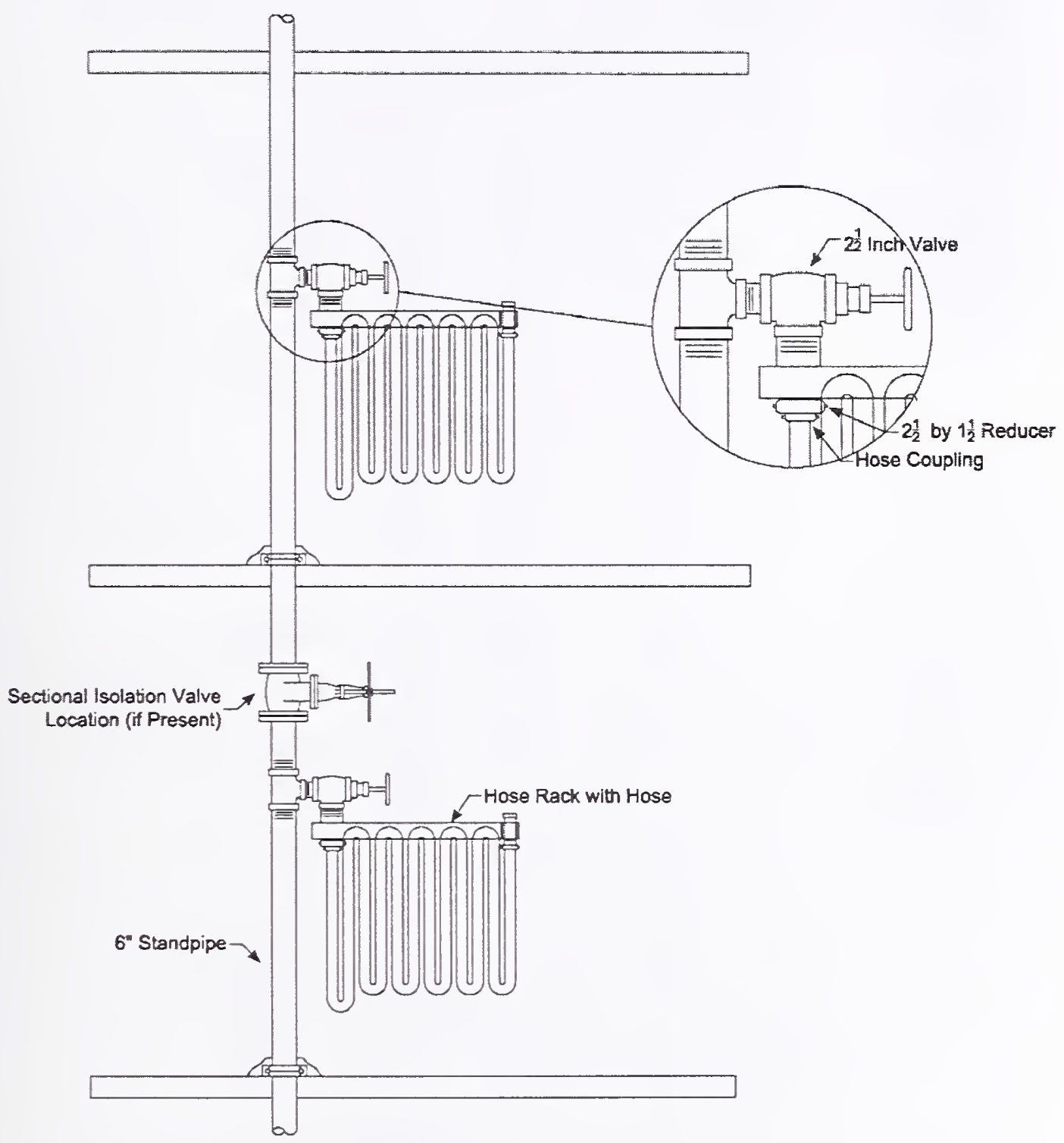

Figure B-6. Typical hose rack arrangement. 


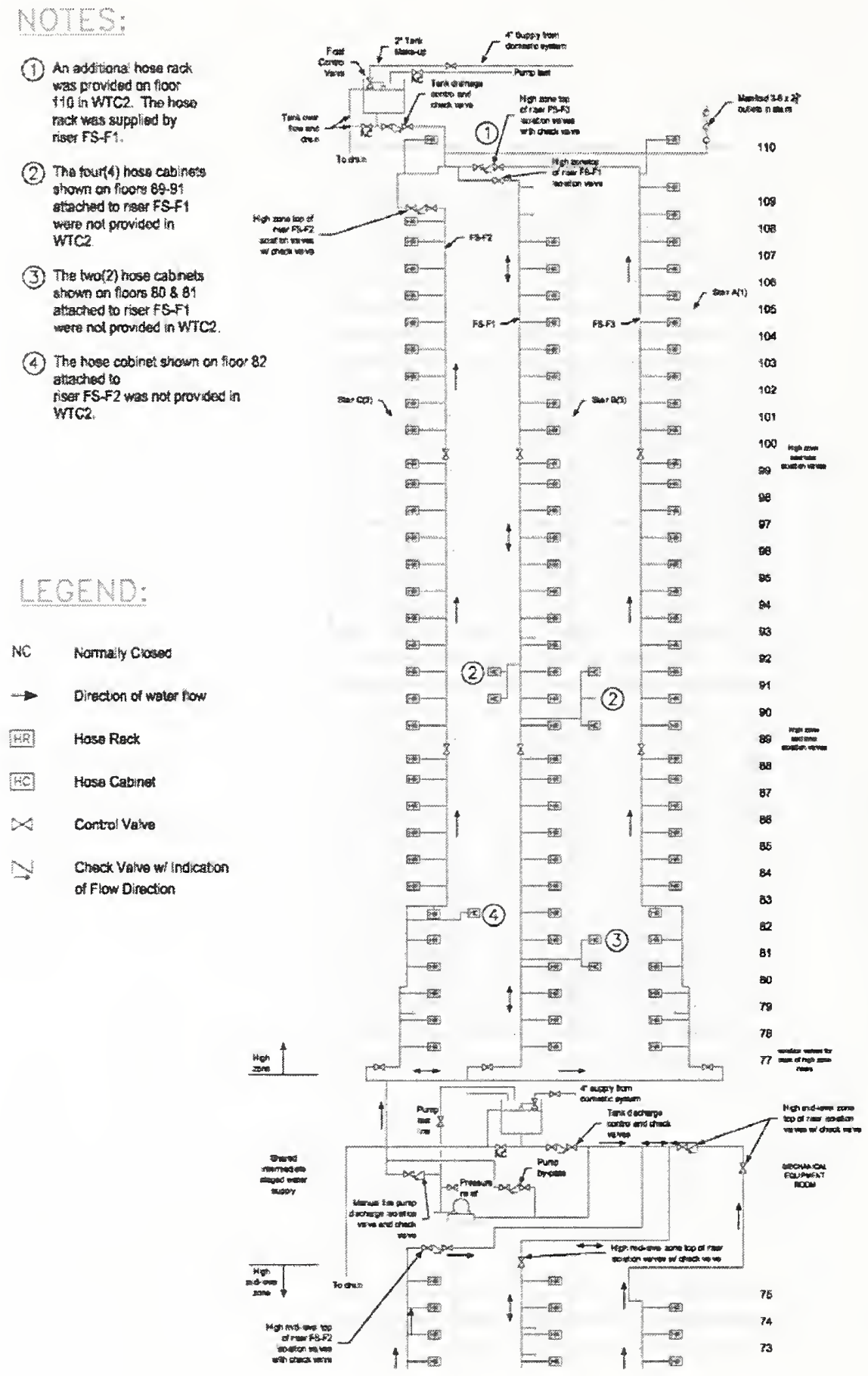

Figure B-7. WTC 1 high zone standpipe system and noted differences in WTC 2. 


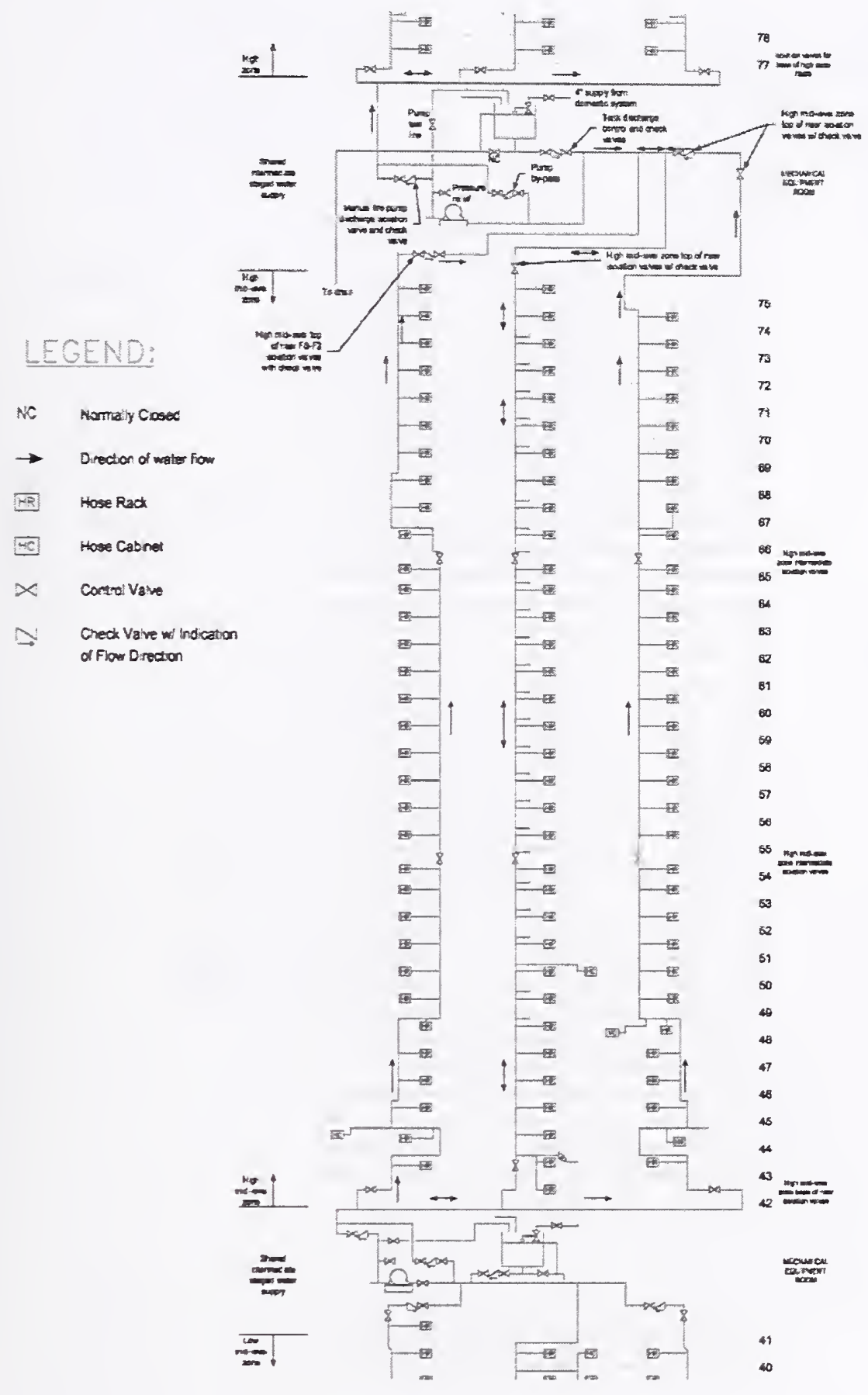

Figure B-8. WTC 1 upper mid-level zone standpipe system and noted differences in WTC 2. 


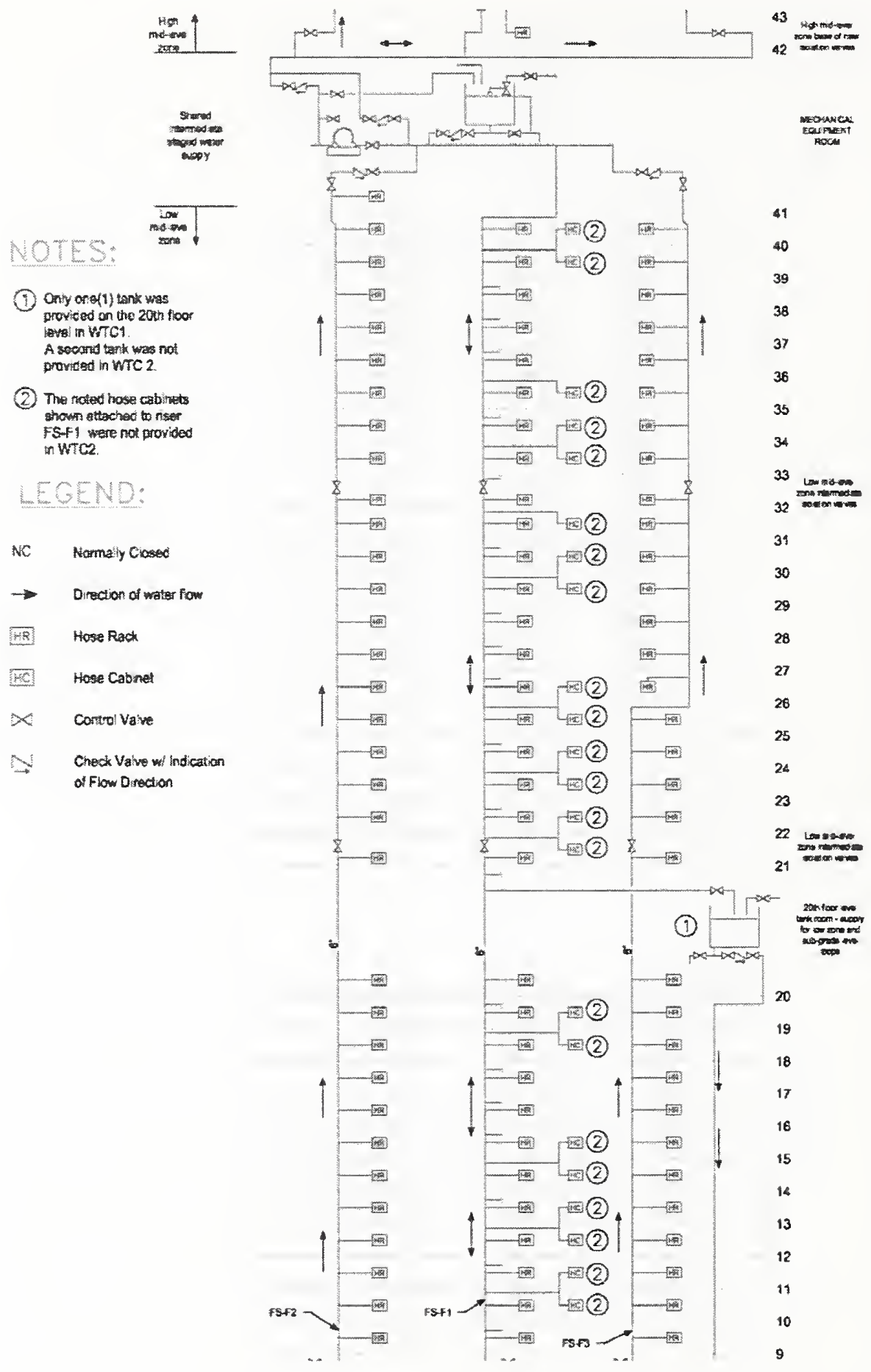

Figure B-9. WTC 1 lower mid-level zone standpipe system and noted differences in WTC 2. 


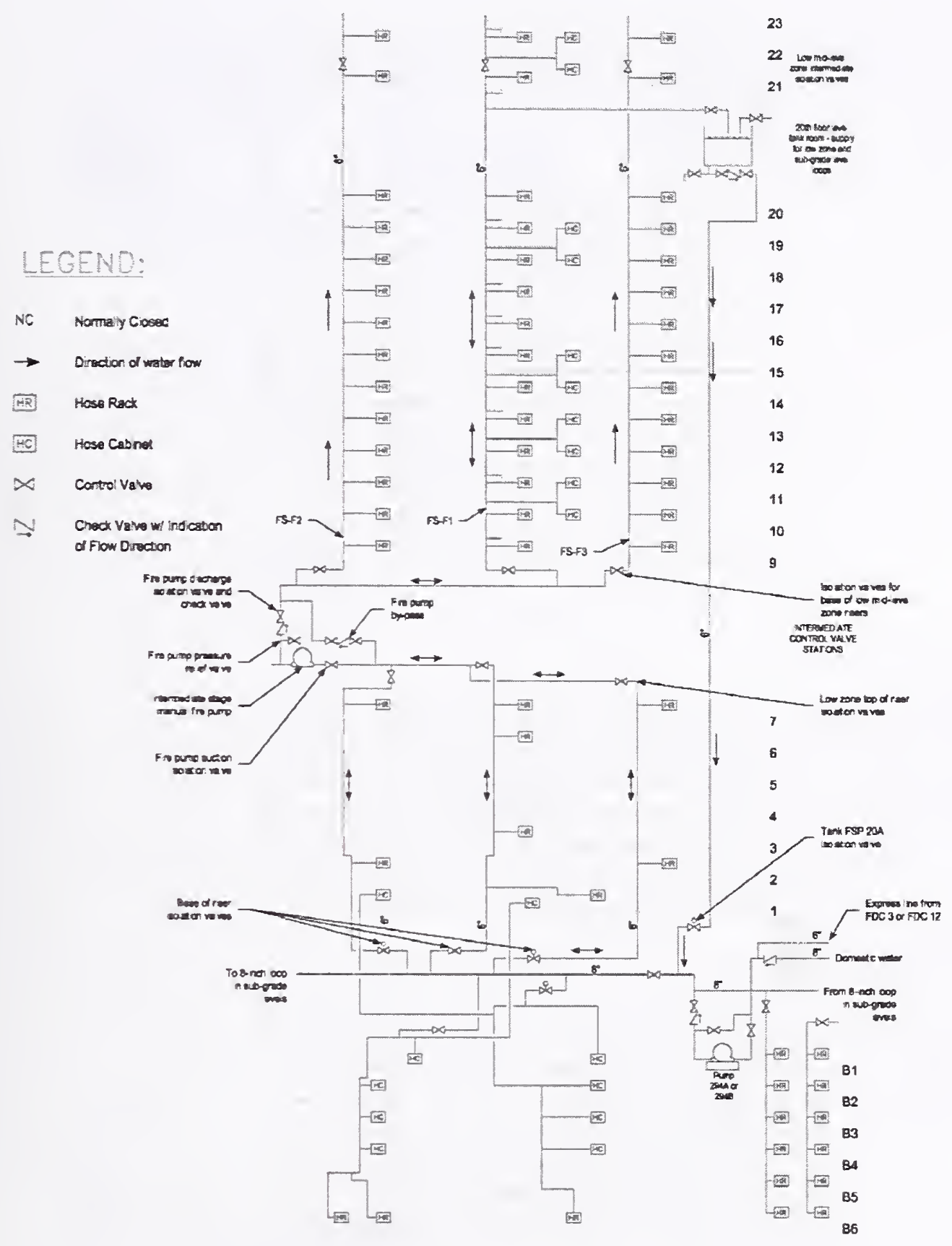

Figure B-10. WTC 1 low zone standpipe system and noted differences in WTC 2. 


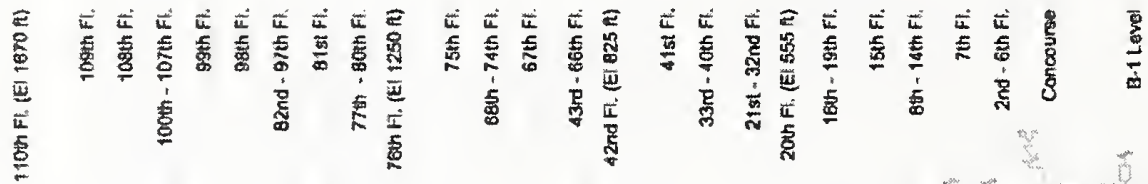
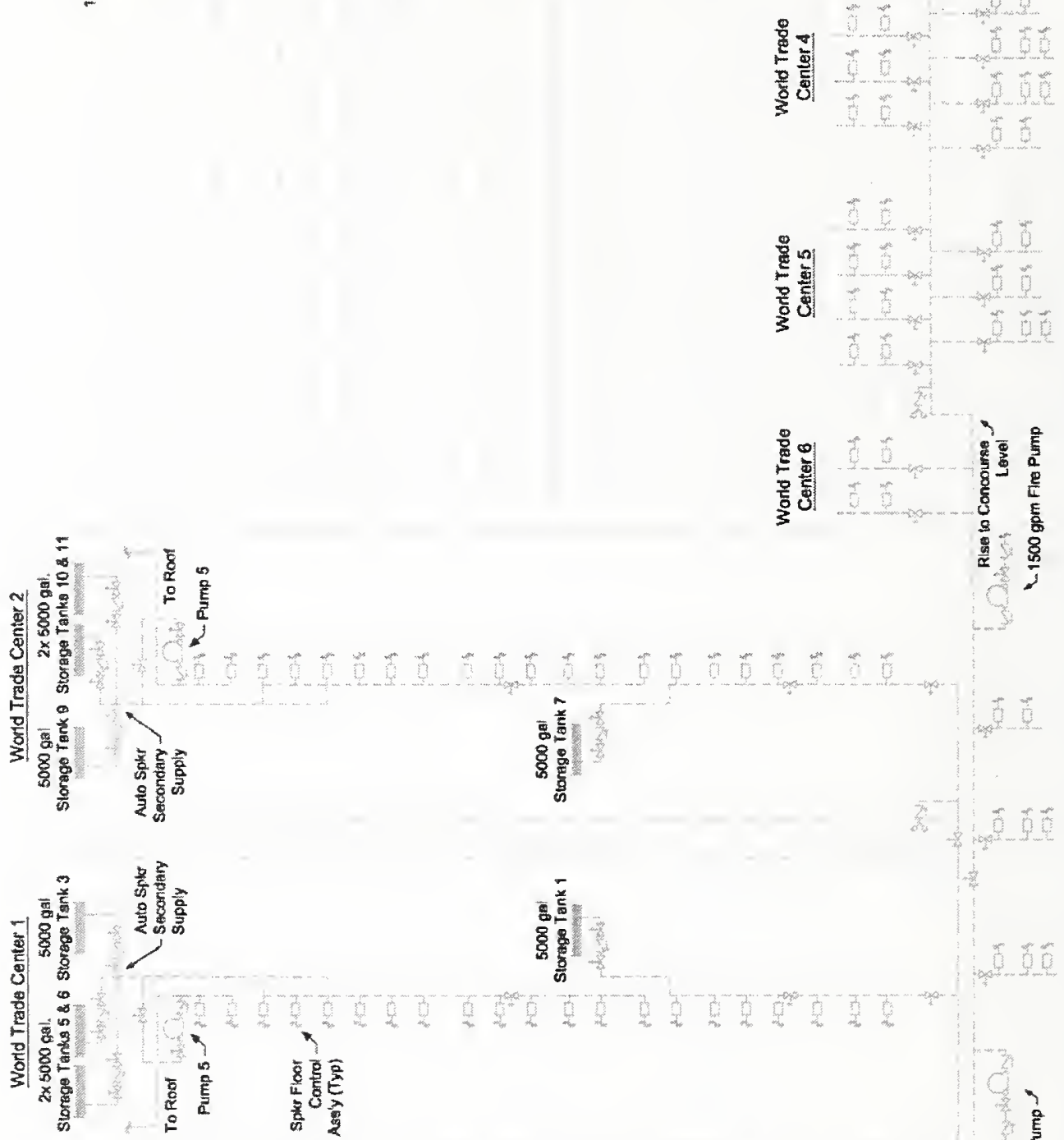

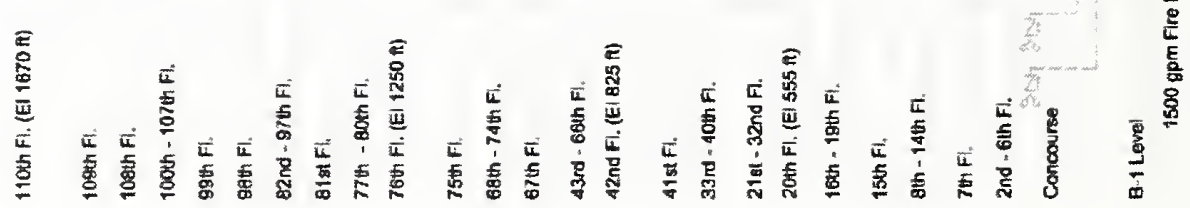

Figure B-11. Riser diagram, tower sprinkler systems, WTC 1 and WTC 2. 


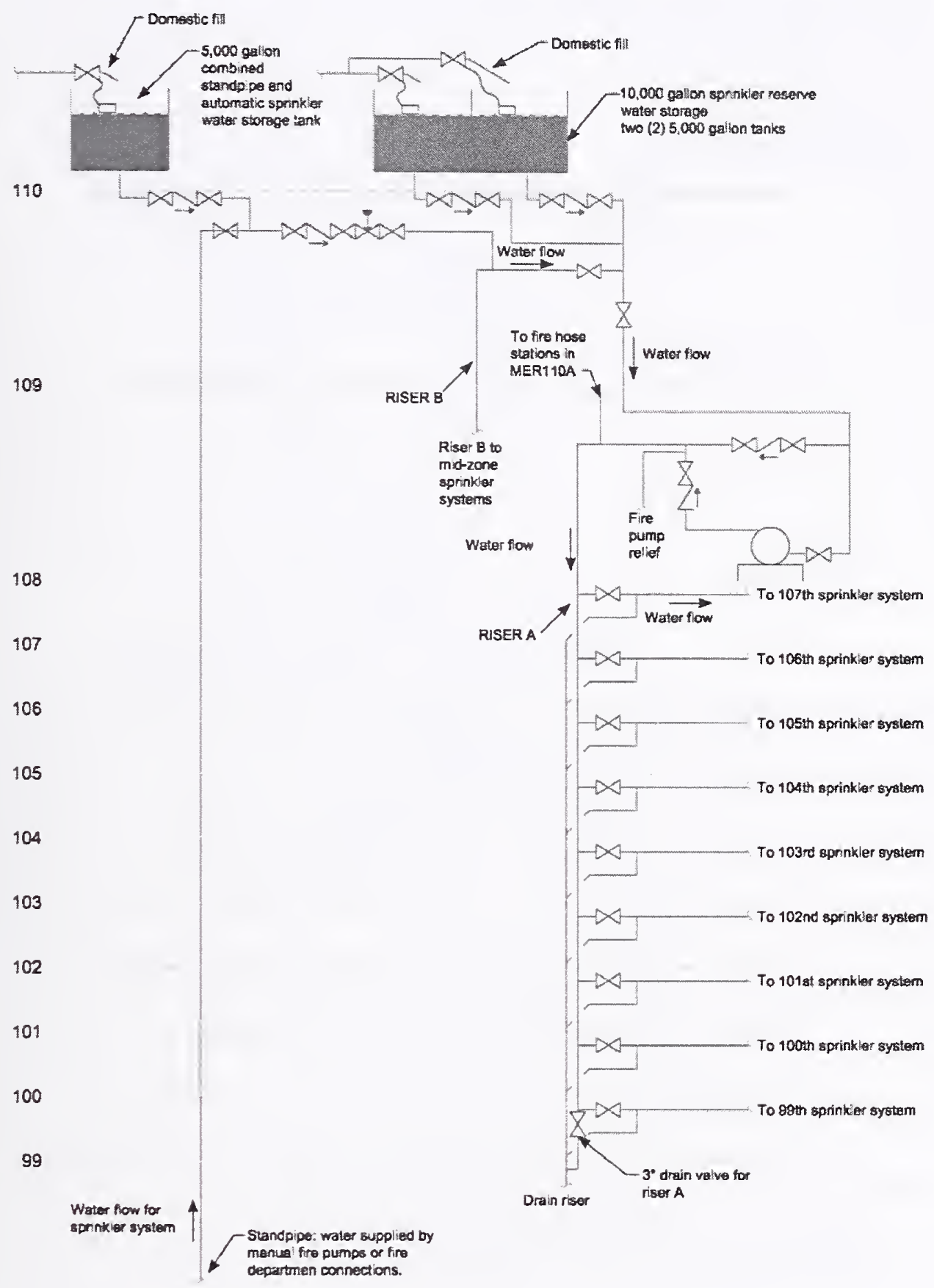

Figure B-12. High zone sprinkler systems, WTC 1 and WTC 2. 


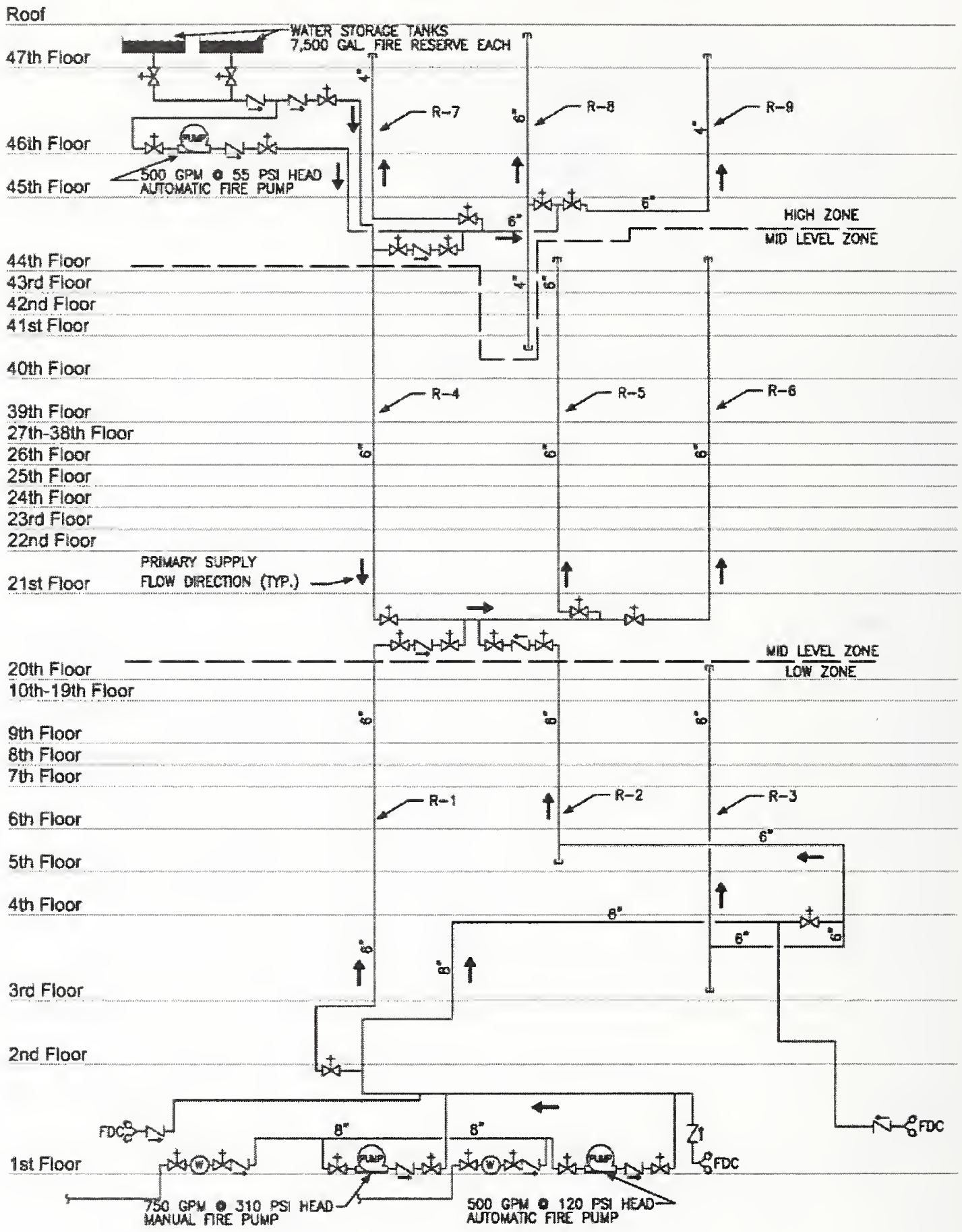

Figure B-13. Supply riser schematic, WTC 7. 


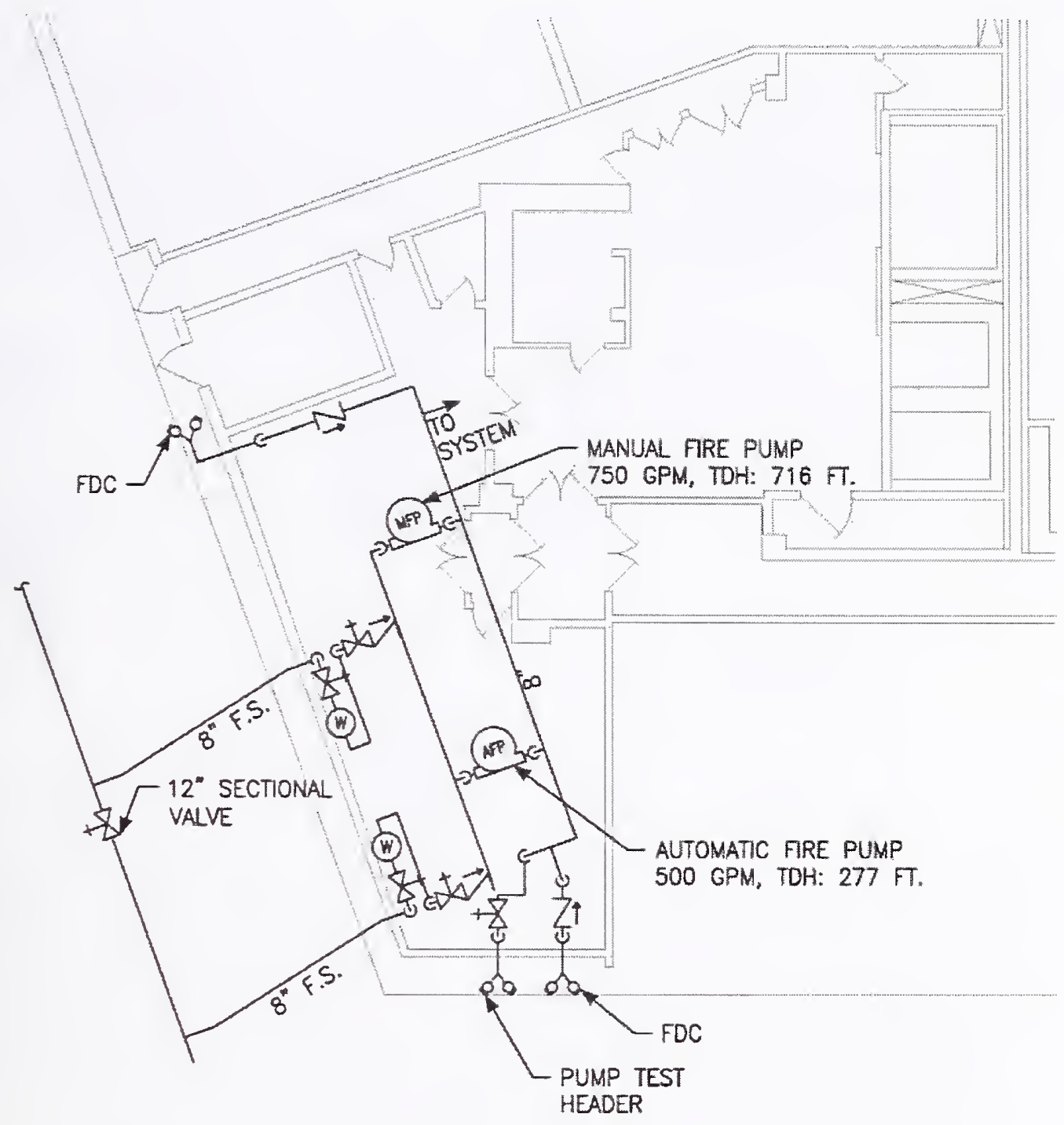

Figure B-14. First floor fire pump room, WTC 7. 


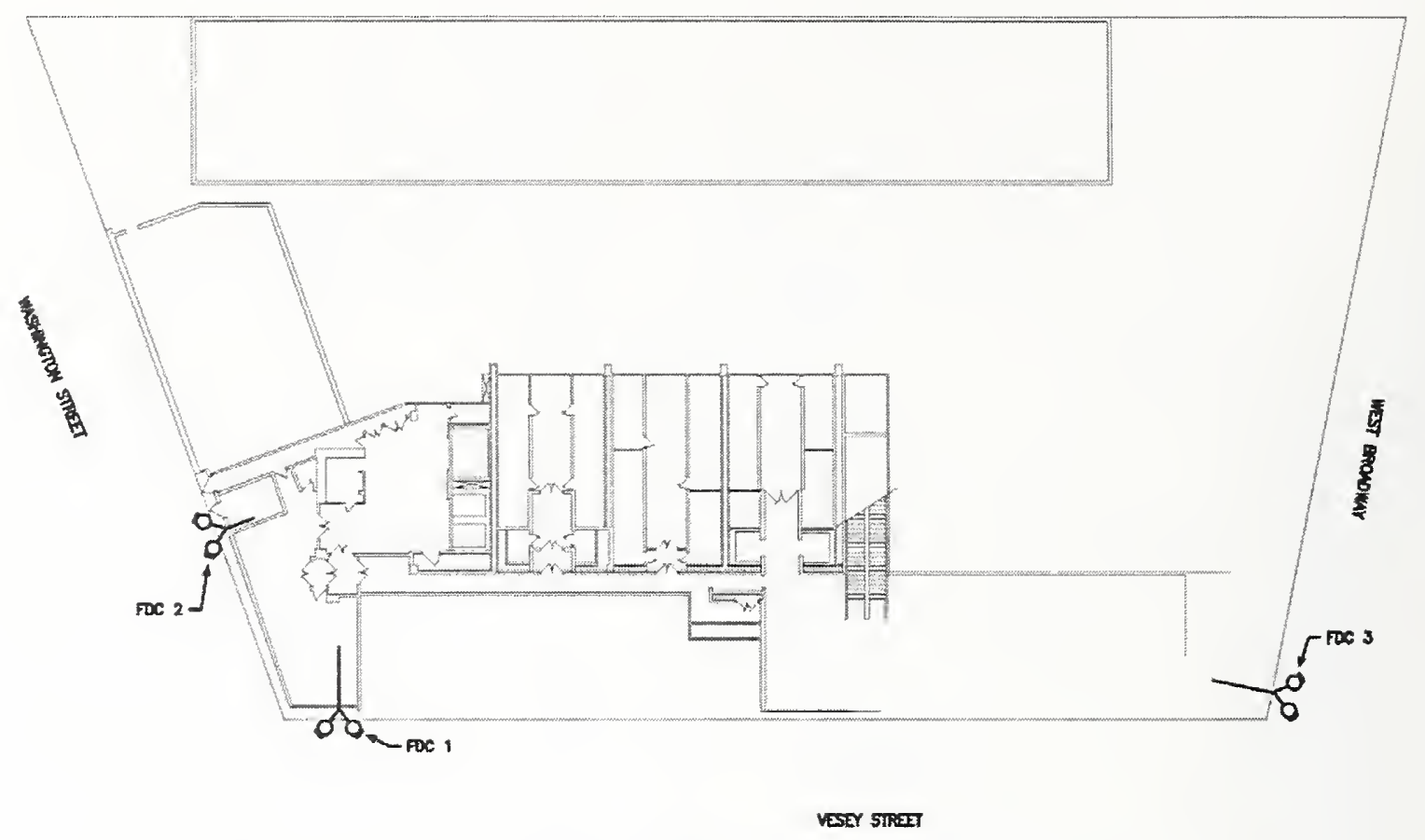

Figure B-15. Fire department connection locations, WTC 7. 


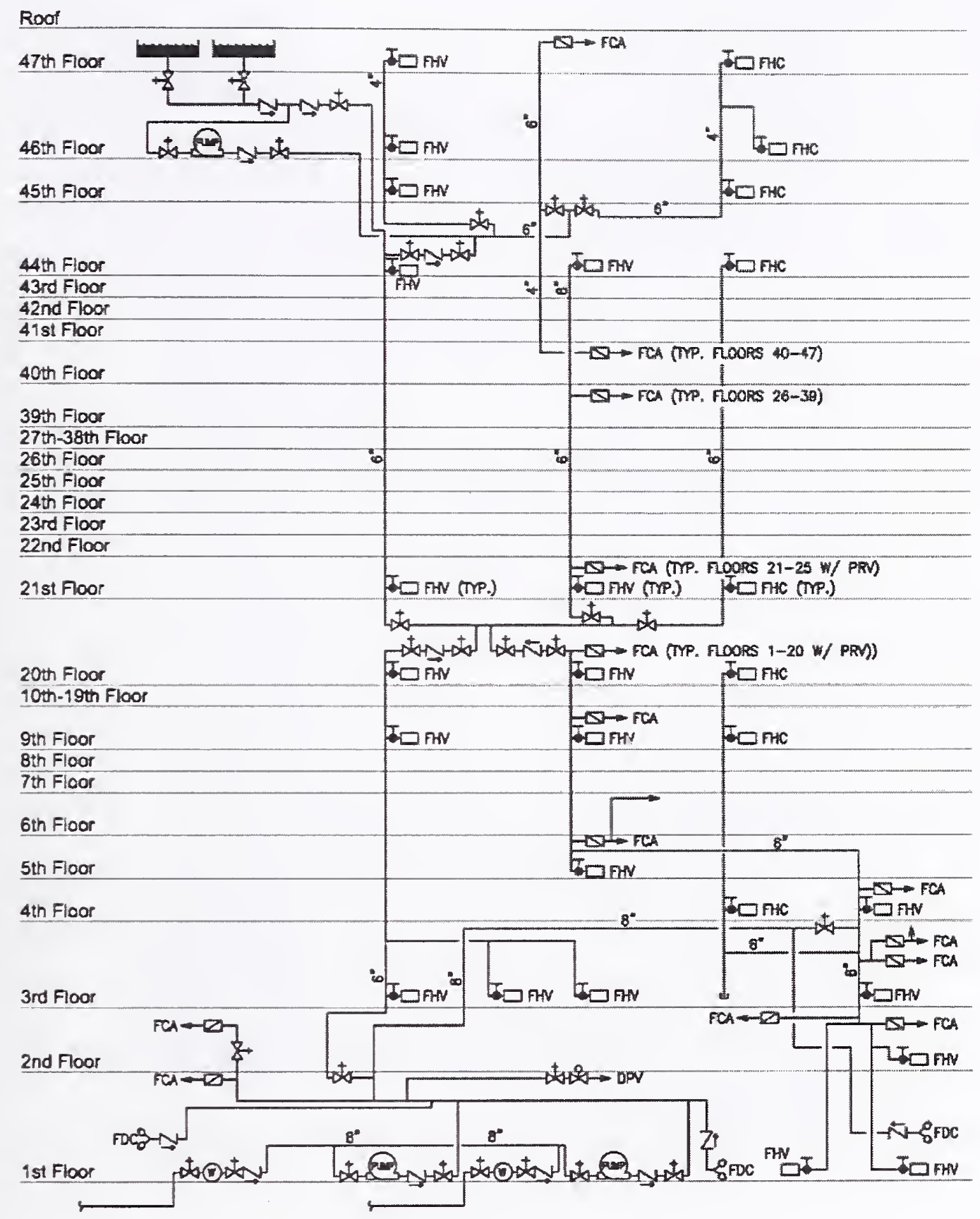

Figure B-16. Floor control valve and fire hose valve/cabinet locations, WTC 7. 
NOTE: AL FUE OL PIPANG SHOWN IN ADOTION TO THE PIPAKS IN THE RUEL OL PUMP ROCM IS ABOVE GROUNO. ALL OTHER PIPING CONNECTNA TANKS TO PUMP ROOM ARE BELOW GTON10.

6,000 GN FUE OHL TANK ON NEZ2WNANE ABOVE EIIV STORAGE AREA

FUE PUNP ROON PROTECTED BY DFY PTPE SPRIMKER STSTEN

FUEL CL RISTRS UP TO:

1) (2) GEN 5 I ANO (1) $275 \mathrm{GN}$ OAY TANK ON 5th FOOR

FUE OU FSERS UP TO 1) (3) $\mathrm{CN}, 5 \mathrm{NT}$ NWD (1) $275 \mathrm{GN}$ DAY TANK ON 7th ROOR. 2) (1) GKN SET ANO DAY TWK ON sth floor

(2) $12,000 \mathrm{GN}$ FUE STORAOE TANKS BORAOE TANKS
BEOA GRADE

Source: Reproduced with permission of Swanke et al. 1998.

Figure B-17. Fuel oil system and suppression protection schematic, WTC 7. 


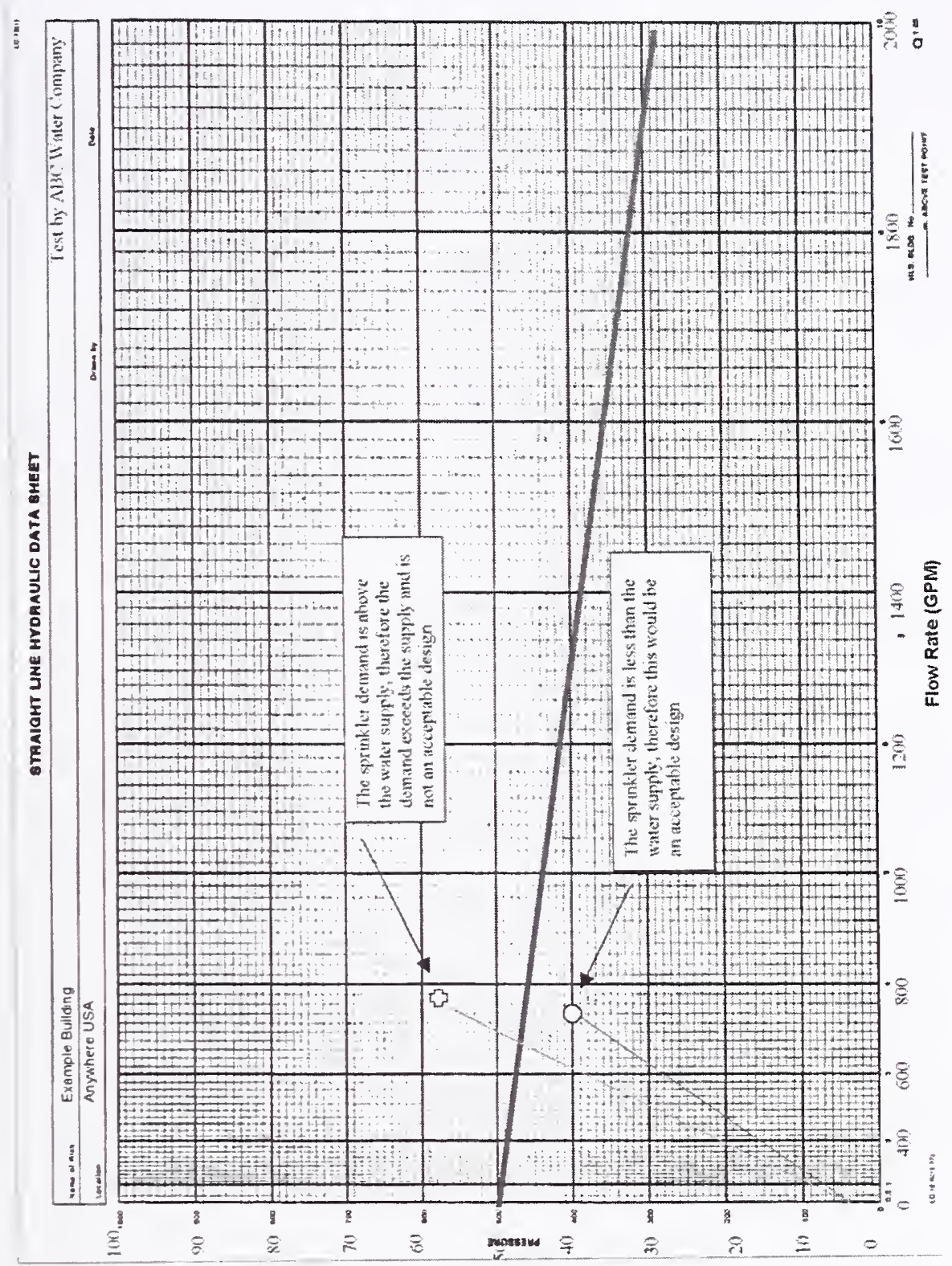

Figure B-18. Example water supply graph with pass and fail sprinkler system demands. 


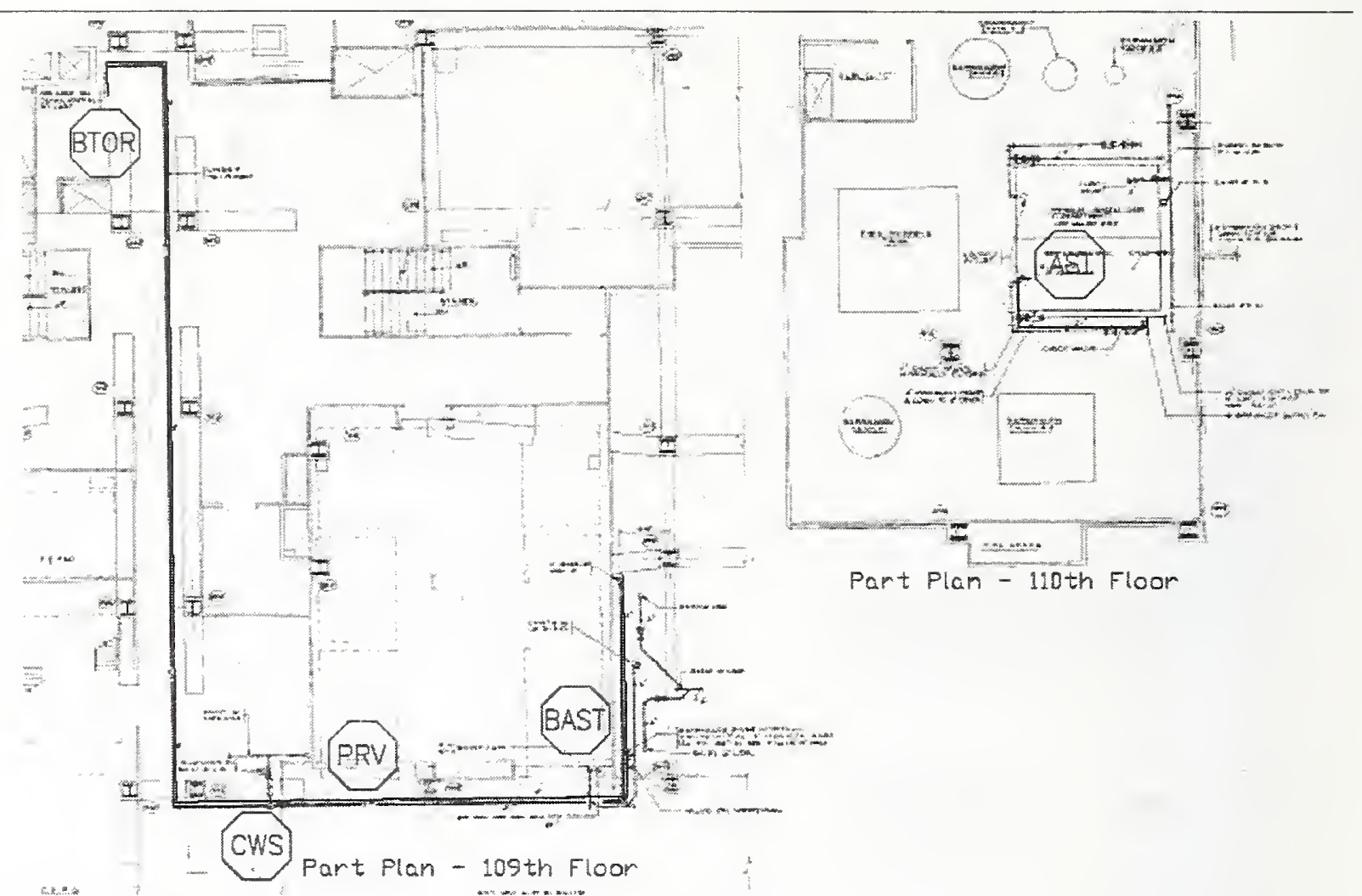

Source: Reproduced with permission of The Port Authority of New York and New Jersey.

Figure B-19. Hydraulic node layout, 110th floor tank and supply mains, 109th floor. 


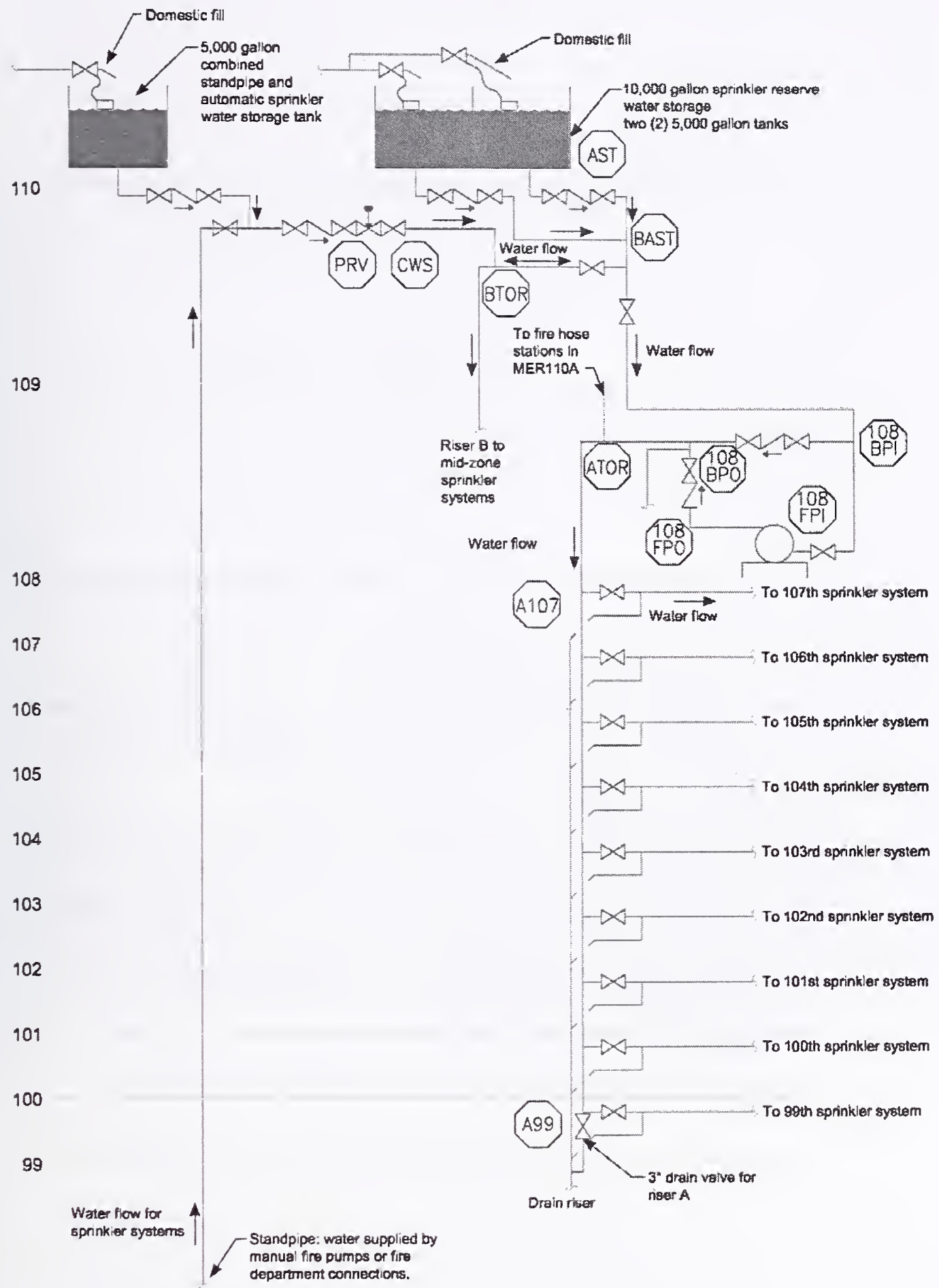

Figure B-20. Hydraulic node layout, high zone riser A. 


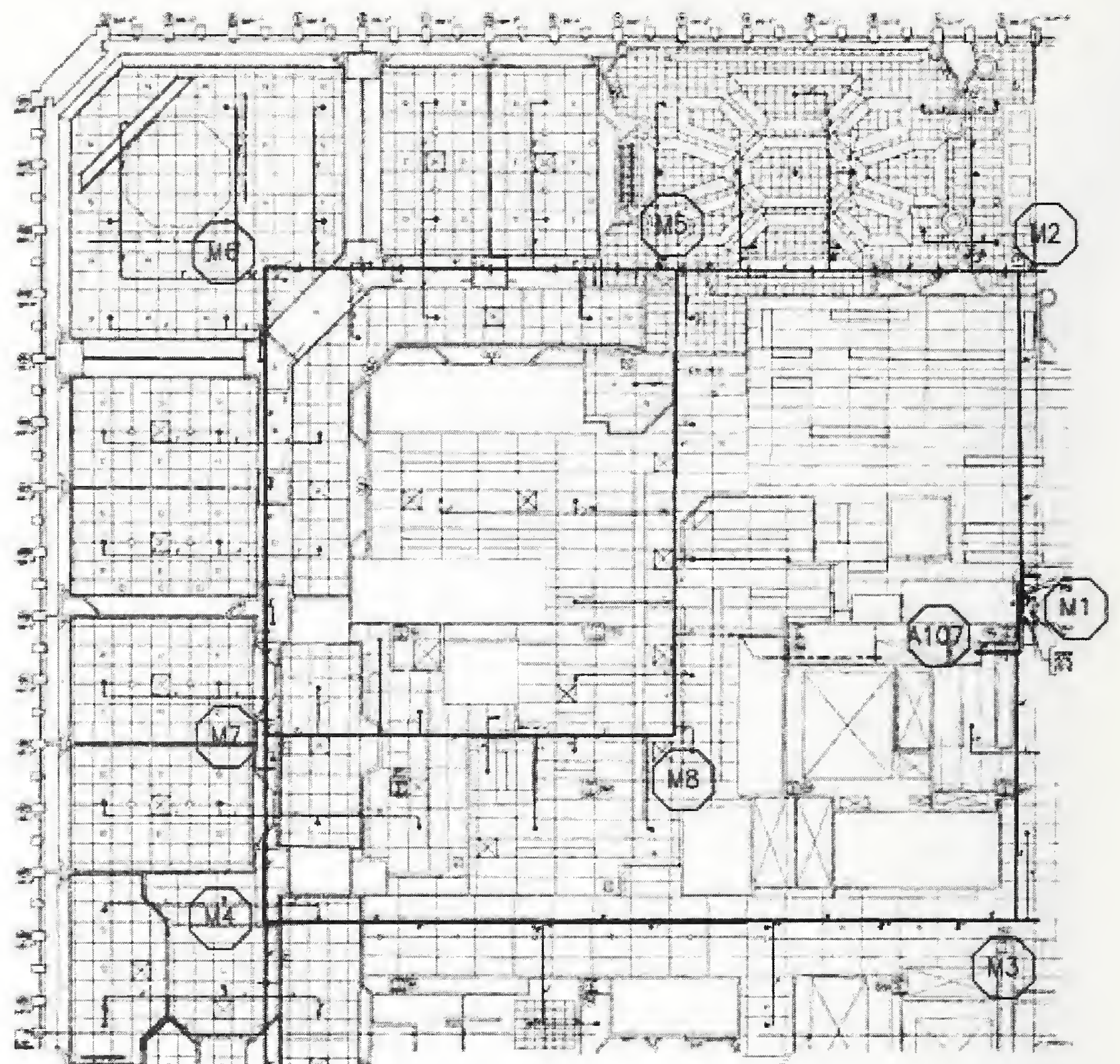

Source: Reproduced with permission of The Port Authority of New York and New Jersey.

Figure B-21. Hydraulic node layout, 107th floor NW quad., WTC 1. 


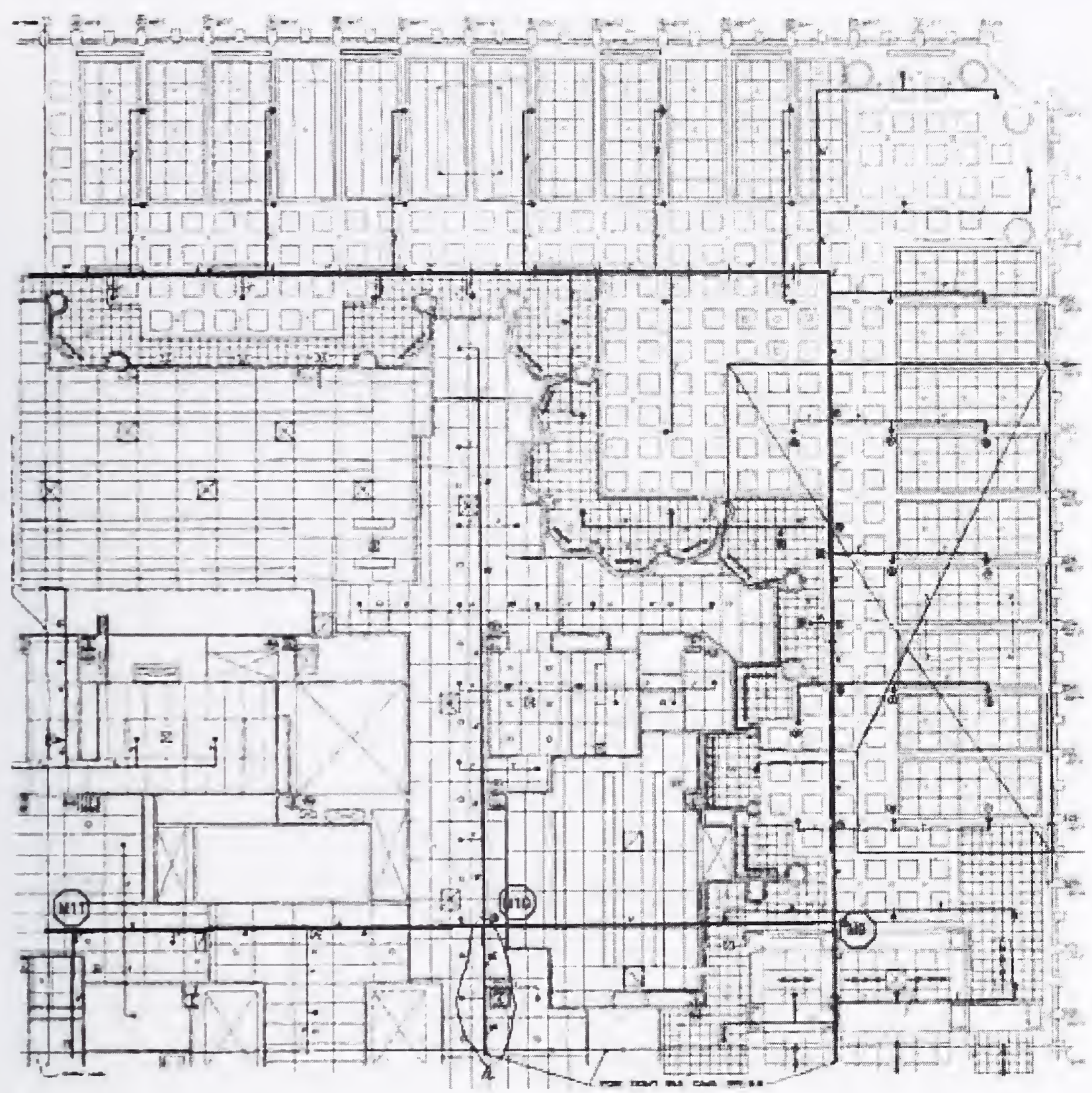

Source: Reproduced with permission of The Port Authority of New York and New Jersey.

Figure B-22. Hydraulic node layout, 107th floor NE quad., WTC 1. 


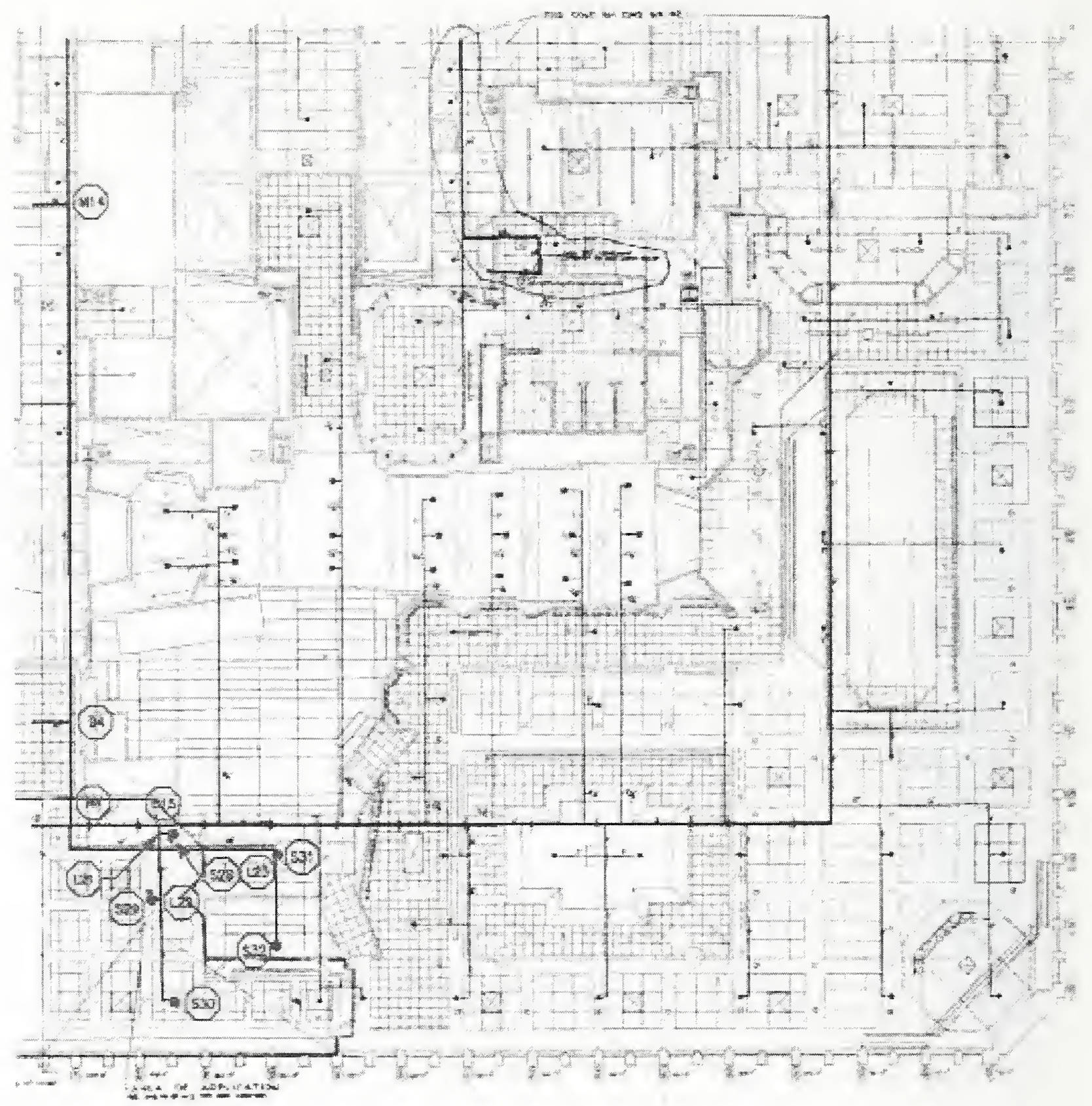

Source: Reproduced with permission of The Port Authority of New York and New Jersey.

Figure B-23. Hydraulic node layout, 107th floor SE quad., WTC 1. 


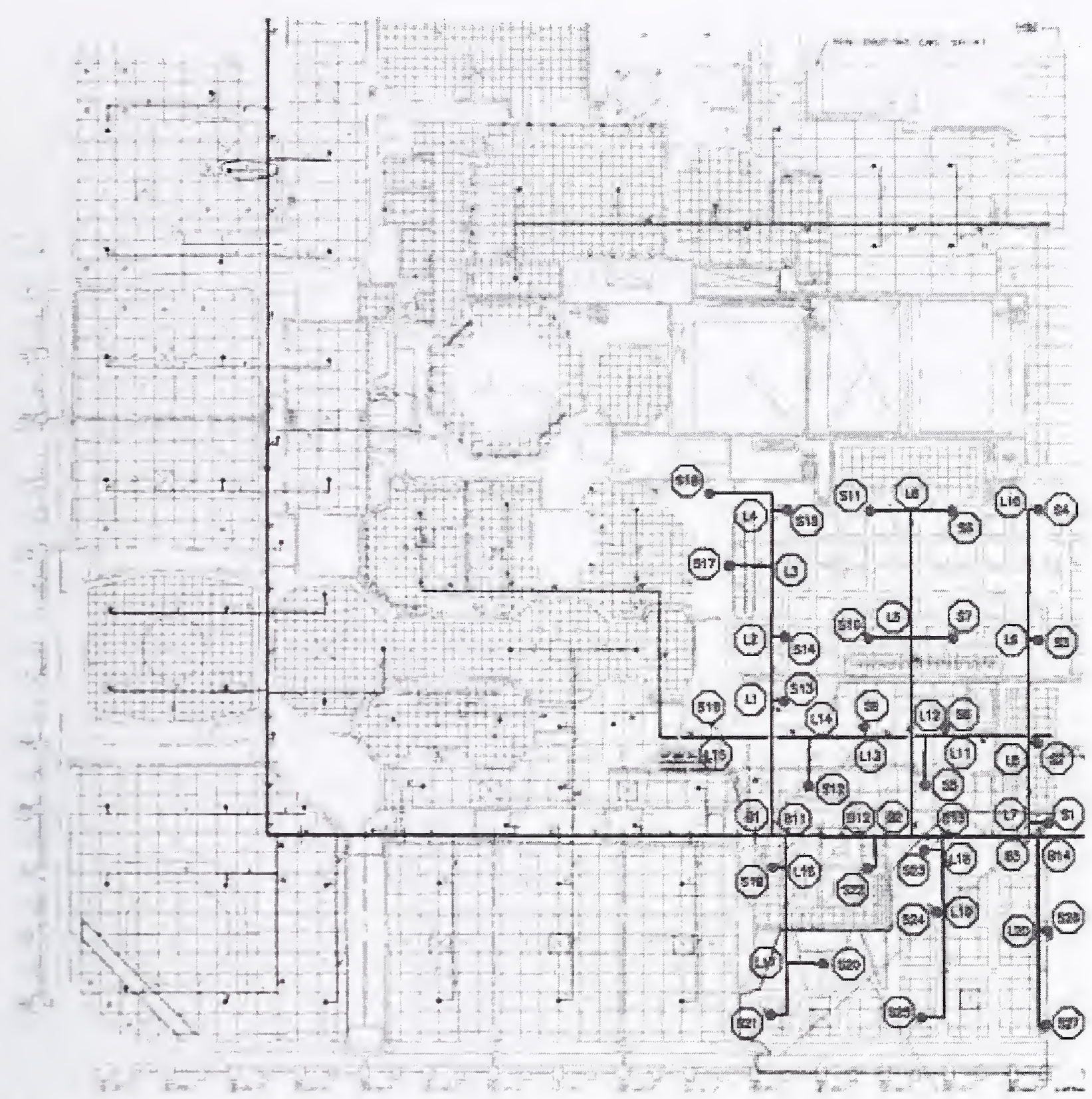

Source: Reproduced with permission of The Port Authority of New York and New Jersey.

Figure B-24. Hydraulic node layout, 107th floor SW quad., WTC 1. 


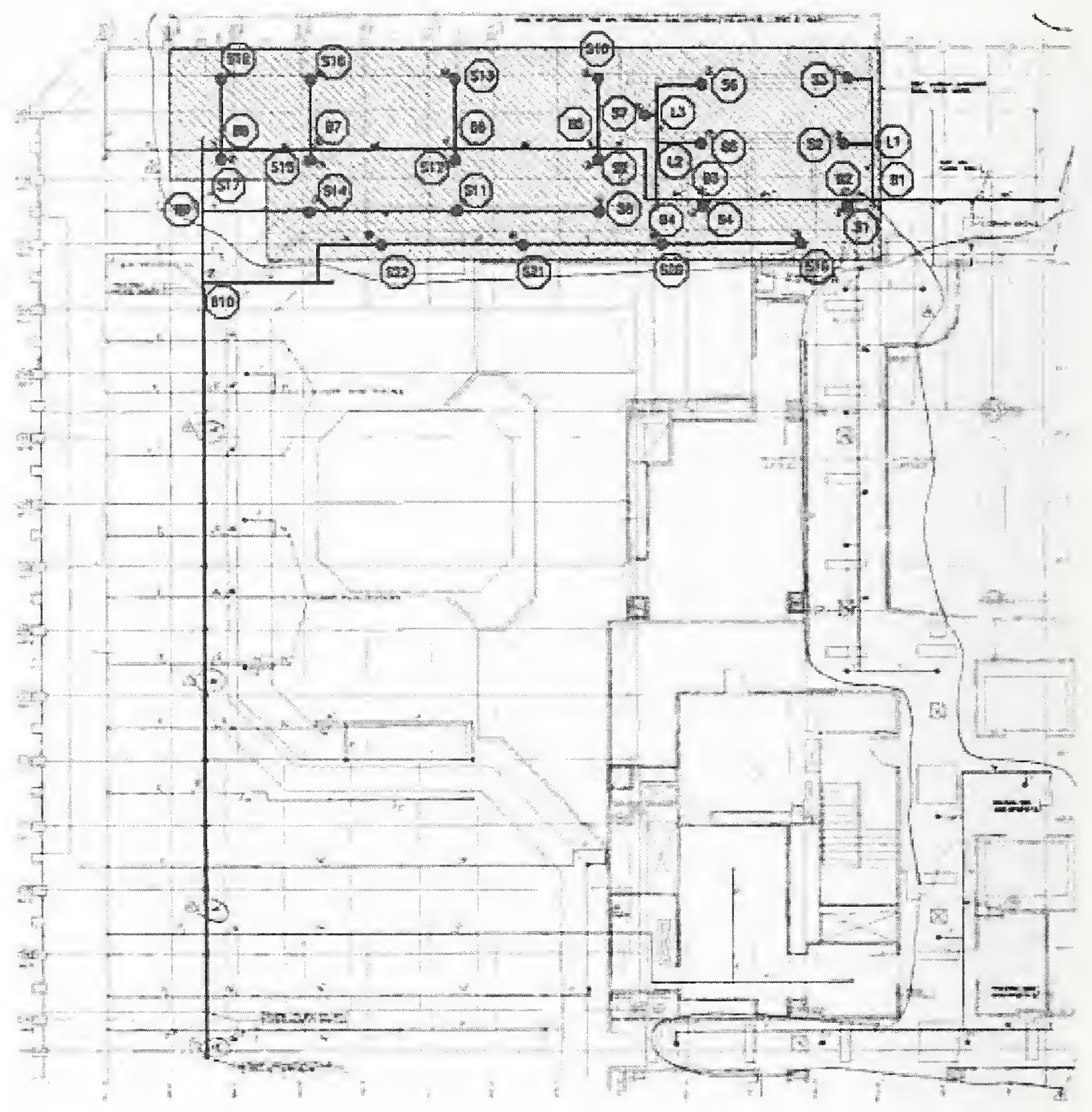

Source: Reproduced with permission of The Port Authority of New York and New Jersey.

Figure B-25. Hydraulic node layout, 107th floor NW quad., WTC 2. 


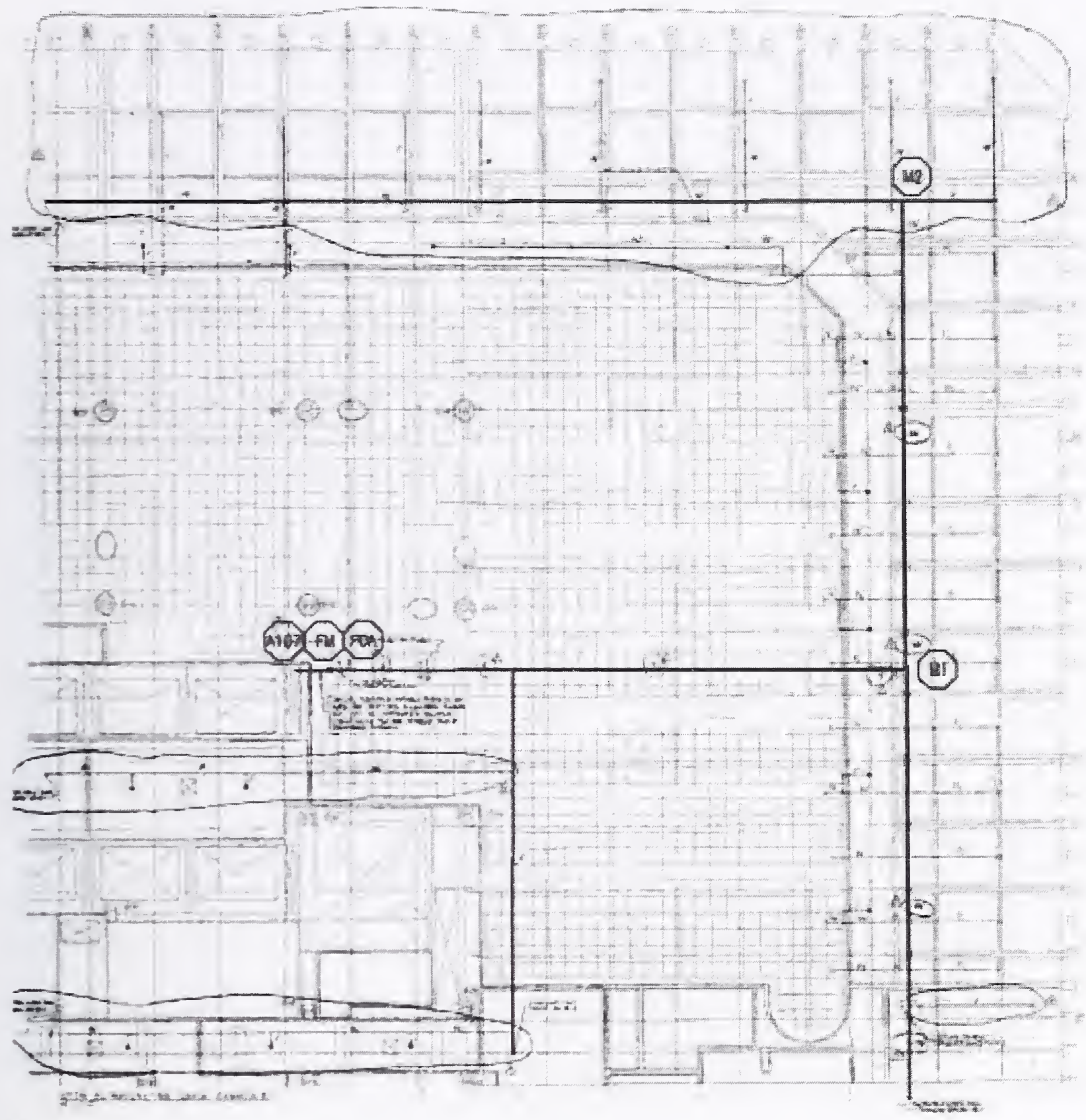

Source: Reproduced with permission of The Port Authority of New York and New Jersey.

Figure B-26. Hydraulic node layout, 107th floor NE quad., WTC 2. 


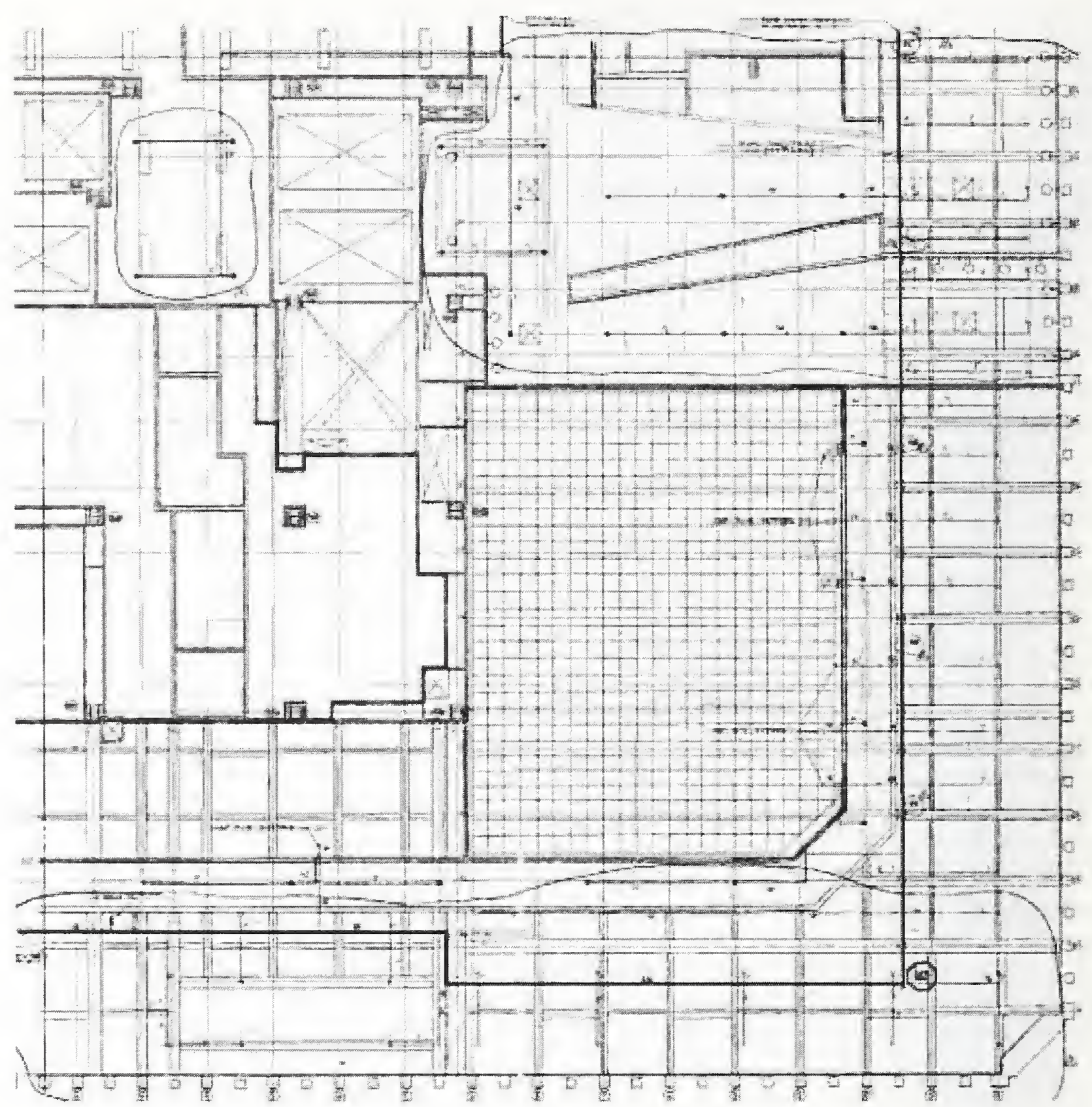

Source: Reproduced with permission of The Port Authority of New York and New Jersey.

Figure B-27. Hydraulic node layout, 107th floor SE quad., WTC 2. 


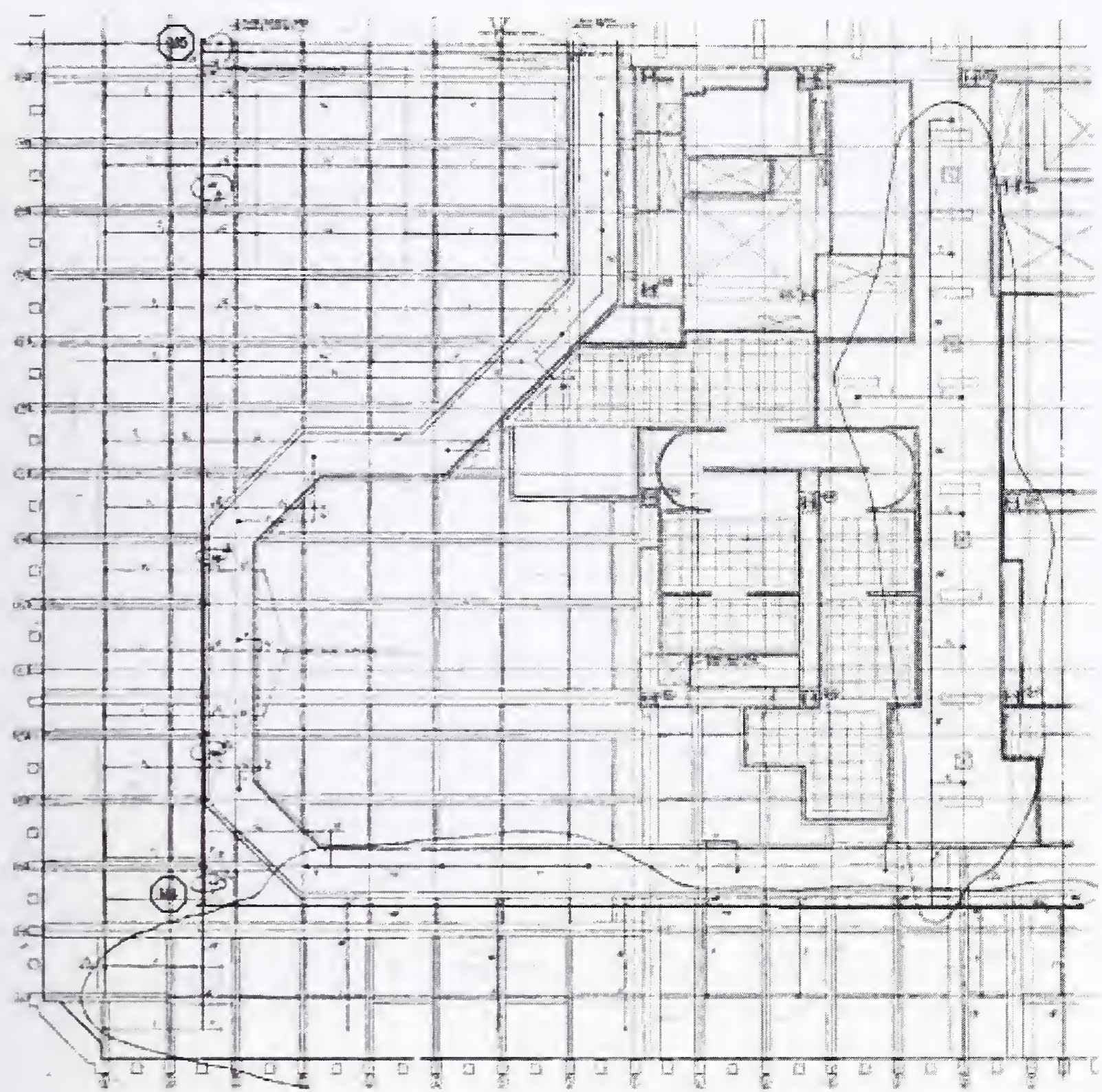

Source: Reproduced with permission of The Port Authority of New York and New Jersey.

Figure B-28. Hydraulic node layout, 107th floor SW quad., WTC 2. 


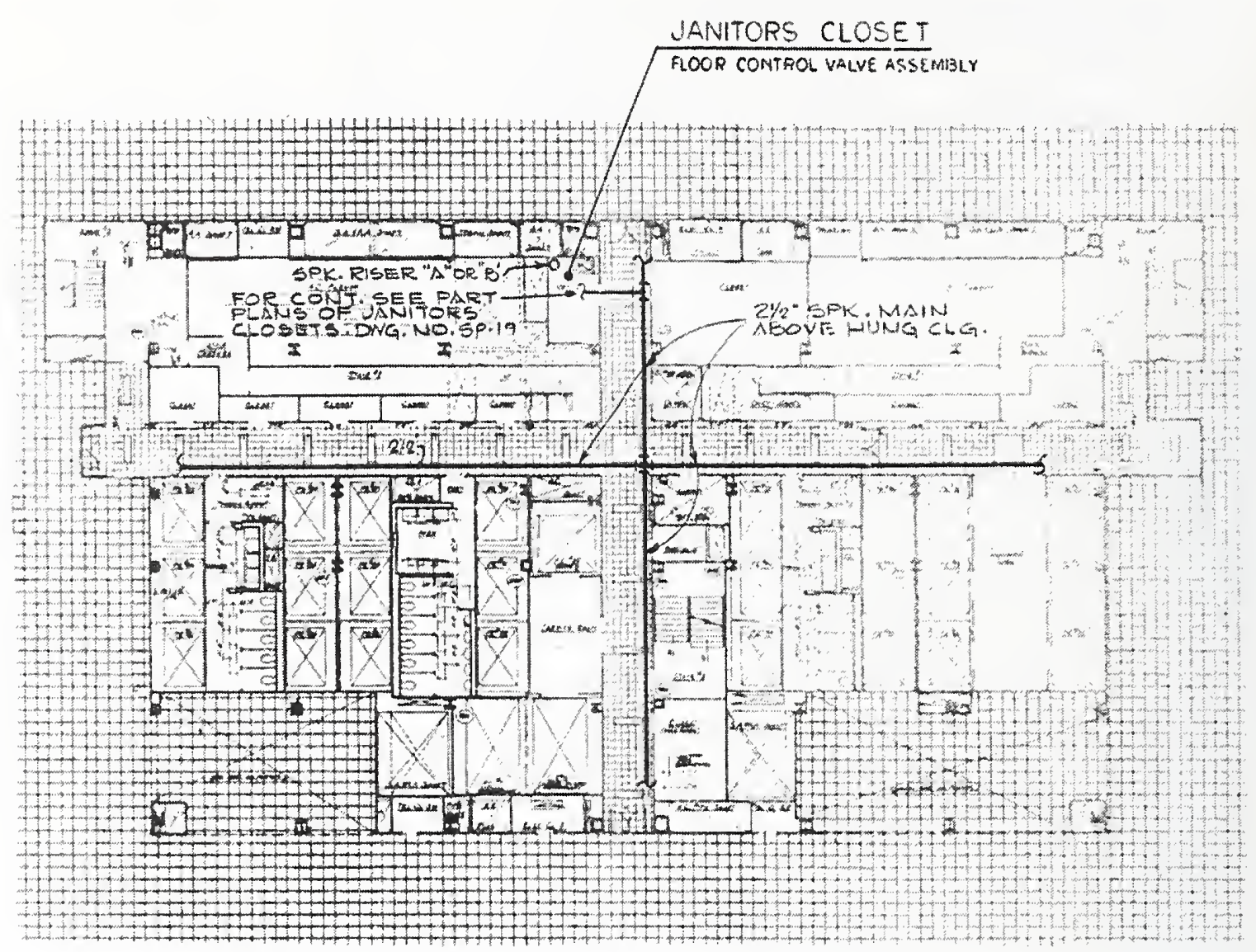

TYPICAL PLAN FLOORS 82 THROUGH 105

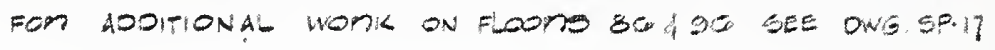

Source: Reproduced with permission of The Port Authority of New York and New Jersey.

Figure B-29. Typical high zone sprinkler system core layout. 


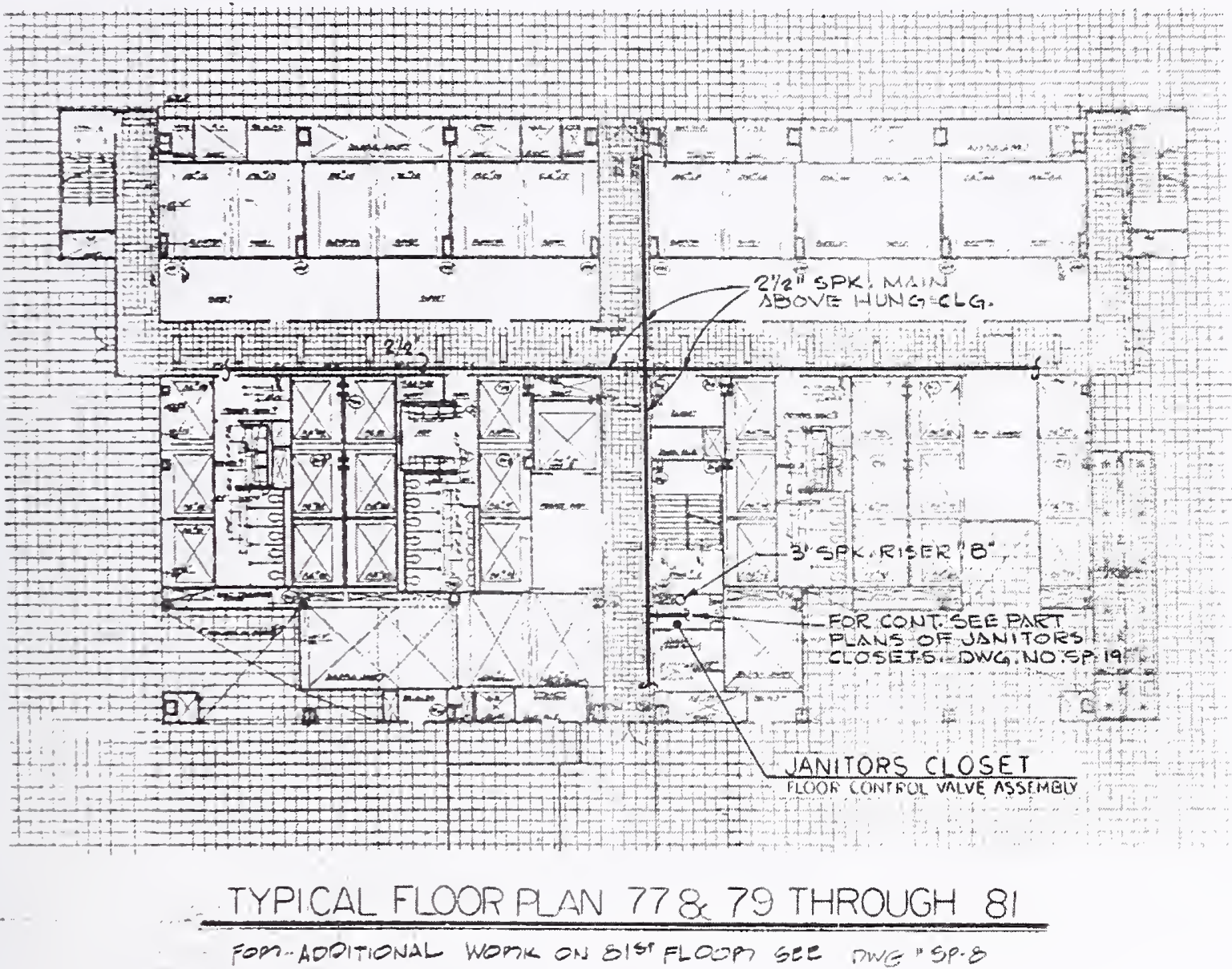

Source: Reproduced with permission of The Port Authority of New York and New Jersey

Figure B-30. Typical mid-level zone sprinkler system core layout. 


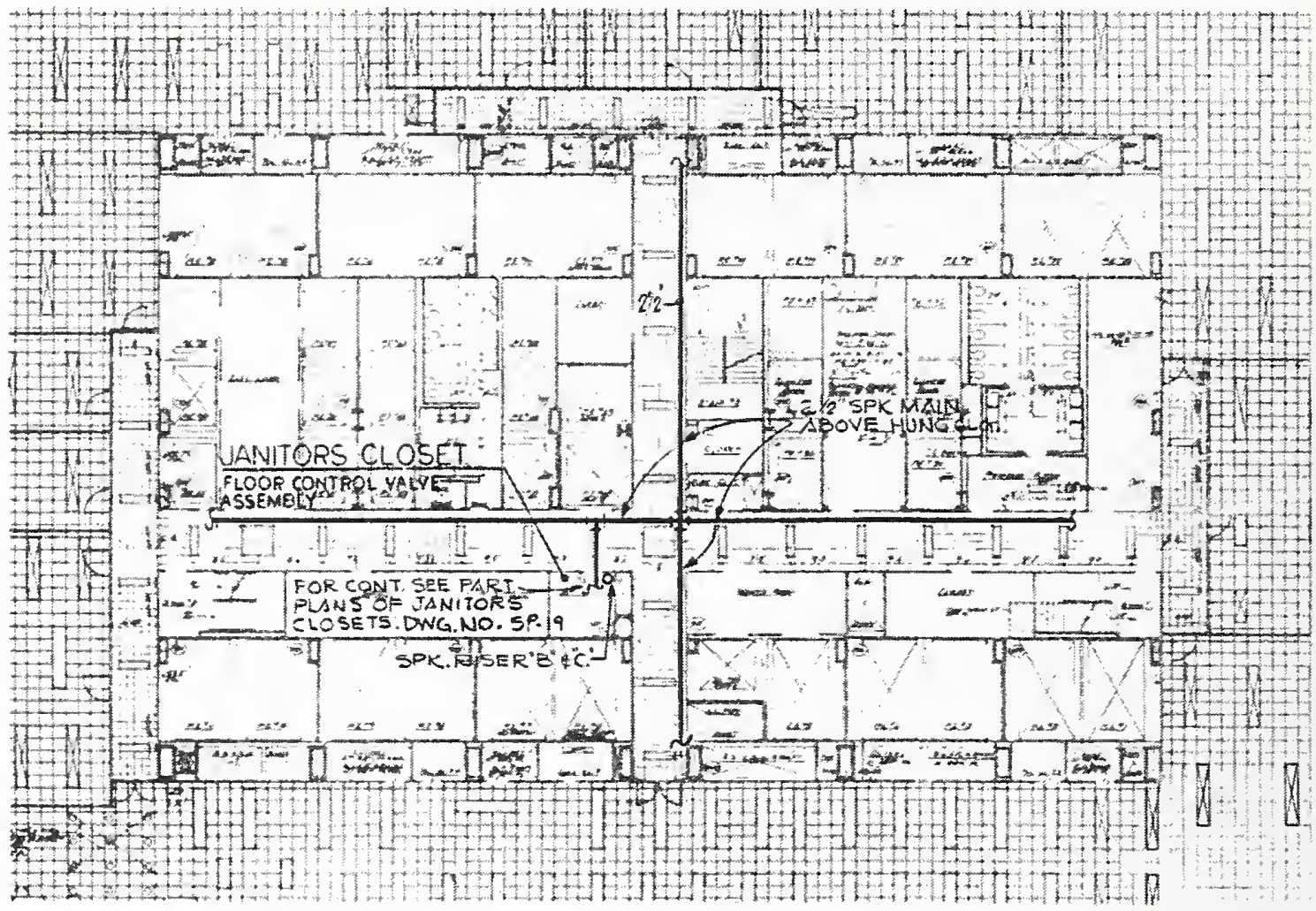

\section{TYPICAL PLAN FLOORS 9 THROUGH 40}

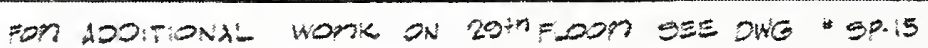

Source: Reproduced with permission of The Port Authority of New York and New Jersey.

Figure B-31. Typical low zone sprinkler system core layout. 


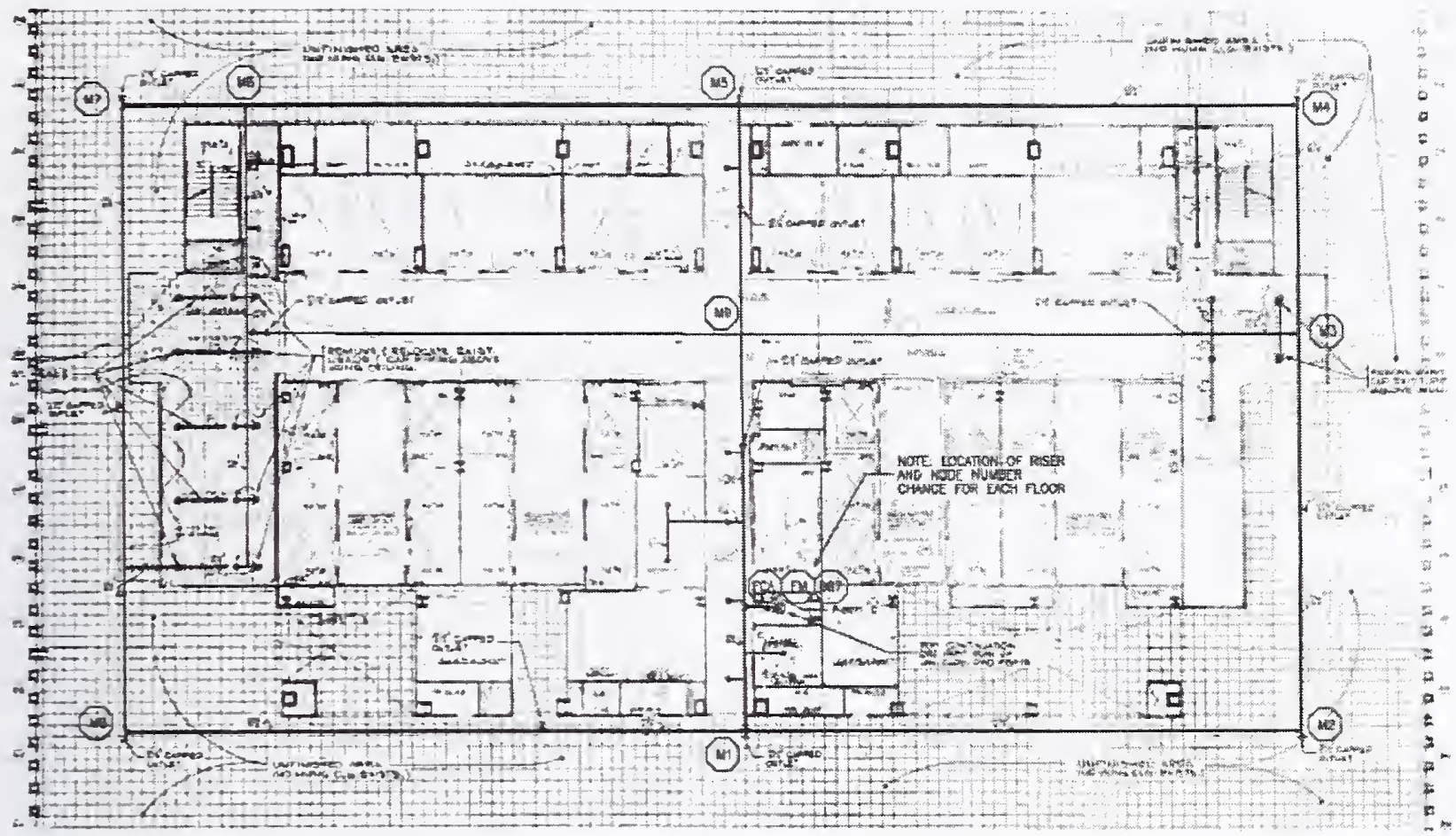

Source: Reproduced with permission of The Port Authority of New York and New Jersey.

Figure B-32. Typical looped sprinkler main layout. 


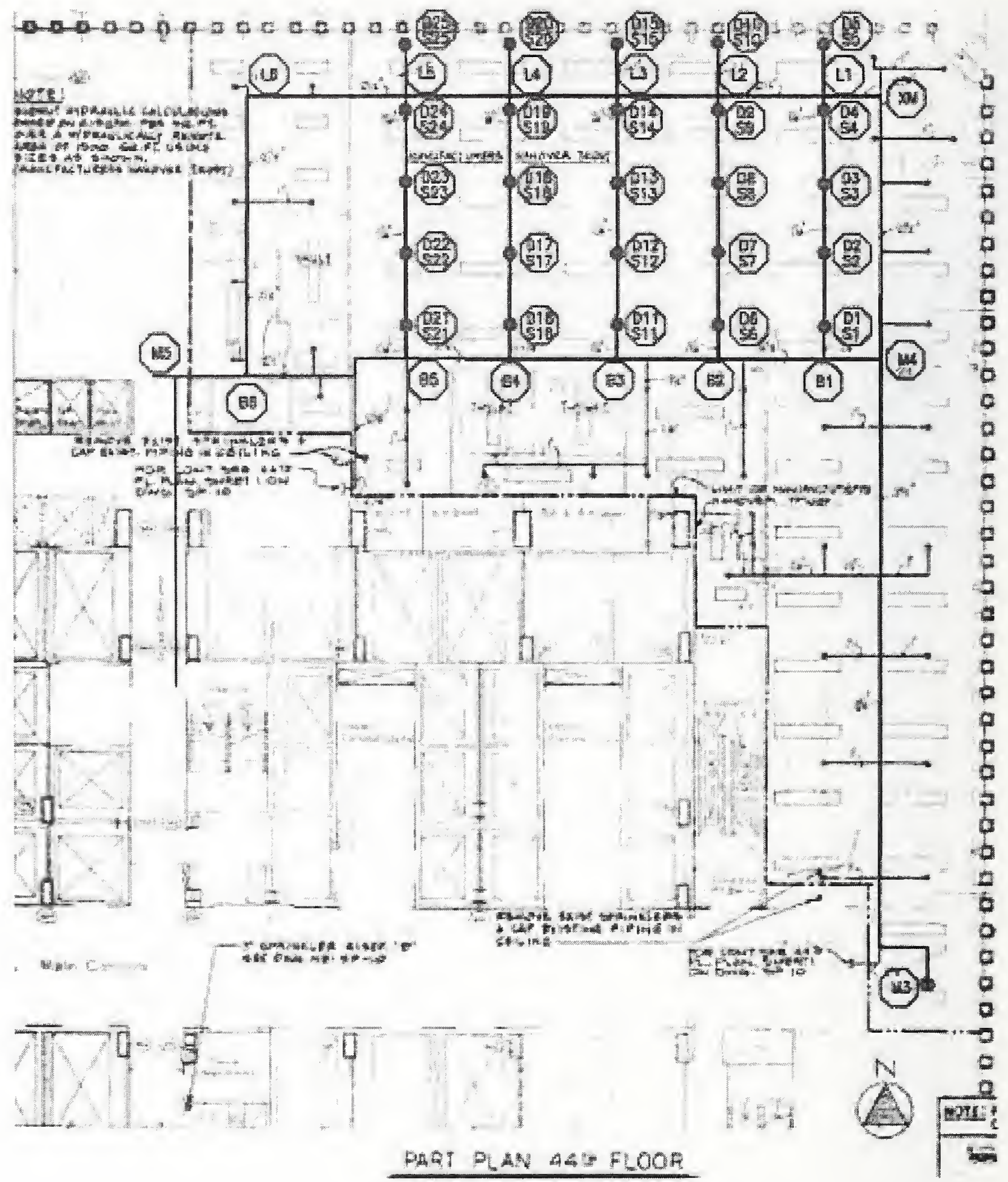

Source: Reproduced with permission of The Port Authority of New York and New Jersey.

Figure B-33. Typical Ordinary Hazard grid sprinkler system layout. 


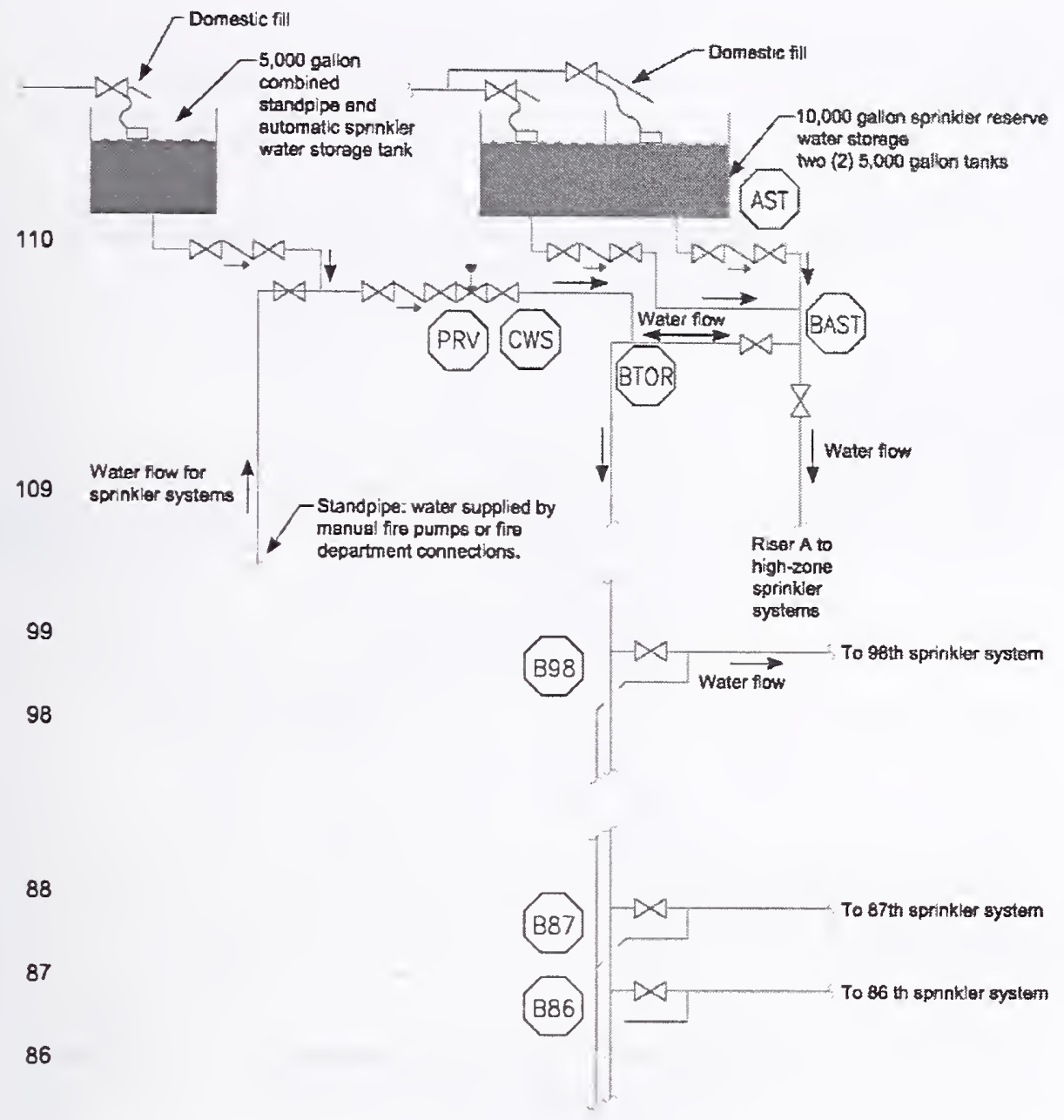

Note: 32nd through 86th Floor sprinker systems contaked pressure-roducing valves.

33

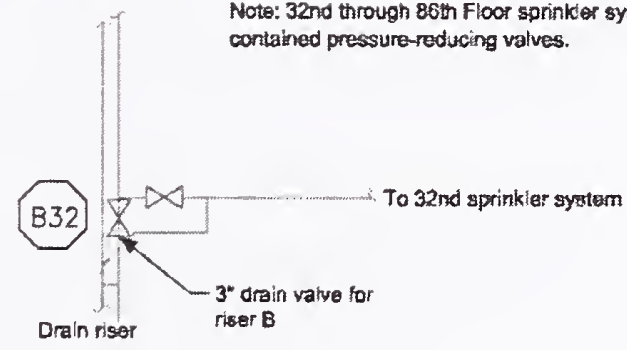

Figure B-34. Hydraulic node layout, mid-level zone riser B. 

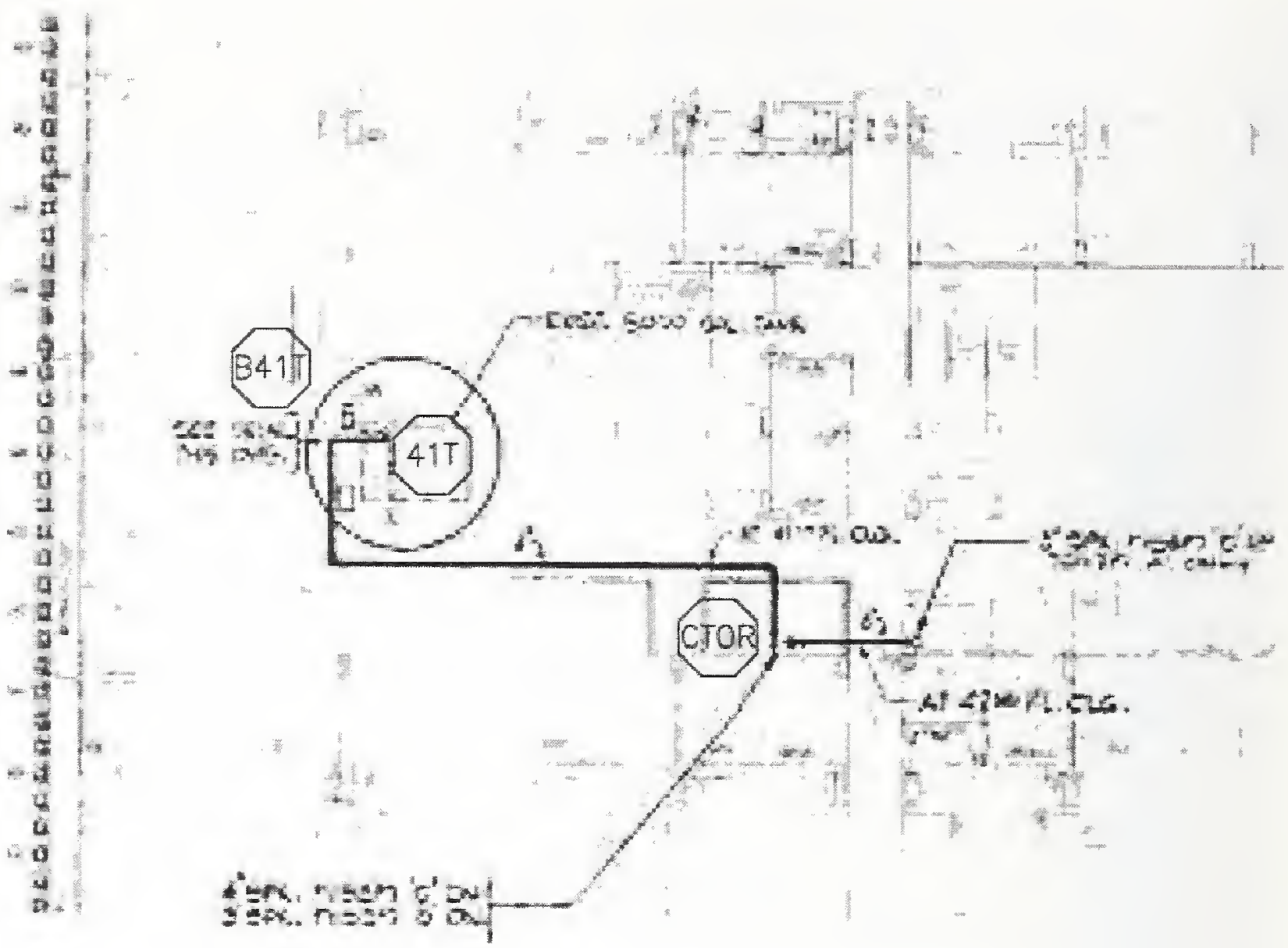

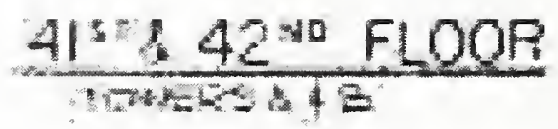

Source: Reproduced with permission of The Port Authority of New York and New Jersey.

Figure B-35. Low zone water storage tank arrangement, 41 st and 42 nd floors. 
$\frac{\overline{8}}{8}$
$\frac{8}{4}$
$\frac{10}{1}$

$\begin{array}{ll}\frac{8}{4} & \frac{8}{4} \\ \frac{5}{5} & \frac{5}{2}\end{array}$

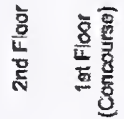

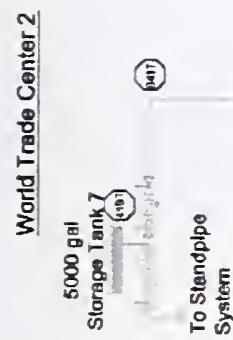

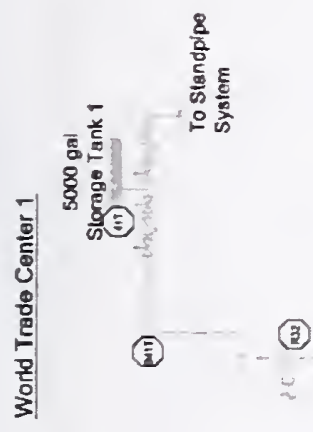

(2) (a)

(8)

$\frac{8}{4}$
$\frac{8}{4}$
$\frac{0}{6}$

噌毫

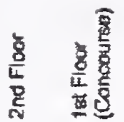

Figure B-36. Hydraulic node layout, low zone riser C. 


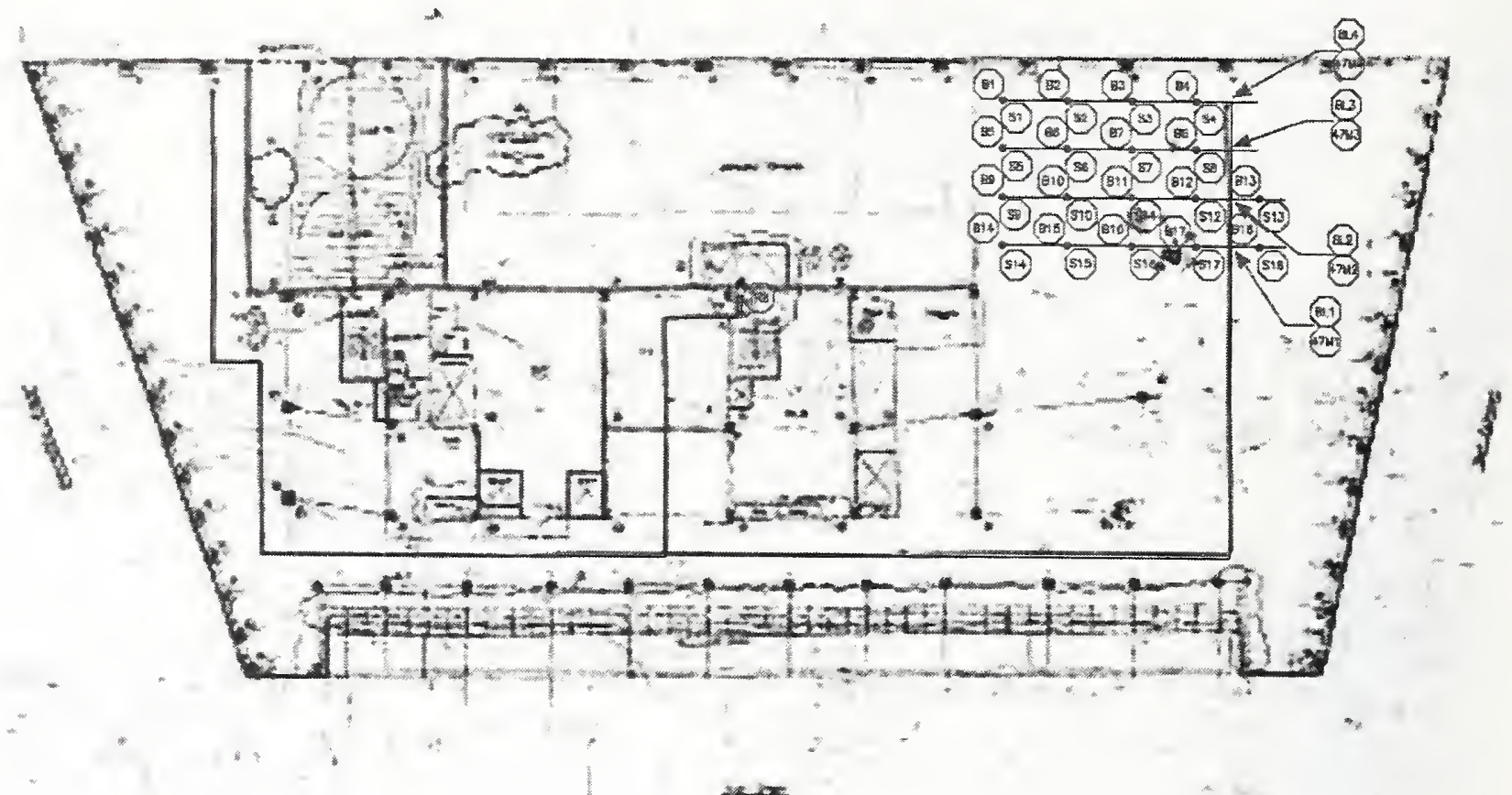

Source: Reproduced with permission of Syska \& Hennessy 1984.

Figure B-37. Hydraulic node layout, 47th floor, WTC 7.

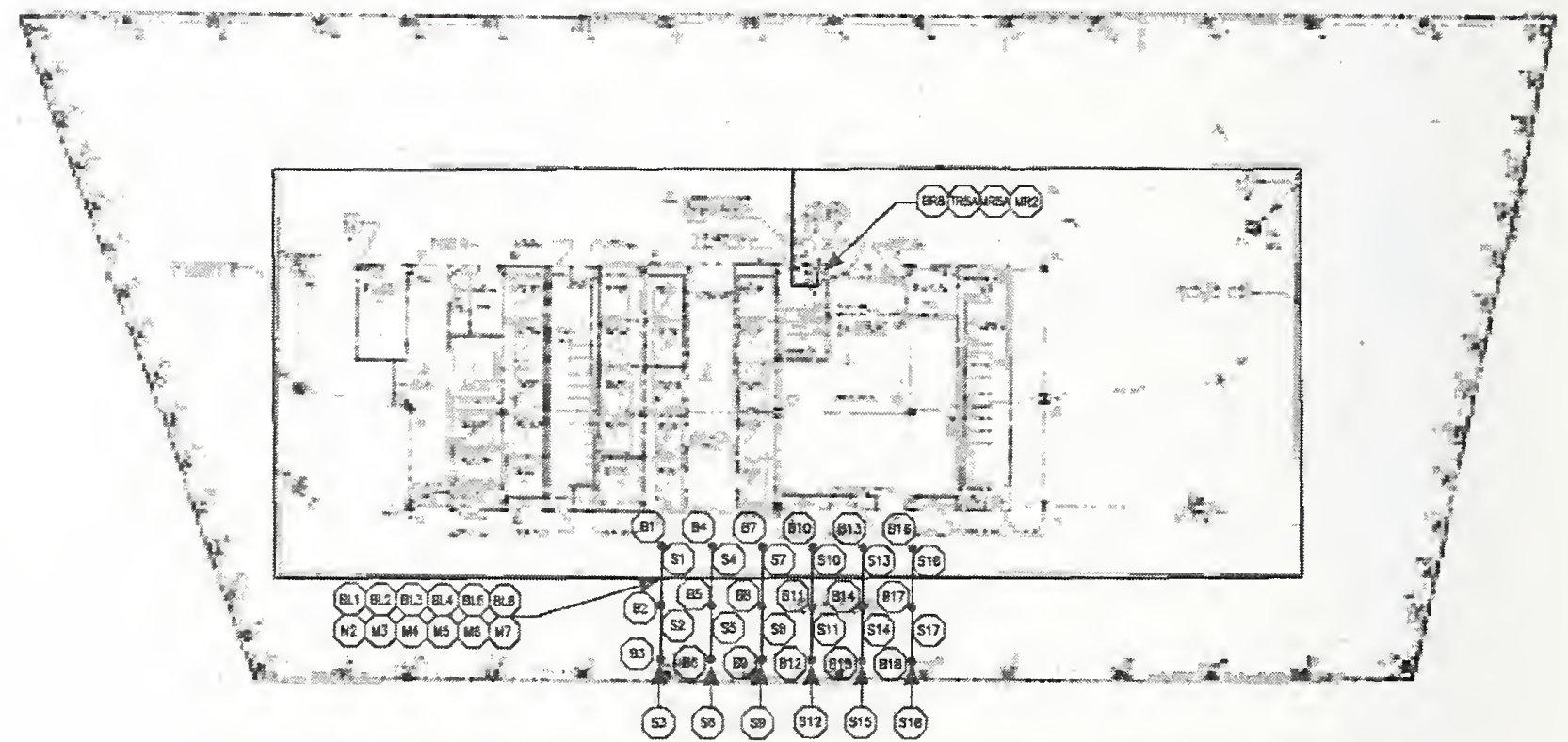

Source: Reproduced with permission of Syska \& Hennessy 1984.

Figure B-38. Typical floor hydraulic node layout, WTC 7. 


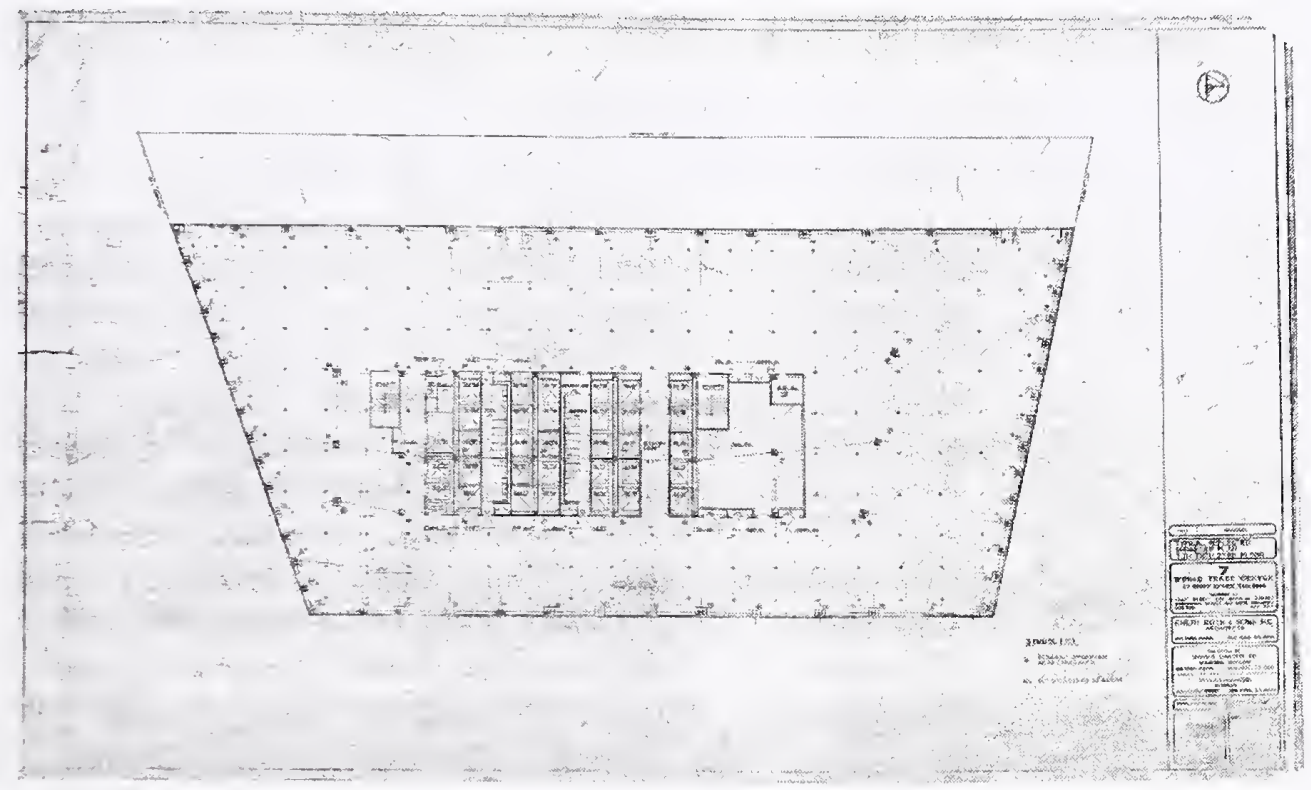

Source: Syska \& Hennessy 1984. Reproduced with permission of The Port Authority of New York and New Jersey.

Figure B-39. Typical sprinkler layout, floors 7 to 23 , WTC 7.

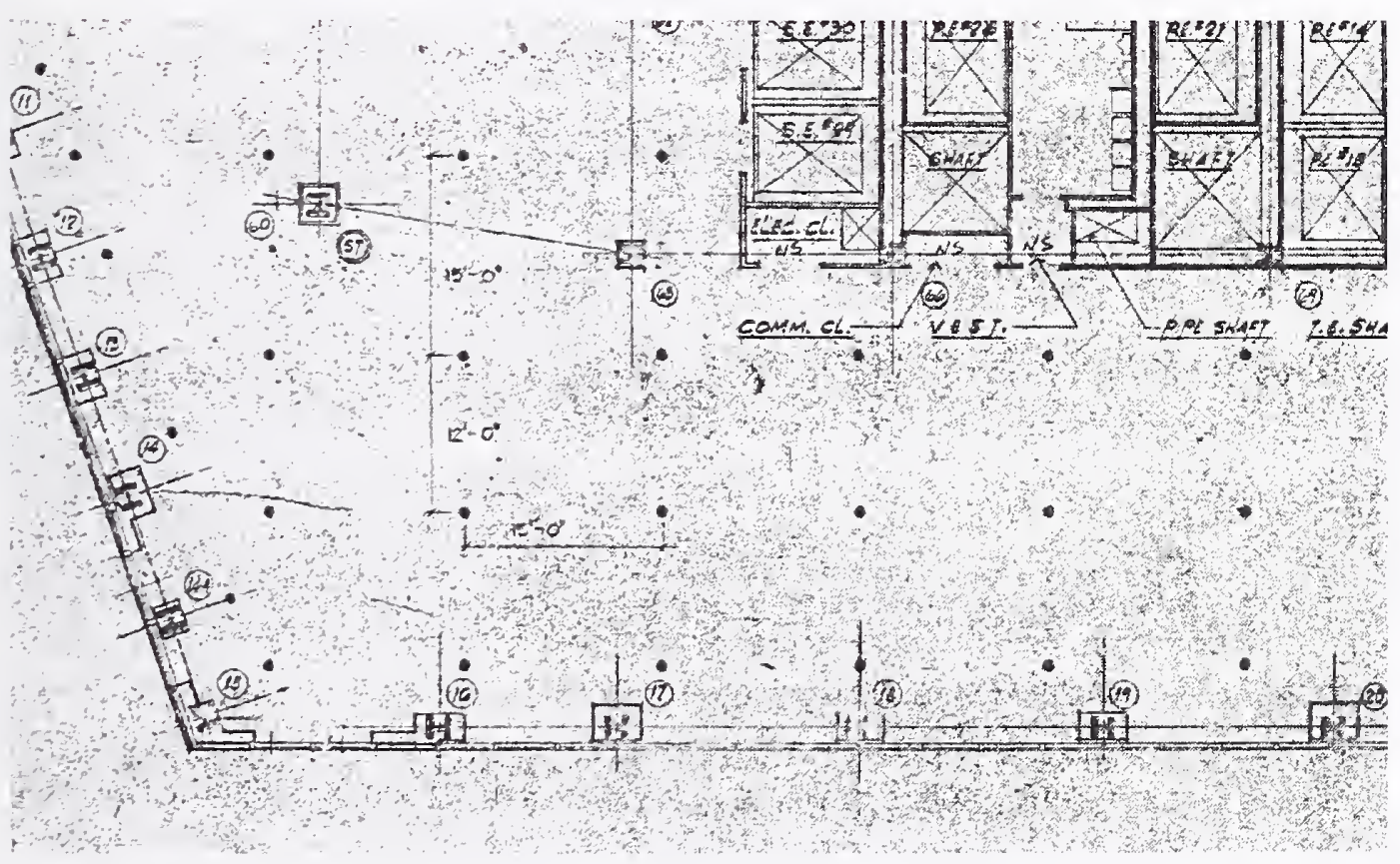

Source: Syska \& Hennessy 1984. Reproduced with permission of The Port Authority of New York and New Jersey.

Figure B-40. Typical sprinkler layout, floors 7 to 23 , WTC 7 . 


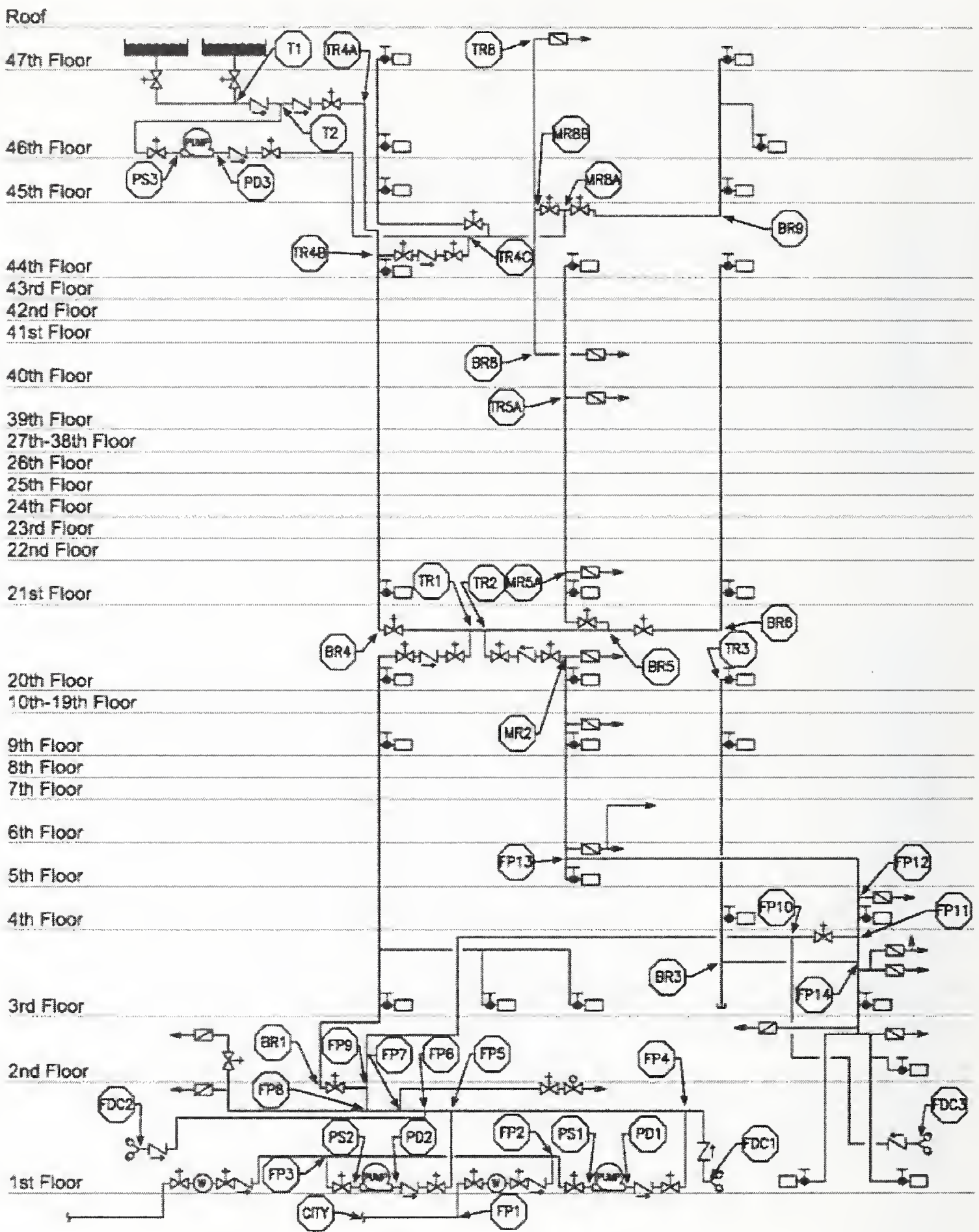

Hydraulic Calculation Riser - Node Identification

Figure B-41. Hydraulic calculation node riser, WTC 7. 


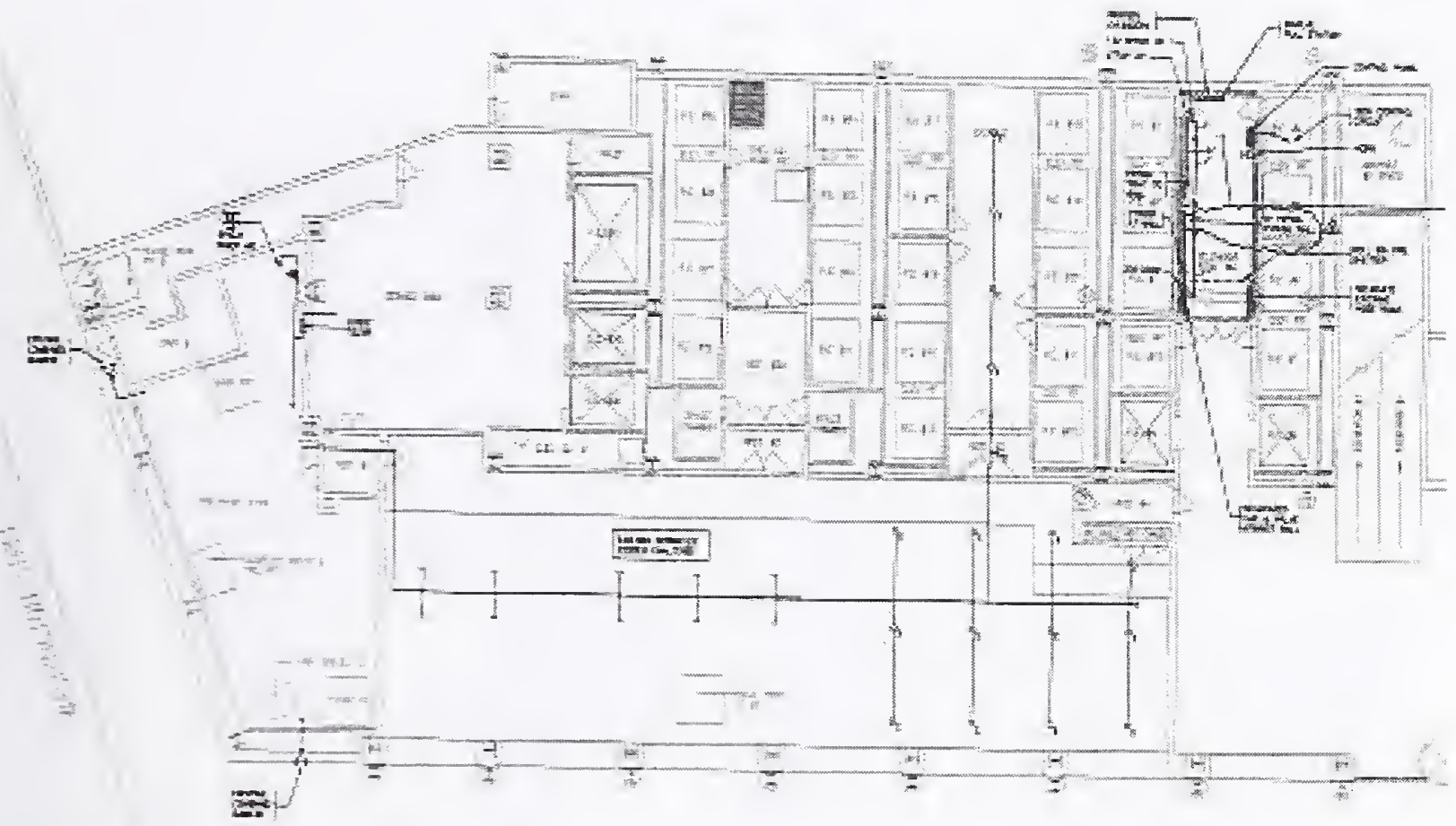

Source: Reproduced with permission of The Port Authority of New York and New Jersey.

Figure B-42. First floor loading dock sprinkler configuration, WTC 7.

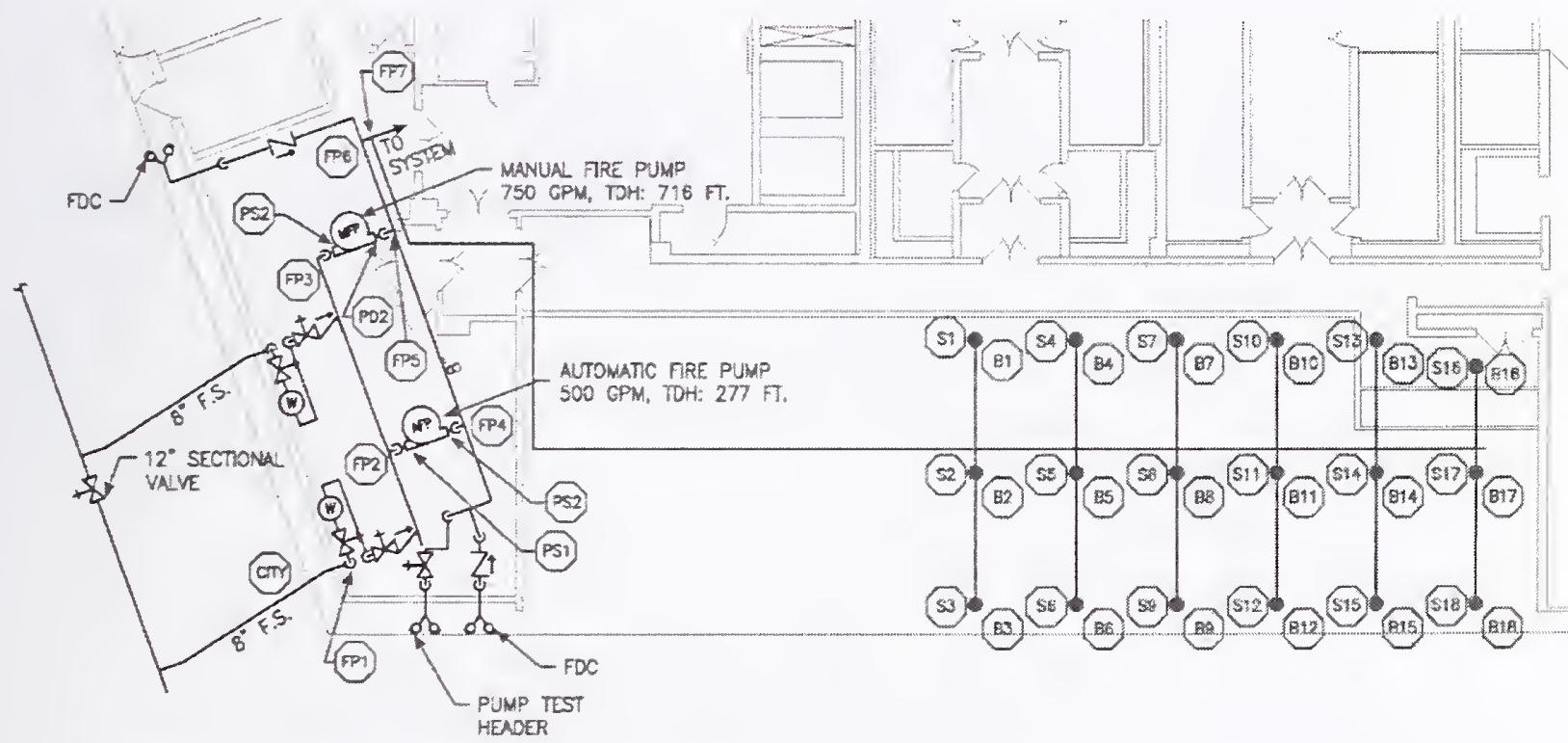

Source: Reproduced with permission of The Port Authority of New York and New Jersey.

Figure B-43. First floor and fire pump room hydraulic node layout, WTC 7. 


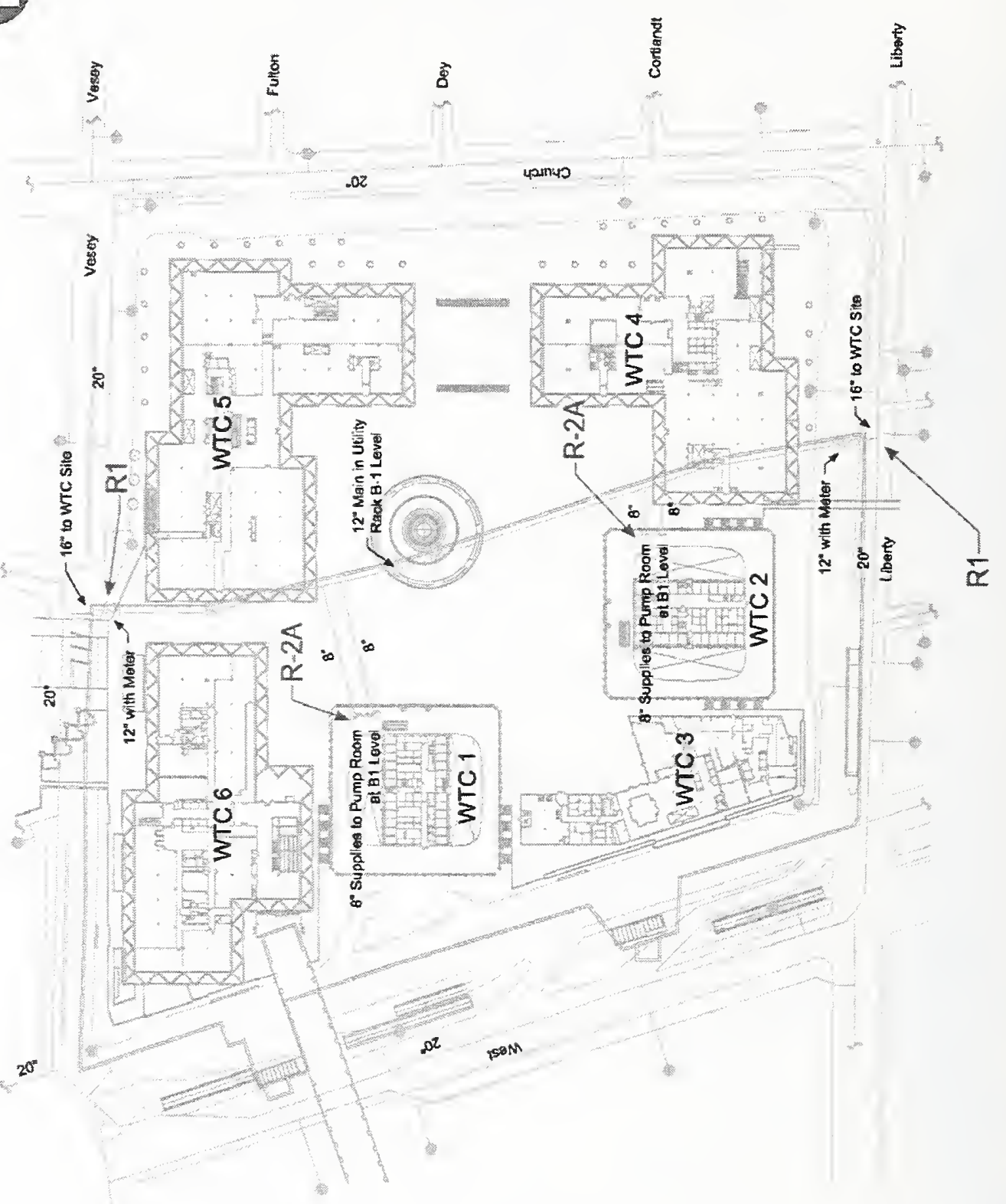

Source: Reproduced with permission of The Port Authority of New York and New Jersey.

Figure B-44. Redundancies associated with the WTC complex water supply. 


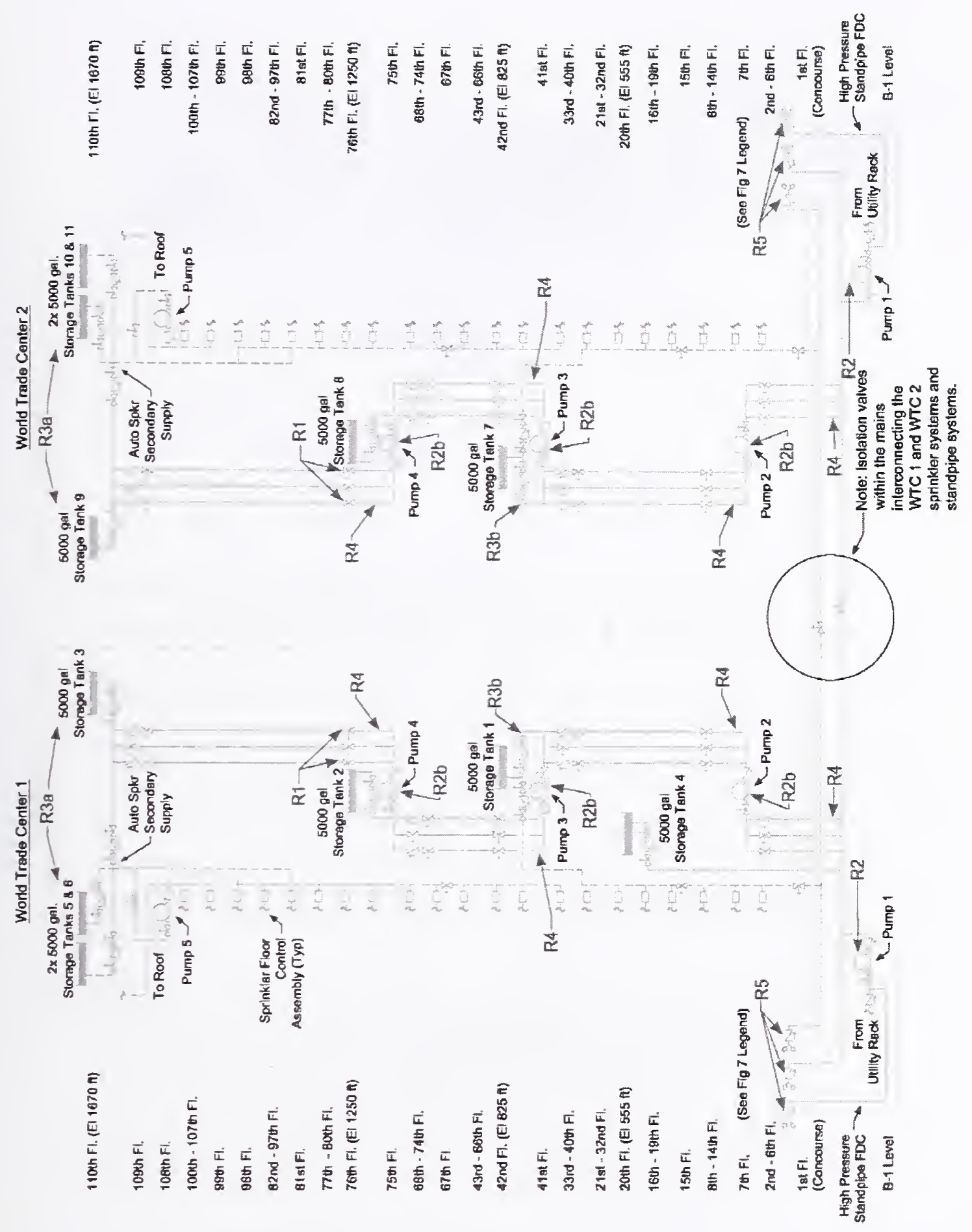

Figure B-45. Redundancies associated with the sprinkler and standpipe systems. 


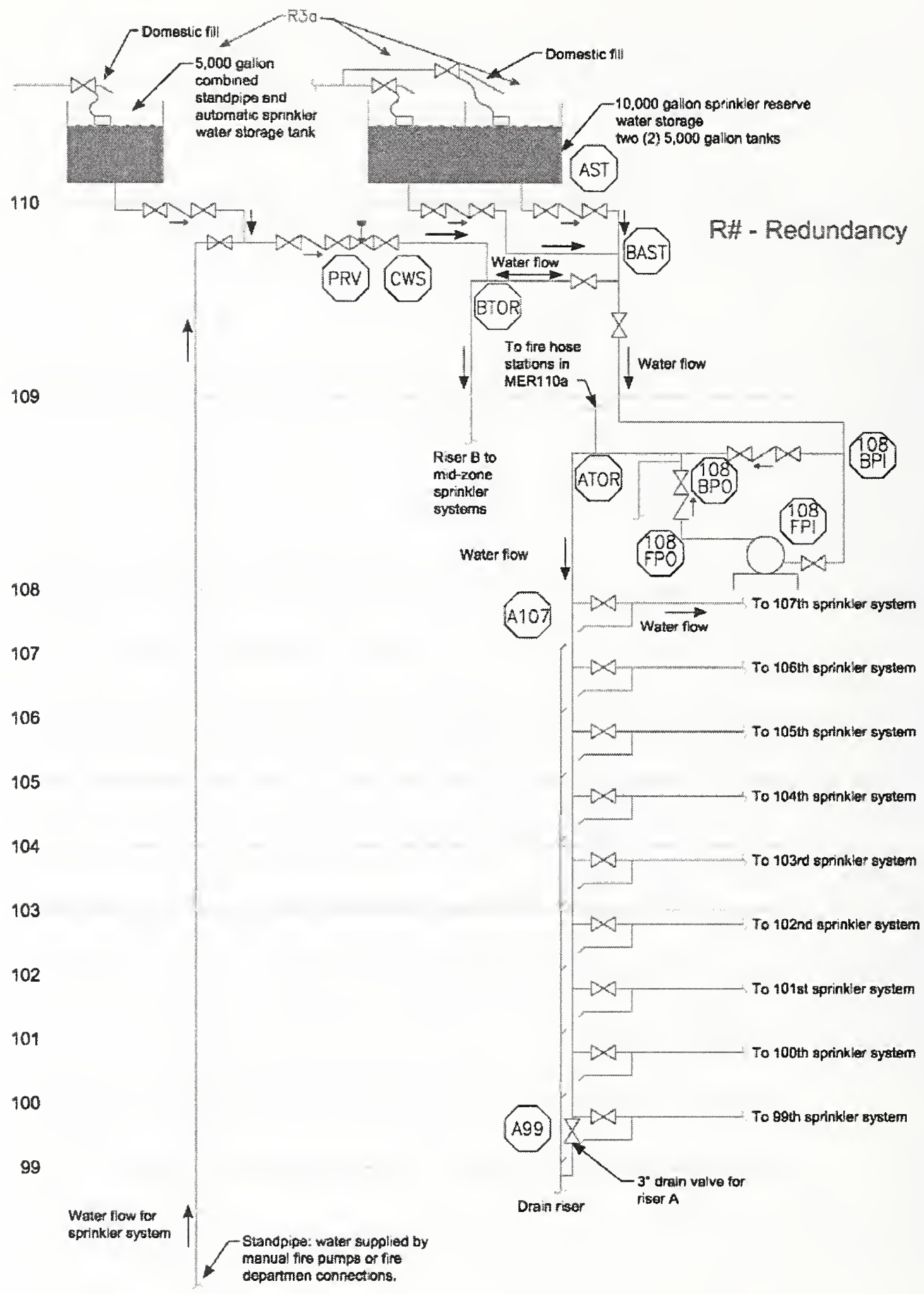

Figure B-46. Redundancies associated with high zone sprinkler system riser A. 


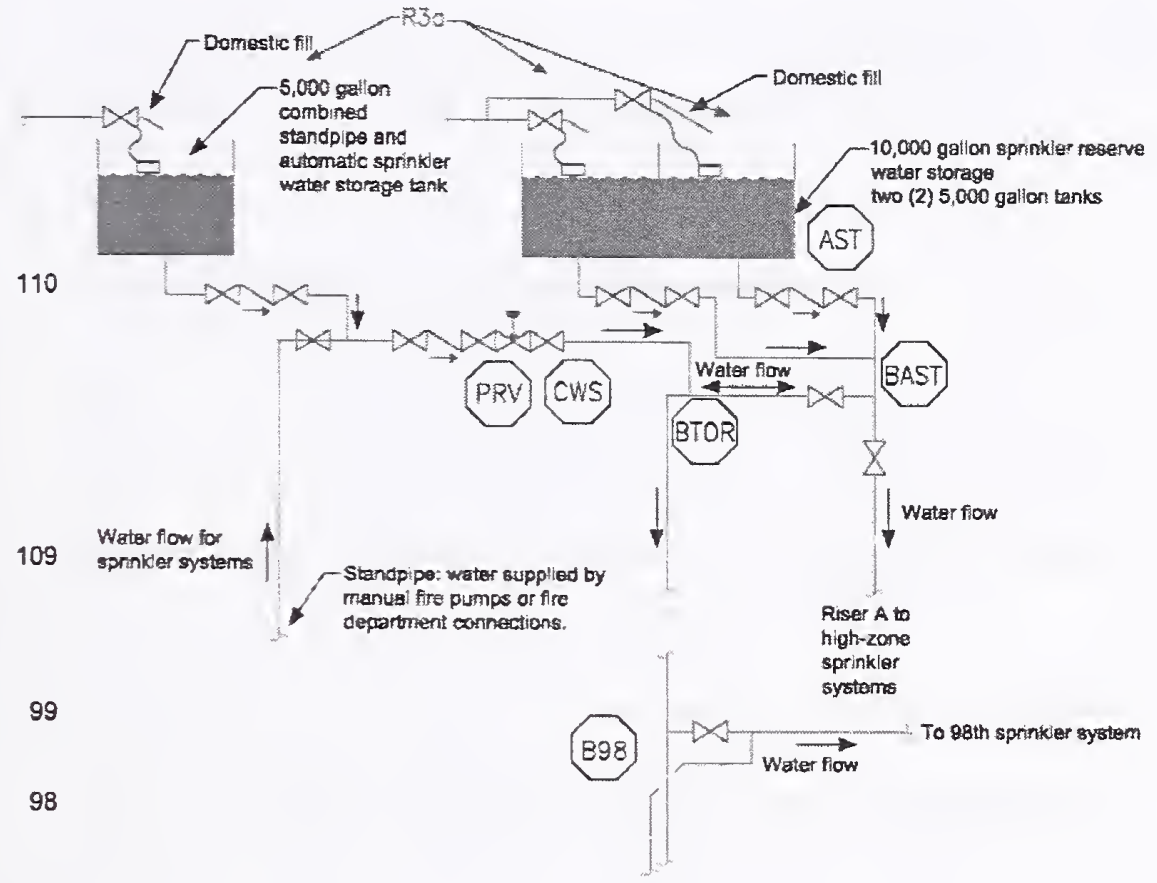

88

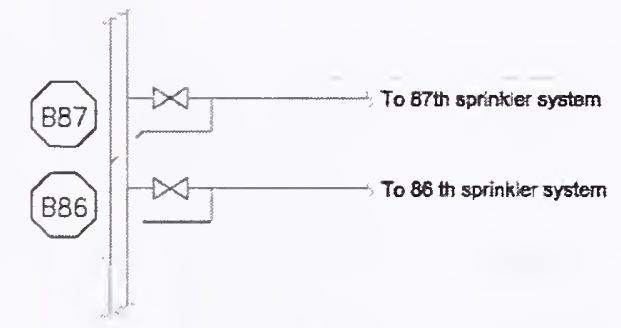

86

Note: 32no through B5th Fioor sprinkler systems

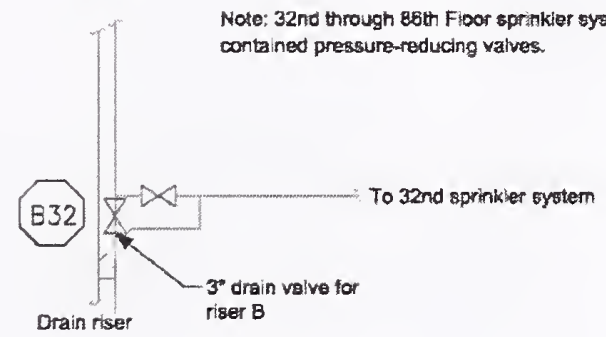

32

Orain rise

Figure B-47. Redundancies associated with mid level zone sprinkler system riser B. 


$$
\begin{array}{ll}
\frac{8}{4} \\
\frac{8}{6}
\end{array}
$$

$$
\frac{5}{5}
$$

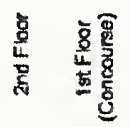
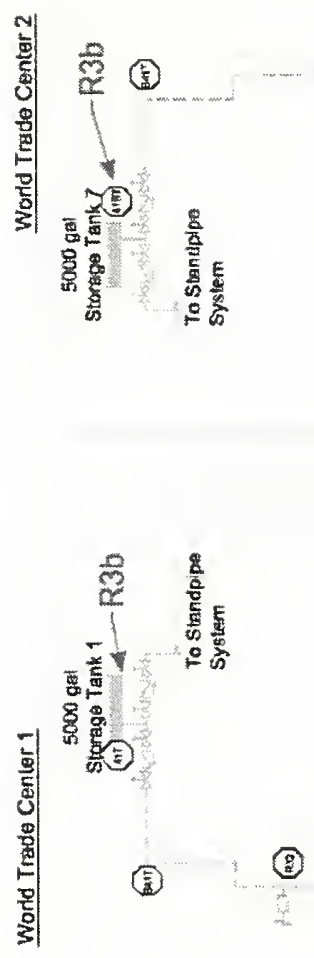

(3) (2)

(e)
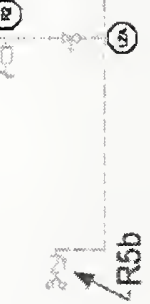

$$
\frac{\sqrt{\frac{5}{4}}}{\frac{8}{4}}
$$

兽竞

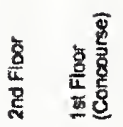

Figure B-48. Redundancies associated with low zone sprinkler system riser C. 


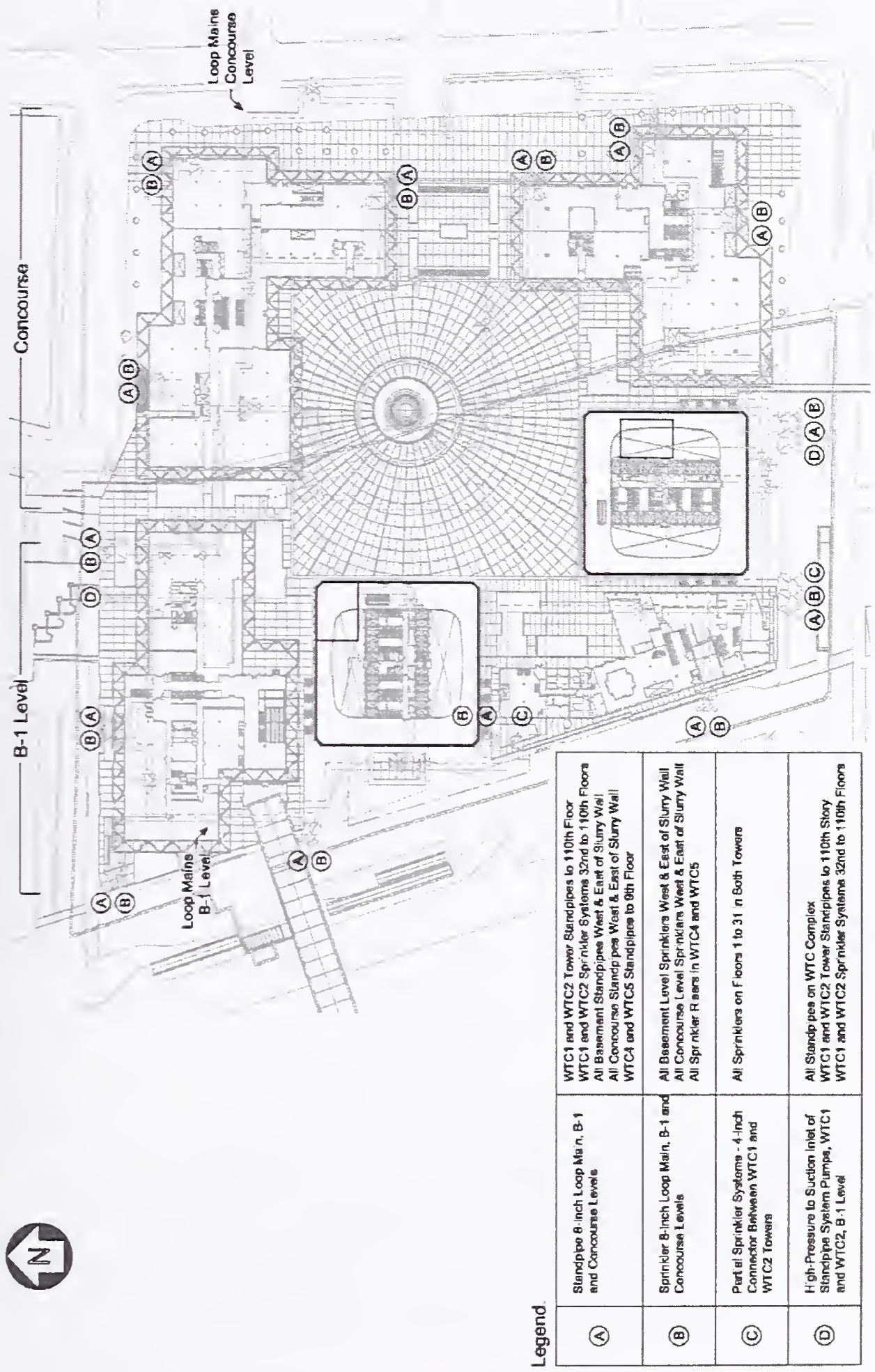

Source: Reproduced with permission of The Port Authority of New York and New Jersey.

Figure B-49. Redundancies associated with the WTC complex fire department connections. 


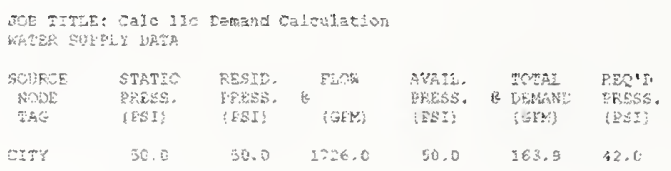

A:GTELGATE ILCA REALYSIS:
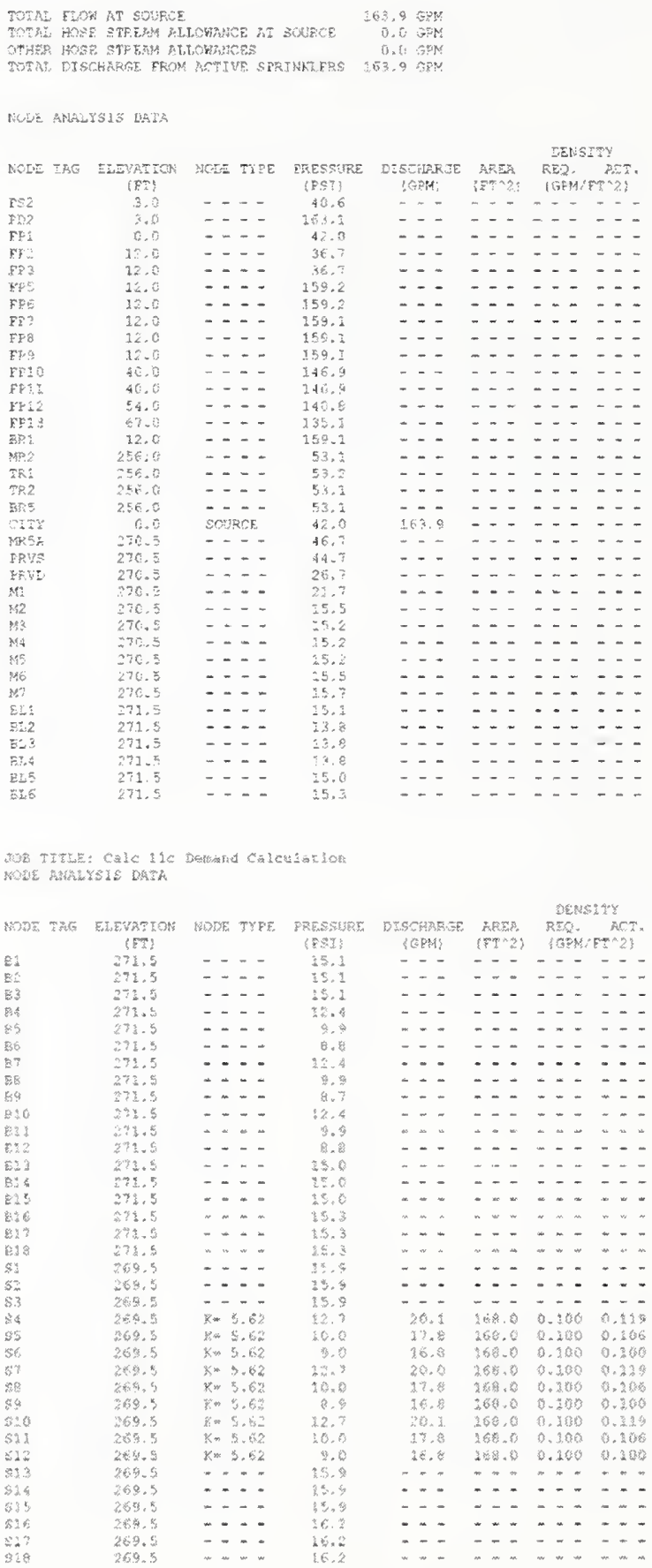

Figure B-50. Calculation 11c (demand calculation), WTC 7. 
Roof

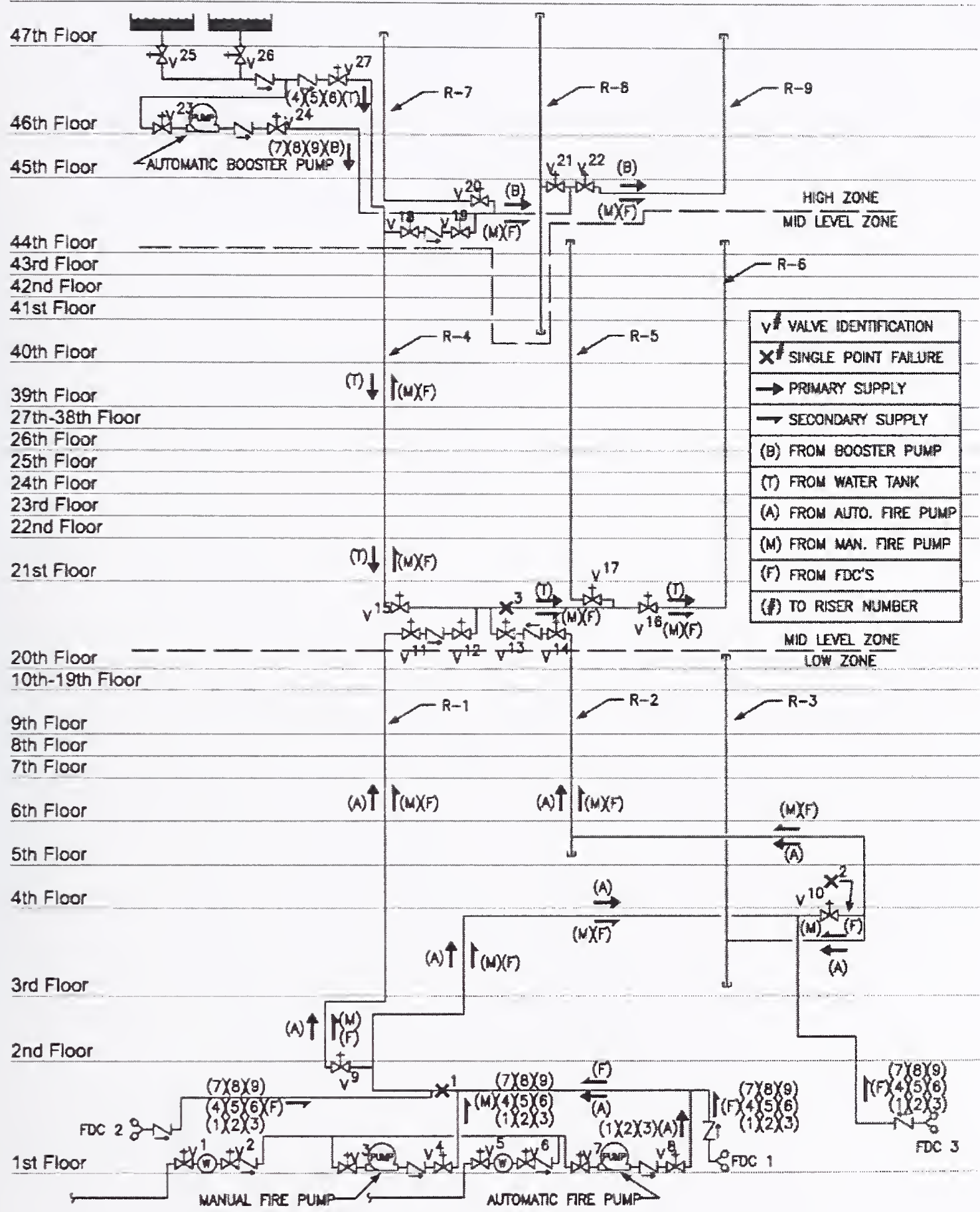

Direction of Flow - Primary and Secondary Supplies to Zones

Figure B-51. Primary and secondary supply water flow diagram, WTC 7. 
This page intentionally left blank. 



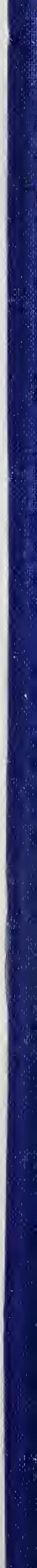

